Universidad Jaime I

Departamento de Educación

Área de Didáctica de la Expresión Musical

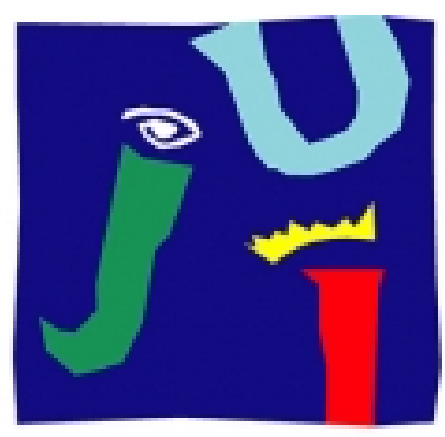

UNIVERSITAT

JAUME•I

\title{
LA FORMACIÓN EN LA EXCELENCIA MUSICAL EN LOS \\ CONSERVATORIOS SUPERIORES. EXPLORACIÓN Y PUESTA EN \\ PRÁCTICA DESDE LA ACCIÓN DOCENTE
}

\author{
Memoria de Tesis Doctoral realizada por \\ Eulalia Isabel Gorbe Martínez
}

Tesis doctoral dirigida por:

Prof. Dra. Amparo Porta Navarro

Prof. Dr. Rafael Martín Castilla

Para optar al grado de

Doctor por la Universitat Jaume I

Castellón, abril de 2017 



\section{Agradecimientos}

En primer lugar me gustaría destacar la labor de mis directores de tesis, doña Amparo Porta Navarro y don Rafael Martín Castilla. Sin su ayuda este trabajo nunca habría llegado a ver la luz. Su apoyo se ha reflejado tanto en el papel de directores como en el de amigos, pues en los momentos complicados siempre he sentido que era mucho más importante la parte humana que la académica. Esto lo agradezco profundamente.

Doña Amparo Porta confió en mí y me dio los consejos para que mis ideas, fruto del entusiasmo por enseñar, fueran tomando forma hasta llegar, con mucho esfuerzo y dedicación, a este resultado, de un calado más académico y científico gracias a sus sabios consejos.

Don Rafael Martín Castilla sigue enseñándome hoy lo mismo que cuando fue mi profesor, hace ya unos cuantos años. Fue precisamente él quien me animó a que realizara una tesis sobre el asunto que tenemos aquí, pues siempre confió en mis ideas y me apoyó para conseguir llevarlas a cabo, con sus comentarios, sus ánimos y su ayuda.

Debo citar también al profesor John Sloboda quien, desde que leí el primer artículo que cayó en mis manos, me pareció un ejemplo de profesor e investigador al que me encantaría parecerme. Entonces no sabía aun que iba a tener la suerte de poder conocerle personalmente en su primera visita a España y, en entrevista personal, referirle las ideas que iba madurando para mi tesis. Fue en ese mismo momento cuando me animó a llevarla a cabo y a publicar los resultados, de modo que pudiera hacerse lo mismo en otros lugares, e incluso se prestó a leer y revisar las preguntas de los test que pasé a alumnos y profesores. Igualmente, le expuse la idea de que el alumno de la enseñanza superior podía ser consciente de que él mismo tenía que ser su mejor profesor y, por tanto, podía aplicar todo lo que el profesor Sloboda recomendaba para mejorar como tal, a lo que me dio no sólo su visto bueno, sino que me animó a desarrollar el concepto.

También quiero agradecer a mis alumnos, por supuesto a los que han formado parte de la investigación en este tiempo, por muchas razones. En primer lugar, por sus comentarios sinceros y sus ganas de aprender, confiando siempre en lo que les proponía y, en segundo lugar, por obligarme a reflexionar y, muchas veces, darme cuenta de lo que estaba haciendo, notando 
la cercanía incluso afectiva que se creaba en el aula (alguno llegó a comentar que todos estaban “enchufados") y que, a la postre, convertía mi clase en una caja de sorpresas.

Del mismo modo, al resto de alumnos que he tenido a lo largo de mi vida docente, algunos de los cuales son hoy compañeros, y que también me han mantenido "tarareando" la tesis, lo que me ha permitido que una gran parte del trabajo la haya hecho sin darme cuenta.

Debo también agradecimiento a mis compañeros, los que han participado rellenado la encuesta, los que han sido alumnos anteriormente (y que me han valorado más el cómo daba las clases que lo que decía), que me han hecho darme cuenta con el tiempo de que todo era importante y, en especial, a los compañeros de mi departamento, por haberme dado puntos de vista alternativos que me han ayudado a valorar el trabajo en equipo.

Y, por último aunque no por ello menos importante, el agradecimiento a mi familia y amigos, que en los momentos más duros han sabido encontrar energías para ayudarme aun cuando ellos también necesitaran ayuda, convirtiéndome en una estudiante convencida y apoyada, al igual que mis alumnos.

A todos ellos gracias.

Castellón, 7 de abril de 2017 


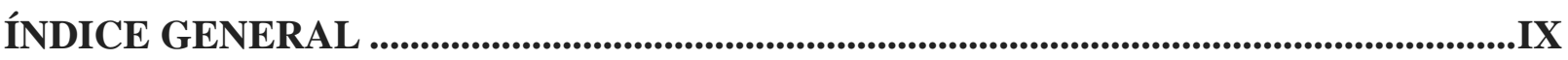

ÍNDICE DE FIGURAS........................................................................................................XI

ÍNDICE DE TABLAS...........................................................................................................XIII

PARTE I PRESENTACIÓN_.......................................................................................... 1

1 INTRODUCCIÓN ...................................................................................................................3

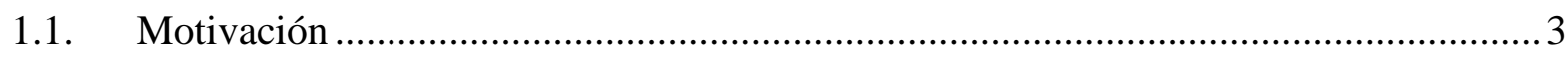

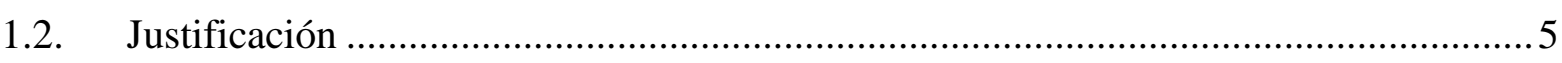

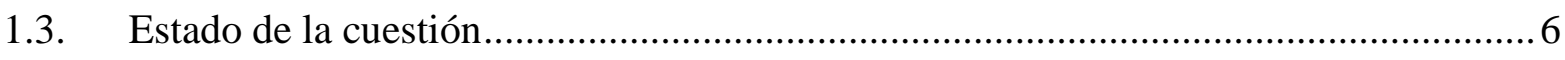

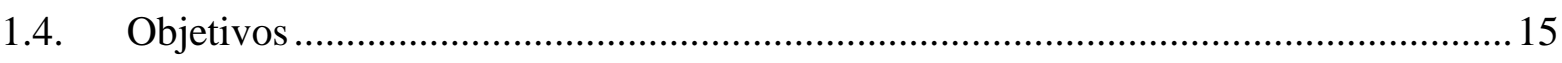

1.5. Enfoque metodológico aplicado a la investigación ................................................... 16

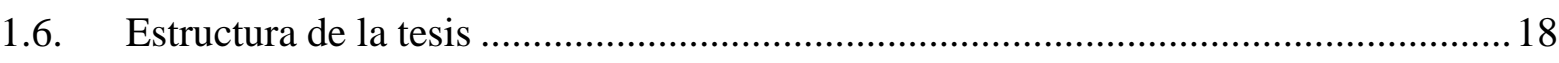

PARTE II MARCO TEÓRICO ................................................................. 21

2 EL CONCEPTO DE EXCELENCIA............................................................................ 23

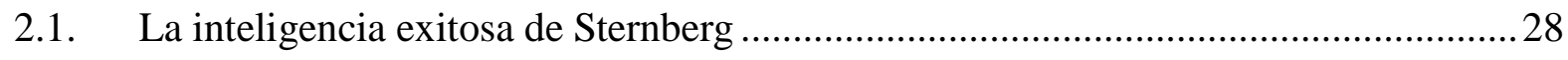

2.2. Las inteligencias del futuro de Gardner ................................................................ 44

2.3. Mentalidad fija y mentalidad en crecimiento de Dweck ..............................................64

3 LA EXCELENCIA MUSICAL ................................................................................................ 73

3.1. Estadios o fases en el camino a la excelencia musical...............................................79

3.2. El músico en el estadio avanzado: el músico profesional ...........................................89

3.3. El concepto de excelencia musical en la actualidad ............................................... 97

4 HERRAMIENTAS ÚTILES PARA TENER ÉXITO COMO MÚSICO PROFESIONAL

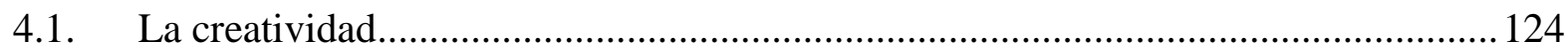

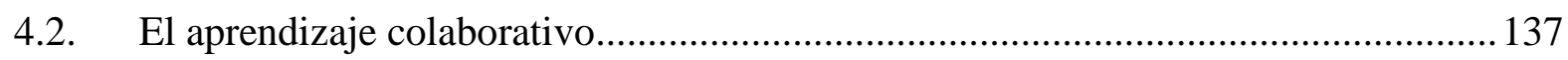

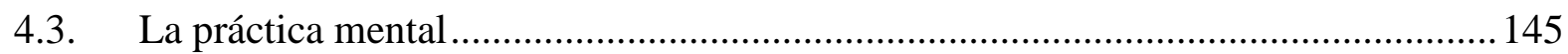

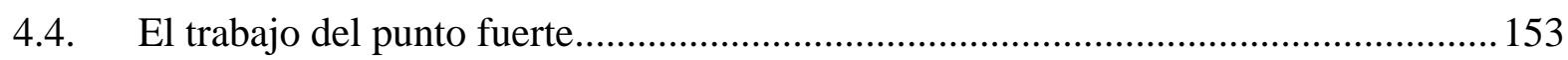

4.5. La enseñanza de música en los conservatorios superiores como logro individual y social. Propuesta de un aprendizaje complejo ................................................................ 158 
PARTE III FASE EXPERIMENTAL ........................................................... 165

5 FASE EXPERIMENTAL .................................................................................167

5.1. Aproximación metodológica: investigación acción ............................................... 167

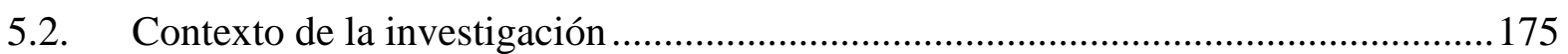

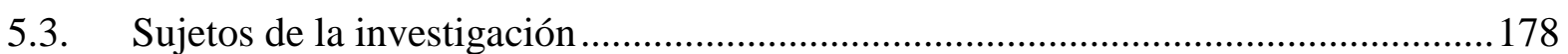

5.4. Métodos de investigación utilizados ....................................................................... 181

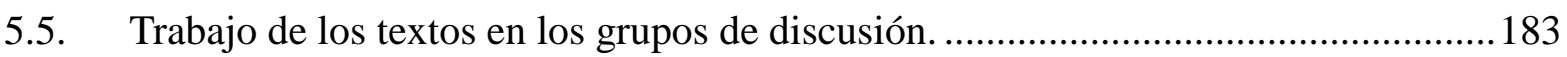

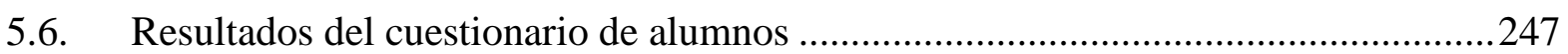

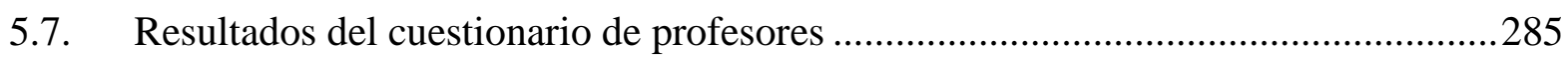

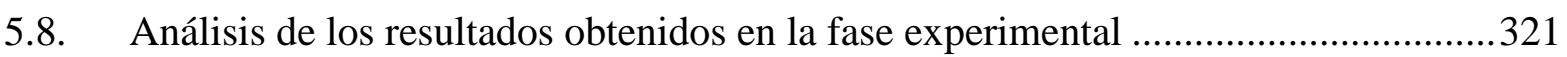

PARTE IV CONCLUSIONES Y LÍNEAS FUTURAS ................................. 331

CONCLUSIONES.........................................................................................................................333

FUTURAS LÍNEAS DE INVESTIGACIÓN ...............................................................................349

REFERENCIAS BIBLIOGRÁFICAS ........................................................................353

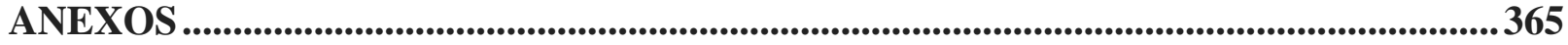

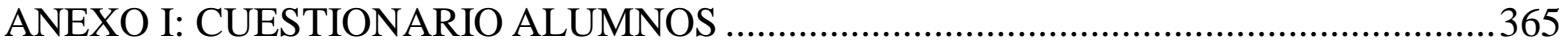

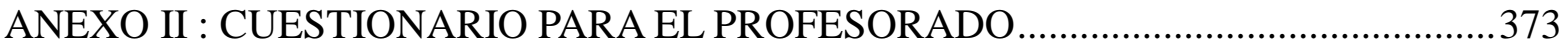

ANEXO III Gráfica comparativa de las preguntas 1 a 20, cambios producidos entre

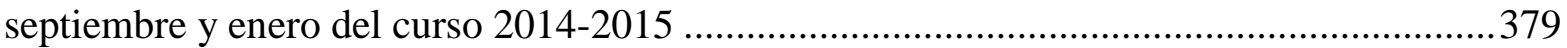

ANEXO IV: Gráfica comparativa de las preguntas 21 a 40, cambios producidos entre

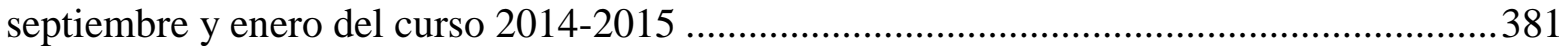

ANEXO V: Gráfica comparativa de las preguntas 41 a 60 , cambios producidos entre

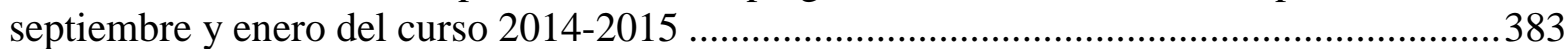

ANEXO VI: Gráfica comparativa de las preguntas 61 a 80, cambios producidos entre septiembre y enero del curso 2014-2015.

ANEXO VII: Gráfica comparativa de las preguntas 1 a 20 , cambios producidos entre septiembre y enero del curso 2015-2016.

ANEXO VIII: Gráfica comparativa de las preguntas 21 a 40, cambios producidos entre septiembre y enero del curso 2015-2016

ANEXO IX: Gráfica comparativa de las preguntas 41 a 60 , cambios producidos entre septiembre y enero del curso 2015-2016.

391

ANEXO X: Gráfica comparativa de las preguntas 61 a 80, cambios producidos entre septiembre y enero del curso 2015-2016 
Ilustración 1. Esquema: Búsqueda de la excelencia. Elaboración propia...............................27

Ilustración 2. Esquema: Inteligencia exitosa de Sternberg. Elaboración propia.

Ilustración 3. Esquema: Inteligencias de Gardner y cómo desarrollarlas. Elaboración propia 63

Ilustración 4. Esquema de la mentalidad fija y de la mentalidad en crecimiento de Dweck. Elaboración propia.

Ilustración 5. Propuesta para pasar de mentalidad fija a mentalidad en crecimiento.

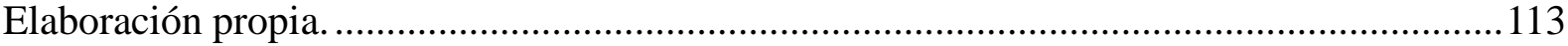

Ilustración 6. El estudiante de música convencido y apoyado. Elaboración propia ...............119

Ilustración 7. El conservatorio del siglo XXI. Elaboración propia........................................136

Ilustración 8. Esquema: La excelencia para todos. Elaboración propia. .................................158

Ilustración 9. Esquema: Propuesta de aprendizaje complejo. Elaboración propia. .................164

Ilustración 10. Definición de la propuesta del aprendizaje complejo...................................169 



\section{ÍNDICE DE TABLAS}

Tabla 1. Traducción y adaptación del diagrama de Nigel Holme, en Dweck, 2006:245 67

Tabla 2. Traducción y adaptación de los estadios del desarrollo musical (adaptación de los modelos del Sports-related de Abbott y Collins, 2004) en McPherson y Lehmann, 2012:41).82

Tabla 3. Características de los primeros años de desarrollo (traducción del cuadro de McNamara et al. 2006:291).... 83

Tabla 4. Características psicológicas del desarrollo de la excelencia en los primeros años de desarrollo (traducción del cuadro de McNamara et al., 2006:292). 84

Tabla 5. Características del estadio intermedio de desarrollo (traducción del cuadro de McNamara et al., 2006:293).

Tabla 6. Características psicológicas del desarrollo de la excelencia en el estadio intermedio de desarrollo (traducción del cuadro de McNamara et al., 2006:292)..... 86

Tabla 7. Características de los últimos años de desarrollo (traducción del cuadro de McNamara et al., 2006:296)

Tabla 8 Características psicológicas del desarrollo de la excelencia en lo últimos años de desarrollo (traducción del cuadro de McNamara et al., 2006:298) 88 

PARTE I

PRESENTACIÓN 



\section{INTRODUCCIÓN}

\subsection{Motivación}

Elegir este tema de investigación para realizar mi tesis parte de mi propia experiencia como profesora de Conservatorio Superior, concretamente 17 años impartiendo diversas asignaturas en el Conservatorio Superior de Navarra (Didáctica de la Música, Didáctica de la Especialidad, Psicopedagogía, Prácticas del Profesorado, Música y Movimiento, Estética, Técnica corporal, Didácticas Específicas, Conjunto Instrumental, Conciertos Didácticos y Metodología de la investigación) y otros 4 en el Real Conservatorio Superior de Danza de Madrid (impartiendo la asignatura de Música aplicada a la Danza). En el desarrollo de mi docencia, he sido siempre consciente de la necesidad imperiosa de seguir mejorando, de cara a ayudar a los alumnos en su lucha por desarrollar las habilidades que les sean más útiles para su futuro como músicos. La enorme diversidad de alumnos que han pasado por nuestras manos, con sus historias particulares de proyectos, sueños, problemas, fracasos, superaciones, éxitos, etc., me han hecho ver que la única forma de atender a esa búsqueda de la mejoría es desde el conocimiento más amplio posible de lo que son las características y las herramientas necesarias para que ese alumnado alcance su desarrollo óptimo.

Esa experiencia que he citado me ha hecho ver con claridad que la mejor forma de atender a las necesidades de los alumnos era recurrir a las investigaciones científicas. Mi trabajo como profesora de Pedagogía Musical me ha permitido conocer de primera mano el estado actual de las investigaciones que se vienen realizando en torno al trabajo de los músicos y las circunstancias que influyen en su rendimiento. Y ese conocimiento es el que me ha llevado a plantear la necesidad de aplicar todos esos estudios a la práctica diaria de los conservatorios, o mejor dicho, a la práctica diaria del Conservatorio Superior de Música de Navarra, que es el entorno donde una puede ejercer su influencia de manera más directa. Esa práctica diaria es la que nos venía mostrando cómo la máxima aspiración de cualquiera que accede a este tipo de estudios es alcanzar su rendimiento óptimo, algo que podríamos llamar "excelencia musical".

No cabe duda de que este objetivo es el que ha animado a todos los músicos de la historia (aunque podríamos hacerlo extensivo a cualquier actividad profesional: todo el que se dedica a algo intenta alcanzar la excelencia en su campo, al menos en teoría). Desarrollar al máximo 
sus capacidades, explotar el talento natural que cada uno puede tener, alcanzar el éxito... Pero si esto es absolutamente cierto, no lo es menos que el contexto en el que vivieron Palestrina, Monteverdi, Bach, Beethoven, Schönberg o Miles Davis son tan diversos que no se puede pensar en un concepto único de "excelencia musical". Parafraseando a Aristóteles, podríamos decir que la excelencia musical se dice de muchas maneras, en función de una serie importante de factores entre los que el contexto histórico es quizá uno de los más relevantes. Y llegamos así al punto de partida que motiva esta tesis (y que se añade al que nos ha servido para presentarla en las líneas anteriores).

La razón de investigar este tema es la siguiente: gracias a las últimas investigaciones (Eccles, O'Neill y Wigfield, 2005; Ivaldi y O'Neill, 2010; O'Neill, 2011; Hallam y Gaunt, 2012 y Dobson y Gaunt, 2015) se ha demostrado la necesidad de redefinir a qué llamamos excelencia musical. Como evidencian las autoras citadas, el panorama musical está cambiando: la industria está haciendo que aparezcan nuevas áreas de trabajo, mientras que otras áreas tradicionales (que antes eran imprescindibles) van perdiendo protagonismo. Es importante ser conscientes de que muchos campos de trabajo se están reduciendo, al tiempo que otros completamente nuevos van apareciendo, desplazando a los anteriores, sin contar con los que puedan seguir añadiéndose a la lista en las próximas décadas. La pregunta inevitable que surge es evidente: ¿las habilidades que necesitan los músicos contemporáneos son las mismas que se necesitaban hace cien años, es decir, en el momento en que se constituyeron los conservatorios de música en su formato actual? Pregunta de partida que tiene otra derivada: ¿Les estamos preparando realmente para el mundo profesional al que tendrán que enfrentarse cuando abandonen nuestras aulas?

La contribución que podemos aportar es, a nuestro juicio, la de arrojar un poco de luz sobre las necesidades actuales y reales de los estudiantes de música en la educación superior en el siglo XXI. Esa primera aportación iría seguida, indudablemente, de un esfuerzo para que esas necesidades se atendieran convenientemente desde las instituciones, estableciendo una nueva forma de entender la educación musical en sus niveles superiores, es decir, en los conservatorios superiores de música. Podemos decir, en este sentido, que algo se está moviendo ya en el mundo de los conservatorios. Como veremos un poco más adelante, al centrarnos en el estado de la cuestión, los principales centros docentes superiores de música de los cinco continentes están implicados en esa búsqueda y esa mejoría, abriendo líneas nuevas de investigación, que enlazan con las anteriores y que descubren nuevas posibilidades. 
La mejor prueba de esto es la existencia de The Reflective Conservatoire Conference, congreso trianual que presentaremos en su momento, y cuya intención principal es dar a conocer esas líneas de investigación que pueden permitir la redefinición del concepto de "excelencia musical" y hacer que el alumnado de los Conservatorios esté más cerca de conseguirla.

\subsection{Justificación}

La principal motivación que empuja a realizar esta tesis es la necesidad que todo profesor tiene de estar en constante actualización, de cara a ofrecer a sus alumnos lo mejor de sí mismo y que éstos puedan alcanzar un estado óptimo de desarrollo personal. No cabe duda de que el proceso de enseñanza-aprendizaje es uno de los más fascinantes que existen en la sociedad humana y aún menos duda nos cabe de que es algo que está en un constante proceso de desarrollo y cambio. El siglo en el que acabamos de entrar nos ha enfrentado con una serie de retos a los que hay que dar respuesta de uno u otro modo. La sociedad está cambiando, las formas de vida están cambiando $y$, en lógica consonancia, las formas de enseñar y aprender han de ajustarse a esos cambios.

Pero más aún, el desarrollo de las ciencias y sus aplicaciones a los diversos campos de estudio y trabajo está siendo espectacular. Es innegable que el siglo XX ha sido el más fecundo en lo que a desarrollo científico y tecnológico se refiere y eso ha permitido una mejora en todos los aspectos de la vida, desde la esperanza de vida, su calidad y otra multitud de aspectos de los que hay que felicitarse (sin que esto sirva para ocultar las muchas miserias que ha traído también ese siglo ya finalizado y que no viene a cuento referir aquí). Del mismo modo, esos avances han llegado también al mundo de la enseñanza $y$, en concreto, al de la enseñanza musical. Es por ese motivo que resultaría de una miopía casi denunciable mantener posiciones que pertenecen a tiempos más cercanos al siglo XIX que al mundo en el que vivimos.

Pero no sólo se trata de esto. A nuestro alrededor se respiran aires de cambio en el ámbito de los conservatorios de música. Como comprobaremos en el apartado siguiente, en todo el mundo se vive con interés esta situación, que va a dejar retrasados a todos los que no se adhieran a este movimiento. En los conservatorios de más prestigio ya se están llevando experiencias piloto, investigaciones prácticas y otro tipo de actividades que están en consonancia o llevan a cabo lo que las investigaciones científicas sugieren. Era, pues, casi 
obligatorio iniciar algo similar también en nuestro propio ámbito. Esperemos que esta iniciativa no sea algo aislado sino que pueda convertirse en una más de un buen montón de experiencias similares (como nos consta que ya existen en algunos lugares de nuestra geografía).

Por último, señalar que la investigación que hemos llevado a cabo es perfectamente viable y generalizable, dada la diversidad de estudiantes que tenemos (no sólo procedentes de la Comunidad Foral de Navarra, sino de muchas otras, tanto limítrofes como más alejadas), lo que permite trabajar con diferentes perfiles, edades, intereses, etc. En consecuencia, los resultados que hemos obtenido pueden perfectamente servir como punto de partida para ulteriores investigaciones, como comentaremos igualmente en nuestras conclusiones.

\subsection{Estado de la cuestión}

Casi por definición podríamos decir que la labor de un conservatorio superior es, precisamente, conseguir que sus alumnos se conviertan en intérpretes, compositores, directores y pedagogos excelentes. Dicho de otro modo, la búsqueda de la excelencia es la nota característica de los conservatorios de música, ya desde su aparición a finales del siglo XVIII. Pero esa excelencia se puede buscar de muchas maneras y, como sucede con todos los elementos que forman parte de una sociedad, depende siempre de cómo sea esa sociedad y en qué momento histórico estemos viviendo. Parece evidente que no se debería trabajar de igual modo en un conservatorio actual, en pleno siglo XXI, que en cualquiera de los muchos que ya había a mediados del siglo XIX, aunque lo cierto es que en algunos aspectos podemos decir que no han cambiado demasiadas cosas en los últimos cien años. Alguien podría acusarnos de criticar negativamente a los conservatorios sin pruebas que avalen semejante afirmación. En nuestro favor citaremos dos ejemplos (uno de los cuales desarrollaremos más adelante): el primero es una cita de Benjamin Franklin y tiene un tono irónico que no podemos dejar pasar: "En este mundo nada puede darse por seguro excepto la muerte, los impuestos y la 
inmutabilidad de los conservatorios"1; el segundo es el texto presentado en 2015 por David Myers, profesor de la Facultad de Música de la Universidad de Minnesota, titulado "Creatividad, diversidad e integración: un manifiesto por un cambio radical en la educación de los músicos del siglo XXI".

A pesar de lo que acabamos de afirmar, no cabe ninguna duda acerca de que, en la actualidad, los investigadores están volcados por completo en la tarea de analizar el papel y el funcionamiento de los conservatorios de música, para hacer propuestas de cambio que nos permitan dar un nuevo enfoque y una nueva proyección a los mismos, de cara a formar a los músicos excelentes del siglo XXI.

La lista de psicólogos, pedagogos, musicólogos y otros especialistas puede ser interminable a la hora de hablar de la situación actual de la cuestión. A lo largo de nuestra tesis irán apareciendo los nombres de Sloboda, Csikszentmihaly, Hallam, Gaunt, Dweck, etc., a los que hay que sumar otros tantos que nos dejaremos en el tintero por falta material de tiempo y espacio. Pero la pregunta ahora es ¿en qué situación nos encontrábamos en el momento en que se llevó a cabo nuestra investigación en el Conservatorio Superior de Navarra?

Podríamos aquí intentar una recensión de las investigaciones realizadas en estos asuntos, pero la tarea se nos antoja poco menos que imposible. Quizá la mejor manera de acercarnos al estado de la cuestión sea The Reflective Conservatoire Conference, un congreso trianual que se celebra en Londres, bajo los auspicios de la Guildhall School of Music and Drama y cuya última reunión tuvo lugar entre el 26 de febrero y el 1 de marzo de 2015. Este Congreso, que se celebró por primera vez en 2006, no pretende ser una mera reunión de investigadores exponiendo sus teorías de manera más o menos rígida y teórica, sino más bien todo lo contrario. La idea es reunir a investigadores, intérpretes, profesores, estudiantes, equipos

1 Se trata de una manipulación de la cita original de Franklin, que no incluyó en su frase jocosa a los conservatorios. La frase se la debemos a Toni Woodcock, presidente del conservatorio de Nueva Inglaterra, en el discurso de cierre de la Reflective Conservatoire Conference de 2015. 
directivos de conservatorios, patrocinadores y todos aquellos que estén interesados en el devenir de los Conservatorios de música, como lo demuestra el hecho de que la asistencia a las sesiones está abierta a todo el público que lo desee de manera gratuita. La idea consistía en reunir a toda esa gente que hemos citado anteriormente, pero no sólo del Reino Unido, sino de todo el mundo. La respuesta de este último congreso al que nos referimos ha sido espectacular: más de 400 ponentes, procedentes de más de 90 países de los cinco continentes.

Como decimos, todo comenzó en 2006, como respuesta a una idea de Helena Gaunt, vicedirectora de la Guildhall School of Music e investigadora de prestigio (como tendremos ocasión de comprobar a lo largo de nuestra tesis). Y, como muestra de la actualidad de la investigación que estamos llevando a cabo, no hay más que observar el título que animó este cuarto congreso: "Creativity and changing cultures". Creatividad y culturas cambiantes. ¿Qué nos está diciendo este título? Para dar respuesta a esta pregunta, tenemos que retrotraernos al anterior congreso, celebrado en 2012, tras el que el profesor John Sloboda lanzó un reto a investigadores, profesores y alumnos, articulado en los siguientes puntos:

1.- Articular la naturaleza del cambio que queremos provocar en nuestros estudiantes, teniendo en cuenta que éstos, por lo general, expresan su intención de definir su éxito en términos de mejoría técnica al tiempo que encajan en una "sociedad mejor": para ello hay que redireccionar la forma en que trabajan los conservatorios;

2.- Convertir los conservatorios en comunidades dotadas de sentido, es decir, que haya consistencia entre lo que contamos al mundo que somos y lo que realmente vivimos como instituciones;

3.- Transformar la competición entre las instituciones en cooperación. Sloboda lo plantea con una irónica pregunta: ¿cómo podemos reemplazar la lucha entre conservatorios por tener al "mejor fagotista" por proyectos de cooperación que propicien una identidad más coherente y una mayor influencia en la sociedad?

Basta echar un vistazo a los títulos de las ponencias, mesas redondas, conferencias y talleres para hacernos una idea de cómo la idea de cambio, de búsqueda de otra forma de trabajar, de convertir la excelencia en un concepto de resonancias novedosas, es la que preside el mundo de la pedagogía musical en el momento actual. He aquí un pequeño listado que nos puede ilustrar lo que decimos: "Conservatorios en la comunidad", "Innovaciones e 
interdisciplinariedad en el desarrollo del currículo", "Hacia un círculo virtuoso: el ciclo superior de los estudios en el conservatorio como diálogo creativo, reflexión crítica y desarrollo de las disciplinas", "Los conservatorios en el 2020 y más allá”, "La composición como un proceso colaborativo", "Aproximaciones interdisciplinarias a la improvisación como un proceso colaborativo", "Repensando las habilidades de los músicos profesionales", "Cambios en los conservatorios" y así sucesivamente. Como podrá comprobarse, prácticamente todos los temas que van a aparecer en esta tesis están en primera línea de la reflexión pedagógica, psicológica y musicológica dentro de los conservatorios superiores de música.

En los párrafos que siguen vamos a hacer una breve recensión de las investigaciones que se presentaron en este congreso, en función de los temas fundamentales que se tratan en el cuerpo central de la tesis. Quizá los dos temas "estrella" del Congreso fueron la necesidad de un cambio profundo en los conservatorios (tanto en sus currículos como en la forma en que se relacionan con el entorno social en el que viven) y la importancia del trabajo colaborativo. Puede que el exponente más relevante de la situación de los conservatorios sea el Manifiesto presentado por David Myers, en representación de la College Music Society (la organización nacional de profesionales de los estudios superiores de música). Su título no puede ser más revelador: "Creatividad, diversidad e integración: un manifiesto por un cambio radical en la educación de los músicos del siglo XXI". Su objetivo es hacer un llamamiento de cara a conseguir una revisión completa de la finalidad y la estructura de los estudios musicales. Los pilares en los que fundamenta esa reconversión global son la creatividad, la diversidad y el aprendizaje integrado, para alcanzar el rigor, la excelencia, el sentido y la vitalidad tanto en el conocimiento teórico como en la práctica musical.

En la misma línea de cambio, pero interactuando con la comunidad, tenemos el proyecto en que está embarcada la Academia Noruega de Música, junto con el ayuntamiento de Hammerfest (la ciudad más septentrional del mundo) y que responde de manera parcial al desafío lanzado por John Sloboda en el Congreso de 2012. De entrada, la Academia ha integrado el programa como parte de las materias que se deben superar para obtener el Master que ofrece, con el objetivo de que las perspectivas de los estudiantes se amplíen en su papel como músicos. La intención global del programa es la de incrementar el interés por la música en la sociedad, ampliar las actividades culturales y, de paso, hacer de Hammerfest un lugar más atractivo donde vivir. Este proyecto de colaboración tiene lugar en el primer curso del 
master (que tiene una duración de dos años) e implica la participación activa en actividades locales de todo tipo, de cara a atraer la atención del público por la música. Esa participación activa es en todo momento monitorizada y pasada por la reflexión, dado que los estudiantes (entre 15 y 20 cada año) colaboran con músicos locales, potenciando especialmente la reflexión conjunta sobre la experiencia, tanto de los estudiantes entre sí, como entre estudiantes y profesores y entre los miembros de la comunidad, todo ello a través de cuestionarios, observaciones y entrevistas, poniendo especial énfasis en los momentos que se consideren más significativos e interesantes para los alumnos. Lo que se espera es que, a lo largo de esta experiencia, se vayan consiguiendo nuevas metas y nuevos objetivos, entre los que ya empiezan a destacar algunos: los estudiantes ya están manifestando el enriquecimiento personal y musical que para ellos supone la experiencia (sobre todo de cara a su carrera profesional como músicos), pero la discusión ha entrado ya en la necesidad de efectuar cambios en el currículo de la Academia, algo que podrían compartir con otras instituciones musicales con idénticas aspiraciones.

Una misma intención guía el estudio realizado por Glenn Carruthers, Decano de la Universidad Wilfrid Laurier (Canadá) y antiguo presidente de la ISME (International Society for Music Education). Carruthers afirma que, pese a que existe un casi unánime consenso en la necesidad de efectuar cambios en los conservatorios para adaptarse a las nuevas necesidades del siglo XXI, su estudio muestra que menos de la mitad de las instituciones dedicadas a estudios musicales superiores en Canadá ha llevado a cabo algún tipo de cambio significativo al respecto. Por eso, afirma categóricamente que es necesario realizar urgentemente cambios importantes que salven el abismo que separa a los conservatorios (con sus currículos anquilosados) de la comunidad en las que están asentados. Es más, su idea es la de que deben ser un servicio comunitario más, sin olvidar la excelencia musical y cultural que anima la existencia de los conservatorios de música.

Muchas otras ponencias abundaron en esa misma necesidad ("Cambios en el conservatorio", donde Paul Alan Baker defiende la necesidad de sacar a los conservatorios de su aislamiento social; "Conservatorios en la sociedad: el caso italiano", donde la profesora Leonella Grasso dirigió una mesa redonda en la que se expusieron con crudeza los problemas a los que se enfrentan los conservatorios italianos y, por extensión, el resto; y tantos otros...), pero quizá el más interesante fue la serie de ponencias que presentó Geir Johansenn, miembro de la Academia Noruega de Música, y que, de manera mucho más amplia que la experiencia de 
Hammerfest, respondía al reto del profesor Sloboda. El título era escueto: "Conservatorios en la sociedad", pero su alcance es más que interesante. Las tres preguntas de las que parte son éstas: ¿de qué manera afecta la sociedad a los conservatorios de música? ¿De qué manera pueden, o podrían, afectar los conservatorios a la sociedad contemporánea? ¿Cómo reflexionan los conservatorios sobre esta relación recíproca? La investigación/reflexión se llevó a cabo durante el curso 2013-2014 y fue llevada a cabo por un grupo de investigadores y profesores de diferentes conservatorios de Europa y Australia. No podemos aquí sintetizar todas las aportaciones que se hicieron a través de diferentes ponencias y mesas redondas, pero sí creemos interesante reseñar dos de las ideas centrales, prácticamente los ejes alrededor de las cuales giran todas las demás: la necesidad imperiosa de sacar a los conservatorios de su aislamiento elitista y abrirse a una sociedad cambiante, contribuyendo a ese cambio de manera activa y positiva; y la obligación de comprometerse con el desarrollo de los estudiantes, proporcionándoles no sólo la típica formación técnica, sino también la situación de las investigaciones y los proyectos de innovación.

El otro "tema estrella" del Congreso, como hemos comentado, fue la importancia del trabajo colaborativo, algo que está cada vez más en alza, frente a la idea tradicional del músico intérprete solitario y virtuoso. De entre las numerosas ponencias e investigaciones presentadas en el Congreso, nos parece interesante reseñar tres de ellas. La primera se presentó en mesa redonda, dando a conocer un proyecto de colaboración en procesos compositivos, tarea que tradicionalmente se ha considerado, fuera de toda discusión, un proceso individual, casi propio del "genio". Julian Phillips, profesor de composición de la Guildhall School, dirigió un programa de composición colaborativa junto a Philip Venables (compositor de la Royal Opera House) y Stephen Plaice (escritor), con resultados más que satisfactorios.

La segunda investigación que queremos destacar es la llevada a cabo por Gemma Carey, Profesora de Pedagogía en el Conservatorio de la Universidad de Queensland (Australia). Su estudio se basó en la necesidad de llevar a cabo reflexiones críticas conjuntas entre profesores, de manera que se lograran las mejores prácticas docentes (Gaunt, 2007). Para ello llevó a cabo una experiencia piloto en diversos conservatorios australianos, en los que parejas de profesores reflexionaban críticamente sobre sus clases individuales, grabadas previamente en vídeo. El objetivo era mejorar su práctica docente a través del enriquecimiento mutuo, objetivo que parece haberse conseguido, de modo que esta experiencia piloto intentará imponerse de manera oficial en el trabajo de los conservatorios australianos. 
Por fin, la tercera experiencia destacable es el par de proyectos presentados por Ingrid Maria Hanken, directora del Centro de Excelencia Musical de la Academia Noruega de Música. Y nos parece interesante porque agrupa todo lo que ha aparecido anteriormente, es decir, las ventajas de la colaboración entre profesores, entre alumnos y entre profesores y alumnos. Por un lado, dos estudios (llevados a cabo por Morten Carlsen y Kristin Kjølberg) incidieron sobre las ventajas del trabajo colaborativo entre estudiantes; y por otro lado, Helena Gaunt investigó sobre los beneficios del trabajo colaborativo entre profesores. Las conclusiones, invariablemente, apuntaron siempre en la necesidad de ir implantando estos procedimientos de trabajo en los conservatorios, de cara a un mejor desarrollo de la enseñanza, en aras de conseguir la tan ansiada excelencia musical.

Tal como hemos hecho al abordar la situación actual del tema en términos generales, aprovecharemos la celebración el año pasado del III Congreso de Conservatorios Superiores de Música (San Sebastián, 24-26 de noviembre de 2016), para tomar el pulso a la cuestión. Parece evidente que todos aquellos que están trabajando en alguna línea de investigación importante en relación con los Conservatorios de Música debería estar allí y, de este modo, hacer partícipes a todos del estado de sus investigaciones, sus propuestas y sus ideas.

Lo primero que nos encontramos al analizar la celebración de dicho Congreso son las diez líneas de investigación que se propusieron como armazón teórico del mismo. Concretamente las que siguen:

1. Formación del profesorado del ámbito de la educación superior de música.

2. Selección del profesorado: acreditaciones, oposiciones y prácticas.

3. Perfeccionamiento del profesorado.

4. Evaluación: procedimientos y resultados.

5. Promoción profesional del profesorado: vertical y horizontal, accesos y oposiciones.

6. Relación de los centros superiores de música con otros niveles de educación musical (Universidades, Conservatorios profesionales, Escuelas de Música, etc.).

7. Proyectos para la calidad de vida desde la música.

8. Conciertos y audiciones didácticas. Público nuevo.

9. Nuevas profesiones de la música. 
10. Propuestas de investigación, innovación y desarrollo en los centros superiores de música. Como vemos, de las diez líneas propuestas sólo tres de ellas se plantean la posibilidad de plantearse una nueva manera de enfocar el trabajo que se realiza en los conservatorios: las números 3,7 y 10 . Podríamos incluir la número 6 también... si se hiciera referencia a la relación con el resto de la sociedad y no insistiera en permanecer encerrada en el marco de la música académica. Y, dicho sea de paso, creemos que estamos siendo generosos al incluir la línea 3 en esta categoría.

Aun así, podemos afirmar que el discurso de la necesidad de cambio sí está calando en algunos sectores del profesorado de conservatorios superiores. Echemos un vistazo a algunas de las ponencias que se presentaron al Congreso, así como a algunas de las mesas redondas que se celebraron, para confirmar lo que decimos: "Mirando al futuro: propuestas de investigación, innovación y desarrollo en los centros superiores de música" (Mesa redonda), con la intervención de José Luis Aróstegui y Celia Ruiz Bernal (CSM de Granada), Itziar Larrinaga (Coordinadora de investigación e innovación de Musikene), Nerea López de Vicuna (Office Manager de la AEC, Asociación Europea de Conservatorios) e Isabel Gondel (Federación Nacional de Estudiantes de Música); "Formación, procesos de selección, evaluación y promoción del profesorado de los centros superiores de música” (Mesa redonda), con Eva Ferreira (Directora de Unibasq, Agencia de Calidad del Sistema Universitario Vasco), Antonio Narejos (Peer-review de MusiQuE, Organismo de Evaluación Externa dedicado a la mejora de la Educación Musical Superior), Álvaro Zaldívar (CSM Murcia), y Ma Amparo Porta (Universidad Jaume I); "Proyectos para la calidad de vida desde la música. Conciertos y audiciones didácticas. Público nuevo" (mesa redonda), con Basilio Fernández (Presidente de la Asociación Española Psicología de la Música), Mikel Cañada (Presidente de ROCE, Red de Organizadores de Conciertos Educativos), Patxi del Campo (Director del Instituto Música Arte y Proceso) y Miguel Martín (Director del Festival de Jazz de Donostia-San Sebastián). "Programa formativo para la mejora de la calidad en los Centros de Educación Superior musical en España”, ponencia a cargo de Begoña Alonso Savín; "La educación emocional en el aula de música como recurso para favorecer el desarrollo integral y el bienestar del alumnado", ponencia de Emilia Ángeles Campayo Muñoz y Alberto Cabedo Mas; “Aprendices de brujos. La autorregulación del aprendizaje musical”, ponencia de Ignacio Montero García-Celay, Amalia Casas Mas e Irene Martínez Cantero; "Diagnóstico y evaluación de los profesores de música como herramienta de mejora de la docencia en los 
Conservatorios Superiores", ponencia de $\mathrm{M}^{\mathrm{a}}$ Encarnación Bernal Martínez y Rolando Serafín Bernal Martínez; "El aprendizaje colaborativo en la enseñanza superior de música”, ponencia de Eulalia Gorbe Martínez y Amparo Porta Navarro; "El perfil psicológico de los artistas: un estudio de fortalezas en los estudiantes de música”, Diego Calderón, Josep Gustems, Caterina Calderón y Carolina Martín; "Perfil del futuro músico profesional: formación, inquietudes y expectativas” ponencia de Miren Gotzone Higuera Bilbao; “¿Conservar o Innovar?”, ponencia de Leandro A. Martín; "Concepciones del profesorado sobre los inicios de la actividad musical extraescolar", ponencia de Amalia Casas Mas, Ignacio Montero García-Celay, Irene Martínez Cantero.

Si bien no encontramos ninguna apuesta del tipo que nos encontrábamos en el Congreso de Londres (los interesantes casos de Noruega o Australia, abriendo los conservatorios a la colaboración con el resto de la sociedad), sí vemos que la inquietud en torno a éste y otros temas va encontrando su lugar en las reflexiones que se hacen sobre la situación actual de los conservatorios superiores. Quizá o más cercano a lo que apuntábamos en el anterior paréntesis sería la mesa redonda citada en último lugar, donde se aventuraba la posibilidad de utilizar los conciertos y las audiciones didácticas como forma de mejorar la calidad de vida, no sólo de los que asisten, sino también de los propios músicos.

En otra línea (que también forma parte de nuestra investigación) queremos destacar las aportaciones realizadas en torno al punto fuerte de los músicos ("El perfil psicológico de los artistas: un estudio de fortalezas en los estudiantes de música"), a nuestro juicio uno de los campos de investigación que pueden ser más fecundos de cara a conseguir la excelencia musical. Y lo mismo podemos decir de esas aportaciones hechas desde la psicología ("La educación emocional en el aula de música como recurso para favorecer el desarrollo integral y el bienestar del alumnado"), que buscan eso mismo a la luz de las nuevas teorías que ponen el foco en el desarrollo de las distintas inteligencias que tenemos los seres humanos.

Vemos igualmente que el papel de los profesores se revela como algo que debe estar en continua revisión ("Diagnóstico y evaluación de los profesores de música como herramienta de mejora de la docencia en los Conservatorios Superiores", "Concepciones del profesorado sobre los inicios de la actividad musical extraescolar"), dado que el proceso que busca la excelencia no es un proceso de aprendizaje exclusivamente, sino de enseñanza-aprendizaje, pero en unas condiciones muy peculiares: la clase individualizada, con todo lo que ello conlleva. 
Por último, destacar también las aportaciones hechas en torno a la importancia del aprendizaje colaborativo, reflejado en dos ponencias, "El aprendizaje colaborativo en la enseñanza superior de música” y “¿Conservar o Innovar?”, lo que demuestra que los temas que presentamos en esta investigación están encontrando acomodo en nuestros conservatorios, si bien a un ritmo quizá algo lento.

\subsection{Objetivos}

Hemos dividido los objetivos que han guiado la presente investigación en dos grupos: objetivo general y objetivos específicos. Alrededor de ellos se desarrollan los capítulos que constituyen esta tesis doctoral, sirviendo de hilo conductor y de punto de referencia constante.

\section{Objetivo General}

Conocer las herramientas y habilidades necesarias para convertirse en un músico excelente y buscar los medios para lograrlo en su aplicación específica en el Conservatorio Superior de Música de Navarra.

Este objetivo general se despliega en otros tres objetivos específicos, que pasamos a reseñar a continuación:

\section{Objetivo Específico 1}

Obtener una idea clara de lo que constituye la excelencia musical en el siglo XXI, de manera que se pueda transmitir a los alumnos y éstos la hagan suya.

\section{Objetivo Específico 2}

Conocer las características del estudiante ideal de la enseñanza superior, así como del entorno ideal necesario que debe acompañarle, de cara a conseguir la excelencia.

\section{Objetivo Específico 3}

Localizar las herramientas útiles para el estudiante de música a la hora de buscar la excelencia musical e indagar sobre la forma de aplicarlas. 


\subsection{Enfoque metodológico aplicado a la investigación}

Lo que hemos realizado en nuestra investigación sigue el esquema básico de la investigación acción definido en el círculo que aporta Tripp (2003, en Cohen, Manion y Morrison, 2015: 354), utilizamos este esquema para explicar el curso que ha seguido nuestro trabajo con el alumnado del Conservatorio Superior de Navarra.

Tripp parte del hecho de que existe el reconocimiento de un problema, o en sus propias palabras: "identificación, evaluación y formulación" de esa situación problemática. El propio Tripp dice claramente que el término "problema" no debe entenderse en un sentido restrictivo, sino que hace referencia a cualquier situación en que se detecte la necesidad de introducir algún tipo de innovación dentro de un programa escolar (el ejemplo es del propio Tripp). En nuestro caso, el punto de partida (el "problema" detectado) fue la necesidad de buscar nuevas formas de conseguir la excelencia en los conservatorios superiores de música. En efecto, convertir al alumnado en músicos excelentes parece ser el objetivo principal de estos centros educativos y, sin embargo, año tras año vemos entre nuestro alumnado evidentes muestras de desencanto y frustración. Nos parecía necesario realizar algún tipo de investigación que implicara, al mismo tiempo, una actuación sobre el terreno. Y, siempre siguiendo a Tripp, diseñamos nuestro primer plan de acción, que incluía unos cuestionarios iniciales y un trabajo en aula, concentrado sobre las investigaciones referidas al tema que nos ocupaba.

Esta segunda etapa, tras el diseño del plan de acción, es la que comenzamos a desarrollar diseñando los cuestionarios y poniéndolos a prueba sobre grupos de control (Castelfranco Veneto, así como en el propio conservatorio un curso antes de iniciar la investigación con otro grupo de similares características) de cara a perfeccionarlos antes de llevarlos a cabo sobre el terreno. Todo ello, por supuesto, incluye la comunicación a los interesados de lo que se iba a realizar, para contar con su aquiescencia y participación voluntaria.

Una vez completadas estas dos primeras fases de la investigación, llegaba el momento de pasar a la acción directa. Es decir, poner en práctica los cuestionarios, trabajar en el aula con los textos de las investigaciones para luego debatirlas en los grupos de discusión y repetir al final el mismo cuestionario. Es lo que Tripp llama propiamente "investigación acción" y que consta de dos estadios: la primera recogida de datos y el análisis de los mismos. En nuestro caso, esta fase de acción tuvo un desarrollo más amplio, dado que (como ya hemos 
comentado) se desarrolló a lo largo de dos cursos académicos, con lo que el trabajo de recogida de datos, trabajo directo y análisis posterior fue más prolijo y abundante. Obviamente, a lo largo de este proceso, y tal como es propio de este tipo de investigaciones, aparecieron nuevos elementos, surgieron nuevas dudas y se propusieron nuevas actuaciones. El ejemplo del Aprendizaje Complejo, la idea de que cada uno ha de ser su propio profesor o la importancia de la práctica mental son ejemplos que ilustran esta idea (y que han sido desarrollados convenientemente en los apartados que se les dedican en la presente tesis).

Quedaría finalmente la última fase de la investigación acción, que no es otra que la de evaluar el trabajo para, consecuentemente, volver al punto de partida (el "problema") y redefinir los objetivos, para procurar que ese problema deje de considerarse como tal, en el sentido de que se ha actuado para que esté, de algún modo, en vías de transformación. En nuestro caso, la etapa de evaluación y reflexión es precisamente en la que nos encontramos a la hora de elaborar este trabajo y plantear futuras líneas de investigación que sigan aportando beneficios en la dirección que apuntamos, apoyados en los resultados obtenidos aquí.

Se abordó en esta investigación un objetivo general: "Conocer las herramientas y habilidades necesarias para convertirse en un músico excelente y buscar los medios para lograrlo en su aplicación específica en el Conservatorio Superior de Música de Navarra”.

Para verificar el cumplimiento del objetivo general se decidió dividirlo primero en una serie de objetivos específicos sobre cada uno de los cuales se aplicó un enfoque metodológico particular.

En el caso del objetivo específico $1^{\text {o }}$ "Obtener una idea clara de lo que constituye la excelencia musical en el siglo XXI, de manera que se pueda transmitir a los alumnos y éstos la hagan suya", se realizó una búsqueda bibliográfica sistemática que permitió conocer en profundidad a los principales autores de referencia que aparecen a lo largo de esta tesis.

Para el cumplimiento del objetivo específico 2 "Conocer las características del estudiante ideal de la enseñanza superior, así como del entorno ideal necesario que debe acompañarle, de cara a conseguir la excelencia", además de la revisión bibliográfica profunda, se realizó un estudio sobre el terreno partiendo del propio entorno de enseñanza superior en el que desarrollo mi actividad docente. Así se llevó a cabo la intervención dentro de un paradigma cuasi-experimental puesto que no se realizó una selección aleatoria de la muestra, sino que se 
trabajó con los propios alumnos, pero se realizó una intervención y se establecieron una serie de mecanismos que actuaron como grupos de control en diferentes momentos de la investigación.

Finalmente, para evidenciar el cumplimiento del objetivo específico 3 "Localizar las herramientas útiles para el estudiante de música a la hora de buscar la excelencia musical e indagar sobre la forma de aplicarlas", se dedicó la parte más significativa de la intervención y observación llevada a cabo en esta investigación. Estos apartados quedarán más detallados en la sección correspondiente a la fase experimental y los resultados de estos procesos son los que se exponen a lo largo de la tesis, según el esquema que se explica en el apartado siguiente.

\subsection{Estructura de la tesis}

La tesis se compone de cuatro partes diferenciadas: introducción, marco teórico, fase experimental y, conclusiones y futuras líneas de investigación.

El presente capítulo 1, que corresponde a la introducción, es donde se están desgranando las líneas generales que sirven de base a la tesis. Hemos expuesto el tema principal, demostrando su actualidad y pertinencia, al presentar el estado actual de la cuestión. En éste hemos podido comprobar cómo el mundo de los conservatorios musicales está viviendo una lenta pero sostenida revolución en sus planteamientos, de la mano de los más prestigiosos investigadores de todos los campos. Posteriormente hemos definido los objetivos que se pretenden alcanzar, que sirven de sustrato a toda la tesis doctoral. A continuación se ha hecho referencia al enfoque metodológico usado en la presente investigación, sustentado en el conocimiento riguroso de las investigaciones existentes sobre el tema, para pasar luego a analizar una serie de experiencias llevadas a cabo en el marco del Conservatorio Superior de Navarra (trabajo de textos, cuestionarios, grupos de discusión, etc.), que servirán para llegar a las conclusiones que cerrarán la tesis.

Como hemos dicho en el anterior párrafo, del enfoque metodológico se deriva ya la propia estructura de la tesis, que se inicia con la "segunda parte: marco teórico". En ésta se presenta el desarrollo de los fundamentos teóricos que van a servir de base a la tesis y que se toman de las investigaciones actuales en el terreno de la música. 
En el capítulo 2, que lleva por título "El concepto de excelencia", se presentan las tres investigaciones más relevantes acerca del concepto que está en el fondo de nuestra tesis. De este modo, hemos dividido el capítulo en otros tantos apartados, que servirán para exponer la teoría de la inteligencia exitosa de Sternberg, las inteligencias del futuro de Gardner y la teoría de la mentalidad fija y en crecimiento de Dweck.

El capítulo 3, titulado "La excelencia musical" pasa a abordar cómo ese concepto general analizado en el anterior capítulo se concreta en el campo de la música. Así, lo primero que se hace es precisamente redefinir (tal como explicábamos al inicio de esta introducción) el concepto de excelencia musical, de modo que sirva de catapulta para preparar el camino de cara al éxito profesional como músico (aplicando precisamente las teorías presentadas en el primer capítulo). En un primer apartado, se comentan las fases o estadios que nos llevan a la excelencia musical, apoyándonos en las investigaciones de McPherson y Lehmann (2012) y McNamara et al. (2006). Posteriormente, en el segundo apartado, nos centramos en el análisis que las investigaciones actuales hacen de las estrategias usadas por los músicos profesionales para alcanzar la excelencia musical, de modo que puedan ser útiles para mejorar la enseñanza musical. Finalmente, en el tercer apartado hablamos del concepto de excelencia musical en la actualidad, desde tres perspectivas: la primera, el modo en que Hallam y Gaunt (2012) nos presentan los diez puntos fundamentales para desarrollar el éxito como músico profesional; la segunda, la posibilidad de cambiar de mentalidad fija a mentalidad en crecimiento en la enseñanza superior; y la tercera, introduciendo la idea del "estudiante de música convencido y apoyado", como soporte en su camino hacia el éxito.

El capítulo 4, denominado "Herramientas útiles para tener éxito como músico profesional", hace honor a su título y pasa revista a las estrategias y herramientas que han ido perfilándose (a lo largo de la presentación del desarrollo teórico) como las más interesantes de cara a obtener ese estado óptimo que hemos llamado "excelencia musical". Podemos avanzar ya aquí que se trata de las siguientes cinco herramientas: la creatividad, el aprendizaje colaborativo, la práctica mental, el trabajo del punto fuerte y la propuesta de un aprendizaje complejo.

Una vez cerrado el marco teórico, se presenta la fase experimental en el capítulo 5, que llena toda la tercera parte de la tesis. En ella se exponen los resultados del trabajo de campo realizado en el Conservatorio Superior de Música de Navarra, contrastándolos constantemente 
con los objetivos planteados al inicio de la misma. Este capítulo se divide asimismo en ocho secciones, que comentamos brevemente a continuación.

La primera sección, “Aproximación metodológica: investigación acción”, explica el modo en que se ha llevado a cabo el trabajo de campo. La segunda, "Contexto de la investigación", nos introduce en el Conservatorio Superior de Música de Navarra, en sus principales características. La tercera, "Sujetos de la investigación", muestra el perfil de los estudiantes que han sido objeto del trabajo realizado. La cuarta, "Métodos de investigación utilizados", desgrana la metodología seguida en la investigación. La quinta, "Trabajo de los textos en los grupos de discusión", expone con todo detalle el proceso seguido con los alumnos de varios grupos y varios cursos lectivos en torno a las investigaciones teóricas que sirven de referencia a la tesis. La sexta, "Resultados del cuestionario de alumnos" presenta los resultados que depararon unas encuestas realizadas a los sujetos de la investigación a lo largo de dos cursos lectivos (2014-2015 y 2015-2016). Se aportan aquí tablas y gráficos que servirán para refrendar las conclusiones que luego se detallarán en el apartado dedicado específicamente a ellas. Igualmente, se describe cómo se llevó a cabo el cuestionario y, finalmente, se recogen las reflexiones realizadas por los alumnos al finalizar nuestra investigación, comparando los dos test realizados y viendo los cambios que se reflejan en ellos. La séptima, "Resultados del cuestionario de profesores", presenta los resultados del test que respondieron casi todos los profesores del claustro del Conservatorio, aportando igualmente las tablas y gráficos que servirán luego en el análisis final. Por fin, la octava, “Análisis de los resultados obtenidos en la fase experimental", desarrolla la parte más interesante del capítulo, pues es donde se ponen en relación los resultados con el marco teórico de la tesis, poniendo en relación todas las herramientas utilizadas y las consecuencias que se han seguido de su aplicación.

Una vez desarrollado el cuerpo básico de esta tesis doctoral, no queda más que pasar a los dos últimos capítulos. En el primero de ellos, "Conclusiones", se presentan los hallazgos que pueden inferirse de este estudio en relación con los objetivos planteados. Y en el segundo, "Futuras líneas de investigación", se plantean posibles campos de interés, que surgen de los interrogantes aparecidos a lo largo de nuestra investigación. La tesis se cierra con el listado bibliográfico usado en el estudio, al que siguen una serie de anexos de interés para entender mejor el desarrollo de la fase experimental, así como los cuestionarios utilizados y las gráficas comparativas de los cambios producidos entre los cuestionarios realizados en septiembre y enero de cada uno de los dos cursos objeto de la investigación. 


\section{PARTE II}

MARCO TEÓRICO 



\section{EL CONCEPTO DE EXCELENCIA}

Antes de analizar y desarrollar el concepto de excelencia musical, es necesario aclarar convenientemente qué se entiende por excelencia. Para ello, usaremos lo que Robert Sternberg (2005) denomina "developing expertise", esto es, considerarlo como un proceso continuo de adquisición y consolidación de un conjunto de habilidades necesarias para un alto nivel de maestría en uno o más campos de la vida. Para Sternberg, un experto es una persona que ha desarrollado sus competencias en un alto nivel. El desarrollo de las habilidades se convierte en competencias que se dominan y el desarrollo de las competencias conduce a la excelencia. A lo largo de este proceso se adquiere y amplía el conjunto de habilidades, e igualmente se mejoran las que cada uno tiene, aumentando la eficacia en la utilización de las mismas.

La búsqueda de la excelencia es, sin duda, un tema de atención destacada en la psicología desde hace un siglo y, según los investigadores actuales (Hambrick et al., 2014), seguirá siéndolo en los años venideros. Hace veinticuatro años, Ericson, Krampe y Tesch-Römer, (1993) propusieron que conseguir un rendimiento excelente era producto de un largo periodo de "práctica deliberada" más que de una habilidad innata o "talento". Ericsson et al. (1993) definían la "práctica deliberada" como la dedicación a actividades muy estructuradas que incluían altos niveles de concentración y que no eran intrínsecamente divertidas. Distinguían claramente esta "práctica deliberada", por una parte, del trabajo que incluye actuaciones, concursos y otras actividades que se pagan $\mathrm{y}$, por otra parte, de tocar, donde incluían actividades que no tenían un objetivo concreto (como cobrar o aprender) y que eran divertidas de por sí. En sus estudios realizados sobre violinistas y pianistas (1993), concluían que para conseguir la excelencia era necesaria la práctica rigurosa de unas 10.000 horas de trabajo.

El éxito de esta concepción lo ejemplifican Hambrick et al. (2014), cuando comentan que esta investigación ha sido citada en la literatura científica unas mil veces. Pero, igualmente, muestran que sus conclusiones han sido rotundamente criticadas por numerosos autores (Gardner, 1995; Sternberg, 1996; Schneider, 1998, Marcus, 2012 entre otros, en Hambrick, 2014). En concreto, Hambrick et al. (2014) se preguntan si la práctica deliberada es todo lo que se necesita para llegar a ser un experto en ajedrez y en música. Los estudios en los dos ámbitos arrojan conclusiones similares, mostrando que la práctica deliberada no explica todas 
las diferencias individuales en la calidad del rendimiento que se adquiere, ni siquiera la mayoría de ellas, evidenciando que otros factores también deben tenerse en cuenta para poder explicar estas diferencias. En concreto, en los estudios realizados, entre los músicos se encontró que la práctica deliberada explicaba alrededor del $30 \%$ de las diferencias variables en la interpretación, dejando alrededor del $70 \%$ sin explicar y potencialmente explicable por otros factores. Su conclusión es que la práctica deliberada no es suficiente para explicar las diferencias individuales en la interpretación musical. (2014: 43).

Ackerman (2014) explica que cualquier tipo de posición extrema en relación con los factores que son determinantes para conseguir una interpretación excelente o de élite (el talento natural o lo aprendido) acaba por ser ridícula, pues ambos, naturaleza y educación, son necesarios para conseguir una interpretación excelente. En el mismo sentido, analiza las características fundamentales del talento para predecir las diferencias individuales en la interpretación experta o de élite. De este modo, concluye afirmando que lo que importa es cómo estos elementos encajan para proporcionar una visión integral del talento y su trascendencia. Y, por supuesto, conocer las limitaciones de los procedimientos usados para identificarlo a la hora de descubrir qué individuos desarrollarán finalmente niveles de interpretación de experto.

Aunque queda mucho por hacer hasta lograr entender los mecanismos de desarrollo del talento y la forma de favorecer ese desarrollo, es necesario apuntar que la búsqueda que aquí se propone se apoya en tres ideas fundamentales:

1. Toda búsqueda de la excelencia debe estar apoyada en el saber existente. Nada se crea de la nada y las aportaciones que llamamos "nuevas" son síntesis, reorganizaciones o puntos de vista distintos de una misma realidad que intentamos entender y la mejor manera de conocer ese saber es valorando el conocimiento y la investigación en conjunto, no como aportaciones individuales. Interesante a este respecto la cita del Diálogo sobre la poesía escrito en 1800 por Friedrich Schlegel:

El arte descansa en saber, y la sabiduría del arte es su historia. Es esencialmente propio del arte vincularse a lo ya dotado de forma, y por ello la historia se remonta de generación en generación de grado en grado, cada vez más en la antigüedad, hasta la primera fuente originaria. Para nosotros los modernos, para Europa, esta fuente se encuentra en la Hélade, y para los helenos y su poesía lo fue Homero y la antigua escuela de los Homéridas (2005:6) 
Sólo conociendo lo que hay podemos aportar algo "nuevo" y útil para el conjunto. Por eso es fundamental que alumnos y profesores demos importancia al conocimiento de lo que ya se ha estudiado e investigado como punto de partida para el desarrollo de la excelencia.

2. La idea o producto que merece la etiqueta de "excelente" surge de la sinergia de muchos recursos y no sólo de la mente de una única persona. Es lo que aplica Csikszentmihalyi (1996:1) cuando habla de la creatividad y que se explicará con más detalle en el capítulo siguiente, la cual se puede trasladar a la excelencia sin mayores problemas. Así, podemos decir que ocurre lo mismo que con la creatividad, que cuando se consigue algo excelente no es casi nunca el resultado de una visión repentina, sino que llega después de años de duro trabajo. La idea que expresa Csikszentmihalyi acerca de la creatividad se puede aplicar igualmente a la excelencia: es más fácil aumentar la excelencia cambiando las condiciones del entorno que intentando hacer que la gente, de forma individual, sea excelente. Es interesante a este respecto recordar la célebre frase del musicólogo español del siglo XIX Felipe Pedrell "lo poco que sabemos lo sabemos entre todos". Esta frase debería servirnos también de inspiración para hacer nuestra propuesta: si queremos conseguir la excelencia, tendremos que hacerlo entre todos y será importante cambiar las condiciones del entorno, es decir, que es responsabilidad del conservatorio y de todos los que formamos parte de él, así como de las estructuras más grandes de las que depende, el hacer un buen trabajo y no achacar los fracasos sólo a personas individuales. Como explica Air-Girl Tan, el desarrollo de la excelencia, al igual que el del talento y la creatividad, es contextual (2013:19). Es decir, su desarrollo sólo es posible por la acción e interacción entre personas y por la relación de estas personas con las instituciones sociales y culturales.

\section{Para conseguir la excelencia es necesario crear un ambiente que proporcione} libertad de acción y estimulación de ideas, junto con una actitud de respeto y apoyo entre todos los miembros de la comunidad educativa. Es la misma idea que usa Csikszentmihalyi en relación con la creatividad. Y para conseguirlo tendremos que desarrollar herramientas que ayuden a entender y valorar a los demás como personas individuales con las particularidades que cada uno tiene, lo que implica que será necesario adaptarse a las necesidades de cada uno, tanto en los ambientes, espacios y formas de actuar, como buscando medios distintos para desarrollarse. Algunas de estas 
herramientas se estudian en el siguiente capítulo, así como el conocimiento de los distintos estilos de pensamiento, la inteligencia emocional, el desarrollo de la creatividad, el conocimiento y valoración de la mente respetuosa como una de las mentes más importantes en el futuro, etc.. Para conseguir este respeto a cada persona por sus particularidades, será necesario valorar la diferencia y desterrar hábitos erróneos, como el estímulo de la competencia. Habrá, sin embargo, que valorar su propio desarrollo individual y sus propias formas de hacer como maneras útiles de aportar distintas visiones. Todo esto teniendo en cuenta, por supuesto, que hay que partir del conocimiento, del dominio de la técnica y del esfuerzo continuado además de las aportaciones individuales, como los únicos medios loables para conseguir la excelencia. 


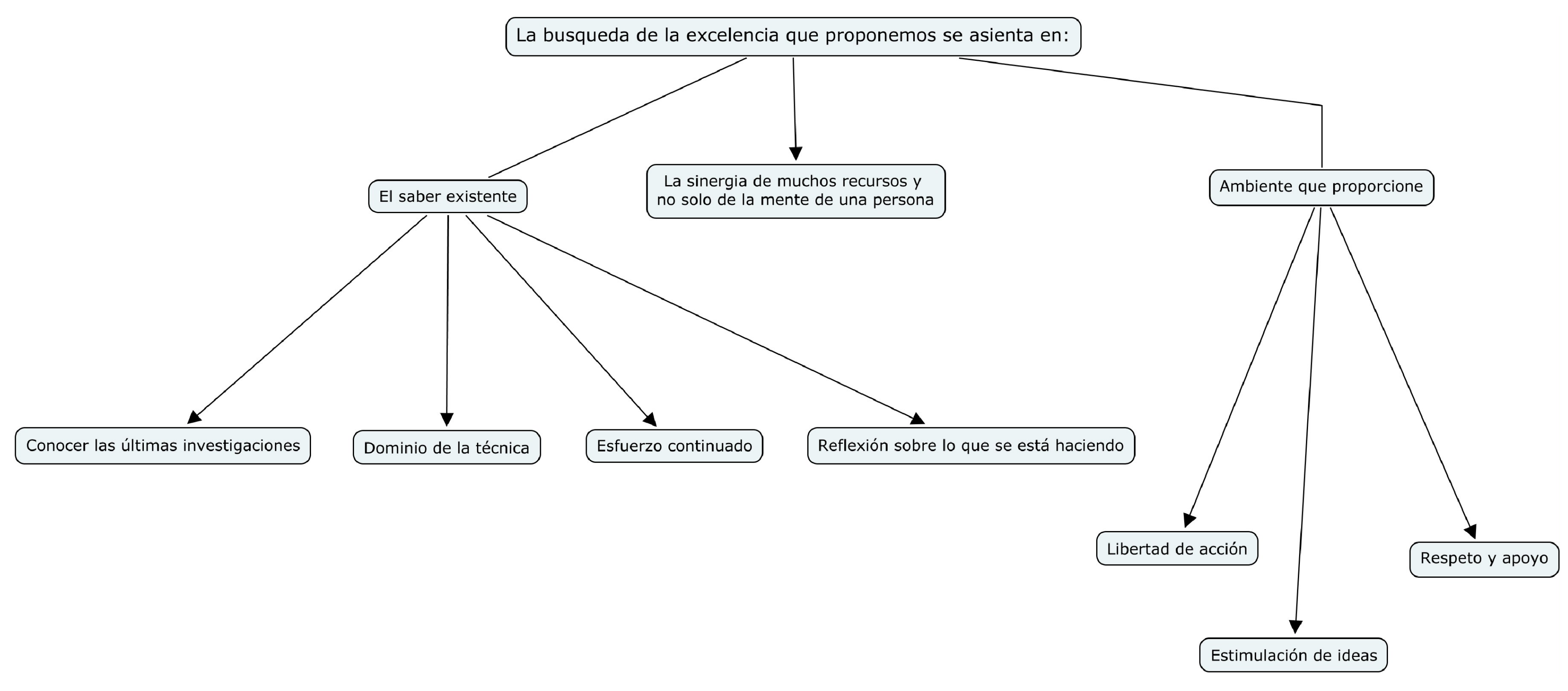

Ilustración 1. Esquema: Búsqueda de la excelencia. Elaboración propia. 
Pero todo esto no es suficiente a la hora de presentar el concepto de excelencia. Si queremos entrar en profundidad en lo que esto significa hay que tener en cuenta los elementos que desarrollamos a continuación.

\subsection{La inteligencia exitosa de Sternberg}

El término "inteligencia exitosa" se lo debemos a Robert Sternberg, profesor de la Universidad de Yale, cuyas principales investigaciones se centran en el estudio de la inteligencia. Es en su trabajo Inteligencia exitosa donde, antes de adentrarse en dar una definición de inteligencia, expone la forma en que exploró lo que se conocía sobre la inteligencia hasta ese momento. Cuenta así cómo en 1921 los editores del Journal of Educational Psychology pidieron a catorce psicólogos famosos su opinión sobre qué es la inteligencia. El resultado fue una variopinta muestra de definiciones y aproximaciones, pero lo más destacable fue comprobar cómo, en muchas de ellas, se advertían dos temas comunes: por un lado, que la inteligencia era la capacidad para aprender de la experiencia y, por el otro, que era la capacidad para adaptarse al medio (1996:93).

Sternberg considera estos dos temas comunes algo muy importante: en primer lugar, la capacidad para aprender de la experiencia implica que las personas inteligentes no son las que no cometen errores, sino más bien las que aprenden de ellos y no siguen incurriendo una y otra vez en lo mismo. Y, en segundo lugar, la adaptación al medio significa que ser inteligente va más allá del hecho de obtener puntuaciones altas en los test o buenas calificaciones en la escuela. Habría que incluir además otros elementos como manejarse en un empleo, entenderse con los demás y llevar la vida en general.

Setenta y cinco años después del simposio inicial, en otro estudio realizado por Sternberg y Detterman (1986 en Sternberg, 1996) se pidió a veinticuatro expertos diferentes sus opiniones sobre la naturaleza de la inteligencia y, una vez más, los expertos enfocaron los temas del aprendizaje a partir de la experiencia y la adaptación al medio. Sin embargo, los expertos de este segundo estudio cargaban más el acento que los anteriores en el papel del metaconocimiento, esto es, de la comprensión y el control de los propios procesos de pensamiento (por ejemplo, durante la solución de problemas, el razonamiento y la toma de decisiones). En este segundo estudio también se ponía más énfasis en el papel de la cultura, 
señalando que lo que en una cultura se consideraba inteligente, en otra podía tenerse por una estupidez. En cuanto a las teorías más explícitas sobre la naturaleza de la inteligencia explica que no hay nada que se aproxime siquiera a un consenso entre los expertos, ni siquiera en torno a cómo se la debe estudiar. (Sternberg, 1996: 93-96).

En base a todo esto (y a sus propios estudios) Sternberg desarrollará su teoría de la inteligencia exitosa que trataremos de explicar a continuación, dedicando especial atención a su posible relación con lo que nos ocupa en este trabajo.

\subsubsection{Los tres aspectos de la inteligencia exitosa}

Sternberg explica que tener inteligencia exitosa es pensar bien de tres maneras diferentes: analítica, creativa y práctica. Estos tres aspectos de la inteligencia exitosa están íntimamente relacionados, de modo que hay que tener en cuenta que el pensamiento analítico hace falta para resolver problemas y juzgar la calidad de las ideas, que la inteligencia creadora hace falta para formular buenos problemas y buenas ideas y que la inteligencia práctica es necesaria para usar las ideas y su análisis de una manera eficaz en la vida cotidiana. También incide en que la inteligencia exitosa es más efectiva cuando se equilibran los tres aspectos: el analítico, el creativo y el práctico. Pero lo más importante es saber cuándo y cómo usar esos aspectos de la inteligencia exitosa, es decir, no basta simplemente con tenerlos. Para Sternberg, las personas con inteligencia exitosa no sólo tienen habilidades, sino que reflexionan sobre cuándo y cómo usar esas habilidades de manera efectiva. (1996:131).

El autor también insiste, por un lado, en que ciertas tareas pueden requerir el uso de mayores o menores dosis de estas formas de inteligencia y, por otro, en que es necesario fomentar todos estos tipos de inteligencia. En este sentido, termina concluyendo que tener inteligencia exitosa es ser capaz de recurrir a sus tres aspectos en el momento oportuno, por ejemplo: analizar un problema, producir una solución creadora y luego llevarla a la práctica. (1996:150).

El proceso de resolución de problemas que propone Sternberg consta de los siguientes pasos:

1. Reconocimiento del problema. Explica que las personas con inteligencia exitosa no esperan a que los problemas les golpeen en la cabeza, sino que reconocen su existencia antes de que se les escapen de las manos y dan comienzo al proceso de resolución. (1996:164). 
2. Definición del problema. Sternberg afirma que las personas con inteligencia exitosa definen correctamente los problemas y, en consecuencia, resuelven los problemas con los que realmente se enfrentan y no problemas extraños a la situación. De esta manera, no volverán a encontrarse con los mismos problemas en su vida. También se esfuerzan para decidir qué problemas vale la pena resolver y cuáles no. (1996:167).

3. Formulación de una estrategia de resolución de problemas. Sternberg reconoce en las personas con inteligencia exitosa la habilidad de formular cuidadosamente las estrategias para la resolución de problemas. En particular, explica, estas personas se centran en la planificación a largo plazo antes que apresurarse y luego tener que repensar sus estrategias (1996:169).

4. Representación de la información. Otras habilidades que reconoce Sternberg como típicas de las personas con inteligencia exitosa son, por un lado, la de ser capaz de representar lo más cuidadosamente posible la información acerca de un problema $\mathrm{y}$, por el otro, la de centrarse en la manera de utilizar efectivamente esa información. (1996:172).

5. Asignación de recursos. Sternberg afirma que las personas con inteligencia exitosa piensan cuidadosamente acerca de la asignación de recursos, tanto a corto como a largo plazo. Consideran las proporciones entre los riesgos y las recompensas y luego escogen las asignaciones que ellos creen que maximizarán su compensación. (1996:175).

6. Control y evaluación. Sternberg explica que las personas con conducta inteligente no siempre adoptan las decisiones correctas, pero controlan y evalúan sus decisiones y luego corrigen sus errores a medida que los descubren. (1996:177).

Otro elemento especialmente importante en el concepto de inteligencia exitosa de Sternberg es la idea del equilibrio. En su opinión, nuestra sociedad se preocupa exageradamente por las cantidades, parece siempre que cuanto más mejor, algo que contrasta poderosamente con la forma de hacer de otras culturas, sobre todo las orientales, que cargan más el énfasis en el equilibrio que en las cantidades. La inteligencia exitosa, como la define Sternberg, depende al menos tanto del equilibrio como de la cantidad, tanto en el desarrollo de las habilidades necesarias, como en el conocimiento del momento oportuno para usarlas. (1996:200). Así visto, se puede decir que "la inteligencia exitosa no es estática, sino dinámica". (1996:154).

El estudiante "dotado", para Sternberg, es el que es capaz de extraer lo máximo posible de sus capacidades naturales aprovechando sus virtudes y compensando sus debilidades. (1996:154). 
A las palabras de Sternberg habría que añadir que, para poder hacer esto, es necesario crear un ambiente que proporcione libertad de acción y estimulación de ideas, además de una actitud de respeto y apoyo entre todos los miembros de la comunidad educativa. Este apoyo será fundamental ya que, como Sternberg apunta, en realidad no hay ninguna medición completamente "objetiva" de la inteligencia, de la creatividad ni de ninguna otra cosa. La medición siempre está relacionada con las normas y las expectativas de un grupo particular en una época particular y en un lugar particular, de modo que la manera en que se evalúa un trabajo depende de quién evalúa. Análogamente, las mediciones de la creatividad deben verse en este contexto de interacción entre el producto y quienes lo evalúan (1996:207).

\subsubsection{El estímulo de la creatividad y su desarrollo en la enseñanza superior de música.}

En su libro sobre la inteligencia exitosa, Sternberg desmonta el mito del coeficiente intelectual que lleva a suponer que las habilidades no pueden desarrollarse. Él afirma que sí que pueden desarrollarse y que la mejor prueba de ello se encuentra cuando se examinan doce características de las personas creativas con inteligencia exitosa y se explora cómo se pueden desarrollar estas características (1996:208-222). Nosotros vamos a aplicar estas ideas para ver cómo se pueden desarrollar estas características en nuestros alumnos de la enseñanza superior de música.

1. Las personas con inteligencia exitosa buscan activamente modelos y luego se convierten ellos mismos en tales. (Sternberg, 1996:208).

Para Sternberg, nadie desarrolla la inteligencia creativa cuando se le dice que lo haga, sino cuando se le muestra cómo hacerlo. Para demostrarlo, pone el ejemplo de cómo al recordar los maestros que influyeron más en el desarrollo de cada uno, probablemente no se piensa en los maestros que con más contenido llenaban sus lecciones sino aquellos cuya manera de pensar y de actuar sirvieron como modelo. Los maestros que recordamos tienden a ser los que equilibraban la enseñanza del contenido con la enseñanza de cómo pensar con y acerca de ese contenido. Por lo tanto, para estimular la creatividad es necesario ser creativo. En general, las personas con inteligencia exitosa han tenido buenos modelos. Y, por supuesto si queremos desarrollar la inteligencia exitosa, cuanto antes comencemos mejor.

Para aplicarlo al contexto en que nos movemos, lo que tendríamos que hacer es animar a los alumnos a buscar intérpretes que les atraigan por su forma de tocar y, al mismo tiempo, obras de repertorio que les gusten y les hagan disfrutar del instrumento. Igualmente, profesores que 
les entusiasmen por su forma de disfrutar de la música y de disfrutar con la enseñanza de la misma, que les contagien su entusiasmo por la música, sean intérpretes, compositores, musicólogos o investigadores. La influencia del adulto clave que sirve de modelo se ha revelado como una de los factores fundamentales para el desarrollo de las habilidades musicales (Sloboda et. al., 1996) y en este estudio, como veremos más adelante en la enseñanza superior, siguen sirviendo como inspiración a veces modelos de intérpretes famosos pero también en muchos casos modelos muy cercanos: un profesor al que admiran o un compañero que toca con él y en ocasiones su mismo instrumento. Suele ser un compañero al que se respeta y admira como un buen modelo a seguir y en la mayoría de los casos porque, además de tocar muy bien, es un modelo de persona que respeta a sus compañeros y disfruta haciendo un buen trabajo con ellos.

2. Las personas con inteligencia exitosa cuestionan los supuestos y estimulan a otros a hacer lo mismo. (Sternberg, 1996:208).

Sternberg afirma que, sin el impulso de los que cuestionan los supuestos, poco o ningún progreso se hubiera hecho en ninguna empresa humana e insiste en que deberíamos estimular a los niños y a los adultos a cuestionar los supuestos. También insiste en la importancia de comprender por qué pensamos o actuamos como lo hacemos y explica que todo pensamiento creativo comienza con un por qué.

Muchas veces los músicos, apremiados por todo el trabajo que debemos llevar a cabo, hacemos las cosas sin cuestionarlas, tocamos un repertorio marcado por otro aunque no sea el que nos apasiona, sin preguntarnos ni para qué nos sirve; tomamos clases con profesores que en realidad no responden a nuestras necesidades ni musicales ni vitales y nos conformamos con copiar la forma de tocar de otro o en un sólo estilo porque se considera la "forma correcta" o "el estilo que controlan". Todo esto es lo que habría que cambiar: cuestionar lo que hacemos y ayudar a los demás a cuestionar lo que hacen.

3. Las personas con inteligencia exitosa se permiten cometer errores y lo permiten a los demás. (1996:209).

Cuando se explora un territorio nuevo es inevitable cometer errores. Pero lo que distingue a los grandes pensadores es que aprenden de sus errores o nos ponen en condiciones de aprender de ellos. En general, la gente piensa de una manera determinada porque es más seguro y no quiere cometer errores, ya que en su aprendizaje escolar han aprendido que no 
está bien cometerlos. Como consecuencia de ello terminan con miedo a errar y evitan correr el riesgo del pensamiento independiente, aunque a veces defectuoso, capaz de conducir al desarrollo de la inteligencia creativa. La conclusión de Sternberg es que las respuestas "correctas" estimulan el conformismo y no la creatividad.

En música se lucha insistentemente por evitar el error y eso acarrea muchos problemas. Desde que se dan los primeros pasos en la enseñanza musical parece que no se puede hacer buena música si se da una nota equivocada, de modo que a menudo el miedo a fallar una nota hace que todo salga inseguro y con miedo. En ocasiones sería muy útil que alguien nos dijera: "falla la nota, fállala", para poder hacerlo sin miedo y ver cómo se hace mal. Tendríamos que ser conscientes de que del error se aprende y que lo importante es aprender a solucionar los errores que vamos a cometer mientras aprendemos. Deberíamos sacudirnos el miedo al error y ver que es imposible hacer algo que valga la pena sin equivocarse antes, que cometer errores nos ayuda a buscar nuevas estrategias para hacer las cosas bien y que la música no es sólo dar la nota correcta, sino que hay muchas cosas importantes que hay que trabajar. Los músicos, en muchas ocasiones, tenemos la sensación de que tratar el error con benevolencia lleva implícito que somos poco exigentes, pero ser exigente no es no permitirse cometer errores sino trabajar en solucionarlos. Además, muchas veces el error es relativo, a veces es simplemente una visión distinta o una manera diferente de hacer las cosas.

4. Las personas con inteligencia exitosa asumen riesgos sensatos y estimulan a los otros a asumirlos. (Sternberg, 1996:213).

Sternberg ha comprobado, por medio de la investigación, que la gente evitaba relativamente el riesgo y que las personas con mayor creatividad se inclinan a asumir mayores riegos. Las personas creativas están dispuestas a correr los riesgos necesarios para producir la obra que los demás terminarán admirando y respetando. Y que al asumir estos riesgos, a veces las personas creativas fallarán estrepitosamente y tenemos que permitírselo. Evidentemente, el riesgo "sensato" al que se refiere no tiene nada que ver con poner en peligro la vida, sino que se refiere a los riesgos implícitos en la exploración de nuevas ideas y nuevas maneras de hacer las cosas, el riesgo de ser "diferentes". En las escuelas, en su mayor parte, no se estimula la asunción de riesgos. Por el contrario, los niños aprenden muy pronto cómo opera el sistema y se dan cuenta de que para tener éxito es menester conseguir muy buenas calificaciones y para conseguir muy buenas calificaciones hay que mostrar buen sentido y conformismo. Podría parecer que la asunción de riesgos es para los incautos. 
Por esta razón, sólo si permitimos e incluso estimulamos la asunción del riesgo intelectual ayudaremos a los estudiantes, e incluso nos ayudaremos a nosotros mismos, a liberar el potencial creativo. Es casi un deber del maestro el premiar a quienes asumen riesgos. Es más, para Sternberg a los estudiantes que asumen un riesgo sensato en un encargo o en un proyecto, debiera otorgárseles créditos por su creatividad, aun cuando el proyecto pueda mejorarse, en lugar de premiar la obediencia y el conformismo, como se hace habitualmente.

Este punto está, obviamente, muy relacionado con el anterior: para no cometer errores, lo que hacemos los músicos es no asumir riesgos. Así, lo que hacemos es tocar lo que ya nos sabemos, lo que sabemos que podemos tocar bien, en el estilo que controlamos y con todas las convenciones sociales, del profesor, del momento, mientras que, en realidad, deberíamos ponernos retos, explorar formas diferentes, estilos diferentes, instrumentos diferentes incluso. También deberíamos tocar obras que sabemos que no vamos a tocar bien, pero que nos van a permitir aprender o disfrutar por el solo hecho de intentarlo. Todo esto serviría además como entrenamiento para tocar en público, pues uno de los problemas que más paraliza al músico (y en ocasiones le imposibilita para la actuación) es el miedo a equivocarse, a cometer errores. Si se estuviera acostumbrado a ver el error como algo necesario para seguir aprendiendo, no asustaría tanto el asumir riesgos y se vería el "fallar" una nota como algo necesario para poder tocar, expresar y comunicar, porque el que no arriesga no falla, pero tampoco aprende nada nuevo ni disfruta de ese aprendizaje de la misma manera, pues no incluye nada suyo. Es como copiar o repetir en lugar de interpretar. Como profesores también se debería asumir riesgos y no limitarse a lo que hace todo el mundo por no chocar con la institución o con lo ya establecido. Ésta sería la mejor forma de animar, dar ejemplo y ser modelo de asunción de riesgos y de permitir y estimular la creatividad.

5. Las personas con inteligencia exitosa buscan tareas que permitan la creatividad tanto para sí mismas como para los demás (Sternberg, 1996:214).

Si nuestras escuelas quieren estimular la creatividad y el desarrollo de la inteligencia creativa, han de incluir al menos algunas oportunidades para el pensamiento creativo en sus actividades y en sus test. La única limitación en lo tocante a las tareas que se puedan encargar está en la imaginación del maestro.

Una de las preocupaciones que se han manifestado en los músicos con respecto a este tema la refleja muy bien Gary McPherson (2000), cuando señala que esa falta de estímulo de la creatividad se ha dado claramente en la enseñanza instrumental. En concreto, culpa al 
profesor de esta falta de desarrollo de la habilidad creativa en los alumnos e insiste en que es tarea del profesor el esforzarse por cambiarlo. El creciente énfasis en la técnica y en la ejecución de música partiendo desde la notación ha dado como resultado que la enseñanza instrumental se orientara demasiado hacia la agilidad, de un modo ramplonamente conductista, sin permitir a los estudiantes oportunidades apropiadas para desarrollar tanto su "vista" como su "oído". Como otros autores han señalado (Aranosian, 1982 y Rooke, 1991), no es suficiente enseñar sólo las habilidades técnicas y la historia de su empleo si esperamos que los jóvenes músicos contemporáneos hagan un uso original e innovador de estas habilidades. Habría que preguntarse si los docentes de instrumentos no tienen a sus alumnos demasiado programados y si les conceden poca o ninguna libertad para experimentar con sus inclinaciones personales (Aranosian, en McPherson, 2000). Rooke (en McPherson, 2000) insiste en que la mayoría de los docentes enseñan a sus alumnos conceptos técnicos, auditivos y de notación, alentándoles a que almacenen interna y externamente habilidades para su propia ejecución y para el aprendizaje y la apreciación de las creaciones de los otros, preguntándose si no habría llegado la hora de demostrar a los niños cómo explorar, expresar y comunicar sus propias ideas como un aspecto importante de su aprendizaje instrumental y su desarrollo interior. Estas ideas ilustran la preocupación que lleva a McPherson a investigar sobre el tema y a obtener unas conclusiones que sugieren que la ejecución de un instrumento debería abarcar algo más que el sólo aprender a ejecutar música a partir de la notación. Sus investigaciones llevan a la conclusión de que es fundamental adquirir cinco estilos visuales, auditivos y creativos de habilidades musicales que define como: leer a primera vista, ejecutar música ensayada, tocar de oído y de memoria e improvisar. Y, en lo que se refiere a la forma en que se enfrenta el estudiante con la práctica, muestra que la forma de pensar sobre sí mismo, sobre la tarea y la realización de la misma es tan importante como la cantidad de tiempo que dedica a practicar con su instrumento. (McPherson, 2000).

Ya que en la enseñanza superior se pasan muchas horas estudiando, sería muy útil aprender a hacer un estudio creativo, incluyendo tanto la lectura a primera vista, como el estudio de obras, además de tocar de oído y de memoria, improvisando y componiendo, inventando una parte de lo que tocamos, buscando distintas formas de trabajar la técnica o el sonido, animándonos siempre y animando a compañeros y alumnos a buscar tareas creativas que incluyan la forma de explorar, expresar y comunicar ideas propias y ponerlas en común con los demás, al mismo tiempo que se desarrollan las habilidades musicales. Para hacer el trabajo 
creativo entre todos, necesitamos la seguridad de poder hacerlo bien, entender la tarea y cómo hacerla, poder utilizar nuestras propias ideas y compartirlas con los demás en un ambiente que anime a desarrollar el conocimiento y el esfuerzo compartido de una manera libre y sin presiones.

Los profesores deberíamos buscar siempre la manera de proponer tareas creativas a nuestros alumnos que les ayudaran a estudiar, mejorar y actuar, dando ejemplos nosotros mismos con un trabajo creativo. Mauro Urriza explica que cualquier músico debería animarse a realizar la pequeña locura que supone la grabación del primer disco. No cabe duda de que es complicado, pero al mismo tiempo apasionante y que, a pesar de los malos ratos, es una experiencia que merece la pena. Textualmente "Animo a todo el mundo que tenga inquietudes y quiera plasmar su música en un $\mathrm{CD}$ a que lo haga. Fuera miedos y perezas" (Urriza, 2010:76).

6. Las personas con inteligencia exitosa definen y redefinen activamente los problemas y ayudan a los demás a hacer lo propio (Sternberg, 1996:218).

En este punto, Sternberg explica que una de las maneras de estimular la inteligencia creativa consiste en permitir que la gente escoja sus propias maneras de solucionar problemas y, a veces, que vuelva a escoger cuando se dé cuenta de que su elección fue errónea. Esta elección debería hacerse seriamente e insiste en que cuanta más amplitud se dé a los estudiantes, tanto mejor aprenderán a elegir sabiamente los problemas y los proyectos que quieren desarrollar, lo que es sin duda un elemento esencial de la creatividad.

En estudio activo es donde el músico está constantemente definiendo y volviendo a definir los problemas que se le presentan. El músico tiene que escucharse y saber lo que hace mal para arreglarlo, debe cuestionarse y concretar el origen del problema para poder resolverlo. Para ejemplificar lo que queremos decir, hablaremos de un alumno de nuestros grupos de discusión. El muchacho en cuestión toca un instrumento de viento y en alguna ocasión le ha ocurrido el tener la sensación de que los dedos no podían hacer un pasaje por ser demasiado difícil. Pero una vez que reflexiona e intenta redefinir el problema, descubre que lo que ocurre es que se asusta ante lo que ve como una dificultad y entonces no manda el aire necesario para realizarlo. Así, en el momento en el que es consciente de que basta con mandar el aire necesario, el pasaje difícil se convierte en un pasaje sencillo o, al menos, asequible. Otro ejemplo interesante que ocurre a muchos estudiantes es que piensan que no van a poder tocar 
pasajes rápidos y en lugar de definir bien el problema y trabajar ese pasaje rápido, ralentizan toda la obra ante esa dificultad. No piensan que no han trabajado bien ese pasaje, lo que piensan es que no son capaces de tocarlo a esa velocidad. Por eso es tan importante que se trabaje también la seguridad en sí mismo, para poder volver a definir los problemas y buscar distintas maneras de solucionarlos sin miedo a equivocarse. Como explica Sternberg "si nunca tienen oportunidad de elegir, nunca aprenderán a hacerlo" (1996:218). Es importante acostumbrarse a elegir y a buscar distintas soluciones si la primera no funciona, pues es la única forma de aprender a elegir correctamente la próxima vez que se nos plantee el mismo problema o uno similar.

7. Las personas con inteligencia exitosa buscan recompensas por la creatividad y recompensan a su vez la creatividad (Sternberg, 1996:218).

Sternberg reconoce que él recompensa explícitamente los esfuerzos creativos de sus estudiantes. Cuando les encarga artículos, les dice que valorará las cosas habituales (demostración de su conocimiento, su despliegue de habilidades analíticas y, por supuesto, una buena redacción). Pero que por encima y más allá de todo eso tendrá en cuenta y premiará la creatividad. Lo que importa no es que él esté o no de acuerdo con lo que ellos dicen, sino si producen ideas nuevas que representen una síntesis entre ideas de las que han oído hablar o sobre las que han leído y su propia manera de pensar. Por supuesto, entiende que haya profesores que se quejen de que no pueden evaluar respuestas creativas con la misma objetividad que aplican a los test de opciones múltiples o a los de respuestas breves. En cierto sentido, naturalmente tienen razón. Hay cierto sacrificio de la objetividad. Pero también insiste en que su investigación, así como la de otros, muestra una notable coherencia entre las evaluaciones de creatividad de diversos evaluadores. Además, si no se evalúa la creatividad es que realmente no se le da la importancia que realmente tiene. De hecho, es imposible conseguir la objetividad absoluta en cualquier tipo de evaluación. Es preferible que los estudiantes realicen un trabajo creativo que sea evaluado con un poco menos de objetividad a que nunca se les permita el trabajo creativo sólo para que los profesores puedan mantener una apariencia de objetividad en la evaluación.

En el ámbito que nos ocupa es habitual encontrarnos con las mismas objeciones para no evaluar la creatividad: lo difícil que es su evaluación. En ocasiones, incluso, se pide que todos los músicos que se presentan a un examen de un curso o a un premio toquen una misma obra con ese mismo argumento. Consideramos que esto es uno de los hábitos o prácticas erróneas 
que habría que eliminar del ámbito musical, pues se limita el poder de elección sobre el repertorio que tocan de los alumnos, cuando se sabe que es una de las técnicas de enseñanza que mejor pueden ayudar a desarrollar la motivación intrínseca de los músicos: la elección del repertorio que tocan (Hallam, 1998). Sí que es cierto que cuando se permite la inclusión de la creatividad, los alumnos de las enseñanzas superiores lo reciben con los brazos abiertos. Tenemos el ejemplo de una muy buena práctica en este sentido en el concierto fin de carrera de los alumnos de la especialidad de guitarra clásica en el Conservatorio Superior de Música de Navarra, concierto en el que suelen incluir una obra inventada por ellos. Y esto no se produce de manera anecdótica, sino que este trabajo de exploración e invención de las posibilidades creativas de cada alumno se trabaja con el profesor de instrumento durante los cuatro años de carrera y también lo hacen los que cursan guitarra como segundo instrumento. Con esta práctica, los alumnos aprenden a ver recompensada su creatividad y a exigir ser recompensados por ella, al mismo tiempo que aprenden que se puede evaluar y que ven la manera en que se puede hacer este tipo de evaluación. Aprenden también a que crear conjuntamente ayuda a hacer labor de grupo, tan necesaria para hacer algo que de verdad valga la pena.

8. Las personas con inteligencia exitosa se permiten tiempo para pensar creativamente y se lo permiten a los demás (Sternberg, 1996:219).

Según Sternberg, somos una sociedad con prisa y dejamos poco tiempo libre para pensar. Por lo tanto, tampoco los profesores ni los estudiantes lo tienen y mucho menos para pensar creativamente. Por eso, si queremos que los estudiantes desarrollen habilidades de pensamiento creativo hemos de darles tiempo para que lo hagan.

Como expresa muy claramente Amabile, "Las ideas verdaderamente innovadoras raramente se originan de la noche a la mañana" (2004:42). Nosotros añadiríamos, como ya hemos explicado, que además debe conocer todo lo que se sabe sobre el tema, esforzarse y contar con el apoyo de los demás. Las prisas no llevan a nada y todo músico necesita tener paciencia para conseguir hacer suya una obra y poderla tocar con garantías, incluso en situaciones comprometidas. Aún así es difícil que se ensaye todo lo que se necesita para conseguir una creación en grupo que no sólo sea la suma de esfuerzos individuales. El aprender a crear conjuntamente es necesario para conseguir algo que de verdad sea brillante y el hacer esa labor con el tiempo necesario es una de las asignaturas pendientes de los músicos del siglo $\mathrm{XXI}$, ya que pesa la tradición del músico que se prepara para ser solista, de modo que sólo 
invierte el tiempo en tocar solo. Aunque en este siglo XXI cada vez es más necesario el trabajo de grupo y el desarrollo de las habilidades sociales también para el músico (Dobson y Gaunt:2015), de momento todavía nos queda mucho por hacer en estas enseñanzas para que se valore este trabajo en su justa medida. Como indican las últimas investigaciones (Hallam:2012), hay algunas habilidades requeridas en la práctica instrumental, como por ejemplo la lectura a primera vista, la escucha y la improvisación, que se desarrollan mejor tocando con otros que con la práctica individual.

9. Las personas con inteligencia exitosa toleran la ambigüedad y alientan la tolerancia a la ambigüedad de los demás (Sternberg, 1996:220).

El desarrollo de una idea creativa casi siempre lleva tiempo, un período durante el que tendemos a sentirnos incómodos e impacientes. A menudo, queremos la solución rápida, y esto puede hacer que, si no dedicamos el tiempo necesario o desarrollamos la habilidad para tolerar la ambigüedad, sea fácil lanzarse prematuramente a una solución deficiente. Así, para lograr el máximo de nuestro potencial creativo, tenemos que ser capaces de tolerar la incomodidad de una situación ambigua el tiempo suficiente como para producir lo mejor o lo más próximo a lo mejor de que seamos capaces.

Como músicos, sabemos que es necesario dedicar bastante tiempo para estar seguros a la hora de tocar una obra, porque interpretar una obra bien tocada necesita mucho estudio. En ocasiones, la prisa nos lleva al fracaso porque aunque en ocasiones parece que la obra está bastante clara, no la dominamos, no hemos dejado el tiempo suficiente para aprenderla, analizarla, escucharla interiormente, pensar cada parte, etc., en resumidas cuentas, no la hemos interiorizado lo bastante como para interpretarla correctamente en una situación comprometida. Este sentirse apremiado por el tiempo, la sensación de "la tendría que tener ya montada" o "la tendría que saber ya" no permite la reflexión y el estudio necesario que puede llevarnos después a una actuación brillante. Es preciso ser conscientes de la necesidad de tomarse ese tiempo para poder hacer las cosas bien, aunque hay que tener cuidado para que no nos sirva de excusa y dejarlo todo para el último momento. Es interesante también darse cuenta de que hay personas que dejan todo para el último momento por su misma autoexigencia, es decir, quieren hacerlo tan bien que nunca es el momento ideal para realizarlo, de modo que al final lo tienen que hacer en el peor momento y sin dejarse ese tiempo de reflexión del que hemos hablado. Como profesores, es importante ayudar a los alumnos a entender estas formas de trabajar, intentando que cada uno reflexione sobre su 
propia forma de hacerlo para que encuentre el punto ideal para él, el que mejor le sirva para abordar las tareas y para poder trabajar con los demás de forma eficiente.

10. Las personas con inteligencia exitosa comprenden los obstáculos que las personas creativas deben enfrentar y superar. (Sternberg, 1996:221).

Es casi inevitable que el pensamiento creativo no encuentre resistencia. La cuestión que plantea no es si encuentra resistencia, sino si el pensador creativo tendrá fortaleza para perseverar en ella. Afirma que la creatividad es más bien castigada que premiada y que, sin embargo, los pensadores verdaderamente creativos que se mantienen en carrera y están dispuestos a pagar el precio a corto plazo, cosecharán el éxito a largo plazo.

Para el músico, es muy importante el desarrollo del poder de recuperación. Como todo profesional, el músico va a tener que reconocer las dificultades y momentos de dudas y lo que deberá hacer es aceptarlos y buscar la manera de superarlos. Hallam y Gaunt insisten en que, para poder conseguir el éxito como músico profesional en este siglo XXI, va a ser importante reconocer que estas dificultades existen y, en este sentido, apuntan dificultades específicas de este gremio, como por ejemplo la existencia de excesivas autocríticas y la competitividad, que dificulta en gran manera la autosuperación. En definitiva, para poder conseguir el éxito como músico profesional en este siglo XXI es importante recibir evaluaciones constructivas y ser realista con las experiencias negativas (2012:4).

11. Las personas con inteligencia exitosa están dispuestas a crecer. (Sternberg, 1996, 222).

Cuando una persona tiene una idea creativa importante, quizá tienda a quedarse allí e invertir todo el resto de su carrera en perseguir esa idea, porque, tal vez, puede asustarse de que la próxima idea no sea tan buena o que con la nueva idea desaparezca el éxito al que uno se ha acostumbrado, o simplemente porque nos volvemos complacientes y dejamos de ser creativos. La complacencia también puede deberse a nuestra propia pericia. Todos somos susceptibles de ser víctimas de nuestra propia pericia, atrincherados en maneras de pensar que puedan haber funcionado bien en el pasado, pero que no necesariamente lo harán en el futuro. Ser creativo significa estar dispuesto a salirse de las casillas que hemos construido, de modo que es importante hacerlo antes de quedar encerrados en ellas.

Una de las ideas que en más ocasiones han criticado los alumnos de la enseñanza superior de sus profesores es que están anclados en procedimientos que pueden haber funcionado en el 
pasado, pero que no es necesario que lo haga así en el futuro. Más aun, los profesores no buscan nuevas herramientas de enseñanza, pensando que lo que ha funcionado con uno puede funcionar de igual modo que los demás; o incluso que lo que le ha servido a él para formarse como músico le puede servir a todos. Esto, que en principio puede ser útil, no debería eliminar la posibilidad de buscar nuevas herramientas, caminos diferentes, tanto por parte del profesor como por parte del alumno, para encontrar una solución que le sirva a éste, que en muchas ocasiones será muy distinta a la que le sirvió al profesor o a la que ha utilizado éste con otros alumnos: utilizar distinta digitación (pues se tienen manos distintas), necesidad de repertorio distinto (pues se tienen gustos o necesidades distintas), distintos recursos para enfrentarse al público (pues se tienen personalidades distintas), etc. Para eso hace falta ser creativo, como dice Sternberg, pero también tener la humildad de reconocer que no siempre sabemos cómo ayudar a cada alumno y que tenemos que seguir aprendiendo, estando dispuestos a cambiar nuestros hábitos y maneras habituales de actuar si vemos que no funcionan.

A este respecto, la investigación sobre la enseñanza de la práctica instrumental propone que, para que la práctica fuera más efectiva, se debería procurar, entre otras cosas, lo siguiente:

Ser consciente de la particularidad de cada estudiante. Cuando se trabaja con un estudiante puede que no funcione lo mismo que con otros. Es necesario dedicar tiempo a intentar de forma seria nuevas estrategias con el alumno y a disuadirle de las inútiles. Muestra las estrategias que usan los expertos, pero no impongas simplemente lo que tú hacías cuando eras estudiante. (Lehmann y Jorguesen, 2012:686)

12. Las personas con inteligencia exitosa reconocen la importancia de adaptarse al medio personal. (Sternberg, 1996:220).

Sternberg presenta esta última estrategia argumentando que es tan importante para los maestros y los padres como para los estudiantes. Esta idea surge del hecho de que la creatividad no es en realidad un fenómeno objetivable. Cita a Csikszentmihaly, (del que hablaremos ampliamente al hablar de la creatividad en el segundo capítulo) para explicar que lo que se considera creativo es una interacción entre una o varias personas y el medio en el que trabajan (Csikszentmihaly, 1988). En una obra más reciente, Csikszentmihaly amplía esta idea y resalta la necesidad de estudiar la creatividad no como un hecho puramente individual, sino como algo que puede producirse cuando interactúan los pensamientos y obras de una 
persona con el contexto sociocultural que le inspira (1996:6). Sternberg insiste en que el mismo producto que en una época o lugar se premia como creativo puede ser descalificado por vulgar en otra época u otro lugar.

Todo músico debería tener claro que debe adaptarse al público ante el cual va a tocar y también que va conseguir lo mejor de sí mismo cuando haga lo que le gusta. Es decir, que va a tener que adaptarse a un contexto, de modo que es importante que sea consciente de que si elige ese contexto, si puede elegir para qué público va a tocar o dónde y también qué repertorio le gusta tocar y para quién quiere tocar va a poder realizar un mejor trabajo. La investigación muestra que la gente realiza su trabajo más creativo cuando le entusiasma lo que hace (Amabile, 2000:43). En la investigación sobre el desarrollo de las habilidades musicales también se reconoce que la autoestima y el conocimiento que cada alumno tiene de sí mismo repercute profundamente en el desarrollo de los objetivos personales (Hallam, 1998). La comprensión de lo que mantiene la motivación de cada uno, los contextos que son más adecuados para el trabajo de cada músico y el conocimiento del público al que se dirige y cómo conseguir una mejor conexión de cada músico con su público son reconocidos como fundamentales para tener éxito como músico profesional en el siglo XXI (Hallam y Gaunt, 2012). Un alumno de nuestro estudio dice a este respecto: "para poder tocar bien, es muy importante amar lo que se interpreta, estando al mismo tiempo preparado para recibir críticas, tanto positivas como negativas, pero creyendo en lo que haces".

En conclusión, parece imprescindible, de cara a tener una inteligencia exitosa (que sería una herramienta básica de cara a conseguir la excelencia musical) encontrar ese equilibrio entre las partes analítica, creativa y práctica que dirigen nuestro pensamiento y nuestra acción. El músico del siglo XXI que buscamos necesita, ineludiblemente, poseer una inteligencia exitosa equilibrada.

Para tener una idea más clara de lo que nos dice Sternberg presentamos a continuación un mapa conceptual en el que se percibe con claridad ese equilibrio del que hablamos: 


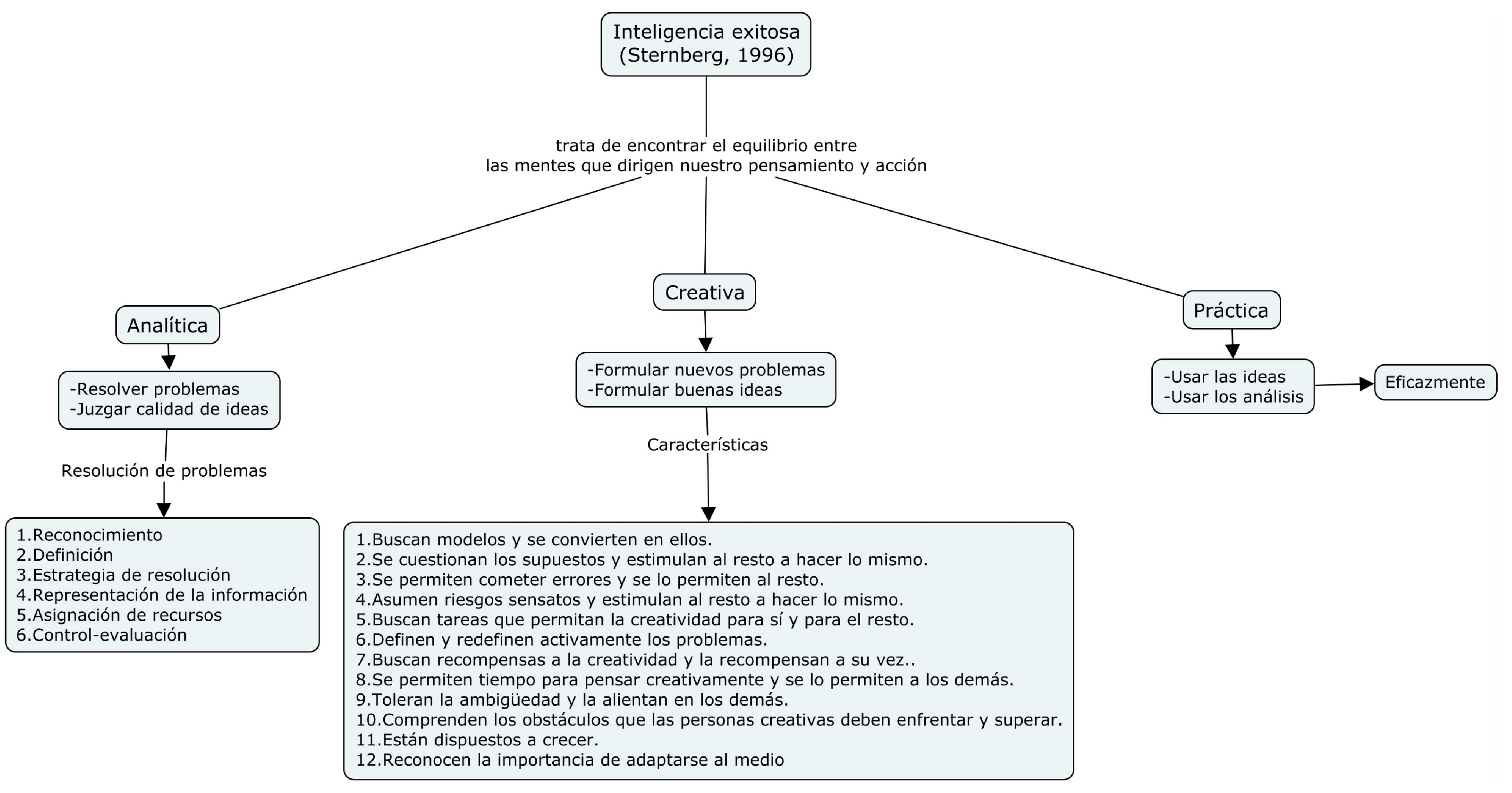

Ilustración 2. Esquema: Inteligencia exitosa de Sternberg. Elaboración propia. 


\subsection{Las inteligencias del futuro de Gardner}

Esta idea de la inteligencia que estamos presentando, y que habla de una capacidad que está en continua transformación, nos anima a pensar que ese desarrollo será diferente a lo largo de la historia, y por eso nos parece importante presentar la propuesta de Gardner, especialmente el estudio donde valora las cinco inteligencias que considera fundamentales para el siglo XXI. $\mathrm{Y}$, obviamente, al desarrollarlas veremos la forma en que podemos trabajar cada una de ellas en la música.

Howard Gardner es un psicólogo, investigador y profesor de la universidad de Harvard, conocido en el ámbito científico por sus investigaciones en el análisis de las capacidades cognitivas y por haber formulado la teoría de las inteligencias múltiples. En su obra Las cinco inteligencias del futuro: un ensayo educativo nos presenta las habilidades cognitivas específicas que, a su modo de ver, serán las más apreciadas en el futuro y que por tanto habrá que seguir desarrollando a lo largo de la vida.

Gardner insiste en que los cambios a los que estamos asistiendo en estos inicios del tercer milenio exigen nuevas formas y nuevos procesos educativos y describe las cinco clases de mente que en su opinión tendrán más importancia en el futuro: la mente disciplinada, la mente sintética, la mente creadora, la mente respetuosa y la mente ética. (Gardner, 2005:10).

\subsubsection{La mente disciplinada}

Al hablar de mente disciplinada, Gardner intenta oponer esta forma de pensar a la memorización forzada de una lista creada por otra persona. Así, presenta una mente que desea seguir aprendiendo, que disfruta aprendiendo y que intenta aprender cada vez más. Asegura que es necesario adquirir un método disciplinado para abordar los temas de importancia, de modo que además de adquirir formación útil, este conocimiento adquirido tenga más solidez y más flexibilidad porque se habrá adquirido en un contexto significativo, resaltando la idea de que el aprender algo de forma profunda nos generará el deseo de querer aprender más. Dice textualmente:

Al igual que las experiencias más destacadas de la vida (desde el orgasmo hasta la caridad) su logro genera el deseo de querer más. Cuando se ha entendido bien una obra 
concreta, una guerra particular o un concepto físico o biológico dado, se aviva el deseo de lograr una comprensión más amplia y más profunda. Es improbable que quien comprende bien las cosas llegue a aceptar alguna comprensión superficial. Habiendo mordido el fruto del árbol de la comprensión, lo más probable es que vuelva a él una otra vez en busca de un alimento intelectual que le deje saciado (Gardner, 2005:38).

Este deseo de lograr una comprensión más amplia y más profunda del que nos habla Gardner es lo que creemos necesario para buscar la excelencia y es lo que debemos fomentar en nuestros alumnos de las enseñanzas superiores.

¿Pero cómo conseguir esta mente disciplinada? Gardner nos propone cuatro pasos básicos (2005:33-34):

\section{Identificar temas o conceptos verdaderamente importantes dentro de la disciplina.}

Según dice el autor, algunos tendrán que ver con el contenido y otros con el método. En nuestro caso, para intentar conseguir la excelencia musical tendríamos que identificar qué contenidos y técnicas son verdaderamente importantes para un músico e intentar desarrollarlas tanto como se pueda. En cada asignatura sería necesario identificar lo fundamental dentro de la disciplina, por ejemplo, como instrumentistas tendríamos que señalar las cinco habilidades básicas que nos señala McPherson: tocar a primera vista, tocar de oído, tocar de memoria, improvisar e interpretar repertorio ensayado (2000) y ser conscientes de que es importante trabajarlas desde el principio, porque es lo verdaderamente esencial para seguir manteniendo ese deseo de seguir aprendiendo. Pero no bastaría con lo señalado por McPherson, sino que habría que añadir otro aspecto central, como el que nos señalan Hallam y Gaunt ${ }^{2}$ (2012): la idea de que para conseguir el éxito como músico es fundamental que el propio alumno asuma la responsabilidad de su propio desarrollo y persiga lo que le apasione. Para eso tiene que saber identificar cuáles son los contenidos y técnicas que tiene que desarrollar para conseguir lo que le apasiona y ser un estudiante activo capaz de automotivarse, planificarse y marcarse sus propios objetivos sin esperar a que se los marquen los demás. Es decir, que además de las habilidades básicas musicales necesitamos otras habilidades de personalidad: una capacidad

2 De esta idea hablaremos con más profundidad en capítulos posteriores, porque merece un desarrollo independiente. 
expresiva, una capacidad de automotivación y confianza en nosotros mismos, elementos que nos van a ayudar a desarrollar ese deseo por seguir aprendiendo, a desarrollar esa mente disciplinada de la que nos habla Gardner.

2. Dedicar a estos temas el tiempo necesario. Se puede comprobar fácilmente cómo el disfrute sin prisas nos puede ayudar a tener una conexión mucho más personal con nuestro instrumento (o con lo que estemos aprendiendo) de forma que nos ayude a fomentar esa mente disciplinada o esas ganas de seguir aprendiendo. Sin embargo, parece que en ocasiones se premia más el resultado inmediato que el esfuerzo que requiere paciencia y resultados a largo plazo. Tenemos que ser conscientes, como nos apuntan Hallam y Gaunt, de que para desarrollar altos niveles de pericia en cualquiera de las posibilidades que el campo profesional ofrece al músico (compositor, intérprete, docente, arreglista, etc.) se requiere tiempo tanto para adquirir conocimientos musicales como para desarrollar una amplia gama de habilidades y destrezas que serán necesarios para que estos conocimientos sean usados (2012:23).

3. Abordar los temas de varias maneras. La educación orientada a la comprensión de la disciplina tendrá que sacar partido de las diferentes formas de aprender. Según esta teoría, habría que poner más énfasis en las distintas vías de acceso que tienen las personas a la hora de encarar un objeto de estudio, de forma que el profesor pueda llegar a más estudiantes abordando el tema desde distintas perspectivas o utilizando distintas vías, porque cada alumno puede aprenderlo y concebirlo de varias maneras. Nos dice textualmente:

El uso de múltiples vías de acceso permite lograr dos objetivos importantes. En primer lugar, el enseñante llega a más estudiantes, porque algunos aprenden mejor por medio de debates, con obras de arte o identificándose con un experto. En segundo lugar, este enfoque demuestra cómo es la verdadera comprensión. Toda persona que comprende a fondo un tema o un método puede concebirlo de varias maneras. Y a la inversa, una persona revela sus limitaciones en relación con un tema si sólo puede conceptuarlo de una manera. ${ }^{3}$ (Gardner, 2005:33-34)

\footnotetext{
3 También nos expondrá más adelante que la facultad de concebir un tema de múltiples maneras es, igualmente esencial para desarrollar la mente sintética y la mente creativa.
} 
En música, como en todo, es necesario siempre analizar distintos puntos de vista. Por ejemplo, a la hora de interpretar será pertinente abordar el trabajo desde la escucha y la grabación, escuchar a otros (tanto tocando como expresando su opinión sobre el asunto, de modo que se puedan tener distintas versiones y opiniones) y grabarnos para poder realizar una escucha más objetiva de nuestro propio trabajo. También será necesario analizar los distintos puntos de vista a la hora de estudiar. En definitiva, cada uno debe encontrar la forma de estudiar que más responda a sus necesidades, pues como demuestra Hallam (1995) en sus detallados estudios, los métodos de práctica son muy individuales y ninguno muestra una correspondencia con el éxito.

\section{Establecer unas "demostraciones de la comprensión" y dar abundantes} oportunidades a los estudiantes para que revelen su comprensión en una variedad de condiciones. Gardner explica que para poder demostrar que una comprensión es sólida, es necesario que el estudiante pueda aplicar esta supuesta comprensión a un ejemplo que sea nuevo para él, que no sólo repitan lo que se le ha enseñado. Nos dice: "En síntesis, ésta es la razón de que la mayoría de las medidas normalizadas del aprendizaje sean tan poco útiles, ya que no revelan si un estudiante realmente puede hacer uso del material- la materia- que ha recibido en clase" (Gardner, 2005:35).

Aquí el autor nos reta a conseguir el más difícil todavía: que el alumno demuestre que lo que ha aprendido es importante para él, lo ha hecho suyo y por eso es capaz de aplicarlo en distintas situaciones y contextos. Para que esta "demostración de la comprensión" de la que habla Gardner se pueda dar, es necesario que el proceso de aprendizaje se haya realizado de forma correcta, es decir, que no sólo se ha aprendido viendo y entendiendo cómo está codificado lo que queremos aprender, sino que también son necesarias repetidas oportunidades para ponerlo en práctica, así como la motivación suficiente para dedicar el tiempo necesario para esta puesta en práctica en diferentes situaciones y contextos (Sloboda, 1987).

Podemos decir, en palabras de Gardner, que una persona es disciplinada en la medida en que ha adquirido unos hábitos que le permitan realizar un avance constante $\mathrm{y}$, en esencia, perpetuo hacia el dominio de una técnica, un arte o un corpus de conocimiento. Estas personas seguirán aprendiendo y desarrollando su comprensión disciplinaria por dos razones: 1) porque comprenden que cada vez hay más conocimientos, datos y métodos y por lo tanto deberán 
estudiar toda la vida; 2) porque disfrutan y en el fondo se apasionan con el proceso de aprender sobre el mundo. (Gardner, 2005:40).

Quizá una idea especialmente atractiva para el tema que nos ocupa es tener claro cómo puede el profesor ayudar a conseguir esta mente disciplinada. Sloboda nos explica que lo mejor que puede hacer un profesor para mejorar como tal es conocer al alumno, quererle, tener altas expectativas en lo que puede lograr y darle buena información (1987). Se puede decir que el profesor actual no es la persona que únicamente tiene que transmitir un conocimiento o que tiene que enseñar a ver cómo está codificado algo para poder aprenderlo, pues ahora mismo esta transmisión del conocimiento se puede obtener de muchas maneras. Hoy día existen casi infinitas formas de acercarnos a cualquier concepto susceptible de ser aprendido, especialmente desde que internet se convirtió en una herramienta universal. Ahí podemos ver, escuchar y casi tocar un sinfín de información, aplicada a distintos estilos y explicada de muy diferentes maneras y por distintas personas. Por eso, el mayor reto del profesor en este momento es ayudar al alumno a saber cómo lo puede poner en práctica según sus características particulares y en distintas situaciones, además de ayudarle a conseguir la motivación necesaria para hacerlo. Y, para conseguir esto último le debe enseñar la utilidad de lo que va a aprender, así como ayudarle a aprender a automotivarse y a buscar sus propias formas de aplicar lo que aprende en distintos contextos o situaciones. Como se muestra en la investigación actual, para tener éxito como músico profesional es necesario, entre otras cosas, ser capaz de marcarse sus propios objetivos a corto y medio plazo, hacerse responsable de su propio desarrollo y seguir lo que le apasiona (Hallam y Gaunt, 2012:4). Todas estas herramientas son las que le van a ayudar a conseguir esta mente disciplinada que va a ser tan estimulante para seguir aprendiendo y para llegar a ser un buen músico.

Hallam (1998), analizando las características biográficas de músicos de reconocido prestigio y de muchos estudiantes de música, llega a la conclusión de que para ayudar a desarrollar la motivación intrínseca de los alumnos se deberían utilizar las siguientes técnicas de enseñanza: a) exponerles a distintos tipos de música de una manera libre para ampliar las posibilidades de respuesta emocional a la música, b) dejarles participar en las decisiones sobre el estilo y la dificultad de la música que van a aprender y decidir si quieren o no interpretar la música en público y examinarse y c) para estimular a los alumnos los profesores deben generar sorpresas, dudas, contradicción y debate. Lo que propone es que las tareas musicales sean interesantes para los alumnos y con un nivel de complejidad óptimo, es decir, que los enfrente a retos que 
sean practicables y que ellos tengan margen para decidir lo que quieren tocar. Esto debería seguir siendo así en la enseñanza superior, y para ello será fundamental que el profesor ayude a los alumnos a desarrollar su propio criterio para hacer las cosas de forma correcta, a elegir el repertorio que quieren tocar y a disfrutar de lo que toca en cada momento.

\subsubsection{La mente sintética}

La capacidad de entretejer información procedente de distintas fuentes en un todo coherente es vital en el mundo de hoy. (...) Según el Premio Nobel de física Murray Gell-Mann, la mente más preciada en el siglo XXI será la mente capaz de sintetizar. (...) Pocas personas, y aún menos instituciones, tienen el don de inculcar la capacidad de síntesis. Y, para colmo, cuando la capacidad de sintetizar se desea y se cultiva carecemos de normas o criterios para determinar si una síntesis es productiva o prematura, defectuosa o totalmente errónea (Gardner, 2005:41-42).

Al mismo tiempo que nos presenta la dificultad de conseguir la mente sintética, Gardner también nos apunta que, a pesar de todo, el ser humano intenta sintetizar y en ocasiones lo logra. Esta tarea exige combinar elementos originalmente separados o distintos, cosa que solemos hacer en las narraciones, taxonomías, conceptos complejos, metáforas evocadoras, teorías, metanarraciones y en el trabajo interdisciplinario. Este trabajo interdisciplinario lo considera la forma de síntesis más ambiciosa, aunque para que pueda llamarse así debería suponer una combinación adecuada de dos disciplinas como mínimo y no bastaría con que se yuxtapongan, sino que deberían estar realmente integradas. Nos muestra así cómo la capacidad de cada persona para emplear metáforas o su capacidad para transferir contenidos de una disciplina a otra es muy diferente y cita a Aristóteles, para quien la capacidad de crear buenas metáforas era una marca del genio. Llegados a este punto, Gardner presenta la diferencia entre la inteligencia-láser (que estudia un tema en profundidad pero pasa por alto las influencias recíprocas) y la inteligencia-reflector (no estudia las cosas con tanta profundidad, pero siempre está examinando el entorno y puede distinguir conexiones con más facilidad).

Para nuestro trabajo es especialmente interesante lo que citamos a continuación:

También he observado que hay dos tipos muy diferentes de personas que se sienten atraídas por el trabajo de carácter interdisciplinario: unas son curiosas, están bien informadas y son propensas a realizar saltos mentales bien fundados; otras rechazan el pensamiento lineal y metódico y tienden a 
realizar saltos mentales que pueden caer en el descuido o hasta en el desatino. Esta dicotomía se puede aplicar por igual a enseñantes y a estudiantes. Incluso cabe preguntarse si las distintas inteligencias se inclinan por distintas formas de síntesis. En relación con los tipos de síntesis antes propuestos, puede que la mente lingüística prefiera los relatos, que la mente lógica se incline por las ecuaciones o las teorías, que la mente espacial prefiera los mapas o los planos y que la mente corporal-cinestésica se centre más en el equilibrio entre fuerzas opuestas. Si así fuera, se plantearía la cuestión de si es posible efectuar una síntesis de orden superior entre distintas formas de integración, quizás a través del conocimiento de uno mismo (lo que yo llamo "inteligencia intrapersonal”) (Gardner, 2005:50-51).

En este punto, nuestro autor plantea un reto a la educación: ¿es posible desarrollar una mente disciplinada sin menoscabar el potencial para el pensamiento sintético? Parece que no hay una respuesta fácil pues, como reconoce Gardner, nuestros conocimientos sistemáticos sobre la manera de inculcar una mente sintetizadora son minúsculos. Al respecto, comenta que los niños tienen una fuerte tendencia a establecer e incluso a forzar conexiones, de modo que parece ser un recurso intelectual que puede ser muy valioso de cara a utilizarlo en el futuro, ya que supone el establecimiento de conexiones entre diversas redes neuronales. Aunque estas conexiones pasen a un segundo plano durante un tiempo, parece ser que pueden perdurar y que, bajo determinadas circunstancias, podrían volver a ser utilizadas. En ese sentido, afirma que es interesante acelerar las conexiones que la mente infantil establece con tanta facilidad en lugar de censurarlas o limitarlas.

A este respecto, propone tres intervenciones que pueden ser útiles:

1. Identificar explícitamente los elementos constitutivos de un buen proyecto o de una buena solución a un problema. Para esto, marca como esencial el uso de modelos así como que el educador sea capaz de identificar las dimensiones que caracterizan los proyectos o las soluciones que se consideran excelentes, adecuadas o inaceptables. En música, sería muy adecuado reconocer cuáles son los rasgos propios de un compositor o estilo y qué rasgos son los que definen una buena composición en cada época o estilo. Ser capaces de identificar estos elementos comunes entre ellos y relacionar obras y estilos nos ayudaría a aplicar lo aprendido a lo nuevo y a aprender nuevas cosas más rápidamente.

2. Enseñar tipos de síntesis, tales como narraciones, taxonomías, conceptos complejos, metáforas evocadoras, teorías, metanarraciones y trabajos interdisciplinarios. Las síntesis suponen mezclar guiones, marcos y conceptos que normalmente se consideran por separado; esto tiene algo de artístico. Como nos dice Gardner, los estudiantes que poseen 
varias representaciones de la misma idea o del mismo concepto tienen muchas más probabilidades de llegar a una buena síntesis que los que poseen una sola representación de esa idea o ese concepto. El hecho de apreciar las virtudes de dos o más perspectivas le coloca en una posición mucho más sólida para integrar o sintetizar estas líneas de conocimiento. Con respecto a la música también podemos destacar la importancia de ver la música desde distintas prácticas para colocarnos en una posición ventajosa. Sloboda nos dice que los alumnos que además de la práctica formal participaban en prácticas informales (que incluían improvisaciones y aprender melodías de memoria) avanzaban más rápido, ya que además de adquirir las habilidades técnicas para controlar el instrumento y el repertorio también dedicaban tiempo y esfuerzo a ver cómo funcionan las estructuras musicales. (Sloboda et al., 1996). En la misma línea, Hallam y Gaunt (2012) insisten en la importancia para el músico del siglo XXI de estar preparado para las nuevas oportunidades de aprendizaje, tanto formales como informales, que se le presenten, y ser tan bueno como sea posible en el aprendizaje en diferentes contextos. Asimismo, les anima a buscar oportunidades para desarrollar las habilidades de improvisación en cualquier estilo musical.

3. Hacer una crítica útil y constructiva de las síntesis, conexiones o integraciones que presentan los alumnos. Prácticamente en todos los problemas o proyectos hay respuestas que son más adecuadas que otras. A los estudiantes les es muy útil conocer diferentes soluciones, diferentes métodos para llegar a ellas y diferentes procedimientos para evaluarlas.

Una reflexión de Gardner muestra la idea de que en épocas anteriores la mente sintetizadora era más asequible y que actualmente vivimos en una época en que nuestras mentes con más talento saben cada vez más sobre ámbitos cada vez más restringidos. Para contrarrestar esta tendencia propone dos antídotos básicos:

1. Formar a las personas para que puedan participar con eficacia en grupos interdisciplinarios en universidades y otras instituciones de enseñanza superior, donde se impulse la cooperación entre expertos de distintas disciplinas.

En este punto se hace una llamada explícita al colectivo que nos interesa en esta investigación: la enseñanza superior. Y remarca la necesidad de impulsar la cooperación 
algo que también está muy de actualidad en la investigación en la educación musical Un trabajo destacable sobre este tema es el estudio sobre el aprendizaje colaborativo en la educación musical superior llevado a cabo por Gaunt y Westerlund (2013), donde señalan que es más que evidente el impacto que el aprendizaje colaborativo tiene en el contexto de la educación superior, especialmente a la hora de apoyar el desarrollo de importantes habilidades, tales como ser más responsables a la hora de controlar su propio aprendizaje y ser menos dependiente de las instrucciones directas del profesor; y de igual modo, facilitar la creatividad y respaldar las habilidades de los estudiantes que le permitan integrarse en contextos profesionales de cara a ser lo suficientemente flexibles para encajar con la diversidad. A este respecto, la investigación realizada por Gaunt (2007) con alumnos de enseñanza superior sobre la enseñanza y el aprendizaje de la respiración en el oboe, ya ponía de relieve la importancia que había tenido en el proceso de investigación el hacer que los participantes reflexionaran sobre su propio aprendizaje durante un tiempo y compartieran sus experiencias con el grupo. Esta reflexión ayudó a los estudiantes a tomar conciencia de su propia forma de trabajar, lo que les permitió beneficiarse de otras perspectivas e ideas y determinar alternativas y modificaciones para las suyas propias. Gaunt insistía en que este tipo de experiencias no eran una característica común de la enseñanza instrumental en la educación superior, de modo que se empezaba a demostrar el impacto que el contexto donde se aprende tiene en los alumnos, destacando la importancia de las relaciones que se desarrollan entre los profesores y entre los alumnos. Esto sugiere que la naturaleza de los contextos de aprendizaje en conservatorios necesita ser estudiado con más detalle, particularmente en relación con las teorías relativas al aprendizaje en la enseñanza superior. Asimismo, apunta que seguir construyendo en áreas de trabajo que ahora están empezando a desarrollarse en algunos conservatorios tendrá un valor incalculable. Otro enfoque para este tema es el que presentan Collen Conway y Thomas Hogman (2009), en su conocido trabajo Teaching Music in Higher Education. En él se presenta con claridad meridiana el cambio de paradigma experimentado en la enseñanza superior, y más concretamente, en el contexto de aprendizaje, pues se ha pasado de un contexto competitivo e individualista a un contexto de aprendizaje cooperativo en clase, donde los distintos grupos de colaboración trabajan de manera conjunta (e incluso con los de otros centros) para conseguir mejores resultados; un contexto en el que se reconoce y valora muy positivamente la diversidad cultural y el valor de la comunidad. En este nuevo paradigma, el profesor ya no representa un poder identificado con la autoridad y el control, 
sino que el poder es compartido entre estudiantes y profesores, que aúnan fuerzas para buscar las mejores soluciones por medio de la comunicación, la colaboración y el acceso a la información. Un acceso a la información que se produce de forma conjunta, animados por la idea de que tanto aprender como enseñar es una tarea compleja que requiere un entrenamiento considerable y continuo a lo largo de la vida.

2. Creación de programas educativos dirigidos específicamente al perfeccionamiento de la capacidad de síntesis. En música esta capacidad de síntesis se debe trabajar desde el inicio, pues toda interpretación, composición o improvisación es la unión de técnica, práctica, conocimientos y expresión y para que se reconozca la valía de lo que se interpreta, compone o improvisa es básico conseguir una buena síntesis de todos estos elementos. En los grupos de discusión, los alumnos echan de menos el reconocimiento de esta integración y la valoración de las demás disciplinas distintas al instrumento. Remarcan que en ocasiones el mismo profesor de instrumento les dice que tienen demasiadas asignaturas que les quitan tiempo de tocar.

Para que estos enfoques puedan ser eficaces, Gardner insiste en que es necesario que se den dos condiciones: Por un lado, la necesidad de modelos (personas dotadas para la multiperspectiva, el trabajo interdisciplinario y /o la síntesis). Por otro lado, necesitamos criterios (específicos de cada misión o tema en concreto) que permitan diferenciar entre las integraciones excelentes, las adecuadas y las inaceptables. Como afirma Gardner: "algunas síntesis serán más sencillas que otras, pero puede que las más valiosas sean las que supongan un salto creativo" (Gardner, 2005:58). En música, muchos autores, estilos y obras surgen por la síntesis de las ideas de otros, razón por la cual parece de enorme importancia tener en cuenta esta mente, que es la que nos puede llevar en ocasiones a una nueva creación, a una genial interpretación, composición o improvisación y por tanto es necesario potenciarla y valorarla.

\subsection{3. . La mente creativa}

"En esta época de creciente globalización la creatividad se busca, se cultiva y se elogia." (Gardner, 2005:59). Como vemos por esta cita de Gardner, parece que la creatividad es un valor en nuestra época, y sin embargo muchas veces no sabemos cómo trabajarla y mucho 
menos cómo evaluarla, pasando en ocasiones a parecer menos importante por este hecho ya que lo que no se evalúa no se considera tan importante. Sternberg ${ }^{4}$ señala que es preferible que los estudiantes realicen un trabajo creativo que sea evaluado con un poco menos de objetividad a que nunca se les permita el trabajo creativo, con el único objetivo de que los maestros puedan mantener una apariencia de objetividad en la evaluación (1996:219). No estamos acostumbrados a exigir el reconocimiento ante algo creativo, pues muchas veces lo más valorado es el conformismo, el hacer las cosas igual que los demás, el no destacar sino el hacer lo que se pide y punto. Hemos visto cómo nuestros alumnos en la enseñanza superior incluso piensan que es mejor hacer lo que se les pide antes que luchar por desarrollar un estilo propio mucho más arriesgado, y con frecuencia dejan que sea el mismo profesor de instrumento el que imponga qué repertorio tocar en su concierto fin de carrera o qué tema elegir en su trabajo fin de carrera, en lugar de arriesgar y luchar por hacer lo que realmente quieren, sabiendo que si eligieran ellos, lo harían con mucha más entrega y entusiasmo, de modo que de modo que se reflejaría claramente en el resultado final. De hecho así pasa. Como dice Sternberg: "Es casi inevitable que el pensamiento creativo encuentre resistencia. La cuestión no es si encuentra resistencia, sino si el pensador creativo tendrá fortaleza para perseverar ante ella" (1996:222).

Gardner se suma a la idea que sugiere Mihaly Csikszentmihalyi sobre la creatividad, cuando explica que ésta nunca es el logro de una sola persona, sino que son tres los elementos que interactúan: el primero es una persona que haya dominado un ámbito de actuación y que ofrezca continuas variaciones en éste; el segundo elemento es el ámbito cultural donde trabaja la persona, con sus reglas, sus modelos, sus posibilidades y sus limitaciones; el tercer elemento es el campo social, el conjunto de personas e instituciones que ofrecen las experiencias educativas y las oportunidades de actuación y que en última instancia juzgan el mérito de la persona y de su supuesta creación

La creatividad se da si y sólo si el producto de una persona o de un grupo en un ámbito es reconocido por el campo como algo innovador y si ejerce una influencia real y tangible en el posterior trabajo realizado en ese ámbito (Csikzentmihalyi, en Gardner, 2005:62) 
Ya hemos tenido noticia de estos elementos en el apartado 1.1, como totalmente necesarios para conseguir algo creativo. Y volveremos sobre ellos en el siguiente capítulo, al hablar de la creatividad como una de las herramientas útiles para el profesor. Gardner insiste en que es evidente que todo creador necesita un mínimo de inteligencia y de técnica y que por cada escritor o compositor con talento que abre nuevos caminos hay centenares que se contentan o se resignan con el papel de lo que él llama "meros" expertos. Un experto sería alguien que, tras diez o más años de formación, ha alcanzado la cima de la práctica del ámbito en el que actúa:

El creador destaca por su temperamento, su personalidad y su actitud. Es una persona eternamente insatisfecha con el trabajo, las normas y las respuestas del momento. Emprende nuevas direcciones y disfruta siendo diferente de los demás, por lo menos, sabe sobrellevar esa diferencia. Si se topa con una anomalía (un nuevo acorde musical, un resultado inesperado en un experimento) no se echa atrás: procura entenderla para determinar si se trata de un error trivial o de una verdad importante hasta entonces desconocida. Es una persona enérgica e inmune a las críticas. Todos fallamos de vez en cuando, pero los creadores son quienes fallan más y, en no pocas ocasiones, de una manera espectacular: sólo una persona dispuesta a levantarse y a volver a intentarlo una y otra vez puede aspirar al logro creativo. Y cuando un logro ha sido refrendado por el campo, el creador prototípico no se duerme en los laureles: emprende otro camino desconocido, plenamente preparado para afrontar el fracaso a cambio de tener la oportunidad de volver a dejar huella. La actividad creadora suele estar llena de disgustos y sinsabores, pero el "fluir" que suele acompañar a una verdadera intuición o a un nuevo logro puede crear adicción. (Gardner, 2005:65).

Tras definir al creador, pasa a hablar de cómo se podría educar al creador durante toda la vida. Empieza explicando que los niños de cinco años no necesitan de ningún estímulo para adoptar una actitud creadora, pues no sólo se sienten intrigados por una amplia variedad de temas, también se empeñan en explorarlos y se entusiasman buscando soluciones. Así, explica que en cierto sentido la mente del niño de cinco años representa la cima del poder creativo y que el educador debería intentar mantener viva la mente y conservar la sensibilidad infantil. Para ello propone mantener abiertas varias posibilidades y alimentar el entusiasmo por la exploración. Es interesante mostrar diferentes soluciones a un mismo problema y, al mismo tiempo, hacer que los que están aprendiendo conozcan a personas creativas, además de ofrecer actividades ajenas a la rutina escolar donde se premie la innovación y se toleren los errores. 
Volviendo al caso que nos ocupa, es evidente que en música se debería poner el esfuerzo en educar al creador. Para conseguir esto, Sloboda (1984) insiste en que en los objetivos de la enseñanza se debería incluir un currículum orientado, unas técnicas orientadas y un desarrollo individual orientado. Y lo que parece evidente es que lo que falla es el desarrollo individual orientado. Se ha visto que los alumnos de la enseñanza superior echan de menos ese desarrollo individual orientado: insisten en que se les deja muy poca libertad para trabajar un estilo propio. Parece que es más habitual insistir en conseguir unas habilidades más generales y dejar para más adelante (cuando terminen sus estudios superiores) el desarrollo de un estilo personal. Hallam y Gaunt (2012) insisten en que el estudiante de música debe desarrollar los aspectos de su trabajo que le animen a tomar riesgos y explorar cosas nuevas ya que estimularán su creatividad, la búsqueda de ideas innovadoras, y le ayudará a ampliar su flexibilidad como músico. También anima a desarrollar la capacidad de recuperación. Explica que todo el mundo tiene dificultades y momentos de duda pero que los músicos exitosos son aquellos que son capaces de hacer frente a ello, aprender y seguir adelante Ya hemos visto (en el punto 1.1.1. de este capítulo) cómo podemos intentar desarrollar la creatividad con la propuesta de Sternberg y su inteligencia exitosa.

\subsubsection{La mente respetuosa}

Personalmente me inclino más por el concepto de respeto. En lugar de pasar por alto las diferencias, de dejarnos inflamar por ellas o de intentar aniquilarlas mediante el odio o el amor; invito a todos los seres humanos a que acepten las diferencias, a que aprendan a vivir con ellas, a que valoren y respeten a quienes forman parte de grupos distintos del suyo. (Gardner, 2005:79)

Como vemos, Gardner invita a valorar y respetar los grupos distintos del nuestro. En nuestros días parece que es algo que todo el mundo comparte, pero el propio Gardner aporta ejemplos en los que la historia se encarga de demostrar que no es así: "lo ideal sería que la responsabilidad de fomentar el respeto a las diferencias y de demostrar públicamente ese respeto se distribuyera por toda la sociedad" (Gardner, 2005:82). En relación a la educación, afirma que el cometido de los educadores está cada vez más claro y que si queremos formar adultos respetuosos con las diferencias lo que tendremos que hacer es ofrecer lecciones y modelos educativos que fomenten esta actitud. Al igual que en los tipos de aprendizajes vistos anteriormente (disciplinario, sintético y creador) el papel de los profesores como modelos constituye un punto de partida básico. Nos explica que los estudiantes toman buena nota del 
trato mutuo que se dispensan los profesores, de su trato con otros adultos y de su trato con los alumnos mismos, sobre todo si pertenecen a grupos minoritarios. También resalta la poderosa influencia de los elementos curriculares que seleccionan los profesores, las formas de tratar el material curricular y también lo que no selecciona o se quita de en medio antes de tiempo. Sloboda (1987) explica cómo el mejor soporte para una enseñanza eficaz es el buscar un grupo de profesores con el que puedas compartir tus dudas y problemas, en los que confies y donde pueda haber un mutuo reconocimiento y apoyo.

Gardner expone igualmente que se pueden plantear dos objeciones a lo que nos propone. La primera, que el hecho de evitar las discusiones no hace que se garantice más la tolerancia. Para solucionarlo, afirma que los prejuicios deben expresarse para poder examinar sus elementos de verdad y de falsedad y evitar que se acaben enquistando. La segunda objeción es que no hay que sacrificar disciplinas en pro del estudio de las relaciones entre grupos, pero que además de enseñar estas disciplinas con materiales "neutrales", también es importante incluir casos en los que las relaciones de grupo sean un factor esencial. Como dice Gardner:”el respeto hacia los demás debería impregnar toda nuestra vida” (2005:88).

Para llegar a ser un músico o un profesor excelente es necesario respetar a los demás, así como conocer nuestras limitaciones y posibilidades. Y está claro que esto es necesario trabajarlo desde el principio, no subestimando instrumentos, tipos de sonido o estilos distintos al nuestro y, por supuesto, valorando las dificultades de cada uno (para lo que es necesario, como siempre, un mayor conocimiento de lo distinto). En nuestros grupos de discusión, cuyas conclusiones se exponen en apartados posteriores, se muestran ejemplos muy ilustrativos sobre este tema, tanto de prácticas donde se que la mente respetuosa es fundamental como casos en los que se descubre claramente la necesidad de trabajar en ella para conseguir un mejor entendimiento.

Tal como dicen Hallam y Gaunt, el desarrollo de las habilidades de colaboración e interpersonales son necesarias para el músico profesional en el momento actual, ya que la colaboración es una parte esencial del trabajo del músico, tanto si eres un compositor, un músico de conjunto, un solista, un profesor, un investigador, un programador de conciertos o un simple organizador. En el pasado, se nos ha acostumbrado a pensar en la experiencia del músico como algo individual, pero esto es algo que está cambiando rápidamente. Las habilidades interpersonales (por ejemplo la escucha, el apoyo, la empatía...) son de vital 
importancia, pero no ya sólo en el terreno de la música, sino en cualquier ámbito comunicativo. Incluso si la colaboración es sólo una pequeña parte de una práctica musical específica, estas habilidades serán vitales en el proceso de búsqueda y gestión del trabajo. (Hallam y Gaunt, 2012:5)

\subsubsection{La mente ética}

En este capítulo, Gardner parte del hecho de que la mayoría de nosotros dedicamos la mayor parte de nuestra vida al trabajo, y en consecuencia concluye que hay un tipo de mentalidad que debería manifestar y potenciar toda persona en el ejercicio de su profesión. Así, define el mundo en el que le gustaría vivir como un mundo caracterizado por el "buen trabajo", concepto que es definido como el trabajo que es al mismo tiempo excelente y ético. El consagrado psicólogo describe cómo en los diez años anteriores a la publicación de este libro él y sus colegas han estado explorando la naturaleza del buen trabajo, intentando determinar qué factores contribuyen a conseguirlo, cuáles se le oponen y cuál es la mejor manera de incrementar su presencia.

Como profesores de enseñanza superior, tenemos que ser conscientes de lo importante que es trabajar bien y con rigor. Y esto debe ser así porque somos un ejemplo de lo que debe ser el trabajo a lo largo de la vida. Hay que ser conscientes de que igual que se piensa que el público se merece lo mejor y para ello se ensaya, el alumno también se merece con más motivo que preparemos la clase pues son un público diario (que paga la entrada todos los días) y merece más respeto si cabe que el que nos ve sólo una vez. También hay que destacar que para aprender a hacer un buen trabajo hay que tener en cuenta el respeto al resto de compañeros o profesionales, empezando por cosas tan simples como la puntualidad y el estudiar para no hacerle perder el tiempo al otro, buscando buenos referentes en el trabajo e intentando ser referente de otros. También es importante, además de lo dicho, buscar que los de alrededor también lo hagan, ayudándoles cuando esté en nuestra mano y haciéndoles ver cuándo no es correcto. Los alumnos de la enseñanza superior son conscientes de que esta mente ética está calando hondo en músicos de reconocido prestigio, como los casos de Daniel Baremboim, que pretende buscar un lugar de encuentro que propicie un escenario de paz para Israel y Palestina, o de John Sloboda, que en su tarjeta se presenta como activista por la paz.

Parece evidente que en la enseñanza musical se busca, ya desde el principio, un "buen trabajo". Todo el mundo sabe que son necesarios la constancia y el esfuerzo diario para 
obtener resultados satisfactorios: no es posible tocar todo la última noche para aprobar un examen. Por eso está claro que la forma de trabajo que se pide al alumno es muy comprometida (como a los deportistas). En este sentido, una de las preguntas que se suele asociar a la práctica es ¿cuánto tiempo dedicarle? Y, sin embargo, es más necesario preguntarse cómo practicar. En este sentido, Lehmann, Sloboda y Woody (2007) afirman que el problema ha sido dar por hecho que los músicos sabemos practicar de forma correcta. Por esta razón, la tarea fundamental del profesor de música es la de ayudarles a realizar un buen trabajo diariamente, a crear la mente disciplinada de la que habla Gardner para que el músico disfrute tocando, sintetizando y creando, para que pueda hacer un buen trabajo a través de la música si la elige como forma de trabajo, para que pueda disfrutar conociéndola mejor si la elige como forma de ocio o para que pueda conocer este lenguaje simbólico como otra forma de expresión más que le pueda ser útil para ampliar su visión del mundo, del mismo modo que conocer el lenguaje matemático u otro idioma distinto al propio. Es decir, que el trabajo que se haga con la música sea de calidad, que tenga significado para el que la interpreta tanto si lo hace de forma profesional como si no.

Ahora bien, ¿cómo llevar a cabo esta tarea? El propio autor, respondiendo a esta pregunta, plantea tres apoyos fundamentales:

- Apoyo vertical. En el hogar es donde primero comienza la orientación ética. Los niños observan cómo trabajan sus padres dentro y fuera de casa y también a otros adultos que tienen influencia formativa en ellos.

- Apoyo horizontal. Los compañeros y colegas adquieren gran importancia en la sociedad actual. La calidad de los compañeros es importante durante toda la vida pero, según añade Gardner, mucho más durante la adolescencia.

- Vacunas periódicas. Contactos con personas y experiencias que recuerden el significado del buen trabajo, como por ejemplo, el contacto con personas y experiencias que recuerden lo que significa esto; y también "vacunas de choque" para combatir ejemplos negativos, como el castigo de los plagios o los inventos falsos.

Por supuesto, es también importante la calidad de las instituciones donde se trabaja: si los niveles de exigencia son elevados, si quienes las dirigen se esfuerzan por trabajar bien y seleccionan a personas que trabajan bien, es más sencillo hacer un buen trabajo. 
En nuestro estudio hemos podido comprobar que todos estos apoyos siguen siendo muy importantes en la enseñanza superior. Los alumnos reconocen el apoyo que tienen todavía en sus padres y en sus hermanos (en muchas ocasiones son los hermanos las personas con las que hablan sus problemas con respecto al instrumento, pues si los padres no saben lo que es tocar un instrumento, creen que no van a poder entenderlos). Sloboda (1994) demuestra que el constante apoyo familiar es uno de los factores que influyen en el grado de destreza musical. Igualmente, se reconoce el de los compañeros y profesores que les sirven de ejemplo y de apoyo. Como dicen Hallam y Gaunt (2012), para conseguir el éxito como músico profesional es fundamental que se busque un círculo de profesores de confianza, de mentores y amigos para apoyar su desarrollo, así como involucrarse en grupos y comunidades que les interesan o puedan serles útiles. Todos los músicos confían en redes extensas: artistas, colaboradores creativos, empresarios, agentes, programadores y amigos críticos. Tener un conjunto sólido de relaciones de esta naturaleza acelerará su aprendizaje, abrirá puertas y proporcionará conocimientos y habilidades importantes, además de apoyo psicológico.

Para llegar a ser un buen profesional, Gardner señala que es necesario estar dispuesto a realizar un buen trabajo y no cejar en este propósito. Para este fin propone usar lo que él llama las cuatro $\mathrm{M}$ :

1. Misión: qué objetivos tiene la persona con su actividad.

2. Modelos: es importante entrar en contacto con modelos (directamente o a través de textos) que encarnen el buen trabajo e igualmente señala como interesante el extraer buenas lecciones de modelos negativos.

3. Mirarse al espejo: versión individual. Autoanalizar tu propia forma de trabajar, para ver si su actuación es correcta y qué debe hacer para mejorar. Por supuesto, es también importante pulsar la opinión de otras personas.

4. Mirarse al espejo: responsabilidad profesional. Cuando se comienza en una profesión es importante centrarse en hacer bien el trabajo propio. Pero a medida que se alcanza la madurez profesional, es igualmente importante controlar que los compañeros y colegas también lo hagan, para pedir cuentas si es necesario. Trae a colación, en este sentido, la frase de Molière: "somos tan responsables de lo que hacemos como de lo que no hacemos". (Gardner, 2005:104). 
En conclusión, para él es fundamental que los jóvenes que se están formando empiecen a pensar en función de misiones, modelos y espejos en que mirarse:

En la medida en que esto llegue a formar parte de su arquitectura mental y en la medida en que estén preparados para variar de rumbo cuando sea necesario, podrán asumir la principal responsabilidad por la excelencia, la dimensión ética y el significado de su trabajo (Gardner, 2005:105).

En el caso concreto de la música, para poder hacer un buen trabajo en la enseñanza superior va a ser fundamental conocer cuáles son las necesidades del músico de este siglo, cuáles son los modelos en los que debemos fijarnos, (imitar los buenos modelos y evitar los malos), cuáles son nuestros aciertos y errores y cuáles los de los demás $\mathrm{y}$, como hemos señalado anteriormente, aprender a trabajar en grupo, ya que es necesario el apoyo entre personas para generar ideas y colaboraciones artísticas y para ello es necesario trabajar de forma respetuosa y ética.

Tras estudiar las ideas de Gardner sobre las mentes que serán más valoradas en el siglo XXI parece muy atrayente la aspiración de trabajar las cinco mentes analizadas en la enseñanza superior de música. Por desgracia, el propio autor es consciente de que es muy complicado modificar las prácticas con las que las personas o educadores se han formado y en las que se sienten cómodas. Esta resistencia natural puede adoptar distintas formas: conservadurismo, modas, posibles riesgos e impotencia. Para atajar todo esto, aconseja que tengamos paciencia y busquemos el momento y el lugar donde puedan tener más acogida para ir poco a poco. Por su parte, Sloboda (1987) indica que para enseñar eficazmente tenemos que estar muy vigilantes para no repetir esquemas estériles y periclitados, pues tendemos a obrar tal como hemos sido tratados. Explica que si no nos hemos sentido escuchados ni estimados ni hemos sentido una confianza puesta en nosotros, nos va a ser muy difícil llevar a cabo estas tareas con otros. Insiste en que el stress que padecen nuestros alumnos se debe a la ansiedad, a la poca autoestima y al miedo al fracaso, junto con las ansiedades acumuladas en torno a experiencias de interpretación musical y de aprendizaje. Por todo ello, será necesario cambiar el clima y buscar un ambiente donde el alumno se sienta ayudado y no juzgado, para poder así desarrollar estas cinco mentes tan necesarias en el futuro.

Llegados a este punto, nos parece interesante (a la par que curioso) los ejemplos concretos que Gardner cita como modelos de algunos tipos de mente: Ramón y Cajal como mente disciplinada, Pablo Picasso como mente creativa y Pau Casals como mente ética. Aun así, y a 
pesar de la pertinencia de estos modelos, insiste en que los ejemplos más eficaces son las personas que se conocen personalmente y que ilustran día a día las características esenciales de los roles deseados. Como ejemplo de esto que estamos diciendo, podemos citar de nuevo el grupo de alumnos de nuestro estudio. Al pedirles que pensaran en modelos de estos tipos de mentes, además de recurrir a los lógicos músicos de reconocido prestigio, aparecían también ejemplos de familiares (casi siempre sus padres) y de compañeros (en especial los que tocaban su mismo instrumento o con los que tocan en grupos pequeños). Y nos parece interesante resaltar aquí el hecho de que lo que más valoraban de estos modelos era la mente respetuosa y la mente ética, por encima de las demás.

En la página siguiente incluimos un mapa conceptual de lo explicado en este capítulo, de forma que se pueda tener la teoría de Gardner a la vista de una manera sinóptica. 


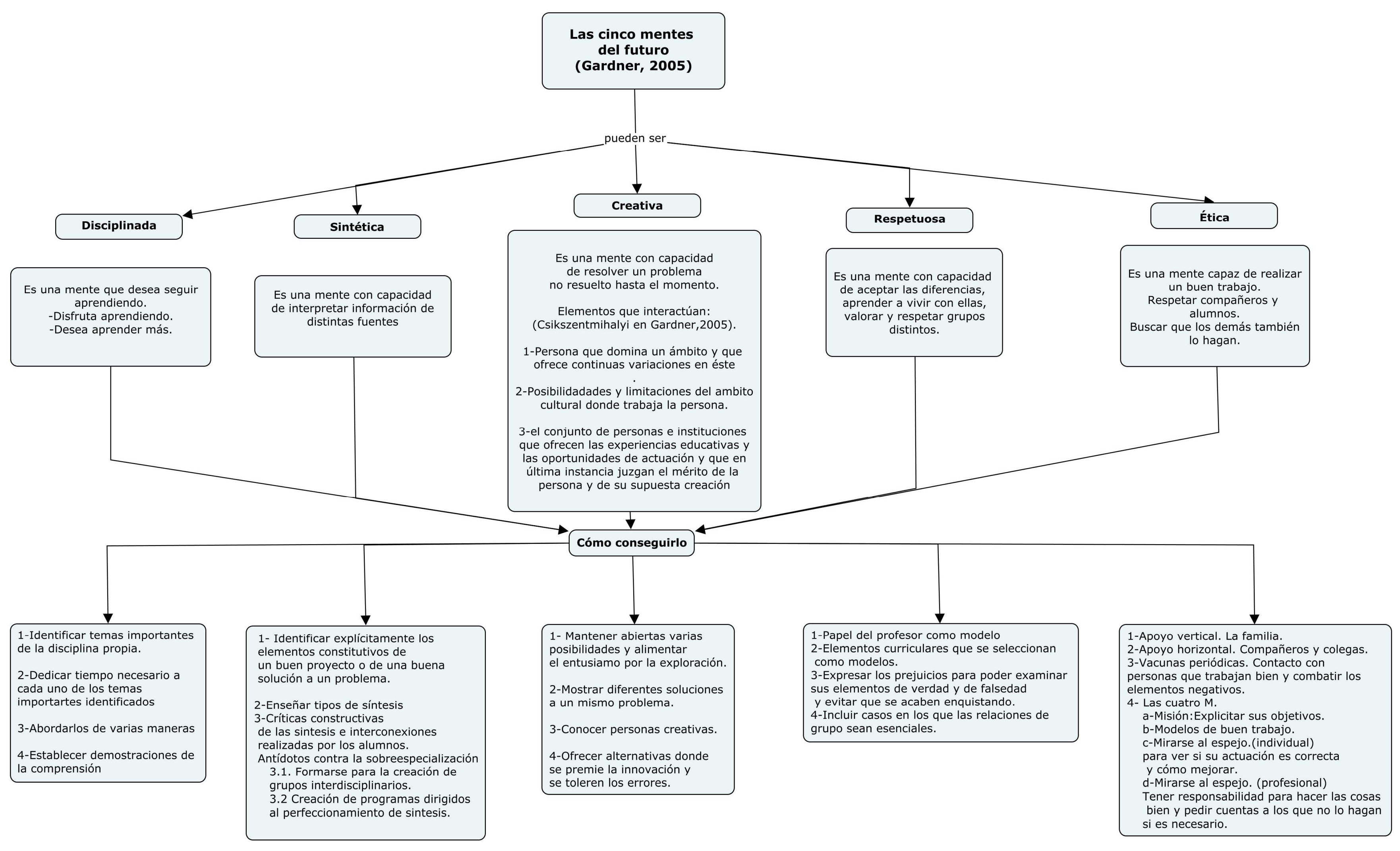

Ilustración 3. Esquema: Inteligencias de Gardner y cómo desarrollarlas. Elaboración propia 


\subsection{Mentalidad fija y mentalidad en crecimiento de Dweck}

Hemos visto ya las aportaciones de Robert Sternberg sobre la inteligencia exitosa y la de Howard Gardner y sus cinco mentes del futuro, ambas bastante conocidas en términos generales. Pero existe otra que consideramos de gran importancia en relación con el concepto de inteligencia: el estudio de Carol Dweck (1998, 2006) sobre la mentalidad fija y la mentalidad en crecimiento.

Carol Dweck es una de las investigadoras de más prestigio en el campo de la personalidad, la psicología social y el desarrollo psicológico. Es por esta razón que sus puntos de vista pueden ser muy útiles para nuestro estudio, particularmente en lo que se refiere a su teoría de las dos mentalidades. Pero antes de centrarnos en ésta, hay que entender una serie de conceptos previos, en concreto, los patrones de motivación y los tipos de objetivos de éxito que propone para el aprendizaje.

\subsubsection{Conceptos básicos:}

A. Patrones de motivación

Para Dweck existen dos tipos de patrones motivacionales:

a) Un patrón motivacional orientado al dominio de la tarea (mastery oriented), que se caracteriza por la implicación activa en el aprendizaje de tareas que suponen un cierto reto o desafío. Los estudiantes que usan este patrón de motivación hacen frente a los retos con entusiasmo y muestran un esfuerzo más intenso que los que no presentan este tipo de patrón motivacional, al tiempo que mantienen el optimismo y utilizan estrategias efectivas cuando se enfrentan a los obstáculos (Diener y Dweck, 1987 en Dweck, 1998).

b) Un patrón motivacional de indefensión (helpless), caracterizado por la tendencia a evitar los retos que presentan riesgo de errores o fallos, conllevando asimismo la autoculpabilización del sujeto que lo aplica. Al mismo tiempo, éste suele infravalorar su capacidad intelectual y tiende a mostrar sentimientos negativos que obstaculizan las estrategias de resolución de problemas (Diener y Dweck, 1987 en Dweck, 1998). 
B. Objetivos de éxito (achievement goals)

Existen dos tipos de objetivos o metas claramente diferenciadas, según Dweck. Cada uno de ellos representa distintas formas de aproximación, compromiso e implicación en las tareas y actividades de aprendizaje, diferentes percepciones y creencias sobre la capacidad y el esfuerzo y utilizan distintos patrones motivacionales:

a) Los objetivos de aprendizaje (learning goals), que suponen un interés por la adquisición y desarrollo de nuevas capacidades y conocimientos, están vinculados con el patrón motivacional descrito anteriormente que se orienta al dominio de la tarea (mastery oriented)

b) Los objetivos de rendimiento (performance goals), que suponen un interés por obtener juicios y valoraciones positivas sobre la propia capacidad y por tratar de evitar los negativos, están asociados con el patrón motivacional de indefensión (helpless) descrito anteriormente.

Según esta distinción parece evidente que, en función de qué objetivos se apliquen más o menos conscientemente, algunos sujetos tenderán a aprovechar cualquier situación que se les presente como un reto, un desafío o una ocasión para aprender, mientras que otros preferirán evitar esas situaciones (e incluso huirán de ellas como de la peste, por ejemplo, un examen, un curso, etc.) antes que afrontar la posibilidad de un error o un fracaso.

\subsubsection{Teorias de la mentalidad}

Una vez presentados estos conceptos básicos estamos ya en condiciones de presentar las investigaciones de Dweck sobre la inteligencia, es decir, la distinción que hacen entre la mentalidad fija y la mentalidad en crecimiento.

En sus investigaciones acerca de la inteligencia (Bandura y Dweck, 1985; Dweck y Leggett, 1988), Dweck concluye que la idea que cada estudiante tiene sobre la naturaleza de su inteligencia determina su forma de actuar, de pensar y de sentir. Por decirlo más claramente, los estudiantes que creen que su inteligencia es una característica inamovible, que tienen sólo una cantidad de inteligencia y que no pueden hacer nada para cambiarla son los que favorecen los objetivos de rendimiento sobre los objetivos de aprendizaje. Esto significa que están constantemente (com-) probando que la inteligencia que tienen es la adecuada, es decir, que 
tienen que parecer inteligentes, para reforzar esa concepción previa. Sería casi como la castidad de la mujer del César. A esta concepción de la propia inteligencia la denomina Dweck "mentalidad fija", porque la inteligencia se concibe como una entidad estática y fijada ya de antemano. En contraste con lo anterior, se encuentran los estudiantes que creen que su inteligencia es una cualidad moldeable, y que se puede cultivar y desarrollar. A esta concepción Dweck la denomina "mentalidad en crecimiento" o de incremento progresivo, porque aquí la inteligencia se concibe como algo que puede ir aumentando gracias al esfuerzo. Los estudiantes que tienen este tipo de mentalidad prefieren las tareas que les permiten mejorar su nivel de capacidad en cada objetivo, las que les sirven para validar la existencia de distintos niveles de habilidad.

En algunas investigaciones se demuestra que las teorías de la inteligencia de los estudiantes también pueden predecir su incapacidad o desamparo frente a las dificultades (los de mentalidad fija) en comparación con la respuesta de dominio o control de otros estudiantes (los de mentalidad en crecimiento). Es curioso que estos dos tipos de mentalidad no tengan nada que ver con el nivel de habilidad de partida para realizar la tarea y lo que sí es claro es que los de mentalidad en crecimiento están más preparados para aprender y disfrutan más haciéndolo (Dweck, 1998).

Ahora bien, ¿estos dos tipos de mentalidad que Dweck nos presenta están ya predeterminados en cada uno de nosotros $\mathrm{y}$, por consiguiente, son inamovibles? ¿O por el contrario se puede modificar $\mathrm{y}$, en consecuencia, transitar de uno a otro, alterando o modificando algún tipo de elemento que afecte a los individuos? En unos estudios realizados por la propia Dweck, en colaboración con Dinces y Tenney (en Dweck y Leggett, 1988), se procedió a manipular experimentalmente las teorías de la mentalidad de los niños por medio de la lectura de textos vitales y persuasivos para determinar si estas teorías podrían tener un efecto directo en los objetivos de los estudiantes. Los resultados muestran que los estudiantes expuestos a los textos relativos a la teoría de la inteligencia estática preferían elegir objetivos de logro antes que los objetivos de aprendizaje, superando significativamente a los estudiantes que leyeron los textos sobre la teoría de la inteligencia en crecimiento. Estos hallazgos sugieren: primero, que las teorías de la inteligencia de los estudiantes son maleables y segundo, que podemos ejercer un efecto causal en los objetivos que los estudiantes persiguen. Para aclarar esto, incluimos a continuación (ver Tabla 1), una adaptación del diagrama de Nigel Holme al respecto, que la propia Dweck incluye en su obra. 
MENTALIDAD FIJA

\section{MENTALIDAD EN \\ CRECIMIENTO}

La inteligencia es estática puede desarrollarse.

Dirigida por

Un deseo de parecer inteligente Un deseo de aprender y por eso y por eso tiene tendencia a: tiene tendencia a:

Desafíos, retos

Evitar los desafíos.

Recibir los desafíos con los brazos abiertos.

Obstáculos

Ponerse a la defensiva o Persistir a pesar de los abandonar con facilidad ante un contratiempos obstáculo o dificultad.

Esfuerzo

Ver el esfuerzo como algo Ver el esfuerzo como el camino improductivo o peor. a la perfección.

Críticas Ignorar el "feedback" negativo Aprender de las críticas. aunque sea útil.

Éxito de los otros

Sentirse amenazado por el éxito

Aprender y encontrar inspiración de los otros. en el éxito de los demás

Como resultado Pueden estancarse pronto y Alcanzan siempre mayores lograr menos de su potencial logros.

real.

Tabla 1. Traducción y adaptación del diagrama de Nigel Holme, en Dweck, 2006:245 
De lo dicho anteriormente se desprende la afirmación de que es preferible tener una mentalidad en crecimiento antes que una mentalidad fija. Para tratar de demostrar esto, se realizó un estudio en estudiantes universitarios (llevado a cabo por Zhao y Dweck en 1994; en Dweck, 1998). En dicho estudio se les pidió a los estudiantes que se imaginaran en alguna situación de fracaso académico. A continuación debían contar cómo se sentirían, qué pensarían y qué harían en respuesta a los problemas que se les presentaban. Los resultados de dicho estudio mostraban claramente que los estudiantes que tienen una idea de la inteligencia como algo fijo e inmutable suelen culpabilizarse, infravaloran su capacidad intelectual, presentan sentimientos negativos hacia ellos mismo y en ocasiones incluso se autodenigran. Todo esto les lleva a obstaculizar sus propias estrategias de resolución de problemas cuando se enfrentan con dificultades. En cambio, los que ven su inteligencia como algo que se puede desarrollar hacen frente a los retos con entusiasmo y muestran un esfuerzo más intenso, mantienen el optimismo y utilizan estrategias efectivas cuando se enfrentan a los obstáculos.

Parece claro que existen estos dos tipos de mentalidad, como nos demuestran los estudios de Dweck y sus colaboradores. Es, por tanto, evidente que habría que hacer algo en relación con nuestra labor docente en conservatorios superiores de música. Ahora bien, ¿es aplicable esta teoría acerca de las inteligencias a la enseñanza superior de música? Más aún (y aquí estaría el propósito principal de nuestra investigación), ¿Es posible cambiar la mentalidad de los alumnos de la enseñanza superior de música, transitando de la mentalidad fija a la mentalidad en crecimiento? En la experiencia docente, lo que interesaría saber en última instancia es qué podemos hacer los profesores de estas enseñanzas para ayudar a nuestros alumnos a que transiten de la una a la otra, e incluso más, que tanto profesores como alumnos seamos conscientes de que se puede cambiar y de la utilidad de ese cambio para poder aprender mejor. Como nos dice la propia Dweck, la idea que cada uno tiene sobre su inteligencia puede conducir a disfrutar con los retos, a reconocer y valorar la utilidad del esfuerzo, a ser capaz de resistir ante los contratiempos y a un mucho mayor éxito creativo ${ }^{5}$ (Dweck, 2006:12).

Es interesante comprobar que estos mismos estudiantes de enseñanza superior, cuando reflexionan sobre su propia forma de aprender, y tras conocer algunos estudios sobre el tema

5 "How can one belief lead to all this, the love of challenge, belief in effort, resilience in the face of setbacks, and greater more creative success?" (2006:12). 
(Sloboda, 1987; Sternberg, 1996; Dweck, 2006; Hallam y Gaunt, 2012), se empiezan a plantear qué tipo de mentalidad tienen, si la denominada mentalidad en crecimiento o, por el contrario, si es la llamada mentalidad fija o si incluso en algunos momentos es de un tipo y en otros, del contrario. Ellos mismos reconocen que en ocasiones, según el estado de ánimo (la tensión o la presión exterior, la ansiedad o la depresión) es mucho más fácil pensar según los parámetros de la mentalidad fija. Incluso personas que en principio se habían catalogado como personas con mentalidad en crecimiento se descubren en momentos pensando y actuando como si tuvieran una mentalidad fija. Aquí se nos vuelven a plantear nuevas preguntas ¿qué ocurre con los dos tipos de mentalidad en la edad adulta? ¿Es posible que la inteligencia fija de personas ajenas a nosotros nos haga cambiar nuestra propia mentalidad en determinados momentos? ¿Puede ser que los aprendizajes que hemos tenido nos hayan hecho aplicar una u otra según el momento? ¿Se puede cambiar la mentalidad en función del estado de ánimo o de las circunstancias?

Vamos a comentar algunos ejemplos bastante sorprendentes que nos han hecho reflexionar sobre estos temas, ayudándonos a establecer nuestras preguntas de investigación:

El primer caso es el de una violinista, estudiante de cuarto de enseñanza superior en el Conservatorio Superior de Música de Navarra con muy buen nivel musical, que reconoce que se ha dado cuenta de que ella pensaba que tenía mentalidad en crecimiento porque siempre estaba dispuesta a aprender y le gustaban los retos y, sin embargo, al analizar el problema en profundidad se ha dado cuenta de que en un aspecto tenía mentalidad fija. Para explicar esto, comenta que en algunas situaciones de tensión pierde la concentración y no toca a su nivel. Reconoce ahora que no quería darse cuenta de que tenía miedo escénico, y que achacaba siempre esta inseguridad a la falta de técnica, de modo que ponía todos sus esfuerzos en mejorarla ${ }^{6}$. De hecho, aunque ha tenido repetidas oportunidades para trabajarlo, no quería ni siquiera reconocer dónde estaba el problema. Prefería ocultarlo y ocultárselo ella misma y no enfrentarlo, dejando pasar algunas oportunidades que le hubieran proporcionado herramientas para solucionarlo. Dicho más claramente, el curso pasado no se apuntó a un curso específico

6 Es cierto que un mayor control de la obra nos da más seguridad pero no es lo único para presentarse ante el público. 
que se ofertó en su mismo centro sobre el tema. En su caso, el conocer los dos tipos de mentalidad que nos muestra Dweck le ha hecho reconocerlo y ver la necesidad de afrontarlo y así poder cambiar ese punto débil.

El segundo caso es el de un percusionista que también estaba convencido de que tenía mentalidad en crecimiento. Nos parece muy curioso para ilustrar el punto sobre la percepción de que el esfuerzo es inútil o útil según en qué caso. Este estudiante piensa que cuando estudia en la caja, aunque sea sólo media hora, obtiene un beneficio inmediato, resultados visibles, exactamente aquello que se propone. Sin embargo, cuando toca en la marimba no sucede lo mismo. Puede estudiar cuatro horas el mismo día y no consigue nada, más aun, piensa que hace un esfuerzo inútil. Siguiendo los estudios de Dweck, podríamos afirmar que cuando está disfrutando con la tarea que se marca al tocar la caja, su cerebro se activa para trabajar a tope. Sin embargo, cuando toca la marimba, aunque él crea que está concentrado, no consigue mejorar y no ve el progreso. Pensamos que esto es debido a que al tocar la marimba no disfruta porque no le ve utilidad. La razón de todo esto es que tiene la mentalidad fija de que la marimba sólo la va a tocar si llegara a ser solista en una orquesta y, dado que duda mucho que pueda alcanzar este objetivo, es incapaz de sacar rendimiento de ese estudio. En cambio, es consciente de que la caja es un instrumento que le puede proporcionar más oportunidades de éxito (de hecho ya trabaja tocando este instrumento en una banda), de modo que al estudiar la caja está concentrado y aprovechando el tiempo que dedica.

Como se puede comprobar con los dos casos descritos, es fácil encontrar en la misma persona situaciones en las que se encuentran con mentalidad fija y otras situaciones en las que parece que se tenga mentalidad en crecimiento. Y aquí surge una nueva pregunta a la que responder con nuestra investigación ¿es posible pasar de mentalidad fija a mentalidad en crecimiento? ¿se podrán utilizar los recursos personales que son útiles para cada uno en la mentalidad en crecimiento también a la mentalidad fija? Trataremos de dar respuesta a estas cuestiones en el apartado práctico de esta tesis, más concretamente en una de las prácticas que realizamos con los grupos de discusión, y donde pusimos en juego, precisamente, este interesante problema.

Para cerrar el capítulo, incluimos también un mapa conceptual que confiamos en que sirva para hacer más claro el conjunto de las ideas que Dweck pretende transmitirnos al respecto de la dicotomía mentalidad fija/en crecimiento. 


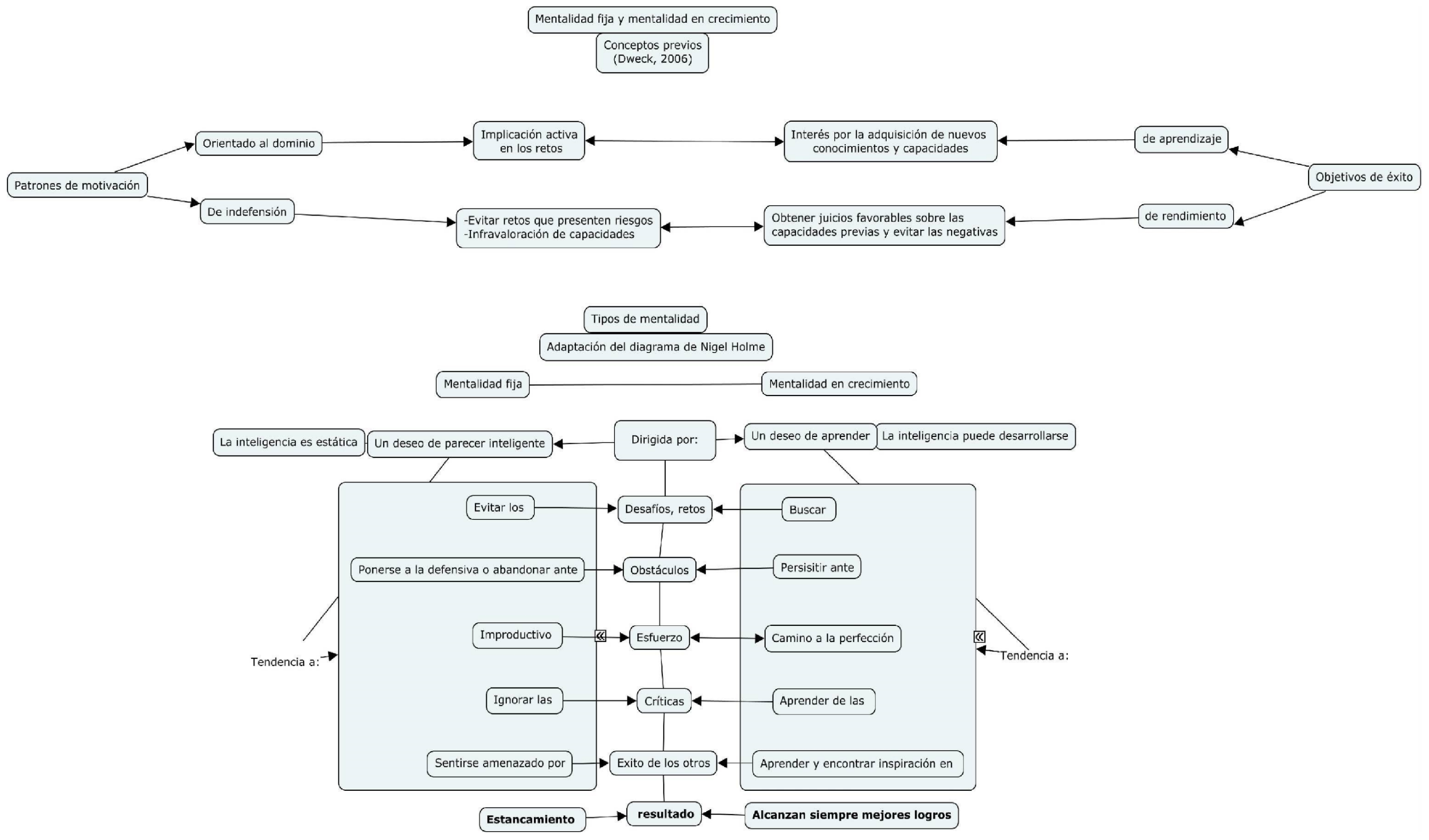

Ilustración 4. Esquema de la mentalidad fija y de la mentalidad en crecimiento de Dweck. Elaboración propia. 



\section{LA EXCELENCIA MUSICAL}

Lo primero que habría que decir al hablar de la excelencia musical es que se trata de un concepto tan amplio y de tanta actualidad, que siempre existe el riesgo de que, por un lado, algo importante pueda quedarse fuera $\mathrm{y}$, por otro, que cualquier cosa que se diga quede desfasada con rapidez. Siendo conscientes de esto, hemos optado en este estudio por señalar los hallazgos más relevantes para nuestro estudio por su posible aplicación a las enseñanzas superiores de música y más concretamente al tema que nos ocupa. Como Sloboda ha argumentado, la aplicabilidad debería ser un factor más explícito en la planificación de la estrategia de investigación, tanto a nivel individual como institucional (2005b) y se puede añadir que, si se demuestra esa funcionalidad de la investigación, se podría conseguir una mayor valoración, tanto por los músicos como por la sociedad en general. De hecho, en las investigaciones actuales sobre este tema sí que hay un evidente interés en que dichos estudios se lleven a la práctica y, la mayoría de ellas incluyen sus propias recomendaciones para que así sea.

Se puede considerar como precursor de la investigación sobre la excelencia musical el estudio que Sosniak llevó acabo en 1985 con 21 pianistas. A raíz de éste sugiere que, en la música clásica occidental, los músicos pueden haber acumulado hasta unos dieciséis años de práctica individual antes de alcanzar niveles que les permitan obtener el reconocimiento internacional. Lo normal era que se empezara a tocar con muy poca edad, para ir incrementando la cantidad de práctica hasta llegar a unas cincuenta horas a la semana en la adolescencia.

Otro estudio pionero fue el de Manturzewska (1990), que entrevistó a 165 músicos profesionales polacos de entre 21 y 89 años. Esta investigación se diseñó como un estudio exploratorio del desarrollo del talento de los músicos profesionales a lo largo de su vida. El propósito de este estudio era recoger datos empíricos sobre la trayectoria de la vida profesional del músico, así como aprender sobre la estructura de la vida del músico, conocer sus etapas y dimensión, de cara a reconocer los factores que influyen en el desarrollo y el éxito de los músicos profesionales en las distintas etapas de la vida y en los distintos campos musicales. Los resultados de esta investigación sugieren que el desarrollo profesional del músico está muy influido tanto por los factores socioculturales como por los factores biológicos. El análisis del contenido de las biografías recogidas sugiere que el entorno 
familiar y la motivación intrínseca son los factores que más influyen en el desarrollo musical. Este análisis también saca a la luz la importancia de los profesores, los compañeros y el soporte socioemocional en el desarrollo del talento a lo largo de la vida. Puede decirse, en conclusión, que el desarrollo de los músicos parece ser un proceso de asimilación cultural y ajuste a los cambios que se producen con la edad y en el entorno y que dura toda una vida (en algunos casos, transitando a lo largo de varias generaciones familiares). Parece consistir en una serie de estadios de desarrollo que difieren tanto en la estructura de la conducta musical y motivación como en la estructura de la actividad musical y el logro que se consigue.

En los años 90 son también muy valorados los trabajos de Sloboda y otros colegas, donde de cara a conseguir un resultado excelente se resalta la importancia de la familia, (unos padres implicados), el profesor (de calidad y muy implicado, que ayude al alumno a comprometerse con la práctica) y el alumno intrínsicamente motivado que adquiere un compromiso con la práctica deliberada (Sloboda y Howe, 1990). Recordemos que la "práctica deliberada", definida como necesaria para el rendimiento excelente (Ericsson et. al., 1993) incluía dos características: por un lado, se entendía como tal la práctica dedicada a actividades muy estructuradas y diseñadas específicamente para mejorar la interpretación individual (y que no eran intrínsicamente divertidas) y, por otro lado, se añadía la exigencia de altos niveles de concentración.

Con respecto a la práctica deliberada para conseguir la excelencia musical, Gursson (1998), Miklaszewski, (1989) y Nielsen (1999) sugieren que hay unas estrategias típicas de práctica deliberada empleada por los expertos, que incluyen el uso de la digitación mental, el pensamiento silencioso, la alteración del tempo de la obra de forma consciente y la práctica de secciones más largas que los no expertos (en McPherson y Zimmerman, 2002, 332)

Howe y Sloboda (1991a) concluían que había más de un camino hacía la excelencia musical y que cada uno es único, pero que el compromiso individual, la familia, el profesor y la práctica tenía un rol importante (1991b). En los trabajos de Davidson, Howe, Moore y Sloboda (1996), Howe, Davidson, Moore y Sloboda (1995) y Sloboda, Davidson, Howe y Moore (1996) se sugiere que los que consiguieron desarrollar la habilidad musical de manera exitosa tenían como factores en común el respaldo de los padres, un maestro amable, amplias oportunidades de practicar unidos a altos niveles de tiempo invertidos en la práctica formalmente fijada por el docente, incluyendo también el compromiso informal automotivado (como la 
improvisación o ejecución de canciones sólo "por diversión"). En estos trabajos en los que participa John Sloboda también se explora la motivación como necesaria para tocar y mejorar, se demuestra la importancia de las creencias de los músicos adolescentes sobre su habilidad y valores a la hora de conseguir más eficacia. En esta misma línea, Susan Hallam (1998) insistirá en que la autoestima y el conocimiento de sí mismo repercutirá profundamente en el desarrollo de los objetivos personales del músico.

Sloboda, en su obra The Musical Mind, explica que la habilidad musical está compuesta por muchas subhabilidades que hay que tener en cuenta. Más aun, esa idea de tener que prestar atención a muchas cosas al mismo tiempo era una característica del músico experto, que consigue su maestría a través del despliegue simultáneo de todas esas habilidades de forma constante y de manera que esté al servicio de la estructura general de la composición musical. Colocándose él mismo en el papel del profesor, afirmaba que uno de los grandes obstáculos de muchos alumnos era el requisito de atender a varias dimensiones de la experiencia musical a la vez. Un alumno puede ser bastante capaz de tocar un pasaje con la dinámica apropiada, pero cuando se le pedía que además fraseara, perdía el control dinámico y cuando se le pedía una tercera modificación perdía las otras dos características. Cada habilidad está presente, pero utilizarla de forma adecuada excluía el prestar atención significativa a otros aspectos. El experto no tenía más capacidad de atención que los demás, sino que conseguía utilizar estos recursos de forma automática. (1995:93).

En un trabajo suyo posterior, realizado con otros investigadores (Davidson, Howe y Sloboda, 1997) se exploran los constituyentes distintos de la excelencia musical: la técnica y la expresión, considerando que dicha excelencia es una síntesis de ambas. Parecía aceptado en Occidente que los aspectos técnicos y mecánicos de la interpretación podían ser aprendidos, mientras que los aspectos expresivos se consideraban más bien instintivos o naturales. Sin embargo, Sloboda en una investigación previa (1985), ya había demostrado concluyentemente que aunque el uso de la expresividad puede variar mucho entre distintos músicos, haciendo posible una expresión musical personal, la expresión musical es racional y obedece a determinadas reglas. Así, señala cinco características que prueban la racionalidad de la interpretación expresiva: 1. es sistemática (hay relación clara entre el empleo de ciertos recursos y algunos elementos estructurales de la música como los fines métricos o fraseológicos), 2. muestra comunicabilidad (es decir el oyente reconoce más fácilmente la estructura cuando la expresividad está presente que cuando no lo está). 3. muestra estabilidad: 
un intérprete experto podrá reproducir fielmente la misma interpretación expresiva en ocasiones separadas temporalmente varios meses. 4. una interpretación expresiva muestra flexibilidad (se puede atenuar, exagerar o cambiar el contorno expresivo para cambiar el contorno expresivo para destacar determinados aspectos de la música) y 5. muestra automatismo (el intérprete no siempre es consciente de los pormenores sobre cómo una intención expresiva se traduce en acción $)^{7}$. Como se ve, la investigación amplía el campo sobre lo que se debe explorar, aprender y enseñar para seguir mejorando. En esta misma investigación, se señalan como figuras importantes en la adquisición de las habilidades musicales a los padres, hermanos, compañeros, intérpretes profesionales y profesores, concluyendo que las habilidades interpretativas musicales no surgen "porque sí", sino que se desarrollan de forma previsible con unas circunstancias ambientales específicas, circunstancias que se podrían considerar fáciles de hacer confluir en la mayoría de los entornos educativos. Sin embargo, los autores se preguntan por qué no consiguen los jóvenes en la sociedad occidental el alto nivel generalizado de otras sociedades no occidentales y nos dan su opinión poco alentadora explicando que, en nuestra sociedad, en contra de las influencias ambientales más simples y efectivas lo que predomina es la corriente de la "cultura del arte", que favorece la idea de que la mayoría de las personas son incapaces de alcanzar un nivel musical alto, haciendo cada vez más difícil el aprendizaje musical mediante la creciente profesionalización y especialización de la actividad musical. Parece que hay pocas esperanzas de que la música sea accesible a la mayor parte de la población, ya que se convierte en mercancía y objeto de compra-venta. Como se ve, están en la línea que hemos apuntado sobre la necesidad de procurar un entorno con recursos, así como un ambiente que proporcione las condiciones de accesibilidad. Sin este requisito, difícilmente puede alcanzarse la excelencia.

El educador musical noruego Siw Nielsen, en sus numerosos estudios sobre la teoría del aprendizaje autorregulado y su aplicación a los músicos (1997,1998,1999, 2000), concluye que los estudiantes necesitan reflexionar sobre el uso de estrategias de aprendizaje (seleccionar áreas relevantes, juntar partes de la pieza como un todo y relacionar imágenes auditivas de la partitura con la interpretación de la pieza) durante la práctica como un

\footnotetext{
7 Para profundizar en este tema véase: Juslin, P. N., y Sloboda, J. A. (2006). Music and emotion: theory and research. Oxford New York: Oxford University Press.
} 
prerrequisito para ser capaz de usar una amplia variedad de habilidades de forma sistemática (En McPherson y Zimmerman, 2002:335).

Gabrielsson's (1999), en su extenso resumen sobre las investigaciones sobre interpretación musical, explica que los músicos exitosos establecen un plan estratégico de cómo controlar y supervisar cómo están tocando cuando estudian o interpretan. La práctica variada, el ensayo mental, los ejercicios motóricos, las técnicas de memorización, el responder a su feedback perceptivo y el construir una representación mental que puede ser fácilmente trasladada a sonido son algunas de las muchas estrategias que son integradas en armonía por el intérprete experto. (En McPherson y Zimmerman, 2002:335).

Para el aprendizaje de la autorregulación se sugiere a los profesores de música que permitan a los alumnos la oportunidad de elegir el orden en el que se elige el repertorio asignado. También deberían ofrecer a los estudiantes elecciones reales entre los mejores materiales y métodos para aprender. Si siempre aprenden las piezas que seleccionan sus profesores parece que las tocan sólo para satisfacer a éstos y no porque ellos mismos quieren aprenderlas. Permitir alguna elección con respecto al tipo de pieza que se toca puede ser importante para ayudar a crear el sentimiento de control de su propio aprendizaje. Esto puede hacer al alumno un participante más activo en su proceso de aprendizaje (McPherson, 1989).

Hallam (1997, 2000), en sus estudios sobre violinistas, muestra que los músicos expertos han desarrollado unas habilidades metacognitivas que los capacita para hacer una evaluación precisa de sus puntos fuertes y débiles. Estas habilidades les permiten responder a diferentes situaciones interpretativas y desplegar una amplia variedad de estrategias con las que pueden resolver gran variedad de problemas técnicos y expresivos. Estas habilidades metacognitivas en los expertos parecen ser muy individuales, y sin embargo, hay similitudes en algunos aspectos de la práctica, junto con las lógicas y considerables variaciones entre los individuos. (En McPherson y Zimmerman, 2002:336).

Eccles, O' Neill y Wigfield (2005) hablan de que las creencias sobre su habilidad se pueden conceptualizar como autopercepciones, donde incluyen los conceptos de autoconcepto de habilidad y expectativas de éxito. Cuando los alumnos se sienten bien en una actividad particular que les divierte y son conscientes de que son buenos en eso y confían en que les va a salir bien tienen más posibilidades de éxito. O’Neill (1999) demuestra que los estudiantes se 
comprometen más con la música cuando creen en su habilidad y valoran la actividad que hacen. (En Ivaldi, 2011:209).

McPherson y Zimmerman (2002) descubrieron que los logros durante los primeros nueve meses de estudio dependían mucho más del compromiso del alumno que de la cantidad de tiempo dedicada. Independientemente de las horas empleadas, un alumno convencido de que tocará su instrumento durante toda su vida hará progresos más rápidos que cualquier alumno consciente de que sólo tocará el instrumento durante pocos años.

Cuando se compara la práctica de los profesionales y los aprendices, Hallam (2001 a) encuentra que los profesionales, a menudo, suelen presentar más pensamiento metacognitivo, un mejor análisis de los problemas musicales, el uso de estrategias sofisticadas, la organización de la práctica y una gran capacidad de concentración (en Miksza, 2011a).

Chaffin y Lemieux (2005), en su ensayo sobre cómo conseguir mejorar la excelencia musical, explican que uno de los objetivos de la psicología había sido comprender la naturaleza del talento excepcional. Su ejemplo es la obra de Galton, Hereditary Genius, donde tras analizar a quienes habían obtenido grandes logros, lo atribuyó a la combinación de unos dones naturales heredados y la capacidad para esforzarse, unida a la habilidad de concentrarse en una meta específica. Es difícil hablar con claridad acerca de las condiciones naturales, pero sí que se han realizado progresos en el estudio de la capacidad para esforzarse y la habilidad de concentrarse en una meta específica. El ensayo realizado por Chaffin y Lemiex se centraba en estas dos ideas de la fórmula de Galton aplicada a los músicos. Así, para convertirse en un intérprete, sea cual sea su talento heredado, deberían estar dispuestos a trabajar duro para conseguir la excelencia musical. Es interesante destacar que señalaban expresamente que la acumulación de horas de estudio no era suficiente, pues elevar la destreza a un nivel alto exigía también que el tiempo dedicado al estudio fuese eficaz, ya que se necesitaba mucho tiempo para conseguir cualquier mejora en la eficacia del estudio, pues por pequeña que fuera podía producir enormes diferencias. Además, identificaban las cinco características generales del estudio eficaz (concentración, establecimiento de objetivos, auto-evaluación, selección de estrategias y visión general), las cuales integran para Galton la capacidad de enfocar y pulir nuestras habilidades. La intención de Chaffin y Lemiex es la de enumerar los principales requisitos de la excelencia musical para así facilitar a intérpretes y profesores la labor de reconocer y juzgar sus propias habilidades (así como las de sus colegas y alumnos), y de 
encontrar la estrategia más efectiva para incrementar su rendimiento. Los requisitos que enumeran son: 1. Cantidad de estudio (la regla de los diez años), 2. Calidad del estudio, 3. Características fundamentales de la excelencia musical (concentración, establecimiento de objetivos, auto-evaluación, estrategias, visión general de la idea musical completa).

Gerald Klickstein (2009), afamado intérprete y excelente profesor durante más de treinta años, plantea unos hábitos de excelencia necesarios para todo músico. En su opinión, y ya que el objetivo de la práctica es preparar las actuaciones, será imprescindible que la práctica que busca la excelencia incluya los hábitos que son necesarios en el escenario. Por eso, insiste en que hay que hacer énfasis en estos hábitos en cada momento de la práctica para que la excelencia llegue a estar "configurada por defecto", tanto en el ensayo como bajo los focos. Los hábitos de excelencia que Klickstein marca como indispensables y que deben ser reforzados en cada ensayo son: 1. Facilidad, 2. Expresividad, 3. Precisión, 4. Vitalidad rítmica, 5. Sonido excelente, 6 Atención focalizada y 7. Actitud Positiva (2009:21).

\subsection{Estadios o fases en el camino a la excelencia musical}

Para que el talento se desarrolle en todo su potencial hay que recorrer un largo camino. Y en este camino se han encontrado unos estadios clave que inciden en ese desarrollo (y que estudiaremos a continuación), aunque McPherson y Lehmann (2012) han dejado claro que, después de más de cincuenta años de investigación sobre el desarrollo musical, no hay una única y unánime voz que unifique de manera definitiva las fases o estadios del desarrollo musical; antes al contrario, lo que encontramos es un interesante abanico de estudios, cada uno de ellos poniendo el énfasis en uno u otro aspecto. En realidad, los progresos efectuados en el análisis del desarrollo musical no se centran en encontrar ningún consenso, sino en reconocer los retos que el músico va a encontrar en su camino. Y en una de estas investigaciones, Transitions and the development of expertise (Hallam, 2010), se recogen las formas en que la transición de una etapa a otra puede influir en el desarrollo del perfeccionamiento musical. En este trabajo, Hallam analiza lo que conocemos sobre el desarrollo del perfeccionamiento musical ("expertise"), los cambios que se producen en el cerebro al desarrollarse este perfeccionamiento y cómo las transiciones entre distintos contextos de aprendizaje y los retos que se presentan en cada momento pueden influir en el desarrollo de este aprendizaje. Para ello presenta una serie de proposiciones que tienen que 
ver con la forma que esta transición puede influir en el perfeccionamiento musical, las evidencias en las que se apoyan esas proposiciones y las implicaciones en educación a las que estas evidencias dan lugar.

De entre los estudios realizados sobre las fases o estadios que llevan a la excelencia musical, hemos seleccionado dos, por las interesantes aportaciones que ofrecen. El primero de éstos incluye un cuadro en el que presentamos una adaptación que McPherson y Lehmann hicieron sobre un trabajo de Abbott y Collins aplicado al deporte. Los autores explican que a medida que se va avanzando en el desarrollo musical también van cambiando las orientaciones de aprendizaje, tanto el número de actividades como el juego y la práctica deliberada, así como el papel de los padres (de estar directamente implicados como organizadores y conductores del aprendizaje, además de como espectadores, a estar indirectamente implicados como espectadores) los profesores (de ayudante y amigo a músico experto) y los amigos (que pasan de ser compañeros de juego y estímulo a soporte emocional (2012:41)

En el segundo estudio, presentamos el trabajo de McNamara et al. The pathway to excellence: the role of psychological characteristics in negotiating the challenges of musical development (2006), que investigaron el rol que las características psicológicas cumplían a la hora de enfrentarse a los retos del desarrollo musical. Con tal objeto, entrevistaron a ocho músicos de renombre internacional, de cara a identificar los retos de cada estadio del desarrollo musical y las características psicológicas que pueden permitir a los aspirantes a músico mantener este proceso de desarrollo. De este modo, dividen en tres estadios el camino a la excelencia: los primeros años, un estadio intermedio y los estudios avanzados (siguiendo aquí el modelo de Bloom, 1985). Las conclusiones de la investigación sugieren que mientras algunas características psicológicas destacan en la carrera y facilitan un desarrollo continuo, otras son especialmente importantes como puntos clave de cada estadio y de manera crítica como puntos de transición. Dado el interés que esta investigación tiene para informar a los educadores musicales, hemos traducido y adaptado los cuadros que proponen en las tres etapas de desarrollo con sus características en el desarrollo general y las características psicológicas del desarrollo de la excelencia musical. Las letras usadas en mayúscula identifican a cada uno de los músicos entrevistados y se usó este "código" para garantizar el anonimato de los mismos. 


\section{Estadio de muestreo}

- Oportunidades de participación

- Apoyo y estímulo familiar activo.

- Profesor de música cariñoso.

- Énfasis en la diversión como camino hacia el desarrollo de las habilidades.

A: Macrotransición: formación de la identidad musical

\section{Estadio de especialización}

- Desarrollo técnico y musical.

- Apoyo familiar.

- Reconocimiento del talento y el éxito.

- Incremento de la experiencia musical específica.

- Relación con colegas de mentalidad similar.

- Formación de identidad como músico

B: Macrotransición: priorización musical

\section{Estadio de inversión}

- Los padres hacen cambios en el estilo de vida para apoyar el aprendizaje.

- Experiencias y formación de alta calidad.

- Tomar decisiones colaborativas (alumno-profesor)

C: Macrotransición: práctica musical a nivel de experto 


\section{Estadio de mantenimiento}

- Mantiene el mejor foco de interpretación.

- Desarrolla un sistema efectivo para enfrentarse al incremento de demanda (p.ej. el estrés, las audiciones públicas, etc.)

D: Macrotransición: nivel consistente de interpretación musical

Tabla 2. Traducción y adaptación de los estadios del desarrollo musical (adaptación de los modelos del Sports-related de Abbott y Collins, 2004) en McPherson y Lehmann, 2012:41). 


\section{PRIMEROS AÑOS}

Fascinado por tocar música

Ambición temprana

Tocar como pasión

Aprendizaje (músico A,B,C,D,E,F,G,H)

Desarrollar habilidades de manera temprana

La música aportando sentido de identidad

Práctica consciente durante la edad temprana

Muchas exigencias durante la edad temprana

Práctica (músico A,B,C,D,F,G,H)

Sacrificios

Compromiso temprano

Inicio en la música sin presión externa

Fácil implicación

Entorno y condiciones musicales

Inicio informal temprano en la música

(músico A,B,C,D,E,F,H)

Habilidad natural evidente

Diversión y placer

Good music system in place

Importancia de los profesores

Poco apoyo de la familia

Apoyo (músico A,B,C,F,G,H)

Expectativas de los demás

Apoyo familiar

Tabla 3. Características de los primeros años de desarrollo (traducción del cuadro de McNamara et al. 2006:291). 
Características psicológicas del desarrollo de la

excelencia

Primeros años

Aprendizaje de las cosas con rapidez

Habilidad natural

Habilidad natural

(músicos A,C,D,G,H)

Sacrificios hechos

Dedicación

Dedicación

(músicos A,B,C,D,F,H)

Compromiso

Planificación

Objetivos de la carrera obtenidos pronto

(músicos A,B,D,E,G,H)

Factores limitadores

Falta de confianza temprana

(músico A)

Tabla 4. Características psicológicas del desarrollo de la excelencia en los primeros años de desarrollo (traducción del cuadro de McNamara et al., 2006:292). 


\section{ESTADIO INTERMEDIO}

Importancia de la red social

Expectativas del sistema

Competiciones

\section{Sistema}

Transición a la música en el instituto (músicos: A,B,C,D,E,F,G,H) (¿conservatorio?)

El currículo académico no prepara para la realidad de la profesión

Importancia de apoyo claro

Influencia de otras personas de manera significativa

Apoyo

(músicos:A,B,D,E,F,G,H)

Importancia de los profesores

Capaz de concentrarse por sí solo en su carrera

Aparición de un camino claro a seguir

Expectativas que aumentan

Entorno

positivo

(músicos:A,B,D,E,F,H)

Aprendizaje y dedicación como parte del desarrollo

Naturaleza competitiva

Limitaciones de la música en la educación Aspectos negativos del entorno escolar (músicos: E,F,G,H)

Falta de flexibilidad dentro de la educación escolar musical

Incremento de la práctica consciente

Aprendizaje y desarrollo como algo vital

Práctica

$\mathrm{y}$

aprendizaje

Construcción de un banco de prácticas

(músicos:A,B,C,D,E,F,G,H)

Juicios externos

Tabla 5. Características del estadio intermedio de desarrollo (traducción del cuadro de McNamara et al., 2006:293). 
Importancia de la autoestima

Robustez

Autoestima

Autocomprensión

(músicos: B,E,H)

Establecer objetivos

Planificación

Deseo de lograrlos

(músicos: A,F,G)

Centrarse

Adaptación

Re-evaluación

Adaptación y aprendizaje

Versatilidad

(músicos:A,B,D,E,G,H)

Aprender de los errores

Deseo de cometer errores

Muchas habilidades necesarias para triunfar

Desarrollo social

Multitarea

multihabilidades

Importancia de las habilidades sociales para el

(músicos: A,B,D,F,G,H)

desarrollo

La capacidad natural no es suficiente para el éxito

Disciplina

Autodeterminación

Dedicación y determinación

Dedicación

(músicos: A,B,D,E,F,H)

Compromiso

Autoestima

Tabla 6. Características psicológicas del desarrollo de la excelencia en el estadio intermedio de desarrollo (traducción del cuadro de McNamara et al., 2006:292). 


\section{ULTIMOS AÑOS}

Desafíos personales

Ambición de otras personas importantes

Familia / Entorno

Desafío de combinar familia y música

(músicos: B,C,E,F,H)

Relaciones personales complicadas

Comprensión de que el sistema es importante

Importancia de las redes sociales

Realidad de la profesión

Carrera / Sistema

Restricciones financieras

Necesidad de vivir

(músicos: A,B,C,D,E,G,H)

Desarrollo continuo

Transición a la profesión

Dificultad para continuar con la interpretación

Importancia de un banco de prácticas

Aprender cómo interpretar

Aprendizaje 'microondas'

Ser cada vez más selectivo

Interpretación

(músicos: A,B,C,D,E,F,G,H)

Amor por tocar

Fascinación por la música

Tabla 7. Características de los últimos años de desarrollo (traducción del cuadro de McNamara et al., 2006:296) 
Capacidad para re-evaluar

Versatilidad

Creatividad

Ser único

Capacidada para adaptarse

Flexibilidad / empleabilidad

Versatilidad

Adaptabilidad

(músicos:B,D,E,F,H)

Mirar más allá de lo estipulado (the box)

Esforzarse por cosas nuevas

Importancia de la autoestima

Mantenerse positivo

Autoestima

(músicos:A,B,D,E,F,H)

Comprenderse a uno mismo

Ser selectivo en los últimos años

Planificación

Tomar posiciones estratégicas en el control de la carrera

(músicos:A,B,E,F,G,H)

Determinación

Robustez a la hora de mantener la carrera

Determinación

(músicos:A,B,D,E,F,H)

/Dedicación

Dedicación y compromiso

Importancia de la personalidad

Habilidades sociales

Multi-habilidades / multi-tarea

Multihabilidades

(músicos:A,B,D,F,G,H)

Disciplina

Disciplina

Autodisciplina

(músicos:B,D,H)

Impulso subyacente

Persistencia

Impulso

(músicos:A,B,H)

Perseverancia a la hora de mantener progresos

Tabla 8 Características psicológicas del desarrollo de la excelencia en lo últimos años de desarrollo (traducción del cuadro de McNamara et al., 2006:298) 
En las conclusiones obtenidas en este estudio se destaca lo siguiente: parece existir una línea ascendente en el desarrollo hasta los últimos años, momento en el cual los participantes manifiestan que es cuando empiezan a tener dificultades en el reto de combinar la familia y la práctica musical, destacando que la práctica y el conocimiento acumulado les permite vivir de rentas y mantener su nivel, aun cuando no puedan dedicar tanto tiempo como les gustaría a practicar y aprender. Es también interesante constatar cómo se vuelven más selectivos en lo que eligen.

La duración típica de la carrera de un músico de nivel es considerable y los entrevistados manifiestan claramente que encuentran dificultades a la hora de mantener su nivel de interpretación durante tanto tiempo. Y apuntan igualmente que la habilidad natural, aunque necesaria, no es suficiente para tener éxito en los últimos años de desarrollo, señalando que la perseverancia, la autoconfianza, la determinación, la dedicación y el compromiso son también cruciales. Todos resaltan asimismo la necesidad de ser capaz de adaptarse y ser flexible al acceder a la música para aprovechar al máximo las oportunidades.

\subsection{El músico en el estadio avanzado: el músico profesional}

Una vez expuesto cuál es el camino más o menos común que siguen los músicos a lo largo de su carrera, vamos a centrarnos en lo que es el objeto de nuestro estudio, es decir, el músico avanzado, el que está en los últimos estadios de ese proceso: el músico profesional que busca la excelencia. A este respecto, Papageorgy et al., en Perceptions and predictions of expertise in advanced musical learners (2010), ofrecen pistas sobre las percepciones que tienen los estudiantes de música avanzados de cómo llegar a ser un experto en la materia. Un examen de los factores que modelan los puntos de vista de los músicos sobre las habilidades musicales y los indicadores de preparación experta (o pericia) indica que las variables de género, edad, género musical y experiencia profesional están ligadas a las actitudes musicales y a la manera en la que se examinan a sí mismos. Los resultados indican que las mujeres, los músicos que no son músicos clásicos y los estudiantes universitarios pueden ser más propensos que los hombres, los intérpretes clásicos y los músicos profesionales respectivamente a tener una actitud menos positiva hacia los aspectos de sus habilidades y su pericia como intérprete. Se encuentra una gran diferencia entre las habilidades musicales "ideales" y "percibidas". Esta investigación concluye que es importante que tanto los músicos como los que les educan sean 
conscientes de esa diferencia y traten de limitar el salto entre lo ideal y lo que se percibe. Las aspiraciones de los músicos deben permanecer dentro del límite razonable para que no se midan con estándares inalcanzables que pueden minar su autoestima. Insisten en que los profesores deberían promover un saludable y equilibrado acercamiento a la interpretación, explicando que los músicos deberían tener como objetivo producir interpretaciones musicales personales, más que comparar su interpretación con la de sus compañeros o tratar de emular a figuras consolidadas en el género musical elegido. Del mismo modo, deberían facilitar un punto de vista más constructivo de la interpretación, enfatizando que cada interpretación tendría también que entenderse como una oportunidad para aprender y mejorar las habilidades interpretativas.

Por último, esta investigación resalta las características que predicen y explican la variabilidad en los puntos de vista de los músicos avanzados y las actitudes en relación al perfeccionamiento musical y las autoevaluaciones de los niveles personales de este perfeccionamiento. Éstas incluyen tener control de nuestras habilidades musicales, atribuir gran importancia al aprendizaje y autorregulación de habilidades, tener alta autoestima, bajos niveles de ansiedad, tener interpretaciones de alto nivel musical y preparación para la autoeficacia que derive en disfrutar de las actividades musicales y atribuir mucha importancia a las habilidades musicales señaladas y a las cualidades relativas al perfeccionamiento. Igualmente, el estudio destaca los elementos que los músicos pueden usar como referencia a la hora de evaluar la importancia de las habilidades musicales en general y de sus propias habilidades en particular, así como su grado de perfeccionamiento especializado. La investigación señala que estos elementos de referencia representan amplias áreas en los que la educación musical superior puede centrarse. Por ejemplo, actividades que animen a los músicos a desarrollar las habilidades de interpretación (como, por ejemplo, el manejo de la ansiedad escénica, la resistencia y el estrés diario), la mejora de las habilidades de preparación técnica (como la cantidad y calidad de la práctica, la perseverancia y la motivación) y la promoción del desarrollo de habilidades transferibles (tales como habilidades de presentación, organización, manejo del tiempo e interpersonales), habilidades todas ellas que serán beneficiosas para el desarrollo de la seguridad en la interpretación, la mejora de la práctica eficiente y el mantenimiento de una larga carrera ( Papageorgi et al., 2010). 
Recogiendo los frutos de sus investigaciones y las aportaciones de otros colegas, ${ }^{8}$ Hallam $(2012,122-123)^{9}$ presenta una serie de estrategias usadas por los expertos para conseguir la excelencia musical:

1. La mayoría de los músicos profesionales cuando están en los primeros pasos del aprendizaje de una obra tienen ya una visión general de la misma. La manera en la que esto es aprendido depende de su habilidad para desarrollar una representación auditiva interna de la música desde el análisis de la partitura

2. La estructura de la música determina cómo se divide en secciones para practicar

3. Las subsecciones pueden ser identificadas dentro de la estructura para prestar atención a los problemas técnicos

4. Cuanto más compleja es la música, más pequeños tienen que ser los fragmentos con los que se trabaja.

5. A medida que se trabaja en la práctica, los fragmentos se hacen más largos, sin embargo todavía se puede seguir trabajando en los más pequeños.

6. Cuando el trabajo en una obra está a punto de completarse, la longitud de los pasajes en los que se trabaja tiende a igualarse.

7. Parece desarrollarse una estructura jerárquica en la cual los planes de interpretación están gradualmente integrados en un todo coherente. Este plan se guía más por las consideraciones musicales que por las técnicas.

8. Hay una diversidad individual considerable en la forma en la que los músicos practican. Las estrategias incluyen tocar la música sin paradas, tocar y parar sobre la

8 Wicinski, 1950; Miklaszewski, 1989, 1995; Chaffin and Imreh, 1994, 1997; Chaffin and Lemieux, 2004; Chaffin et al., 2002; Hallam:1992, 1995a, 1995b, 2001b; Nielsen, 1997a, 1997b, 1999; Williamon and Valentine, 2002; Williamon et al., 2002

9 Traducción propia del original (Hallam, 2012:122-123) 
marcha para practicar secciones, o seleccionar secciones con un objetivo particular. La elección de estas formas depende del estadio particular de práctica alcanzado.

9. El estudio de la técnica está en función de un análisis detenido de la obra, la repetición, los intentos deliberados de aumentar la velocidad, y las variaciones del material (por ejemplo, ritmo, técnica de arco, toques con la lengua).

10. La progresión detallada de la práctica de una pieza determinada difiere en respuesta a la música misma, los resultados de aprendizaje, el plan de interpretación integrado parece ser igual para todos. Los caminos para conseguirlo sí que parecen ser distintos, dependiendo de los automatismos preferidos y las estrategias cognitivas adoptadas.

El conocimiento de estas estrategias presentadas por los expertos y extraídas por Hallam de las investigaciones, así como las implicaciones que conllevan para la enseñanza musical (que se analizan en el capítulo tercero), serán muy útiles para la búsqueda de un modelo de enseñanza que responda a las necesidades de los estudiantes de la enseñanza superior.

\subsubsection{Investigaciones actuales sobre el músico profesional}

Las investigaciones recientes insisten en lo que se podría mejorar en la enseñanza musical. Las conclusiones a las que llega Bonnevile (2014) son: en primer lugar, que los profesores de música, a la hora de enseñar, deberían centrar su atención en el perfeccionamiento de dos habilidades: la autorregulación y la práctica deliberada; y en segundo lugar, que los músicos que tienden a centrarse en acumular una gran cantidad de tiempo de práctica y a menudo pasan por alto la calidad de su práctica, podrían beneficiarse si se les recordara con frecuencia que la práctica informal o tiempo de práctica "vacía" no se ha probado que tenga efecto en el logro musical. Esto es, que practicando menos se pueden llegar a mejores resultados si esta práctica está siempre focalizada hacia objetivos claros, o dirigida y acompañada por estrategias efectivas de autorregulación y práctica deliberada. De hecho, este estudio muestra que una gran cantidad de tiempo de práctica sin objetivos claros puede ser perjudicial para conseguir dichos objetivos musicales.

Por su parte, Miksza (2015) estudia el efecto de la enseñanza de la autorregulación en el éxito interpretativo, la autoeficacia musical y la práctica de los intérpretes de instrumentos de viento avanzados. Y llega a la conclusión de que, ya que los músicos pasan una gran cantidad de tiempo y esfuerzo en la práctica individual en sus carreras, determinar cómo podrían ser 
guiados los estudiantes para comprometerse con su práctica de una forma autorregulada es una importante tarea, tanto para los profesores como para los investigadores. Para ayudar en esta tarea, examina elementos pedagógicos que espera sirvan de ayuda para los que deseen entender cómo ayudar a los estudiantes para aprender mejor ayudándose a sí mismos. Y sus resultados parecen alinearse con la afirmación general de la teoría de la autorregulación (McPherson y Zimmerman, 2011; Zimmerman, 1989), que explica que un estudiante efectivo es el que es capaz de priorizar y seleccionar sus objetivos importantes, aplicar las conductas de forma estratégica según los retos a los que se enfrenta y manejar de forma eficiente su tiempo y esfuerzo. Los resultados de su estudio sugieren varias aplicaciones potenciales como la importancia de ayudar al estudiante a autorregularse, incluyendo instrucciones que atañen a la concentración, el establecimiento de objetivos y la planificación durante la práctica.

Araújo (2015) explora las conductas de práctica autorregulada en músicos avanzados (profesionales). Las conclusiones de su investigación sugieren que la autorregulación que se realiza a través de los recursos personales puede ser el aspecto más relevante de la autorregulación para la práctica eficiente entre los músicos de más nivel. Igualmente demuestra que la autorregulación que se realiza a través de recursos externos decrece con la experiencia. Además, el tiempo de práctica está negativamente relacionado con la edad y positivamente con la organización de la práctica y la autorregulación a través de recursos externos, sugiriendo con esto que lo músicos jóvenes son más dependientes del uso del tiempo, la organización y los recursos externos.

En su estudio sobre el aprendizaje colaborativo en la educación musical superior, Gaunt y Westerlund (2013) explican que es más que evidente el impacto que el aprendizaje colaborativo en el contexto de la educación superior, especialmente a la hora de apoyar el desarrollo de importantes habilidades, tales como ser más responsables a la hora de controlar su propio aprendizaje y ser menos dependiente de las instrucciones directas del profesor; y de igual modo, facilitar la creatividad y respaldar las habilidades de los estudiantes que le permitan integrarse en contextos profesionales de cara a ser lo suficientemente flexibles para encajar con la diversidad. A este respecto, la investigación realizada por Gaunt (2007) sobre la enseñanza y el aprendizaje de la respiración en el oboe en alumnos de enseñanza superior (y que citábamos al hablar de las mentes del futuro de Gardner) ya señalaba la importancia de la reflexión sobre el propio aprendizaje y el hecho de compartir sus experiencias con el grupo. Esta reflexión ayudó a los estudiantes a tomar conciencia de su propia forma de trabajar, lo 
que les permitió beneficiarse de otras perspectivas e ideas y determinar alternativas y modificaciones para las suyas propias. Este tipo de experiencias no son una característica común de la enseñanza instrumental en la educación superior, de modo que se empezaba a demostrar el impacto que el contexto donde se aprende tiene en los alumnos, destacando la importancia de las relaciones que se desarrollan entre los profesores y entre los alumnos. Esto sugiere que la naturaleza de los contextos de aprendizaje en conservatorios necesita ser estudiado en más detalle, particularmente en relación con las teorías relativas al aprendizaje en la enseñanza superior. Y todo apunta a que seguir trabajando en áreas donde ahora están empezando a desarrollarse estas ideas en algunos conservatorios tendrá un valor incalculable. Esperemos que también esta concienciación e importancia del trabajo en grupo llegue a los conservatorios españoles ${ }^{10}$.

Esta idea de la importancia del aprendizaje colaborativo para el músico y que por lo tanto debería incluirse en la educación musical también se resalta en la investigación realizada por Dobson y Gaunt (2015). Al analizar los factores que se consideran necesarios para lograr la excelencia en una orquesta, las autoras llegan a la conclusión de que es necesario que los músicos de una orquesta de élite estén dispuestos a escuchar, comunicar y adaptarse a los demás, tanto en los ensayos como en los conciertos. Se dan cuenta de que el énfasis en las investigaciones de orquesta se ponía sobre todo en la relación entre el director y la orquesta y en los mecanismos que utilizaba el director para liderar y tomar decisiones con respecto a la orquesta $^{11}$. Sin embargo, sus resultados indican niveles más complejos de negociación y comunicación entre los miembros de la orquesta y que no se reducen simplemente a la relación director-resto de la orquesta. Los intérpretes entrevistados ponían mucha más atención en señalar las complejas habilidades requeridas para comunicarse e interactuar con los colegas que las requeridas para seguir las instrucciones del director. Por todo ello, insisten que en los conservatorios se deberían trabajar las habilidades sociales e interpersonales, habilidades que consideran vitales para lograr la excelencia, es decir, explorando la forma de ayudar a los estudiantes a focalizar en los procesos de escucha y adaptación al grupo al mismo

10 De hecho, si con este trabajo se consiguiera este objetivo, ya nos daríamos por más que satisfechos.

11 Remitiéndonos a las investigaciones sobre estos temas de Boerner y von Streit, 2005; Hunt, Stelluto, y Hooijberg, 2004; Koivunen y Wennes, 2011. 
tiempo que se trabaja la perfección técnica, y explorando maneras diferentes de introducir a los estudiantes en orquestas profesionales o recreando estos contextos de trabajo en los distintos niveles durante su aprendizaje, reajustando el sistema de evaluación para dar gran énfasis a la evaluación de las habilidades colaborativas de cada individuo cuando trabaja con otros y educando a los estudiantes sobre la importancia de mantener la cohesión social en el contexto de la orquesta, dejando claro que las convenciones de comportamiento que se esperan pueden ser diferentes en distintas agrupaciones. También recomiendan seguir haciendo más investigación con intérpretes de talla internacional para identificar cómo adquirieron estas habilidades y cómo creen que pueden ser mejor asimiladas por las nuevas generaciones de jóvenes que aspiren a ser músicos de orquesta.

Gembris y Heye (2014) examinan la forma de envejecer de los músicos de la orquesta sinfónica y, en su importante investigación, inciden en que ser un músico excelente toda la vida lleva implícito que tanto los músicos de forma individual como la orquesta (entendida como un todo) necesitan pasar a la acción y crear las condiciones adecuadas que permitan a sus miembros mantener sus niveles de interpretación musical a medida que se van haciendo mayores. Esto debe incluir el tipo de práctica, entrenamiento e instrucción, iniciativas para el cuidado de la salud la mejora de las condiciones de trabajo y la reducción del estrés. Los músicos mayores son también importantes para los músicos jóvenes, porque les proporcionan un modelo en varios aspectos, incluyendo la forma de aceptar el envejecimiento. Una visión realista del envejecimiento debe incluir no sólo las carencias o pérdidas que vienen con la edad sino también sus beneficios, como por ejemplo: la experiencia, los hábitos y la sabiduría musical. En este sentido la implicación que encontramos clara para inculcar a nuestros alumnos es que deberían ser conscientes de la importancia del cuidado de sí mismos para poder crecer, mantenerse y envejecer como músicos.

Por último, nos parece interesante terminar con algunas de las aportaciones que Varela et al. (2016) indican en relación a la autorregulación y el aprendizaje musical y sus implicaciones en la enseñanza. En una revisión sistemática sobre el tema, los autores señalan que la investigación reciente sobre cómo los individuos consiguen sus objetivos musicales se ha enriquecido gracias a los estudios que investigan la práctica musical desde la óptica de la autorregulación, la planificación orientada por objetivos, la adaptación cíclica y la reflexión de los pensamientos, sentimientos y acciones. Esta revisión analiza las evidencias prácticas disponibles para identificar las relaciones entre los procesos contenidos en el modelo de la 
autorregulación de Zimmerman (2000) ${ }^{12}$ y las variables del aprendizaje musical específico. También intenta descubrir cómo la conducta autorreguladora se ve reflejada en las instrucciones de música general y las intervenciones diseñadas para mejorar la autorregulación. Los resultados sugieren la instrucción de autorregulación como la variable más fuertemente relacionada con el aprendizaje musical. En concreto, ponen como ejemplo que los profesores necesitarían prestar atención al explicar las estrategias de práctica, para explicar al mismo tiempo la conciencia del uso apropiado de las mismas; deberían fomentarse las habilidades del manejo del tiempo recordando la necesidad de dejar sitio para hacer actividades informales y creativas de cara a mantener los niveles de motivación; y debería posiblemente renunciar a algún grado de control en sus lecciones, por ejemplo dejando a los estudiantes una mayor autonomía en la elección del repertorio, ya que las investigaciones insisten en la interesante relación que se establece entre alta autorregulación y autoselección del repertorio. Algunos estudios (Azevedo, 2006) muestran que dejar a los estudiantes seguir sus propios intereses puede tener un efecto positivo en el compromiso de los estudiantes y en el desarrollo de la voluntad. La elección de su propio repertorio presupone la presencia de un objetivo musical y de la motivación intrínseca necesaria para su logro.

La posibilidad de autograbarse también se ha reconocido (Varela et al, 2016) como una manera de incrementar la perseverancia entre los músicos principiantes, como un instrumento para autocontrolarse de manera efectiva. Se ha demostrado ya que es una herramienta que ayuda a fortalecer la creencia de que el trabajo realizado se está llevando a cabo con eficacia. La tecnología moderna permite a los músicos guardar y monitorizar su progreso, algo que puede ayudar a proporcionar la motivación necesaria para perseverar a lo largo del tiempo. Se conoce poco sobre el impacto que esta tecnología tiene en la autorregulación musical o en la unión entre el apoyo social y la autorregulación. Resaltan la investigación de Hadwin y Oshige (2011) que describen el aprendizaje co-regulado y la regulación compartida socialmente como formas de aprendizaje autorregulado que pone el énfasis en las interacciones colectivas y en la colaboración.

12 Esta teoría mantiene que para que los objetivos se puedan alcanzar de forma autónoma los individuos deben ser capaces de controlar su conducta, el contexto y sus estados cognitivos y afectivos, antes, durante y después de la actividad de aprendizaje (Zimmerman, 2000 en Varela et al., 2016) 
En las implicaciones que esta revisión sistemática propone para los educadores, se incluye la reflexión de que es poco probable que los profesores de música acepten la necesidad de autorregulación y por eso insiste en que lo que se requiere es una discusión de cómo las instrucciones de autorregulación pueden ser integradas de manera respetuosa en la enseñanza práctica. Plantea como crucial las contribuciones de los profesores en la investigación futura, así como la necesidad de que los profesores se den cuenta del poder de la tecnología de manera que sea efectiva y eficiente y para eso les parece que puede ser recomendable que se extiendan los resultados de esta revisión en los conservatorios de música y en los congresos, a la vez que se proporcione la guía necesaria para su utilización a los profesores en su desarrollo profesional diario o con soporte on line que responda a sus necesidades. También resalta la importancia que hemos visto en otros autores de seguir investigando, de observar la forma en que se aprende y de ir abriendo nuevas posibilidades. Espera que en unos años podamos tener una teoría de la autorregulación en el aprendizaje instrumental que incluya el aprendizaje co-regulado donde los propios participantes se impliquen más activamente en la generación de teorías y modelos que les sirvan de ayuda para su propio aprendizaje.

\subsection{El concepto de excelencia musical en la actualidad}

Hallam y Gaunt (2012) muestran la necesidad de redefinir a qué llamamos excelencia musical. El panorama musical está cambiando, la industria nos muestra muchas áreas emergentes mientras que otras profesiones que antes eran imprescindibles van perdiendo protagonismo. Nos damos cuenta de que muchos campos de trabajo se están reduciendo y podemos decir que otros van apareciendo y seguirán haciéndolo. Podemos preguntarnos si estamos preparando a nuestros alumnos para ser excelentes en el momento en el que les va a tocar vivir o si seguimos educándolos para profesiones que ya están caducas. ¿Las habilidades que necesitan los músicos contemporáneos son las mismas que se necesitaban hace cien años? Como ya se analizado anteriormente, Dobson y Gaunt (2015) insisten, en sus últimas investigaciones, en que los conservatorios deberían trabajar las habilidades sociales e interpersonales, habilidades que consideran vitales para lograr la excelencia. Exponen que esta excelencia en una orquesta sólo es posible si sus integrantes están dispuestos a escuchar, comunicar y adaptarse a los demás, tanto en los ensayos como en los conciertos y que habría que seguir investigando cómo los intérpretes profesionales han adquirido estas habilidades para que los conservatorios intentaran equipar con ellas a las nuevas generaciones de 
aspirantes a músicos de orquesta desde sus estudios en el conservatorio. Los profesores de conservatorio tendríamos que preguntarnos si estamos cumpliendo con nuestra función de profesores del siglo XXI: ¿les estamos enseñando a adaptarse a los nuevos cambios y a asumir nuevos riesgos, a ser creativos, a romper barreras y a buscar lo que les apasione?

Hallam y Gaunt insisten en que una cosa que sabemos seguro es que la mayoría de los músicos de ahora hacen trabajos profesionales que no esperaban hacer. De la misma manera, los estudiantes de música van a tener que aplicar sus habilidades y su experiencia de una manera que sus profesores ni siquiera pensaron. Por eso no es sorprendente que la investigación demande el desarrollo de una amplia variedad de habilidades y experiencias tanto como estudiante como en la transición a la vida profesional. El refinamiento de las habilidades musicales es, por supuesto, esencial. Sin embargo es necesario complementarlas con otras cualidades necesarias, tales como la imaginación, autoconfianza, versatilidad, habilidades interpersonales y la habilidad de reconocer oportunidades de trabajo y de generarlo. Dicho esto, parece evidente que (como iremos ampliando posteriormente) lo más importante para un músico es el desarrollo de la resiliencia y, al mismo tiempo, la necesidad de asumir que van a seguir siendo estudiantes toda su vida, de modo que puedan manejar la incertidumbre y las oportunidades que se les puedan presentar (algo que cambia con mucha rapidez). En este contexto es visible que muchas universidades y conservatorios están tomando una visión más holística de las habilidades de los músicos y tienen como meta equipar a sus estudiantes con este tipo de habilidades, como por ejemplo: salud y bienestar, administración y gestión musical y habilidades emprendedoras (2012:73).

¿Cómo podemos hacer todo esto? Por supuesto, sería muy arriesgado decir que vamos a conseguirlo. Somos realistas y, por lo tanto, conscientes de que no es tarea fácil. Sin embargo, sí que creemos que es tarea del profesor intentarlo y, sobre todo, hacer conscientes a los alumnos de enseñanza superior de que ellos mismos son los que tienen que buscar esa excelencia y que deben, por tanto, conocer todo lo que la investigación está avanzando en este tema, porque les puede ayudar en su búsqueda no sólo de la excelencia, sino lo que nos parece más necesario: seguir mejorando a lo largo de toda su vida, para lo cual es necesario ver cuáles son los fallos que cada uno tiene individualmente y que "todavía" están sin resolver, pero que pueden solucionarse si realmente se tiene interés por cambiarlos y se trabaja en ellos. Por eso es importante explicar que las investigaciones pueden proporcionarle en algunas ocasiones las herramientas para hacerlo. Este "todavía" en el que insiste Carol Dweck (1999:11) es en lo que los profesores tenemos que creer y en lo que insistir para ayudar a los 
estudiantes a ver la posibilidad de conseguir cambiar las cosas si se lo proponen. Quizá tendríamos que decir que, como profesores, "todavía" no tenemos claro cómo podemos ayudar a los alumnos de la enseñanza superior a conseguir la excelencia, pero que tenemos que seguir investigando y estudiando lo que dicen los últimos hallazgos para poder adaptarnos a las necesidades de nuestros alumnos, haciendo nuestro trabajo de la mejor manera posible. El facilitar este conocimiento de la investigación a los alumnos puede ayudarles a ver nuevos puntos de vista y a construir un sistema de valores propio. Como dice Cox (2014)" la investigación se puede utilizar como conductor para incrementar la autonomía".

Estamos convencidos, con O' Neill (2014), de que el conocimiento de las investigaciones sobre lo que debería ser la práctica instrumental y pedagógica puede entrar en conflicto con lo que realmente se está enseñando en los Conservatorios Superiores de Música. Pero quizá este conocimiento se pueda convertir en una crítica constructiva que nos permita valorar lo que se está haciendo bien y nos dé la oportunidad de cambiar lo mejorable. Cox (2014) también anima a los estudiantes de conservatorio a conocer los procesos y métodos de la investigación artística. Según Cox, este conocimiento les convertirá en profesionales más versátiles, con una mentalidad más abierta y con una mayor capacidad de desarrollo como músicos. Si analizamos cómo está la situación en España, Gutiérrez $(2007)^{13}$ plantea la necesidad de proponer cambios desde el interior de la institución docente dada la situación de crisis que vive el modelo actual de Conservatorio, para evitar que vengan desde fuera (cambios legislativos, presión social, etc.).

\subsubsection{Preparando el camino para el éxito como músico profesional}

Actualmente, como se ha visto en las investigaciones señaladas en los puntos anteriores, para tener éxito como músico y que este éxito dure toda la vida, se requiere flexibilidad y resiliencia. La profesión de músico está cambiando constantemente y los aprendizajes que se consiguen en los años de carrera no son suficientes para mantener una carrera a lo largo de la vida. Los músicos necesitan evaluar su trabajo constantemente, estar abiertos a los retos y a las nuevas ideas y no tener miedo de enfrentarse a ellas. Esto requiere confianza en sí mismo y una disposición para asumir riesgos y reflexionar sobre los resultados obtenidos. Además, 
parece también necesario el desarrollo de relaciones positivas con colegas que puedan actuar como amigos para el intercambio de críticas constructivas o como mentores que respalden estos procesos (Hallam y Gaunt, 2012:271).

Susan Hallam y Helen Gaunt han recopilado en su trabajo Preparing for Success: a Practical Guide for Young Musicians los puntos que creen fundamentales para desarrollar el éxito como músico profesional, un libro donde se hace una recopilación exhaustiva del estado actual de las investigaciones. De este modo, podemos tener una visión de conjunto de lo que debe ser el músico profesional en el siglo XXI, identificando la variedad de habilidades, conocimientos y actitudes que pueden ser importantes para tener éxito en su campo. Precisamente, en el primer capítulo nos presentan lo que las autoras denominan "Diez formas de preparar el éxito como músico profesional" (Hallam y Gaunt, 2012:3-5). A continuación, presentaremos esos diez puntos $^{14} \mathrm{y}$ en la parte práctica comentaremos las reflexiones que los alumnos de la enseñanza superior del Conservatorio Superior de Música de Navarra han realizado en los grupos de discusión sobre los temas que nos presentan:

1- Sé responsable con tu desarrollo y persigue lo que te apasiona. Sé un aprendiz activo. Trabaja en un plan de desarrollo personal y mantenlo actualizado, buscando el aporte de los mentores, amigos y otros músicos profesionales. Aclara las habilidades musicales básicas que son importantes para tu éxito y desarrolla de éstas tanto como puedas. Estate preparado para las nuevas oportunidades de aprendizaje, tanto formales como informales, y sé tan bueno como sea posible en el aprendizaje en diferentes contextos. Sé honesto acerca de lo que te parezca difícil, pero no evites estas cosas. Busca oportunidades que sean a la vez divertidas y desafiantes. Pide retroalimentación de la gente que sea constructiva. Sé consciente de cuán inconsistente y subjetiva puede ser la evaluación en la música.

2- Entiende lo que te motiva y por qué, lo que te trae satisfacción y construye tu confianza. Cuestiona y nutre tu conexión con el arte y tu público. Recuerda por qué haces lo que haces. Piensa en lo que te motiva como músico y cómo tus aspiraciones pueden alinear mejor tus habilidades musicales y profesionales. ¿Qué ayuda a mantener tu motivación? ¿Qué contextos son los más adecuados para tu trabajo? ¿Quién es tu público y

14 En traducción propia a partir del original 
cómo conectas con ellos? Estate informado acerca de las posibilidades y explora nuevos contextos.

3- Desarrolla habilidades de colaboración e interpersonales. La colaboración es una parte enorme de hacer música - no importa si eres un compositor, un músico de conjunto, solista, o creando un trabajo elaborado, la enseñanza, la investigación, la programación o la organización. En el pasado, a menudo estuvimos acostumbrados a pensar en la experiencia como algo individual, pero esto está cambiando rápidamente. Las habilidades interpersonales (por ejemplo la escucha, el apoyo, empatía...) son de vital importancia tanto a nivel musical como en todo tipo de comunicación. Incluso si la colaboración es sólo una pequeña parte de una práctica musical específica, estas habilidades serán vitales en el proceso de búsqueda y gestión del trabajo.

4- Encuentra un círculo de profesores de confianza, mentores y amigos para apoyar tu desarrollo. Involúcrate en grupos y comunidades que te interesan o pueden serte útiles. Todos los músicos confían en redes extensas: los artistas, colaboradores creativos, empresarios, agentes, programadores y amigos críticos (amigos en los que se puede confiar para dar información y actuar honesta y constructivamente). Busca a maestros de alta calidad, mentores y amigos críticos en los que confías y cuya opinión valoras. Tener un conjunto sólido de relaciones de esta naturaleza acelerará su aprendizaje, abrirá puertas y proporcionará conocimientos y habilidades importantes, y apoyo psicológico. Un programa de estudio crea su propia comunidad. Se usa para aumentar el apoyo entre personas y para generar ideas y colaboraciones artísticas. Otras redes también son importantes, proporcionar acceso a los contextos profesionales, habilidades adicionales y apoyo personal. Participar proactivamente en esas comunidades también ayudará a clarificar su identidad musical y profesional.

5- Explora, se arriesgado, extiéndete más allá de tus límites actuales. Los aspectos de tu trabajo que te animan a tomar riesgos y explorar cosas nuevas estimularán tu creatividad e ideas innovadoras, y ampliarán tu flexibilidad como músico. Cuanto más desarrollamos la experiencia intensa en un campo estrecho, más difícil es que traduzcamos esa experiencia y la apliquemos en otros contextos. Esto puede ser frustrante si, por ejemplo, te has centrado exclusivamente en actuaciones y encuentras que no estás recibiendo suficiente trabajo en ese campo. Busca oportunidades para desarrollar las habilidades de improvisación en 
cualquier estilo musical. Utiliza estos para construir tu confianza en el trato con lo desconocido, y la toma de decisiones. La improvisación es también una gran manera de construir habilidades de colaboración.

6- Comprométete con la tecnología. La tecnología es una parte cada vez más importante de práctica profesional en la música. Piensa en las maneras en las que puede ser una parte útil de tu práctica. Puede utilizarla para:

- Grabar, crear, componer, documentar, analizar y archivos musicales.

- Comunicar, compartir y vender música.

- Organizar y promover eventos.

- Apoyo y seguimiento de su aprendizaje.

- Ayuda a reflexionar.

Ten en cuenta que tu experiencia con la tecnología puede ser mayor que la de tus maestros, $\mathrm{y}$ puede que tengas que encontrar otras vías para desarrollar tus conocimientos y habilidades.

7- Apoya tu salud y bienestar. El siglo XX fue testigo de un aumento sin precedentes en los casos de los músicos que sufren de enfermedades físicas, estrés y agotamiento. Mantenerse saludable y evitar tales dificultades es vital. Como intérprete, trátate a ti mismo como un atleta, ten en cuenta que la mente y el cuerpo son una parte integral de lo que haces y dependen el uno del otro. Se deben desarrollar juntos. Ten en cuenta los esfuerzos particulares de tu campo de trabajo, y toma las riendas de tu equilibrio trabajo - vida.

8- Sé organizado y confiado, y dirígete a sí mismo de manera eficaz. La mayoría de los músicos tienen una vida laboral muy variada, y muchos encuentran que no tienen rutinas especialmente regulares. Esto pone de relieve la importancia de ser capaz de manejar tu propio tiempo y organizar tu horario, a menudo con conflicto de prioridades. Presta atención a los componentes esenciales de la profesionalidad, tales como:

- Mantener un diario organizado

- Llegar a tiempo 
- Planificar el futuro

- Comunicar cualquier dificultad en el momento oportuno

- Estar preparados

- Tiempo para pensar en las decisiones

- Tiempo libre/ de descanso

9- Trata a tu trabajo como un negocio de gestión de finanzas y cuestiones de propiedad intelectual y desarrolla habilidades empresariales. Un estudio de músicos de conservatorio ha demostrado que los problemas financieros se perciben como una de las barreras más fuertes para el éxito. Reconoce la importancia de la financiación. Aprende a presupuestar de forma realista y planifica el futuro. ¿Cuáles son los costos de estudiar en diferentes programas y en diferentes países? Considera qué subvenciones, becas y ayudas hay disponibles. Sé consciente de los impuestos y mantén las cuentas apropiadas. Estate informado sobre cuestiones relativas a los derechos de autor, propiedad intelectual y derechos de comunicación pública. Debes saber lo que vale la pena tu trabajo y asegurarte de que, por ejemplo, tus resultados creativos estén protegidos. Considera las formas de ganar dinero, que también van a desarrollar las habilidades pertinentes.

10- Desarrolla la resiliencia (poder de recuperación). Reconoce tus dificultades, momentos de dudas, acéptalos y busca la forma de solucionarlos. Todo el mundo tiene dificultades y momentos de dudas. Los músicos exitosos son aquellos que son capaces de hacer frente a ello, aprender y seguir adelante. Es muy fácil que los músicos sean excesivamente auto-críticos o se abrumen por un sentimiento de competencia con el que nunca tendrán éxito. Concéntrate en la búsqueda de una retroalimentación constructiva. Aprende a tratar de forma realista las experiencias negativas o comentarios destructivos y evita obsesionarte con ello. Todos los músicos serios saben que van a tener que soportar algunos golpes. Calcula cómo involucrar los desafíos de manera que ayuden a sostener un nivel saludable de autoestima sin evitar dificultades importantes

\subsubsection{La mentalidad en crecimiento y su aporte para los músicos}

Una vez analizado lo que entendemos por excelencia musical, las investigaciones que más interés nos han despertado al respecto por su aplicabilidad en la enseñanza musical superior y el estudio de los pasos que fruto de estas investigaciones se recomienda al futuro músico para 
conseguir el éxito como músico profesional (Hallam y Gaunt, 2012), parece el momento oportuno de presentar las investigaciones que, siguiendo la teoría de Carol Dweck (Dweck, 1987:2006) sobre los distintos tipos de mentalidad (fija y en crecimiento) ${ }^{15}$, se han aplicado al campo musical. Lo que nos proponemos ahora es ver cómo han sido estudiados en música estos dos tipos de mentalidad y las implicaciones que sus hallazgos pueden tener para la enseñanza musical.

Susan O’Neill ha sido una de las investigadoras que más se ha preocupado por este tema ${ }^{16}$, aplicando la teoría de Dweck al campo musical. En este sentido cuenta cómo en los inicios de su tesis doctoral intentaba encontrar un método que le permitiera cuantificar y contabilizar sistemáticamente las diferencias en motivación y logro que podían encontrarse entre los niños que estaban aprendiendo a tocar un instrumento musical. Se preguntaba por la razón que movía a algunos jóvenes a perseverar en la práctica musical mientras que otros de igual nivel o potencial hacían pocos progresos o incluso abandonaban. Y del mismo modo se pregunta por qué entre los chicos más competentes había algunos que flojeaban ante las dificultades y evitaban los retos sin desarrollar todo su potencial, mientras, que por el contrario, entre los niños menos competentes en principio, aparecen algunos que les atraen los retos y consiguen niveles de habilidad musical que nadie había previsto en su conducta musical inicial (O' Neill, 2011).

En un estudio llevado a cabo con John Sloboda (O’Neill y Sloboda, 1997) demuestran que la actuación de los niños en los test de cognición musical está influida no sólo por sus niveles en las habilidades cognitivas, sino también por su estado afectivo y conductual. Así, encontraron que los niños con un patrón motivacional orientado al domino de la tarea (mastery oriented) consiguen mejores progresos que aquellos que tienen una teoría de la inteligencia como algo fijo, que piensan que su habilidad musical es una característica inamovible y que no pueden hacer nada para cambiarla. Además, su examen de la práctica que realizaban estos niños reveló que aquellos que tienen esta mentalidad fija tenían que practicar el doble para coneguir

15 Teoría desarrollada en el punto 1.1.3 del primer capítulo y que va a ser clave en el desarrollo de la investigación que propondremos en la fase experimental.

16 O’ Neill, 1994 a, O’Neill, 1994 b, O’Neill, 1996, O’Neill, 1997, O’Neill, 2001, O’Neill y Sloboda, 1997, O’Neill et al. 2000, O’Neill et al. 2002, O' Neill, 2011. 
los mismos resultados que aquellos que tenían el patrón motivacional orientado al dominio de la tarea, sugiriendo que tendían a hacer menos efectiva y eficiente su práctica. Por lo general, en los años escolares los buenos estudiantes pueden no encontrar tareas con dificultad suficiente para crear actuaciones de fracaso o debilidad y los patrones motivaciones inadaptados pueden no influir en sus logros a largo plazo hasta los últimos años de la escuela, cuando los niños con el patrón motivacional de indefensión (helpless) ${ }^{17}$ pueden empezar a evitar los cursos que supongan un reto o incluso abandonar los cursos que planteen la posibilidad de fracasar. Sin embargo, en música, los patrones motivacionales inadaptados pueden influir en el logro del niño mucho más pronto que en otras actividades académicas, ya que al empezar a tocar un instrumento hay muchos obstáculos y dificultades (la postura, la posición, el ritmo, la afinación, la notación). Como resultado, muchos niños experimentan dificultades y fracasos muy pronto en su entrenamiento instrumental y es en estas circunstancias en particular cuando aparecen las diferencias entre los patrones motivaciones de dominio de la tarea o de indefensión. Por eso apuntan que sería interesante una mayor investigación en este área para poder obtener alguna explicación sobre por qué algunos niños perseveran con la práctica instrumental, mientras que otros con igual habilidad musical o potencial hacen pocos progresos o incluso abandonan su entrenamiento después de un breve periodo de tiempo.

Los resultados de este estudio han tenido importantes implicaciones para los músicos. En concreto, explican que se debería prestar mucha atención a la influencia de los estados afectivos y conductuales entre los niños que experimentan dificultades mientras se persiguen objetivos de rendimiento (performance goals) ${ }^{18}$ relativos al logro (por ejemplo en exámenes, competiciones entre compañeros, etc.). Como ejemplo comentan cómo los profesores que intentan ganarse la confianza de los niños proporcionándoles tareas donde siempre tienen

17 Caracterizados por la tendencia a evitar los retos que presentan riesgo de errores o fallos, conllevando así mismo la autoculpabilización del sujeto que lo aplica. Al mismo tiempo éste suele infravalorar su capacidad intelectual y tiende a mostrar sentimientos negativos que obstaculizan las estrategias de resolución de problemas (Diener y Dweck, 1987, en Dweck, 1998).

18 Suponen un interés por obtener juicios y valoraciones positivas sobre la propia capacidad y por tratar de evitar los negativos, asociados con el patrón motivacional de indefensión. 
éxito y evitan el fracaso pueden en realidad estar aumentando la vulnerabilidad de algunos niños con patrones motivacionales de indefensión, ya que, en esta situación los niños ganan menos experiencias de fracaso y pueden empezar a verlo como algo a evitar, más que una parte del proceso de aprendizaje. Todo esto les hace insistir en la importancia de poner el énfasis en los objetivos de aprendizaje y en las tareas que buscan el reto personal, (tareas suficientemente difíciles para ser un reto, pero no tanto como para causar frustración). De esta manera, los profesores pueden crear un ambiente educativo donde los niños valoren los objetivos de aprendizaje (learning goals) ${ }^{19}$ y respondan con conductas que se orienten al dominio de la tarea. Además proporcionándoles feedback en el que se explicite las razones de sus resultados de aprendizaje y que les ayuden a ampliar sus estrategias y conocimientos en lugar de simplemente hacer juicios de su habilidad interpretativa, los profesores pueden ayudar a los niños a ganar control sobre su propio aprendizaje y ayudarles a desarrollar estrategias adaptativas en respuesta al fracaso.

O’ Neill (2011) también ha examinado el rol que la motivación, las auto-teorías y la resiliencia ocupa en el desarrollo de la mente en crecimiento de los músicos jóvenes y destaca la importancia de desarrollar la mente en crecimiento y, al mismo tiempo, sugiere que la mentalidad en crecimiento en los músicos jóvenes les puede servir como un factor de protección que puede promover la resiliencia (de la que hemos hablado anteriormente) y que esta resiliencia les puede ayudar a mantener la motivación y a reducir los efectos negativos de la adversidad, el fracaso y los eventos estresantes de la vida. En este sentido, explica cómo los educadores pueden ayudar también a los estudiantes animándoles a reflexionar críticamente sobre sus propias auto-teorías y objetivos, así como qué deben examinar los mensajes que son inherentes a sus propias prácticas pedagógicas, para asegurarse de que están transmitiendo a sus alumnos una mentalidad en crecimiento sobre el aprendizaje. Como ejemplo interesante, comenta cómo al hablar de un músico en concreto como un "genio", los profesores, inconscientemente, estamos enviando el mensaje de que un músico nace y no se hace, lo que lleva aparejado que la habilidad musical es una característica fija. Una estrategia más productiva sería animar a los estudiantes a fijarse en identificar las características del músico que ellos admiran en cuanto a su esfuerzo, su dedicación y la capacidad de resiliencia que

19 Objetivos que suponen un interés por la adquisición y desarrollo de nuevas capacidades y conocimientos, relacionados con el patrón motivacional que se orienta al dominio de la tarea (mastery oriented) 
demuestra cuándo se enfrenta con problemas, obstáculos o barreras para conseguir su éxito.

Smith (2005), en su estudio con alumnos de la enseñanza superior de música, demostró que los alumnos que tenían una consideración fija de la habilidad musical se implicaban mucho más para realzar su ego (ser mejor que los otros) que por el dominio de la tarea en sí. Cuanto más se apoyan los estudiantes en una creencia fija más probable es que se apoyen en los objetivos que demuestran una mayor habilidad con relación a los otros (ego-approach) y, en especial, en los objetivos que evitan demostrar su falta de habilidad con relación a los otros (ego-avoid). Todo esto encaja con lo que se había predicho teóricamente como una cadena de causalidades: si la habilidad musical es innata y fija, se debe intentar demostrar que se tiene y, por supuesto, evitar demostrar que no se tiene. Igualmente muestra que los que creen que la habilidad musical es maleable y mejora con la práctica efectiva y el esfuerzo muestran un deseo de buscar retos, desean aprender y tienden a persistir en la práctica. En sus recomendaciones para la educación destaca la importancia de ver el concepto de talento como un concepto vago o de poco valor, al tiempo que recuerda que el rol de la educación es servir al desarrollo musical de cada individuo y que los profesores y los directores de grupos deberían promover objetivos que tengan que ver con los objetivos en la tarea, evitando la utilización de los objetivos cuyo único fin es reforzar el ego tanto como sea posible. Esto es, algo que ya había explicado McPherson (1987) cuando señalaba lo relevante que el estudio de Covigton y Beery (1976) puede ser para la música. Estos dos autores diferencian entre el elogio y el estímulo, explican que el elogio puede ser a veces coercitivo en su naturaleza (similar a un soborno) porque se centraliza en el estudiante más que en lo que el estudiante está haciendo, mientras que el estímulo expresa satisfacción por lo que el estudiante está aprendiendo y logrando y, por tanto, se centra en la tarea. En este sentido, el elogio puede inducir a involucrar el ego mientras que el estímulo alienta a centrarse en la tarea. Pero McPherson insiste en que los profesores: “deberían tratar siempre de que su estímulo sea sincero y la crítica constructiva a fin de fortalecer en sus alumnos la confianza en su propio potencial" (1987:33).

Matthews y Kitsantas (2013), en las conclusiones de su estudio con instrumentistas universitarios, relatan que estos estudiantes que tocan en grupo conseguían una mayor eficacia colectiva y una mejor interpretación si su director tenía el patrón motivacional orientado al dominio de la tarea (mastery oriented) y si ellos mismos se motivaban con la actuación. Asimismo, aporta además unas sugerencias para directores y educadores musicales que 
permitan mejorar la guía y el respaldo de los músicos, así como el desarrollo musical competente en el conjunto. Concretamente, sus conclusiones sugieren que los directores que crean un clima de ensayo que fomente la motivación de los estudiantes, haciendo énfasis en el dominio y desarrollo de las habilidades y que además fomenten un aprendizaje global, conducen a aumentar en el alumno las creencias sobre su eficacia y a ver de forma positiva sus posibilidades, mucho más que los ensayos focalizados en los resultados interpretativos. Además, hacen hincapié en la importancia de entender el oficio de la dirección y el desarrollo de métodos efectivos para enseñar a futuros directores. A este respecto, se sugiere que los directores que crean un clima de ensayo adecuado logran motivación en el estudiante, y se enfatiza en el desarrollo de habilidades que le ayudan a tener una mejor consideración de sí mismo y de su trabajo, lo que le lleva a conseguir una mejor interpretación.

Cogdill (2015) aplica la investigación en motivación y en el aprendizaje a la educación musical y proporciona sugerencias para cambiar la percepción del talento, ampliándolo al ámbito de las actividades musicales en las escuelas, incluyendo una valoración auténtica; y enseña a los profesores cómo mejorar la motivación en los estudiantes y el aprendizaje en clase de música. En este artículo, explica cómo la investigación actual en motivación y aprendizaje puede ayudar a los profesores a identificar estrategias para ayudar a los estudiantes a tener éxito y a perseverar en la práctica musical. En esta revisión destaca la comprensión de los dos tipos de inteligencia (fija y en crecimiento), además de las teorías del autoconcepto, autoeficacia, autodeterminación y el conocimiento del funcionamiento del cerebro. Recomienda a los profesores que proporcionen feedback a los estudiantes sobre la importancia de la persistencia y de demostrar el esfuerzo, elementos indispensables para desarrollar la inteligencia en crecimiento sobre su habilidad musical. Insiste en que estas creencias sobre su habilidad musical deberían fomentarse en las clases de música de la enseñanza general, ya que la música es inherente al ser humano, y las oportunidades de participar y disfrutar de la música a lo largo de su vida debería enfatizarse en la cultura escolar. En los modelos actuales que propone para conseguir el éxito, explica que muchos profesores son conscientes de la importancia de reflexionar sobre su propia pedagogía a la hora de enseñar, de forma que esa reflexión les permita desarrollar estrategias para seguir mejorando. Muchos profesores entienden que, como los estudiantes y la sociedad cambia, ellos también deben adaptarse a esas necesidades que cambian. El resultado es que proporcionan un ambiente de aprendizaje seguro, acogedor y atractivo; del mismo modo, invierten su tiempo y energía en tomar conciencia de los conocimientos de los estudiantes 
para conectar con ellos, demostrándoles que los valoran. Estos procesos también ayudan al profesor a entender las diferentes necesidades de aprendizaje de sus estudiantes: eligen las actividades musicales que tienen el interés y el nivel de complejidad apropiado para fomentar la motivación y las ganas de seguir aprendiendo; actividades que permitan desarrollar la creatividad cómo hacer que los alumnos compongan, toquen obras originales o composiciones de otros, a solo o en conjunto, presentar a su clase un aspecto musical que sea de su interés personal; actividades que se han utilizado como métodos para motivar en el pasado y que siguen siendo útiles. La autora insiste en la trascendencia de las experiencias que tienen los alumnos en este campo, pues una vez que los estudiantes se hacen la idea de que no pueden con la música, el profesor puede que no tenga otra oportunidad de conseguir engancharlos. Estas creencias limitadoras les pueden quitar una vida de disfrute musical. Por eso insiste en que lograr una inteligencia en crecimiento sobre la habilidad musical, especialmente cuando se está en los primeros cursos, podría ayudar a los alumnos a tener la motivación necesaria para persistir en el aprendizaje musical.

Como vemos Cogdill incide en la importancia de desarrollar la mentalidad en crecimiento para lograr motivar a los estudiantes a aprender música, ayudándoles a persistir y a realizar actividades musicales a lo largo de toda su vida. Insiste en que, para ello, el profesor también debe tener unas características particulares que nosotros podríamos resumir diciendo que estos deben tener también mentalidad en crecimiento que se esfuerzan por seguir aprendiendo, por conocer lo que los alumnos necesitan y les enseñan estrategias para persistir en la tarea y ser independientes, lo que será decisivo en los estudios superiores (Lehmann y Jorguesen, 2012).

Con nuestra investigación nos proponemos que los alumnos de la enseñanza superior conozcan la teoría de los dos tipos de mente: fija y en crecimiento (Dweck, 1999 y 2006) y que puedan descubrir si tienen una o la otra o si, como pensamos, hay en algunos momentos o campos en particular en los que tienen una y en otros otra y que el conocimiento de su existencia y la posibilidad y ventajas que reporta la mentalidad en crecimiento les haga desarrollarla y ayudar a sus compañeros a que también la desarrollen. Para poder hacer lo que nos proponemos hay que ser conscientes de que es importante crear un entorno de aprendizaje donde cada alumno esté abierto a cambiar si es necesario y le favorece, donde compartir el conocimiento sea la mejor forma de aprender, y donde conocerse y conocer a los demás sea el punto de partida para aprender mejor, de forma efectiva, manteniendo el optimismo. 
Para ello, partiremos de los trabajos de Dweck y sus colaboradores (ya expuestos con detalle anteriormente) donde se mostraba claramente que los estudiantes que tienen una idea de la inteligencia como algo fijo e inmutable suelen obstaculizar sus propias estrategias de resolución de problemas cuando se enfrentan con dificultades. Y que, en cambio, los que ven su inteligencia como algo que se puede desarrollar hacen frente a los retos con entusiasmo y muestran un esfuerzo más intenso, mantienen el optimismo y utilizan estrategias efectivas cuando se enfrentan a los obstáculos (Dweck, 2006). Como hemos visto, estos dos tipos de inteligencia también han sido estudiados en música constatando lo interesante de fomentar el desarrollo de la mentalidad en crecimiento, tanto en los músicos de la enseñanza superior (Smith, 2005), como en los músicos profesionales (Matthews y Kitsantas, 2013), así como en la enseñanza musical a niños (O’Neill, 1997, O’Neill y Sloboda, 1997), concretamente en alumnos con edades comprendidas entre los seis y los diez años. Y lo interesante es que se ha llegado a las mismas conclusiones que Dweck. Los hallazgos de Dweck (1998, 2006 y 2007) y de O'Neill y Sloboda (1997) sugieren que las teorías de la inteligencia de los estudiantes son maleables y que podemos ejercer un efecto causal en los objetivos que persiguen éstos. Es decir, que con la lectura de textos relativos a la teoría de inteligencia en crecimiento se ven más capaces de conseguir lo que se proponen.

Lo que se quiere examinar es si en los conservatorios superiores de música se puede aplicar esta teoría de las inteligencias y al mismo tiempo si es posible que los alumnos de la enseñanza superior de música transiten, en el caso que sea necesario de la inteligencia fija a la inteligencia en crecimiento, e incluso que apliquen los trucos que les funcionan de manera individual en lo que se les da bien, en los aspectos o contextos donde se ven con inteligencia en crecimiento, a otros contextos o aspectos en los que se ven con inteligencia fija. Para esto será necesario que conozcan esta teoría, de modo que vean que esa posibilidad existe, así como que estudien las investigaciones sobre el aprendizaje musical y la excelencia, de modo que sean conscientes de que es importante trabajar en función de sus necesidades, habilidades y expectativas individuales. Igualmente importante es que vean cómo pueden contribuir e intercambiar conocimientos, experiencias y hallazgos que se complementen con los de sus compañeros, para lograr esa excelencia en grupo (tan necesaria) buscando que estén motivados a reflexionar y a dedicar el tiempo y el esfuerzo necesario para conseguirlo. Especialmente importante en este sentido nos parecen los estudios de Dweck (2007) que muestran que los estudiantes pueden mejorar su motivación para aprender simplemente siendo informados acerca de los dos tipos de inteligencia señalados (fija y en crecimiento). La propia 
Cogdill trae a colación un dicho popular: "Conocer es poder" que es perfectamente aplicable a todo lo que estamos comentando aquí sobre la educación musical.

Dweck (2007) demostraba que conocer los dos tipos de inteligencia ya les mejoraba su motivación para aprender. Nosotros queremos dar un paso más y ver si los estudiantes de la enseñanza superior de música se pueden dar cuenta de que utilizan estrategias diferentes cuando están en mentalidad en crecimiento. Así, les vamos a pedir que intenten analizar esas estrategias o trucos que utilizan en un ámbito en el que se sienten competentes, de modo que prueben a utilizarlo en otro en el que se vean con inteligencia fija. El ser capaz de imaginar cómo aplicar los trucos que ya se tienen en la inteligencia en crecimiento a la inteligencia fija hace que la fija deje de serlo, pues abrimos la posibilidad de utilizar nuestras propias estrategias personales que ya son eficaces para nosotros y nos gustan (por eso son las que aplicamos en lo que nos gusta y se nos da bien) y, por tanto, lo que descubrimos es la posibilidad de hacer que lo que antes nos parecía imposible se vea un poco más accesible. Al realizar esto, lo que sucede es que cada uno está aplicando su propio autoconocimiento, pues analiza lo que hace él y le gusta, cuál es su punto fuerte (donde tiene mentalidad en crecimiento) y su punto débil (donde tiene mentalidad fija) y trabaja la autodeterminación (al abrir la posibilidad de aplicar algo suyo está tomando decisiones propias a ese respecto y reflexionando sobre cómo hacerlo, lo que es el primer paso para llevarlo a cabo) y la independencia que, según Jorgensen (2012), era la habilidad más necesaria para el músico, pues él mismo es el que se está dando cuenta de qué es lo que puede cambiar al elegir entre un amplio abanico de posibilidades (pues, en ocasiones, incluyen habilidades musicales, de personalidad, hábitos y estrategias individuales). Ver que busca dónde aplicarlo y ser capaz de exponerlo y compartirlo con sus compañeros nos sirve para darnos cuenta de que el ámbito en el que lo aplica ya deja de ser algo inalcanzable para convertirse en algo posible, pues ya tenemos hasta estrategias individuales para conseguirlo. Así, podríamos pasar del no puedo al “todavía” no me sale del que habla Dweck (1999).

O’Neill y Sloboda (1997), en su estudio con niños, concluían que la práctica efectiva y eficiente la conseguían los niños que tenían la mentalidad en crecimiento y que los que no tenían este tipo de mentalidad, necesitaban hacer el doble de práctica para conseguir los mismos resultados. Si conseguimos que los alumnos de la enseñanza superior utilicen esas estrategias personales que llevan a cabo en los ámbitos donde manifiestan mentalidad en crecimiento (y que les ayudan a hacer la tarea de forma más efectiva y eficiente) en los 
ámbitos en los que tenían mentalidad fija, pueden dejar de tener mentalidad fija en ese ámbito para transformarla en mentalidad en crecimiento. 


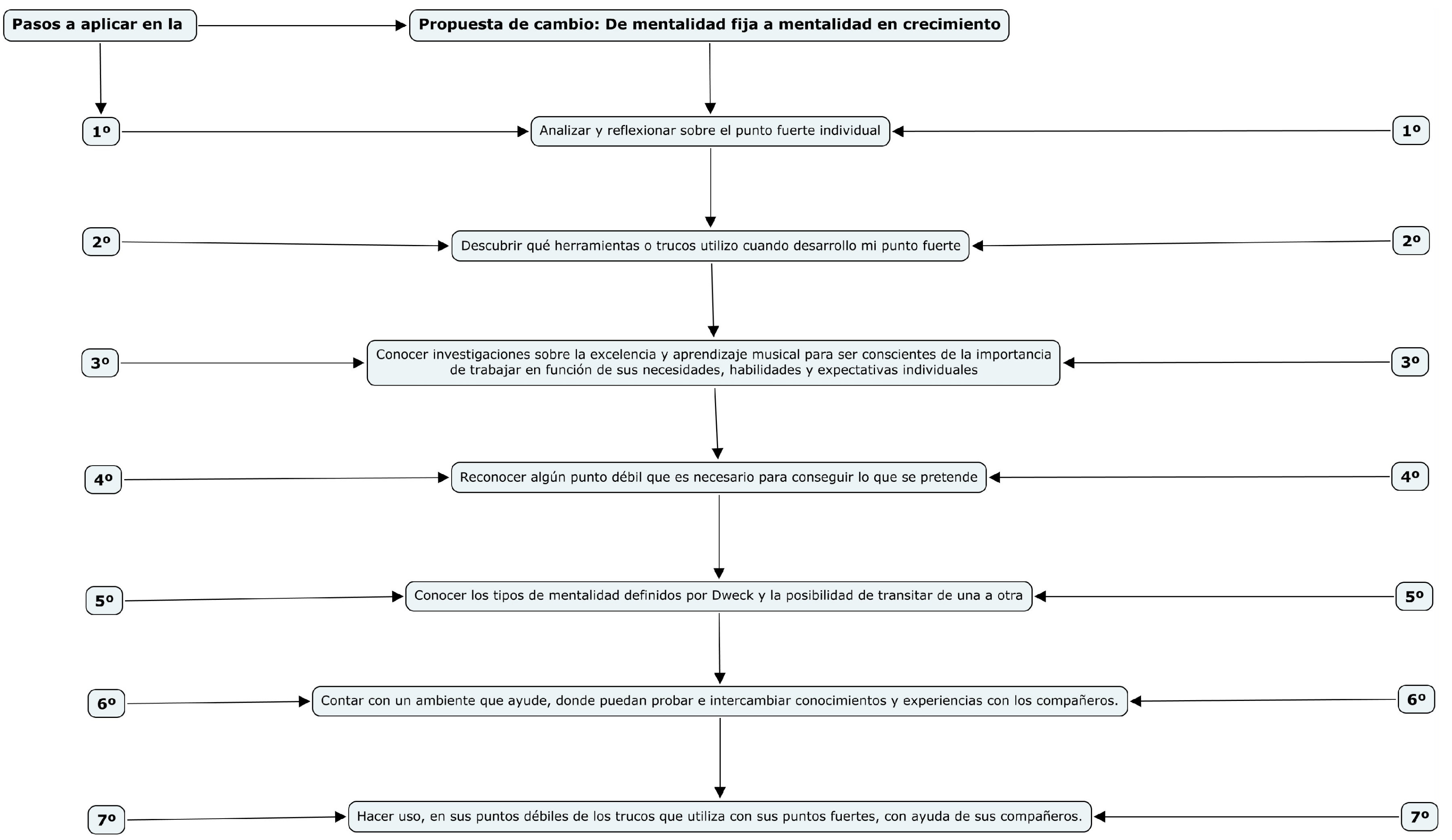

Ilustración 5. Propuesta para pasar de mentalidad fija a mentalidad en crecimiento. Elaboración propia. 


\subsubsection{El músico convencido y apoyado}

Se ha visto que el desarrollo de la excelencia musical es un proceso que tiene distintas etapas y que cada etapa tiene unas necesidades muy exigentes en cuanto al desarrollo de habilidades, organización de la práctica y desarrollo personal y que este proceso necesita muchos recursos personales e institucionales para llegar a buen término.

Para utilizar estos recursos de forma apropiada se ha visto que los músicos utilizan métodos de práctica muy individuales y ninguno de ellos muestra correspondencia con el éxito (Hallam, 1995). Del mismo modo, se puede decir que las habilidades metacognitivas de los músicos expertos y la forma de regular y estructurar su práctica, así como la forma de refinar su técnica o preparase para un concierto son muy diferentes (Hallam, 2000). En este sentido es importante señalar también que la autorregulación a través de los recursos personales parece ser el aspecto más relevante de la autorregulación para la práctica eficiente entre los músicos avanzados. (Araújo, 2015). Teniendo en cuenta estas investigaciones, se puede llegar a la conclusión de que para poder hacer uso de los recursos personales que cada uno ha desarrollado es necesario tener un buen conocimiento de sí mismo y una alta autoestima, características que también se ha visto que repercuten profundamente en el desarrollo de los objetivos personales de los músicos expertos (Hallam, 1998).

Otra idea a resaltar y en la que también se insiste en las últimas investigaciones (Dobson y Gaunt, 2015) es la de que los conservatorios deberían trabajar las habilidades sociales e interpersonales, habilidades que consideran vitales para lograr la excelencia. Afirman que esta excelencia en una orquesta sólo es posible si sus integrantes están dispuestos a escuchar, comunicar y adaptarse a los demás, tanto en los ensayos como en los conciertos, e insisten en que habría que seguir investigando cómo los intérpretes profesionales han adquirido estas habilidades.

Si tenemos en cuenta todo lo anterior, podemos darnos cuenta que al buscar la excelencia se está buscando un músico convencido de lo que hace, pues es él quien debe explorar sus recursos personales (que se ha demostrado son los más efectivos para él) y además debe saber relacionarse con los demás, para lo cual debe sentirse apoyado por sus compañeros, profesores y demás estructuras sociales que le rodean. Volveríamos 
aquí al punto de partida de nuestro modelo de excelencia donde nos apoyábamos en tres ideas fundamentales:

1. Toda búsqueda de la excelencia debe estar apoyada en el saber existente. El conocimiento de lo que se ha estudiado sobre la excelencia musical puede ayudar a entender mejor qué se está buscando cuando se estudia o se enseña música, qué puede ayudar a conseguirlo y sobre todo a eliminar malas prácticas que pueden llevar incluso a conseguir el efecto contrario de lo que se persigue. De hecho el conocimiento por parte de nuestros alumnos de algunas de las investigaciones les ha ayudado a reflexionar sobre lo que están haciendo y a plantearse cómo pueden mejorarlo.

2. La idea o producto que merece la etiqueta de "excelente" surge de la sinergia de muchos recursos y no sólo de la mente de una única persona. Es evidente que el desarrollo de un músico excelente es una tarea compleja que normalmente cuenta con muchos recursos. Es conocida la importancia del entorno en todo el proceso de su desarrollo, la influencia social, el rol de los profesores (que también deben ser excelentes), compañeros y familia pero también las instituciones, (que son las que proporcionan los profesores y compañeros) además de las expectativas y objetivos que se generan en el mismo músico (un factor muy determinante para conseguir la excelencia dependen de ese entorno). En nuestros alumnos en la enseñanza superior surge el problema económico cuando se plantean estudios más especializados y el sistema de becas no está equiparado con el nivel de excelencia que se pretende conseguir. Como ejemplo concreto en esto podemos decir que muchos alumnos de nuestro conservatorio ni se plantean irse como alumnos de Erasmus (como ya se ha comentado), porque la beca no cubre los gastos e incluso las clases de master de algunos profesores de primera línea que se ofertan en nuestro conservatorio no son gratuitas (como debería ser en una enseñanza pública) sino que se deben de pagar aparte. Por eso, podemos decir que en la búsqueda de excelencia siempre se tendría que tener en cuenta que el apoyo institucional es necesario para que esa excelencia no llegue sólo a unos pocos y que las expectativas puedan ser iguales para todos, premiando su habilidad y esfuerzo. 
3. Para conseguir la excelencia es necesario crear un ambiente que proporcione libertad de acción y estimulación de ideas, junto con una actitud de respeto y apoyo entre todos los miembros de la comunidad educativa.

Está claro que la profesión de músico es más diversa que en épocas pasadas, que hay muchos tipos de músico excelente con perfiles muy distintos y que es necesario (apoyados en el conocimiento y en el esfuerzo) buscar formas individuales de hacer las cosas, respetando a los demás y buscando el complemento en los demás reconociendo puntos fuertes y débiles de todos y tratando de crear un ambiente donde poder desarrollarse sin presiones y sin tener que perder para ello las propias señas de identidad. En esta línea hay también mucho que trabajar pues, como se muestra a lo largo de nuestro trabajo los alumnos echan de menos ese desarrollo individual orientado del que hablaba Sloboda (1987) que debería ser tan importante como el desarrollo del currículo orientado y de las técnicas orientadas y que en muchas ocasiones parece que no se puede realizar dentro de la enseñanza superior del conservatorio y que hay que esperar a terminar los estudios superiores para poder hacer ese desarrollo individual tan necesario para toda persona.

Csikszentmihalyi define la creatividad como el resultado de la interacción de un sistema compuesto por tres elementos: una cultura que contiene reglas simbólicas, una persona que aporta novedad al campo simbólico y un grupo de expertos que reconocen y validan la innovación. Las tres condiciones son necesarias para que una idea creativa, un producto o un descubrimiento tenga lugar. $(1996,6)$. A nuestro modo de ver, la excelencia musical se podría incluir en el mismo esquema como una aplicación de lo que el autor propone, pues es necesaria la cultura que contiene las normas simbólicas, la persona que aporta su interpretación, composición o aportación al campo musical y un grupo de expertos que reconocen y validan la persona como buen intérprete, compositor o autor en el campo musical. Csikszentmihalyi resalta la necesidad de estudiar la creatividad, no como un hecho puramente individual, sino como algo que puede producirse cuando interactúan los pensamientos y obras de una persona con el contexto sociocultural que le inspira. Esto mismo es lo que mantenemos en el caso de la excelencia musical. Csikszentmihalyi habla además de tres factores importantes que se ponen en juego en toda creación: el campo, el talento individual y el ámbito. 
El campo es la disciplina, el área del saber donde se produce una obra determinada, que tiene que ver con la cultura y que contiene unas reglas simbólicas que deben ser aprendidas. En nuestro caso, este campo del saber se encuentra en el terreno de la música. El talento individual se refiere a las capacidades creativas individuales de cada uno. Y finalmente, el ámbito es definido como el conjunto de "expertos" que validan la novedad que introduce esa idea o esa creación dentro del campo. Es decir, los que deciden si algo es verdaderamente novedoso o no en ese campo. Así pues, para Csikszentmihalyi se puede hablar de creatividad cuando alguien, a partir de su talento individual, hace una aportación en un campo determinado y esta aportación es reconocida por el ámbito. En este sentido, nosotros podríamos definir a alguien como excelente en el campo musical cuando a partir de su talento individual hace una aportación al campo de la música y esta aportación es reconocida por el ámbito.

En esta aplicación se podría ver claramente la idea del músico convencido y apoyado, un músico que domina el campo, que conoce la música y cómo utilizarla, que aporta sus habilidades o características desarrolladas, podríamos decir su "talento desarrollado", y es reconocido como músico excelente por el ámbito. Para lograr este reconocimiento fundamentalmente tiene que convencer durante toda su carrera y tiene que estar apoyado durante toda su carrera. Vamos a ver esto con más detenimiento:

En los primeros años, el músico tiene que convencer de que sirve para la música, de su habilidad para que le sea ofrecida la oportunidad de aprender música. Aunque supuestamente la enseñanza de la música en España se oferta en la enseñanza general, en realidad no se le dedica apenas tiempo y si alguien quiere poder seguir estudios musicales tiene que acudir al menos a una escuela de música o a la enseñanza privada. Por ello, como hemos visto, en este primer estadio de desarrollo musical tiene que convencer a su familia para que le apunte y mantenga en estos estudios y tiene que ser apoyado por su familia, profesor y amigos. Como apunta Hallam, en el mundo Occidental el acceso a la enseñanza se ha limitado frecuentemente a aquellos que podían permitirse pagar por las clases. Las oportunidades para aprender gratis han sido relativamente pocas (2012:652).

En un segundo estadio de desarrollo el mismo músico tiene que tener capacidad de convencer todavía más, pues tiene que demostrar que es capaz de mantener su hábito de 
estudio, que sus habilidades van mejorando y que es bueno no sólo en música sino en todo lo demás, ya que socialmente la música se considera como un estudio simultáneo a otros pero no principal, y por tanto será muy difícil para un músico de estas edades convencer de que quiere ser músico y dedicarse a este ámbito de forma tan metódica como sería necesario para alcanzar la excelencia si no va bien en lo demás (como se ha visto, esto es difícil incluso para los músicos de enseñanza superior que se topan con el rechazo y la incomprensión incluso de familiares y amigos). Y por supuesto vuelve a necesitar el apoyo tanto económico como de cualquier otro tipo (personal, emocional, etc.) de buenos profesores y familiares que le animen y le enseñen a disfrutar con la música y con el esfuerzo que supone.

En la enseñanza superior ya hemos visto que volvemos a necesitar al músico convencido, seguro de que es eso lo que quiere estudiar, con capacidad para elegir y con la autoestima necesaria para seguir esforzándose y disfrutar con ella y además con la valentía de arriesgarse a ser "rechazado" socialmente por su elección. Y, al mismo tiempo, necesita ser apoyado por su familia y sería deseable también por el estado, en su papel de dispensador de becas que le ayuden a seguir formándose en función de su capacidad y esfuerzo.

Y, por supuesto, para ser un músico excelente va a necesitar seguir convenciendo toda la vida, manteniendo su nivel y su capacidad de convencer con lo que hace y seguirá necesitando el apoyo del público y de su círculo de confianza que le haga seguir creyendo en lo que hace. 


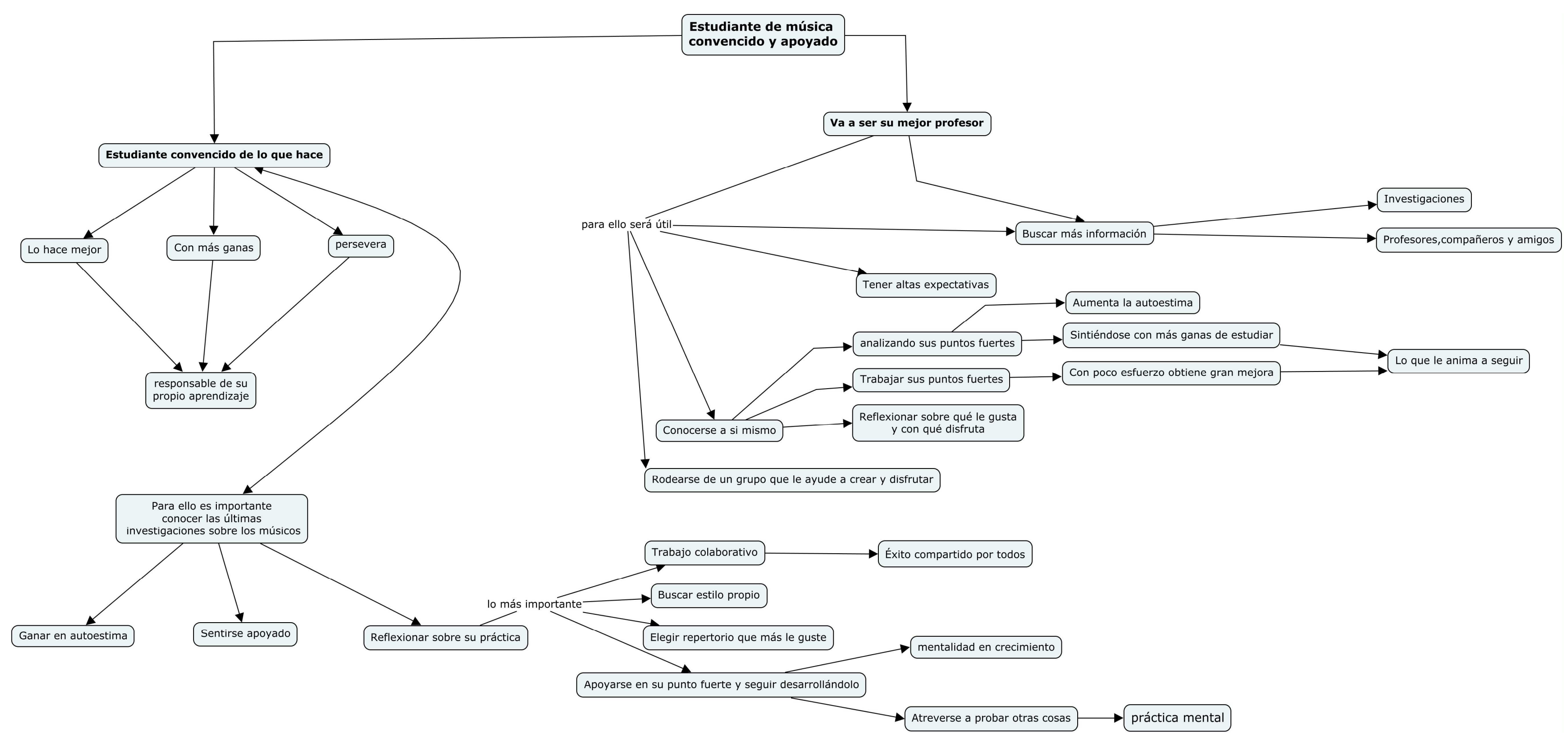

Ilustración 6. El estudiante de música convencido y apoyado. Elaboración propia 



\section{HERRAMIENTAS ÚTILES PARA TENER ÉXITO COMO MÚSICO PROFESIONAL}

Como dijimos en la introducción, el principal objetivo de esta tesis es comprobar que el conocimiento de las investigaciones en su campo es una herramienta de gran utilidad para el alumnado de la enseñanza superior de música, dado que estar al tanto de lo que dicen aquéllas les puede otorgar seguridad, confianza y una mayor proyección en su futura carrera (desde el instrumentista hasta el profesor, pasando por cualquier otra de las posibilidades profesionales que se ofrecen a nuestros alumnos). Contar con estudios contrastados que avalen todo el proceso que están siguiendo permite que su trabajo diario les sea más grato y fecundo, impulsándoles así a continuar un proceso de aprendizaje que, a nadie se le escapa, es duro y lleno de dificultades.

De este modo, nuestra primera tarea consistía en presentar precisamente el núcleo de esas investigaciones, para que el alumnado pudiera tener conocimiento de ellas y así poderlas llevar a la práctica en su trabajo diario y, consecuentemente, estudiar el impacto que producía en su desarrollo educativo. Sin embargo, el espectro que el campo de la investigación nos ofrece es tan amplio que, inevitablemente, se impone la tarea de seleccionar aquéllas que produzcan un mayor impacto en el proceso de enseñanza-aprendizaje. Como suele suceder en estos casos, es el propio desarrollo de la investigación el que nos acabó decantando y seleccionando por sí mismo cuáles son las más interesantes y más útiles.

Dicho de otra manera, a medida que nuestra investigación avanzaba nos dimos cuenta de que nos ocurría exactamente lo que sugiere la investigación cualitativa, es decir, que al profundizar en el tema e ir analizando los datos, se van introduciendo temas, interpretaciones y propuestas se empiezan a descubrir otras vías interesantes de trabajo que nos llaman la atención y la focalizan de manera clara (McMillan y Schumacher, 2007:414). Y esto es así porque a medida que se llevaba a cabo el trabajo con los alumnos, y dado que se trataba de un trabajo interactivo, ellos mismos fueron comprobando la utilidad práctica (casi inmediata) de algunas propuestas y esto obligaba casi de manera inevitable a que dedicáramos más esfuerzo 
a profundizar en esos temas y, consecuentemente, a relegar otras líneas de investigación que no eran consideradas de tanta utilidad (o al menos no de tanta utilidad inmediata para los alumnos con los que estábamos trabajando).

Como decimos, el trabajo con los grupos de discusión fue el que nos permitió, gracias a su dinamismo, ir seleccionando y profundizando en aquellos temas que los propios alumnos comprobaban empíricamente que eran los más fecundos. Es obvio que esta apreciación se refiere de manera clara al presente estudio, pero los resultados cosechados nos permiten intuir que es más que posible que sean de aplicación más general, razón por la que animamos a que se siga esta vía de trabajo en otros conservatorios superiores de música.

Los grupos de discusión, tal como venimos comentando, fueron los que, de algún modo, nos mostraron el camino a seguir. Así, nos dimos cuenta muy pronto de que el conocimiento de las investigaciones de Dweck (2006) sobre mentalidad fija y mentalidad en crecimiento eran fundamentales para el alumnado, puesto que ellos mismos descubrían cómo ser conscientes de esa realidad les permitía conseguir mejores logros en su trabajo e incluso más aún, utilizando sus recursos individuales, ser capaces de modificar su mentalidad fija por mentalidad en crecimiento para crecer como músicos excelentes ayudados por el grupo y así integrábamos el aprendizaje colaborativo (tal y como tendremos ocasión de comprobar en las páginas que siguen). A esta propuesta de Dweck se sumaron las investigaciones realizadas en torno al aprendizaje colaborativo y el empleo de la práctica mental (esta última, una propuesta de rabiosa actualidad, apoyada en las investigaciones en el campo de la neurología), técnicas ambas muy poco o nada utilizadas en la enseñanza superior y que tan estupendos resultados puede dar si se aplica de manera habitual. Ambas investigaciones y las prácticas realizadas con los alumnos en los grupos de discusión nos han hecho reflexionar sobre qué podía ayudar a los alumnos a conseguir la excelencia musical y llegamos a la intuición de que un apartado al que no se da demasiada importancia en la enseñanza superior es el desarrollo y trabajo del "punto fuerte de cada músico" pues hay tantas cosas que aprender en la música y tantos puntos débiles que trabajar y es tan fácil y estamos tan acostumbrados a señalar los errores y corregir los fallos que otra herramienta que hemos considerado fundamental resaltar y que ha sido de gran utilidad para los alumnos implicados en nuestro trabajo ha sido el hecho de profundizar en la importancia que tiene "el punto fuerte" de cada músico, dado que el desarrollo de éste es lo que puede llevarlo a la excelencia. 
Por decirlo de otra manera, es muy difícil destacar en algo que se nos da mal (el "punto débil") y es siempre difícil trabajar sobre estas debilidades, sobre todo, porque no es nada motivador un trabajo en el que no se pueden alcanzar resultados de manera rápida. Por eso es tan importante el ser consciente del "punto fuerte", la habilidad que lo hace original, diferente $\mathrm{y}$, por lo tanto, no competitivo, dado que cada uno tiene su propio "punto fuerte", algo en lo que puede ser el mejor, sin perjuicio de que pueda colaborar con los demás para que cada uno desarrolle el suyo propio y consiga una excelencia particular que le haga original. O incluso por eso mismo que acabamos de comentar (y que iría en la línea del aprendizaje colaborativo). Por eso insistimos en lo valioso de ser consciente del "punto fuerte", profundizando en la importancia que tiene conocerlo, valorarlo y desarrollarlo, de cara a conseguir la excelencia, sin dejarlo nunca de lado porque en eso ya somos bastante buenos, es decir, estamos en el camino de la excelencia. En efecto, es gracias a ese "punto fuerte" por lo que podemos ser excelentes, pues es el que nos mantiene en la convicción (nos hace estar convencidos y convencer) de que merece la pena el esfuerzo y de que conseguiremos resultados muy valiosos. Y esto, precisamente, por el hecho objetivo (que se desprende sin duda alguna de nuestra investigación, como veremos al hacer el análisis de las encuestas realizadas) de que los alumnos de música son muy conscientes de cuáles son sus puntos débiles, que son los que de manera constante se trabajan, se estudian y a los que se dedica más tiempo, lo que de manera habitual suele conducir a situaciones de frustración, debido a que, con mucho esfuerzo, se conseguían pocos resultados (precisamente por eso hablamos de que son "puntos débiles"), al tiempo que dejaban a un lado (o lo trabajaban sólo de manera secundaria) lo que consideraban sus puntos fuertes, que es precisamente lo que podría conducirles a la excelencia. No en vano son precisamente los puntos fuertes, es decir, aquello que mejor se les da, aquello en lo que destacan: un aspecto de su práctica musical en el que, con poco esfuerzo, se consiguen grandes avances. Estas ideas nos conducen también a la propuesta de aprendizaje complejo, que parte de otra idea fraguada en la reflexión y el trabajo en los grupos de discusión: la de que el estudiante de música debe ser consciente de que en muchas ocasiones va a ser su mejor profesor, ya que es quien mejor se conoce y el que va a tener más cerca y de ahí nuestra propuesta de "aprendizaje complejo", donde se expone cómo se puede mejorar para ayudarse a sí mismo toda la vida. 


\subsection{La creatividad}

"La música es una de las actividades más creativas y complejas del ser humano y parece que implica numerosas regiones y circuitos del cerebro". (Newton, 2015:3). Los músicos parece que tienen como herramienta necesaria la creatividad en todas sus actividades. Y, como ya se ha tratado en el primer capítulo al hablar de las inteligencias necesarias para el siglo XXI, la inteligencia creadora es considerada una de las cinco inteligencias que más trascendencia tendrán en el futuro (Gardner, 2005).

Autores como Christine Charyton (2015) opinan que los estudiantes necesitan pensar creativamente para encontrar empleo, seguir mejorando en sus carreras y desarrollar su propio éxito personal y económico. Insiste en que la creatividad es una necesidad vital que todavía se tiende a subestimar, especialmente en ciencia y aún más en la integración de ciencia y arte. $\mathrm{Si}$, como ya hemos señalado, la música es una de las actividades más creativas en la que se implica el cerebro humano, parece lógico pensar que entender mejor la creatividad puede ayudarnos a mejorar como músicos.

\subsubsection{La creatividad como herramienta para desarrollar la implicación en la tarea}

Mihaly Csikszentmihalyi (1996:2) entiende la creatividad como la principal fuente de significado de nuestras vidas por varias razones, aunque selecciona dos como las más importantes: la primera es que los humanos compartimos el $98 \%$ de nuestro mapa genético con los chimpancés y explica que lo que nos diferencia de ellos es el lenguaje, los valores, las expresiones artísticas y los conocimientos científicos y tecnológicos, y señala que la creatividad es el resultado del ingenio individual que ha sido reconocido, recompensado y transmitido a través del aprendizaje, señalando que sin creatividad sería difícil distinguir los humanos de los simios.

La segunda razón que presenta Csikszentmihalyi es que la creatividad es algo tan fascinante que cuando estamos involucrados o inmersos en ella sentimos que estamos viviendo más plenamente que durante el resto de nuestra vida, proporcionándonos un profundo sentido de ser parte de una entidad más grande que nosotros. Además la creatividad también produce un resultado que añadir a la riqueza y complejidad del futuro. 
Teniendo esto en cuenta, habrá que decir que la creatividad puede ser una herramienta muy útil para desarrollar esa motivación intrínseca que ayude a insistir en la práctica de lo que queremos aprender. Este sería el paso previo para poder crear en ese campo, así como una gran ayuda para el desarrollo de la mente disciplinada de la que hablaba Gardner (2005). Esto es así porque cuando algo nos gusta vamos a querer repetirlo y no nos vamos a conformar con un conocimiento superficial en el que esté implicada la creatividad, sino que vamos a buscar esa sensación de plenitud que nos ayudará a seguir siendo creativos.

\subsubsection{Definición de creatividad}

Csikszentmihalyi define la creatividad como el resultado de la interacción de un sistema compuesto por tres elementos: una cultura que contiene reglas simbólicas, una persona que aporta novedad al campo simbólico y un grupo de expertos que reconocen y validan la innovación. Las tres condiciones son necesarias para que una idea creativa, un producto o un descubrimiento tengan lugar. (1996:6). El autor resalta la necesidad de estudiar la creatividad no como un hecho puramente individual, sino como algo que puede producirse cuando interactúan los pensamientos y obras de una persona con el contexto sociocultural que le inspira. Csikszentmihalyi habla de tres factores importantes que se ponen en juego en toda creación: El campo, el talento individual y el ámbito.

En el capítulo anterior definíamos ya lo que eran estos conceptos. Baste recordar que el campo hace referencia al área del saber del que nos ocupamos, el talento se define como las capacidades creativas de cada individuo y el ámbito como el entorno social (representado por los “expertos") que dan valor y reconocen las novedades que se aportan.

\subsubsection{El trabajo de la creatividad}

Csikszentimihályi explica que el proceso creativo ha sido descrito tradicionalmente en cinco pasos. El primero es un periodo de preparación, a través del cual uno puede llegar a estar inmerso, conscientemente o no, en una serie de tareas problemáticas que son interesantes y despiertan la curiosidad. La segunda fase de este proceso creativo es un periodo de incubación, durante el cual las ideas dan vueltas alrededor del umbral de la consciencia. Es en este momento cuando las conexiones inusuales pueden producirse. Al intentar solucionar un problema de forma consciente, se procesa la información de una forma lineal y lógica, pero cuando las ideas aparecen sin que sean dirigidas por nosotros, cuando no tienen un camino 
marcado y estrecho, pueden aparecer combinaciones inesperadas. El tercer componente del proceso creativo es el "insight", también llamado el momento "Aha” (que en español debería ser el momento “Ajá”), cuyo ejemplo más famoso es el instante en que Arquímedes gritó "Eureka". El cuarto componente es la evaluación, es decir, el momento en el que la persona debe decidir si el "insight" es una idea valiosa y merece la pena seguir trabajando en ella. Éste es a menudo el momento más emocionante del proceso, el momento en el que uno se siente más indeciso e inseguro. Es también el momento en el que el control de las reglas del campo y la propia visión del mismo entran en juego de manera importante. ¿Es esta idea realmente nueva?, ¿qué pensaran mis colegas de esto? En definitiva es el periodo de la autocrítica y del examen de conciencia. Por último, el quinto componente del proceso es la elaboración. Éste es probablemente el componente que ocupa más tiempo y supone el trabajo más duro. Precisamente a esto se refería Edison cuando dijo que la creatividad consiste en un uno por ciento de inspiración y un noventa y nueve por ciento de transpiración.

El proceso creativo es menos lineal que recurrente. Cuántas repeticiones tienen lugar, cuántas vueltas se supone que hay que dar, cuántas pistas son necesarias, dependiendo de la profundidad y amplitud de la tarea con la que tratemos. A veces la incubación de la idea dura años, otras veces tiene lugar en pocas horas. A veces la idea creativa incluye un "insight" grande y muchas otros pequeños. En algunos casos, como en la teoría de la evolución de Darwin, el conocimiento fundamental aparece lentamente, en flases separados y desconectados y lleva años unirlos en una idea coherente. (Csikszentmihalyi, 1996:79-82)

\subsubsection{La experiencia de flujo}

Esta experiencia óptima es la que Csikszentmihalyi definió como flujo ("flow") porque muchas de las personas creativas a las que entrevistó describieron la sensación que tenían de cuando las cosas iban bien, casi de forma automática, sin esfuerzo, en un estado de conciencia muy concentrado. Prácticamente todos los entrevistados la describían en los mismos términos sin importar la actividad a la que se dedicaban. Y la descripción tampoco variaba mucho en función de la cultura, el género o la edad; viejos y jóvenes, ricos y pobres, hombres y mujeres, americanos y japoneses parecían experimentar el placer de la misma forma, incluso cuando hacían cosas muy diferentes para conseguirlo. 
Nueve elementos principales fueron mencionados una y otra vez al describir cómo se siente alguien cuando siente esta experiencia:

1. Están claras las metas en cada paso del camino. En contraste con lo que pasa en la vida diaria, en el trabajo o en casa, donde a menudo las necesidades son contradictorias y nuestros propósitos inseguros, en estado de flujo se tiene la seguridad de lo que es necesario hacer. El músico sabe qué nota tocar después, el alpinista cuál es su próximo movimiento, el cirujano se da cuenta de qué incisión debe hacer en cada momento, etc.

2. Hay una respuesta inmediata (o feedback) de cada una de las acciones. De nuevo en contraste con la vida diaria, en una experiencia de flujo se es consciente de lo bien que se está haciendo. El músico escucha correctamente la nota que ha tocado, el alpinista encuentra inmediatamente que su movimiento era correcto, etc.

3. Hay un equilibrio entre los retos y las habilidades. En flujo, sentimos que las habilidades que cada uno tiene están perfectamente conectadas con las tareas a realizar. En la vida diaria se puede sentir a menudo que el reto es demasiado alto en relación con las habilidades que se poseen, lo que da lugar a sentimientos de frustración y ansiedad. $\mathrm{O}$, al contrario, uno siente que el potencial que se posee es más grande que las oportunidades para desarrollarlo, de modo que lo que se produce es aburrimiento. Jugar al tenis o al ajedrez contra un oponente mucho mejor lleva a la frustración; hacerlo con uno mucho peor lleva al aburrimiento. En un juego realmente placentero, los jugadores están en equilibrio en la fina línea entre el aburrimiento y la ansiedad.

4. Acción y conciencia están mezclados. Es típico en la experiencia diaria que nuestras mentes estén separadas de lo que estamos haciendo. Sentados en clase, los estudiantes pueden aparentar que están prestando atención al profesor, pero lo que están pensando en realidad es en la comida o en la cita de la noche anterior. El trabajador piensa en el fin de semana y la madre está limpiando la casa preocupada por su hijo, la mente del jugador de golf está preocupada por si su swing les gustará a sus amigos. En flujo, sin embargo, nuestra concentración se centra en lo que hacemos. La concentración de la mente en un solo punto es requerida por la cercana combinación entre el reto y la habilidad, lo que hace posible la claridad de metas y la constante disponibilidad de la respuesta. 
5. Las distracciones están excluidas de la consciencia. Otro elemento típico del flujo es que sólo se es consciente de lo relevante en ese momento, en el aquí y ahora. Si el músico piensa en su salud o en problemas de impuestos cuando toca, es más fácil que falle una nota. Si la mente del cirujano está en otras cosas en una operación, la vida del paciente está en peligro. El flujo es el resultado de una concentración intensa en el presente, la cual nos alivia del miedo habitual que causa depresión y ansiedad en la vida diaria.

6. No hay miedo al fracaso. Mientras estamos en flujo, estamos demasiado implicados para preocuparnos por el miedo. Algunas personas lo describen como un sentimiento de control total, aunque en realidad no sea cierto, es sólo que este problema ni siquiera aparece. Si lo hiciéramos, no podríamos estar totalmente concentrados, porque nuestra atención podría estar dividida entre lo que hacemos y el sentimiento de control. La razón por la que el fracaso no aparece es que en flujo es claro lo que hay que hacer y nuestras habilidades son potencialmente adecuadas a los retos.

7. La autoconsciencia desaparece. En nuestra vida diaria, estamos siempre monitorizando cómo nos mostramos a los demás, estamos alerta para defendernos de los desprecios potenciales y ansiosos por crear una impresión favorable. Normalmente esta conciencia de nosotros mismos es una carga. En flujo, estamos tan implicados en lo que estamos haciendo que no nos preocupamos de proteger el ego. Cuando un episodio de flujo ha terminado, normalmente aparece un fuerte concepto de sí mismo; sabemos que hemos tenido éxito al encontrarnos con un reto difícil. Podemos incluso sentir que nos hemos salido de los márgenes del ego y se ha llegado a formar parte de una larga entidad más grande, al menos temporalmente.

8. El sentido del tiempo se distorsiona. Generalmente, en flujo olvidamos el tiempo, y las horas pueden pasar en lo que parece unos pocos minutos. O también ocurre lo contrario: un patinador artístico cuenta que una vuelta rápida que en tiempo sólo dura un segundo parece que dura diez veces más. En otras palabras, el tiempo del reloj no marca igual que el periodo de tiempo experimentado. Nuestra sensación de cuánto tiempo pasa depende, por lo tanto, de lo que estamos haciendo.

9. La actividad llega a ser autotélica. Siempre que estas condiciones estén presentes, empezamos a disfrutar sea lo que sea lo que produce tal experiencia. Puede que tenga miedo de usar un ordenador y aprenda a hacerlo sólo porque mi trabajo dependa de ello. 
Pero si mi habilidad mejora y reconozco lo que el ordenador me permite hacer, puedo empezar a disfrutar también de usarlo sólo por el placer que produce en sí mismo. En este momento la actividad llega a ser autotélica, es decir, que tiene un fin en sí misma. Algunas actividades como el arte, la música y los deportes son normalmente autotélicas. No hay ninguna razón para hacerlas excepto para sentir la experiencia que provocan. Muchas cosas en la vida son exotélicas, las hacemos no porque nos diviertan sino como puente para conseguir otros objetivos. Y algunas actividades se incluyen en ambos grupos: el violinista es pagado por tocar y el cirujano consigue estatus y dinero por operar, así como disfrutan de hacer lo que hacen. En muchos sentidos, el secreto de una vida feliz es aprender a conseguir el estado de flujo en tantas cosas de las que tenemos que hacer como sea posible. Si el trabajo y la vida familiar llegan a ser autotélicas, entonces no hay nada malgastado en nuestra vida y todo lo que hacemos merece la pena por sí mismo.

Investigaciones más recientes (O'Neill, 1999; Baker, 2005; Garces-Bascal, 2013; Marin y Battacharya, 2013) confirman estos nueve puntos descritos por Csikszentmihalyi sobre la experiencia de flujo. De hecho inciden en la importancia que dan los estudiantes a sus profesores a la hora de sentir la experiencia de flujo, pues dicen que son éstos los que les sirven de inspiración, ya que también ellos mismos son artistas en activo, que les trasmiten no sólo el conocimiento técnico sino que también hacen mucho énfasis en el proceso creativo y no sólo en el producto. También reconocen como fundamental el acercamiento individual, de modo que proporcione respuestas a los progresos del alumno, además de animarles constantemente y apoyarles cada vez que tengan que enfrentarse con las dificultades de su arte. Csikzentmihaly insiste en que los profesores que se recuerdan como importantes son quienes transcienden el rol institucional en favor de una enseñanza más personal. Y esto, podemos añadir, debería de ser una condición indispensable si lo que se busca es un resultado excelente.

Las implicaciones que estas investigaciones (Garces-Bascal, 2013) tienen a nivel pedagógico son las siguientes: 1. La importancia de tener una conexión personal con los estudiantes que les ayude a comprometerse con su formación. 2. La importancia de una respuesta inmediata a su progreso en sus respectivos campos. 3. La inspiración que se deriva de ver a sus profesores 
actuando o al menos teniendo un conocimiento de primera mano de lo que quiere decir estar en un área determinada y 4. El sentido de pertenecer a una comunidad que se alimenta en el centro que permite a cada uno expresar su sensibilidad artística.

Hemos llevado esta formulación teórica al conservatorio Superior en el que trabajamos, y al preguntar a los alumnos si habían experimentado la sensación de flujo, la unanimidad fue la tónica. Las únicas diferencias estriban en el lugar donde la han experimentado. Así, unos decían haberla sentido sólo en los ensayos, mientras que otros la habían tenido también en conciertos. A este respecto es muy ilustrativa la anécdota de una violinista que tocaba con un grupo de cámara en una audición. En un momento dado, se concentró tanto en su propia tarea, que se olvidó del resto de compañeros que tocaban con ella, llegando al extremo de inventarse una parte, porque no recordaba lo que tenía que tocar. Sorprendentemente, no se sintió mal, sino que siguió tocando porque "sabía lo que tenía que hacer", de modo que continuó como si estuviera interpretando ella sola. Para completar la historia tenemos el testimonio de una de sus compañeras en aquella audición. Esta explicaba que todo el grupo se dio cuenta de lo que estaba pasando, de modo que intentaron seguirla como buenamente pudieron, hasta que volvió a engancharse con la parte que estaba escrita, de modo que pudieron seguir hasta el final como si nada hubiera pasado. En palabras textuales:

Fue alucinante ver cómo pasaba de nosotros, prácticamente como si no estuviéramos allí, y estaba tan tranquila... No sé cómo llegamos al final, no sabemos lo que hicimos. Es una pena que no se estuviera grabando.

\subsubsection{El conservatorio superior como espacio creativo}

Decíamos anteriormente, citando a Newton (2015), que la música es una de las actividades más creativas en las que se implica el cerebro humano. Hemos visto también que a los estudiantes se les pide ser creativos para poder aprender de forma más exitosa (Stenberg, 1996; Hallam y Gaunt, 2012; Stoeger, 2013). Y los mejores profesores en las enseñanzas superiores utilizan igualmente la creatividad como una de sus mejores herramientas (Bain, 2004; Knight, 2005). Siendo esto así, nos parece que el Conservatorio Superior, un entorno donde queremos desarrollar la excelencia musical y donde pretendemos preparar a músicos del siglo XXI, debería ser uno de los espacios creativos que reclama Csikszentmihalyi como necesarios para la consecución de obras creativas. Este autor explica que la idea o producto que merece la etiqueta de "creativo" surge de la sinergia de muchos recursos y no sólo de la 
mente de una única persona. Así, demuestra que es más fácil aumentar la creatividad cambiando las condiciones del entorno que intentando hacer que la gente piense más creativamente. $\mathrm{Y}$ añade que un logro creativo no es casi nunca el resultado de una visión repentina, un flash que se enciende en la oscuridad, sino que llega después de años de duro trabajo. (1996:1). Teniendo esto en cuenta, deberíamos preguntarnos cómo se puede convertir el Conservatorio Superior de Música en un espacio creativo, cuyas estructuras faciliten la creatividad y favorezcan su desarrollo.

Lo que estamos comentando tiene relación directa con lo que comentaremos posteriormente y que avala el propio Csikszentmihalyi: los ambientes exitosos son los ambientes que proporcionan libertad de acción y estimulación de ideas, todo unido a una actitud de respeto y apoyo hacia los genios potenciales, que curiosamente suelen ser los de autoestima más frágil (1996:140). Es importante conocer que esta parte también es necesaria para el desarrollo creativo, en el sentido de que se debe buscar la forma de "humanizar" los espacios y las estructuras, algo mucho más necesario que otros recursos a los que solemos dedicar más esfuerzos.

Como asegura Sternberg, es evidente que cada país tiene ideas distintas sobre lo que constituye el pensamiento creativo. (Kaufman y Sternberg, 2006:1). Esto lleva a pensar, lógicamente, que el fomento de la creatividad será distinto en los distintos países y se hará, por tanto, de manera diferente en los distintos espacios creativos que se propicien. Las preguntas que surgen son muchas, como por ejemplo: ¿qué se puede aprender de las distintas formas de llevarlo a cabo en cada país? ¿Es trasladable lo que se hace en un sitio a otro? Y la que parece que podría ayudar más (o al menos facilitar la tarea de búsqueda) ¿qué puntos de acuerdo se pueden encontrar en las investigaciones realizadas en distintas partes del mundo sobre la creatividad?

Sternberg da un poco de luz a la tercera pregunta que planteamos con respecto al consenso sobre lo que es creativo en distintas partes del mundo. Para él, hay ciertos asuntos en los que hay acuerdo, aunque ciertamente no son muchos, de modo que lo que plantea es la defensa de algunas generalizaciones sobre las que sí hay consenso. Son las siguientes: (Sternberg y Kaufman, 2006:2) 
1. La creatividad implica el pensamiento dirigido a producir ideas o productos que son relativamente innovadores y en algún aspecto, convincentes.

2. La creatividad no es ni completamente exclusiva de un campo específico ni completamente general para todos los campos. Tiene elementos de un campo específico y elementos de un campo general. El potencial de ser creativo puede tener algunos elementos generales pero, para adquirir el conocimiento necesario que uno necesita a la hora de hacer contribuciones creativas, se debe desarrollar el conocimiento y las habilidades necesarias en el campo particular en el que se va a hacer la contribución creativa.

3. La creatividad puede medirse, al menos en algún grado.

4. La creatividad puede desarrollarse, al menos en algún grado.

5. La creatividad no es tan altamente recompensada en la práctica como se supone que tendría que serlo en teoría.

Dicho esto, insiste en que, curiosamente, lo más notable sobre la investigación creativa en el mundo es precisamente la escasez de investigación sobre la creatividad, en comparación con la cantidad de investigación que se dedica a otros temas, y que la poca investigación que hay está relativamente poco sistematizada. Las razones que Sternberg (Sternberg y Kaufman, 2006:2-3) sugiere como más probables son las siguientes:

Primera: los gobiernos dicen que quieren creatividad pero sus acciones contradicen sus palabras. Muchos de los gobiernos del mundo dependen de la ignorancia para su existencia. En las autocracias, la educación, y especialmente el pensamiento creativo, supone una de las mayores amenazas para su existencia. En las democracias se podría esperar que la creatividad estuviera más valorada, y probablemente lo es. Sin embargo, muchos de los gobiernos han sido elegidos sólo por la ignorancia y la estrechez de miras de la gente que les eligió. La última cosa que estos gobiernos quieren es el pensamiento crítico y creativo que pudiera amenazar su existencia.

Segunda: la creatividad es dificil de estudiar. Sternberg (1996) asegura que la creatividad como problema de estudio es un trabajo de amplia envergadura, poco manejable y difícil de entender y que muchos científicos preferirán estudiar otros fenómenos que les permita usar el método científico tradicional de análisis. Además, a menudo los estudios sobre creatividad 
necesitan mucho tiempo para llevarse a cabo, lo que unido a los pocos incentivos existentes y, sobre todo, a la presión que se ejerce sobre los profesores para que publiquen (pues de ello depende su trabajo en muchas ocasiones) hace que éstos se decanten por estudios con poca complejidad y desechen este tipo de investigaciones que se desarrollan a largo plazo.

Tercera: la investigación en creatividad no es una de las áreas de la investigación más importantes. Sternberg (1996) insiste en que no es un tema que se considere muy importante para la investigación, ni en psicología ni en educación, esto es, se trata de un campo de investigación que está un poco al margen del resto. Es evidente que trabajar en un área de las que consideradas "de poca importancia" tiene sus desventajas: por un lado se consigue menos prestigio trabajando en esa área, y por otro lado es más difícil conseguir trabajo. Para colmo, es más difícil acceder a publicaciones de prestigio y también hay más problemas para difundir lo investigado.

Cuatro: los mecanismos de selección en la mayoría de los países no favorecen el surgimiento de gente creativa para estudiar creatividad. La pregunta que se plantea Sternberg es cómo se llega a ser un investigador independiente que estudie creatividad. La respuesta a esta pregunta está relacionada con la sumisión existente en los medios académicos. Lo habitual es que se recompense mejor a los estudiantes que hacen lo que su mentor quiere que hagan. Dicho de otro modo, los mentores están más interesados en que las contribuciones de los estudiantes tengan que ver con su propia investigación, antes que con producciones enfocadas a sus propias ideas creativas. Más aun, para llegar al momento académico donde se tiene un mentor, se tiene que pasar por las enseñanzas elemental, media y superior, en un sistema donde lo que se recompensa es la conformidad.

Quinto: Hay un efecto de popularización. La creatividad, más que otros campos en psicología y educación, ha sido objeto de programas populares que no han sido rigurosamente testados. Al menos al principio había pocos incentivos para que esos programas fueran rigurosamente evaluados. Por eso la creatividad se ha unido en la mente de mucha gente con la comercialización más que con la investigación rigurosamente científica.

Este efecto de popularización de la creatividad es todavía más claro en la creatividad musical, donde parece que el mero hecho de estar inspirado sirve para componer una canción sin 
ningún tipo de esfuerzo. Vivimos en una sociedad donde incluso se les vende a los niños programas para hacer canciones, como si no hiciera falta ningún tipo de preparación para hacerlo.

Si se tiene en cuenta que, habitualmente, las instituciones son el reflejo de los estados, tendríamos que analizar cómo se presentan estos elementos en los conservatorios superiores de música, de modo que se pudiera ver cuál es el estado en que se encuentran y, consecuentemente, en qué medida se podrían proponer cambios que mejoraran el entorno y así facilitar las infraestructuras necesarias que estimularan tanto la libertad de acción como el desarrollo de ideas creativas. Se profundiza en este punto más adelante, al hablar de los retos de los conservatorios en el siglo XXI.

Recientes investigaciones en el campo de la enseñanza musical (Hallam, 2012) aportan ideas interesantes sobre la importancia del entorno. Así, insisten en que, en la práctica actual, los profesores de música utilizan una metodología que está constreñida por el contexto, la naturaleza de la materia, el sistema de evaluación y el curriculum (Hallam e Ireson, 1999 en Hallam, 2012:166). En este sentido, los profesores de música como grupo tienden a adoptar un enfoque dirigido o autoritario en su enseñanza, dominando la clase magistral. En todas las áreas de la educación musical, la mayor parte del aprendizaje es dirigido por el profesor con poco énfasis en facilitar el aprendizaje del alumno por sí mismo, cuando precisamente este tipo de aprendizaje sea esencial para fomentar la creatividad musical. Hallam insiste en que el profesor, en particular, puede facilitar la idea fundamental de que el proceso creativo necesita tiempo para desarrollarse, de modo que se eliminen las presiones cortoplacistas que imperan en los programas actuales. A los estudiantes hay que darles tiempo, creando oportunidades para desarrollar sus ideas y para reflexionar. Y la forma de conseguirlo es que el entorno sea capaz de proporcionarles crítica constructiva y le ayude a plantearse dudas sobre la manera en que su trabajo progresa. Según esta autora, los profesores pueden ayudar a los alumnos a mejorar las habilidades de aprendizaje de la siguiente manera: diseñando los procesos de aprendizaje a través de una gran variedad de tareas, discutiendo estrategias alternativas de entre las que se puedan utilizar y ayudando a los estudiantes a evaluar sus puntos fuertes y débiles. Es evidente que lo que está proponiendo es una forma más libre y creativa de enseñar, una forma de enseñanza que cree un ambiente donde se fomente la creatividad, tanto individual como colectiva. 
La importancia de la creatividad colectiva se está convirtiendo en uno de los pilares de la excelencia en la actualidad. Estamos empezando a ver como necesarios los equipos creativos e innovadores que compartan la misma visión, que sean capaces de crear una atmósfera de trabajo participativa y no amenazante, que sean capaces de construir con el tiempo un clima de excelencia, en el que se acepten y debatan los retos más atrevidos y que de esta manera intenten conseguir ayudas y financiación para poner en funcionamiento sus ideas. (Hayes, 1989). Podemos decir que la adquisición de la excelencia puede ser conceptualizada como una larga serie de decisiones de aprendizaje creativas (Stoeger, 2013). 


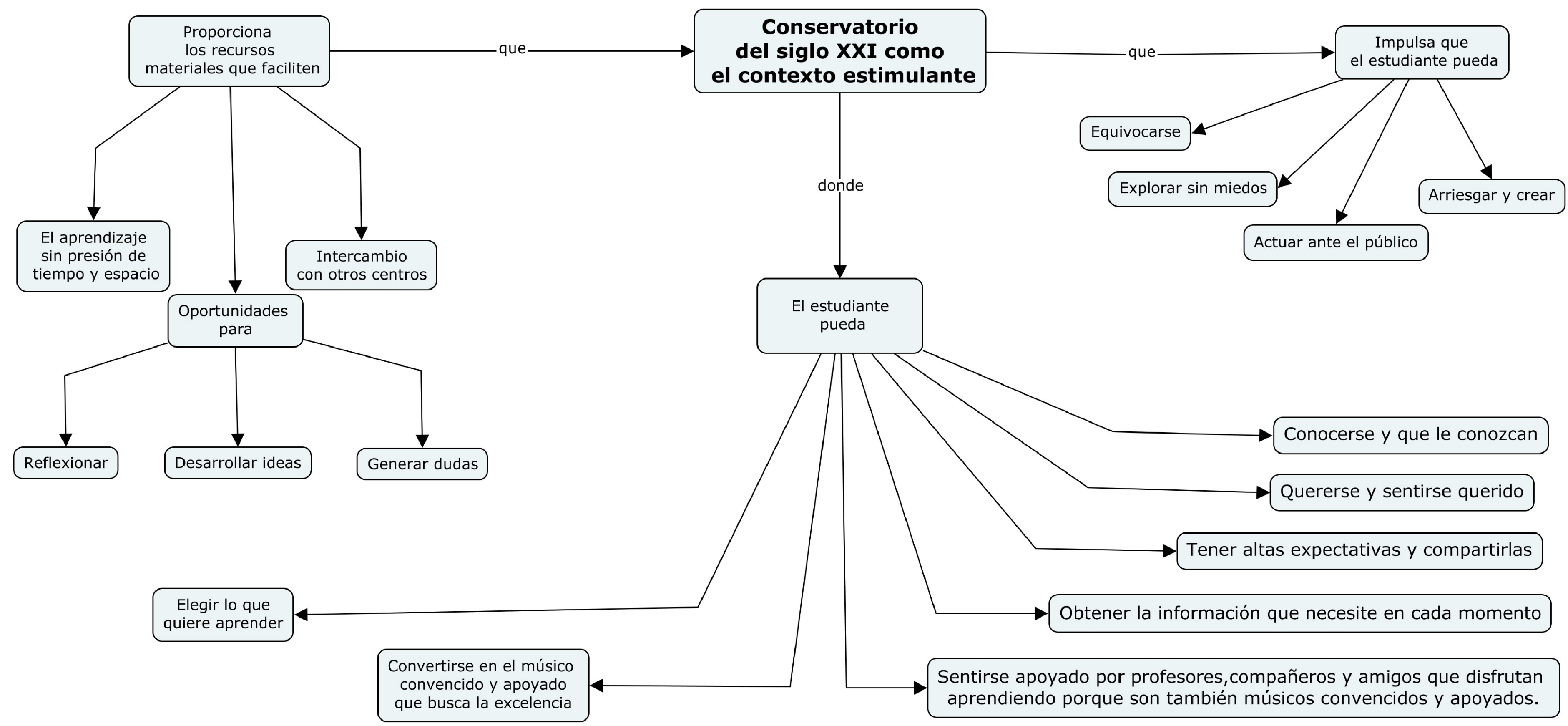

Ilustración 7. El conservatorio del siglo XXI. Elaboración propia. 


\subsection{El aprendizaje colaborativo}

Collen Conway y Thomas Hogman, en su famoso trabajo Teaching Music in Higher Education, (2009) exponen claramente la diferencia que se ha experimentado entre el viejo y el nuevo paradigma en la enseñanza superior, concretamente, el paso necesario que se ha dado en el contexto de aprendizaje, pasando de un contexto competitivo e individualista a un contexto de aprendizaje cooperativo en clase, donde los equipos colaboran en el mismo centro y también con otros centros para conseguir un mejor desarrollo; un contexto en el que se ha pasado de un clima de conformidad y uniformidad cultural a la valoración y el reconocimiento de la diversidad cultural y el valor de la comunidad. El profesor ya no ejerce el poder con autoridad y control, sino que el poder es compartido entre estudiantes y profesores, buscando la solución a los problemas por medio de la comunicación, la colaboración y el acceso a la información. Un acceso a la información que se produce de forma compartida y con la idea de que tanto aprender cómo enseñar es una tarea compleja que requiere un entrenamiento considerable y continuo a lo largo de la vida.

A lo largo de mi experiencia como profesora en el Conservatorio Superior de Música de Navarra, he comprobado que el intercambio que se producía entre estudiantes de enseñanza superior con realidades muy distintas ayudaba mucho a ver diferentes perspectivas musicales y sociales, y que ese intercambio de ideas que se producía les permitía aprender a unos de otros, compartiendo proyectos, ideas y viendo enfoques muy distintos sobre la realidad musical. Siempre hemos pensado que el poder asistir a clases de grupo con mezcla de alumnos (estudiantes de clásico y de jazz, estudiantes de edad avanzada con mucho recorrido como músicos pero que deseaban seguir aprendiendo y otros que acababan de terminar el instituto, con realidades musicales y sociales muy distintas) ayudaba mucho a ver diferentes perspectivas y tener una visión de la música muy enriquecedora y muy útil de cara a su vida profesional. La educación musical superior se soporta en tres ejes que tienen su mirada puesta en el docente y el alumno (Porta, 2015). Nos alegra comprobar que las investigaciones actuales en el campo de la educación musical superior (Burnard y Haddon, 2015; Woznicki, L., 2015; Dobson y Gaunt, 2015; Gaunt y Westerlund, 2013; Hallam y Gaunt, 2012; Conway y Hodgman, 2009) apoyan nuestras intuiciones de que esta mezcla y este ambiente que como profesora intentaba mantener, un ambiente en el que cada uno desde su realidad pudiera cuestionar, reflexionar y valorar los contenidos que se presentaban, era lo que mejor podíamos 
hacer como profesores: enseñarles a reflexionar sobre lo que están haciendo, cuestionarlo y aprender de todos: compañeros y profesores; era construir un espacio donde el respeto y las ganas de aprender hicieran que todos tuvieran ganas de opinar y cuestionar, debatir con energía, enfadarse y reírse, sembrando la duda, el debate y la sorpresa, buscando argumentos y ejemplos válidos para demostrar sus opiniones, analizando su práctica como músicos y como profesores en muchos casos y contrastando con lo que decían las investigaciones que se les presentaban, de modo que se intentara aplicar todo lo que aprendían a su vida como músicos y como profesores, probando semana a semana las nuevas propuestas que se les planteaban y comentando a los demás sus logros, dudas o fracasos como parte del proceso en el que estábamos todos implicados: equivocarnos para mejorar, aprendiendo del error ${ }^{20}$.

Lo que queremos hacer con nuestra investigación actual es que los alumnos sean conscientes de que el aprendizaje colaborativo es una de las herramientas más útiles para desarrollarse como músico, que es muy útil en la educación superior y que va a seguir siendo muy útil en su vida profesional como intérprete, compositor, musicólogo o profesor. Queremos que, además de ser conscientes de esta utilidad, conozcan las estrategias que les pueden ayudar a mejorar ese aprendizaje colaborativo, conociendo las últimas investigaciones al respecto y poniéndolo además en práctica para que comprueben su utilidad por sí mismos.

Con respecto al trabajo colaborativo en la educación superior en general, son muy aleccionadoras las teorías expuestas por Ken Bain (2004) en su trabajo What the Best College Teachers do. Bain apuesta por desarrollar lo que él llama "un contexto de aprendizaje de naturaleza crítica" ${ }^{21}$. En este contexto la gente aprende confrontando problemas fascinantes, tareas auténticas que les reta a confrontar ideas, repensar sus creencias y examinar sus modelos mentales de realidad. Este contexto crea las condiciones en las que los estudiantes

\footnotetext{
${ }^{20}$ Como señala Sternberg: "la capacidad para aprender de la experiencia implica que las personas inteligentes no son las que no cometen errores, sino más bien las que aprenden de ellos y no siguen incurriendo una y otra vez en lo mismo" (1996:93)
} 
sienten el control de su educación y pueden aplicar el trabajo colaborativo con otros, pues en este contexto sí que confían en que su trabajo será considerado de forma justa y honesta y no le importará equivocarse pues siente que recibirá una evaluación útil de compañeros expertos que le ayudará a mejorar. Además propone cómo crear oportunidades de aprendizaje para construir este ambiente de aprendizaje. Nos parece que la puesta en práctica de sus enseñanzas, entre otras, puede ayudarnos en nuestra tarea de crear el compromiso con la comunidad académica y en la mejora de las prácticas de aprendizaje colaborativo. En la misma línea nos parecen muy interesantes las aportaciones de Peter Knight (2005) sobre el profesorado de Educación Superior y cómo formarse para conseguir la excelencia donde también da mucha importancia al contexto social de las tareas que se programan. Igualmente importantes son las aportaciones de Thierry de Duve, que también nos trasmite la importancia del contexto de aprendizaje en la formación artística. Duve señala que trasmitir está bien pero que lo esencial es crear el terreno de cultivo fértil, donde reine un clima de libertad de modo que los estudiantes estén preparados para los imprevistos y puedan permanecer despiertos, ser sensibles e inteligentes y que elijan crear escuela al menos tanto como los profesores (1992).

Es por esta razón que nos parece que el conservatorio superior, un entorno donde queremos desarrollar la excelencia musical y donde pretendemos preparar a músicos del siglo XXI, debería ser uno de los espacios en los que se debe crear ese ambiente colaborativo donde reine la libertad para expresarse, aprender e investigar. Nos parece interesante incluir las ideas de Csikszentmihalyi, que hablan de la necesidad de crear espacios creativos como imprescindibles para la consecución de obras creativas. Este autor explica que la idea o producto que merece la etiqueta de "creativo" surge de la sinergia de muchos recursos y no sólo de la mente de una única persona. Así, demuestra que es más fácil aumentar la creatividad cambiando las condiciones del entorno que intentando hacer que la gente piense más creativamente. Y añade que un logro creativo no es casi nunca el resultado de una visión repentina, un flash que se enciende en la oscuridad, sino que llega después de años de duro trabajo. (1996:1). Teniendo esto en cuenta, podríamos preguntarnos cómo se puede convertir el Conservatorio Superior de Música en un espacio creativo, cuyas estructuras faciliten la creatividad y favorezcan su desarrollo.

En relación con esta idea, Csikszentmihalyi sugiere que también las instituciones y no sólo los estados pueden promover el desarrollo de ideas creativas. En este sentido, define los ambientes exitosos como los ambientes que proporcionan libertad de acción y estimulación de 
ideas, junto con una actitud de respeto y apoyo hacia los genios potenciales, quienes, aunque pueda parecer paradójico, suelen tener una autoestima muy frágil, lo que les hace necesitar mucho cariño y cuidado amoroso (Csikszentmihalyi, 1996:140). Es importante conocer que esta parte también es necesaria para el desarrollo creativo, en el sentido de que se debe buscar la forma de "humanizar" los espacios y las estructuras, algo mucho más necesario que otros recursos a los que solemos dedicar más esfuerzos.

Como vemos, hay una interesante labor en el terreno del aprendizaje colaborativo en la enseñanza superior donde podemos investigar. En concreto, en la enseñanza superior de música también encontramos importante documentación al respecto. Un trabajo destacable sobre este tema es el estudio sobre el aprendizaje colaborativo en la educación musical superior llevado a cabo por Gaunt y Westerlund (2013), donde señalan que es más que evidente el impacto que el aprendizaje colaborativo tiene en el contexto de la educación superior, especialmente a la hora de apoyar el desarrollo de importantes habilidades, tales como ser más responsables a la hora de controlar su propio aprendizaje y ser menos dependiente de las instrucciones directas del profesor; y de igual modo, facilitar la creatividad y respaldar las habilidades de los estudiantes que le permitan integrarse en contextos profesionales de cara a ser lo suficientemente flexibles para encajar con la diversidad. A este respecto, la ya citada investigación realizada por Gaunt (2007) con alumnos de enseñanza superior sobre la enseñanza y el aprendizaje de la respiración en el oboe ${ }^{22}$, ponía de relieve la importancia que había tenido en el proceso de investigación el hacer que los participantes reflexionaran sobre su propio aprendizaje durante un tiempo y compartieran sus experiencias con el grupo. Esta reflexión ayudó a los estudiantes a tomar conciencia de su propia forma de trabajar, lo que les permitió beneficiarse de otras perspectivas e ideas y determinar alternativas y modificaciones para las suyas propias. Este tipo de experiencias no son una característica común de la enseñanza instrumental en la educación superior, de modo que se empezaba a demostrar el impacto que el contexto donde se aprende tiene en los alumnos, destacando la importancia de las relaciones que se desarrollan entre los profesores y entre los alumnos. Esto sugiere que la naturaleza de los contextos de aprendizaje en conservatorios necesita ser estudiado con más detalle, particularmente en relación con las teorías relativas al 
aprendizaje en la enseñanza superior. Esperemos que también esta concienciación e importancia del trabajo en grupo llegue a los conservatorios españoles.

Esta idea de la importancia del aprendizaje colaborativo para el músico, y que por lo tanto debería incluirse en la educación musical también es resaltada por Burnard y Haddon (2015), quienes insisten en que la enseñanza superior de música debería proporcionar un ambiente de aprendizaje donde los estudiantes se sintieran seguros y se atrevieran a romper las normas y asumir riesgos, donde pudieran ver lo que están haciendo como un trabajo en construcción y no como algo terminado para que se les permita experimentar y equivocarse, consiguiendo así fomentar una mayor creatividad y una búsqueda de aprendizajes colaborativos con otros profesionales con proyectos fuera del currículo que les permitiera ver otros puntos de vista distintos al académico. Woznicki (2015) señala que hay otros modelos de aprendizaje instrumental que no son sólo en relación de clase individual de profesor y alumno, sino que los alumnos pueden recibir clase de instrumento en grupo e incluso de varios profesores al mismo tiempo. Resalta que la autoevaluación que hace el alumno suele ser muy pobre y en ocasiones muy negativa, y sin embargo suele evaluar y ser evaluado mucho mejor por sus compañeros y profesores. Estas evaluaciones formativas son muy necesarias para el aprendizaje instrumental, de cara a ser consciente de sus puntos fuertes y débiles, por lo que insiste en que en la enseñanza superior se deberían fomentar estos modelos de aprendizaje colaborativo. Hallam insiste en que no hay que subestimar todo lo que un alumno puede aprender de otro (2012:171). Como vimos anteriormente, las investigaciones demuestran que no sólo no hay que subestimar esa posibilidad de aprender colaborativamente, sino que debería ser una constante en su proceso educativo, y más aún si pensamos en lo que suele ser el entorno "habitual" de un músico: la orquesta (o cualquier otro tipo de agrupación). En las páginas citadas traíamos a colación el estudio de Dobson y Gaunt (2015) en el que las investigadoras concluían que es absolutamente necesario que los músicos de una orquesta estén dispuestos, de manera continua, a escucharse unos a otros, no sólo en la dirección en que se suele interpretar estas "negociaciones", es decir, de manera vertical entre el director y el conjunto de músicos que forman la orquesta, sino de manera horizontal, es decir, las que establecen los miembros de la orquesta entre sí. Parece ser, resaltaban Dobson y Gaunt, que requiere más habilidades interpersonales la comunicación entre iguales (o supuestamente iguales) que la que se da entre el director y el resto. 
De lo que estamos hablando, obviamente, es de aprendizaje dirigido al trabajo colaborativo. Si el proceso de enseñanza-aprendizaje incluye estos procesos de adaptación al grupo, recreando el trabajo en orquestas (al tiempo que se trabaja la perfección técnica, por supuesto) y si se reajusta el sistema de evaluación para incorporar las habilidades colaborativas de los individuos, no cabe duda de que redundará en acercarnos a la excelencia musical. Y es evidente también, como señalan las autoras, que se debe seguir investigando en esta línea, para saber cómo se adquieren estas habilidades y cómo se desarrollan.

Hallam y Bautista (2012), por su parte, sostienen que quizá las habilidades más importantes que hay que desarrollar para tocar un instrumento hoy en día son las que capacitan a los alumnos para llegar a ser independientes y autónomos. Es importante conseguir una mayor autoconfianza e independencia para autorregularse con la ayuda del apoyo del grupo. Para ello, es necesario animar a los alumnos a ser estudiantes independientes, lo que requiere hacerles pensar por sí mismos, y eso lleva inevitablemente a que se cuestionen la práctica que se está usando, algo que puede ser incómodo para el profesor, que con frecuencia es reticente a la hora de permitir a sus estudiantes tomar un rol activo en su proceso de aprendizaje. Por eso es importante apoyarse en el grupo y aprovechar las oportunidades para tocar, improvisar, componer y actuar con otros, investigando y buscando el feedback de terceras personas, así como intentar asegurar que el ambiente de aprendizaje que le rodea le conduce a conseguir sus objetivos. (Ese ambiente o contexto de aprendizaje del que tanto estamos hablando y parece imprescindible hoy en día). Y añaden los autores que, para el que desee dedicarse a la carrera musical, también le serán requeridas habilidades sociales necesarias para trabajar con otros músicos, con promotores y con el público, así como habilidades de planificación y organización y habilidades de gestión del tiempo. (Hallam y Bautista, 2012:669). Habilidades todas ellas que se desarrollan en el trabajo colaborativo que se propone.

Hallam y Gaunt (2012) también insisten en la importancia de desarrollar habilidades de colaboración e interpersonales, lo que sería uno de los objetivos del trabajo colaborativo que se plantea. Las autoras destacan que la colaboración es una parte fundamental de la tarea de hacer música, tanto si eres compositor, músico de conjunto, solista, profesor, investigador u organizador de eventos musicales. En el pasado se consideraba la experiencia musical como algo individual y esto es algo que está cambiando rápidamente. Se puede añadir a esta reflexión que quizá en el conservatorio es importante profundizar en esta idea, dado que todavía no ha calado mucho y que nos parece necesario implantar. Los alumnos siguen 
sintiendo que se les exige sobre todo en el terreno de su desarrollo individual y mucho menos el trabajo de estas habilidades de colaboración e interpersonales, tan necesarias hoy en día. Las autoras insisten en que las habilidades interpersonales (por ejemplo la escucha, el apoyo, la empatía) son de vital importancia tanto a nivel musical como en todo tipo de comunicación. Añaden, incluso, que si la colaboración es sólo una pequeña parte de una práctica musical específica, estas habilidades serán vitales en el proceso de búsqueda y gestión del trabajo. Se puede decir que es casi imprescindible buscar apoyo en compañeros, amigos músicos y grupos que le entiendan y animen en todos los aspectos que incluye la música. Para las autoras, es fundamental buscar maestros de alta calidad, mentores y amigos críticos en los que confiar y cuya opinión sea valorada por el que la recibe, pues tener un conjunto sólido de relaciones de esta naturaleza acelerará su aprendizaje, le abrirá puertas y le proporcionará conocimientos y habilidades importantes, además de apoyo psicológico. El músico debe participar activamente en comunidades musicales para aumentar el apoyo entre personas y para generar ideas y colaboraciones artísticas, intentando también formar parte de otras redes que le pueden proporcionar acceso a los contextos profesionales, habilidades adicionales y apoyo personal, además de ayudarle a clarificar su identidad musical y profesional.

En las agrupaciones de enseñanza más informal, como las agrupaciones folklóricas, también se ha destacado el papel que tiene el músico como miembro de un grupo y como su implicación en el grupo ayuda a mantener la motivación. El músico que colabora en las decisiones acerca de dónde ir, qué repertorio montar, cuál exhibir y de qué manera, logra un sentimiento mayor de compromiso que le impulsa a una implicación intensa (Martín, 2012:350).

Recientes investigaciones en el campo de la enseñanza musical (Hallam, 2012) aportan ideas interesantes sobre la importancia del entorno. Así, insisten en que, en la práctica actual, los profesores de música utilizan una metodología que está constreñida por el contexto, la naturaleza de la materia, el sistema de evaluación y el curriculum (Hallam e Ireson, 1999 en Hallam 2012:166). En este sentido, los profesores de música como grupo tienden a adoptar un enfoque dirigido o autoritario en su enseñanza, dominando la clase magistral. En todas las áreas de la educación musical, la mayor parte del aprendizaje es dirigido por el profesor con poco énfasis en facilitar el aprendizaje del alumno por sí mismo, cuando precisamente este tipo de aprendizaje sea esencial para fomentar la creatividad musical. Hallam insiste en que el profesor, en particular, puede facilitar la idea fundamental de que el proceso creativo necesita 
tiempo para desarrollarse, de modo que se eliminen las presiones cortoplacistas que imperan en los programas actuales. A los estudiantes hay que darles tiempo, creando oportunidades para desarrollar sus ideas y para reflexionar. Y la forma de conseguirlo es que el entorno sea capaz de proporcionarles crítica constructiva y le ayude a plantearse dudas sobre la manera en que su trabajo progresa. Según esta autora, los profesores pueden ayudar a los alumnos a mejorar las habilidades de aprendizaje de la siguiente manera: diseñando los procesos de aprendizaje a través de una gran variedad de tareas, discutiendo estrategias alternativas de entre las que se puedan utilizar y ayudando a los estudiantes a evaluar sus puntos fuertes y débiles. Es evidente que está proponiendo una forma más libre y creativa de enseñar, una forma de enseñanza que cree un ambiente donde se fomente la creatividad, tanto individual como colectiva.

La importancia de la creatividad colectiva se está convirtiendo en uno de los pilares de la excelencia en la actualidad. Estamos empezando a ver como necesarios los equipos creativos e innovadores que compartan la misma visión, que sean capaces de crear una atmósfera de trabajo participativa y no amenazante, que sean capaces de construir con el tiempo un clima de excelencia, en el que se acepten y debatan los retos más atrevidos y que de esta manera intenten conseguir ayudas y financiación para poner en funcionamiento sus ideas. (Hayes, 1989).

Varela et al. (2016), en su reciente investigación sobre los estudiantes de música y la tecnología moderna superior, encuentran evidencias de que la tecnología que permite a los músicos registrar y monitorizar su progreso les puede ayudar a proporcionar la motivación necesaria para perseverar a lo largo del tiempo. Además, advierten que se conoce poco sobre el impacto que esta tecnología tiene en la autorregulación musical o en la unión entre el apoyo social y la autorregulación. En ese sentido, señalan la investigación de Hadwin y Oshige (2011), donde describen el aprendizaje co-regulado y la regulación compartida socialmente como formas de aprendizaje autorregulado que pone el énfasis en las interacciones colectivas y en la colaboración.

Estas ideas constituyen un modelo de trabajo a seguir en gran medida en la investigación que aquí se proyecta: la búsqueda de ese contexto estimulante que ayude a crear, el buscar 
respuestas que nos ayuden a estar más seguros en la labor del profesor en la enseñanza musical superior y a los alumnos a poder aprender e investigar de forma colaborativa y sin dependencias de un único profesor.

Para entender cómo se trabaja esta metodología nos hemos valido de los contenidos de las asignaturas de Didáctica de la Música y de las Especialidades (que se imparte como obligatoria para los alumnos de $4^{\circ}$ curso de interpretación este último año) y en las de Didácticas Específicas, que se imparte en tercero para los alumnos de Pedagogía. La actividad consiste en explicar los contenidos de las mismas utilizando las herramientas del aprendizaje colaborativo. Para ello, y en cada tema, se trabajan en primer lugar los contenidos, conociendo lo que dicen las investigaciones; después se pide a los estudiantes una reflexión (tanto individual como conjunta) y un análisis de las investigaciones, aplicándolo a su caso en concreto. Esto sirve para que hagan una reflexión en torno a qué puntos fuertes y débiles tienen, lo que les ayuda a conocerse mejor y a organizar su propio aprendizaje, con la ayuda de las estrategias del aprendizaje colaborativo y en función de sus necesidades y gustos, consiguiendo rendir mucho más.

\subsection{La práctica mental}

Se ha definido la Práctica Mental como "el ensayo imaginario o cognitivo de una destreza física sin movimientos musculares específicos" (Fine et al., 2015:2) Es decir, estamos hablando de una estrategia de aprendizaje que, en principio, chocaría frontalmente con la idea, de ascendencia cartesiana, según la cual los seres humanos estamos compuestos por dos sustancias completamente distintas: el cuerpo y la mente (o alma en el lenguaje más tradicional). Hemos dicho que se trata de una idea de ascendencia cartesiana pero, en realidad, podemos decir que se remonta a la Antigüedad clásica (Platón y Aristóteles, aunque éste proponía una unión vital de ambas sustancias, sin perjuicio de que fueran completamente distintas). Más aun, en prácticamente todos los sistemas de creencias humanos se establece esta dicotomía, en mayor o menor grado, cuando se establece que el ser humano es un compuesto de cuerpo y alma (o almas). Y no es difícil entender que así sea. Al fin y al cabo, la experiencia cotidiana nos muestra cómo las experiencias físicas y mentales, aunque puedan tener algún tipo de relación, funcionan de manera distinta e independiente. Es más, las 
experiencias mentales ajenas a lo físico (sueños, desdoblamientos, alucinaciones, ingesta de drogas, etc.) vendrían a confirmar la autonomía de ambas esferas. En realidad, Descartes significa sólo el hecho de llevar al límite esta separación, esto es, considerar no sólo que son diferentes, y hasta cierto punto autónomas, sino que se trata de dos sustancias completamente distintas, separadas, independientes e inconmensurables. Sería, curiosamente, un seguidor de la filosofía de Descartes, el judío ateo ${ }^{23}$ Baruch Spinoza, el primero en proponer una visión completamente distinta de la cuestión.

Spinoza, en su obra Ética demostrada según el método geométrico, propuso una explicación radicalmente distinta: cuerpo y mente no son más que dos manifestaciones (atributos) de una misma y única sustancia: Dios o la Naturaleza ${ }^{24}$. De este modo, ambos elementos son “expresiones paralelas de la misma sustancia" (Jaquet, 2013). Así, cuerpo y mente son inseparables, siendo ambos (por así decirlo) cortados por el mismo patrón. La frase de Spinoza es tajante: "el orden y conexión de las ideas es el mismo que el orden y conexión de las cosas" (Ética, Libro II, Proposición VII). Por desgracia, las ideas del filósofo holandés (pero de ascendencia hispano-portuguesa) cayeron en saco roto. O, como dice Antonio Damasio de una manera más hermosa: "su intuición fue revolucionaria para la época pero no tuvo impacto alguno en la ciencia. Un árbol cayó en silencio en el bosque y allí no había nadie que diera testimonio de ello", y añade de manera tan tajante como impactante: "las implicaciones teóricas de estas ideas no se han digerido, ni como intuición spinoziana ni como hecho establecido de manera independiente" (Damasio, 2003:206). En efecto, a la muerte de Spinoza su obra (que no publicó en vida por temor al escándalo que podían haber producido... y de hecho se produjo posteriormente) fue considerada impía, peligrosa, terrible y cuantos calificativos pueda imaginarse para anatematizarla. Sólo en el siglo XIX se le empezó a recuperar desde el Idealismo hegeliano, aunque cayó de nuevo en el olvido a lo largo del siglo XX, para volver a primera línea a finales de este mismo. Ha sido precisamente el neurólogo Antonio Damasio quien lo ha recuperado de manera especial en su obra (ya

\footnotetext{
23 Spinoza, judío de nacimiento y familia, será el primer autor que postule un ateísmo abierto en su obra, razón por la cual se le expulsó de la comunidad judía de Amsterdam, a la que pertenecía.

24 Naturaleza que tiene infinitos atributos, de los cuales sólo conocemos esos dos, dada nuestra limitación.
} 
citada en líneas anteriores) En busca de Spinoza. Neurobiología de la emoción y los sentimientos $^{25}$. Como se desprende del subtítulo, el libro se ocupa de la relación entre emociones y sentimientos (algo muy poco estudiado por la neurología hasta la actualidad, todo sea dicho), pero para poder ocuparse de ambos elementos tan determinantes en nuestra conducta, Damasio ha de dejar claro cuál es el funcionamiento de lo que se ha solido llamar cuerpo y mente. Citamos a continuación un fragmento quizá algo largo del primer capítulo, pero que ilustra perfectamente lo que queremos decir y, sobre todo, lo que vamos a explicar más adelante: "El cerebro utiliza varias regiones específicas que trabajan en concierto para representar una miríada de aspectos de las actividades del cuerpo en forma de mapas neurales. Esta representación es un compuesto, una imagen siempre cambiante de la vida en acción. Los canales químicos y neurales que conducen al cerebro las señales con las que puede pintarse este retrato de la vida son tan" específicos como la tela que las recibe. El misterio de cómo sentimos es ahora un poco menos misterioso" y más adelante añade: "La emoción y las reacciones relacionadas están alineadas con el cuerpo, los sentimientos con la mente. La investigación de la manera en que los pensamientos desencadenan emociones, y en que las emociones corporales se transforman en el tipo de pensamientos que denominamos sentimientos o sensaciones, proporciona un panorama privilegiado de la mente y el cuerpo, las manifestaciones evidentemente dispares de un organismo humano, único y entrelazado de forma inconsútil" (Damasio, 2003:13-14).

Para la neurología y la psicología actual no hay la menor duda: mente y cuerpo son dos elementos inseparables de un mismo ser, que interactúan de manera constante y que construyen $^{26}$ la conducta y todo lo que explica, en su enorme complejidad, eso que hemos dado en llamar "individuo humano". Ahora bien, ¿qué utilidad tiene todo esto dentro del tema que nos ocupa? La respuesta es evidente: si cuerpo y mente son inseparables y trabajan al unísono, parece lógico pensar que la práctica mental debería ser una herramienta algo más que interesante en el aprendizaje de disciplinas que requieran la ejecución de complejas

25 Es interesante citar aquí otra obra suya anterior: "El error de Descartes", donde refutaba precisamente esa separación tradicional que se ha hecho entre cuerpo y mente (o alma)

26 Y se construyen mutuamente... 
secuencias motoras, tales como el deporte, la cirugía y, por supuesto, la música. La proliferación de estudios en ese sentido durante los últimos 5 años así lo demuestra. Dedicaremos los párrafos que siguen a comentar algunos de ellos, los que más interesantes hemos considerado para nuestro trabajo y sin la pretensión de agotar el tema ni de ser exhaustivos.

De la importancia que tiene la práctica mental da cuenta un artículo publicado en $2011^{27}$ : Best practice for motor imagery: a systematic literature review on motor imagery training elements in five disciplines, de Schuster, Hilfiker, Amft, Scheidhauer, Andrews, Butler, Kischka y Ettlin, donde se citaban 133 estudios realizados en los que se analizaban 141 intervenciones usando la práctica mental en cinco disciplinas: educación, medicina, música, psicología y deporte. Citamos a continuación un párrafo que da cuenta de lo que estamos diciendo acerca del interés del asunto: “en las dos últimas décadas, la publicación de literatura sobre práctica mental se ha incrementado de manera impresionante, pasando de las 122 publicaciones existentes hasta 1980 a las 20.011 publicadas tan sólo en 2009” (Schuster et al., 2011:2).

\subsubsection{Investigaciones actuales sobre la práctica mental}

Comentaremos a continuación tres estudios realizados en los últimos años (2013-2015) y lo haremos cronológicamente:

1.- En 2013 los profesores Nicolò Bernardi, Matteo De Buglio, Pietro Trimarchi y Emanuela Bricolo, del Departamento de Psicología de la Universidad de Milano-Bicocca, en colaboración con Alfonso Chielli, del Conservatorio Giuseppe Verdi de Milán, realizaron un estudio titulado: Mental practices promotes motor anticipation: evidence from skilled music performance. En éste afirmaban: "tanto en la práctica deportiva como en la interpretación musical se ha evidenciado que las combinaciones adecuadas de práctica mental y práctica física da resultados similares a la realizada sólo con práctica física”. Más aun, “en el campo de la música se ha mostrado que la práctica mental por sí sola puede conducir a los mismos cambios plásticos en el sistema motor que los que se producen con la repetición de la práctica

${ }^{27} \mathrm{Y}$ que, por lo tanto, no incluye los que comentaremos a continuación, dado que son mucho más recientes. 
física". Partiendo de esta idea, estos profesores italianos buscaban llevar esta afirmación a un terreno en el que no había estudios: los efectos de la práctica mental sobre el "movement training", concepto que podríamos traducir como "la ejecución precisa del movimiento en el momento oportuno". Como afirman en su estudio, esa ejecución precisa juega un papel esencial en la interpretación musical (lo mismo que en la práctica deportiva ${ }^{28}$ ). Un músico debe anticipar los movimientos de muchas partes de su cuerpo para asegurar una ejecución fluida (de igual manera que lo hace un atleta al coordinar todos sus movimientos).

El estudio, realizado sobre 16 pianistas (10 mujeres y 6 hombres), consistió en dividirlos en dos grupos, uno de los cuales sólo trabajaba con práctica mental y el otro con práctica física. Y los resultados fueron espectaculares, tal como se deriva de las conclusiones de los autores del mismo y que reflejamos a continuación: “el presente estudio confirma todos los hallazgos anteriores, mostrando un incremento absoluto en los picos de velocidad alcanzados tanto con práctica mental como con práctica física. Pero esta observación se complementa con el descubrimiento de que, usando práctica mental, los movimientos no sólo son más rápidos, sino que se ejecutan antes" y añaden: "el presente estudio ha mostrado, por primera vez, que la práctica mental es similar a la práctica física a la hora de promover un patrón de anti-fase en la coordinación entre las extremidades del cuerpo" (Bernardi et al., 2013:10-11).

2.-Otro estudio de 2013 nos parece también muy interesante, por cuanto se refiere directamente al aprendizaje musical: Auditory and motor imagery modulate learning in music performance, llevado a cabo por Rachel Brown y Caroline Parker, del Departamento de Psicología de la Universidad McGill de Montreal. Las autoras partían de la base de que existe una evidencia sustancial que demuestra una correspondencia estrecha ente los intervalos temporales de los movimientos ejecutados y los simplemente imaginados. Dicho con más claridad: a la gente le lleva el mismo tiempo producir que imaginar las mismas acciones (los ejemplos que dan Brown y Palmer son escribir una carta y caminar una distancia determinada, extraídos de experimentos llevados a cabo por Decety y Michel en 1989 y Sirigu en 1996, respectivamente). Las autoras citan buen número de estudios previos que demuestran cómo la práctica mental conduce a los mismos cambios en las respuestas neuronales que la práctica

\footnotetext{
${ }^{28} \mathrm{Y}$, añadiríamos nosotros, en la práctica de la cirugía, por poner otro claro ejemplo
} 
física o, de modo más explícito en lo que respecta a nuestro trabajo, que el entrenamiento de una secuencia motora vía práctica mental puede conducir a mejoras considerables de esa secuencia al tiempo que al incremento de la activación e córtex órbito-frontal, similar al observado tras la ejecución de la práctica física de esa misma secuencia (Jackson et al., 2003).

Lo que plantearon Brown y Palmer significaba dar un paso más: ¿puede la práctica mental ayudar en la recuperación de secuencias musicales que se han aprendido, cuando el sujeto está sometido a interferencias? La cuestión es más profunda de lo que parece: si la práctica mental funciona como parece, podría ser de gran ayuda a músicos profesionales (aquí podríamos decir incluso, a músicos que buscan la excelencia) a la hora de desarrollar sus posibilidades musicales.

Para el experimento, se usó a pianistas expertos que debían aprender nuevas melodías y recuperarlas posteriormente, midiendo la exactitud con se producía dicha recuperación (tono y tiempo, particularmente). Un grupo aprendía escuchándolas (pero sin tocarlas al piano) y el otro grupo tocándolas en un teclado sin sonido. La recuperación de las melodías se hacía en presencia de un auditorio ("interferencias"). A todos ellos se les presentaron diversos tipos de interferencias: a los primeros especialmente durante la fase de aprendizaje y a los segundos durante la fase de recuperación.

Las conclusiones, nuevamente, fueron espectaculares. La práctica mental demostró una vez más ser de gran ayuda tanto para el aprendizaje como para la recuperación exacta de lo aprendido. Más aun, la práctica mental resultó ser más útil para la ejecución de memoria que el aprendizaje realizado sólo con práctica física (aunque, obviamente, la influencia de la práctica mental varía según cada individuo).

3.- El tercero de los estudios que traemos a colación es el realizado en septiembre de 2015 por Sarah Kraeutner, Laura MacKenzie, David Westwood y Shaun Boe, de la Dalhousie University: Characterizaing skill acquisition through motor imagery with no prior physical practical. Es decir, y aquí está lo audaz del experimento, adquisición de una habilidad cualquiera sin práctica física previa. 
Una vez más, la base neurológica desde la que se parte es la misma que llevamos glosando en todo el apartado: la imagen mental de un movimiento produce una activación cerebral similar a la producida por la ejecución de ese movimiento ${ }^{29}$. Las autoras del experimento citan más de 20 estudios anteriores que certifican la eficacia del uso de la práctica mental (en este caso, centrado de manera especial en su modalidad de imaginación motórica, es decir, representación mental de un movimiento físico). A partir de ahí, se planteó un experimento que buscaba ir un poco más allá, tratando de saber ya no si la práctica mental es una ayuda muy eficaz para la adquisición de habilidades físicas, sino si se podía adquirir una de éstas sólo a través de aquéllas.

El experimento que se llevó a cabo era simple de realizar pero complejo de explicar (como se comprobará a continuación) y se aplicó a 64 voluntarios universitarios (42 mujeres y 22 hombres) de entre 19 y 26 años, divididos aleatoriamente en dos grupos, uno que llevaría a cabo la práctica mental y otro la práctica física. Ambos grupos trabajaron sobre una tarea de aprendizaje de secuencia implícita, una forma de aprendizaje en la que se repite una secuencia aparentemente aleatoria, pero en la que hay incrustada una secuencia que se repite y que hay que ejecutar motóricamente. Para ello, se colocó a los participantes ante un ordenador donde las teclas $\mathrm{V}, \mathrm{C}, \mathrm{X}$ y Z se numeraron del 1 al 4 para asignar cada una a un dedo de la mano izquierda (o la derecha en el caso de los zurdos). A cada uno se le proporcionaron unos auriculares, por donde iban escuchando las secuencias numéricas. Los participantes del grupo de práctica mental no podían apretar las teclas (si se hacía, se consideraba un error) y los del grupo de práctica física debían cerrar los ojos y apretar la tecla (si no se hacía, se consideraba error). Como se ha dicho, la secuencia implícita consistía en 10 dígitos que se repetían 20 veces de igual manera dentro de un bloque más amplio que constituía el $20 \%$ del total. Como decimos, sencillo de ejecutar, pero complejo de explicar (y lo hemos simplificado notablemente, todo sea dicho). Lo importante, sin embargo, fueron los resultados.

\footnotetext{
29 Es momento ya de volver sobre lo que planteábamos teóricamente al principio: la unidad sustancial de cuerpo y mente, planteada hace 4 siglos por Spinoza y demostrada por la neurología ya desde finales del siglo pasado.
} 
Tal como reflejan expresamente en sus conclusiones, este estudio demuestra que se puede adquirir una habilidad física simplemente a través de práctica mental. En efecto, los resultados obtenidos por el grupo de práctica física fueron tan buenos como los del grupo de práctica mental, aunque éste sigue siendo inferior a la práctica física en la generalización de los efectos de la práctica física (como, por otra parte, no podía ser de otro modo). En conclusión, no cabe ninguna duda a la hora de evaluar más que positivamente la práctica mental como una ayuda valiosísima en la adquisición y mejora de habilidades que requieren una ejecución motora.

Aparte de estos tres interesantísimos experimentos, queríamos citar un estudio realizado en abril de 2015 por Philip Fine, Karen Wise, Ricardo Goldenberg y Anabela Bravo: Performing musicians' understanding of the terms 'mental practice' and 'score analysis'. Se trato de una entrevista realizada online a 89 intrumentistas (60 británicos, 21 portugueses y 8 españoles), de entre 19 y 70 años, 46 hombres y 40 mujeres (3 no especificaron género), un $56 \%$ de los cuales eran profesionales, el $27 \%$ semiprofesionales y el restante $17 \%$ amateur. La encuesta planteaba 18 preguntas sobre lo que entendían por práctica mental y su utilidad en el trabajo que realizaban (la otra parte del estudio insistía sobre el análisis de partituras, que no citaremos por no tener relación directa con lo que tratamos). De las conclusiones extraídas por los autores hay dos elementos que nos parecen interesantes: en primer lugar, la falta de consenso en torno a lo que significa práctica mental, algo que destacan los propios autores del estudio de manera expresa, incidiendo en el hecho de que habría que trabajar en el futuro sobre el asunto, dada la importancia que tiene. Y, en segundo lugar, el acuerdo general de todos los entrevistados acerca de la eficacia de las distintas formas de práctica mental que pueden usarse. Cada uno sugirió sus estrategias particulares, pero todos coincidieron en señalar que era de gran utilidad para la ejecución, la interpretación, la memorización, la solución de problemas, la preparación mental, la eficacia, etc. Y, lo más curioso de todo, los autores citaban, al final de las conclusiones, el estudio de Bernardi et al. (el mismo que hemos comentado en primer lugar) para demostrar lo acertado de todas estas afirmaciones.

Con todo lo dicho, parece inevitable afirmar la importancia de la práctica mental dentro de las herramientas del músico en la búsqueda de la excelencia. Hasta ahora, lo que siempre se había 
tenido en cuenta (a veces de manera casi obsesiva) era la multiplicación exacerbada de la práctica física $^{30}$. Y no cabe duda de que ésta es la herramienta principal para cualquiera que quiera dominar una disciplina que requiera habilidades motoras finas (como hemos señalado anteriormente, deportistas, médicos cirujanos, músicos, etc.). Pero en las últimas décadas los avances neurológicos están demostrando lo que algunos ya habían adelantado hace 4 siglos: la correlación existente entre lo que llamamos "cuerpo" y lo que denominamos "mente" y que se concreta en la imbricación existente entre el uno y la otra. Así, la práctica mental, hasta ahora poco menos que una excentricidad practicada por algunos ${ }^{31}$, es una estrategia de extraordinaria importancia en la adquisición de habilidades físicas. Los experimentos comentados (que no son más que una muestra mínima de los miles que existen, tal como hemos indicado unas líneas más arriba), avalan lo que decimos, de forma que la conclusión se impone casi por sí sola: todo músico que pretenda conseguir un alto nivel de pericia musical y dar lo mejor de sí mismo debería incluir entre sus estrategias de aprendizaje la práctica mental. Y, para ello, es fundamental que los profesores de música, tanto en conservatorios como en escuelas de música y similares, conozcan en qué consiste, cuáles son sus modalidades y posibilidades, así como los estudios realizados al respecto (si no todos, por pura imposibilidad material, sí aquellos que son más relevantes), para de este modo poder transmitírselo a sus alumnos y que éstos le saquen todo el partido posible.

\subsection{El trabajo del punto fuerte}

Aunque hemos definido la excelencia desde el principio de nuestro estudio como: "un proceso continuo de adquisición y consolidación de un conjunto de habilidades necesarias para un alto nivel de maestría en uno o más campos de la vida” (Sternberg, 2005), parece una contradicción decir que buscamos la excelencia y que todos los alumnos del Conservatorio

\footnotetext{
${ }^{30}$ Podríamos citar aquí de nuevo la teoría de las 10.000 horas de práctica física necesaria para alcanzar el dominio de la técnica instrumental.

${ }^{31}$ Aunque, a decir verdad, la encuesta realizada por Fine et al. demuestra que, de algún modo, todos los músicos usan algún tipo de práctica mental en su aprendizaje personal, si bien no de manera "formal", son más bien de manera "autodidacta".
} 
Superior de Música de Navarra van a ser excelentes músicos, pues en la misma palabra excelente lleva incluida la idea de sobresalir, de ser mejor que los demás. Sin embargo se puede ser excelente en muchas cosas, la idea de que conseguir la excelencia es algo uniforme es equivocada, pues se puede ser excelente como músico en formas muy diferentes y siendo excelente en muchos aspectos distintos. Podemos ver que aunque haya que desarrollar unas habilidades básicas o como dicen las investigaciones las habilidades que deberíamos desarrollar para tener éxito como músico en el siglo XXI (Hallam y Gaunt, 2012) ${ }^{32}$, lo cierto es que no todos los músicos excelentes tienen todas las habilidades desarrolladas al mismo nivel, y es necesario ser conscientes de que es importante trabajar el punto fuerte porque es donde tenemos facilidad para seguir mejorando y es donde realmente se puede sobresalir y ser excelente. En muchas ocasiones, la frustración llega al ver que no se mejora y muchas veces es porque se trabajan mucho los puntos débiles y no tanto los puntos fuertes, que son los que ayudan a mantener la motivación y a disfrutar con el trabajo bien hecho. Suele ser más fácil encontrar estrategias para trabajar el punto débil porque siempre se está a un menor nivel de profundización y siempre es más fácil darse cuenta de las faltas que se comenten y, sin embargo, es más complicado seguir trabajando y mejorando de forma creativa y con garantías de que es una buena manera de trabajar algo que ya está muy bien y en lo que en algunos casos el alumno puede estar en un mayor nivel, incluso superando a su profesor. Esta idea del trabajo del punto fuerte para conseguir la excelencia no es exclusiva de los músicos. Lo mismo ocurre con otras artes. Se puede decir que la pintura española en general es una escuela pictórica en la que se destaca como punto fuerte el color sobre el dibujo, dando mayor importancia a la representación de texturas y calidades que a definición de su forma. En definitiva, que es más importante el efecto final que la corrección. Podemos poner como ejemplos el caso de Zurbarán que aunque no era muy bueno con la perspectiva consigue cautivar al público (Cherry, 1997) y el caso de Goya que no lograba representar muy bien anatómicamente el cuerpo y sin embargo conseguía potenciar lo humano por medio del color y la textura (Glendinning, N. (1992). Tras el genio de estos artistas podemos descubrir el desarrollo de su punto fuerte como su mayor atracción, de forma que sus puntos débiles se perdonan sin problemas.

\footnotetext{
${ }^{32}$ Y que detallamos en el primer capítulo
} 
Para poder ser capaz de pasar por alto sus puntos débiles en un momento determinado, el artista debe estar muy convencido de lo que hace. De hecho, el considerar algo como punto débil puede ser un punto fuerte en otro momento. Dado que la atención es limitada el artista debe ser capaz de darse cuenta de en qué debe de poner sus esfuerzos en cada momento.

Si tenemos en cuenta todo esto, no se puede tener la noción simplista de que la buena enseñanza es sólo cuestión de técnica. Es necesario ser consciente de la importancia de crear un buen ambiente de aprendizaje donde el alumno pueda desarrollarse según sus características y necesidades. Si esto es así, podemos afirmar lo que dice Bain: "la mejor enseñanza es a menudo una creación intelectual y un arte interpretativo” (2004:174).

La labor creativa del profesor consistirá muchas veces básicamente en ayudar al alumno a planificarse y organizarse, teniendo en cuenta sus características y necesidades, sus puntos fuertes y débiles, trabajando lo que se considera más necesario en cada momento (aunque en ocasiones no sea lo más agradable para él), alternándolo con el trabajo de su punto fuerte, dándole estrategias para seguir trabajando el punto fuerte, siendo ambos conscientes de qué es lo que le puede llevar a la excelencia y explicándole la necesidad de trabajar otras cosas (en ocasiones más difíciles para él) pero necesarias para el mejor desarrollo como músico (sin olvidarse de que el trabajo de algunos de sus puntos débiles también le puede ayudar a mejorar su punto fuerte). Pero sobre todo su labor debe dirigirse hacia la motivación, pues el ver la facilidad con la que mejora en algún aspecto (su punto o puntos fuertes) le va a ayudar a perseverar en la tarea que se convierte en "autotélica" (que se recompensa por sí misma). Para conseguir todo esto va a ser necesario crear el entorno natural para el aprendizaje crítico, apoyándose en el conocimiento de lo que se sabe sobre los músicos y las investigaciones recientes y siendo conscientes también de la importancia de los recursos personales e institucionales para llegar a buen término.

En el desarrollo de nuestra investigación, al preguntar a los alumnos de música de la enseñanza superior por sus puntos fuertes, su respuesta más inmediata es que no tenían puntos fuertes o no tenían muy claro en qué son muy buenos. Por supuesto, aquí también entra el factor cultural que identifica que parece que decir que se es bueno en algo, se ve como un rasgo de prepotencia. Sin embargo, al preguntarles sobre sus puntos débiles las respuestas son muy rápidas, todos tienen claro qué hacen mal. Al hacerles reflexionar sobre por qué hay tanta facilidad para reconocer el punto débil, un comentario que llama la atención es: "Es fácil 
tenerlo claro porque te machacan con tus defectos todo el tiempo". A los que no encontraban sus puntos fuertes se les pidió que preguntaran en su entorno más cercano a personas que les conocieran y apreciasen sobre sus puntos fuertes y algunos se quedaron muy sorprendidos de que las personas de su entorno coincidieran en ocasiones con su punto fuerte cuando ellos no eran conscientes de que lo tenían. El que los demás les dijeran que lo tenían les ayudó mucho a poder reconocerlo.

Lo que reconocen todos los alumnos de nuestros grupos de discusión es que trabajan mucho sus puntos débiles y que, en ocasiones, se les hace muy duro por la poca eficacia que ven en su trabajo. Dedican mucho tiempo para conseguir muy poco. La idea de la importancia de seguir trabajando el punto fuerte porque en eso es en lo que pueden ser excelentes les parece novedosa. De hecho, algunos incluso reconocen que eran buenos en algo que casi no trabajaban porque se concentraban en trabajar lo que se les daba mal y se dan cuenta de que van perdiendo la habilidad en la que eran muy buenos. Al animarles a trabajar su punto fuerte, explicándoles que es lo que les dará más satisfacción, ya que es en lo que tienen más facilidad, con un poco de trabajo se darán cuenta de que avanzan mucho, aumentando su motivación. Un ejemplo de esto es un testimonio que lo explica de la siguiente forma:

Desde que he incluido en mi tiempo de práctica el trabajo de la improvisación (donde siempre he tenido facilidad y casi tenía olvidado) disfruto mucho más y aprovecho más no sólo ese trabajo, sino todo el tiempo de estudio.

Para nosotros es interesante conseguir que los alumnos sean conscientes de que, si han llegado a la enseñanza superior de música, es porque tienen el talento necesario para ello. Más aun, que han dedicado el esfuerzo necesario para conseguirlo y, por lo tanto, tienen que reconocer sus puntos fuertes, de modo que puedan apoyarse en ellos y así poder seguir desarrollando su talento. Solo así podrán enfrentarse a sus puntos débiles, de cara a desarrollarse profesionalmente como músicos. Como dicen Ackerman y Hambrick, "el talento es importante", pero podemos añadir que esto, en realidad, no es un problema, porque todos tenemos algún talento propio. En esta línea, Hallam y Gaunt (2012) dicen que para tener éxito como músicos necesitamos conocer a la perfección nuestras debilidades y nuestros puntos fuertes. En nuestra opinión, los músicos, al menos en España, están constantemente centrándose en sus puntos débiles y, en consecuencia, tratando de solucionarlos. Es algo que 
no está mal, desde luego, pero sería quedarnos con una visión parcial, reduccionista y, en cierto modo, negativa de uno mismo. Por eso es importante trabajar en lo que se nos da bien, en nuestros propios talentos, de cara a motivarnos y conseguir la excelencia.

En este sentido, nos parece interesante ilustrar este punto con un ejemplo ocurrido este año. El día antes de las vacaciones de Semana Santa uno de los alumnos participantes en la investigación me comentó que tenía un problema: no tenía motivación para estudiar. Literalmente: "no tengo ninguna gana de tocar ni de estudiar. Cada vez es más difícil aprender algo porque, como nos has enseñado, Sloboda dice que hay tres elementos fundamentales que se deben poner en práctica: saber cómo está estructurado el material, ponerlo en práctica y motivarme para ensayarlo tanto como hace falta. Y en estos momentos no sé qué hacer para motivarme". Al preguntarle por las causas de esa falta de motivación (si no le gustaba el profesor, el instrumento o el repertorio; o si tenía problemas personales con su familia, amigos o pareja) contestó que, en ese sentido, no había nada que objetar. A continuación, le pregunté cuál creía que era su punto fuerte con el instrumento y me contestó que lo que mejor se le daba era llegar con facilidad a los agudos. Le pregunté si seguía trabajando este aspecto, es decir, si podía mejorar en este aspecto, a lo cual me sonrió y me dijo que lo intentaría, a ver si la cosa mejoraba. Pasadas las vacaciones, volví a preguntarle por el asunto y me contó una divertida anécdota. Estaba tocando con un amigo y, como si fueran dos chiquillos, empezaron a retarse para ver cuál de los dos podía llegar más alto y con más facilidad. En un momento dado, el amigo se detuvo, le miró con cara de sorpresa y le preguntó: "¿pero cómo diablos puedes hacer eso? ¡Es genial!". Su respuesta fue algo así como que no lo sabía, que era su talento personal, pero que podía aun mejorarlo si lo trabajaba. Evidentemente, había encontrado su motivación a partir de lo que él mismo había trabajado en clase. 


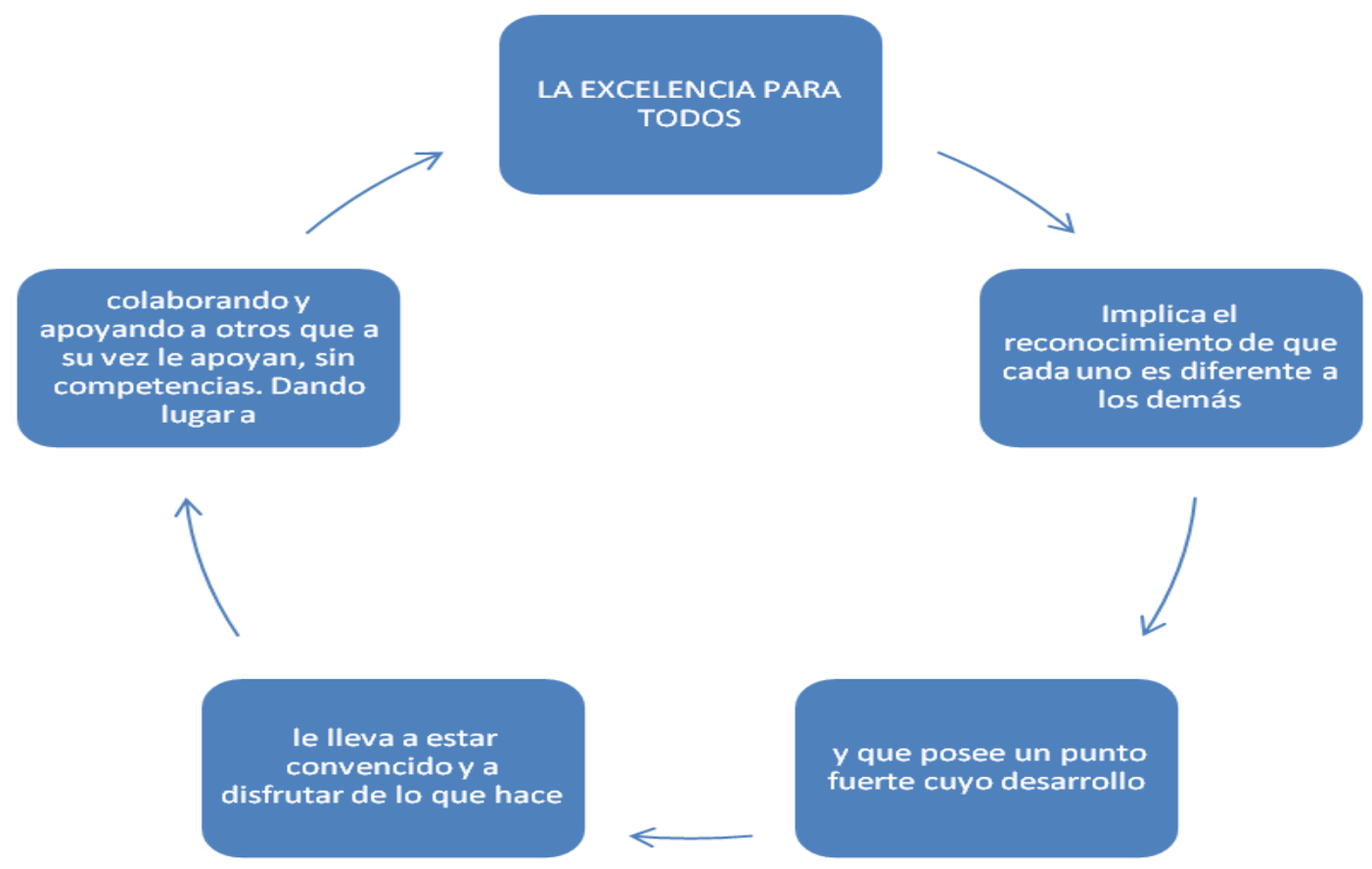

Ilustración 8. Esquema: La excelencia para todos. Elaboración propia.

\subsection{La enseñanza de música en los conservatorios superiores como logro individual y social. Propuesta de un aprendizaje complejo}

La propuesta de aprendizaje complejo que proponemos se deriva de las tres ideas fundamentales ya expuestas y explicadas anteriormente:

1-Toda búsqueda de la excelencia debe estar apoyada en el saber existente,

2- la idea o producto que merece la etiqueta de "excelente" surge de la sinergia de muchos recursos y no sólo de la mente de una única persona; y

3- para conseguir la excelencia es necesario crear un ambiente que proporcione libertad de acción y estimulación de ideas, junto con una actitud de respeto y apoyo entre todos los miembros de la comunidad educativa.

John Sloboda, como ya ha quedado dicho anteriormente, insiste en que el profesor mejore constantemente en su práctica docente, y para ello aportaba cuatro elementos imprescindibles: conocer al alumno, quererle, tener altas expectativas y darle buena información. Y, en línea 
con lo que venimos diciendo, insiste en que es muy útil fundar un pequeño grupo con intereses comunes, mutuo reconocimiento, aprecio y estímulo, con trato respetuoso y no crítico para revisar su práctica docente en ese momento (Sloboda, 1987, 335-355).

En la propuesta que ahora se expone, se parte de la idea de que cada uno de los alumnos de la enseñanza superior va a ser su propio profesor a lo largo de la vida (el que va a estar más tiempo con él y el que va a tener más a mano en todo momento) y que, por tanto, se puede aplicar el esquema que Sloboda utiliza para ver qué puede hacer para mejorar como profesor de sí mismo. En esta propuesta se aplican estas ideas, actualizándolas e incluyendo las últimas investigaciones sobre el tema.

Antes de poder aplicar esta idea (la de que cada alumno sea su propio profesor) hay que ser conscientes de que es importante conocerse y ver en qué podemos cambiar, estar abierto a cambiar si es necesario y nos favorece, y la utilidad de ese cambio para aprender mejor. Para ello, se parte de los trabajos de Dweck y sus colaboradores (ya expuestos con detalle en el capítulo primero) donde se mostraba claramente que los estudiantes que tienen una idea de la inteligencia como algo fijo e inmutable suelen obstaculizar sus propias estrategias de resolución de problemas cuando se enfrentan con dificultades. Y que, en cambio, los que ven su inteligencia como algo que se puede desarrollar hacen frente a los retos con entusiasmo y muestran un esfuerzo más intenso, mantienen el optimismo y utilizan estrategias efectivas cuando se enfrentan a los obstáculos (Dweck, 2006). Como también se ha visto anteriormente, estos dos tipos de inteligencia también han sido estudiados en música (O’Neill, 1997, O’ Neill y Sloboda, 1997, en McPherson y Zimmerman, 2002) y concretamente en alumnos con edades comprendidas entre los seis y los diez años llegando a las mismas conclusiones que Dweck (tal como hemos reseñado anteriormente). Estos hallazgos sugieren que las teorías de la inteligencia de los estudiantes son maleables y que podemos ejercer un efecto causal en los objetivos que persiguen éstos. Es decir, que con la lectura de textos relativos a la teoría de inteligencia en crecimiento se ven más capaces de conseguir lo que se proponen. Susan O’Neill también ha examinado el rol que la motivación, las auto-teorías y la resiliencia ocupan en el desarrollo de la mente en crecimiento de los músicos jóvenes (2011). Todo esto nos ha servido como punto de partida para nuestra propuesta.

Lo que se quiere lograr con ésta es ver si en los conservatorios superiores de música se puede aplicar esta teoría de las inteligencias y si es posible que los alumnos de la enseñanza superior 
de música transiten, en el caso que sea necesario, de la inteligencia fija a la inteligencia en crecimiento e incluso que apliquen los trucos que les funcionan de manera individual en lo que se les da bien, en los aspectos o contextos donde se ven con inteligencia en crecimiento, a otros contextos o aspectos en los que se ven con inteligencia fija. Para esto será necesario que conozcan esta teoría, de modo que vean que esa posibilidad existe, estudien las investigaciones sobre el aprendizaje musical y la excelencia para que sean conscientes de que es importante trabajar en función de sus necesidades, habilidades y expectativas individuales, y cómo pueden contribuir e intercambiar conocimientos, experiencias y hallazgos que se complementen con los de sus compañeros para lograr esa excelencia en grupo tan necesaria, de modo que estén motivados a reflexionar y dedicar el tiempo y el esfuerzo necesario para conseguirlo.

Como se explicaba anteriormente, para poder cambiar algo es necesario conocer bien qué es lo que queremos cambiar y qué podemos mejorar con el cambio. Para ello utilizamos la idea de que nuestros alumnos sean sus mejores profesores, aplicando las ideas de Sloboda para mejorar como profesor. Esta reflexión sobre nuestra forma de hacer las cosas, necesidades e intereses ayuda a poder después plantear la forma de pasar a aplicar las estrategias de la habilidad exitosa de cada uno a otras habilidades no exitosas pero necesarias para lo que quiero conseguir. Con ello, se intenta pasar de mentalidad fija a mentalidad en crecimiento, aplicando lo que ya se haya comprobado como útil para cada uno y que se ha visto que le funciona de forma personal e individual en su habilidad exitosa.

\subsubsection{El estudiante de músicas como su mejor profesor.}

En lo que sigue vamos a utilizar el modelo que Sloboda (1987) propone para mejorar como profesor, pero de modo completamente nuevo: la idea es que el alumno asuma que ellos mismos han de convertirse en sus propios profesores y, en ese sentido, que puedan ser incluso "su mejor profesor" (al tiempo que reflexionan sobre su propia práctica).

Los ejercicios que se van a ir proponiendo se han actualizado con la lectura de algunas de las últimas investigaciones en cada uno de los puntos que se proponen: 
A. Conocerse a sí mismo. Análisis de la habilidad exitosa de cada uno

Es importante conocerse a la hora de trabajar, ver qué estilo de pensamiento utiliza cada uno, cuáles son sus puntos fuertes y débiles y la capacidad de trabajo y resiliencia. También se les pide que reflexionen sobre su propia práctica, tanto a la hora de interpretar como de estudiar. Para ello nos apoyamos en las investigaciones sobre el tema (Hallam et. al., y Nielsen, 2004) y se les pide que sean capaces de reconocer cuándo, cómo, dónde y con quién prefieren practicar y actuar. En este sentido, para conocerse mejor también es muy interesante analizar la habilidad exitosa o lo que dominan sin demasiado esfuerzo.

El análisis de la habilidad exitosa de cada uno permite:

$\rightarrow$ Conocerse en su mejor momento. Reconocer el estado que lleva a conseguir experiencias sublimes, momentos especiales y la sensación de flujo (lo que Csiszentimihalyi, 1996, llama "flow")

$\rightarrow$ Darse cuenta de cómo utiliza la mentalidad en crecimiento en este campo (Dewck, 2006)

$\rightarrow$ Ser consciente de dónde pone el foco de atención para hacerlo bien (Buma et al., 2015, Goleman, Gonzáles y Mora, 2013)

$\rightarrow$ Analizar cómo utiliza la creatividad cuando se está en buen momento (Csikszentimihályi, 1996; Sternberg, 1996; Gardner, 2005; Kaufman y Sternberg, 2006)

$\rightarrow$ Reconocer qué estilo de aprendizaje utiliza y si es capaz de cambiarlo o no en función de las necesidades. (Sternberg, 1997 y Zhang, 2013). "Entendiendo tu propio estilo y las formas de pensar de los demás, verás mejor cómo conocerte a ti mismo y saber cómo ser eficaz con otros". (Sternberg, 1997:44)

$\rightarrow$ Analizar cómo maneja las emociones y cómo consigue el control de la situación (Ciarrochi, Forgas y Mayer, 2001)

\section{B. $\quad$ Quererse}

Es importante conocer las formas en las que cada uno se autorrecompensa. Averiguar qué le gusta y con qué disfruta cada uno y utilizar la forma que le es más gratificante para hacer las cosas de forma individual y creativa, apoyándose en las habilidades específicas que tiene cada 
uno y en su estilo de aprendizaje. Seguir trabajando el punto fuerte o la habilidad exitosa, es decir, el talento que tenemos más fácilmente desarrollable para conseguir experiencias autotélicas, es decir experiencias que se recompensan por sí mismas y de las que no se espera una recompensa posterior. El trabajo en nuestro punto fuerte, donde con un poco de esfuerzo obtenemos mucho desarrollo, es lo que anima a seguir buscando para seguir disfrutando.

$\rightarrow$ Analizar las estrategias para lograr bienestar (Csikszentimihályi, M. y Csikszentimihályi, I., 2006). Disfrutar de la consecución de nuestros objetivos individuales, y a nuestra manera, a lo largo de la vida.

\section{C. $\quad$ Tener altas expectativas}

$\rightarrow$ Plantear objetivos y retos que le ayuden a desarrollarse.

$\rightarrow$ Buscar actividades que se recompensen en sí mismas y que se apoyen en sus puntos fuertes.

$\rightarrow$ Disfrutar de la consecución de sus objetivos a su manera a lo largo de la vida, adaptándose a las necesidades individuales que se presenten en cada momento.

\section{Darse buena información}

$\rightarrow$ Conocer las últimas investigaciones sobre cómo conseguir la excelencia musical (Hallam y Gaunt, 2012 hacen una buena compilación de lo que sería interesante tener en cuenta).

$\rightarrow$ Conocer cuáles serán las habilidades cognitivas específicas más apreciadas en el futuro y que, por tanto, deberíamos seguir desarrollando toda la vida. (Gardner, 2005)

$\rightarrow$ Buscar opiniones de distintos profesores, amigos y mentores en los que confiemos.

E. $\quad$ No aislarse

Fundar un pequeño grupo de apoyo con interés común, mutuo reconocimiento, aprecio y estímulo, con trato respetuoso y no crítico para revisar:

$\rightarrow$ Qué es bueno en las situaciones y realizaciones de cada uno en ese momento.

$\rightarrow$ Qué es lo que está siendo más difícil o insatisfactorio 
$\rightarrow$ Qué planes y metas tiene cada uno para el próximo período

$\rightarrow$ Qué medios y ayudas necesitarán para lograr cumplir sus objetivos.

\subsubsection{Aplicar las estrategias del punto fuerte a otras habilidades no exitosas.}

Se pide que apliquen de forma individual alguna de las estrategias que utilizan en su habilidad exitosa a otras habilidades no exitosas pero necesarias para lo que se quiere conseguir. Se pretende que con la lectura de las investigaciones y el conocimiento de la teoría de los dos tipos de mente fija y en crecimiento (Dweck, 1999 y 2006) apliquen cada uno de forma individual lo que ha comprobado que es útil para él y ha comprobado que le funciona de forma personal e individual a su habilidad exitosa. 


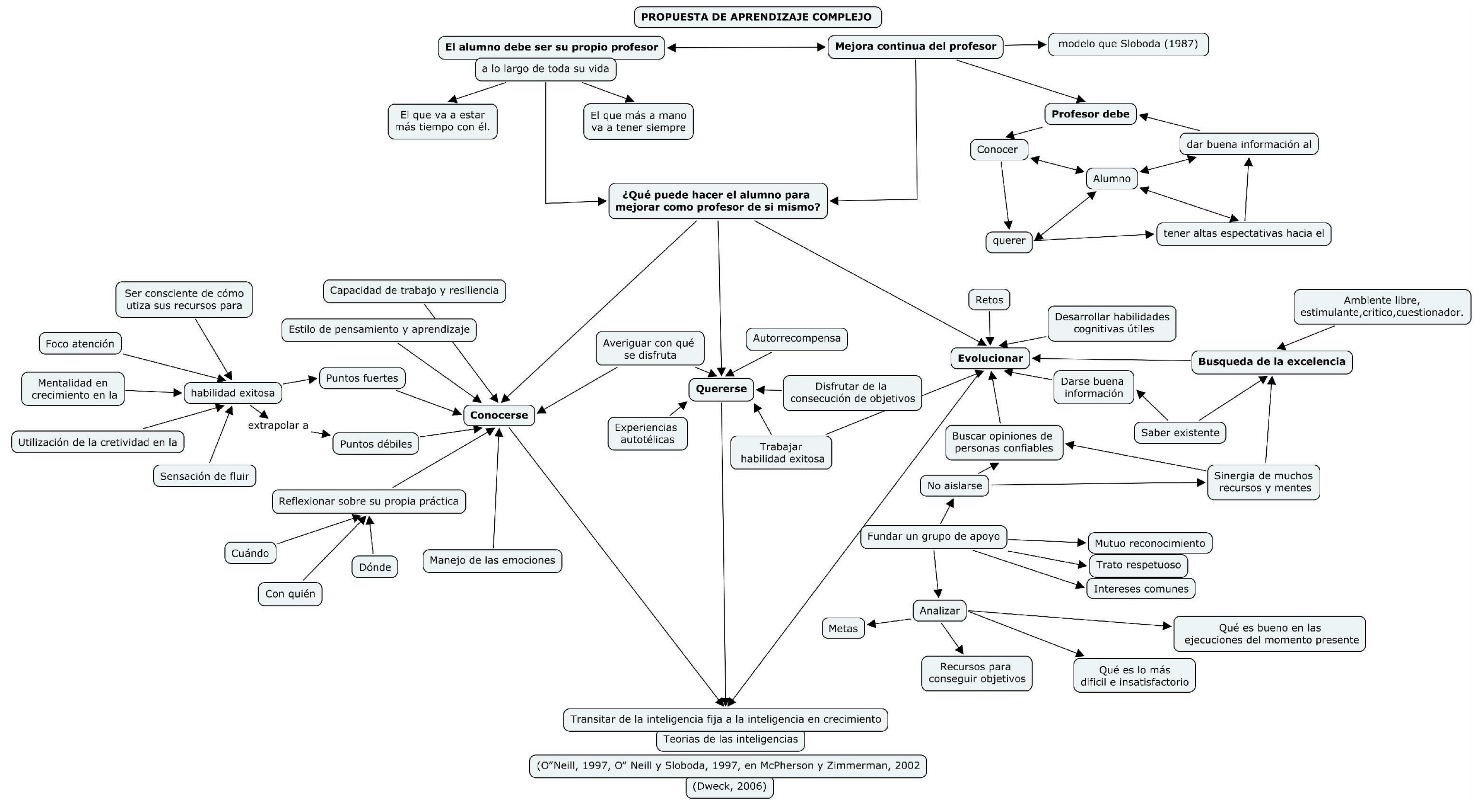

Ilustración 9. Esquema: Propuesta de aprendizaje complejo. Elaboración propia. 


\section{PARTE III}

FASE EXPERIMENTAL 



\section{FASE EXPERIMENTAL}

\subsection{Aproximación metodológica: investigación acción}

El trabajo que hemos realizado se enmarca dentro de la investigación acción. De las múltiples definiciones que se pueden encontrar sobre este estilo de investigación (Corey,1953; Hopkins, 1985; Elliot, 1978; Carr y Kemmis, 1986; Kemmis y McTaggart, 1992; Cohen y Manion, 1994; Somekh, 1995, en Cohen, Manion y Morrison, 2011) parece que la que mejor podría encajar con el planteamiento de nuestra investigación es la de Ebbutt, que define la investigación acción como un estudio sistemático que combina la acción y la reflexión con la intención de mejorar la práctica (1985, en Cohen, Manion y Morrison, 2011: 345).

Según Cohen, Manion y Morrison (2011:129) este modelo de investigación tiene como propósitos los siguientes: planificar, implementar, revisar y evaluar una intervención diseñada para mejorar la práctica de un problema local; fortalecer a los participantes en la investigación por medio de su implicación en la investigación y la ideología crítica; desarrollar la práctica reflexiva; promover la democracia social y la igualdad; unir práctica e investigación y promover la investigación colaborativa. Su foco se centra en las prácticas cotidianas, los resultados de las intervenciones, el fortalecimiento de los participantes, la práctica reflexiva, la igualdad y democracia social y la toma de decisiones. Las características que se pueden destacar son que tiene un contexto específico, los participantes actúan como investigadores, se trabaja la reflexión en la práctica, tiene un carácter intervencionista, es decir, lideran la solución de problemas "reales" y encuentran necesidades "reales", se produce un fortalecimiento de los participantes, se trabaja la colaboración, se promueve la práctica y la igualdad y los participantes están muy involucrados en la investigación.

Pero además (y añadimos esto porque nos sentimos plenamente identificados con lo que dicen estos autores) Hult y Lennung (1980:241-50) y McKernan (1991: 32-33) en Cohen, Manion y Morrison 2011: 346), sugieren que la investigación acción ${ }^{33}$ :

33 Traducción propia del original en inglés. 
- trabaja por resolver problemas prácticos al tiempo que amplía el conocimiento científico;

- mejora las competencias de los participantes;

- es colaborativo;

- se desarrolla directamente in situ;

- usa la retroalimentación desde los datos en un proceso cíclico en curso;

- busca entender situaciones sociales particularmente complejas;

- busca entender los procesos de cambio dentro de los sistemas sociales;

- se lleva a cabo dentro de un marco ético consensuado;

- busca mejorar la calidad de las acciones humanas;

- se centra en los problemas que son de inmediata preocupación para los participantes;

- es participativa;

- tiene a evitar el paradigma de investigación que aísla y controla las variables;

- es formativa, es decir, que la definición del problema, los objetivos y la metodología pueden cambiar durante el proceso de investigación acción;

- incluye evaluación y reflexión;

- es metodológicamente ecléctica;

- contribuye a una ciencia de la educación;

- se esfuerza por conseguir que la investigación sea útil y compartida por los participantes;

- es dialógica y celebra la conversación y el diálogo;

- tiene un propósito crítico;

- se esfuerza por ser emancipatoria.

En nuestro caso, el principal foco de atención de la investigación se ha centrado en mejorar las herramientas que ayudan a los estudiantes de la enseñanza superior de música a buscar la excelencia musical. Para ello se intentó que los participantes se implicaran en la investigación (tal como se ha comentado en el párrafo anterior), reforzando su responsabilidad en lo que estaban haciendo y analizando de forma crítica las prácticas que realizaban para su consecución, apoyándose para ello en las últimas investigaciones, en la reflexión sobre la práctica que realizan y en el trabajo colaborativo. La investigación invitaba a reflexionar 
sobre su propia práctica durante un cuatrimestre, al mismo tiempo que compartían experiencias con un grupo. El compartir experiencias con el grupo se convirtió en un elemento muy significativo dentro de la investigación, pues hizo que cada uno de los participantes tomara conciencia de su forma de hacer las cosas y pudiera compararla con otras perspectivas, lo que les permitió beneficiarse en conjunto de las prácticas e ideas de los demás, encontrando otras alternativas y ayudándoles a mejorar o modificar las suyas propias. Todo esto se desarrolló en un ambiente de aprendizaje crítico que, como hemos comentado, fue un catalizador necesario para ese trabajo en grupo que estábamos realizando y que no es ni más ni menos que el aprendizaje colaborativo que utilizamos posteriormente como una herramienta imprescindible para desarrollar la "propuesta de aprendizaje complejo", donde aparece el modelo de estudiante convencido y apoyado que creíamos necesario para desarrollar la excelencia musical.

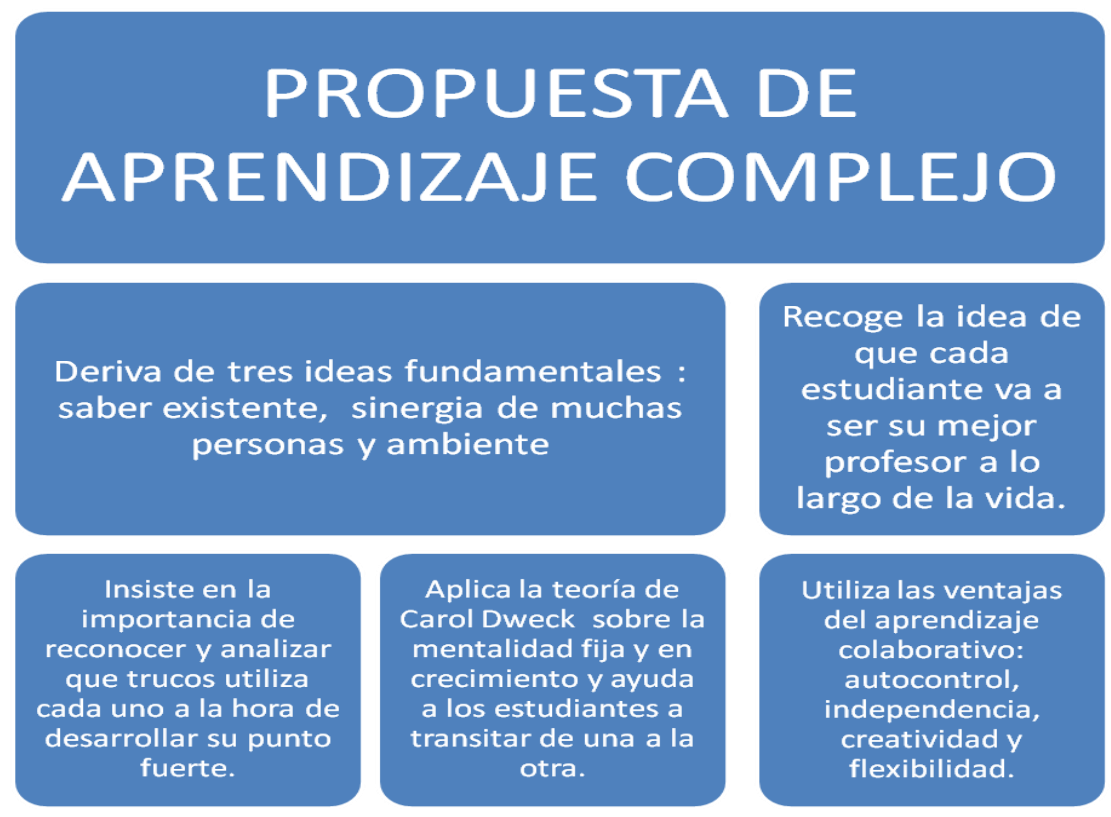

Ilustración 10.. Definición de la propuesta del aprendizaje complejo.

La idea fundamental es que los estudiantes se den cuenta de la importancia de la lectura de las investigaciones y cómo el conocimiento y la reflexión al respecto podía ayudarles a conseguir la excelencia musical. Para ello se prepararon una serie de lecturas que les hicieran reflexionar sobre lo que estaban haciendo, y que fueran especialmente atractivas y útiles para, a partir de las mismas, pedirles que hicieran unas actividades que reforzaban lo contenido en las lecturas. 
Al hilo de esto debían hacer una serie de experiencias que les ayudaran a reflexionar sobre su propia práctica, ayudados por sus compañeros y utilizando el aprendizaje colaborativo. Todo esto se enmarca dentro de una "propuesta de aprendizaje complejo" que se caracteriza por:

a- Deriva de las tres ideas fundamentales expuestas en el capítulo primero de la presente tesis y que tienen como objetivo el desarrollo de la excelencia: se apoya en el saber existente (para lo cual, precisamente, necesita seguir aprendiendo y estar al día de lo que dicen las últimas investigaciones); necesita muchos recursos materiales y personales y necesita de un ambiente que proporcione libertad de acción y estimulación de ideas, junto con una clara actitud de respeto y apoyo entre todos los miembros de la comunidad. Recoge igualmente la idea de que cada estudiante de la enseñanza superior va a ser su propio profesor a lo largo de la vida, de modo que le es muy útil aplicar las ideas que propone Sloboda (1987) para tratarse mejor a sí mismo (conocerse, quererse, tener altas expectativas, proporcionarse buena información y no aislarse); las que proponen Hallam y Bautista (2012:667-669) para desarrollarse como estudiante independiente (aprovechar las oportunidades para tocar, improvisar, componer y actuar con otros, desarrollar habilidades creativas, metacognitivas y autorreguladoras para manejar el aprendizaje y la motivación, identificar objetivos a corto, medio y largo plazo y trabajar en su consecución; trabajar tanto el ensayo mental como el físico e intentar asegurarse de que el ambiente de aprendizaje que le rodea le conduce a conseguir sus objetivos, entre otros) y las que proponen Lehmann y Jorguesen (2012:686-687) para que los profesores enseñen a sus alumnos a que su práctica sea más efectiva. Esta reflexión sobre sí mismo, su forma de hacer las cosas, necesidades e intereses y su confrontación con la investigación le ayudará a poder plantear mejoras.

b- Insiste en la importancia de reconocer, analizar y ver qué trucos utiliza cada uno, (muchas veces de manera intuitiva o inconsciente) a la hora de desarrollar su "punto fuerte".

c- Aplica la teoría de Carol Dweck $(1998,2006)$ sobre la mentalidad fija y en crecimiento y ayuda a los estudiantes de la enseñanza superior a transitar de la inteligencia fija a la inteligencia en crecimiento. El solo hecho de conocer que existen las dos les ayuda a cambiar de una a la otra y este cambio es mucho más sencillo en un contexto de aprendizaje colaborativo.

d- Utiliza las ventajas del aprendizaje colaborativo en la educación musical superior, reconocidas por Gaunt y Westerlund (2013), que señalan el impacto que tiene a la hora de 
apoyar el desarrollo del control del propio aprendizaje, la independencia, la creatividad y la flexibilidad. En nuestra propuesta, el contar con un grupo de apoyo a la hora de aprender le va a ayudar al alumno a estar convencido, reconocido y valorado, lo que le lleva a valorar lo que tiene de individual, valioso $\mathrm{y}$, por tanto, excelente, de modo que pueda utilizarlo en otros momentos de forma creativa para ampliar su campo de excelencia.

La investigación ha sido mixta, aunque haciendo especial hincapié en lo cualitativo. Decimos que es cualitativa, en cuanto que emplea técnicas cara a cara para recoger los datos de la gente en sus escenarios naturales, de manera que los datos se puedan interpretar en función de los significados que la gente les da (McMillan y Schumacher, 2007). Y eso es precisamente lo que hemos hecho en esta investigación: utilizar esas técnicas que nos permitían ponernos "cara a cara" con el objeto y los sujetos del mismo: la excelencia musical y sus herramientas por un lado y el alumnado del Conservatorio Superior de Música de Navarra por el otro.

Para ayudar a los estudiantes a entender la importancia de conocer las investigaciones de cara a conseguir la excelencia musical se han diseñado unas actividades de aplicación que partían de las propias investigaciones estudiadas. De este modo, se les ayuda a reflexionar sobre su propia práctica como músicos, lo que les proporciona una primera visión sobre la utilidad de este trabajo. Con ello se espera que los estudiantes adquieran este hábito que les sirva no sólo como estudiantes sino también en su futura vida profesional. Este trabajo de lectura y aplicación individual se ha llevado al aula, lugar donde se desarrollan los grupos de discusión y donde los estudiantes expresan sus hallazgos y dificultades. Los detalles de lo que se realiza en cada clase y las reflexiones realizadas por los alumnos se comentan en el apartado referido a los grupos de discusión.

El propósito inicial de nuestra intervención práctica consistía en que los alumnos conocieran algunas de las investigaciones que más útiles podían ser para su desarrollo como músico y que, a partir del trabajo sobre estas investigaciones, consiguieran un conocimiento útil y significativo para ellos. Por eso, desde el principio del diseño de la investigación se tuvo presente que todo lo que hiciéramos les debía ayudar a reflexionar sobre las cuestiones más importantes que les pudieran preocupar como músicos, así como sobre lo que estaban haciendo en ese momento y cómo mejorarlo. En la propuesta de aprendizaje complejo, que ya hemos expuesto anteriormente, se parte de la idea de que cada uno de los alumnos de la enseñanza superior va a ser su propio profesor a lo largo de la vida (el que va a estar más 
tiempo con él y el que va a tener más a mano en todo momento), aunque por supuesto no será el único y que, por tanto, la reflexión sobre lo que está haciendo va a ser un elemento fundamental en su formación. Los beneficios de esta reflexión van a ser, por lo tanto, tan válidos para nuestros alumnos como los presentados para los profesores que ponen en práctica una enseñanza reflexiva. Estos beneficios son: liberarlos de acciones rutinarias e impulsivas, ayudarles a estar más seguros de sus acciones y sus decisiones, proporcionarles información para tomar decisiones, ayudarles a reflexionar críticamente en todos los aspectos de su trabajo, ayudarles a desarrollar estrategias para la intervención y el cambio y reconocerles como profesionales, entre otras cosas (Farrell 2007: 7). Como vemos, todos ellos son beneficios muy útiles para la consecución de la excelencia que se busca en la enseñanza superior.

Para promover la reflexión en los alumnos, propusimos las siguientes actuaciones con ellos:

$1^{\circ}$ Hacerse preguntas: sólo la realización del primer cuestionario en septiembre ya les ayuda a reflexionar. Se ve claramente en alguno de los comentarios que surgen tras su realización: "me ha hecho plantearme preguntas que nunca había pensado".

$2^{\circ}$ Comparar lo que piensan pasado un tiempo y realizadas determinadas actividades, viendo en qué cambian y en qué mantienen su opinión. Para ello, al repetir el cuestionario y dejar que ellos mismos lo comparen con el primero (el realizado en septiembre) con el segundo (realizado en enero), ellos mismos pueden reflexionar sobre los cambios que encuentran y sobre las razones que les han llevado a ese cambio.

$3^{\circ}$ Aplicar a su caso concreto lo que dicen las investigaciones. El tener que aplicarlo hace que tengan que reflexionar sobre lo que más se adapta a lo que ellos están haciendo, en qué están de acuerdo y en qué no y si les parece útil cambiarlo o no y por qué. Todo esto les empuja a reflexionar tanto sobre lo que están haciendo como sobre lo que han hecho y lo que harán en el futuro, ayudándoles en la toma de decisiones futuras.

$4^{\mathrm{o}}$ Prestar atención a puntos de vista alternativos. El tener que comparar, en los grupos de discusión, sus ideas con compañeros que tienen realidades musicales y sociales muy distintas (alumnos de clásico y de jazz, estudiantes de edad avanzada con mucho recorrido como músico con otros que acababan de terminar el instituto) también obliga a reflexionar aportando ideas y enfoques muy distintos sobre la realidad musical. Este hecho hace que la 
reflexión que se produce sea mucho más enriquecedora y útil de cara a su vida profesional, según ellos mismos señalan.

La investigación llevada a cabo en el Conservatorio Superior de Música de Navarra se ha desarrollado a lo largo de dos cursos académicos (2014-15 y 2015-16) en las asignaturas de Didáctica de la Música y las Especialidades, que cursan los alumnos de $4^{\circ}$ curso en las especialidades de Interpretación, Composición y Musicología y de Didácticas Específicas, que cursan los alumnos de $3^{\circ}$ de la especialidad de Pedagogía.

Los alumnos fueron seleccionados en función de su matrícula, es decir, de si estaban matriculados en estas asignaturas. Para que la muestra fuera significativa, se eligió la asignatura de $4^{\circ}$, que es obligatoria para todo el alumnado (menos los de la especialidad de Pedagogía) y la de $3^{\circ}$, que es obligatoria para los de la especialidad citada. De este modo, tendríamos una representatividad amplia, al menos dentro del contexto de nuestro conservatorio. Para dar mayor validez a nuestro estudio se suma el hecho de que el alumnado que cursa sus estudios en el Conservatorio Superior de Música de Navarra procede no sólo de nuestra comunidad, sino de casi todas las comunidades autónomas del estado español, lo que convierte a la muestra en decididamente significativa.

Tal como hemos avanzando al inicio de este apartado, el modelo de investigación acción tiene como objetivo afrontar un problema local mediante la planificación, la revisión y la evaluación de una intervención diseñada ad hoc para el mismo, al tiempo que se da nuevas fuerzas a los participantes en la misma, al implicarles directamente en la propia investigación. Una de las herramientas principales de esta investigación es la importancia que se concede a la reflexión y la colaboración dentro del grupo de sujetos investigados. De hecho, éstos se convierten, de algún modo, en investigadores, dado que lideran la solución de problemas reales que les afectan, al estar directamente involucrados en la investigación. (Cohen, Manion y Morrison, 2011).

Las actividades diseñadas para desarrollar la investigación (que, no lo olvidemos, pretende buscar la excelencia musical a partir del conocimiento de las investigaciones sobre el tema) han partido, como se ha reseñado, de la lectura de estudios que supusieran algo interesante para nuestro alumnado. Esa lectura se ha complementado con diversas actividades que luego se han comentado en grupos de discusión, donde se reflexionaba y se trataba de sacar 
aplicaciones prácticas para los estudiantes. En otras palabras, se buscaba que hubiera una reflexión crítica por parte del alumnado, y que ésta se convirtiera en una costumbre que no dejaran de lado en su vida profesional.

Así pues, las actuaciones propuestas fueron las siguientes:

a) realizar un cuestionario al principio de curso, que les sirve para hacerse preguntas acerca de su condición de músico y de la práctica cotidiana como tal;

b) repetir ese mismo cuestionario al final de la intervención pedagógica del cuatrimestre, de modo que exista una comparación crítica entre ambas series de preguntas y respuestas. La reflexión al respecto entendíamos que sería muy interesante;

c) aplicar lo que se comenta en las investigaciones a casos concretos vividos por los estudiantes. Esto les obliga a entender bien lo que aquéllas quieren decir y a reflexionar sobre lo que han hecho, lo que están haciendo y lo que harán en el futuro;

d) comparar sus puntos de vista con los demás, a partir de la participación en los grupos de discusión. La propia heterogeneidad de los grupos enriquecía notablemente las reflexiones y los enfoques aportados por los estudiantes.

Los citados cuestionarios se pasaron a todos los alumnos participantes en la investigación, dejando clara la voluntariedad de la misma y garantizando el anonimato de cada uno en todo momento. Para esto, se les pidió que hicieran una marca personal en cada cuestionario, de manera que cada uno pudiera reconocer el suyo, sin que ello supusiera una identificación ajena. Como hemos dicho, se les pasó al principio del curso y al final del mismo, pero antes de la evaluación, para evitar que ésta pudiera interferir en los resultados (Cisneros-Cohernour, 2008). De igual modo, se pasó otro cuestionario al profesorado, aprovechando la celebración de un claustro e, igualmente, garantizando el anonimato. Este cuestionario incluía algunas preguntas similares a las del alumnado, pero era menos exhaustivo. Podemos decir aquí que, del mismo modo que el alumnado de nuestro centro tiene un perfil de lo más variado en cuanto a procedencia, edad e intereses (lo que lo convierte en bastante significativo), otro tanto se puede decir del profesorado, que también tiene una procedencia de lo más heterogénea, incluyendo cuatro italianos, tres argentinos y un rumano. 
Por lo que respecta a los grupos de discusión, se organizaban dentro de cada grupo y se intentaba que no fueran muy numerosos (un máximo de 5 alumnos por grupo). El trabajo en estos pequeños grupos se llevaba siempre al gran grupo, tras una labor de vaciado y reflexión previa. Pero esto suponía, en primer lugar, un trabajo personal (la lectura del texto elegido, que representaba un aspecto de la investigación que se considera interesante, además de las actividades propuestas sobre el mismo), que luego se llevaba al grupo y acababa con la puesta en común global.

\subsection{Contexto de la investigación}

La investigación se ha llevado a cabo en el Conservatorio Superior de Música de Navarra, que es un centro público, dependiente del Departamento de Educación del Gobierno de Navarra. En este centro se imparten los estudios superiores de música, dentro del marco del Espacio Europeo de Educación Superior (EEES). Desde el curso 2011-12, se encuentra situado dentro de lo que se ha denominado "Ciudad de la Música", un entorno que está integrado por el propio Conservatorio Superior, el Conservatorio Profesional y otras entidades culturales (como la Biblioteca Pública de Navarra o la Filmoteca de Navarra, entre otras).

El objetivo principal del Conservatorio Superior de Música de Navarra es la formación de profesionales cualificados en las ramas de la interpretación, la musicología, la composición y la pedagogía musical, dotándoles de altos niveles de formación técnica, artística, teórica y humanística. Dentro de ese objetivo general se enmarcan otros, que podríamos denominar secundarios, pero que no son menos importantes que el primero. Así, este conservatorio busca también formar personas con capacidad técnica, espíritu crítico constructivo y sentido de la responsabilidad, con la máxima calidad, eficacia y rentabilidad social. De igual modo, se intenta potenciar una formación musical amplia, que permita a nuestros alumnos adaptarse a la diversidad de opciones laborales actuales y futuras en el campo de la música, teniendo como finalidad primordial su desarrollo profesional e inserción laboral.

Las nuevas instalaciones (que este curso cumplen apenas 5 años) cuentan con 6 aulas para asignaturas colectivas, 25 aulas instrumentales, 25 cabinas de estudio, 25 aulas de música de cámara, 3 aulas de percusión, un aula de órgano, una aula de movimiento, una aula de orquesta, coro y big band, un auditorio (Auditorio Guelbenzu) para audiciones de aula, una sala de informática y nuevas tecnologías, una biblioteca, una mediateca y un gran auditorio 
(Auditorio Remacha), con capacidad para 400 espectadores, además de varios despachos, oficina administrativa, conserjería y cafetería. En total, 7.438 metros cuadrados útiles.

En la actualidad, el Conservatorio Superior de Música de Navarra es miembro de la AEC (Asociación Europea de Conservatorios) y está en posesión de la Extended University Charter, la Carta Erasmus que le permite ofrecer a su alumnado, profesorado y personal no docente la posibilidad de participar en movilidades por estudios, prácticas o docencia en el extranjero.

Es interesante reseñar también que el Conservatorio Superior de Música de Navarra, como complemento a la formación que ofrece a sus alumnos, organiza constantemente cursillos y masterclasses. En los últimos años han impartido cursos en el Conservatorio Superior de Música de Navarra muchas de las principales figuras de la interpretación y de la docencia.

Durante los cursos en los que se desarrolló la presente investigación (2014-15 y 2015-16), la plantilla del centro estaba formada por 81 y 78 profesores, respectivamente. Y el número de alumnos se elevaba a 326 y 312.

\section{Alumnos matriculados en los dos cursos en los que se ha realizado la investigación por especialidades}

\begin{tabular}{lcc}
\hline Modalidad / Especialidad & Curso 14-15 & Curso 15-16 \\
\hline Acordeón & 7 & 5 \\
\hline Arpa & 1 & 2 \\
\hline Bajo eléctrico Jazz & 8 & 6 \\
\hline Batería Jazz & 10 & 13 \\
\hline Canto Jazz & 13 & 12 \\
\hline Canto & 7 & 9 \\
\hline Clarinete & 10 & 8 \\
\hline Composición & 9 & 10 \\
\hline Contrabajo Jazz & 8 & 6 \\
\hline
\end{tabular}




\begin{tabular}{|c|c|c|}
\hline Fagot & 3 & 5 \\
\hline Flauta travesera & 11 & 11 \\
\hline Guitarra eléctrica Jazz & 13 & 12 \\
\hline Guitarra & 12 & 10 \\
\hline Musicología & 11 & 14 \\
\hline Oboe & 6 & 4 \\
\hline Órgano & 4 & 3 \\
\hline Pedagogía & 57 & 53 \\
\hline Percusión & 15 & 15 \\
\hline Piano Jazz & 10 & 10 \\
\hline Piano & 15 & 9 \\
\hline Saxofón Jazz & 9 & 10 \\
\hline Saxofón & 10 & 10 \\
\hline Trombón Jazz & 6 & 5 \\
\hline Trombón & 11 & 8 \\
\hline Trompa & 0 & 1 \\
\hline Trompeta Jazz & 10 & 9 \\
\hline Trompeta & 8 & 10 \\
\hline Tuba & 7 & 8 \\
\hline Txistu & 6 & 7 \\
\hline Viola & 4 & 5 \\
\hline Violín & 19 & 18 \\
\hline Violoncello & 6 & 4 \\
\hline
\end{tabular}




\subsection{Sujetos de la investigación}

Los participantes son seleccionados por las asignaturas en las que están matriculados, siguiendo un criterio de conveniencia para seleccionar la muestra, propio de la investigación cuasiexperimental. Fue preciso cumplir una serie de premisas: $1^{\circ}$ que los contenidos se pudieran incluir dentro del currículo de la asignatura, $2^{\circ}$ que incluyera a alumnos de todas las especialidades e instrumentos y $3^{\circ}$ que fuera impartida por la profesora que realiza esta investigación, algo absolutamente necesario para poder invertir el tiempo necesario en la intervención que se proponía. Se plantea así un estudio exhaustivo de los alumnos de cuarto curso del Conservatorio Superior de Música de Navarra en las especialidades de interpretación (clásica y jazz), composición y musicología matriculados en la asignatura de Didáctica de la Música y de las Especialidades (impartida por mí) y los de tercero de la especialidad de Pedagogía en la asignatura de Didácticas Específicas (también impartida por mí), que comparten contenidos durante el primer cuatrimestre del curso. La investigación se realizó durante dos cursos académicos consecutivos (2014-15 y 2015-16), teniendo en cuenta que el alumnado de cada curso académico es diferente, ya que ninguno tuvo que repetir la asignatura. En ambas asignaturas las sesiones tenían una duración de hora y media.

Los alumnos del primer curso en el que se trabajó sobre la búsqueda de la excelencia arrojan unos datos realmente heterogéneos, ya que hay ciertas discrepancias entre los que responden al primer cuestionario y los que lo hacen al segundo (algo que hemos explicado en su momento). A continuación hacemos un desglose de los mismos por género, edad y especialidad en la que estaban inscritos.

Respondieron al cuestionario en septiembre de 201431 hombres y 24 mujeres (55 en total), con mayoría de edades comprendidas entre los 20 y los 30 años (41 individuos). El resto se distribuía de la siguiente manera: 9 alumnos de entre 31 y 40 años y 2 de entre 41 y 50 años de edad (dos no contestaban a esta pregunta). En cuanto a la especialidad de cada uno, 32 alumnos estaban matriculados en algún instrumento de clásica, 15 en Jazz, 6 en Pedagogía, 1 en Musicología y 1 en Composición, como se puede observar en la siguiente tabla: 


\begin{tabular}{cccc}
\hline Hombres & 31 & Hombres & 27 \\
Mujeres & 24 & Mujeres & 23 \\
\hline Edad & & & 38 \\
\hline $20-30$ & 41 & $20-30$ & 8 \\
$31-40$ & 9 & $31-40$ & 4 \\
$41-50$ & 2 & $41-50$ & \\
\hline $\mathrm{NC}$ & 3 & & \\
\hline
\end{tabular}

Especialidad

\begin{tabular}{cccc}
\hline Clásico & 32 & Clásico & 30 \\
Jazz & 15 & Jazz & 13 \\
Pedagogía & 6 & Pedagogía & 5 \\
Musicología & 1 & Musicología & 1 \\
Composición & 1 & Composición & 1 \\
\hline Total & $\mathbf{5 5}$ & Total & $\mathbf{5 0}$
\end{tabular}




\begin{tabular}{cccc}
\hline Hombres & 18 & Hombres & 18 \\
Mujeres & 14 & Mujeres & 14 \\
\hline Edad & 23 & $20-30$ & 20 \\
\hline $20-30$ & 5 & $31-40$ & 8 \\
$31-40$ & 3 & & 3 \\
$41-50$ & 1 & $41-50$ & 1 \\
\hline
\end{tabular}

Especialidad

\begin{tabular}{cccc}
\hline Clásico & 22 & Clásico & 22 \\
Jazz & 5 & Jazz & 5 \\
Pedagogía & 2 & Pedagogía & 2 \\
Musicología & 3 & Musicología & 3 \\
\hline Total & $\mathbf{3 2}$ & Total & $\mathbf{3 2}$
\end{tabular}

Como veremos, la primera discrepancia se produce en el número de alumnos participantes en el cuestionario de enero de 2015. Sólo 50 responderán, es decir, 5 menos que a principio de la actuación pedagógica. Y esto trae como consecuencias, que el resto de las cifras tampoco cuadre. De esos 50, 27 fueron hombres y 23, mujeres, con 38 de edad comprendida entre los 20 y los 30 años. Los 12 restantes se distribuyen así: 8 con edad comprendida entre los 31 y los 40 y 4 con una edad entre los 41 y los 50. En cuanto a las especialidades en que estaban 
matriculados, 30 lo estaban en Clásico, 13 en Jazz, 5 en Pedagogía, 1 en Musicología y 1 en Composición.

Los datos del segundo curso son más homogéneos. De entrada, coincide el número de alumnos que responden al cuestionario en los dos momentos: 32, así como la distribución de géneros (14 mujeres y 18 hombres) y la de especialidades pedagógicas (22 de Clásico, 5 de Jazz, 2 de Pedagogía y 3 de Musicología). La única discrepancia que hayamos es la de las edades, pero se puede explicar por el simple hecho de que 3 personas cumplieran años en el periodo de tiempo entre una y otra tarea y cambiaran de franja de edad, como veremos a continuación: en septiembre de 2015 había 23 alumnos de entre 20 y 30 años, 5 de entre 31 y 40 y 3 de entre 41 y 50 ( 1 no contestaba), mientras que en enero de 2016, había 20 de entre 20 y 30,8 de entre 31 y 40 y 3 de entre 41 y 50 (y nuevamente uno no contestaba).

En la investigación acción interesa recoger información de todos los sujetos implicados en la realidad a investigar, razón por la cual los instrumentos que hemos utilizado para la recogida de datos se han aplicado principalmente a los estudiantes reseñados anteriormente (unidades de análisis) y con ellos se ha trabajado en grupos de discusión. Además, se les ha pasado un cuestionario antes y después de nuestra intervención, lo que nos ha ayudado a clarificar la intervención y a reflexionar sobre la práctica, aunque también se ha obtenido información mediante un cuestionario que se ha pasado al profesorado para comprender el punto de vista de todos los participantes en el hecho estudiado. Los 55 profesores que rellenaron el cuestionario se dividen en las siguientes especialidades: 18 eran profesores de instrumento clásico, 5 de Composición, 5 de Jazz, 4 de Musicología, 3 de Pedagogía, 6 de "Otros” y 15 no contestan.

\subsection{Métodos de investigación utilizados}

El principal método usado ha sido el grupo de discusión, que puede ser considerado como una entrevista grupal. Sin embargo, difiere de la entrevista porque genera un proceso de interacción entre los sujetos seleccionados, es un espacio de intercambio y confrontación organizado por el investigador a partir de la selección de una temática de interés (Cohen et al., 2013), presentada en nuestro caso a través de los textos y las actividades sobre los mismos. El 
grupo de discusión no es espontáneo, sino que es creado por el investigador. Su utilización está recomendada para temas controvertidos, que necesitan de la confrontación para analizar los problemas, las causas y razones de éstos y sus posibles soluciones, recoge el proceso de construcción conjunta de significados, lo que proporciona conocimiento y comprensión del grupo. En definitiva, el objetivo final del análisis es el hallar los marcos de interpretación a partir de los cuales los sujetos dan sentido a un conjunto de experiencias y comportamientos reales.

Dentro de estos grupos el investigador ha actuado como observador participante, es decir, que aquél forma parte del grupo investigado y participa en sus actividades y funciones. Esta pertenencia al grupo a investigar es una ventaja para el docente-investigador, porque lo libera del dilema ético enfrentado a menudo por los investigadores, cuando para observar a un grupo desde su interior deben decidir si revelan o no su función de investigador y de qué manera esta identificación incidirá en la información a recoger (Sagastizabal y Perlo, 2002).

Otro recurso utilizado ha sido la realización de cuestionarios desde una perspectiva cualitativa. En la investigación acción el tipo de cuestionario que se utiliza más frecuentemente es el construido con preguntas abiertas que permiten una mayor extensión y complejidad en la respuesta. Sin embargo, en nuestro caso, hemos preferido hacer preguntas cerradas y reflexionar después sobre los cambios producidos en el alumnado después de la intervención pedagógica. Para ello, el cuestionario se les pasó en dos momentos distintos, primero al inicio del curso, antes de cualquier tipo de intervención por nuestra parte, y luego al final del cuatrimestre, pero antes de los exámenes, para que la calificación no influyera en sus opiniones pues, como señala Cisneros-Cohernour (2008), una calificación positiva puede influir en la respuesta y desvirtuarla por completo.

En este mismo contexto se ha generado otra herramienta muy valiosa, la reflexión que el propio alumnado ha hecho sobre la influencia que el conocimiento de las investigaciones ha tenido en la transformación de sus ideas.

Del mismo modo, y como hemos comentado anteriormente, se le pasó otro modelo de cuestionario al profesorado del conservatorio, para no dejar ningún cabo suelto en esa labor de recogida de datos que queríamos fuera lo más exhaustiva posible. 


\subsection{Trabajo de los textos en los grupos de discusión.}

Para trabajar en clase los temas que podían ser útiles para nuestros alumnos, se ha funcionado según el esquema de "grupos de discusión". Estos grupos estaban compuestos, como mucho, por cinco alumnos, procurando que fueran variando con cada nueva actividad. En las páginas que siguen explicamos detenidamente cómo se realizó el trabajo con cada texto en concreto, pero avanzamos aquí un esquema general.

El trabajo se divide, básicamente, en tres partes: presentación, lectura y ejercicio de aplicación. En primer lugar, se hacía siempre una presentación del autor (su trabajo y su relevancia) y el texto, para dar unas pinceladas generales sobre las cuestiones que se trataban. Y sobre ese texto se trabajaba de manera dirigida, con preguntas que buscaban que el alumno pudiera aplicar lo que leía a su especialidad concreta, así como a su estilo de aprendizaje y sus necesidades particulares. Es importante señalar que, para garantizar que todos se enteraban de en qué consistía la tarea, no sólo se comunicaba de manera oral en el aula, sino que se les enviaba un correo electrónico a todos con las especificaciones concretas de cada caso.

Pero la parte principal en el ejercicio de aplicación, que podía hacerse antes, después o antes y después de la lectura del texto, en función del contenido o contenidos que fueran a trabajar se desarrollaba de la siguiente manera ${ }^{34}$ :

$1^{\circ}$ El profesor explica algún contenido y propone que cada alumno, de manera individual y anónima, apunte en un cuarto de folio y según su propio criterio una aplicación de lo que se ha explicado o preguntado, dejando para ello cinco o diez minutos, según el tipo de elaboración que requiera lo que se pide.

$2^{\circ}$ El profesor recoge todos los folios y se forman los grupos de cinco o seis personas (intentando que sean distintos cada día) y reparte al azar los folios que ha recogido en cada

34 Proponemos el esquema general de funcionamiento, aunque en función de los contenidos que se trabajaban se hicieron modificaciones ad hoc, tal como se especifica más adelante. 
grupo. Los componentes de cada grupo deben proceder al vaciado de lo escrito en los folios, sin tener en cuenta si lo han escrito ellos o no y, tras comentarlo entre ellos, eligen lo que más se repite o lo que les ha parecido más interesante o sorprendente. Para ello se dejan unos diez minutos.

$3^{\circ}$ Cada grupo expone a la clase lo que ha encontrado en el vaciado de las respuestas que le ha tocado analizar y sus dudas, incomprensiones o valoraciones, siempre de forma respetuosa. Para ello se tiene en cuenta el principio importante de trabajo en grupo colaborativo, es decir, valorar lo positivo, entender lo que se ha entregado como algo que está en proceso y que no ha sido elaborado con mucho tiempo como para que pueda ser evaluado como si fuera un trabajo terminado o unas ideas muy asentadas. Asimismo, las sugerencias que se dan por parte de cada uno tienen que entenderse como opciones diferentes y variadas, que tienen por objeto ayudar a profundizar en la reflexión que se está haciendo sobre el tema y servir como ayuda a la hora de que cada uno pueda sacar sus propias conclusiones y elaborar sus propias ideas, conociendo las de los demás. Es decir, intentamos como profesores hacer de moderadores y utilizar las estrategias de aprendizaje que promuevan un entorno de aprendizaje seguro, en el que los alumnos se sientan escuchados y apoyados, tal como indican las investigaciones (Bruffee, 1993, Westerlund y Gaunt, 2013, Rutherford, 2014, Bennett, 2016) que es necesario para que los alumnos de la educación superior puedan dar lo mejor de sí mismos.

En la tabla que sigue, y para una mayor comprensión del trabajo realizado, se ofrece el desglose detallado de los textos que se emplearon a lo largo del curso, incluyendo su temporalización y los contenidos trabajados: 


\begin{tabular}{|c|c|c|c|}
\hline $\begin{array}{c}\text { Curso } \\
\text { 2014-2015 }\end{array}$ & $\begin{array}{c}\text { Curso } \\
\text { 2015-2016 }\end{array}$ & Texto & Contenidos trabajados \\
\hline $\begin{array}{l}\text { Lunes } 8 \text { y martes } 9 \text { de } \\
\text { septiembre }\end{array}$ & $\begin{array}{l}\text { Lunes } 7 \text {, martes } 8 \text { y } \\
\text { jueves } 10 \text { de septiembre }\end{array}$ & $\begin{array}{l}\text { - Información sobre el curso y la investigación y realización del test } \\
\text { anónimo y voluntario. } \\
\text { - Sloboda, J. (1987) ¿Qué puede enseñar la psicología de la música a } \\
\text { los músicos? Música y Educación, 44, 335-355. }\end{array}$ & $\begin{array}{l}\text { - Currículo orientado, técnicas orientadas y desarrollo individual orientado. } \\
\text { - Aprendizaje: codificación, práctica y motivación. }\end{array}$ \\
\hline $\begin{array}{l}\text { Lunes } 15 \text { y martes } 16 \text { de } \\
\text { septiembre }\end{array}$ & $\begin{array}{l}\text { Lunes } 14 \text {, martes } 15 \text { y } \\
\text { jueves } 17 \text { de septiembre }\end{array}$ & $\begin{array}{l}\text { - Sloboda, J. (1987) ¿Qué puede enseñar la psicología de la música a } \\
\text { los músicos? Música y Educación, 44, 335-355. }\end{array}$ & $\begin{array}{l}\text { - Mejorar como profesor: conocer al alumno, quererle, tener altas } \\
\text { expectativas y darle buena información. } \\
\text { - Trabajo en grupo como soporte de una enseñanza eficazmente. }\end{array}$ \\
\hline $\begin{array}{l}\text { Lunes } 22 \text { y martes } 23 \text { de } \\
\text { septiembre }\end{array}$ & $\begin{array}{l}\text { Lunes } 21 \text {, martes } 22 \text { y } \\
\text { jueves } 24 \text { de septiembre }\end{array}$ & $\begin{array}{l}\text { - McPherson, G.. (2000) Investigación de las habilidades requeridas } \\
\text { para tocar un instrumento musical. Boletín de Investigación } \\
\text { Educativo-Musical CIEM, } 7 \text { (19), 4-11. }\end{array}$ & $\begin{array}{l}\text { - Habilidades: lectura a primera vista, ejecutar música ensayada, tocar de } \\
\text { oído y de memoria e improvisar. }\end{array}$ \\
\hline $\begin{array}{l}\text { Lunes } 29 \text { y martes } 30 \text { de } \\
\text { septiembre }\end{array}$ & $\begin{array}{l}\text { Lunes } 28, \text { martes } 29 \\
\text { septiem. y jueves } 1 \\
\text { octubre }\end{array}$ & $\begin{array}{l}\text { - McPherson, G.. (2000) Investigación de las habilidades requeridas } \\
\text { para tocar un instrumento musical. Boletín de Investigación } \\
\text { Educativo-Musical CIEM, } 7 \text { (19), 4-11. }\end{array}$ & $\begin{array}{l}\text { - Músicos expertos: rico repertorio de estrategias } \\
\text { - El elogio y el estímulo }\end{array}$ \\
\hline $\begin{array}{l}\text { Lunes } 6 \text { y martes } 7 \text { de } \\
\text { octubre }\end{array}$ & $\begin{array}{l}\text { Lunes } 5 \text {, martes } 6 \text { y } \\
\text { jueves } 8 \text { de octubre }\end{array}$ & $\begin{array}{l}\text { - Davidson, J. (2006) El desarrollo de la habilidad interpretativa, en } \\
\text { Rink, J. (ed.). La interpretación musical. Madrid: Alianza Música. }\end{array}$ & - Factores que influyen en la potencialidad musical \\
\hline $\begin{array}{l}\text { Lunes } 13 \text { y martes } 14 \mathrm{de} \\
\text { octubre }\end{array}$ & $\begin{array}{l}\text { Martes } 13 \text { y jueves } 15 \text { y } \\
\text { lunes } 19 \text { de octubre }\end{array}$ & $\begin{array}{l}\text { - Davidson, J (2006): El desarrollo de la habilidad interpretativa, en } \\
\text { Rink, J. (ed.). La interpretación musical. Madrid: Alianza Música. }\end{array}$ & - Desarrollo de la motivación intrínseca (Hallam,1995, 1998) \\
\hline $\begin{array}{l}\text { Lunes } 20 \text { y martes } 21 \mathrm{de} \\
\text { octubre }\end{array}$ & $\begin{array}{l}\text { Martes } 20 \text { y jueves } 22 \text { y } \\
\text { lunes } 26 \text { de octubre }\end{array}$ & $\begin{array}{l}\text {-Hallam, S y Gaunt, H. (2012) Preparing for success: A Practical } \\
\text { Guide for Young Musicians. London: Institute of Education. }\end{array}$ & - Consejos para tener éxito como músico profesional \\
\hline
\end{tabular}




\begin{tabular}{|c|c|c|c|}
\hline $\begin{array}{l}\text { Lunes } 27 \text { y martes } 28 \text { de } \\
\text { octubre }\end{array}$ & $\begin{array}{l}\text { Martes } 27 \text { y jueves } 29 \\
\text { octubre y lunes } 2 \text { nov. }\end{array}$ & $\begin{array}{l}\text { - Hallam, S y Gaunt, H. (2012) Preparing for success: A Practical } \\
\text { Guide for Young Musicians London: Institute of Education. }\end{array}$ & - Reflexión sobre si cumplimos o no los consejos de Hallam y Gaunt (2012) \\
\hline $\begin{array}{l}\text { Lunes } 3 \text { y martes } 4 \text { de } \\
\text { noviembre }\end{array}$ & $\begin{array}{l}\text { Martes } 3 \text {, jueves } 5 \mathrm{y} \\
\text { lunes } 9 \text { de noviembre }\end{array}$ & $\begin{array}{l}\text { - Gardner, H. (2005) Las cinco mentes del futuro: un ensayo } \\
\text { educativo. Barcelona: Paidós Ibérica. }\end{array}$ & - Mente disciplinada, sintética, creativa, respetuosa y ética. \\
\hline $\begin{array}{l}\text { Lunes } 10 \text { y martes } 11 \mathrm{de} \\
\text { noviembre }\end{array}$ & $\begin{array}{l}\text { Martes } 10 \text {, jueves } 12 \text { y } \\
\text { lunes } 16 \text { noviembre }\end{array}$ & $\begin{array}{l}\text { - Gardner, H. (2005) Las cinco mentes del futuro: un ensayo } \\
\text { educativo. Barcelona: Paidós Ibérica. }\end{array}$ & -¿Cómo trabajar las cinco mentes en la práctica instrumental? \\
\hline $\begin{array}{l}\text { Lunes } 17 \text { y martes } 18 \text { de } \\
\text { noviembre }\end{array}$ & $\begin{array}{l}\text { Martes } 17 \text { jueves } 19 \text { y } \\
\text { lunes } 23 \text { de noviembre }\end{array}$ & - Sternberg, R. (1996) Inteligencia exitosa. Barcelona: Paidós Ibérica. & $\begin{array}{l}\text { - Pasos para la resolución de problemas. } \\
\text { - Aspectos de la inteligencia exitosa }\end{array}$ \\
\hline $\begin{array}{l}\text { Lunes } 24 \text { y martes } 25 \text { de } \\
\text { noviembre }\end{array}$ & $\begin{array}{l}\text { Martes } 24 \text { jueves } 26 \text { de } \\
\text { noviembre }\end{array}$ & - Sternberg, R. (1996) Inteligencia exitosa. Barcelona: Paidós Ibérica. & $\begin{array}{l}\text { - Estimular la creatividad } \\
\text { - Desarrollo de la inteligencia exitosa. }\end{array}$ \\
\hline $\begin{array}{l}\text { Lunes } 1 \text { y martes } 2 \\
\text { diciembre }\end{array}$ & $\begin{array}{l}\text { Martes } 1 \text { jueves } 10 \mathrm{y} \\
\text { lunes } 14 \text { de diciembre }\end{array}$ & $\begin{array}{l}\text { - Ejercicio de reflexión. Como músico excelente que soy, ¿cómo me } \\
\text { enfrento a mi concierto o trabajo fin de carrera? }\end{array}$ & $\begin{array}{l}\text { - Aplicación de los textos trabajados a un trabajo de reflexión sobre la } \\
\text { excelencia musical. }\end{array}$ \\
\hline $\begin{array}{l}\text { Lunes } 15 \text { y martes } 16 \\
\text { diciembre }\end{array}$ & $\begin{array}{l}\text { Martes } 15 \text { jueves } 17 \text { y } \\
\text { lunes } 21 \text { de diciembre }\end{array}$ & $\begin{array}{l}\text { - Dweck, C. (2006) Mindset. The new psychology of success. How we } \\
\text { can learn to fulfill our potential. New York: Ballantine Books. } \\
\text { Resumen en castell. }\end{array}$ & $\begin{array}{l}\text { - Mentalidad fija y en crecimiento. } \\
\text { - Aplicación de los dos tipos de mentalidad en un cuadro con ejemplos } \\
\text { propios. }\end{array}$ \\
\hline $\begin{array}{l}\text { Lunes } 12 \text { y martes } 13 \\
\text { enero }\end{array}$ & $\begin{array}{l}\text { Martes } 22 \text { diciembre, } \\
\text { jueves } 14 \text { y lunes } 18 \text { ene }\end{array}$ & - Respuesta a dudas y comentarios sobre lo trabajado. & $\begin{array}{l}\text { - Repetición del test anónimo y voluntario. Evaluación de lo trabajado por } \\
\text { parte de los alumnos. }\end{array}$ \\
\hline
\end{tabular}




\subsubsection{Texto 1: Sloboda, J. (1987)}

El primer texto que presentamos a los alumnos (Sloboda, J. (1987) ¿Qué puede enseñar la psicología de la música a los músicos? Música y Educación, 44, 335-355), cumple los requisitos que nos parecían fundamentales para animar a los alumnos a acercarse a las investigaciones y que disfrutaran con el estudio de las mismas:

$1^{\circ}$ Que les pareciera atractivo y con muchos contenidos variados e interesantes para todas las especialidades (tanto para alumnos de pedagogía como de interpretación clásica y de jazz, composición o musicología), y que además diera juego para hacer una aplicación individual y animara al intercambio de ideas en el trabajo en grupo.

$2^{\circ}$ Que estuviera traducido al castellano y tuviera un lenguaje sencillo de comprender hasta para los estudiantes no habituados a leer este tipo de textos.

$3^{\circ}$ Que fuera de un autor de reconocido prestigio y con valor, tanto como figura dentro de la investigación como por su implicación social. Se elige para el primer texto a John Sloboda, autor especialmente querido para mí, lo que me ha ayudado a transmitir a los alumnos el respeto que siento por la investigación y por el autor mismo ${ }^{35}$.

En la primera parte de la sesión dedicada a este texto se explican, en primer lugar, los contenidos referentes al currículo orientado, las técnicas orientadas y el desarrollo individual orientado, así como los contenidos referentes a cómo para aprender algo hace falta saber cómo está codificado, ponerlo en práctica y tener la motivación necesaria para hacerlo tanto tiempo como sea necesario de cara a aprenderlo. Una vez explicado, se les propone como práctica que apliquen la forma de trabajar explicada anteriormente en los pequeños grupos. Se propone que de manera individual realicen estas dos actividades en un folio en blanco y de forma anónima:

1. Escribir mi desarrollo individual orientado (qué hago para conseguirlo)

2. Elige algo que quieras aprender y aplica los tres elementos que propone Sloboda para aprenderlo

35 Como constata la investigación, el "flow" del profesor también se transmite al alumno (Baker, 2005) 
A. Resultados obtenidos sobre el desarrollo individual orientado

Hay una amplia mayoría de comentarios que expresan que no suelen prestar atención a su desarrollo individual. Están esperando a terminar los estudios oficiales para empezar a trabajar su estilo propio y hacer lo que realmente les gusta. En general, expresan que la enseñanza formal en el conservatorio plantea mucha exigencia en algunas cosas que uniforman, pero que no se hace especial hincapié en trabajar en la especificidad de cada uno para buscar su propia forma de expresión. Podríamos aplicar lo que Bennett et al. aplican a la creatividad, donde destacan que muchos estudiantes de música de la enseñanza superior ven el trabajo creativo como una forma de romper las reglas de la enseñanza formal, más que como una parte del aprendizaje formal en sí mismo (2016:31). Lo mismo parece ocurrirles a los estudiantes de nuestra investigación: ven su desarrollo individual, el desarrollo de su estilo propio, como una característica que no encaja con la enseñanza formal. Sería algo así como que para hacerlo hay que romper con este tipo de enseñanza o esperar a que ésta acabe para poder desarrollarlo. Un ejemplo muy esclarecedor es el comentario que nos ofrece una alumna:

Ahora mismo estoy en una situación bastante difícil como intérprete. Estoy prácticamente a punto de acabar mis estudios en el conservatorio y creo que debería tener más claro qué es lo que quiero, cómo quiero sonar, qué estilo creo que es el que mejor encaja según mi personalidad, qué técnicas utilizar. El problema es que me siento un poco encorsetada por la enseñanza formal como si me quisieran llevar a un terreno que no acaba de convencerme. Me encuentro en una encrucijada, que afortunadamente no va a durar más de unos meses.

De igual modo, reconocen que tampoco luchan mucho por elegir lo que les gustaría interpretar y trabajar, sino que se fían del criterio de su profesor y, en general, delegan la responsabilidad de todo esto en él. Un alumno lo expresa muy claro de la siguiente manera:

Ciertamente estoy en duda de dónde o cómo quiero acabar. Lo que podría hacer es informarme y estudiar distintas posibilidades y tener algún referente. Sin embargo, dejo esta tarea a mi profesor

Es curioso que algunos de los alumnos de nuestra investigación se dan cuenta, precisamente en este momento, de que no están haciendo nada por practicar habilidades muy necesarias para lograr ser lo que de verdad les interesa. Un alumno dice textualmente: 
Sinceramente, me resulta difícil especificar cuáles son las técnicas que utilizo en mi desarrollo individual orientado, fundamentalmente porque no tengo exactamente definido cuál es el objetivo concreto que persigo con mi formación.

En este sentido, encontramos alumnos que, en ocasiones, tienen claro lo que quieren hacer, pero que no están haciendo nada por hacerlo y les cuesta tomar las riendas de su propio aprendizaje (tal y como nos dicen las investigaciones que es necesario para conseguir éxito como músico profesional en el siglo XXI -Hallam y Gaunt, 2012-) ${ }^{36}$. Por ejemplo, una alumna expresa que le gustaría dedicarse a cantar musicales, aunque actualmente está cursando el superior de violín, pero resulta que incluso la profesora de canto que le imparte la asignatura de coro le ha dicho que tiene una voz estupenda para los musicales (aparte de que domina perfectamente el inglés) y ni aún así se ha planteado trabajar la voz para ser mejor en eso, de modo que sigue con el violín, instrumento con el que le gusta expresar y tocar, pero con el que no está muy motivada para su estudio. Otro alumno reconoce que le encantaría estudiar dirección de orquesta, pero que de momento está en pedagogía y ni siquiera intentó hacer las pruebas para entrar a esa especialidad. Asimismo, otra alumna expresa que le gustaba mucho más la especialidad de pedagogía, pero que todo el mundo le animó a hacer interpretación, de manera que no se atrevió a cursarla, cuando era lo que deseaba de verdad. Así, sentía como si todo el mundo a su alrededor supiera mejor que ella lo que de verdad le interesa o le conviene. Un alumno sí que reconoce que trabaja mucho lo que él piensa que le hace único:

En mi desarrollo individual orientado intento exprimir lo que considero que es único en mí y lo que hago para conseguirlo, o mejor dicho, mantenerlo, es_no dejarlo de lado nunca en el estudio o en la práctica rutinaria ${ }^{37}$. Es decir, si por ejemplo algo que me hace único es que soy un baterista pero puedo tocar flamenco con la batería, aunque lo "normal" es hacerlo con un cajón flamenco y con la batería se toquen otros estilos como rock o jazz, pues nunca dejar de lado el estudio del flamenco con la batería, aunque pienso que luego igual no voy a darle tanto uso.

\footnotetext{
36 Insistiremos en este tema más adelante, cuando hablemos del trabajo del texto de Hallam y Gaunt, (2012)

37 El subrayado es del propio alumno
} 
Como vemos, y a pesar de todo el desconcierto que existe en este sentido, parece que en algunos alumnos va asentándose la idea de que ellos han de ser sus propios profesores y dirigir su propio aprendizaje.

B. Resultados obtenidos sobre el desarrollo de cómo se aprende

Con respecto al segundo bloque de contenidos importantes de este texto, lo que se les pide es que entiendan los tres componentes esenciales del aprendizaje que se explican en el texto, lo actualicen y sean capaces de poner un ejemplo que les sirva para entender mejor cómo deberían aprender algo que quieran aprender: $1^{\circ}$ Un medio de codificar o estructurar el material para que sea aprendido (en el caso de la música, la mayor parte de la misma tiene una estructura inherente, por lo que no es necesario importar una estructura, sino observar la que ya existe), $2^{\circ}$ Repetidas oportunidades para practicar la técnica: no sólo es suficiente descubrir un sistema de codificación, sino que es necesario ejecutarlo y ponerlo en práctica de manera que se pueda utilizar el mismo conocimiento en distintas situaciones. $3^{\circ}$ Motivación necesaria para practicarlo tanto tiempo como sea necesario para que se aprenda.

En los grupos de discusión quedó claro que el énfasis para aprender siempre se tiende a poner en entender bien la codificación del material o su estructura, y no se insiste en lo importante de llevarlo a la práctica de distintas maneras o en buscar cómo motivar para aprender algo. Fue curioso comprobar cómo les era mucho más fácil poner ejemplos que no fueran musicales, por lo que variamos un poco la propuesta inicial y les sugerimos que buscaran primero algo que estuvieran muy motivados por aprender. ¿Qué querían aprender de verdad? Una vez que esto quedaba claro, debían comprobar si tenían estrategias para trabajarlo, para dominarlo y saber aplicarlo a distintos contextos. Además, para actualizar los contenidos, les presentamos nuevas sugerencias que aparecían sobre este tema en las últimas investigaciones, como la importancia de planificar la práctica y adaptarla a las necesidades de la tarea, asegurándose un contexto que la propicie, así como la utilización de la práctica mental, el análisis y otras estrategias enfocadas a dirigir la atención, elementos todos estos muy útiles para conseguir una práctica más productiva, motivadora y divertida (Hallam, 2012).

En el mismo sentido irían las recomendaciones que se dan a los profesores, como la importancia de hablar abiertamente de la práctica y de los problemas de motivación con los estudiantes, pues a todo el mundo le cuesta encontrar soluciones, desarrollar la resistencia y 
enfrentarse con los inconvenientes, del mismo modo que también es importante que sean conscientes de la particularidad de cada estudiante y de que puede que lo que funciona con uno, puede no hacerlo con otro y que por eso es necesario dedicar tiempo a conocer las estrategias que usan los expertos, evitando repetir acríticamente lo que recibió de su profesor cuando era estudiante (Lehman y Jorguesen, 2012).

En este contexto volvió a aparecer la idea de que, para practicar algunas de las cosas que más les motivaban era necesario acabar los estudios. Un ejemplo de lo que comentamos lo ilustra el baterista anterior cuando dice textualmente:

Soy consciente de que sólo podré aprender a tocar la guitarra española (a pesar de que mi motivación es muy grande porque me encanta el flamenco) cuando haya acabado la carrera porque será entonces cuando disponga de algo más de tiempo libre para practicar ${ }^{38}$.

C. Resultados del alumno como mejor profesor de sí mismo

En la segunda sesión de trabajo con el texto, les pedimos que realizaran el ejercicio propuesto en la tabla de la página siguiente, siguiendo las instrucciones explicadas para el trabajo en grupo en general. Los ejercicios que se van a ir proponiendo se han actualizado con la lectura de algunas de las últimas investigaciones en cada uno de los puntos que se proponen (y que hemos explicado en páginas anteriores).

En lo que sigue vamos a utilizar el modelo que Sloboda (1987) propone para mejorar como profesor, pero de modo completamente nuevo: la idea es que el alumno asuma que ellos mismos han de convertirse en sus propios profesores y, en ese sentido, que puedan ser incluso “su mejor profesor" (al tiempo que reflexionan sobre su propia práctica).

38 A este alumno le explicamos que una de las conclusiones que aparecían como más unánimes en el último Congreso Internacional de Conservatorios Superiores fue que era muy recomendable promover en los alumnos de la enseñanza superior la importancia de tocar dos instrumentos distintos, puesto que el conocimiento de los dos reforzaba mucho las habilidades generales del músico, así como la improvisación, la composición y la pedagogía. En definitiva, buscar la excelencia como músicos y no sólo en la práctica instrumental de un único instrumento en exclusiva. 
Analizo qué puedo hacer para mejorar en lo que ya soy bueno para conseguir más eficacia.

Sloboda dice que para mejorar como profesor se debe: conocer a los alumnos, quererles, tener altas expectativas y darles buena información Además, dice que es interesante tener un grupo de apoyo. Como tú vas a ser tu mejor profesor (o al menos el que vas a tener más cerca) toda la vida, intenta ver cómo puedes aplicártelo a ti mismo. Para eso sigue estos puntos:

$\rightarrow$ Conocerse a sí mismos. Análisis de la habilidad exitosa de cada uno

$\rightarrow$ Quererse

$\rightarrow$ Tener altas expectativas

$\rightarrow$ Darse buena información

$\rightarrow$ No aislarse.

Con todo esto, se intenta que reflexionen sobre la forma en que ellos pueden ayudarse a sí mismos (en la línea indicada de ser su propio profesor) y que tengan presente que la labor creativa del profesor consistirá muchas veces básicamente en crear el ambiente que propicie este trabajo (por lo que ellos deberían buscarlo para sí mismos) y ayudar al alumno (o a sí mismos) a planificarse y organizarse, teniendo en cuenta sus características y necesidades, sus puntos fuertes y débiles, trabajando lo que se considera más necesario en cada momento (aunque en ocasiones no sea lo más agradable para él), alternándolo con el trabajo de su punto fuerte, dándole estrategias para seguir trabajando el punto fuerte, siendo ambos conscientes de qué es lo que le puede llevar a la excelencia y explicándole la necesidad de trabajar otras cosas (en ocasiones más difíciles para él) pero necesarias para el mejor desarrollo como músico (sin olvidarse de que el trabajo de algunos de sus puntos débiles también le puede ayudar a mejorar su punto fuerte). Pero, sobre todo, su labor debe dirigirse hacia la motivación, pues el ver la facilidad con la que mejora en algún aspecto (su punto o puntos fuertes) le va a ayudar a perseverar en la tarea que se convierte de este modo en "autotélica" (que se recompensa por sí misma). Para conseguir todo esto va a ser necesario crear el entorno natural para el aprendizaje crítico, apoyándose en el conocimiento de lo que se sabe sobre los músicos y las investigaciones recientes y siendo conscientes también de la importancia de los recursos personales e institucionales para llegar a buen término. 
D. Resultados sobre la manera de mejorar que los alumnos pueden aplicarse para ser sus mejores profesores.

$\rightarrow$ SOBRE CONOCERSE A SÍ MISMO. EL TRABAJO DE SUS PUNTOS FUERTES Y DÉBILES:

En el apartado 4.4 hemos hablado profusamente sobre el punto fuerte y la importancia que éste tiene, no sólo como contrapunto del punto débil, sino como algo deseable por sí mismo. No fue sorprendente descubrir, en los grupos de discusión, el desequilibrio existente entre el conocimiento que tienen los alumnos de uno y otro "puntos". El punto débil lo tienen todos clarísimo, dado que, como decía un alumno de manera muy expresiva y certera (y que no nos importa repetir por lo que tiene de directo y franco): "es fácil tenerlo claro porque te machacan con tus defectos todo el tiempo".

Sin embargo, parece que es más complicado encontrar e incluso hablar del punto fuerte. Muchos decían desconocer que tuvieran semejante habilidad y otros, llevados por ese prurito cultural que nos impide hablar bien de nosotros mismos, parecían preferir no pronunciarse al respecto. Pero, como ya comentamos en su momento, todo cambió cuando se demostró la eficacia de trabajar precisamente esa faceta en la que ya eran especialmente buenos. La idea consiste precisamente en darle la vuelta a esa idea, tan extendida como perniciosa, que dice que hay que centrarse en trabajar los defectos, los puntos débiles, de cara a convertirlos en buenos, mientras se pone en segundo plano (o directamente se ignora) ese punto de excelencia que es, casi sin duda, el que les ha llevado a entrar en el Conservatorio Superior.

No estamos afirmando aquí que haya que dejar de trabajar el punto débil (decir esto sería una irresponsabilidad), sino que junto a ese trabajo de perfeccionamiento debería potenciarse el desarrollo del talento individual que cada uno tiene y que es, indudablemente, lo que más le acerca a la excelencia.

\section{$\rightarrow$ QUERERSE}

Una de las ideas más destacadas de este punto es la de la confianza que parecen tener en sí mismos los grandes intérpretes a los que los alumnos admiran. Muchos estudiantes de nuestra investigación creen que esa confianza se la da el disfrute que sienten al estar en el escenario haciendo lo que quieren. Lo que se ve es una gran vocación en lo que hacen, pues muchos 
piensan que se premian a sí mismos dedicándose a lo que les gusta y eso para ellos ya es una recompensa. Se demuestran a sí mismos que se quieren, dedicándose a lo que les gusta y disfrutando de ir mejorando en ello. Un alumno lo expresa de la siguiente manera:

A la hora de practicar, lo que me anima es que haya un avance. Eso hace que me motive para seguir practicando. Hay que valorar lo que se consigue pero también lo que ya se tiene. Pienso que eso es muy importante.

\section{$\rightarrow$ TENER ALTAS EXPECTATIVAS}

Con respecto a las expectativas, vemos que, en general, su primer objetivo es terminar la carrera, hasta el punto de que les cuesta mucho mirar un poco más lejos y plantearse metas a más largo plazo. Con la Reforma Europea de las Enseñanzas Superiores, muchos ven como necesario hacer un máster y algunos piensan que no van a tener los medios necesarios para poder seguir estudiando. Parece que para poder tener altas expectativas es necesario también tener dinero. Un alumno del curso 2015-16 de interpretación jazz lo expresa de la siguiente manera:

Mi primer gran objetivo es avanzar, seguir aprendiendo. Por eso me metí en el Conservatorio Superior y lo estoy logrando con creces. Este objetivo está ligado a terminar la carrera. A estas alturas sería un error no terminarla, aún con los esfuerzos que ello conlleva. Me encantaría seguir estudiando pero no sé si podré permitírmelo. Pagarme estos estudios ya me está costando mucho esfuerzo. Otro objetivo es tener mi propio proyecto con temas propios originales y grabar un disco. Es una meta que no tiene fecha de caducidad. El tiempo dirá...

Pero también encontramos excepciones (en concreto dos alumnas de interpretación clásico) que nos hablan de que sus expectativas están ligadas a sus objetivos y que su punto fuerte es la organización y la planificación de objetivos para conseguir lo que se proponen. Una de ellas lo expresa así:

Soy la reina de las listas de objetivos: a largo plazo, a plazo de un año, en el curso, en el cuatrimestre, y hasta semanales. Con el poco tiempo que tengo, si el domingo no planifico mi semana, luego debo sacrificar algo para llegar a todo. Ir tan justa tiene sus inconvenientes, pero es necesario para cumplir mis expectativas. 


\section{$\rightarrow$ DARSE BUENA INFORMACIÓN}

Lo que aparece como más evidente en los grupos de discusión sobre este punto es que la información la reciben principalmente de su profesor de instrumento, especialmente los alumnos de interpretación clásica. Es bastante habitual que lo reconozcan abiertamente de esta manera:

En mi caso mi profesor de instrumento es mi principal referencia como opinión musical.

Es cierto que los alumnos de interpretación jazz, composición y musicología están más habituados a buscar información sobre sus temas de interés por otras vías que los de interpretación clásica. Fundamentalmente esta información la buscan en Internet. Algunos alumnos de interpretación clásica expresan que, en ocasiones, el recibir clases con otros profesores distintos al suyo les parece casi una traición a su profesor (temen que les cambie la técnica o que crean que no confían en ellos) y que incluso escuchar versiones distintas de las obras que tocan para obtener información en algunos casos no está muy bien visto entre sus profesores. Una alumna de interpretación clásica lo expresa de forma muy clara:

La verdad es que siempre he pensado que lo de escuchar el repertorio que interpretaba lo hacía por ser vaga, y que era cosa de un mal estudiante, ya que en más de una ocasión me lo han incluso prohibido. Pero como tengo demostrado que así aprendo más y más rápido, y puedo ser más crítica con esa obra y elegir cosas que nunca se me hubieran ocurrido, he continuado haciéndolo, a "escondidas" de mis profesores, como si de una cosa mala se tratara.

Algunos incluso piensan que el hecho mismo de pararse a pensar sobre lo que están haciendo es novedoso. Una alumna lo expresa contundentemente, valorando el trabajo de reflexión que ha hecho:

En el trabajo que desarrollamos nuestros puntos fuertes y débiles sentí que aprendí mucho, por el mero hecho de reflexionar sobre ello.

Sobre este tema, y en el trascurso de la investigación, se va viendo cómo la reflexión les hace cambiar su idea de conseguir buena información y van viendo que no hay una única forma de 
obtenerla. Una alumna del curso 2015- 2016, participante en nuestra investigación, lo comenta de la siguiente manera:

Me he dado cuenta de que conocer las investigaciones ha conseguido que tenga mucho menos en cuenta la opinión de mi profesor de instrumento y mucho más la de todos los demás profesores. No quiere decir que no valore las aportaciones de mi profesor de instrumento al que respeto, admiro y agradezco todo lo que me ha aportado, sino que me he dado cuenta que no puede ser "la única opinión válida"

Estos testimonios (seleccionados de entre otros muchos) nos hacen ver cómo la reflexión sobre la propia práctica y la consiguiente búsqueda de información para mejorar se han abierto paso en la lista de prioridades de nuestros alumnos.

\section{$\rightarrow$ NO AISLARSE}

Para trabajar en la importancia del grupo de apoyo, se aprovechó la distribución de grupo pequeño que se formaban para trabajar en clase habitualmente y se les pidió que revisaran los puntos que marcaba Sloboda sobre la situación en la que se encuentran ${ }^{39}$. Asimismo se les pidió que pensaran de forma individual si suelen contar con grupos de apoyo, una persona o varias, músicos o no y la utilización que hacían del mismo. La experiencia les resultó muy útil y se llegó a las siguientes conclusiones:

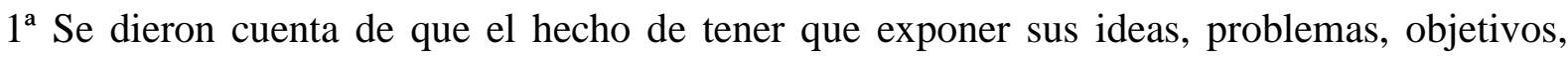
metas y planes a los demás les ayudaba a estructurar las ideas, reflexionar sobre ellas y verlo de una manera más abordable. Una alumna del primer año de la investigación lo de la siguiente manera:

Yo, cuando tengo muchas cosas que hacer, llamo a mi madre y le cuento todo lo que tengo que hacer y me desahogo; y una vez que lo he hecho ya puedo ponerme a trabajar pues parece que ya se me ha aclarado por dónde tengo que empezar, aunque la mayoría de las veces ella no hace nada más que escucharme. 
$2^{\mathrm{a}}$ El compartir problemas con gente que se encuentra en la misma situación o tienen problemas similares les ayuda a verlos desde fuera, de una forma diferente, podríamos decir que de modo más objetivo. Aunque también resaltan la importancia de elegir bien a esos compañeros. Una alumna y un alumno del segundo año de nuestra investigación lo exponen de la siguiente manera:

Cuando hablamos con otros compañeros que tienen problemas semejantes a los nuestros somos capaces de darles solución a ellos y no somos conscientes de que tenemos que aplicar lo mismo para nuestro caso. En la actividad de clase que realizamos aparecieron problemas muy similares, todos relacionados con el trabajo fin de carrera o el concierto fin de carrera. La solución que nos dimos fue no perder la ilusión y trabajar día a día para conseguirlo.

Con mis compañeros de trabajo en la banda, con mis compañeros de Conservatorio, con compañeros que toco Jazz, Soul y otros estilos musicales todas las semanas, siempre estamos comentando diferentes aspectos musicales como la situación actual, las situaciones personales de cada uno, quejas y sugerencias (sobre todo quejas) y la forma de conseguir nuestros objetivos. Hay que saber con quién hablar y a quién escuchar porque hay gente para todo. Yo ya he seleccionado a la gente con quien puedo compartir estas opiniones o vivencias.

$3^{a}$ Muchos se dieron cuenta que en otros ámbitos de su vida sí que tenían esos apoyos, pero no habían encontrado un grupo con el que compartir con confianza en el ámbito musical. Un alumno lo presenta de la siguiente manera:

Tengo un grupo de amigos que me apoya en todo y con los que comparto problemas e ilusiones, pero ninguno pertenece al ámbito musical y en ocasiones no entienden algunos tipos de preocupaciones específicas de ese ámbito. Creo que debería buscar un grupo de confianza también en el ámbito musical para poder compartir otro tipo de experiencias.

$4^{a}$ Otra idea generalizada es que en momentos de tensión lo que hacen es lo contrario de lo que tendrían que hacer, según señala la investigación (Sloboda, 1997; Hallam y Gaunt, 2012), es decir, aparcan su vida social por falta de tiempo y en lugar de utilizarlo a su favor, juega en su contra, porque crean más tensión. Dos alumnos del segundo año de nuestra investigación lo exponen de la siguiente manera: 
Estoy muy nervioso últimamente. Me están entrando agobios que nunca he tenido y ahora me he dado cuenta que quizá es porque estoy asustado por la cantidad de trabajo que implica el concierto fin de carrera. He dejado de relacionarme con la gente con la que normalmente compartía mis problemas e ilusiones.

Soy muy organizada, pero es cierto que hasta ahora no valoraba lo suficiente el tiempo libre. Y disfrutar del tiempo con la pareja, familia o amigos, es igual de importante que una clase. En general, creo que debemos encontrar un equilibrio entre el trabajo y el tiempo libre.

\subsubsection{Texto 2: McPherson, G. (2000)}

Para trabajar este texto (McPherson, G. (2000) Investigación de las habilidades requeridas para tocar un instrumento musical. Boletín de Investigación Educativo-Musical CIEM ,7 (19), 4-11.) se les pide que lo lean de manera individual y reflexionen sobre las ideas que se proponen, dándoles las siguientes pautas:

1. McPherson cita cinco habilidades que considera fundamentales para tocar un instrumento musical (leer a primera vista, tocar de oído, tocar de memoria, tocar música ensayada e improvisar). Explica si trabajas cada una de ellas de forma separada y si lo consideras importante para tu desarrollo como músico, así como si las has trabajado por tu cuenta o por indicación de algún profesor a lo largo de tu carrera.

2. Explica la diferencia entre el repertorio de estrategias utilizadas por los alumnos más jóvenes y los más experimentados según McPherson, y piensa qué tipo de estrategias utilizas tú a la hora de estudiar, así como si sueles utilizar distintas estrategias en un repertorio obligado o en el que eliges tú.

3. Diferencia entre elogio y estímulo y reflexiona sobre situaciones en las que te hayas sentido elogiado o estimulado, analizando el efecto que te ha producido.

Sobre la primera idea, encontramos una gran diversidad de casos en los grupos de discusión, pero sí que se coincide en lo siguiente:

a) La improvisación no se ha valorado lo suficiente para los alumnos de clásico. De hecho, muy pocos habían recibido alguna indicación sobre cómo improvisar antes de tener esa asignatura en la enseñanza superior. La valoración que hacen en este momento sobre su 
importancia varía mucho, en función de quién ha sido el profesor que les ha impartido la asignatura y si les ha hecho darse cuenta de lo provechoso de su utilización, aunque no vayan a dedicarse a ser improvisadores. Sí que están todos de acuerdo en valorar a sus compañeros de jazz, que improvisan muy bien, y a algunos compañeros de clásico que también están muy habituados a hacerlo. Les sorprende también la idea de que improvisar mientras estudian puede ayudarles a hacer un estudio técnico menos aburrido.

b) Algo similar ocurre con la habilidad de tocar de oído: aunque todos lo valoran, los de clásico suelen estar demasiado pegados a la partitura o a tocar de memoria y no consideran que tocar de oído sea una habilidad necesaria. Los alumnos de instrumentos de viento (de todas las especialidades) reconocen que en muchas ocasiones esta habilidad la han desarrollado mucho tocando en la charanga. Una actividad que les parecía muy divertida pero que en ocasiones debían ocultar a su profesor de instrumento, pues les indicaba que en la charanga lo único que podían aprender es a coger muchos vicios, no valorando la parte positiva que les aportaba. Se dan cuenta de que la posibilidad de aprender habilidades muy útiles como músico en contextos no tan formales como el conservatorio no siempre es valorada dentro de éste, pero ellos sí que insistían en que les había sido muy útil también para disfrutar y tener más ganas de seguir estudiando la parte más técnica. Los músicos de jazz la trabajan a diario, sacando solos de oído por indicación de sus profesores y recomiendan a sus compañeros de clásico que lo hagan alguna vez para que sean conscientes de su habilidad y vean cómo puede mejorar si se practica.

La segunda idea interesante que aporta McPherson en este texto es que cuando un estudiante toca una obra elegida por él utiliza estrategias mucho más elaboradas (estrategias que se suelen asociar a músicos más experimentados) que cuando se toca una obra elegida por su profesor, aunque sea la misma persona la que lo realiza. Una alumna que ha tenido esa experiencia lo explica así:

\section{Aprendo más rápido de memoria el repertorio que me gusta que el que me es impuesto}

Aunque la mayoría de alumnos reconocían que disfrutaban más tocando algo que querían tocar que algo que les mandaban, pensaban que utilizaban las mismas estrategias en los dos casos. Para profundizar en este tema realizamos una actividad en clase en la que les pedíamos que tararearan interiormente una obra que hubieran tocado que les gustaba mucho, otra que 
les gustaba mucho aunque no fuera de su instrumento ni la hubieran tocado y otra que no les gustara nada. Después transcribían lo que habían tarareado interiormente y lo apuntaban en la plantilla que les habíamos proporcionado (ver en la siguiente página).

Una vez realizado, tenían que analizar lo que habían escrito y escribir lo que hubieran visto por la parte de atrás del papel que se les había dado. Una vez terminado lo intercambiaban con otros compañeros que sólo podían ver la parte de delante e intentaban sacar conclusiones también de lo que veían. Tras este ejercicio en los grupos de discusión se llegó a la siguiente conclusión:

Todos ellos recordaban mucho mejor las obras que les gustaban (y por eso eran capaces de tararearlas con mayor exactitud) y llegaban a tararear partes importantes del acompañamiento o interpretadas por otros instrumentos diferentes al suyo. En ocasiones incluso obras que habían tocado hacía mucho tiempo. La que no les gustaba, la mayoría no podía ni tararearla y los que lo hacían cometían muchos errores (incluso hubo uno que puso un movimiento y tarareó otro). Otros podían tararearlas pero no recordaban el nombre del autor y su tarareo (según su propia definición) era poco definido, soso y sin ganas. Elegimos algunos comentarios de los alumnos que inciden en lo anterior:

El tarareo de la obra que me gusta lo realizo de forma relajada y acompañada de movimiento con el cuerpo o los brazos. Es una obra en la que la melodía tiene mucho espacio y parece que esté flotando sobre el acompañamiento. Me resulta fácil y cómodo de tocar y tararear ya que es una obra que conozco bien y que me encanta. La obra que no me gusta es un estándar de jazz que me resulta monótono y aburrido, tanto que no recuerdo ni siquiera el nombre del autor. La melodía es sosa a mi parecer, y de ese modo interpreto el tarareo.

Las diferencias que observo entre las obras que me gustan y las que no es sobre todo la expresividad e intensidad, además de la relajación. En la obra que me gusta los puntos suspensivos que pongo al transcribir el tarareo hacen referencia a la calma y el sosiego, mientras que en la que no me gusta se refieren al sopor que produce la melodía. 


\section{Ejercicio de Tarareo}

Nombre:

\section{Especialidad:}

$1^{\circ}$ Piensa en una obra musical que hayas tocado que te encante.

Título:

Autor:

Escribe cómo la tarareas:

$2^{\circ}$ Piensa en una obra musical de cualquier estilo, tocada con cualquier instrumento que te encante.

Título:

Autor:

Escribe cómo la tarareas:

$3^{\circ}$ Piensa en una obra musical que hayas tocado hace tiempo y que no te haya gustado nada.

Título:

Autor:

Escribe cómo la tarareas: 
Actualizando con las nuevas investigaciones, podemos decir que cuando una obra nos gusta la seguimos practicando mentalmente. Y como ya dejamos claro en el capítulo segundo de este trabajo, la práctica mental es algo que se ha demostrado de gran utilidad en el aprendizaje (Bernardi et al.,2013; Brown y Palmer, 2013; Kraeutner et al.,2015), tanto en música como en cirugía o actividades deportivas (todas ellas con exigencia de motricidad fina). Por eso, cuando una obra les gusta la siguen tarareando, siguen trabajándola mentalmente sin ser conscientes y consiguen aprenderla antes con menos esfuerzo para recordarla después con mucha mayor precisión. Un ejemplo de esto nos lo explica una alumna con las siguientes palabras:

La primera obra que he tarareado me encanta, por eso la recuerdo con tanto detalle. Al tararearla, visualizo las notas en la partitura y las posiciones de los dedos como si la estuviera tocando de nuevo.

Otro alumno de interpretación jazz lo explica de la siguiente forma:

En la canción que me encanta percibo claramente cualquier aspecto de ella en los tarareos, como dinámica, articulación, fraseos, etc. La predisposición es total porque es una canción que la tengo en la cabeza todo el día, porque me encanta. Además, los aspectos difíciles los percibo como un desafío a superar. Esto quiere decir que estoy dispuesto a superarlo todo sólo porque me gusta la canción. Sin embargo la canción que no me ha gustado interpretar me produce aburrimiento en la mente, es decir, quiero que se acabe cuanto antes, aunque la haya tocado mil veces y cualquier aspecto técnico que contiene la obra no me he detenido a superarlo porque no me importa tocarla mal ya que yo, personalmente, no quiero tocar esa canción.

Este tema les ha hecho reflexionar mucho y cambiar su opinión con respecto a la importancia de elegir el repertorio que les gusta interpretar, como veremos también en el análisis de los cuestionarios en general y también en casos particulares. En concreto, una alumna, tras hacer el segundo cuestionario, al plantearse la pregunta de si pensaban que habían cambiado mucho su forma de pensar tras trabajar los textos expone:

No creo que haya cambiado mucho mis ideas pero lo que sí que tengo claro es que en mi concierto fin de carrera voy a elegir el repertorio que yo quiera. 
Otro alumno demuestra también claramente que ha reflexionado sobre este punto cuando expresa:

Mi profesor de instrumento no quería que tocara una obra que me encantaba en mi concierto fin de carrera, porque pensaba que era una obra muy difícil y arriesgada a pesar de que era preciosa. Si hubiera sido otro año me habría convencido rápido, pero tras leer las investigaciones sabía que podía disfrutar mucho más en la preparación del concierto si tocaba la obra que yo quería.

Este comentario lo hizo a principio de curso, y al poco tiempo nos dijo que había convencido a su profesor (con ayuda también de los argumentos que le daba la investigación). Y cuando a mitad de curso le preguntamos qué tal iba con su obra, nos dijo:

Esa obra va genial, ahora sólo me falta trabajar todas las demás ${ }^{40}$

Sobre la tercera de las ideas que se ha seleccionado del texto de McPherson (la diferencia entre elogio y estímulo y la reflexión sobre el efecto que les han producido éstos) todos han visto clara la diferencia y han encontrado vivencias donde se han visto elogiados y estimulados (y también lo contrario, aunque no se incidiera sobre ello). Esta reflexión, a raíz de los comentarios que suscitó, se puede decir que les hizo darse cuenta de lo importante que es también para ellos aprender a estimularse a sí mismos y a apreciar esos estímulos de compañeros, profesores y amigos. Una alumna lo expresa de la siguiente manera:

Como alumna, recuerdo días en los que el profesor me ha felicitado por el trabajo y la buena musicalidad obtenida en una interpretación, lo que me supuso la satisfacción de ver recompensado el esfuerzo que había realizado para conseguirlo y seguir mejorando en ese ejercicio que llevaba un largo periodo de estudio, sin conseguir el resultado deseado. Supongo que si me hubiera elogiado

40 En este momento sabemos que le fue muy bien de verdad, pues en su concierto fin de carrera sacó matrícula de honor 
por la buena musicalidad, sin verla como fruto del trabajo, habría pensado que no podía hacer nada por seguir mejorando.

\subsubsection{Texto 3: Davidson, J (2006)}

Para trabajar este texto (Davidson, J: El desarrollo de la habilidad interpretativa, en Rink, J. (ed.) (2006). La interpretación musical. Madrid: Alianza Música.), se les pide que lo lean y reflexionen sobre las ideas que se proponen de manera individual, pidiéndoles que realicen el siguiente ejercicio:

1. Fíjate en los cinco factores ambientales que sugieren los investigadores (Sloboda, Davidson, Howe y Moore en la cita 6 del texto de Davidson) como importantes para el desarrollo musical e intenta ver si se han dado en tu caso, cuándo y de qué manera.

2. La autoestima y el conocimiento de uno mismo repercute profundamente en el desarrollo de los objetivos personales (según nos dice Susan Hallam en la cita 26 del texto de Davidson), por eso nos explica Davidson que los individuos aprenden tareas si valoran la actividad y el resultado o si anticipan el éxito, y la valoración depende de varios tipos de motivación. Explica qué tipos de motivación te afectan, dónde, cómo y cuándo has notado estos tipos de motivación y cómo crees que puedes desarrollarlos.

3. Hallam sugiere unas técnicas de enseñanza para ayudar a desarrollar la motivación intrínseca. Piensa en cómo puedes aplicarlas a ti mismo.

Al trabajar este texto buscamos que el alumno reflexione sobre el desarrollo de su habilidad interpretativa. Conocer cómo la han desarrollado y cómo valoran las actividades que realizan, así como el tipo de motivación que más les influye y qué pueden hacer para seguir desarrollando su motivación les puede ayudar a conocerse mejor, ganar confianza en sí mismos y a disfrutar más de lo que hacen.

Con respecto a los factores ambientales para el desarrollo musical, aparecen los siguientes resultados: 
a) Todos reconocen haber tenido estímulos musicales fortuitos pero frecuentes, en ocasiones, porque los padres o algún familiar cercano tenían relación con la música. Además de los padres, lo que más aparecen son abuelos, tíos, primos y hermanos. Y, en otras ocasiones, esos estímulos aparecen porque había un instrumento en casa que atraía su atención. Transcribimos a continuación dos testimonios de alumnos que lo expresan así:

Crecí en un ambiente musical bastante anodino, pero había un órgano en mi casa y fue desde un principio uno de mis "juguetes favoritos". Se escuchaba música en mi casa, pero nada fuera de lo normal, sin embargo lo suficiente para que me llamara la atención y me empujara a sacarme las melodías en el órgano

En mi casa siempre había alguien cantando o escuchando música, era lo natural. Por eso, para mí cantar siempre ha sido algo muy natural que no me ha costado esfuerzo. La idea de calentar a mí me parecía que era cansar la voz y que lo normal era empezar a cantar porque yo siempre tenía la voz preparada y colocada

b) Con respecto a las oportunidades de explorar libremente durante un periodo prolongado, casi todos los estudiantes reconocen que los padres les animaban a tocar aunque no de manera muy insistente Sí que hay dos alumnos del primer año de la investigación y tres del segundo que recuerdan que tocaban mucho cuando querían y sin que nadie les insistiera.

El hecho de haber tenido siempre a mano el instrumento ha sido esencial. Recuerdo toda mi juventud ligada a algún tipo de teclado, bien fuera el primer órgano, como el piano o los teclados que vinieron después. Siempre he podido tocar cuando me apetecía

c) Oportunidad temprana de experimentar estados emocionales relacionados con la música. En este punto es donde más anécdotas han aparecido. Todos tenían momentos especiales con la música y a los que creen que les deben el ser músicos. Ponemos algunos como ejemplo:

Recuerdo que escuchaba melodías, por ejemplo, en el coche o en un restaurante y me obsesionaba con que se me olvidaran antes de llegar a casa y poder sacarlas en el piano. Cuando conseguía tocarlas experimentaba una gran emoción.

Me parecía muy emocionante cuando descubría nuevos acordes. Al principio, el oído sólo me daba para los grados I, IV y V, pero poco a poco cuando iba 
descubriendo el resto, recuerdo que me fascinaba y componía canciones en las que aparecieran.

Me gustaba mucho tocar el violín con mi hermana. La verdad es que a mí nunca me apetecía tocar y nunca lo habría hecho si no fuera porque mi hermana decía siempre: "vamos a tocar un poco" y yo, por estar con ella, tocaba todo el tiempo que hiciera falta. Más adelante ella dejó el instrumento por algo que le gustaba más, pero yo seguí con ello porque ya se me había despertado el gusanillo. Aún así, sé que si no hubiera sido por ella hoy no sería violinista.

Recuerdo la primera vez que fui a escuchar un concierto de piano: me llevó mi abuelo el año que yo empecé preparatorio de piano porque a él le encantaba escuchar música clásica. Al terminar el concierto fuimos a saludar al intérprete y me firmó el programa. Me hizo mucha ilusión que la dedicatoria fuera: "para mi pequeña colega", aunque creo que me hizo más ilusión ver la cara de emoción de mi abuelo, pues aunque han pasado muchos años todavía la recuerdo.

d) Oportunidad de acumular muchas horas de práctica. En general, todos reconocen que han podido tocar todas las horas que han querido sin problemas, excepto los alumnos de percusión (que no tenían los instrumentos en casa y no siempre podían tocar el instrumento deseado) y algunos de jazz (que notaban que lo que querían hacer parecía un poco al margen y no se valoraba su práctica como algo serio, a lo que se sumaba que, en ocasiones, les costaba mucho conseguir un local para ensayar con su grupo). Un alumno cuenta su vivencia de la siguiente manera:

El instrumento siempre ha estado a mi alcance y he podido tocar siempre que he querido, sin ningún impedimento, aunque es cierto que a veces actuaba la pereza y dejaba todo para el último momento. La cantidad de horas de práctica se incrementó cuando empecé a tocar en la banda del pueblo, pues allí disfrutaba y no me daba tiempo de darme cuenta que dedicaba muchas horas porque estaba acompañado 
e) Factores externos como la presencia de un adulto clave

En general, el adulto clave suele ser alguien de su familia o un profesor al que sienten como muy cercano, accesible y con ganas de ayudar. En ocasiones reconocen apoyo por varios adultos clave: uno dentro del ámbito familiar y otro en el ámbito escolar. Un alumno de nuestro estudio lo refleja así:

La implicación de dos de mis tíos que estudiaron música y tocaban en distintas orquestas fue un factor clave para mi primer acercamiento con la música, pero no la hubiera estudiado de manera profesional si no hubiera sido porque mi profesor del conservatorio habló con mi madre tras un concierto con quince años, comentándole que me veía un gran potencial.

También hemos visto que muchos de los alumnos son muy generosos y piensan que han tenido muchas ayudas en su vida para llegar a donde están, muchos adultos clave a los que agradecer mucho de lo que saben. Demuestran que se han sentido apoyados en toda su carrera. Un alumno lo expresa de la siguiente manera:

Mi primer adulto clave sin duda fue mi primer maestro de trompeta, que me enseñó no sólo a tocar sino también que se podía vivir de la música, aunque no fuera fácil. También podría destacar a mi primer compañero de trompeta, que fue el responsable de que me apuntaran a clases de música. Tenía varios años más que yo e iba por delante de mí, era en el que me fijaba para mejorar día a día (yo también lo veía como un adulto). A partir de ahí una gran cantidad de compañeros y profesores que se han cruzado en mi camino desde entonces, pero no quiero olvidarme de mi hermano Jorge, que empezó poco después que yo y veinte años después seguimos tocando juntos, dando guerra, y lo que nos queda por venir.

Con respecto a la segunda idea del texto, los resultados que aparecen son los siguientes:

1. Todos los alumnos tenían claro que la motivación intrínseca es la que facilita el compromiso a largo plazo con la música y todos reconocen ésta como la más importante de sus motivaciones. Un alumno lo describe de la siguiente manera: 
En momentos de introspección, cuando consigo encajar con el instrumento, parece que la relación entre el instrumento y yo parece fluir de forma casi perfecta, siento la satisfacción del trabajo realizado durante tantos años, y pienso que ésa es la verdadera recompensa, al margen de títulos y elogios externos.

2. No tenían tan claro y manifiestan su sorpresa sobre la importancia de las demás (extrínseca, social y de éxito) y que se vean como motivaciones importantes ya que a menudo precedían a la intrínseca. Sin embargo, cuando se les pide que reflexionen sobre qué tipos de motivación piensan que tienen ellos, aparece siempre la intrínseca y algún tipo de las otras en alguna medida. Un alumno da su punto de vista sobre la motivación social y de éxito con el siguiente comentario:

La motivación social y de éxito son dos factores que me hacen estar al día en mi aprendizaje musical. No los asocio con el conservatorio, sino quizá más con mi faceta de músico autodidacta. Mentiría si dijera que no tiendo a verme triunfando de alguna manera en el mundo de la música, creo que es una motivación que todos tenemos en algún rincón de nuestra mente, sea de una u otra manera.

3. Para los alumnos de más edad una motivación que destaca para seguir con los estudios musicales es la extrínseca: la consecución de un título superior que le abra puertas laborales. Un alumno lo expresa así:

La motivación extrínseca es la razón fundamental por la que continúo actualmente en el ámbito académico. La titulación superior es la motivación que me mantiene en el proceso, pensando que pueda ser interesante para mi futuro profesional

Con respecto a la tercera idea que aparece en el texto: la de cómo se puede ayudar a desarrollar la motivación intrínseca, se obtienen los siguientes resultados:

Lo que más impacto causa en los grupos de discusión sobre este texto es la idea de que se pueda hacer algo para mejorar la motivación intrínseca. Tenían asumido que este tipo de motivación se tenía o no se tenía y la idea de que se puede incentivar o desarrollar resulta muy atrayente para todos.

Todos los alumnos de nuestra investigación consideran que, para ellos, el estar expuesto a muchos tipos de música de una manera libre (la primera de las recomendaciones que aparecen para ayudar a desarrollar la motivación intrínseca) es muy sencillo, debido a las nuevas 
tecnologías y a la cantidad de actuaciones que hay de todo tipo: clásico, folklórico, jazz, pop, rock, etc. A este respecto, lamentan la escasez de tiempo de que disponen, que les lleva a experimentar como pérdida de tiempo el acudir a (o simplemente escuchar) actuaciones de música que no están directamente relacionadas con su instrumento o con el estilo que están tocando, lo que lo convierte en algo así como un freno para disfrutar plenamente de este tipo de actuaciones, cuando debería ser al contrario. Reflexionan sobre la necesidad de cambiar esa mentalidad para poder verlo como una forma más de aprender de un modo distinto a como se hace dentro del aula.

Sobre la segunda recomendación que aparece, la de participar en las decisiones sobre el estilo y la dificultad de la música que se va a aprender y decidir si quieren o no interpretar en público o examinarse, está muy generalizada la idea de que en el ámbito académico no se tiene mucha capacidad de decisión sobre estos temas y tampoco se lucha mucho por tenerla. Reconocen que el alumno está acostumbrado a que decidan por él lo que tiene que hacer, incluso estando en la enseñanza superior. Sí que es habitual que busquen espacios fuera de la enseñanza formal para hacer las cosas a su manera. Dos alumnos lo expresan así:

En algunos ámbitos de mi actividad musical me siento más libre a la hora de tomar decisiones que en otros, supongo, pero es cierto que mayormente, tanto en el ámbito académico como en el profesional, me veo obligado y sin capacidad de decisión tanto a la hora de tocar en público como de examinarme. Asumo que es una parte de mi actividad y lo llevo con naturalidad, pero es cierto que la decisión no sale de mí. Quizá por eso la faceta musical con la que más disfruto es precisamente la mía personal, en la que yo decido cuándo, dónde y ante quién toco, sin obligaciones ni pruebas de ningún tipo

La primera vez que toqué con el grupo de rock, no sabía cómo me iba a sentir, y me sentí libre de hacer lo que quisiera; brincar, hablar por el micro entre canción y canción, bailar... hacía lo que mi cuerpo me pedía y eso fue una experiencia preciosa que me dio un subidón que nunca me había dado. Siempre he tocado en audiciones con unas normas de "seriedad" de la escuela de música o el conservatorio; con la banda siempre manteniendo filas y la compostura para que no te llamen la atención y en la txaranga lo mismo con un poco más de libertad. Como corista y bajista, era la primera vez que realmente podía ser yo. 
La tercera recomendación, la de que los profesores han de generar sorpresa, duda, contradicción y debate, les parece muy interesante y aparecen los extremos, dependiendo del tipo de profesor con el que nos encontremos. Vemos dos opiniones distintas al respecto:

Lamentablemente, diría que la enseñanza musical en mi entorno ha sido siempre muy unidireccional. Eso no quiere decir que no haya profesores que me hayan aportado algo, pero en general he hecho siempre lo que me pedían de forma más o menos obligada. Vamos, que no creo que me hayan hecho muy partícipe de mi proceso de formación.

Estoy muy contento con mi profesor, porque es un gran profesional como músico y como profesor, conoce todo lo necesario para que aprenda, me anima a buscar mi propio estilo, a buscar todo lo que necesite, pero también me da los recursos que necesito para trabajar y me anima a esforzarme valorando todo lo que consigo, contando siempre con mi opinión, gustos y necesidades y sin imponer nada. Siento que me valora como profesional y me ayuda a mejorar cada día.

\subsubsection{Texto 4: Hallam, S y Gaunt, H. (2012)}

Para trabajar este texto (Hallam, S y Gaunt, H. (2012) Preparing for success: A Practical Guide for Young Musicians London: Institute of Education.) se les pide en clase, antes de leerlo y de manera individual y anónima, que escriban sus ideas con respecto a qué creen que es necesario para conseguir el éxito como músico profesional en el siglo XXI. Una vez realizado, se procede a recoger los folios y a distribuirlos en los grupos (tal como se había explicado en la forma general de funcionamiento en los grupos de discusión). Una vez realizado el vaciado en los pequeños grupos y presentado al grupo clase, se presentan también los diez puntos recogidos por Susan Hallam y Helen Gaunt, avalados por las investigaciones más recientes, y se comparan o añaden a los que ya habían aparecido. Tras tratarlo en clase, se les pide que analicen en casa cada uno de los puntos en relación a uno mismo, es decir, si están trabajando cada uno de los puntos que sugieren las autoras, dónde, cómo y cuándo y los que no trabajan por qué razones (si lo considera poco importante, si les parece muy difícil, si en este momento tienen otras prioridades, etc.). También se les pide que piensen dónde, cuándo y cómo lo podrán trabajar mejor. Es curioso constatar la diferencia generacional, como por ejemplo cuando algún joven dice que no lo hace por falta de tiempo, a lo que 
responden los más mayores (ya con cargas familiares) que ahora tiene más tiempo del que van a tener nunca para dedicarlo a lo que quieran, aunque no lo crean.

Para analizar los resultados, vamos a ir señalando cada uno de los puntos trabajados:

1. Sé responsable con tu desarrollo y persigue lo que te apasiona.

Ya hemos dicho al tratar este tema en el capítulo primero de esta tesis, que esta idea era una de las que más había sorprendido a los alumnos de nuestro estudio y que, en la mayoría de los casos, la única decisión que tomaban era entrar al conservatorio y, una vez allí, el resto de decisiones recaían en lo que el centro le ofrece y lo que su profesor de instrumento le propone. Citamos las palabras de una alumna que expone lo siguiente a este respecto:

Para empezar, creo que no nos paramos lo suficiente a reflexionar qué es lo que queremos, qué es lo que nos gusta y nos apasiona. Generalmente vamos movidos por motivaciones internas y externas a las que no ponemos conciencia y nadamos en un mar llevados por la sociedad, junto con otros miles de peces que hacen lo mismo. Si sabes lo que quieres, podrás conseguirlo, buscarás la forma de hacerlo y sabrás qué pasos deberás dar.

2. Entiende lo que te motiva y por qué, lo que te trae satisfacción y construye tu confianza.

Como se ha visto en las palabras de la alumna que citábamos en el párrafo anterior, el alumno de estas enseñanzas tiene claro que no suele dedicar tiempo a reflexionar sobre lo que está haciendo. Sin embargo, este tema es cada vez más necesario para el músico. Dos alumnos en el grupo de discusión cuentan qué es lo que les ayuda a construir su confianza:

Como músico me muevo en ambientes muy diferentes, por lo que mis públicos son muy variados. Debo reconocer que me satisface que le guste a cualquier persona, pero cuando una actuación le ha gustado a un músico me satisface más.

3. Desarrolla habilidades de colaboración e interpersonales.

En nuestros grupos de discusión hemos visto que quizá en el conservatorio es importante profundizar en esta idea, dado que todavía no ha calado mucho. Los alumnos siguen sintiendo 
que se les pide mucho el desarrollo individual y mucho menos el trabajo de estas habilidades de colaboración e interpersonales, tan necesarias hoy en día. Ya señalábamos en el primer capítulo de la tesis, que resulta sorprendente cómo en el grupo de discusión se les escapa "cuando toco solo", incluso cuando están tocando con el pianista acompañante, prueba evidente de que no son conscientes de que están con él y que deberían sentirse acompañados y ver que tienen una responsabilidad compartida en su actuación. Sin embargo, sí que reconocen la satisfacción de desarrollar esas habilidades y la importancia de trabajar con los otros. Dos alumnos lo exponen de la siguiente forma:

El desarrollo de mis habilidades de colaboración va unido al trabajo en grupo. Personalmente, me encanta actuar en grupo, ya sean bandas, orquestas, charangas o cualquier tipo de agrupación, al igual que la enseñanza de mis conocimientos a todo el que esté dispuesto a aprender. Llevo cinco años ejerciendo de profesor de tuba y bombardino y cada día aprendo cosas nuevas.

Me parece muy importante introducir habilidades de colaboración interpersonales en clase, como que un alumno pueda preguntarle a otro, escucharle, practicar con él e incluso con amigos que toquen otros instrumentos. Sería genial que quedáramos para tocar juntos. Eso nos motivaría para continuar estudiando y nos ayudaría a disfrutar de lo que les gusta. Para un músico es casi impensable pensar en una vez que no haya colaborado. Además, la mayoría de las veces se hace por "amor al arte" como se suele decir. Realmente, es porque nos gusta tocar en grupo, compartir, y hacer que la gente disfrute con la música.

4. Encuentra un círculo de profesores de confianza, mentores y amigos para apoyar tu desarrollo.

Uno de los problemas ya comentados al tratar este punto en el primer capítulo es que se sienten incomprendidos por su entorno. Ya se ha comentado cómo en ocasiones hasta la propia familia no valora la carrera musical como cualquier otra. Los que sí tienen este grupo de apoyo lo valoran y lo disfrutan mucho. Dos alumnos lo expresan así:

Moverte en un entorno de confianza siempre ayuda al desarrollo, siempre que dentro del entorno estén profesores, amigos y músicos profesionales críticos con lo que te escuchen y que te ayuden a crecer. 
Tengo un gran grupo de amigos artistas, de los que valoro mucho su opinión. Además, me ayuda a compartir con ellos, porque los temas de los que tratamos muchas veces son muy inspiradores. La forma en la que cada uno ve las cosas es muy diferente a lo que lo son normalmente con las demás personas. Como dice mi padre, "os juntáis lo mejorcico de cada casa", y es cierto. Es un chute de vitaminas juntarme con ellos a pasar una tarde, porque las cosas que surgen en ese ambiente son creativas, incluso echando un pote por Pamplona.

El músico debe participar activamente en comunidades musicales para aumentar el apoyo entre personas y para generar ideas y colaboraciones artísticas, intentando también formar parte de otras redes que le pueden proporcionar acceso a los contextos profesionales, que le empujen a desarrollar habilidades adicionales y apoyo personal, además de ayudarle a clarificar su identidad musical y profesional. Los alumnos de nuestro estudio parece que, en su mayoría, no se atreven "todavía" a desarrollar su identidad musical. Esperan a terminar sus estudios para poder buscar su forma particular de hacer las cosas. Parece como si estuvieran limitados por las exigencias de las enseñanzas superiores, que les impiden desarrollarse como a ellos les gustaría. Aún así, hay notables excepciones y, mientras algunos se sienten muy apoyados por su profesor de instrumento en esa búsqueda de identidad y desarrollo profesional, otros lo hacen al margen de la vida académica.

\section{Explora, sé arriesgado, extiéndete más allá de tus límites actuales.}

Las autoras insisten en la importancia de explorar cosas nuevas para ampliar su flexibilidad como músico. Ya explicamos en el primer capítulo de la tesis que encontrábamos bastantes diferencias entre los alumnos que cursan interpretación clásica y los que cursan jazz. A los alumnos de interpretación clásica les cuesta más ser versátiles. Los alumnos de jazz, que en general también tienen más edad, suelen ser más versátiles, suelen buscar ellos mismos distintas perspectivas (en ocasiones con ayuda de su profesor y otras por su cuenta) y ven muy importante para su desarrollo como músico trabajar distintos estilos y técnicas, además de considerar como básica la improvisación, por ser una habilidad necesaria para un intérprete de jazz. Sí que es cierto que en ocasiones también esperan a terminar los estudios para desarrollar su identidad propia como músico. La sorpresa que produce este punto la expresa una alumna de nuestra investigación con estas palabras: 
Como alumna, considero que pensaba que esto era una debilidad para mí. Que tocar muchos palos me hacía ser débil en todos, que no resaltaba en ninguno, y es cierto que ahora empiezo a valorar qué cosas realmente diferentes me ayudan a ser mejor músico, a hacer trabajos diferentes y espero conseguir hacer un trabajo fin de carrera creativo y aprender muchísimo. Me encanta aprender, y siempre hay cosas que me intriga saber.

6. Comprométete con la tecnología.

Como ya hemos señalado anteriormente, podemos decir que nuestros alumnos sí que son conscientes de que la tecnología es una parte cada vez más importante de la práctica profesional en la música y, en general, todos la utilizan para comunicarse, compartir música y promover eventos. Aunque en otros aspectos señalados por las autoras (como el hacerla útil para su práctica diaria) sí que suele haber diferencias entre los de clásico y los de jazz. Los de jazz suelen utilizar la tecnología también para grabarse, crear y componer, aparte de como apoyo y seguimiento de su aprendizaje y como ayuda para comparar y reflexionar sobre su práctica. Los alumnos de clásico, en cambio, se graban en momentos puntuales aunque sí se han dado cuenta de su utilidad como herramienta para ser más objetivos. También destacan que sus profesores, por lo general, se han quedado bastante obsoletos en este tema. Dos alumnos inciden en este punto comentando lo siguiente:

Como alumna, las nuevas tecnologías prácticamente no existen para mis profesores. Yo las uso cada vez más para mí, y es cierto que son un mundo que estoy descubriendo, incluso para que dos alumnos puedan escucharse mutuamente cada uno desde su casa ... o para todo lo que puedas imaginar. Aún así, todavía tengo mucho que aprender, pero las nuevas tecnologías me ayudan incluso a que mis clases sean mejores, como por ejemplo, a poder ralentizar en el momento una canción para que puedan tocarla sobre la base original, o a bajarla de tono si no llegan...

Las tecnologías son algo que se actualiza diariamente y posiblemente los profesores más mayores y poco actualizados no sepan manejar. Pero hoy en día es fácil aprender y es una herramienta muy práctica que ayuda y mucho. 
El siglo XX fue testigo de un aumento sin precedentes de los casos de músicos que sufrían de enfermedades físicas, estrés y agotamiento. Las autoras (Hallam y Gaunt, 2012) insisten en que mantenerse saludable y evitar tales dificultades es vital.

Como comentamos en el primer capítulo, nuestros alumnos se han mostrado especialmente sensibles a esto pues, desgraciadamente, todos hemos tenido cerca algún músico y profesor de música brillante que ha sufrido problemas por su autoexigencia e inestabilidad en el trabajo. En algún caso, incluso le han llevado a no poder mantener el equilibrio trabajo/vida del que hablan las autoras y ha llegado hasta el suicidio. Esto, que no es exclusivo de nuestro conservatorio, sino que ha afectado también a figuras de renombre admiradas por nuestros alumnos, creemos que debería ser el compromiso de todo profesor: cuidar de la salud física y mental de sus alumnos, haciéndoles conscientes de los problemas que puede acarrear el descuidar este tema por priorizar otros. Quizá por todo esto sus testimonios son muy alentadores:

Dormir bien, comer bien y hacer deporte es necesario para todos. No sólo para que estemos sanos, sino para sentirnos felices también. Yo les animo a mis alumnos a estar en buena forma física, que coman sano y sobre todo que duerman 8 horas. Yo lo hago y me siento mucho más eficaz cuando mantengo estas tres cosas. La semana que no entreno, incluso tengo peor humor.

Como buenos músicos que somos o queremos ser, nuestro trabajo es mayormente mental y en menor medida físico, y la mayoría de las veces de manera sedentaria. Por eso el mantenernos en forma es crucial para nuestro bienestar y así evitar lesiones.

Los alumnos de nuestra investigación también reconocen que, en ocasiones, traspasan el límite, pensando que su cuerpo es una fuente de energía inagotable y llegan a un nivel de estrés que les hace ser menos productivos, hasta que se dan cuenta y tienen que tomarse un tiempo para recuperarse y organizarse mejor. 
8. Sé organizado y confiado, y dirígete a ti mismo de manera eficaz.

Como señalábamos en el capítulo primero al tratar este tema, la organización es un trabajo en el que el músico tiene que estar siempre mejorando. Hasta los alumnos que tienen la organización como su punto fuerte son conscientes de que, en muchas ocasiones, no es posible tener un horario demasiado constante debido a la acumulación de ensayos, prácticas, conciertos, refuerzos, etc. Aún así, intentan cuadrar todo, al menos semana a semana, ya que el tratar de cumplir los horarios y saberlos con antelación les da seguridad en el cumplimiento de las tareas y en la forma de organizarlas. Algunos de los alumnos son conscientes de que, aunque en ocasiones le hayan criticado diciéndole "eres demasiado organizada y responsable", como si de algo malo se tratara, sólo por esa capacidad de organización han sido capaces de llegar a donde están y han podido sacar horas para estudiar lo que necesitaban y también para poder descansar lo que necesitaban.

Muchos alumnos son conscientes de que la organización muchas veces está unida a la autoestima y confianza en sí mismos. Afirman que, cuando están bien, planifican con tiempo, no tienen problemas para comunicar cualquier dificultad en cualquier momento, dejan tiempo para pensar en las decisiones, llegan puntuales, con las cosas preparadas a los ensayos y encuentran tiempo libre para relajarse y pensar. Sin embargo, cuando les entran las dudas y la desconfianza en sí mismos, se vuelven más desorganizados y les cuesta más concentrarse y sacar tiempo para estudiar, así como para descansar. Aún así consiguen ilusionarse y establecer un orden de prioridades o un plan más o menos organizado y lo que eligen intentan hacerlo lo mejor posible. He aquí un testimonio al respecto:

Dentro de nuestra vida musical es imprescindible ser organizado, debido a que suele ser una vida laboral variada. En mi opinión, soy muy organizado y con ello pienso en el futuro cercano para organizarme el presente. El tema del tiempo libre es complicado por la carga de actividades que hago diariamente, pero sí que me gustaría poder sacar un rato libre. Lo que no realizo y estoy intentando cambiar es el comunicar a las personas más próximas a mí las dificultades en los momentos oportunos y poco a poco lo voy haciendo y reconozco que es mejor: así te desahogas y te quedas más tranquilo. 
9. Trata a tu trabajo como un negocio de gestión de finanzas y cuestiones de propiedad intelectual.

Hemos visto que nuestros alumnos, en ocasiones, ven los problemas financieros como una de las barreras más fuertes para el éxito, pues se dan cuenta que no se tienen las mismas posibilidades si se carece de medios económicos. Piensan que algunos estudios o cursos, incluso los programas Erasmus, no están a su alcance, pues aunque durante años han intentado optar a becas y subvenciones, siempre han visto muy difícil que la beca cubra los gastos reales que se originan. Así, la mayoría de nuestros alumnos compaginan el estudio en nuestro conservatorio con algún trabajo que les ocupa más o menos tiempo. En muchas ocasiones, este trabajo está relacionado con la música (dan clases o tienen algunas actuaciones) y en ese caso sí que les gusta realizarlo porque también lo ven como forma de desarrollarse musicalmente. Pero en ocasiones el trabajo que realizan no tiene nada que ver con la música y lo ven como la manera de poder pagarse los estudios musicales, aunque también intentan aprender de ello. Una alumna lo trasmite de la siguiente forma:

La verdad que en este punto, ha sido mi experiencia como camarera la que me ha hecho valorar mi tiempo. Ponerle precio a nuestro tiempo es algo que parece costarnos, pero cuando lo hacemos a los que lo pagan no les resulta extraño hacerlo.

El tema de cómo gestionar legalmente los contratos y entender sus derechos como músico tampoco les parece que juegue a su favor sino todo lo contrario. De hecho, lo ven como una de sus cuestiones pendientes. Son conscientes de que han dedicado muy poco tiempo a informarse acerca de la financiación, subvenciones, impuestos, etc. Quizás no le han dado suficiente importancia. Y a menudo dejan que otros lleven estos temas en su lugar. En algunos casos, explican que es una asesoría la que se ocupa de organizar su papeleo, ya que no han querido invertir su tiempo en esas tareas. Piensan que es otro de los apartados que tendrán que empezar a desarrollar y en el que tendrán que poner más interés al terminar sus estudios y tener que adentrarse con más energía en el mundo laboral, por la cuenta que les trae. Un alumno de nuestra investigación lo expresa de la siguiente forma:

El tema administrativo es muy complejo, las leyes son modificadas cada poco tiempo y en los tiempos que corren aun más. La verdad es que hay mucha competencia en el mismo sector y muchos precios se tiran por los suelos sin 
valorar el trabajo que conlleva. Pero reconozco que es un punto en el que en los estudios se debería de hacer más hincapié del que se hace, para que a la hora de salir al mundo laboral sea más difícil el engañarnos.

\section{Desarrolla resiliencia (poder de recuperación). Reconoce tus dificultades}

y momentos de dudas, acéptalos y busca la forma de solucionarlos.

Como comentamos en el capítulo primero al hablar de este tema, el desarrollo de la resiliencia es una cuestión compleja, que depende mucho de la personalidad de cada uno. Los alumnos reconocen que muchas veces la música puede ser frustrante. Dicen textualmente: "inviertes mucho tiempo e ilusión y no siempre sale todo como uno quisiera. Sin embargo por alguna razón, merece la pena". Reconocen que hacer el cálculo de cómo soportar las dificultades que vendrán es realmente difícil, ya que muchas veces son inesperadas. Como bien dice el texto de Hallam, lo importante es superarlo y aprender de ellas. Son conscientes de que las cosas no salen siempre como uno quisiera, pero que con los años van aprendiendo a aceptar la realidad de otra manera, a ver las carencias y las imperfecciones como algo natural y a no autodestruirse con los pensamientos acerca de sus frustraciones. Aún así, en su mayoría, se consideran muy autocríticos y exigentes, y piensan que esto es más beneficioso que perjudicial para su desarrollo, a pesar de que a veces hayan podido plantearse metas que luego no pudieron conseguir como les hubiese gustado. Intentan ver el lado positivo, resumiéndolo en: "cuando no lo logras, al menos habrás aprendido una nueva forma de cómo no hacer las cosas". Una alumna expresa su vivencia de esta manera:

Me encanta una frase que decía mi abuelo sobre la importancia de recuperarse: "la vida te pone obstáculos, los problemas los pones tú". Y siempre he salido de todos los obstáculos, nada más que pensando en cómo hacerlo. Pero ahora, por primera vez, es con 28 años cuando vivo de la música al 100\%. Todos mis ingresos son gracias a la música y cada año me propongo un mejor trabajo.

Como explicamos al tratar este tema en el capítulo primero de la tesis, la lección que reconocen como que más les cuesta es asumir que no pueden hacerlo todo bien y que van a caer más de una vez. Sí que reconocen fundamental sobreponerse y seguir adelante por el mismo camino o probando otro, así como ser lo suficientemente inteligentes para saber cuándo una barrera es, al menos de momento, infranqueable, o esperar al momento en que puedan hacerle frente. También reconocen como muy importante para superar los obstáculos 
el tomarse en serio todo lo que hagan en el campo musical, tratando a la música con el máximo cariño y respeto. Y, a la hora de superar los obstáculos, valoran mucho, como no podía ser de otra manera, el contar con los demás, crear un ambiente de trabajo cordial, flexible y activo en el que todo el que participe se sienta contento e involucrado con el proyecto que realice. Creen que el sentirse respetado, apoyado (y nosotros añadiríamos convencido) con lo que hacen, es lo que les ayuda a superar los miedos con más facilidad.

Un alumno expresa su opinión sobre el tema de forma escueta y clara:

Es crucial que nosotros mismos tengamos un poder de recuperación grandísimo y con ello reconocer nuestros errores, dificultades, dudas para aceptarlos y buscar la manera de solucionarlos.

\subsubsection{Texto 5: Gardner, H. (2005)}

Una de las ideas más importantes sobre las que hemos estado trabajando a lo largo de la investigación es la necesidad de que todo alumno se convierta en un músico convencido y apoyado (explicada en el capítulo primero de este trabajo). Para poder ahondar en este tema, este texto (Gardner, H. (2005) Las cinco mentes del futuro: un ensayo educativo. Barcelona: Paidós Ibérica.) parece de especial utilidad, pues con el conocimiento de las ideas de Gardner y la búsqueda de las formas de aplicarlas a la música, el estudiante de la enseñanza superior reflexionará sobre si él está trabajando en lo que parece más significativo en el siglo XXI a la luz de la investigación y cómo puede mejorar en este trabajo para conseguir la excelencia. Esta reflexión le ayudará a estar más convencido de lo que hace y a tener herramientas en las que apoyarse para convertirse en un buen músico.

Para trabajar este texto, se empieza por explicar en clase cada una de las mentes allí analizadas y se les pide que apliquen los pasos que Gardner sugiere para trabajar la mente disciplinada, con un ejemplo en concreto y aplicado a la música de forma individual y anónima. Para hacer este ejercicio, utilizamos el esquema general de ejercicio de aplicación explicado al principio del trabajo con los textos. Una vez realizado y analizado, se les pide que hagan el siguiente ejercicio de reflexión en casa para el siguiente día de clase. 


\section{Reflexión sobre el texto de Gardner. Las cinco mentes del futuro. Un ensayo}

educativo.

Aplica al trabajo de algo musical que te gustaría aprender todos los pasos que recomienda Gardner para trabajar cada una de las mentes importantes para el siglo XXI (disciplinada, sintética, creativa, respetuosa y ética). Pon también ejemplos de personalidades musicales que pudieran ser referentes para estas mentes, tanto en tu instrumento como en general.

Del trabajo de este texto obtenemos los siguientes resultados:

\section{1- $\quad$ Mente disciplinada}

Con relación a la mente disciplinada, todos opinan que para ser músico es necesario tener esta mente disciplinada, que te guste saber cada vez más sobre música una vez que empiezas a trabajar en ello. Estas ganas de saber cada vez más o de tocar cada vez mejor es lo que señalan como la principal motivación para perseverar en el estudio o la práctica, aunque reconocen que en ocasiones les entran momentos de duda. En relación con la mente disciplinada y su relación con la música un alumno expone la siguiente reflexión:

Cuanto más sabes, más quieres saber y te automotivas por eso que te gusta y así lo aprendes fácilmente y, para eso, además de identificar bien los elementos de la interpretación, tendríamos que buscar qué es lo que nos gusta y acostumbrarnos a trabajar de diferentes maneras y a elegir el repertorio que tocamos sin dejar que nos lo impongan y así alimentaríamos más nuestra mente disciplinada o nuestra motivación.

En general, les parecen muy interesantes los pasos que indica Gardner para desarrollarla, pues todos creen que la tienen. Uno lo expresa de forma muy clara: “cuanto más sabes, más quieres saber”. Aun así, a todos les gustaría poder desarrollarla y ayudar a sus alumnos, compañeros y futuros alumnos o compañeros a desarrollarla. Por eso les ha parecido muy útil el trabajo de los pasos que propone Gardner para ello: en el primero (que es identificar lo más importante) aparece la idea de que en muchas ocasiones se deja de trabajar lo importante por no identificarlo bien y que muy a menudo se preocupan más por los detalles que por lo que de verdad es interesante. Una alumna lo expresa de forma muy clara: 
Me canso muy rápido de las obras y abandono los detalles, aunque soy consciente que debo trabajar los detalles si quiero realmente disfrutar de la obra y poder ver cómo consigo su interpretación como tiene que sonar. He visto que en ocasiones el trabajo técnico desmotiva porque no se une a la expresión o la comunicación con el público.

Para reflexionar sobre esto, propusimos a los alumnos que pensaran en un músico al que admiraran e intentaran explicar por qué creían que les gustaba. Para ello se utilizó la forma habitual de trabajo en grupo. Primero contestaban de forma individual y anónima a la pregunta, después lo intercambiaban y hacían el vaciado en pequeños grupos y finalmente se ponía en común. En general, lo que contestaban era que lo que más les gustaba era su capacidad de comunicación y expresión. Al preguntarles si en su estudio diario incluían el trabajo de comunicar y expresar, no parece que lo tuvieran muy en cuenta, reflejando que lo más importante para un músico, según ellos, no era lo que trabajaban como más importante. Uno de ellos lo explica de la siguiente forma:

Lo que más me gusta de este músico es la expresividad, la facilidad con que comunica, la seguridad, el entusiasmo, su poder de transmitir, su sensibilidad, características que no suelo preocuparme de trabajar en mi estudio diario.

Como se puede ver, se dan cuenta de que para desarrollar la mente disciplinada sería necesario destacar más qué es lo importante y dedicar tiempo a trabajarlo, como propone el autor en el segundo punto. Para algunos alumnos ésta es la parte más difícil de la práctica instrumental: el estudiar aspectos importantes en los que no se insiste lo suficiente, como la expresividad o el gesto, que es lo que conecta con el público. En ocasiones son conscientes que este trabajo es fundamental para convertirse en músico. Un alumno lo expresa de la siguiente forma:

Dedico tiempo a trabajar mi gesto y expresividad frente al espejo. Creo que no se trabaja de una forma sistemática y he visto que si se trabaja se obtienen muy buenos resultados, muchas veces me han felicitado por cómo consigo transmitir y comunicar como si fuera algo que se tiene o no y yo he comprobado que expreso 
mucho más cuando trabajo el gesto y la expresión en cada obra y lo práctico con este objetivo en concreto.

Con respecto al tercer punto, en el que Gardner insiste en que para trabajar la mente disciplinada es necesario abordar los temas de varias maneras, y al cuarto punto ("establecer unas demostraciones de la comprensión”), los alumnos de los grupos de discusión plantean el problema con el que muchas veces se encuentran: que les faltan formas distintas de trabajar, pareciendo en ocasiones que sólo se pueden hacer las cosas de una manera y que no siempre sienten que se tengan en cuenta sus necesidades, sus puntos fuertes y débiles y que tampoco conocen distintas formas de abordar las tareas que se les encomiendan. Estarían en la línea que sugiere Nielsen (2004) donde evidencia que muchos estudiantes de música en la enseñanza superior tienen la idea de que no se les han enseñado estrategias muy detalladas de cómo practicar y explica que aquellos que están más habituados a usar estrategias metacognitivas tienen más autoeficacia en general. Forcada (2014), en su tesis sobre la enseñanza del violín, recoge la idea de Nielsen anteriormente expuesta y analiza las estrategias que los profesores pueden utilizar para provocar el aprendizaje de los alumnos: práctica física y práctica cognitiva (las dos que se suelen utilizar normalmente) pero también incluye otros tipos de la que se podrían beneficiar tanto profesores como alumnos: la práctica modelada, la práctica guiada y la práctica mental.

Al entablar el debate sobre los distintos tipos de práctica instrumental utilizados, el que echan más de menos los alumnos es la práctica mental que, como hemos visto en la parte teórica de nuestro trabajo, es uno de los que la investigación actual destaca como muy útil para el músico. En relación con el desarrollo de la mente disciplinada de Gardner, tendríamos que decir que este desarrollo le hace al estudiante ser más autónomo e independiente y, en esta línea, Hallam y Bautista (2012:667) proponen trabajar tanto el ensayo mental como el físico como una de recomendaciones para hacer al alumno más independiente.

\section{2- $\quad$ Mente sintética}

Con respecto a la mente sintética, reconocen que la misma labor de interpretación ya debería ser una labor de síntesis pues incluye el conocimiento de la obra, del estilo y del autor, unido a la técnica propia y su forma individual de tocar, igual que la composición y la improvisación. 
La idea de ser original, relacionando diferentes cosas para lograr algo nuevo, les hace reflexionar sobre la importancia de ser curioso, comparar, analizar, identificar los elementos constitutivos de una buena síntesis a través de buenos modelos y aprender a hacer buenas críticas, críticas útiles que permitan conocer diferentes soluciones, propuestas de Gardner que ven fundamentales para el trabajo de músico. Un alumno expone la siguiente reflexión:

La mente sintética también la desarrollamos todos los músicos. Se trabaja en la interpretación de obras, sintetizando las características que conocemos del estilo, nuestros conocimientos técnicos, el análisis, la musicalidad... al igual que a la hora de improvisar, unimos nuestros recursos técnicos a la armonía propuesta y al tipo de rítmica o compás... Para desarrollar esta mente también nos viene bien escuchar diferentes versiones, y comparar y aplicar los recursos utilizados en cada una, seleccionando los que más nos interesen. Como ejemplo de mente sintética tendríamos a Les Luthiers, que combinan humor, música y espectáculo.

En los grupos de discusión llama la atención que Gardner haga una llamada explícita al colectivo al que nos dirigimos: la enseñanza superior. Y, entrando de lleno en el contexto de la música, exponen que esa colaboración es completamente necesaria y que nos falta mucho camino por recorrer. Reflexionan sobre la forma en que el músico suele trabajar en las enseñanzas superiores y concluyen que ellos como músicos están muy acostumbrados a un trabajo individual y que el desarrollo de grupos interdisciplinarios suele ser una asignatura pendiente que, por lo general, no se valora como debiera. Se dan cuenta que en su mismo conservatorio, donde conviven los alumnos de clásico y jazz, no se montan grupos donde toquen alumnos de las distintas especialidades. En ocasiones se quedan gratamente sorprendidos con alguna experiencia, sorpresa que lleva a pensar que no es muy habitual. Para los alumnos implicados, la experiencia de trabajo colaborativo entre profesores ha sido muy sorprendente. Concretamente, dos alumnas que estuvieron un curso académico en Polonia dentro de un programa Erasmus se quedaron gratamente impactadas al ver cómo la profesora de una de ellas ayudaba y aconsejaba a la otra y viceversa. Era evidente que había un trabajo en equipo planificado, donde una valoraba las virtudes de la otra y enviaba a sus alumnos para que aprendieran de ella. Igualmente, un alumno francés nos comentó que en Francia también ha tenido esa sensación de que los profesores no estaban acostumbrados a esa forma de trabajo colaborativo, de modo que cuando viajó a Inglaterra para cursar un master, su sorpresa fue tan considerable como positiva cuando se le aconsejó que tocara para otros profesores y se 
dejara aconsejar por ellos. Por supuesto, esto no sólo lo encontramos en la música clásica: un alumno de Jazz nos comenta que tras un examen con tribunal tuvo la ocurrencia de pedirle a un profesor distinto al suyo su opinión sobre cómo había tocado; el resultado fue que tuvo que pedir disculpas a los dos, ya que lo que experimentó fue que había ofendido tanto a su profesor como al interpelado. Por suerte, ha podido luego conocer las investigaciones de Hallam y Gaunt (2012) para ser un buen músico profesional, de modo que desapareció esa sensación que le había quedado de haber hecho algo mal. Lo correcto, incluso lo recomendable, es precisamente el pedir distintas opiniones a distintos profesionales. Por terminar con los ejemplos, citaremos como algo que valoran mucho los alumnos de nuestro estudio son las audiciones conjuntas entre instrumentos de clásico y jazz, por iniciativa de los dos profesores de guitarra (clásica y jazz), experiencia donde ambos profesores, junto con los alumnos de ambas especialidades, escuchan y aconsejan a todos ellos.

\section{3- $\quad$ La mente creativa}

Con respecto al desarrollo del trabajo de la mente creativa los alumnos de nuestros grupos de discusión insisten en que cuesta mucho salir de lo establecido y crear su propio estilo, porque parece que en la enseñanza formal lo que se prima es hacer las cosas de una forma estandarizada. Y lo que creen necesario tras trabajar este texto de Gardner es buscar su propio estilo, estudiar de forma creativa y aprender a tomar decisiones arriesgadas que les ayuden a salir de la rutina. Un alumno lo expresa de la siguiente forma:

\section{Para desarrollar la mente creativa debemos salirnos de la rutina y afrontar riesgos, no solo en el ámbito musical, sino también en el personal.}

En general, consideran que son muy interesantes las ideas que ofrece Gardner para desarrollar la mente creativa. Con relación a la primera propuesta de mantener abiertas varias posibilidades y alimentar el entusiasmo por la exploración, los alumnos de la enseñanza superior ven que les cuesta bastante probar diferentes estilos y estéticas y que normalmente prefieren quedarse en el estilo al que están más habituados; igualmente les cuesta explorar campos nuevos, en especial en cuarto curso, donde lo que quieren es asegurar que hacen lo que se les pide y parece que esperan a terminar los estudios para explorar otros campos y, cuando lo hacen, es de manera informal, no dentro de las enseñanzas regladas. 
En relación a la segunda propuesta de Gardner, sí que están acostumbrados a buscar diferentes soluciones a un mismo problema. Estos alumnos se sienten inmersos en la era digital, acompañados por las pantallas negras que llevan a todas partes, y con mucha frecuencia tienden a buscar distintas versiones de la obra que tienen que interpretar. Aunque, obviamente, esto no quita para que, en ocasiones, aparezcan problemas, algo que un alumno expresa de la siguiente forma:

Tenemos la posibilidad de acceso a una gran variedad de ejemplos, pero en ocasiones no nos sirve si no tenemos criterios para distinguir qué es o no válido y si no contribuye a aumentar y alentar nuestra capacidad y ganas de ofrecer algo propio.

La tercera propuesta, es decir, la de conocer personas creativas que sirvan de ejemplo, les parece fundamental y a menudo se inspiran en músicos que crean instrumentos nuevos con más posibilidades expresivas y técnicas, músicos que combinan sus repertorios con otras artes o que fusionan o trasladan estilos y consiguen ser originales y buenos modelos como artistas.

La última propuesta de Gardner para desarrollar la mente creativa habla de la necesidad de ofrecer al estudiante actividades ajenas a la rutina escolar, donde se premie la innovación y se toleren los errores. Los alumnos de nuestro estudio opinan que, en ocasiones, dentro del mundo musical tienen la sensación de que el ensayo-error está penado y que esto no ayuda a arriesgarse por miedo a cometer algún error. Exponen que es necesario que les dejen libertad en lo que hacen, y más concretamente en su concierto fin de carrera, añadiendo que, cuando les dejan esa libertad, el resultado es siempre considerable. Alguno comenta lo que les dijo un catedrático de este conservatorio que les había dado libertad para hacer su concierto: "cuando os dejan hacer lo que queréis sin exigiros que toquéis obras determinadas ni nada, y lo montáis vosotros solos, hacéis verdaderas virguerías". De lo que no cabe duda es de que se implican mucho más, no sólo en tocar sino también en la preparación: su entusiasmo es tal que se vuelcan en ese concierto de tal manera que llegan incluso hasta el punto de que convierten el "examen" en un auténtico concierto, con el público llenando la sala. Más aun, lo que se suele hacer es mezclar la música con el teatro y la danza, incluyendo juegos de luces e imágenes, es decir, que no se limitan a una idea de concierto de fin de carrera típico y tópico, sino que van más allá, convirtiéndolo en un espectáculo artístico y no meramente técnico (o 
que cumpla el expediente y punto). No quieren simplemente hacer un concierto sino disfrutar del trabajo bien hecho.

\section{4- $\quad$ La mente respetuosa}

El valor de esta mente para el músico de este siglo está más que claro y, además de lo que dice Gardner, en los grupos de discusión se trabaja lo que nos dicen las investigaciones sobre la importancia del trabajo colaborativo en este siglo XXI, tanto para el estudiante de música superior como para el trabajo en orquesta. Para eso son conscientes de la necesidad de aprender a estudiar en grupo y ser críticos, sabiendo escuchar opiniones y expresando las propias, sabiendo que lo que se intenta es mejorar la labor del conjunto. Un alumno lo explica de la siguiente manera:

La mente respetuosa se trabaja, sobre todo, cuando tocamos en grupo, exponiendo nuestras ideas y llegando a acuerdos con el resto de los compañeros, para conseguir que la interpretación conjunta tenga sentido.

Las medidas que toma Gardner para desarrollar esta mente respetuosa son, en primer lugar, tomar al profesor como modelo. Los alumnos de nuestro estudio ven en el profesor un apoyo y una ayuda, y entienden como fundamental que vean que el profesor respeta al alumno y a sus compañeros. Sin embargo, los alumnos también hablan de que los profesores no siempre respetan otras formas distintas a la suya. Un alumno expresa lo siguiente:

A menudo los profesores suelen criticar pedagogías distintas de las suyas, especialmente en el mundo de la música, donde funcionamos por "escuelas".

Respecto a los elemento curriculares que se seleccionan o se quitan de en medio antes de tiempo, como nos sugiere Gardner, los alumnos de nuestro estudio señalan la poca presencia de otras culturas musicales, así como la falsa concepción de que la música occidental es la dominante y la más rica. También les parece muy útil la idea de expresar los prejuicios para poder examinar sus elementos de verdad y de falsedad evitando que se acaben enquistando. Un alumno lo comenta así:

Los prejuicios se erigen como una barrera entre el mundo real y la mente de quien lo formula, siendo algo muy nocivo en la disciplina musical. Cuando decimos: "no 
me gusta este grupo, este compositor o este estilo, habría que preguntar: ¿no te gusta o no le has dedicado tiempo y una oportunidad?

Gardner también destaca como una medida para desarrollar la mente respetuosa el enseñar casos en los que las relaciones de grupo sean un factor esencial. Los alumnos entienden que en la música, para poder realizar una buena interpretación, casi siempre se requiere más de un intérprete, por lo que el respeto en la profesión es algo necesario y constructivo. Un alumno de nuestro estudio expone cómo es necesario el respeto para poder trabajar en grupo:

El pasado verano, en la Orquesta Joven de Euskadi, tuvimos la oportunidad dos alumnos del Superior de Navarra de fagot (formados en la escuela americana que es la que tiene nuestro profesor) de tocar junto a un chico que venía de la escuela holandesa. Tenía similitudes y diferencias con nosotros pero supimos hacer trabajo en grupo y nuestra cuerda de fagotes funcionó muy bien, aprendimos a respetar las formas diferentes de hacer y llegamos a acuerdos interesantes.

\section{5- $\quad$ La mente ética}

Una idea bastante generalizada es que la tienen todos los músicos y que sin ella no podrían dedicarse a su profesión. Son conscientes que si no hay un buen trabajo diario es imposible conseguir una buena interpretación. El músico no se hace en un día. Un alumno hace la siguiente reflexión:

Se trabaja siendo sinceros con nosotros mismos, organizados y realizando un buen trabajo, nunca eludiendo nuestras responsabilidades, tanto individuales como grupales.

Para desarrollar la mente ética, Gardner propone estar en contacto con modelos que encarnen el buen trabajo, de cara a poder saber cómo se debe proceder. En muchas ocasiones, los alumnos de nuestro estudio ven modelos de buen trabajo en compañeros, profesores y artistas de prestigio. Reconocen que los buenos músicos tienen una visión clara de qué objetivos y rumbo buscan en su profesión, esto es, tienen clara su misión. También les parece muy útil la recomendación de mirarse al espejo en versión individual, el ser conscientes de cuándo su 
actuación es correcta y que para mejorar sea importante consultar la opinión con otras personas. Una alumna lo expresa de esta manera:

La autoevaluación es básica en todas las profesiones. El músico ha de ser honesto consigo mismo, así identificará sus fallos y será capaz de emprender el camino para trabajarlos y conocerá mejor las virtudes a desarrollar. Por supuesto, la retroalimentación por parte de profesionales del entorno y de los propios compañeros es importante: cómo me muestro fuera, qué me aconsejan, qué me alaban.

Otra recomendación que ven muy necesaria es la de que, además de centrarse en trabajar bien cuando se empieza, también es importante cuando se llega a la madurez, así como supervisar si los compañeros y colegas también lo hacen y pedir cuentas si es necesario. Una alumna nos relata un ejemplo de cómo lo ha entendido y aplicado:

Hace unas semanas, en orquesta, a los vientos nos ocurría que no había manera de afinar porque no oíamos bien al oboe, ya que el primer fagot estaba tocando muy fuerte en los tutti. Pues bien, hubo reticencia a decírselo porque parecía una ofensa personal, pero cuando en el descanso se lo comenté me dio las gracias. ¿Por qué? Porque el grupo mejora cuando todos lo hacen lo mejor que pueden y una observación de un compañero es en pro de un bien mayor: que todos sonemos mejor. Bien es cierto que al ser estudiante ese "pedir cuentas" se hace más dificil, ya que todos lo somos y puede parecer pedante que alguien lo haga, dando la sensación de que es más que los demás. Eso es algo que, creo, ha de desterrarse. En la música la labor es en gran parte colaborativa, el trabajar en grupo dando lo mejor de cada uno es lo que, al final, nos hace grandes de verdad.

\subsubsection{Texto 6: Sternberg, $R .(1996)$}

Para seguir ahondando en la idea del músico convencido y apoyado, trabajamos este texto de Sternberg (Sternberg, R. (1996) Inteligencia exitosa. Barcelona: Paidós Ibérica) que les da herramientas para reflexionar sobre lo que pueden hacer para equilibrar la mente analítica, creativa y práctica, de cara a mejorar y encauzar sus esfuerzos de la manera más eficaz. El 
conocer qué hacen los demás nos da seguridad y apoyo para estar más seguros de lo que hace cada uno. Por eso, será muy útil el intercambio de información de las aplicaciones que hace cada uno a la música. Para realizar esto, y tras una presentación en clase del autor y del tema se propondrá (utilizando el ejercicio de aplicación de trabajo en grupo habitual) aplicar el modo de resolución de problemas que propone Sternberg (los seis pasos) a un problema que tenga cada uno, relacionado con la música que tengamos necesidad de resolver en ese momento. Tras exponerlo en clase, se les animará a trabajar en casa el siguiente ejercicio de reflexión:

\section{Ejercicio de aplicación sobre el texto de Sternberg:}

1. Aplicar el modo de resolución de problemas que propone Sternberg (los 6 pasos a un problema nuestro que tenga que ver con la música que queramos resolver).

2. Sternberg nos propone 12 características que se pueden desarrollar para estimular la creatividad. Lo que debes hacer es buscar cómo puedes desarrollar cada una de ellas, aplicado a la música.

3. Sternberg, por último, nos presenta 20 características que pueden actuar como autoactivadores para conducirnos al éxito. La idea es que intentes ver cómo puedes tú utilizar estos autoactivadores en la música en tu caso y en situaciones concretas para ayudarte a ti mismo a llegar al éxito. Por ejemplo, en el punto 1. Las personas con inteligencia exitosa se automotivan: Yo para automotivarme toco siempre algo que me gusta justo después de calentar, así me da menos pereza empezar a estudiar (cada uno tiene que poner lo que se le ocurra para automotivarse analizando su propia práctica).

Para Sternberg, las personas con inteligencia exitosa no sólo tienen habilidades, sino que reflexionan sobre cuándo y cómo usar esas habilidades de manera efectiva. (1996:131). Además reconocen la importancia de adaptarse al medio personal. En el caso de los músicos será fundamental partir de su interés y dejarles libertad a la hora de elegir el repertorio (Hallam, 1995 y Hallam y Gaunt, 2012). Todos los alumnos de nuestro estudio reconocen que, cuando se les ha dejado tocar la obra que les gustaba, la han disfrutado mucho más y la han interpretado mejor que cualquier otra, y cuando han hecho una que no les gustaba en principio, pero que al final han disfrutado tocándola, ha sido porque el profesor les ha ayudado mucho explicándoles el interés que tenía la obra, lo que les iba a aportar y que les 
trasmitiera ese entusiasmo que él tenía por ella para contagiarse de él y poder disfrutar tocándola. Teniendo en cuenta todo lo señalado anteriormente, deberíamos ser conscientes, como profesores de la enseñanza superior, de que si queremos ayudar a nuestros alumnos a conseguir lo mejor de sí mismos, tenemos que ayudarles a darse cuenta de qué es lo que les gusta e intentar partir de ahí para buscar ampliar sus intereses y trasmitirles el entusiasmo por otras cosas que también les puedan interesar, ayudándoles a ser unos músicos más versátiles, pero siendo conscientes de que tienen que buscar lo que les gusta para poder avanzar en ello.

En el texto trabajado, tras dejar claro cuál es la forma en que se puede desarrollar la inteligencia exitosa, el autor va a dar un paso más. Afirma que el éxito es un término relativo y que, como la belleza, puede estar en la mirada del espectador. Y, sin embargo, se puede afirmar que existen algunas características y atributos que tienen en común las personas con inteligencia exitosa, con independencia del grado y de la naturaleza de su éxito. La ausencia de estas características en nuestra propia línea de trabajo y en nuestra vida personal nos puede llevar al autosabotaje y al fracaso, y a la inversa, cuando están presentes pueden servir como autoactivadores y, en última instancia, conducirnos al éxito. (Sternberg, 2006:264). Pensamos que nuestros alumnos de la enseñanza superior tienen esta inteligencia exitosa de la que habla Sternberg y nos parece interesante en cada punto poner ejemplos ilustrativos de cómo ellos han analizado estas características en los grupos de discusión.

\section{Las personas con inteligencia exitosa se automotivan.}

Sternberg incide en que poco importa qué talentos tenga una persona si no está motivada para utilizarlos. En nuestro estudio se ve que una característica de nuestros alumnos es que saben cómo automotivarse. En general les ayuda mucho para motivarse la escucha de diferentes versiones de una misma obra o tema que les gusta y, en este sentido, los alumnos de Jazz insisten en que ver diferentes formas de abordar un mismo solo por músicos diferentes y ver cómo cada una de ellas son perfectas, les anima mucho a intentar también hacer uno distinto. Para casi todos los alumnos de estas enseñanzas el propio disfrute de la música ya es motivante, aunque les gustaría que el reconocimiento social que tiene tocar un instrumento fuera mayor, aunque la mayor motivación que resaltan es la perspectiva de poder ganarse la vida haciendo lo que más le gusta. También se automotivan haciendo disfrutar a los demás y disfrutando de la unión que consiguen tocando con otros músicos a los que valoran y aprecian. 
Las formas que usan para automotivarse en el estudio son variadas: unos se ponen música que les gusta antes de tocar para animarse, otros empiezan tocando algo que les gusta mucho o que tienen muchas ganas de que les salga bien para empezar a estudiar con energía. El interpretar un repertorio que consideran atractivo e interesante les ayuda a querer trabajar más la técnica para que les salga mejor. Algunos se graban para comprobar su aprendizaje y automotivarse con lo que ya han aprendido y otros se motivan simplemente disfrutando al pensar que pueden dedicarse a lo que les gusta, viendo cómo mejoran y cómo van consiguiendo sus objetivos poco a poco. Dos alumnos lo expresan así:

Yo para automotivarme me pongo metas a corto plazo, estudio al principio lo que es más denso o me apetece menos y dejo para el final lo que más me atrae y así estudio desde el principio con más ganas para llegar al final, organizo el tiempo de estudio y el tiempo libre y valoro el progreso, busco maneras de mejorar estudiando y escucho música antes de estudiar.

Lo que más me motiva es tocar en público. Me parece la recompensa a todo el trabajo que hacemos encerrados en la cabina. Yo creo que es lo más bonito, mostrar a la gente el fruto de tantísimo trabajo. Por ello intento aprovechar todas las oportunidades que puedo de tocar en público, ya sea con piano, en bandas, con el grupo en el que toco, con un cuarteto,...Esto lo tengo clarísimo. Tocar con compañeros y que salga bien es algo que me hace feliz y me motiva a seguir a tope.

Consideran igualmente que el profesor les puede ayudar a motivarse. Un alumno lo expresa de la siguiente manera:

En los dos primeros años en el conservatorio superior tenía un profesor de instrumento que trabajaba de forma muy distinta al que tengo ahora, tenía que hacer lo que él me mandaba, digamos que iba supertutelado y no reflexionaba sobre por qué hacía una cosa o la otra. Ahora tengo un nuevo profesor con el que tengo mucha mayor libertad para escoger repertorio, trabajar la técnica, distribuirme el tiempo, etc. La consecuencia es que me siento mucho más maduro, dueño de mi trabajo y responsable de mi evolución. En definitiva, me siento mejor, mucho más motivado e incluso confío más en mí mismo. 
2. Las personas con inteligencia exitosa aprenden a controlar sus impulsos.

Muchos alumnos se tildan de impulsivos e insisten en que quizá es uno de los puntos que tendrían que trabajar más, pero en general son muy meticulosos con su trabajo y tienen mucha paciencia a la hora de estudiar. Como hemos visto en muchos de los testimonios que hemos ido citando, la gran mayoría planifican cuidadosamente sus horas de trabajo y de estudio, como no puede ser de otro modo, pues no cabe ninguna duda de que, en el fondo, es condición sine qua non para tener el nivel que la enseñanza superior les exige. Una alumna lo expresa de esta manera:

Yo, para controlar mis impulsos, analizo las ventajas y desventajas de todo, intento ser capaz de estar centrada en lo que hago, intento controlar los nervios y la cabeza y no me rindo.

\section{Las personas con inteligencia exitosa saben cuándo perseverar.}

Los alumnos reconocen que cuando algo les gusta y tienen claro que les gusta no es mucho esfuerzo perseverar en ello. A pesar de esto, explican que hay otros terrenos musicales en los que tienen que perseverar sin que le gusten en exceso y aquí ponen como ejemplo la obligatoriedad de obtener títulos oficiales en la sociedad en la que viven. Un alumno expresa su opinión con estas palabras:

Hay que tener claro en qué situaciones conviene esforzarse porque esa tarea requiere más trabajo, o porque el resultado que se va a obtener va a ser mejor para el aprendizaje en general. También conviene saber con qué tareas no conviene pasar demasiado tiempo.

\section{Saben cómo sacar el máximo partido de sus habilidades}

Reconocen que en ocasiones es difícil conocerse uno mismo y saber cuáles son sus puntos débiles y cuáles los fuertes. Pero que cuando tienen claro eso, lo demás está prácticamente hecho, de modo que sólo queda explotar sus puntos fuertes e intentar mejorar los débiles. Nosotros les hemos apuntado que también es importante trabajar los puntos fuertes, pues en ocasiones se les olvida esta parte y llegan incluso a dejar de ser tan buenos como eran en su punto fuerte por abandonarlo empleando todo el tiempo en trabajar sus puntos débiles. Dos alumnas del segundo curso de nuestra investigación convencidas de lo que hacen lo expresan así: 
Al conocer mis puntos fuertes, sé cómo explotarlos. Busco obras en las que se vean mis problemas para poder trabajarlos pero también obras en las que puedo estar cómoda y disfrutar.

Debemos conocer bien nuestros puntos fuertes para que nos empujen hacia arriba y motiven. También para que sean nuestro sello personal.

\section{Traducen el pensamiento en acción.}

El famoso "dicho y hecho" reconocen que es una de sus frases favoritas. Se han dado cuenta de que es importante hacer las cosas y no esperar, porque están en un mundo en el que las oportunidades pasan de largo muy rápido. Dos alumnos lo expresan de la siguiente forma:

No me conformo con saber conceptos teóricos, me gusta aplicarlos y proponerme metas realistas.

Intento que los pensamientos positivos pasen a materializarse en música, pero tengo que evitar que los negativos cojan fuerza para que pasen a ser visibles.

6. Se orientan hacia el producto.

Tienen claro que a la hora de diseñar un objetivo, tienen que priorizarlo en la medida de lo posible. Reconocen que tener proyectos musicales y llevarlos a la práctica puede ser de lo más gratificante para ellos. A su vez, comentan que lo contrario puede ser muy frustrante.

Debemos concentrarnos en obtener un buen resultado trabajando de forma eficaz para conseguirlo y no sentirse frustrado por no lograrlo.

Es importante pensar en el resultado final de una obra que vamos a interpretar. Tener presente en todo momento cómo va a sonar, escuchar varias versiones de la obra y adecuarla a tu gusto.

7. Completan las tareas y llegan al final.

Los alumnos son conscientes de que deben concentrarse en obtener un resultado, una impresión musical global en el oyente y en ellos mismos. En esto trabajan con paciencia, sabiendo que es un proceso largo en el que hay que depurar errores, mejorar las cosas, pero 
sobre todo ser musicales. Como todo trabajo creativo, les parece difícil de acabar porque siempre admite mejora y lo que a veces les cuesta es darlo por acabado en algún punto y esperan a que sea el profesor el que les diga que ya está listo. Una alumna expresa este punto con el siguiente comentario:

Al proponerme metas realistas, siempre trato de llegar hasta ellas.

\section{Tienen iniciativa.}

Tener iniciativa es una de las características que más valoran los alumnos de esta enseñanza. En general les encanta crear grupos, bandas, aceptar retos musicales de tipos de música que no tocan habitualmente, mezclar música con otras artes, permitirse abrir su panorama musical. Incluso los que no se ven tomando iniciativas habitualmente, valoran mucho las iniciativas de sus compañeros y sus profesores, y se sienten muy animados a participar en iniciativas propuestas por otros. Los que no toman muchas iniciativas esperan hacerlo al acabar sus estudios superiores, y otros reconocen que tienen más iniciativa fuera de los estudios reglados, donde se atreven más a proponer temas o arreglos propios.

Hacer arreglos para las formaciones en las que estoy y tocar cosas que me gusten, aunque no sea lo que se pide en la carrera, es lo que me hace sentir que soy un músico con capacidad de elección y es cuando disfruto de verdad. Sí que este curso me estoy centrando más en lo que me pide mi profesor, porque es el último de las enseñanzas superiores y no puedo despistarme si quiero terminar bien y hacer un buen concierto fin de carrera.

Siempre trato de crear nuevas ideas o nuevas formas de estudiar para poder mejorar mi rendimiento y mi actuación.

9. No tienen miedo de arriesgarse al fracaso.

En general, tienen claro que lo que se considera un fracaso depende de las expectativas que pongan en ello. Explican así que hay personas que si no obtienen beneficio económico de cualquier proyecto lo consideran un fracaso y que es algo que no les suele pasar a ellos, porque su prioridad es disfrutar haciéndolo. Tienen claro que para arriesgarse tienen que ser conscientes de que no todo lo que hagan tiene que ser perfecto y maravilloso, que tienen que permitirse fallar. Un alumno lo expresa de la siguiente manera: 
En ocasiones es importante enfrentarse al fracaso como un punto de inflexión en el que plantearte tus posibles problemas y como una forma de aprender a solucionarlos. Considero que el fracaso es un paso para poder mejorar y por ello no le doy más importancia de la que realmente tiene.

10. No posterga.

Explican que en este punto siempre se puede trabajar, ya que el postergar hace que ciertos proyectos pierdan la fuerza inicial, aunque algunos también opinan que a otros proyectos les puede venir bien dejarlos reposar un poco. Puede ser que se refieran a la idea (que también comenta Sternberg) de darse tiempo y no tomar decisiones precipitadas, dado que es necesario tomarse el tiempo necesario para que las cosas salgan lo mejor posible y, obviamente, eso tampoco se puede dejar para el último momento. Una alumna lo explica de la siguiente forma:

Trato hacer los trabajos en el momento en el que los proponen, para no retrasar el resto de mis tareas y de otras actividades. Además de que, cuanto antes haces la labor, más frescas tienes las ideas que se han generado en clase y las instrucciones del profesor

11. Aceptan el reproche justo.

Reconocen que en su profesión van a ser juzgados y que no siempre le va a gustar todo a todo el mundo. Dos alumnos lo expresan muy bien con estas palabras:

Si no eres capaz de aceptar críticas de lo que haces, apaga y vámonos. Acepta que no todo lo que haces es perfecto. Yo trato de sacar lo positivo de cada opinión para poder mejorar en mi interpretación.

Las buenas críticas siempre son agradables, pero de los reproches, siempre que sean constructivos, es de donde se aprende. De los reproches injustos hemos de aprender a pasar. Con el tiempo creo que voy aprendiendo a distinguir la intencionalidad de las críticas y cuándo las he de considerar para mejorar.

12. Rehúsan la autocompasión.

Parece que en este punto también tienen muy claro que hacer uso de la autocompasión es lo mismo que autoengañarse, y que en el caso de la música no sirve de nada, porque como ellos 
mismos explican "tocas para los demás”. Sí que algunos han visto que les era fácil pensar desde un punto de vista victimista, pero se han dado cuenta que no les ayudaba a salir reforzados del conflicto. Por eso, prefieren evitar ese tipo de pensamientos e intentar enfocarlos desde un punto de vista más positivo, creyéndose capaces de lograr lo que se proponen y automotivándose para conseguirlo.

Considero que cada error es un paso para poder mejorar y no lo considero como un fracaso; por eso no me autocompadezco.

\section{Son independientes.}

Sí que se reconocen como independientes, pues piensan que muchas veces el hecho de regular su propio estudio y forma de trabajo ya hace que lo sean. Muchos reconocen que les gusta organizarse y hacer las cosas a su manera. Ser independiente es también una gran ayuda para evitar críticas dañinas. Aunque en general procuran no depender de nadie para llevar a cabo una tarea, piensan que a su vez es interesante preguntar o buscar información en otras fuentes y personas para documentarse y buscar ayuda, pero intentando dar siempre un enfoque personal. Insisten en que no depender de nadie puede hacerles avanzar hasta donde quieran. Sin embargo, hay otros alumnos que sí que son conscientes de que muchas veces dependen en exceso de lo que su profesor les dice, recomienda, etc., y no buscan otras opiniones para contrastar.

Yo trato de mantenerme al margen de las influencias negativas e intento mantener mi propio criterio

\section{Tratan de superar las dificultades personales.}

Reconocen que las dificultades personales interfieren y que lo que intentan para ello es tener claros los objetivos propios. De esta manera, piensan que no debería ser difícil apartar los problemas personales. Aun así, muchos de ellos se sienten fuertes y luchadores y no les gusta quedarse enganchados en un problema. Necesitan resolverlo y superarlo porque la sensación de inseguridad y debilidad se acrecienta cuando permanecen en el problema, razón por la cual prefieren resolverlo cuanto antes. Además, se sienten muy gratificados tocando y lo ven como una cura para todos los males. Un alumno lo expresa literalmente así: “cuando te subes a un escenario se olvidan y desaparecen todas las penas". 
15. Se centran y se concentran en alcanzar sus objetivos.

Son conscientes de que no les sobra el tiempo y por eso las horas destinadas al estudio intentan aprovecharlas al máximo, aunque también son conscientes de que a veces el cansancio y otras tareas invaden este tiempo. Aún así, intentan no desperdiciarlo y concentrarse al máximo para obtener el máximo rendimiento. Una alumna de pedagogía explica que cada año hace un mapa de sueños a realizar, a corto y a largo plazo, y que le encanta ver cómo se van cumpliendo unos objetivos y se van creando nuevos, aunque se da cuenta que debe aprender a disfrutar más de los objetivos cumplidos, pues a veces no dedica tiempo a ello. Otra alumna lo explica de la siguiente forma:

Cuando estudio o hago otros quehaceres, trato de concentrarme sólo en lo que estoy haciendo en ese momento y no dejo que mi mente se distraiga con aquello que no tiene que ver con lo que estoy haciendo.

16. No tratan de hacer demasiadas cosas a la vez ni de hacer demasiado pocas.

Este punto depende de cada persona, aunque en general sí que les gusta hacer bastantes cosas, casi siempre de una forma equilibrada. Algunos expresan que consideran todo un arte saber cuántos frentes podemos abrir y cuánto se pueden involucrar en ellos. Reconocen que siempre tienen la sensación de que se meten en más de lo que pueden abarcar, aunque les encanta tener muchos frentes abiertos a la vez y uno expresa que recibe preguntas sobre cómo es capaz de tocar en tantos grupos a la vez, apuntarse a teatro y trabajar y estudiar a la vez. Aunque cuenta que también ha sentido la incomprensión y envidias por hacerlo y le han dicho frases como: "quien mucho abarca, poco aprieta" aunque manifieste que para él es muy enriquecedor. Otros piensan que cada año van bajando el ritmo porque es lo que el cuerpo les va pidiendo (esto lo dicen sobre todo los que son mayores de 30 años) pero que siempre que se comprometen cumplen, y si no van a poder cumplir lo dicen sin problemas, porque no les gusta hacer mal las cosas. Un alumno expone sus impresiones sobre el tema de la siguiente forma:

A veces al hacer muy pocas cosas te relajas demasiado y no tienes la intensidad ni dedicas el suficiente tiempo a esas pocas cosas. Organizo mi tiempo para poder realizar todas las actividades que me propongo pero no me frustro si no las puedo llegar a hacer todas.

\section{Tienen capacidad para aplazar la gratificación.}


Son conscientes de que hay que ser paciente y que los frutos musicales tardan en salir. Señalan que lo importante es estar convencido de que el trabajo está bien hecho y entonces se ve el fruto, aunque es necesario tener paciencia. Una alumna lo expresa de la siguiente manera: "Trato de finalizar todo lo que me propongo antes de tener tiempo libre, de desconectar". Una pianista de jazz incide en este punto diciendo: "en música, merece la pena hacer ejercicios que requieran hacer esfuerzo por poco satisfactorios que sean, porque el proceso se va agilizando con la repetición”. Y explica el truco que utiliza para premiarse cada poco en su misma práctica y así no tener que aplazar tanto la gratificación: "Poco a poco voy aprendiendo a hacer los ejercicios más fatigosos intercalando temas más gratos”.

\section{Son capaces de ver al mismo tiempo el bosque y los árboles.}

Reconocen que en ocasiones les cuesta ver las dos cosas al mismo tiempo. A veces están tan enfrascados en la técnica que se olvidan de disfrutar con la interpretación y, cuando se dan cuenta, ven que han de tener cuidado porque lo que hace a un músico es ver el conjunto, expresar la idea y no quedarse en dar una nota perfecta, aunque también se dan cuenta de que si no dan ninguna nota bien es imposible expresar nada.

Analizo los problemas con diferentes perspectivas para ser capaz de solucionarlos de la forma más eficaz posible.

19. Tienen un nivel razonable de autoconfianza y creen en su capacidad para alcanzar sus objetivos.

Consideran fundamental conocerse a sí mismos, pues es lo que les va a dar autoconfianza. Saber de lo que se es capaz, e intentar ir incluso un poquito más para llegar a puntos donde creían que no podían llegar, quizá porque no se lo permitían. También valoran mucho el ser consciente de su situación y saben que si aceptan un proyecto está claro que es porque pueden defenderlo. También creen que es una gran virtud saber decir que no a tiempo. Por eso insisten en que hay que ser objetivo y saber dónde se pueden meter uno y dónde no. Son conscientes de que nadie puede perseverar ante la dificultad si no confían en sí mismos. Alguno llega a decir que más que una característica, lo ven como un requisito para poder ser músicos. Un alumno expresa la confianza que tiene en sí mismo de la siguiente manera:

Si una obra la has trabajado y te sale en casa, ¿por qué no te va a salir igual o mejor en un auditorio? 
20. Equilibran el pensamiento analítico, el creativo y el práctico.

Este punto les ha parecido muy atractivo a nuestros alumnos, pues tienen claro que tener buenas ideas y no ser pragmático o viceversa es inútil, ya que en ese caso o no se va a conseguir realizar el proyecto o no va a tener la calidad deseada. Por eso ven importante priorizar objetivos. Un alumno resume la forma de equilibrar los tres tipos de pensamiento de esta manera: "Trato de producir buenas ideas y las analizo y juzgo antes de llevarlas a la práctica".

En definitiva, Sternberg afirma que tener una inteligencia exitosa es sinónimo de ser capaces de equilibrar la inteligencia analítica, la creativa y la práctica, así como de utilizarlas en mayor o menor medida (según las circunstancias) y recurrir a cada una de ellas en el momento en que se necesita. Podríamos añadir que esta idea de inteligencia exitosa es perfectamente aplicable al ámbito musical, razón por la cual los alumnos de nuestro estudio se han sentido especialmente identificados con esta idea y, en consecuencia, han podido poner ejemplos prácticos de su propia realidad, que les han ayudado a reflexionar sobre su forma de hacer las cosas, siempre en relación con las ideas que Sternberg propone, buscando aportaciones que les ayuden a seguir avanzando en la búsqueda de la excelencia.

\subsubsection{Texto 7: Dweck, C. (2006)}

En nuestra idea de profundizar en los temas y volver a reflexionar a la luz de lo que vamos aprendiendo con el conocimiento de las investigaciones, volvemos a sacar el tema de cómo les puede ayudar el conocimiento de sí mismos. Conocerse les puede ayudar a rendir más en lo que hacen y a estar más convencidos, que habíamos dicho era una de las ideas en la que seguimos profundizando. Para ello, partimos de los trabajos de Dweck (C. (2006) Mindset. The new psychology of success. How we can learn to fulfill our potential. New York: Ballantine Books. Cuadro resumen en castellano), y una vez presentados los dos tipos de mentalidad y su aplicación a la música (explicado en profundidad en el capítulo primero de esta investigación), les pedimos que intenten ver en qué ocasiones tienen un tipo de mentalidad u otro y cómo se enfrentan a los obstáculos. Para ello les pedimos que rellenen la siguiente tabla: 


\section{Mentalidad en crecimiento (trucos individuales que utilizo y que me funcionan)}

\section{Mentalidad fija (señalar un aspecto en el que creas que tienes este tipo de mentalidad)}

\section{Propuesta para pasar mis trucos de una a la otra}

Y también que realicen el siguiente ejercicio, en el que vamos a incluir la reflexión y el trabajo colaborativo:

\section{Ejercicio de reflexión. Estrategias individuales de mentalidad en crecimiento}

1. Analiza, explica y describe qué estrategias o trucos individuales utilizas cuando tienes mentalidad en crecimiento.

2. ¿Cuáles de las estrategias que has descrito que usas en tu mentalidad en crecimiento crees que son individuales y cuáles piensas que puede que no le funcionen a todo el mundo pero que a ti sí te funcionan? Si no has pensado ninguna que te parezca muy individual intenta pensarlo ahora.

3. ¿Crees que esas mismas estrategias, habilidades o trucos puedes utilizarlos en algún ámbito en el que te hayas descubierto con mentalidad fija? Responde afirmativa o negativamente y explica por qué. Pon ejemplos en concreto.

Para fomentar el trabajo colaborativo, les pedimos que dibujaran una tabla con tres columnas. En la primera tendrían que escribir lo que consideraran su punto fuerte o algo en lo que se sienten con mentalidad en crecimiento, así como los trucos que utilizan en este caso; y en la segunda columna deberían escribir algo en lo que se encuentren con mentalidad fija. Hecho esto, se comparte el resultado con el resto de compañeros, que deberán pensar cómo utilizar esos trucos que cada compañero ha puesto que le son útiles cuando están en mentalidad en crecimiento para que la misma persona pueda aplicarlos cuando los necesiten en algo en que los tengan en mentalidad fija. Así, cada estudiante rellenará el de sus compañeros y después, viendo los consejos que le han dado sus compañeros, cada uno rellenará la tercera columna, es 
decir, la de aplicar los trucos que ellos mismos utilizan en las actividades en que se encuentran con mentalidad en crecimiento para utilizarlos cuando están en mentalidad fija.

Con este sistema intentamos que lo que en principio aparece como en mentalidad fija pueda ir pasando a mentalidad en crecimiento, ayudados por el trabajo colaborativo. Siguiendo los pasos expuestos en el cuadro que hemos utilizado para explicar las dos mentalidades de Dweck, podemos analizar cómo se va cambiando en distintos aspectos:

1. Con respecto a los desafíos, éstos se evitarían en mentalidad fija, pero al trabajar de forma colaborativa, el sólo hecho de comunicar a los demás en qué tenemos mentalidad fija ya es una forma de no evitar ese desafío, sino que mostramos que estamos abiertos a trabajarlo, lo que ya sería un paso para cambiar a mentalidad en crecimiento.

2. Los obstáculos también se afrontan de forma distinta: en mentalidad fija, frente a un obstáculo o dificultad se tiende a abandonar. Sin embargo, en mentalidad en crecimiento se sigue intentando a pesar de los contratiempos. Igualmente, cuando trabajamos de forma colaborativa es más fácil persistir, porque tenemos apoyos que nos ayudan a no abandonar con tanta facilidad.

3. Con respecto al esfuerzo, en mentalidad fija se ve como algo improductivo o peor, pero cuando se utiliza el trabajo colaborativo este esfuerzo empieza a verse siempre útil, porque se tiende a pensar que si no nos va a ayudar a nosotros quizá ayuda a los demás y es una forma de cambiar esa sensación de un esfuerzo inútil y transformarlo en un esfuerzo que conduce a la mejora, tal como se ve en la mentalidad en crecimiento.

4. En la mentalidad fija se tiende a ignorar las críticas cuando no son positivas. Sin embargo, usando el trabajo colaborativo, y dado que la crítica se entiende como algo que sirve para mejorar el conjunto (a lo que se añade el hecho de que quien critica también quiere lo mejor para él), cuando se hace se busca que sirva para aprender, planteándola tal como se ve en la mentalidad en crecimiento.

5. El éxito de los otros puede verse en ocasiones como una amenaza, pero si se trabaja de forma colaborativa y se buscan conjuntamente soluciones para los demás, el result7ado es que se presenta el problema como algo no acabado y puede verse cómo los demás se convierten en una ayuda para solucionarlo, de modo que pasan a ser un buen apoyo y no una amenaza. 
Así, el éxito de los otros también se convierte en su propio éxito, pues todos han colaborado para conseguirlo.

Es curioso cómo al preguntar los trucos o qué hacen para ayudarse que creen que es sólo personal, en principio no se atreven a contarlos, pero cuando ven que las investigaciones explican que lo que define a los grandes, además de su capacidad de concentración, es que hacen las cosas a su manera (Hallam, 1995) empiezan a compartir esos pequeños trucos que son de gran ayuda para todos, (aunque no siempre de la misma manera) y que el compartirlos les ayuda a reafirmarse, a entenderse y a compartir y ver esos trucos o ayudas distintas que les pueden ayudar a estar más convencidos y apoyados y a crear el ambiente de aprendizaje tan necesario para conseguir la excelencia.

En los siguientes cuadros se pueden ver algunas de las propuestas que hemos elegido por ser muy significativas con las soluciones que surgen tras el trabajo en los distintos grupos de discusión. 
Mentalidad en crecimiento (trucos individuales que utilizo y que me funcionan)

Leer a primera vista y tocar en grupo.

Trucos:

1. Tocar en cualquier momento cualquier tipo de música en cualquier instrumento de percusión

2. Buena disposición, relación y buen rollo con los compañeros

3. Escuchar mucha música y de cualquier tipo

Poner especial atención desde el principio en los pequeños detalles para interiorizarlos. Tocar en grupo y escuchar. Trucos: pedir opinión, empastar y pasar tiempo con la gente que toco.

Tocar con otros, en especial con gente a la que aprecio, me siento muy arropada por ellos y disfruto mucho en los ensayos y en el escenario.

Organización y capacidad de trabajo. Como trucos para fomentar esto, siempre me planteo objetivos. Realizo listas de lo que pretendo conseguir hacer y conforme lo hago, lo marco con una cruz. De esta manera voy viendo aquello que ya he logrado, lo cual supone una motivación para conseguir lo demás. A la hora de tocar, creo que mi mayor fortaleza es la limpieza en el sonido. Mi truco o apoyo para lograrlo es la escucha atenta, de manera que cuando detecto suciedad en el sonido, paro y lo repito, buscando limpieza hasta conseguirla.

Buen oído y expresión. Los trucos que utilizo:

- Sacar canciones de oído, grabarme para escuchar lo que he hecho posteriormente.

Cantar como quiero que suene un pasaje y cantarlo mentalmente después.

\section{Mentalidad fija}

\section{Propuesta para pasar mis trucos de una a la otra}

Poca paciencia, quiero las cosas

"ya" y no siempre se puede

Inseguridad escénica. Me pongo nerviosa al tocar.

Inseguridad escénica. Me pongo nerviosa al tocar

Pierdo el control de la tensión en momentos de estrés e incluso

cuando no existe ese momento de estrés.
Practicar la concentración en cualquier momento y en cualquier situación durante poco tiempo en cosas pequeñas y objetivos concretos. Hacerlo relajado para ir mejorando poco a poco. Ser organizado y programar descansos

Tener la misma paciencia conmigo que tengo con los demás, para escucharles y apoyarles. También darme cuenta que, para poder poner atención en los detalles, utilizo la paciencia y asi utilizarla en los demás aspectos.

Un truco que podría aplicar cuando toco sola y me siento insegura sería imaginar que ellos están tocando conmigo también en esa pieza. Tratar de visualizarlo y escuchar en mi mente que parte de mis melodías las realiza una flauta, un violonchelo, una voz... Quizás así me sentiría más segura, acercándome un poco más a la mentalidad en crecimiento.

Durante un concierto, intentar también fijarme mucho en el sonido que estoy haciendo y dividir la obra en secciones, de forma que según vaya terminando una sección, le ponga un cruz imaginaria que me haga sentir bien.

- Focalizar mi atención en el sonido para no perder la concentración y continuar controlando la tensión.

Escuchar la obra y pensar en ella, así como lo que tengo que hacer cuando toco sin el instrumento.

- Apoyarme en mis puntos fuertes: 1. Usar el oído para mantener el control y 2. Usar la expresión para disimular los errores. 
Mentalidad en crecimiento (trucos individuales que utilizo y que me funcionan)

Alto nivel de exigencia y capacidad de concentración, muy buena relación con mi profesor. Estoy siempre tocando en distintos grupos, con distintos estilos y normalmente tengo la suerte de considerar como amigos a los músicos con los que toco.

Suelo ver las cosas desde distintos puntos de vista, soy muy trabajadora y me gusta sacar canciones de oído y tocar con otras personas.

Soy muy organizada. Los trucos que me funcionan son:

1. Ir siempre lo más adelantada posible.

2. Hacer una planificación semanal todos los domingos y cumplirla.

3. Si un día no me apetece hacer lo programado, intentarlo y, si no va bien, reestructurar la planificación para hacerlo en otro momento en el que me apetezca más hacerlo.

\section{Persistencia}

Truco: valorar las cosas que hago y ver qué cosas buenas me aportan.

\section{Expresividad}

Trucos: Practicar, ser constante y tener paciencia.
En el trabajo en verbenas había mantenido una actitud de mentalidad fija: cada concierto se me hacía igual que el anterior y no estaba nada motivado con el trabajo que realizaba. Sin embargo, no hacía nada para cambiarlo ya que me había estancado en esta situación y no veía por qué debería cambiarlo.

Ante la crítica del profesor me frustro y bloqueo y tiendo a enfadarme y a no confiar en su criterio.

Me canso muy rápido de las obras y abandono los detalles

Inseguridad

\section{Propuesta para pasar mis trucos de una a la otra}

Por suerte, pronto tuve la oportunidad de conocer a un gran músico y persona que se incorporó a nuestro grupo y él me hizo ver que era posible disfrutar realizando ese trabajo. Comencé por renovar mi equipo y preocuparme más por mi sonido, interactuar con los demás músicos, intentar darlo todo en cada concierto, grabar las actuaciones, ... y multitud de trucos que él me explicó que realizaba, ya que también él se había sentido estancado en una etapa anterior. Ahora mismo disfruto mucho realizando el mismo trabajo y se me hace mucho más satisfactorio

Considero que este es un buen ejemplo de cómo una situación en la que me hallaba en mentalidad fija, pudo transformarse, gracias a un mentor o adulto clave, en una situación de mentalidad en crecimiento.

Intentar analizar el problema desde diferentes puntos de vista, procurando entender qué es lo que no le gusta a mi profesor y por qué, grabándome para escuchar y poder ver los fallos desde fuera. También podría utilizar mi capacidad de trabajar con otros para pedirles su opinión y tocar con otras personas para intentar aprender de ellos, corrigiendo errores, ya que soy buena aprendiendo de oído. También podría preguntarle qué hago bien, para tener un feedback positivo y trabajar con él también las partes positivas, de modo que me ayude a evitar el bloqueo y el enfado en las partes que llevo peor.

Podría hacer una planificación dentro de mi planificación general con cada uno de los detalles y cumplirlo. Además podría dedicar a cada detalle el momento en el que mejor me sienten para trabajar eso en concreto. Trabajar cada detalle como si fuera nuevo, en otro estilo o subdividirlo en tareas más fáciles de cumplir.

Valorar las cosas positivas que sé que hago bien y disfrutar de ellas, pensando en positivo par estar más seguro.

Utilizar el perfeccionismo para seguir siendo constante, con paciencia, para ir ganando seguridad 


\begin{tabular}{|c|c|c|}
\hline $\begin{array}{l}\text { Mentalidad en crecimiento (trucos individuales que utilizo y que me } \\
\text { funcionan) }\end{array}$ & Mentalidad fija & Propuesta para pasar mis trucos de una a la otra \\
\hline $\begin{array}{l}\text { Buen sonido, imitar y tocar en grupo. } \\
\text { Trucos: } \\
\text { 1. Me gusta mucho escuchar y fijarme en cómo tocan los demás y tratar de } \\
\text { tocar igual. } \\
\text { 2. Trabajo el sonido con notas largas y ejercicios fáciles y lentos. } \\
\text { 3. Me siento respaldado tocando en grupo y saco mi mejor versión porque } \\
\text { me motiva trabajar así. }\end{array}$ & $\begin{array}{l}\text { Me cuestan los pasajes rápidos de } \\
\text { digitaciones complicadas. }\end{array}$ & $\begin{array}{l}\text { - Trabajar los pasajes rápidos en grupo con alguien para tratar de imitarlo y para estar más } \\
\text { motivado; igualmente, memorizarlo y trabajarlo rápido por fragmentos cortos y utilizando la } \\
\text { práctica mental. }\end{array}$ \\
\hline $\begin{array}{l}\text { Buen oído, positiva y buena compañera. } \\
\text { Trucos: } \\
\text { 1. Escuchar mucha música } \\
\text { 2. Ser optimista y pensar que siempre puede haber soluciones posibles para } \\
\text { los problemas. } \\
\text { 3. Empatizar con mis compañeros y ayudarles en todo lo que pueda }\end{array}$ & Inseguridad y nervios. & $\begin{array}{l}\text { - Escuchar lo que toco y disfrutarlo sin pensar en otras cosas, cuidarme y ayudarme como } \\
\text { ayudo a los demás y apoyarme en mis amigos para que me ayuden en momentos de duda, igual } \\
\text { que yo les apoyo y les ayudo a ellos. }\end{array}$ \\
\hline
\end{tabular}




\subsection{Resultados del cuestionario de alumnos}

Se adjunta en el Anexo I el diseño y las pruebas del cuestionario que se han pasado a los alumnos. Antes de llevar a cabo dicho cuestionario, se decidió hacer una prueba, para lo cual se contó con 35 alumnos del curso anterior de este mismo conservatorio y con otros 20 del Conservatorio Superior de Música de Castelfranco Veneto $(\text { Italia })^{41}$.

Como decimos, la primera vez que se pasó el test fue en el curso 2013-2014, a un grupo de Didáctica de la Música compuesto por 35 alumnos, donde 17 eran de instrumento clásico, 16 de instrumento jazz y 2 de composición. Esta primera experiencia fue realmente positiva, ya que pudimos comprobar por vez primera cómo el sólo hecho de contestar a las preguntas del cuestionario generaba ya un buen ambiente de trabajo, dado el ejercicio de reflexión que llevaba consigo. Pero quizá lo más destacable de esta primera toma de contacto con el cuestionario fue que nos dimos cuenta de que, al ser tan extenso, era preferible que las preguntas más sencillas de contestar se pasaran al final del mismo, para que el cansancio no afectara a la realización del mismo.

Y así se hizo en la experiencia que tuvimos en el Conservatorio di Musica Agostino Steffani de Castelfranco Veneto, dentro del curso que impartí con el nombre de "Corso di tecniche di consapevolezza ed espressione corporea" (5-10 junio 2014). Allí volvimos a repetir el cuestionario (con el cambio citado) en un grupo de 20 alumnos, donde 13 eran de instrumento clásico, 5 de pedagogía y 2 de musicología. Todos ellos recibieron la actividad con gran interés (quizá porque se salía de lo habitual) y tenemos que decir que el resultado nos animó muchísimo de cara a lo que nos esperaba a lo largo de los cursos siguientes. El ambiente que se generó tras la realización del test, así como el debate que se abrió entre los alumnos acerca de su práctica musical sirvió para anticipar lo fecundo que podría ser cuando se organizara 
de un modo más dirigido.

El resultado de estas pruebas piloto fue bastante satisfactorio, tanto en lo referente a su desarrollo puntual (no les llevaba más de 20 minutos hacerlo) como a las conclusiones. Aun así, nos sirvió para efectuar dos correcciones puntuales de cara a la investigación propiamente dicha: a) algunas preguntas las desdoblamos en dos, ya que podía dar pie a malinterpretaciones o, más comúnmente, a que no se pudiera contestar con exactitud; b) decidimos, como ya se ha comentado, llevar al final del cuestionario las que eran más fáciles de contestar, de modo que se evitara un posible cansancio que distorsionara las respuestas. En un primer momento se pensó en pasar los cuestionarios con el curso ya iniciado, pero finalmente decidimos hacerlo en la primera clase. La razón está en que era metodológicamente más correcto pasar los dos cuestionarios que se pretendía hacer a los alumnos antes de evaluarles, de modo que no hubiera interferencias distorsionadoras por parte del proceso de evaluación y calificación (proceso que debía llevarse a cabo en la última quincena de enero), de modo que, adelantamos todo lo que pudimos el proceso para que estuviera terminado antes de esas fechas.

Así pues, el primer día de clase se les proporcionó una breve información acerca de la investigación, dejando claro que se trataba de algo voluntario y, por supuesto, que la información recogida se trataría de forma anónima y confidencial. En principio, ningún alumno se negó a participar en el proyecto, si bien en el curso 2014- 15, cinco alumnos no rellenaron el cuestionario: tres que estaban de Erasmus, uno que no apareció en todo el curso a pesar de estar matriculado y otro que no vino ese día y, aunque se ofreció para rellenarlo en casa, al final acabó olvidándose del asunto (si bien siguió participando de todo el proceso). En total, el primer cuestionario lo cumplimentaron 55 alumnos y el segundo sólo 50. Por su parte, en el curso 2015-16 el cuestionario fue rellenado por 32 alumnos. A continuación, se les pasó el cuestionario (adjuntado en el Anexo I), pidiendo a los alumnos que hicieran una marca que les permitiera identificarlo posteriormente con facilidad. La idea era que pudieran localizarlo ellos mismos para poder compararlo con el segundo (el que realizarían en enero) de manera que ellos mismos pudieran comprobar lo que había cambiado o se había mantenido y tuvieran ocasión de realizar su propia reflexión sobre esos cambios. Una vez recogido el cuestionario, se dio inicio al proceso de 
ofrecer y mostrar lo que dicen algunas de las investigaciones actuales sobre los temas que se abordan en el cuestionario, es decir, los tipos de mentalidad existentes (mentalidad fija y en crecimiento, Dweck 2006), la inteligencia exitosa, (Sternberg, 2005) las cinco mentes del futuro (Gardner, 2005) y cuestiones relativas a qué podemos hacer para aprender mejor como músicos y profesores de música (Sloboda, 1997, McPherson, 2000 y Davidson, 2006), así como los consejos que según las investigaciones son más útiles para conseguir el éxito como músico profesional en el siglo XXI (Hallam y Gaum, 2012). Todo esto constituyó el corpus fundamental del cuatrimestre, que se desarrolló según lo previsto.

\subsection{1 . Afirmaciones que cambian mucho}

Primera Afirmación: Sé cuáles son las habilidades conocimientos y actitudes necesarias para tener éxito como músico.

\begin{tabular}{|c|c|c|c|c|c|}
\hline \multicolumn{5}{|c|}{ 1a AFIRMACIÓN } \\
\hline \multicolumn{3}{|c|}{ SEPTIEMBRE 2014 } & \multicolumn{3}{|c|}{ ENERO 2015 } \\
\hline Valor & $\begin{array}{c}\text { Total } \\
\text { valores }\end{array}$ & $\%$ & Valor & $\begin{array}{c}\text { Total } \\
\text { valores }\end{array}$ & $\%$ \\
\hline 1 & 0 & $0 \%$ & 1 & 0 & $0 \%$ \\
\hline 2 & 2 & $4 \%$ & 2 & 0 & $0 \%$ \\
\hline 3 & 14 & $25 \%$ & 3 & 2 & $4 \%$ \\
\hline 4 & 28 & $51 \%$ & 4 & 9 & $18 \%$ \\
\hline 5 & 9 & $16 \%$ & 5 & 27 & $54 \%$ \\
\hline 6 & 2 & $4 \%$ & 6 & 12 & $24 \%$ \\
\hline Total & 55 & $100 \%$ & Total & 50 & $100 \%$ \\
\hline
\end{tabular}

19 Afirmación - Septiembre 2014

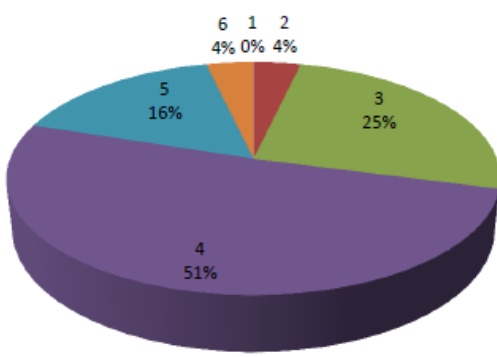

19 Afirmación: Sé cuáles son las habilidades conocimientos y actitudes necesarias para tener éxito como músico.

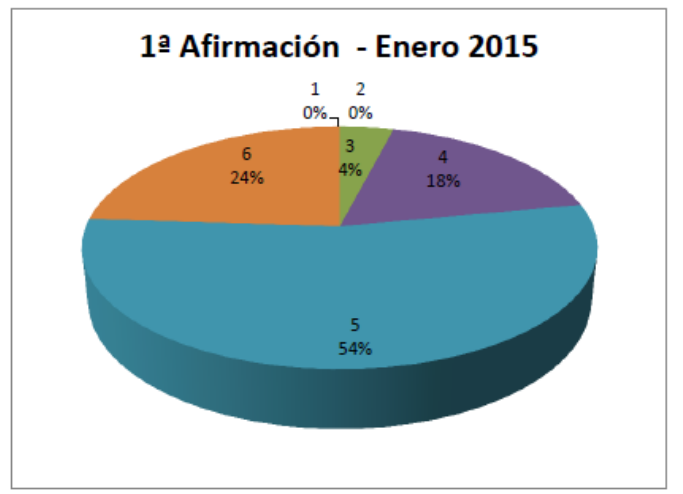

Es de destacar el desplazamiento que se produce desde el inicio del estudio a su conclusión. De ese 51\% que se manifestaba "más bien de acuerdo" en septiembre a un porcentaje similar (54\%) en enero hay todo un mundo. Pero es incluso más espectacular comprobar el peso de dos grupos unidos: los niveles 3-4 (“más bien en desacuerdo" y "más bien de acuerdo", es decir, cierta tibieza intermedia) sumaban el $76 \%$ en septiembre, es decir, las tres cuartas del alumnado que participaba en el 
estudio. Pues bien, casi ese mismo porcentaje (un 78\%) se manifestaba "completamente de acuerdo" o "de acuerdo", es decir, los segmentos 5-6 de la escala de valoración, en la segunda fase del test. Parece evidente que se ha producido una clara mejora en su conocimiento de lo que son las habilidades y actitudes necesarias para tener éxito como músico, que es de lo que se trataba, precisamente.

\begin{tabular}{|c|c|c|c|c|c|}
\hline \multicolumn{5}{|c|}{ 12 AFIRMACIÓN } \\
\hline \multicolumn{3}{|c|}{ SEPTIEMBRE 2015 } & \multicolumn{3}{|c|}{ ENERO 2016 } \\
\hline Valor & $\begin{array}{c}\text { Total } \\
\text { valores }\end{array}$ & $\%$ & Valor & $\begin{array}{c}\text { Total } \\
\text { valores }\end{array}$ & $\%$ \\
\hline 1 & 1 & $3 \%$ & 1 & 0 & $0 \%$ \\
\hline 2 & 1 & $3 \%$ & 2 & 0 & $0 \%$ \\
\hline 3 & 5 & $16 \%$ & 3 & 3 & $9 \%$ \\
\hline 4 & 17 & $53 \%$ & 4 & 9 & $28 \%$ \\
\hline 5 & 8 & $25 \%$ & 5 & 13 & $41 \%$ \\
\hline 6 & 0 & $0 \%$ & 6 & 7 & $22 \%$ \\
\hline Total & 32 & $100 \%$ & Total & 32 & $100 \%$ \\
\hline
\end{tabular}

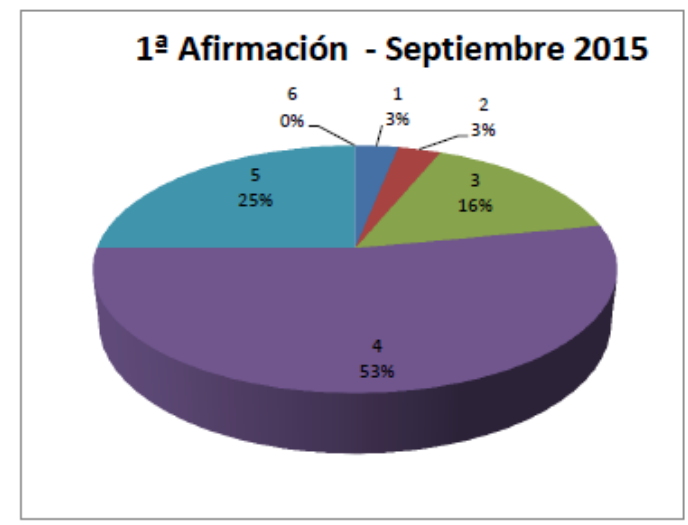

1a Afirmación: Sé cuáles son las habilidades conocimientos y actitudes necesarias para tener éxito como músico.

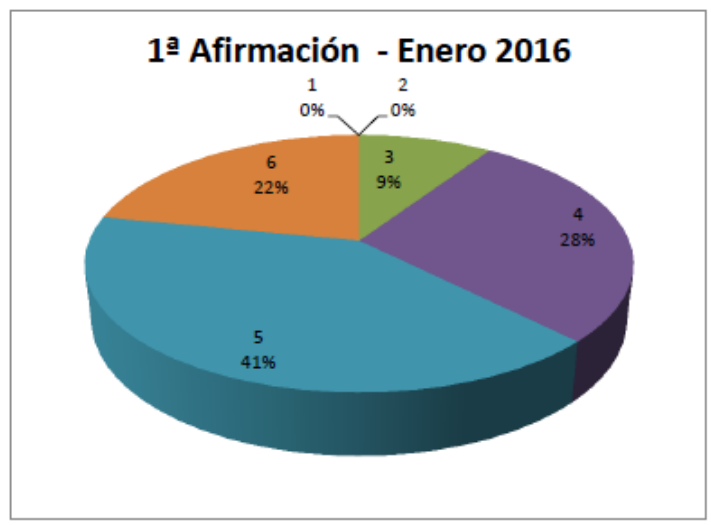

Como se puede ver, los resultados en este segundo año de investigación son prácticamente los mismos. De tener en el segmento 3-4 un 69\% se pasa a un 63\% en los segmentos 5-6. Y, al igual que en el año anterior (algo que no habíamos comentado antes) prácticamente desaparecen las opiniones que se muestran en desacuerdo con la afirmación, pasando del 22\% al 9\% (en el curso anterior habían pasado del $29 \%$ al $4 \%$ ) 
Segunda Afirmación: Conozco las últimas investigaciones sobre lo que debería ser la práctica

instrumental.

\begin{tabular}{|c|c|c|c|c|c|}
\hline \multicolumn{5}{|c|}{ 2a AFIRMACIÓN } \\
\hline \multicolumn{3}{|c|}{ SEPTIEMBRE 2014 } & \multicolumn{3}{|c|}{ ENERO 2015 } \\
\hline Valor & $\begin{array}{c}\text { Total } \\
\text { valores }\end{array}$ & $\%$ & Valor & $\begin{array}{c}\text { Total } \\
\text { valores }\end{array}$ & $\%$ \\
\hline 1 & 11 & $20 \%$ & 1 & 0 & $0 \%$ \\
\hline 2 & 23 & $42 \%$ & 2 & 3 & $6 \%$ \\
\hline 3 & 11 & $20 \%$ & 3 & 10 & $20 \%$ \\
\hline 4 & 7 & $13 \%$ & 4 & 17 & $34 \%$ \\
\hline 5 & 3 & $5 \%$ & 5 & 14 & $28 \%$ \\
\hline 6 & 0 & $0 \%$ & 6 & 6 & $12 \%$ \\
\hline Total & 55 & $100 \%$ & Total & 50 & $100 \%$ \\
\hline
\end{tabular}

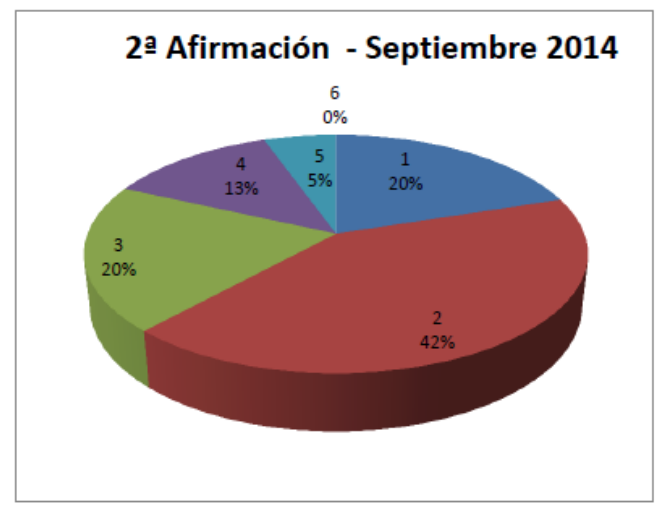

2a Afirmación: Conozco las últimas investigaciones sobre lo que debería ser la práctica instrumental.

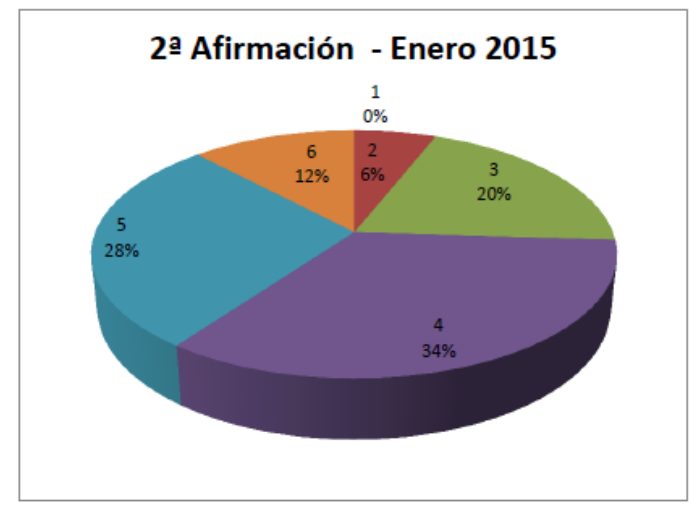

Como no podía ser de otra manera, los resultados cambiaron a lo largo del curso. Precisamente porque uno de los objetivos del mismo era darles a conocer esas investigaciones sobre lo que debería ser la práctica instrumental. Y los datos lo corroboran abierta y contundentemente. La inmensa mayoría (el 82\%) afirmaba no estar de acuerdo con esa afirmación, repartida de manera casi homogénea en los tres niveles en que se estructura ese desacuerdo $(20 \%, 42 \%$, y $20 \%$ respectivamente para “completamente en desacuerdo", “en desacuerdo" y "más bien en desacuerdo"). Esa mayoría se desplazaba casi por completo en el test de enero, hasta alcanzar un $74 \%$ de acuerdo (repartido entre "más bien de acuerdo", "de acuerdo" y "completamente de acuerdo" de la siguiente manera: $34 \%, 28 \%$ y $12 \%$ ). Lo que no podemos dejar de señalar es ese curioso $26 \%$ que sigue afirmando no conocer esas investigaciones, a pesar de haber sido estudiada en clase. Una explicación plausible es algo que igualmente se planteó en los grupos de discusión: en el momento en que se empiezan a conocer las investigaciones, uno se da cuenta de todo lo que desconoce y la sensación es precisamente que no ha hecho más que acercarse mínimamente. Dicho de otro modo, son más conscientes de la necesidad de seguir conociendo y 
aprendiendo en ese sentido.

\begin{tabular}{|c|c|c|c|c|c|}
\hline \multicolumn{6}{|c|}{$2 \beth$ AFIRMACIÓN } \\
\hline \multicolumn{3}{|c|}{ SEPTIEMBRE 2015 } & \multicolumn{3}{|c|}{ ENERO 2016 } \\
\hline Valor & $\begin{array}{c}\text { Total } \\
\text { valores }\end{array}$ & $\%$ & Valor & $\begin{array}{c}\text { Total } \\
\text { valores }\end{array}$ & $\%$ \\
\hline 1 & 4 & $13 \%$ & 1 & 0 & $0 \%$ \\
\hline 2 & 14 & $44 \%$ & 2 & 0 & $0 \%$ \\
\hline 3 & 8 & $25 \%$ & 3 & 5 & $16 \%$ \\
\hline 4 & 3 & $9 \%$ & 4 & 12 & $38 \%$ \\
\hline 5 & 3 & $9 \%$ & 5 & 11 & $34 \%$ \\
\hline 6 & 0 & $0 \%$ & 6 & 4 & $13 \%$ \\
\hline Total & 32 & $100 \%$ & Total & 32 & $100 \%$ \\
\hline
\end{tabular}

2a Afirmación - Septiembre 2015

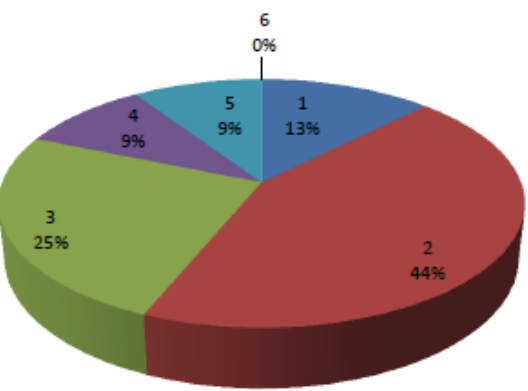

2a Afirmación: Conozco las últimas investigaciones sobre lo que debería ser la práctica instrumental.

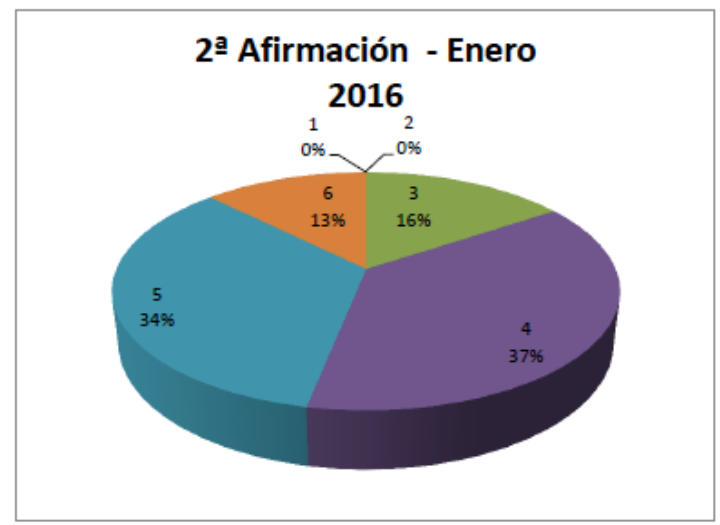

Lo mismo sucede en el test del siguiente año. De un $82 \%$ (idéntico porcentaje que el año anterior) que dice estar en desacuerdo con que conoce esas investigaciones (13\%, 44\% y $25 \%$ respectivamente entre "completamente en desacuerdo", "de acuerdo" y "más bien en desacuerdo") se pasa a un $85 \%$ en el test de enero (significativamente más que el año anterior y repartido entre "más bien de acuerdo", "de acuerdo" y "completamente de acuerdo" de este modo: 38\%, 34\% 13\%). Lo que nos congratula es que haya bajado el porcentaje de aquellos que dicen estar en desacuerdo (y sólo "más bien en desacuerdo") con la afirmación. En esta ocasión se queda en el $16 \%$, frente al elevado $26 \%$ del curso anterior. 


\begin{tabular}{|c|c|c|c|c|c|}
\hline \multicolumn{5}{|c|}{ 7a AFIRMACIÓN } \\
\hline \multicolumn{3}{|c|}{ SEPTIEMBRE 2014 } & \multicolumn{3}{|c|}{ ENERO 2015 } \\
\hline Valor & $\begin{array}{c}\text { Total } \\
\text { valores }\end{array}$ & $\%$ & Valor & $\begin{array}{c}\text { Total } \\
\text { valores }\end{array}$ & $\%$ \\
\hline 1 & 2 & $4 \%$ & 1 & 0 & $0 \%$ \\
\hline 2 & 2 & $4 \%$ & 2 & 0 & $0 \%$ \\
\hline 3 & 11 & $21 \%$ & 3 & 5 & $10 \%$ \\
\hline 4 & 15 & $28 \%$ & 4 & 10 & $20 \%$ \\
\hline 5 & 19 & $36 \%$ & 5 & 27 & $54 \%$ \\
\hline 6 & 4 & $8 \%$ & 6 & 8 & $16 \%$ \\
\hline Total & 53 & $100 \%$ & Total & 50 & $100 \%$ \\
\hline
\end{tabular}

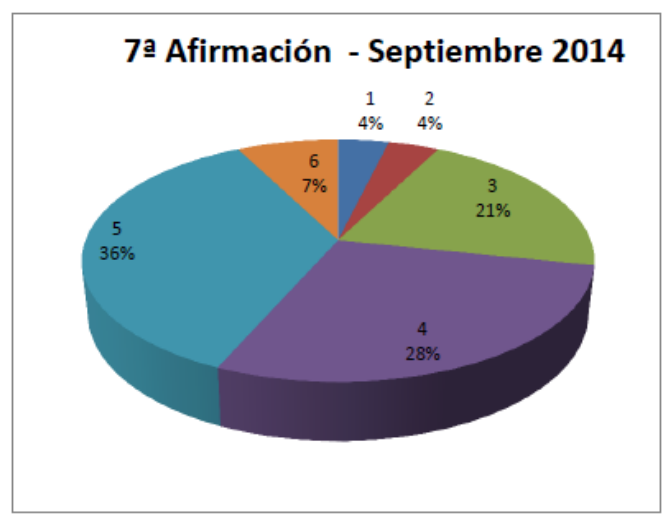

7ạ Afirmación: No me importa reconocer mis puntos fuertes.

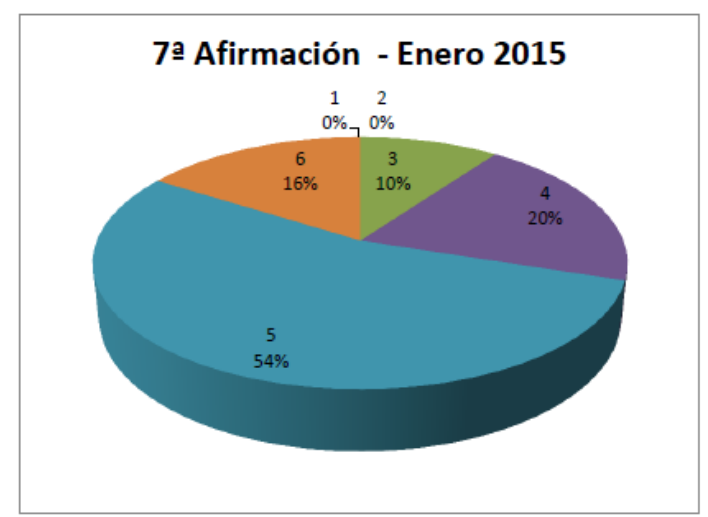

Un importante éxito tuvo, a nuestro juicio, el trabajo que se hizo sobre el punto fuerte, como se puede apreciar en estas gráficas. El 29\% que aún se manifestaba reticente a aceptar ese reconocimiento se convirtió en un exiguo $10 \%$ al final de la investigación. Pero es quizá más significativo cómo se desplaza el acuerdo: el "de acuerdo" sube del 36\% al mayoritario 54\% y el "completamente de acuerdo" lo hace del $8 \%$ al 16\%, exactamente el doble. Parece que, afortunadamente, se va avanzando hacia ese reconocimiento del punto fuerte, que a nosotros nos parece fundamental. 


\begin{tabular}{|c|c|c|c|c|c|}
\hline \multicolumn{5}{|c|}{ 7 AFIRMACIÓN } \\
\hline \multicolumn{3}{|c|}{ SEPTIEMBRE 2015 } & \multicolumn{3}{|c|}{ ENERO 2016 } \\
\hline Valor & $\begin{array}{c}\text { Total } \\
\text { valores }\end{array}$ & $\%$ & Valor & $\begin{array}{c}\text { Total } \\
\text { valores }\end{array}$ & $\%$ \\
\hline 1 & 2 & $6 \%$ & 1 & 0 & $0 \%$ \\
\hline 2 & 2 & $6 \%$ & 2 & 0 & $0 \%$ \\
\hline 3 & 4 & $13 \%$ & 3 & 2 & $6 \%$ \\
\hline 4 & 8 & $25 \%$ & 4 & 6 & $19 \%$ \\
\hline 5 & 11 & $34 \%$ & 5 & 16 & $50 \%$ \\
\hline 6 & 5 & $16 \%$ & 6 & 8 & $25 \%$ \\
\hline Total & 32 & $100 \%$ & Total & 32 & $100 \%$ \\
\hline
\end{tabular}

7ạ Afirmación - Septiembre 2015

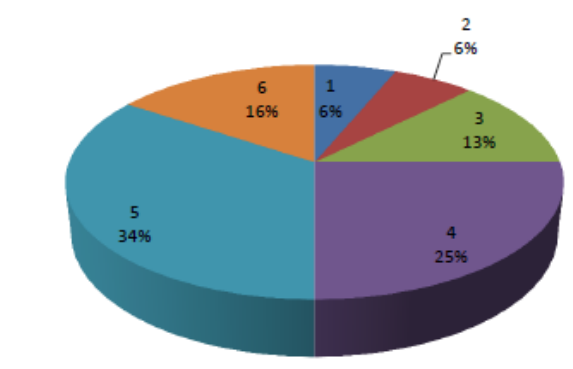

7ạ Afirmación: No me importa reconocer mis puntos fuertes.

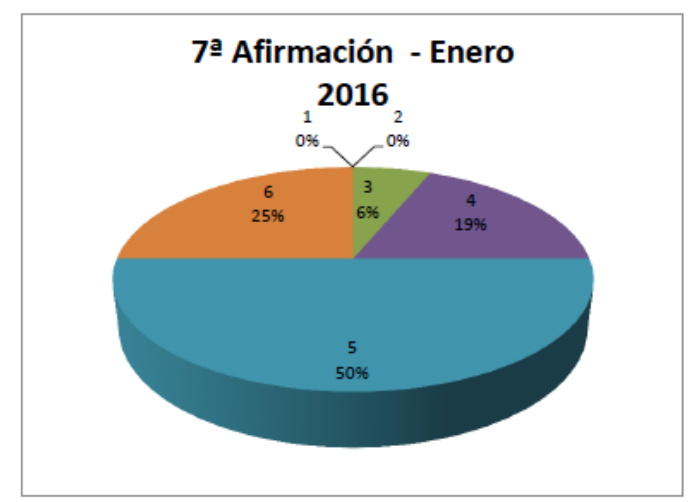

Algo similar (casi idéntico), sucede el curso siguiente. El 25\% que se mostraba reticente a aceptar ese punto fuerte se convierte en un casi inexistente $6 \%$ al final del cuatrimestre. Y el desplazamiento que señalábamos el curso anterior vuelve a producirse casi en las mismas proporciones. El "de acuerdo" sube del 31\% al 50\% y el "completamente de acuerdo" lo hace del 16\% al 25\%. Nos parece que los datos hablan por sí mismos y no necesitan más comentario. 
5.6.2 Afirmaciones que se mantienen estables:

Octava afirmación: Sé cuáles son mis puntos débiles

\begin{tabular}{|c|c|c|c|c|c|}
\hline \multicolumn{5}{|c|}{8 AFIRMACIÓN } \\
\hline \multicolumn{3}{|c|}{ SEPTIEMBRE 2014 } & \multicolumn{3}{|c|}{ ENERO 2015 } \\
\hline Valor & $\begin{array}{c}\text { Total } \\
\text { valores }\end{array}$ & $\%$ & Valor & $\begin{array}{c}\text { Total } \\
\text { valores }\end{array}$ & $\%$ \\
\hline 1 & 0 & $0 \%$ & 1 & 0 & $0 \%$ \\
\hline 2 & 0 & $0 \%$ & 2 & 0 & $0 \%$ \\
\hline 3 & 0 & $0 \%$ & 3 & 1 & $2 \%$ \\
\hline 4 & 10 & $18 \%$ & 4 & 5 & $10 \%$ \\
\hline 5 & 28 & $51 \%$ & 5 & 29 & $60 \%$ \\
\hline 6 & 17 & $31 \%$ & 6 & 13 & $27 \%$ \\
\hline Total & 55 & $100 \%$ & Total & 48 & $100 \%$ \\
\hline
\end{tabular}

8a Afirmación - Septiembre 2014 $1 \quad 2 \quad 3$

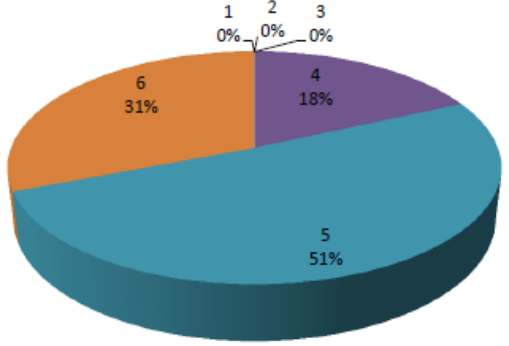

8aA Afirmación: Sé cuáles son mis puntos débiles.

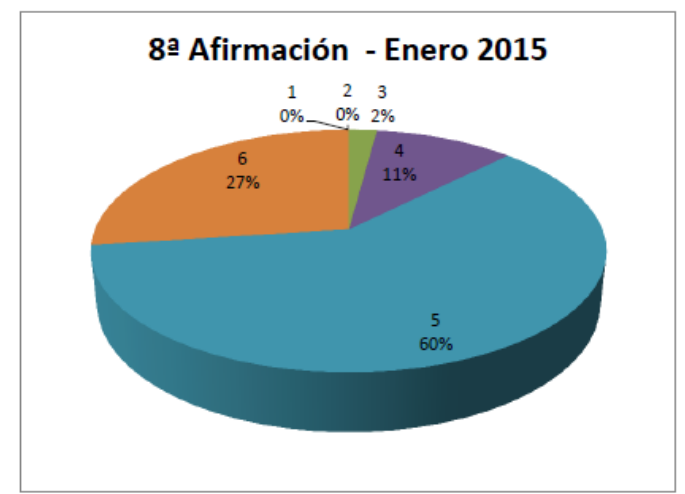

Es interesante apreciar cómo esta afirmación apenas varía a lo largo de la investigación. Las variaciones en cada apartado son mínimas (por no decir anecdóticas), lo que, a nuestro juicio, demuestra claramente el hecho que hemos comentado en las páginas dedicadas a comentar el tema en cuestión: el punto débil de los músicos es algo que se machaca de manera insistente en los conservatorios de música, hasta el punto de que es algo de lo que el alumno es consciente desde el primer momento. 


\begin{tabular}{|c|c|c|c|c|c|}
\hline \multicolumn{5}{|c|}{8 AFIRMACIÓN } \\
\hline \multicolumn{3}{|c|}{ SEPTIEMBRE 2015 } & \multicolumn{3}{|c|}{ ENERO 2016 } \\
\hline Valor & $\begin{array}{c}\text { Total } \\
\text { valores }\end{array}$ & $\%$ & Valor & $\begin{array}{c}\text { Total } \\
\text { valores }\end{array}$ & $\%$ \\
\hline 1 & 0 & $0 \%$ & 1 & 0 & $0 \%$ \\
\hline 2 & 0 & $0 \%$ & 2 & 0 & $0 \%$ \\
\hline 3 & 0 & $0 \%$ & 3 & 1 & $3 \%$ \\
\hline 4 & 8 & $25 \%$ & 4 & 5 & $16 \%$ \\
\hline 5 & 15 & $47 \%$ & 5 & 16 & $50 \%$ \\
\hline 6 & 9 & $28 \%$ & 6 & 10 & $31 \%$ \\
\hline Total & 32 & $100 \%$ & Total & 32 & $100 \%$ \\
\hline
\end{tabular}

8ª Afirmación - Septiembre 2015

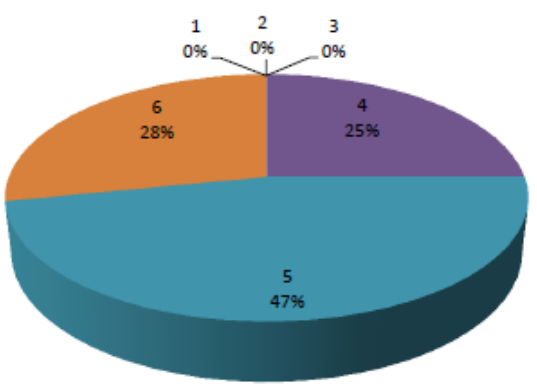

8a Afirmación: Sé cuáles son mis puntos débiles.

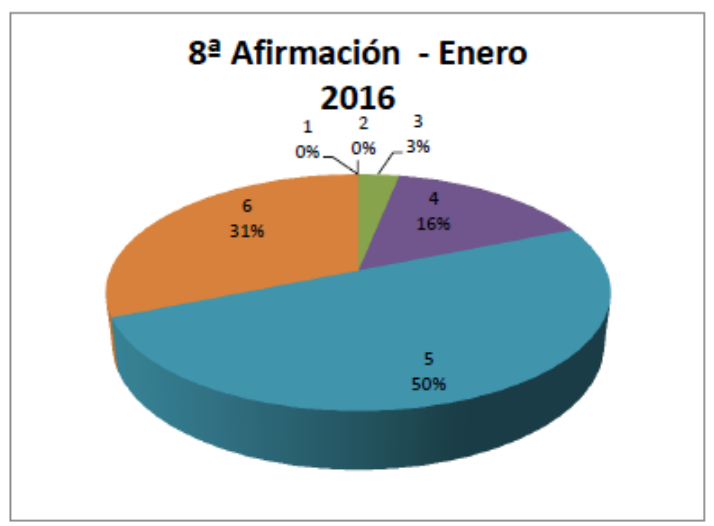

Los resultados obtenidos en la consulta realizada al siguiente curso son similares. Tanto en el primer año como en el segundo las variaciones fueron mínimas, por no decir inexistentes. Y como hemos dicho ya en anteriores ocasiones, esto en sí mismo no es nada preocupante, siempre que se combine con el trabajo en otros aspectos, especialmente el del punto fuerte, que es el que de manera más clara nos puede conducir a la excelencia. 
Vigésima afirmación: Tengo unas ciertas habilidades musicales y realmente no puedo cambiarlas.

\begin{tabular}{|c|c|c|c|c|c|}
\hline \multicolumn{6}{|c|}{ 20a AFIRMACIÓN } \\
\hline \multicolumn{3}{|c|}{ SEPTIEMBRE 2014 } & \multicolumn{3}{|c|}{ ENERO 2015 } \\
\hline Valor & $\begin{array}{c}\text { Total } \\
\text { valores }\end{array}$ & $\%$ & Valor & $\begin{array}{c}\text { Total } \\
\text { valores }\end{array}$ & $\%$ \\
\hline 1 & 7 & $13 \%$ & 1 & 14 & $28 \%$ \\
\hline 2 & 16 & $0 \%$ & 2 & 21 & $42 \%$ \\
\hline 3 & 20 & $0 \%$ & 3 & 10 & $20 \%$ \\
\hline 4 & 9 & $0 \%$ & 4 & 1 & $2 \%$ \\
\hline 5 & 2 & $0 \%$ & 5 & 2 & $4 \%$ \\
\hline 6 & 1 & $0 \%$ & 6 & 2 & $4 \%$ \\
\hline Total & 55 & $0 \%$ & Total & 50 & $100 \%$ \\
\hline
\end{tabular}

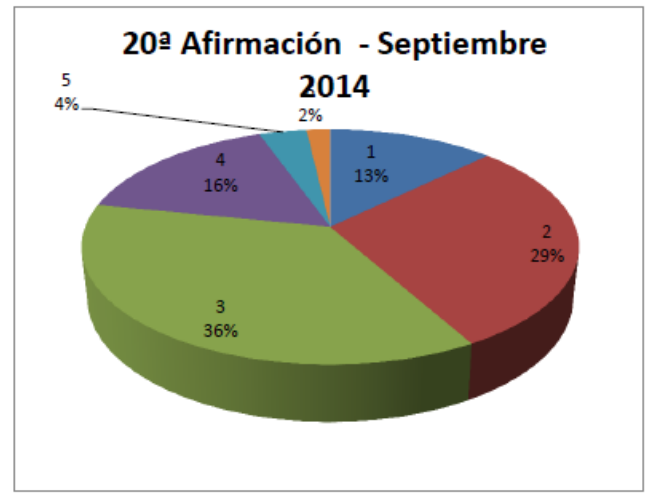

20ạ Afirmación: Tengo unas ciertas habilidades musicales y realmente no puedo cambiarlas.

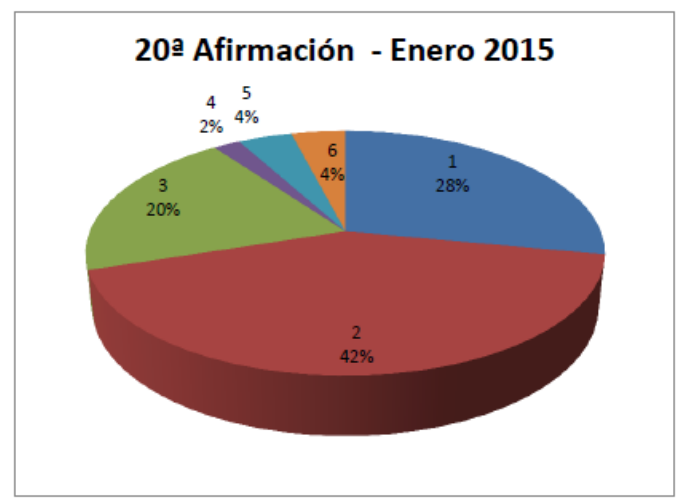

En el caso de la autoconsideración de las habilidades musicales, es curioso constatar cómo siguen sin estar de acuerdo con la afirmación de que no pueden cambiarlas. Tanto en una como en otra encuesta, las tres cuartas partes del alumnado (un 78\%) estaban en desacuerdo con esa opinión (13\% "completamente en desacuerdo", 29\% "en desacuerdo" y 36\% "más bien en desacuerdo"), porcentaje que sube al $90 \%$ en la segunda recogida de datos. Congratula ver que ya antes de nuestra intervención el alumnado ya estaba por la labor de mejorar sus cualidades musicales, como no podía ser de otra manera. En el ánimo de todo músico debe anidar la búsqueda de la excelencia. Pero aun así, es inquietante percibir la existencia de ese $10 \%$ que sigue pensando que tiene esas cualidades de forma fija, aun después de haber conocido las investigaciones al respecto. 


\begin{tabular}{|c|c|c|c|c|c|}
\hline \multicolumn{6}{|c|}{$20 \geqq$ AFIRMACIÓN } \\
\hline \multicolumn{3}{|c|}{ SEPTIEMBRE 2015 } & \multicolumn{3}{|c|}{ ENERO 2016 } \\
\hline Valor & $\begin{array}{c}\text { Total } \\
\text { valores }\end{array}$ & $\%$ & Valor & $\begin{array}{c}\text { Total } \\
\text { valores }\end{array}$ & $\%$ \\
\hline 1 & 11 & $34 \%$ & 1 & 9 & $28 \%$ \\
\hline 2 & 6 & $19 \%$ & 2 & 4 & $13 \%$ \\
\hline 3 & 11 & $34 \%$ & 3 & 11 & $34 \%$ \\
\hline 4 & 2 & $6 \%$ & 4 & 7 & $22 \%$ \\
\hline 5 & 0 & $0 \%$ & 5 & 0 & $0 \%$ \\
\hline 6 & 2 & $6 \%$ & 6 & 1 & $3 \%$ \\
\hline Total & 32 & $100 \%$ & Total & 32 & $100 \%$ \\
\hline
\end{tabular}

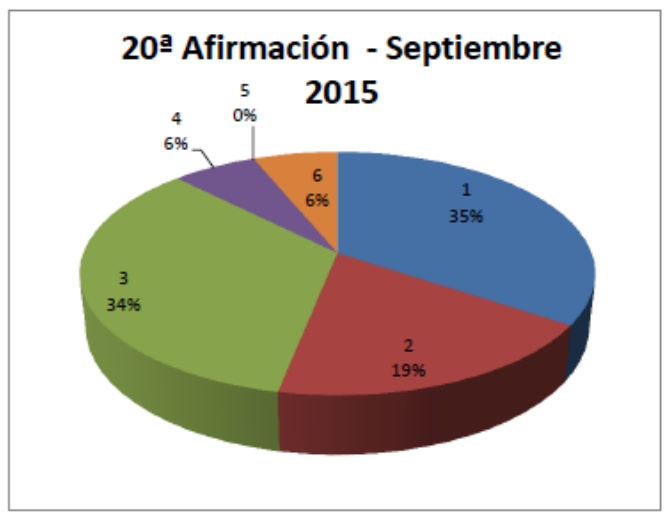

20a Afirmación: Tengo unas ciertas habilidades musicales y realmente no puedo cambiarlas.

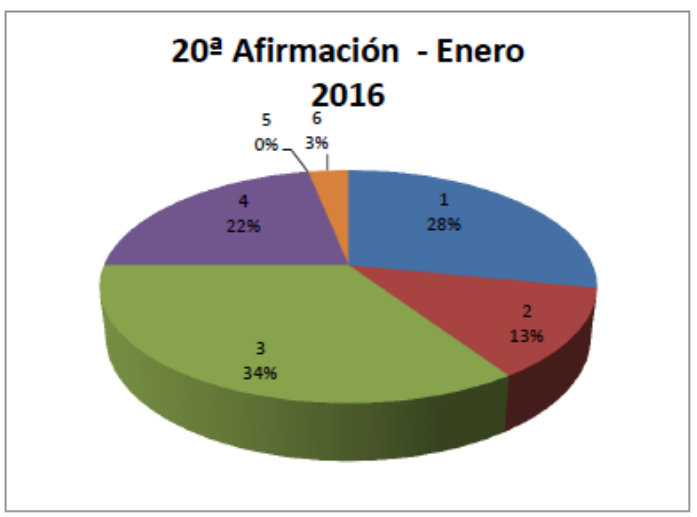

Aunque en líneas generales sucede lo mismo en este curso, es decir, una apabullante mayoría está en desacuerdo con la afirmación (87\% en la primera encuesta y $75 \%$ en la segunda), es inquietante ver cómo el desacuerdo decrece tras nuestra intervención. Ese $22 \%$ que se manifiesta "más o menos de acuerdo" es algo que no deja de sorprender en cierta medida. 
Vigésimo tercera afirmación: Sé perfectamente cuando he entendido algún contenido.

\begin{tabular}{|c|c|c|c|c|c|}
\hline \multicolumn{6}{|c|}{ 23ä AFIRMACIÓN } \\
\hline \multicolumn{3}{|c|}{ SEPTIEMBRE 2014 } & \multicolumn{3}{|c|}{ ENERO 2015 } \\
\hline Valor & $\begin{array}{c}\text { Total } \\
\text { valores }\end{array}$ & $\%$ & Valor & $\begin{array}{c}\text { Total } \\
\text { valores }\end{array}$ & $\%$ \\
\hline 1 & 0 & $0 \%$ & 1 & 0 & $0 \%$ \\
\hline 2 & 0 & $0 \%$ & 2 & 0 & $0 \%$ \\
\hline 3 & 3 & $6 \%$ & 3 & 1 & $2 \%$ \\
\hline 4 & 12 & $22 \%$ & 4 & 9 & $18 \%$ \\
\hline 5 & 26 & $48 \%$ & 5 & 25 & $50 \%$ \\
\hline 6 & 13 & $24 \%$ & 6 & 15 & $30 \%$ \\
\hline Total & 54 & $100 \%$ & Total & 50 & $100 \%$ \\
\hline
\end{tabular}

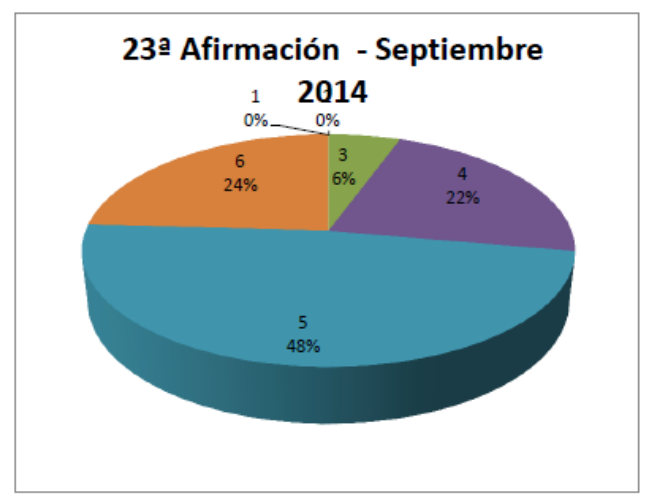

23ạ Afirmación: Sé perfectamente cuando he entendido algún contenido.

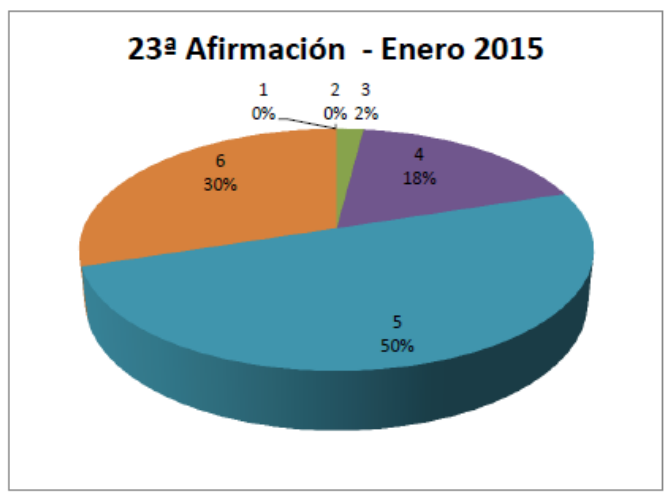

Aquí sí que las cifras son completamente homogéneas. Las variaciones son mínimas y obviamente se puede prescindir de esos porcentajes que apreciamos: en algunos niveles se pasa del $6 \%$ al $2 \%$ o del $24 \%$ al $30 \%$... Es evidente que el alumnado tiene claro cuándo ha entendido algún contenido, no en vano estamos hablando de alumnos de estudios superiores, que se supone tienen una mayor consciencia de lo que son y de lo que quieren. Lo contrario sería preocupante, porque nos llevaría a niveles anteriores de enseñanza, como la secundaria o la primaria, donde el alumno, en efecto, no es muchas veces consciente de si ha entendido o no algún concepto. 


\begin{tabular}{|c|c|c|c|c|c|}
\hline \multicolumn{6}{|c|}{ 23 AFIRMACIÓN } \\
\hline \multicolumn{3}{|c|}{ SEPTIEMBRE 2015 } & \multicolumn{3}{|c|}{ ENERO 2016 } \\
\hline Valor & $\begin{array}{c}\text { Total } \\
\text { valores }\end{array}$ & $\%$ & Valor & $\begin{array}{c}\text { Total } \\
\text { valores }\end{array}$ & $\%$ \\
\hline 1 & 0 & $0 \%$ & 1 & 0 & $0 \%$ \\
\hline 2 & 0 & $0 \%$ & 2 & 0 & $0 \%$ \\
\hline 3 & 2 & $6 \%$ & 3 & 3 & $9 \%$ \\
\hline 4 & 7 & $22 \%$ & 4 & 5 & $16 \%$ \\
\hline 5 & 11 & $34 \%$ & 5 & 15 & $47 \%$ \\
\hline 6 & 12 & $38 \%$ & 6 & 9 & $28 \%$ \\
\hline Total & 32 & $100 \%$ & Total & 32 & $100 \%$ \\
\hline
\end{tabular}

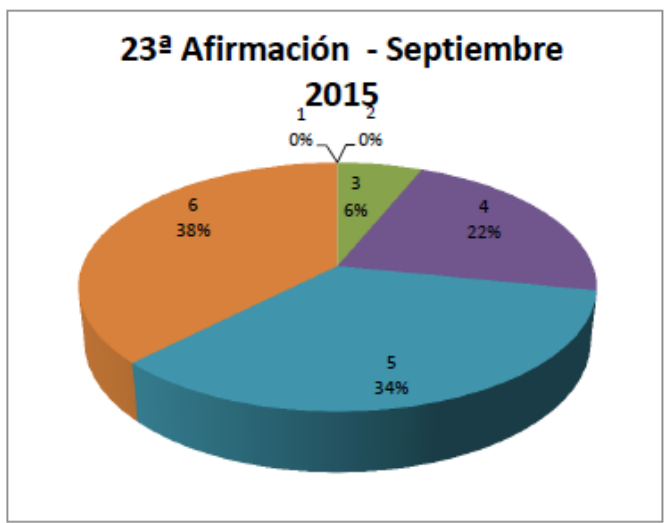

23a Afirmación: Sé perfectamente cuando he entendido algún contenido.

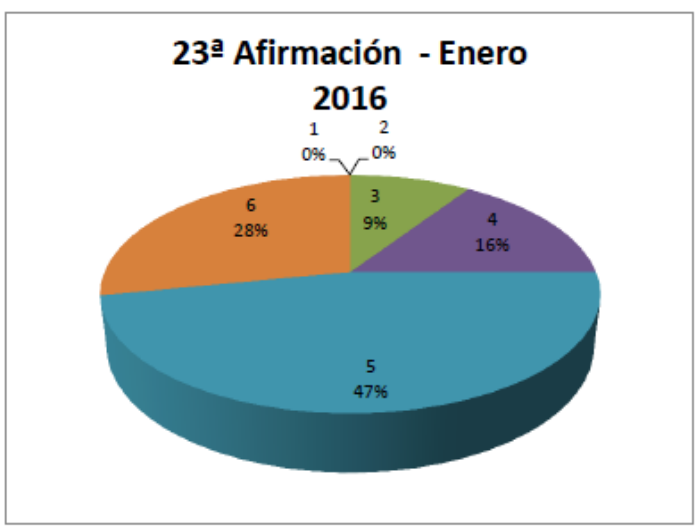

Si en el primer curso en el que se pasó la encuesta las variaciones eran mínimas al valorar esta afirmación, en este segundo curso las diferencias fueron aun menores. Así, la mayor variación se produce en el valor "de acuerdo", que varía 13 puntos, al pasar del $34 \%$ al $47 \%$. Como decíamos antes, no se puede decir que esto resulte especialmente significativo, especialmente viendo los valores generales. 
Vigésimo sexta afirmación: Prefiero que lo que toco le guste a mi profesor y me ponga buenas notas a aprender mucho.

\begin{tabular}{|c|c|c|c|c|c|}
\hline \multicolumn{5}{|c|}{ 26a AFIRMACIÓN } \\
\hline \multicolumn{3}{|c|}{ SEPTIEMBRE 2014 } & \multicolumn{3}{|c|}{ ENERO 2015 } \\
\hline Valor & $\begin{array}{c}\text { Total } \\
\text { valores }\end{array}$ & $\%$ & Valor & $\begin{array}{c}\text { Total } \\
\text { valores }\end{array}$ & $\%$ \\
\hline 1 & 25 & $45 \%$ & 1 & 25 & $50 \%$ \\
\hline 2 & 18 & $33 \%$ & 2 & 18 & $36 \%$ \\
\hline 3 & 7 & $13 \%$ & 3 & 5 & $10 \%$ \\
\hline 4 & 3 & $5 \%$ & 4 & 2 & $4 \%$ \\
\hline 5 & 2 & $4 \%$ & 5 & 0 & $0 \%$ \\
\hline 6 & 0 & $0 \%$ & 6 & 0 & $0 \%$ \\
\hline Total & 55 & $100 \%$ & Total & 50 & $100 \%$ \\
\hline
\end{tabular}

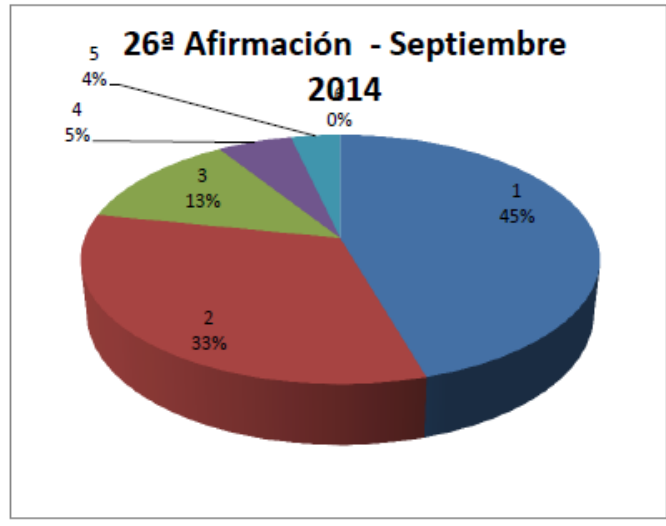

26a Afirmación: Prefiero que lo que toco le guste a mi profesor y me ponga buenas notas a aprender mucho.

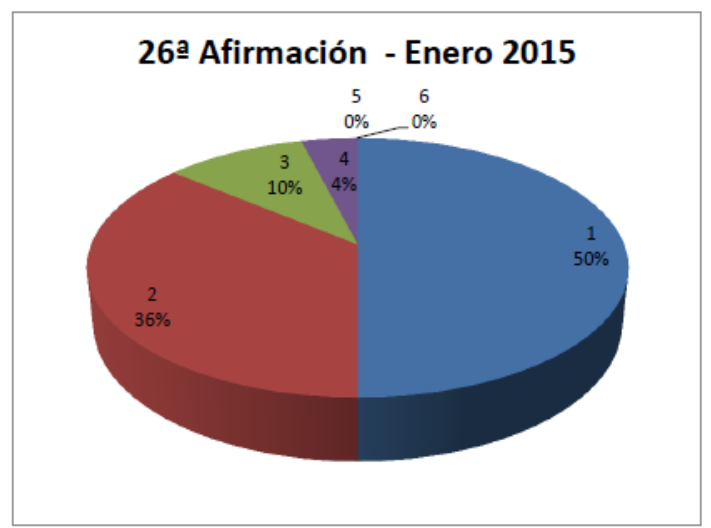

Afortunadamente, la inmensa mayoría del alumnado está en desacuerdo con esta afirmación. Sólo el 9\% manifiesta algún tipo de acuerdo (5\% "más bien de acuerdo" y $4 \%$ "de acuerdo" con un rotundo $0 \%$ en el "completamente de acuerdo") con que prefieren dar gusto al profesor de turno que aprender. Y ese $9 \%$ se convierte en un $4 \%$ en la segunda encuesta, pero sólo en el "más bien de acuerdo", lo que no es demasiado pesimista. El restante $96 \%$ se manifiesta en algún nivel de desacuerdo, siendo el mayoritario el "completamente en desacuerdo", con un 50\%. 


\begin{tabular}{|c|c|c|c|c|c|}
\hline \multicolumn{5}{|c|}{ 26? AFIRMACIÓN } \\
\hline \multicolumn{3}{|c|}{ SEPTIEMBRE 2015 } & \multicolumn{3}{|c|}{ ENERO 2016 } \\
\hline Valor & $\begin{array}{c}\text { Total } \\
\text { valores }\end{array}$ & $\%$ & Valor & $\begin{array}{c}\text { Total } \\
\text { valores }\end{array}$ & $\%$ \\
\hline 1 & 18 & $56 \%$ & 1 & 15 & $48 \%$ \\
\hline 2 & 7 & $22 \%$ & 2 & 5 & $16 \%$ \\
\hline 3 & 6 & $19 \%$ & 3 & 8 & $26 \%$ \\
\hline 4 & 1 & $3 \%$ & 4 & 3 & $10 \%$ \\
\hline 5 & 0 & $0 \%$ & 5 & 0 & $0 \%$ \\
\hline 6 & 0 & $0 \%$ & 6 & 0 & $0 \%$ \\
\hline Total & 32 & $100 \%$ & Total & 31 & $100 \%$ \\
\hline
\end{tabular}

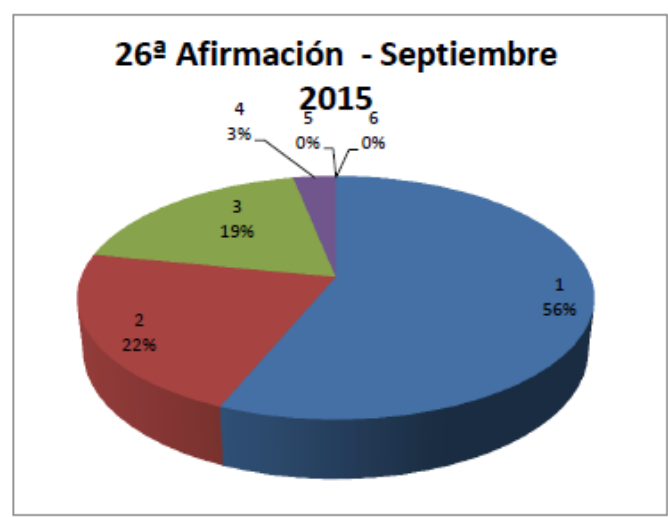

26a Afirmación: Prefiero que lo que toco le guste a mi profesor y me ponga buenas notas a aprender mucho.

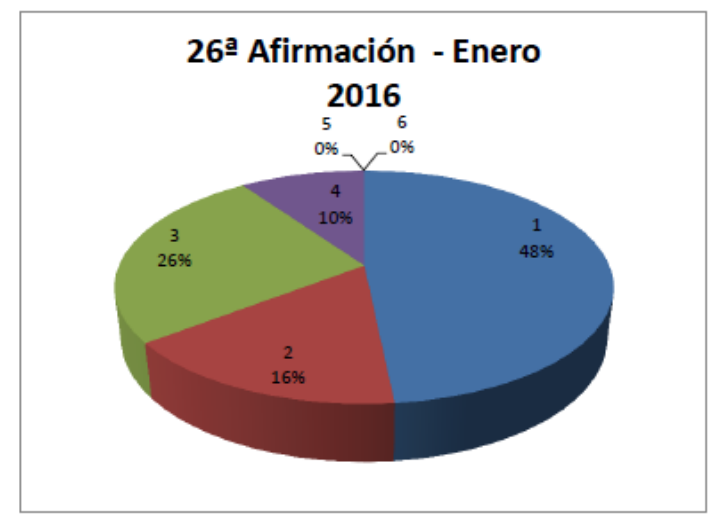

Aunque en este curso los resultados fueron igualmente optimistas al respecto, con una mayoría absolutísima en desacuerdo con la afirmación, hay que señalar el curioso caso de ese exiguo 3\% que estaba "más o menos de acuerdo" en la primera encuesta (nadie más mostraba ningún tipo de acuerdo en ésta) que se transformó en un $10 \%$ en la segunda. Afortunadamente, nadie se incluyó en los otros dos niveles de acuerdo. 
Trigésimo sexta afirmación: Cuando fracaso o no consigo alcanzar los objetivos propuestos pienso que es porque no tengo bastante talento musical

\begin{tabular}{|c|c|c|c|c|c|}
\hline \multicolumn{5}{|c|}{ 36a AFIRMACIÓN } \\
\hline \multicolumn{3}{|c|}{ SEPTIEMBRE 2014 } & \multicolumn{3}{|c|}{ ENERO 2015 } \\
\hline Valor & $\begin{array}{c}\text { Total } \\
\text { valores }\end{array}$ & $\%$ & Valor & $\begin{array}{c}\text { Total } \\
\text { valores }\end{array}$ & $\%$ \\
\hline 1 & 15 & $27 \%$ & 1 & 15 & $30 \%$ \\
\hline 2 & 12 & $22 \%$ & 2 & 17 & $34 \%$ \\
\hline 3 & 12 & $22 \%$ & 3 & 10 & $20 \%$ \\
\hline 4 & 8 & $15 \%$ & 4 & 6 & $12 \%$ \\
\hline 5 & 5 & $9 \%$ & 5 & 2 & $4 \%$ \\
\hline 6 & 3 & $5 \%$ & 6 & 0 & $0 \%$ \\
\hline Total & 55 & $100 \%$ & Total & 50 & $100 \%$ \\
\hline
\end{tabular}

36ạ Afirmación - Septiembre

2014

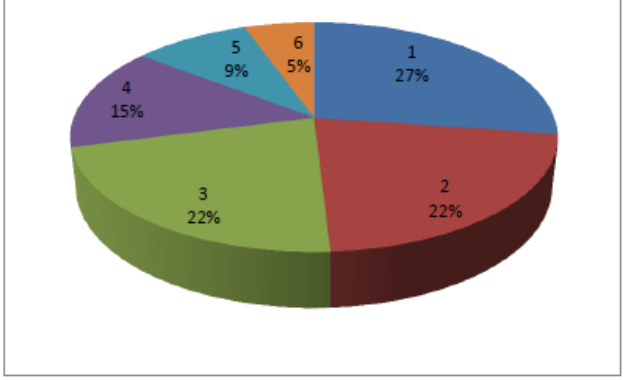

36a Afirmación: Cuando fracaso o no consigo alcanzar los objetivos propuestos pienso que es porque no tengo bastante talento musical.

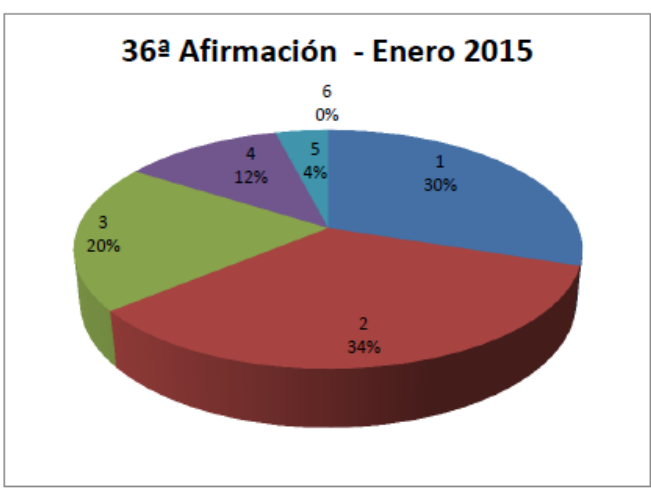

Por fortuna, parece que nuestro alumnado no tiene una visión pesimista de sí mismo. El desacuerdo mayoritario con esta afirmación así lo demuestra, desacuerdo que no varía de manera importante de una encuesta a otra. Si acaso, desciende el pesimismo desde el $29 \%$ de la primera al $16 \%$ de la segunda (bajando sobre todo los niveles "completamente de acuerdo", que pasa del 5\% al 0\%, y "de acuerdo", que pasa del $9 \%$ al 4\%). El resto de niveles se mantiene más o menos estable, lo que habla más o menos bien de la madurez del alumnado. 


\begin{tabular}{|c|c|c|c|c|c|}
\hline \multicolumn{6}{|c|}{$36 \geq$ AFIRMACIÓN } \\
\hline \multicolumn{3}{|c|}{ SEPTIEMBRE 2015 } & \multicolumn{3}{|c|}{ ENERO 2016 } \\
\hline Valor & $\begin{array}{c}\text { Total } \\
\text { valores }\end{array}$ & $\%$ & Valor & $\begin{array}{c}\text { Total } \\
\text { valores }\end{array}$ & $\%$ \\
\hline 1 & 13 & $41 \%$ & 1 & 10 & $31 \%$ \\
\hline 2 & 7 & $22 \%$ & 2 & 7 & $22 \%$ \\
\hline 3 & 5 & $16 \%$ & 3 & 9 & $28 \%$ \\
\hline 4 & 4 & $13 \%$ & 4 & 4 & $13 \%$ \\
\hline 5 & 3 & $9 \%$ & 5 & 2 & $6 \%$ \\
\hline 6 & 0 & $0 \%$ & 6 & 0 & $0 \%$ \\
\hline Total & 32 & $100 \%$ & Total & 32 & $100 \%$ \\
\hline
\end{tabular}

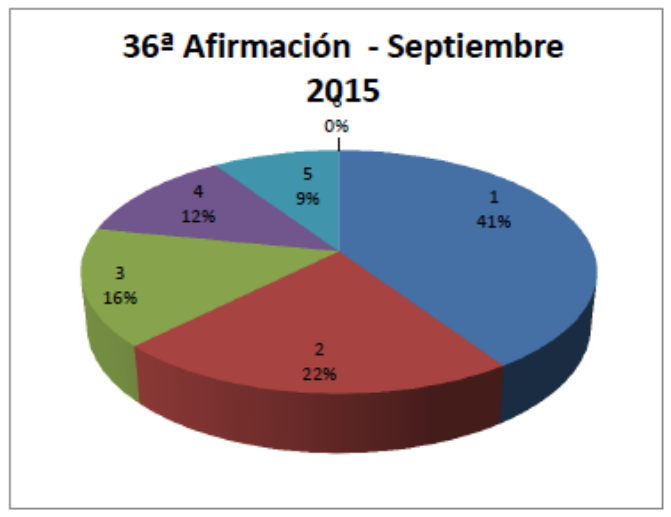

36a Afirmación: Cuando fracaso o no consigo alcanzar los objetivos propuestos pienso que

es porque no tengo bastante talento musical.

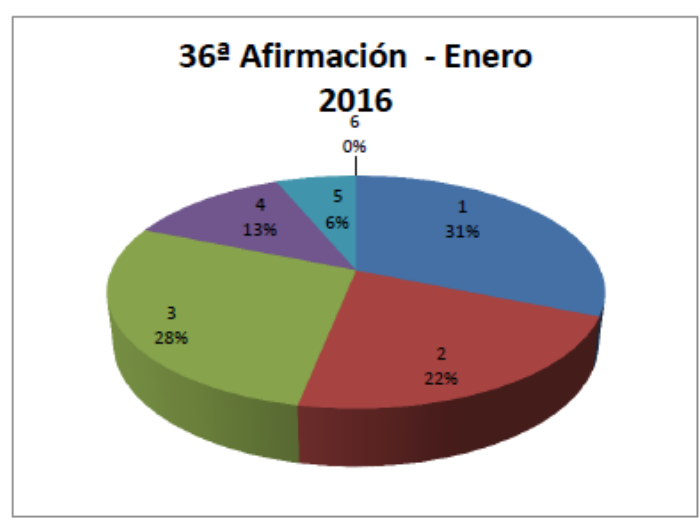

Y la homogeneidad es aún mayor en este curso: el $79 \%$ en septiembre y el $81 \%$ en enero están en algún nivel de desacuerdo con la afirmación. Sólo los niveles "completamente en desacuerdo" y "más o menos en desacuerdo" cambian algo (del $41 \%$ al $31 \%$ y del $16 \%$ al $28 \%$ respectivamente, casi como si cambiaran sus adeptos). El resto se mantiene casi inmóvil (y exactamente igual en dos casos: "en desacuerdo" y "más o menos de acuerdo" (22\% y 13\% respectivamente). Las demás cifras cambian mínimamente. El comentario que podríamos hacer aquí es el mismo que en el caso del anterior curso. 
Trigésimo séptima afirmación: Cuando fracaso o no consigo alcanzar los objetivos propuestos pienso que es porque no he estudiado bastante

\begin{tabular}{|c|c|c|c|c|c|}
\hline \multicolumn{5}{|c|}{ 37a AFIRMACIÓN } \\
\hline \multicolumn{3}{|c|}{ SEPTIEMBRE 2014 } & \multicolumn{3}{|c|}{ ENERO 2015 } \\
\hline Valor & $\begin{array}{c}\text { Total } \\
\text { valores }\end{array}$ & $\%$ & Valor & $\begin{array}{c}\text { Total } \\
\text { valores }\end{array}$ & $\%$ \\
\hline 1 & 0 & $0 \%$ & 1 & 1 & $2 \%$ \\
\hline 2 & 5 & $9 \%$ & 2 & 2 & $4 \%$ \\
\hline 3 & 6 & $11 \%$ & 3 & 4 & $8 \%$ \\
\hline 4 & 15 & $27 \%$ & 4 & 9 & $18 \%$ \\
\hline 5 & 17 & $31 \%$ & 5 & 24 & $48 \%$ \\
\hline 6 & 12 & $22 \%$ & 6 & 10 & $20 \%$ \\
\hline Total & 55 & $100 \%$ & Total & 50 & $100 \%$ \\
\hline
\end{tabular}

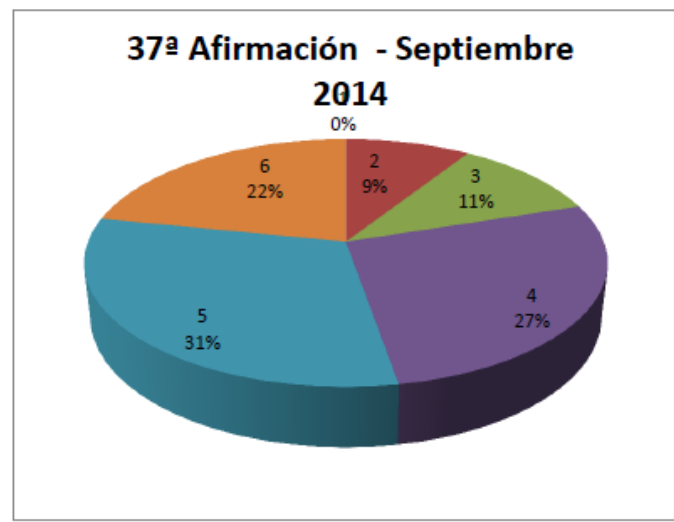

37ạ Afirmación: Cuando fracaso o no consigo alcanzar los objetivos propuestos pienso que es porque no he estudiado bastante.

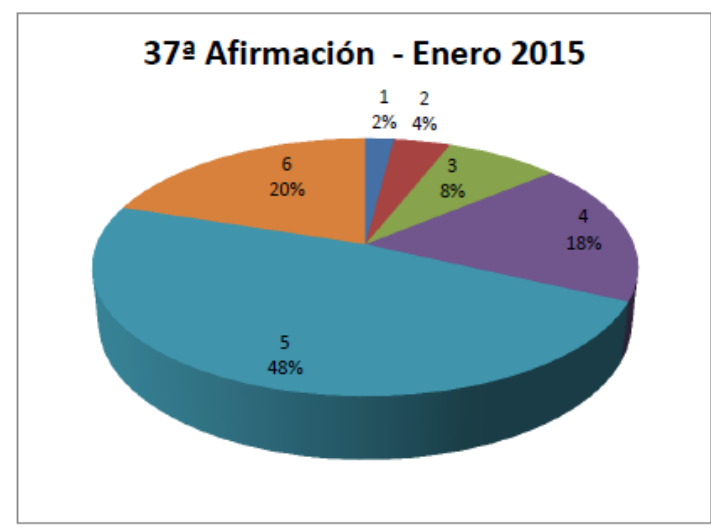

La autocrítica del alumnado es evidente: si las cosas no salen es porque no han estudiando de la manera adecuada. Es decir, que si estudiaran, las cosas irían mejor. El $88 \%$ pensaba así en la primera encuesta y el mismo porcentaje seguía opinando de ese modo en la segunda. El único comentario que podemos permitirnos en este aspecto es que nos congratula comprobar el elevado grado de autoconsciencia que muestra nuestro alumnado. 


\begin{tabular}{|c|c|c|c|c|c|}
\hline \multicolumn{6}{|c|}{37 AFIRMACIÓN } \\
\hline \multicolumn{3}{|c|}{ SEPTIEMBRE 2015 } & \multicolumn{3}{|c|}{ ENERO 2016 } \\
\hline Valor & $\begin{array}{c}\text { Total } \\
\text { valores }\end{array}$ & $\%$ & Valor & $\begin{array}{c}\text { Total } \\
\text { valores }\end{array}$ & $\%$ \\
\hline 1 & 2 & $6 \%$ & 1 & 0 & $0 \%$ \\
\hline 2 & 3 & $9 \%$ & 2 & 2 & $6 \%$ \\
\hline 3 & 5 & $16 \%$ & 3 & 5 & $16 \%$ \\
\hline 4 & 7 & $22 \%$ & 4 & 10 & $31 \%$ \\
\hline 5 & 8 & $25 \%$ & 5 & 8 & $25 \%$ \\
\hline 6 & 7 & $22 \%$ & 6 & 7 & $22 \%$ \\
\hline Total & 32 & $100 \%$ & Total & 32 & $100 \%$ \\
\hline
\end{tabular}

37a Afirmación - Septiembre

2015

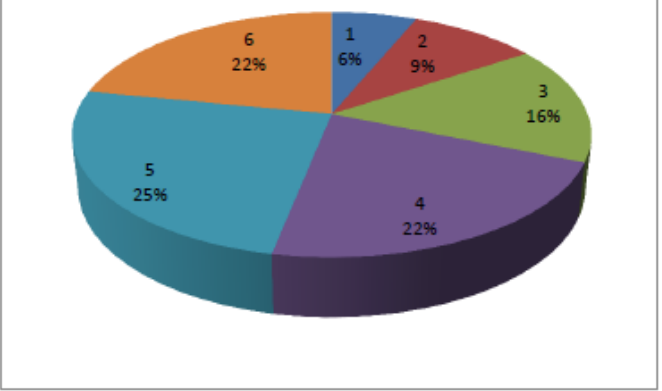

37ạ Afirmación: Cuando fracaso o no consigo alcanzar los objetivos propuestos pienso que es porque no he estudiado bastante.

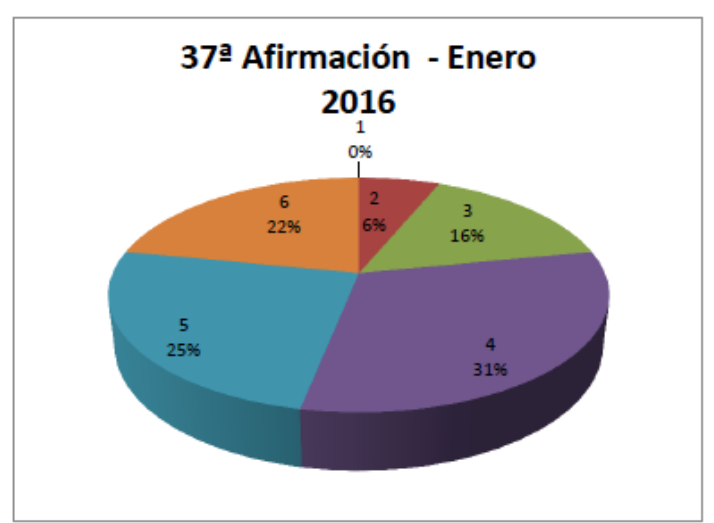

Y lo mismo se repite en este curso. Del $84 \%$ pasan al $88 \%$ al manifestarse de acuerdo con la afirmación. La homogeneidad es tal que se produce en los dos cursos, es decir, en las cuatro encuestas. Las cifras en todas ellas son tan parejas que casi podemos hablar de una forma de pensar asentada y sólida: si las cosas no salen es porque no se han estudiado bien. 
Trigésimo octava afirmación: Cuando fracaso o no consigo alcanzar los objetivos propuestos pienso que es porque no he estudiado de la manera adecuada.

\begin{tabular}{|c|c|c|c|c|c|}
\hline \multicolumn{6}{|c|}{38 AFIRMACIÓN } \\
\hline \multicolumn{3}{|c|}{ SEPTIEMBRE 2014 } & \multicolumn{3}{|c|}{ ENERO 2015 } \\
\hline Valor & $\begin{array}{c}\text { Total } \\
\text { valores }\end{array}$ & $\%$ & Valor & $\begin{array}{c}\text { Total } \\
\text { valores }\end{array}$ & $\%$ \\
\hline 1 & 1 & $2 \%$ & 1 & 0 & $0 \%$ \\
\hline 2 & 1 & $2 \%$ & 2 & 4 & $8 \%$ \\
\hline 3 & 5 & $9 \%$ & 3 & 2 & $4 \%$ \\
\hline 4 & 13 & $24 \%$ & 4 & 13 & $26 \%$ \\
\hline 5 & 23 & $42 \%$ & 5 & 19 & $38 \%$ \\
\hline 6 & 12 & $22 \%$ & 6 & 12 & $24 \%$ \\
\hline Total & 55 & $100 \%$ & Total & 50 & $100 \%$ \\
\hline
\end{tabular}

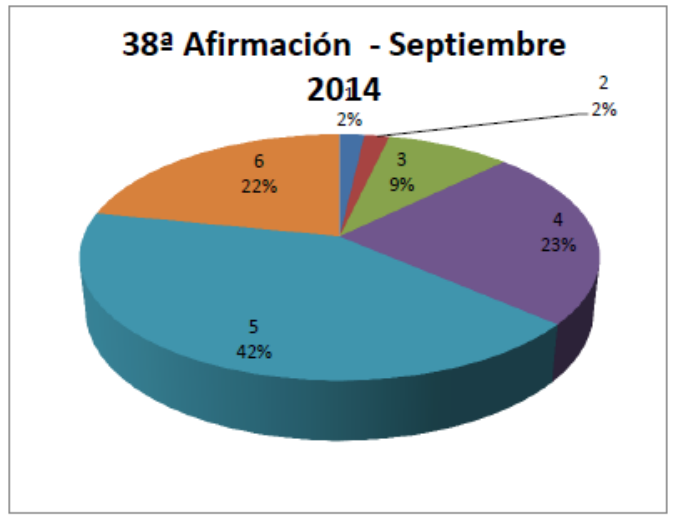

38a Afirmación: Cuando fracaso o no consigo alcanzar los objetivos propuestos pienso que es porque no he estudiado de la manera adecuada.

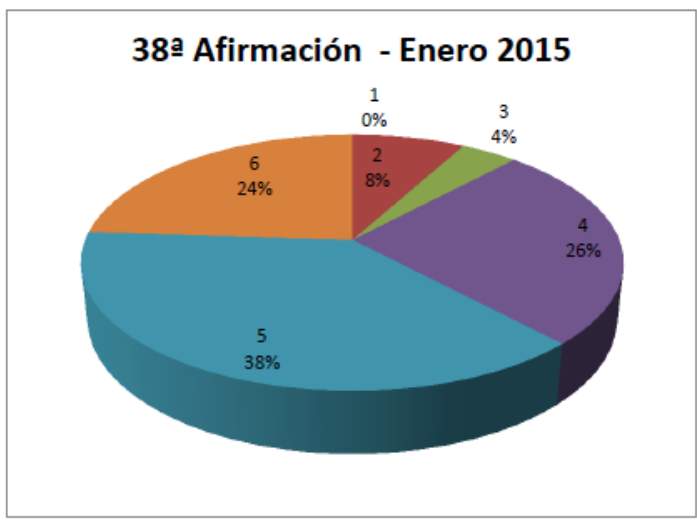

Lo mismo que pasaba con el hecho de no estudiar lo suficiente nos sucede con el estudiar de la manera adecuada. Por lo visto, no se trata sólo de estudiar bastante, sino de hacerlo bien Y esto lo tienen claro los alumnos. Sólo un $13 \%$ estaba en desacuerdo en la primera encuesta $(2 \%, 2 \%$ y $9 \%$ para "completamente de acuerdo", "de acuerdo" y "más bien de acuerdo") por un $12 \%$ de la segunda (0\%, $8 \%$ y 4\%, respectivamente). 


\begin{tabular}{|c|c|c|c|c|c|}
\hline \multicolumn{6}{|c|}{38 AFIRMACIÓN } \\
\hline \multicolumn{3}{|c|}{ SEPTIEMBRE 2015 } & \multicolumn{3}{|c|}{ ENERO 2016 } \\
\hline Valor & $\begin{array}{c}\text { Total } \\
\text { valores }\end{array}$ & $\%$ & Valor & $\begin{array}{c}\text { Total } \\
\text { valores }\end{array}$ & $\%$ \\
\hline 1 & 0 & $0 \%$ & 1 & 0 & $0 \%$ \\
\hline 2 & 4 & $13 \%$ & 2 & 0 & $0 \%$ \\
\hline 3 & 1 & $3 \%$ & 3 & 4 & $13 \%$ \\
\hline 4 & 9 & $28 \%$ & 4 & 7 & $22 \%$ \\
\hline 5 & 11 & $34 \%$ & 5 & 12 & $38 \%$ \\
\hline 6 & 7 & $22 \%$ & 6 & 9 & $28 \%$ \\
\hline Total & 32 & $100 \%$ & Total & 32 & $100 \%$ \\
\hline
\end{tabular}

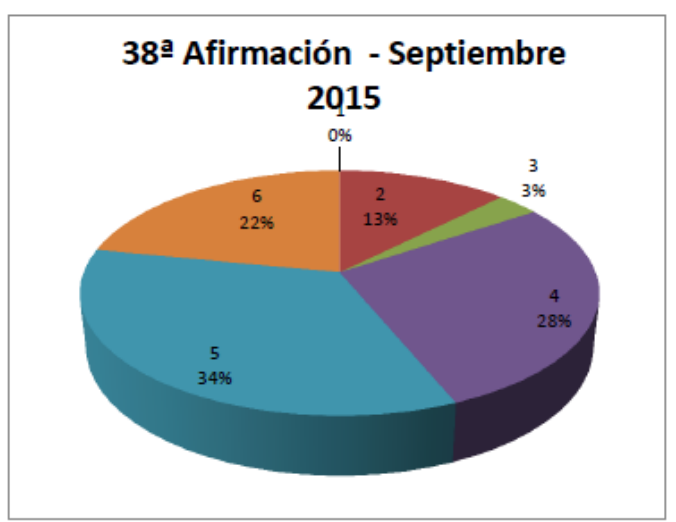

38a Afirmación: Cuando fracaso o no consigo alcanzar los objetivos propuestos pienso que es porque no he estudiado de la manera adecuada.

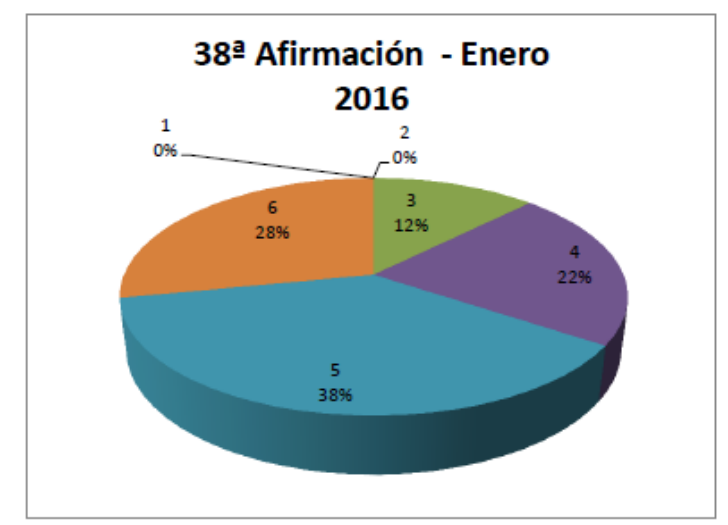

Más contundentes, si cabe, son los resultados de este segundo curso encuestado. Tanto en la primera como en la segunda encuesta un $0 \%$ estaba "completamente en desacuerdo con la afirmación". Y sólo el 16\% manifestaba algún grado de desacuerdo en la primera por un $13 \%$ de la segunda. La inmensa mayoría (84\% en la primera y $88 \%$ en la segunda) están de acuerdo en mayor o menor medida con que el fracaso viene de la mano de un estudio mal planteado. 
Trigésimo novena afirmación: Además de los objetivos que me marca mi profesor yo suelo marcarme mis propios objetivos individuales para cada curso

\begin{tabular}{|c|c|c|c|c|c|}
\hline \multicolumn{5}{|c|}{ 39a AFIRMACIÓN } \\
\hline \multicolumn{3}{|c|}{ SEPTIEMBRE 2014 } & \multicolumn{3}{|c|}{ ENERO 2015 } \\
\hline Valor & $\begin{array}{c}\text { Total } \\
\text { valores }\end{array}$ & $\%$ & Valor & $\begin{array}{c}\text { Total } \\
\text { valores }\end{array}$ & $\%$ \\
\hline 1 & 1 & $2 \%$ & 1 & 1 & $2 \%$ \\
\hline 2 & 4 & $7 \%$ & 2 & 1 & $2 \%$ \\
\hline 3 & 5 & $9 \%$ & 3 & 4 & $8 \%$ \\
\hline 4 & 12 & $22 \%$ & 4 & 7 & $14 \%$ \\
\hline 5 & 19 & $35 \%$ & 5 & 27 & $54 \%$ \\
\hline 6 & 14 & $25 \%$ & 6 & 10 & $20 \%$ \\
\hline Total & 55 & $100 \%$ & Total & 50 & $100 \%$ \\
\hline
\end{tabular}

39a Afirmación - Septiembre 2014

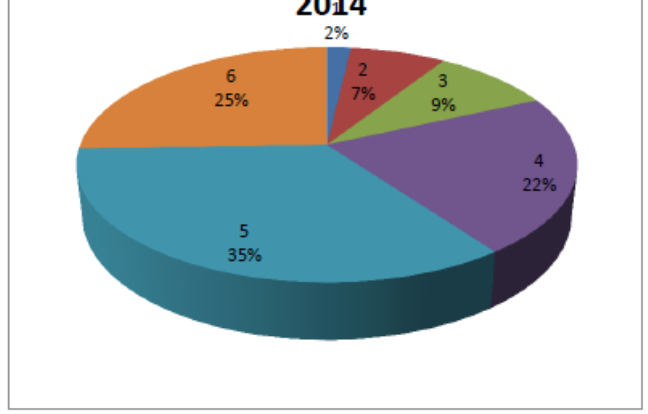

39ạ Afirmación: Además de los objetivos que me marca mi profesor yo suelo marcarme mis propios objetivos individuales para cada curso.

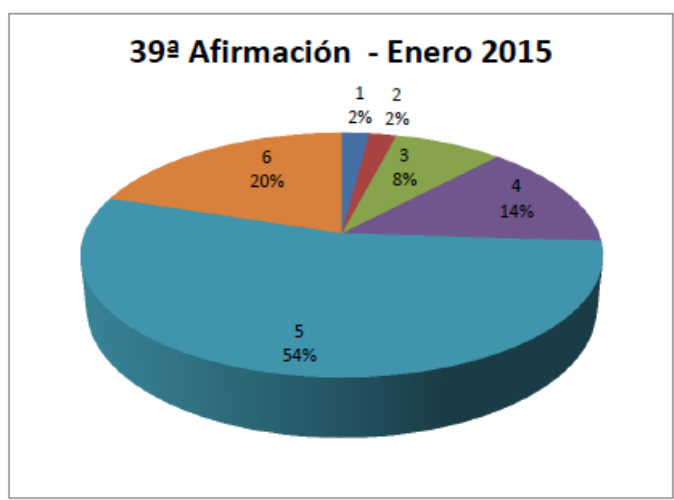

Nos congratula también ver el grado de independencia del alumnado, cuando está de acuerdo con esta afirmación, es decir, cuando afirma marcarse objetivos propios al principio del curso, independientemente de los que le pueda marcar su profesor. El $82 \%$ está de acuerdo en la primera encuesta (repartido de manera bastante homogénea entre los tres niveles establecidos: 22\%, 35\% y 25\% para "más bien de acuerdo", "de acuerdo" y "completamente de acuerdo"), algo que sube al $88 \%$ en la segunda (con valores de 14\%, 54\% y 20\%, respectivamente, es decir, menos homogéneos y apuntando a un mayor acuerdo). 


\begin{tabular}{|c|c|c|c|c|c|}
\hline \multicolumn{6}{|c|}{ 39 AFIRMACIÓN } \\
\hline \multicolumn{3}{|c|}{ SEPTIEMBRE 2015 } & \multicolumn{3}{|c|}{ ENERO 2016 } \\
\hline Valor & $\begin{array}{c}\text { Total } \\
\text { valores }\end{array}$ & $\%$ & Valor & $\begin{array}{c}\text { Total } \\
\text { valores }\end{array}$ & $\%$ \\
\hline 1 & 0 & $0 \%$ & 1 & 2 & $6 \%$ \\
\hline 2 & 2 & $6 \%$ & 2 & 0 & $0 \%$ \\
\hline 3 & 7 & $22 \%$ & 3 & 1 & $3 \%$ \\
\hline 4 & 8 & $25 \%$ & 4 & 11 & $34 \%$ \\
\hline 5 & 8 & $25 \%$ & 5 & 10 & $31 \%$ \\
\hline 6 & 7 & $22 \%$ & 6 & 8 & $25 \%$ \\
\hline Total & 32 & $100 \%$ & Total & 32 & $100 \%$ \\
\hline
\end{tabular}

39a Afirmación - Septiembre 2015

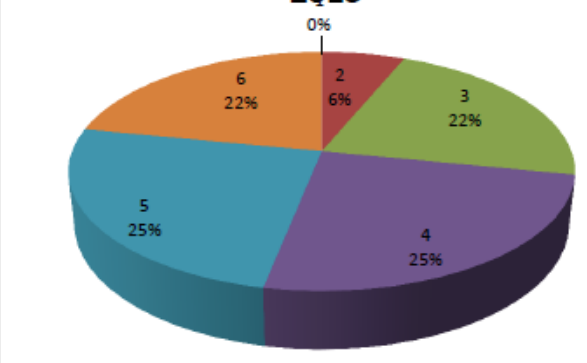

39a Afirmación: Además de los objetivos que me marca mi profesor yo suelo marcarme mis

propios objetivos individuales para cada curso.

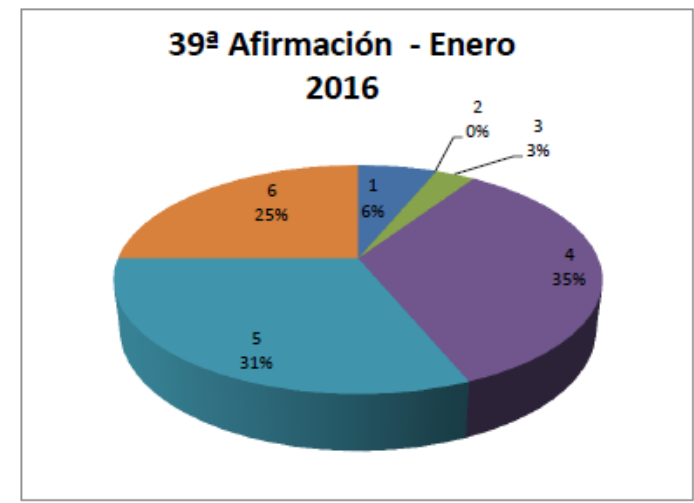

Lo mismo pasa en los resultados del segundo curso al que se encuestó. El $72 \%$ se manifestaba de acuerdo en el primer pase de la encuesta (con una homogeneidad entre los tres niveles casi asombrosa: $25 \%, 25 \%$ y $22 \%$ respectivamente), porcentaje que pasaba al 90\%, aunque manteniendo esa homogeneidad (34\%, 31\% y 25\%). Como vemos, se sigue pensando de manera mayoritaria que hay que marcarse objetivos propios (si bien nos es interesante apreciar esa subida que se manifiesta después de nuestra intervención). 


\subsubsection{Afirmaciones sobre el profesor}

Las cuestiones que vamos a analizar en las páginas que siguen nos van a servir para avalar la teoría, comentada en nuestra tesis, de que al profesor se le conoce con mucha rapidez, es decir, se tiene un acceso rápido a su realidad docente y se establece un juicio de valor claro y distinto casi en los primeros minutos. Y no sólo eso, sino que es difícil que esa apreciación cambie a lo largo del tiempo, salvo que ocurran cambios drásticos en la conducta del mismo. En el corto periodo de tiempo que pasó del primer test al segundo es prácticamente imposible que se produzca ningún cambio. Es más, el conocimiento de nuevas investigaciones sobre la excelencia musical (y lo que rodea a ésta) no tiene por qué menoscabar el papel del profesor ni la apreciación que el alumno tenga sobre aquél (Bain, 2004). Pero vayamos ya con las afirmaciones en cuestión:

Sexagésima afirmación: Mi profesor de instrumento me conoce bastante bien no sólo musicalmente sino también personalmente.

\begin{tabular}{|c|c|c|c|c|c|}
\hline \multicolumn{5}{|c|}{60 a AFIRMACIÓN } \\
\hline \multicolumn{3}{|c|}{ SEPTIEMBRE 2014 } & \multicolumn{3}{|c|}{ ENERO 2015 } \\
\hline Valor & $\begin{array}{c}\text { Total } \\
\text { valores }\end{array}$ & $\%$ & Valor & $\begin{array}{c}\text { Total } \\
\text { valores }\end{array}$ & $\%$ \\
\hline 1 & 2 & $4 \%$ & 1 & 2 & $4 \%$ \\
\hline 2 & 3 & $5 \%$ & 2 & 8 & $16 \%$ \\
\hline 3 & 11 & $20 \%$ & 3 & 4 & $8 \%$ \\
\hline 4 & 16 & $29 \%$ & 4 & 8 & $16 \%$ \\
\hline 5 & 9 & $16 \%$ & 5 & 19 & $38 \%$ \\
\hline 6 & 14 & $25 \%$ & 6 & 9 & $18 \%$ \\
\hline Total & 55 & $100 \%$ & Total & 50 & $100 \%$ \\
\hline
\end{tabular}

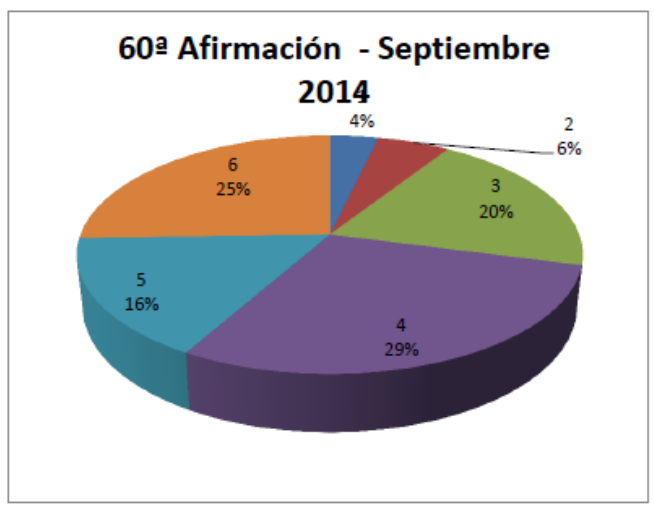

60ª Afirmación: Mi profesor de instrumento me conoce bastante bien no sólo musicalmente sino también personalmente.

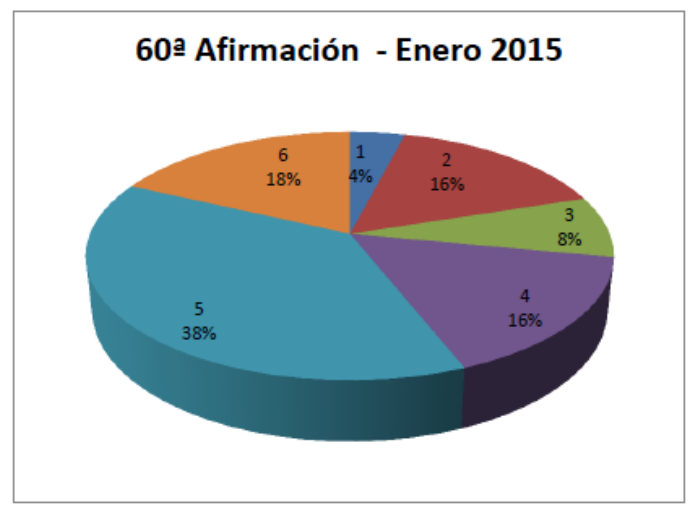

En esta comparativa se produce un fenómeno significativo. Si bien es cierto que cambian los porcentajes de todos los valores (salvo en el caso del "completamente en desacuerdo", que se mantiene en el $4 \%$ ), si consideramos en conjunto los valores que 
manifiestan acuerdo y los que manifiestan desacuerdo, entonces la variación es mínima. Los tres valores que expresan acuerdo pasan del 70\% al 72\%. Parece como si el trasvase de opiniones se produjera siempre entre los valores de la misma tendencia y estuviéramos hablando sólo de "matices".

\begin{tabular}{|c|c|c|c|c|c|}
\hline \multicolumn{5}{|c|}{60 AFIRMACIÓN } \\
\hline \multicolumn{3}{|c|}{ SEPTIEMBRE 2015 } & \multicolumn{3}{|c|}{ ENERO 2016 } \\
\hline Valor & $\begin{array}{c}\text { Total } \\
\text { valores }\end{array}$ & $\%$ & Valor & $\begin{array}{c}\text { Total } \\
\text { valores }\end{array}$ & $\%$ \\
\hline 1 & 0 & $0 \%$ & 1 & 1 & $3 \%$ \\
\hline 2 & 3 & $10 \%$ & 2 & 1 & $3 \%$ \\
\hline 3 & 4 & $13 \%$ & 3 & 4 & $13 \%$ \\
\hline 4 & 11 & $35 \%$ & 4 & 12 & $38 \%$ \\
\hline 5 & 10 & $32 \%$ & 5 & 13 & $41 \%$ \\
\hline 6 & 3 & $10 \%$ & 6 & 1 & $3 \%$ \\
\hline Total & 31 & $100 \%$ & Total & 32 & $100 \%$ \\
\hline
\end{tabular}

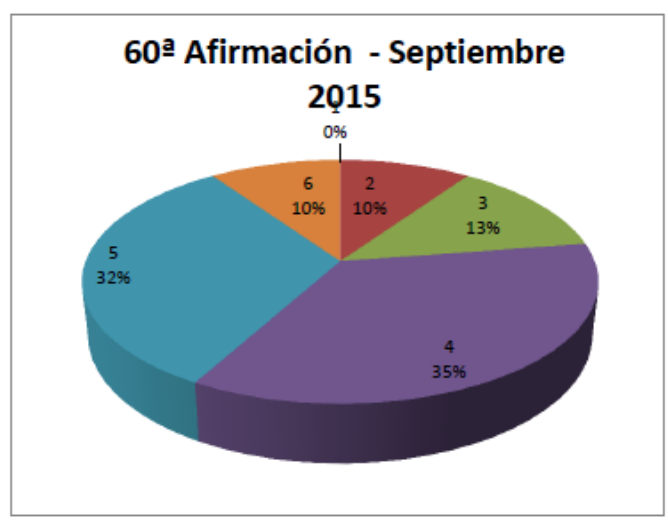

60aㅡ Afirmación: Mi profesor de instrumento me conoce bastante bien no sólo musicalmente sino también personalmente.

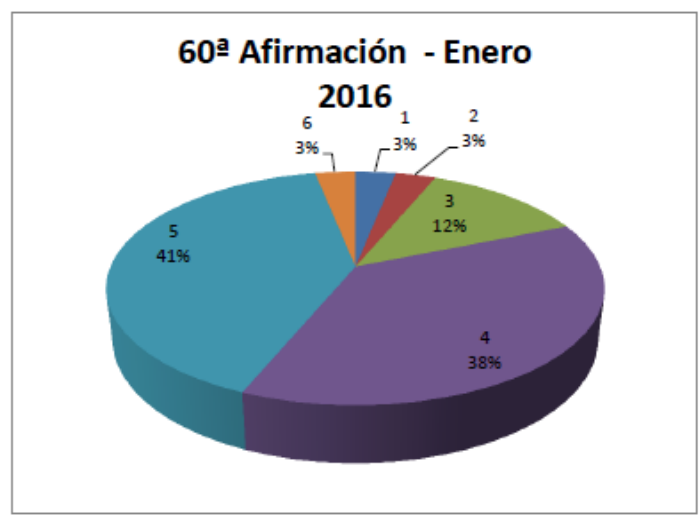

Lo que sucede en el curso siguiente es algo que sigue las mismas pautas que hemos comentado en el apartado anterior. Tomados uno por uno, hay variaciones en algunos de los valores al tiempo que otros se mantienen estables, pero si los tomamos en conjunto, entonces la variación es muy pequeña, como se desprende de las cifras: el acuerdo pasa del $77 \%$ al $82 \%$. 
Sexagésimo primera afirmación: Siento que mi profesor de instrumento me escucha.

\begin{tabular}{|c|c|c|c|c|c|}
\hline \multicolumn{5}{|c|}{61 a AFIRMACIÓN } \\
\hline \multicolumn{3}{|c|}{ SEPTIEMBRE 2014 } & \multicolumn{3}{|c|}{ ENERO 2015 } \\
\hline Valor & $\begin{array}{c}\text { Total } \\
\text { valores }\end{array}$ & $\%$ & Valor & $\begin{array}{c}\text { Total } \\
\text { valores }\end{array}$ & $\%$ \\
\hline 1 & 1 & $2 \%$ & 1 & 3 & $6 \%$ \\
\hline 2 & 4 & $0 \%$ & 2 & 3 & $6 \%$ \\
\hline 3 & 6 & $0 \%$ & 3 & 5 & $10 \%$ \\
\hline 4 & 13 & $0 \%$ & 4 & 6 & $12 \%$ \\
\hline 5 & 18 & $0 \%$ & 5 & 21 & $42 \%$ \\
\hline 6 & 13 & $0 \%$ & 6 & 12 & $24 \%$ \\
\hline Total & 55 & $0 \%$ & Total & 50 & $100 \%$ \\
\hline
\end{tabular}

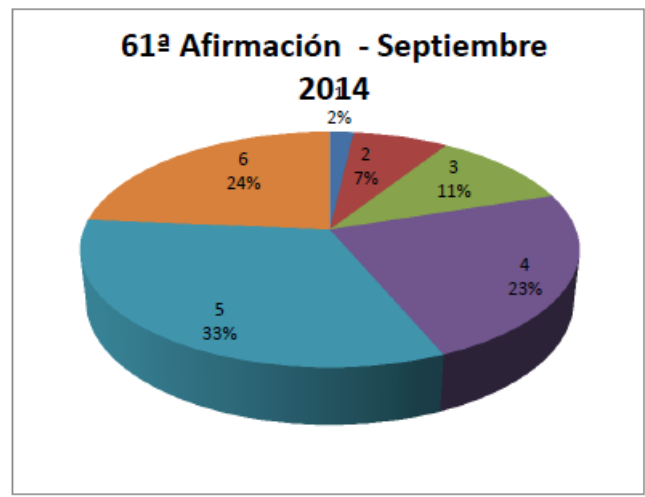

61a Afirmación: Siento que mi profesor de instrumento me escucha.

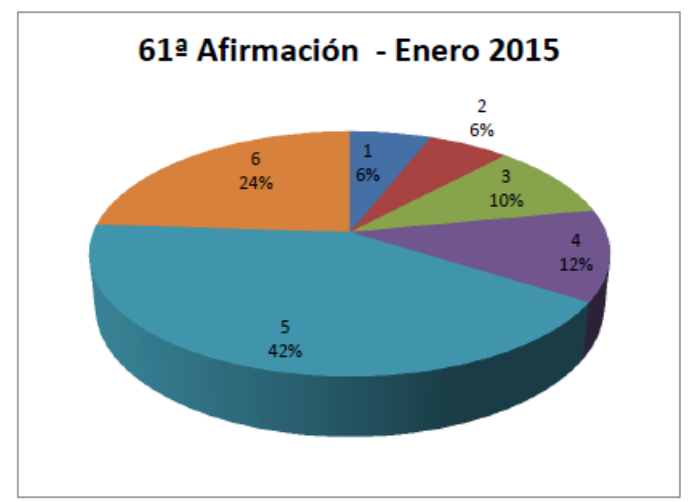

En el caso que nos ocupa, la variación es prácticamente inexistente en todos los niveles. Parece que no se cambia de opinión a este respecto tras conocer investigaciones de ningún tipo. Sólo el "más bien de acuerdo" cambia levemente del $23 \%$ al $12 \%$ y lo mismo sucede con el "de acuerdo", que sube del $33 \%$ al $42 \%$. Pero ese trasvase no afecta a la valoración general de acuerdo, que se mantiene estable: del $80 \%$ pasa al $78 \%$. 


\begin{tabular}{|c|c|c|c|c|c|}
\hline \multicolumn{5}{|c|}{61 IFIRMACIÓN } \\
\hline \multicolumn{3}{|c|}{ SEPTIEMBRE 2015 } & \multicolumn{3}{|c|}{ ENERO 2016 } \\
\hline Valor & $\begin{array}{c}\text { Total } \\
\text { valores }\end{array}$ & $\%$ & Valor & $\begin{array}{c}\text { Total } \\
\text { valores }\end{array}$ & $\%$ \\
\hline 1 & 0 & $0 \%$ & 1 & 0 & $0 \%$ \\
\hline 2 & 2 & $6 \%$ & 2 & 1 & $3 \%$ \\
\hline 3 & 5 & $16 \%$ & 3 & 7 & $22 \%$ \\
\hline 4 & 5 & $16 \%$ & 4 & 8 & $25 \%$ \\
\hline 5 & 12 & $39 \%$ & 5 & 10 & $31 \%$ \\
\hline 6 & 7 & $23 \%$ & 6 & 6 & $19 \%$ \\
\hline Total & 31 & $100 \%$ & Total & 32 & $100 \%$ \\
\hline
\end{tabular}

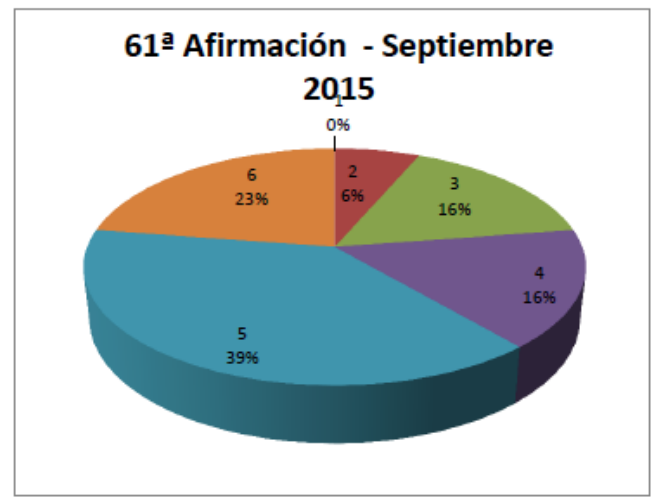

61a Afirmación: Siento que mi profesor de instrumento me escucha.

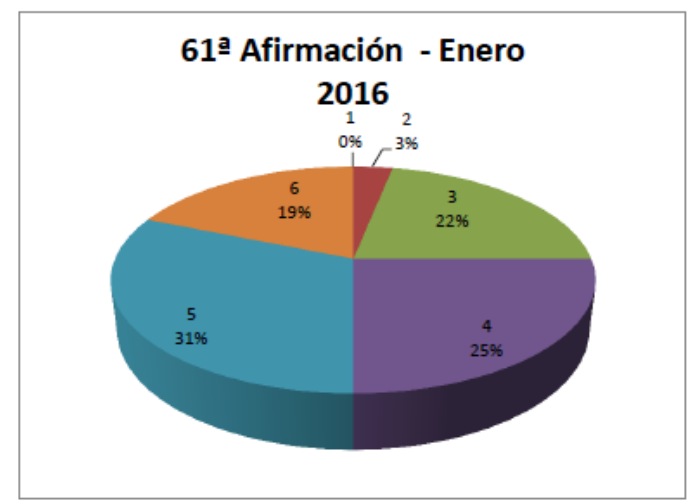

La estabilidad es mucho mayor en el curso siguiente, como se puede apreciar en las estadísticas. No existe ninguna variación significativa, que hace que la valoración de acuerdo respecto a la afirmación se mantenga estable y pase del $78 \%$ al $75 \%$. Es evidente que los alumnos se sienten escuchados por sus profesores de instrumento, lo que es realmente positivo de cara a una buena educación y a un buen aprendizaje. 
Sexagésimo segunda afirmación: Siento que mi profesor de instrumento me aprecia.

\begin{tabular}{|c|c|c|c|c|c|}
\hline \multicolumn{5}{|c|}{62 a AFIRMACIÓN } \\
\hline \multicolumn{3}{|c|}{ SEPTIEMBRE 2014 } & \multicolumn{3}{|c|}{ ENERO 2015 } \\
\hline Valor & $\begin{array}{c}\text { Total } \\
\text { valores }\end{array}$ & $\%$ & Valor & $\begin{array}{c}\text { Total } \\
\text { valores }\end{array}$ & $\%$ \\
\hline 1 & 0 & $0 \%$ & 1 & 2 & $4 \%$ \\
\hline 2 & 3 & $5 \%$ & 2 & 2 & $4 \%$ \\
\hline 3 & 6 & $11 \%$ & 3 & 4 & $8 \%$ \\
\hline 4 & 13 & $24 \%$ & 4 & 8 & $16 \%$ \\
\hline 5 & 21 & $38 \%$ & 5 & 22 & $44 \%$ \\
\hline 6 & 12 & $22 \%$ & 6 & 12 & $24 \%$ \\
\hline Total & 55 & $100 \%$ & Total & 50 & $100 \%$ \\
\hline
\end{tabular}

62a Afirmación: Siento que mi profesor de instrumento me aprecia.
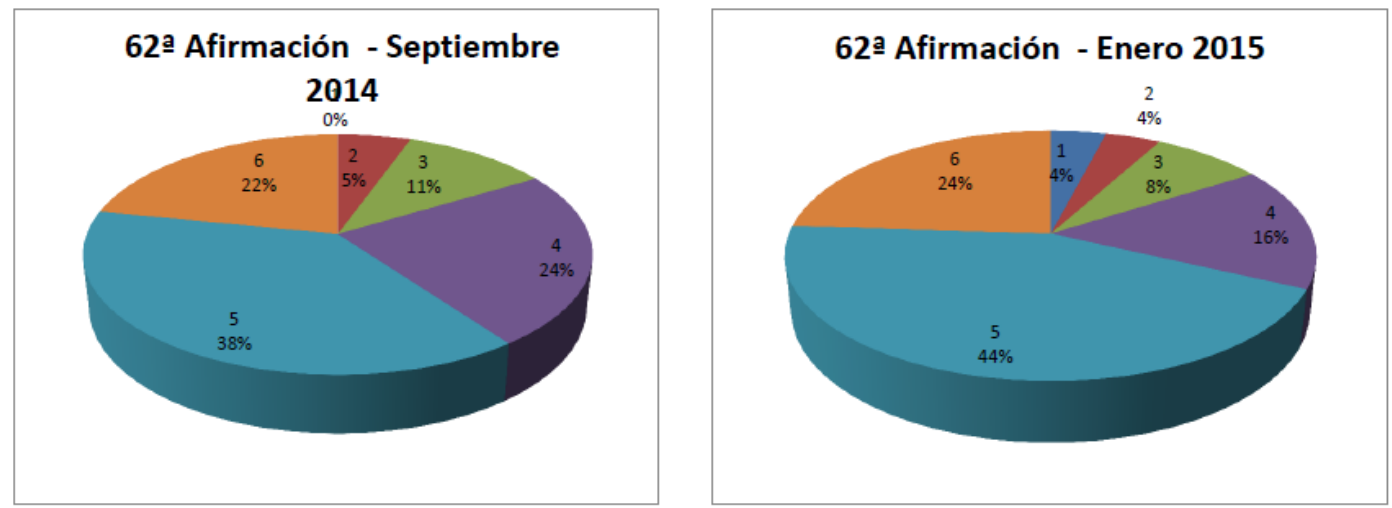

Y lo mismo podemos decir del aprecio que dicen sentir de sus profesores. Un $84 \%$ estaba de acuerdo con esta afirmación en el primer test, cifra que se mantuvo exactamente igual en el segundo, a pesar de que cada valor individual sí experimentase variaciones no demasiado importantes. Tal como estamos viendo, parece que se tratara más de cambio de matiz en la opinión que de cambio en la idea general. 


\begin{tabular}{|c|c|c|c|c|c|}
\hline \multicolumn{6}{|c|}{62 AFIRMACIÓN } \\
\hline \multicolumn{3}{|c|}{ SEPTIEMBRE 2015 } & \multicolumn{3}{|c|}{ ENERO 2016 } \\
\hline Valor & $\begin{array}{c}\text { Total } \\
\text { valores }\end{array}$ & $\%$ & Valor & $\begin{array}{c}\text { Total } \\
\text { valores }\end{array}$ & $\%$ \\
\hline 1 & 0 & $0 \%$ & 1 & 0 & $0 \%$ \\
\hline 2 & 1 & $3 \%$ & 2 & 2 & $6 \%$ \\
\hline 3 & 3 & $10 \%$ & 3 & 0 & $0 \%$ \\
\hline 4 & 7 & $23 \%$ & 4 & 9 & $29 \%$ \\
\hline 5 & 11 & $35 \%$ & 5 & 15 & $48 \%$ \\
\hline 6 & 9 & $29 \%$ & 6 & 5 & $16 \%$ \\
\hline Total & 31 & $100 \%$ & Total & 31 & $100 \%$ \\
\hline
\end{tabular}

62a Afirmación - Septiembre

$2 \mathrm{Q} 15$

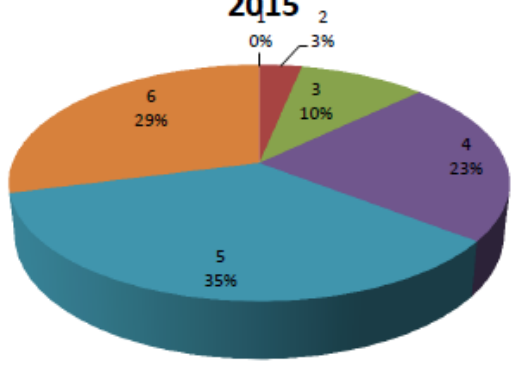

62ª Afirmación: Siento que mi profesor de instrumento me aprecia.

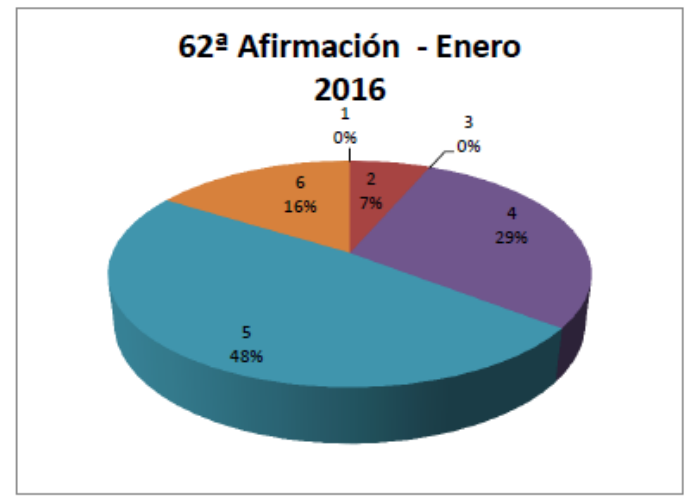

El gráfico muestra que hay una serie de cambios no demasiado importantes en la valoración de algunos valores (que curiosamente son de la misma proporción: un $13 \%$ sube el "de acuerdo" y un 13\% baja el "completamente de acuerdo", lo que parece confirmar la existencia de un trasvase de opinión de un sector a otro). Pero la suma de los valores que manifiestan acuerdo no ofrecen mucha diferencia: del $87 \%$ se sube al 93\%. Es evidente que los alumnos se sienten apreciados por sus profesores de instrumento, algo que nos congratula. 
Sexagésimo cuarta afirmación: Mi profesor de instrumento me da buena información, dando respuestas a las dudas que me surgen en cada momento.

\begin{tabular}{|c|c|c|c|c|c|}
\hline \multicolumn{5}{|c|}{$64^{2}$ AFIRMACIÓN } \\
\hline \multicolumn{3}{|c|}{ SEPTIEMBRE 2014 } & \multicolumn{3}{|c|}{ ENERO 2015 } \\
\hline Valor & $\begin{array}{c}\text { Total } \\
\text { valores }\end{array}$ & $\%$ & Valor & $\begin{array}{c}\text { Total } \\
\text { valores }\end{array}$ & $\%$ \\
\hline 1 & 0 & $0 \%$ & 1 & 0 & $0 \%$ \\
\hline 2 & 2 & $4 \%$ & 2 & 4 & $8 \%$ \\
\hline 3 & 6 & $11 \%$ & 3 & 5 & $10 \%$ \\
\hline 4 & 15 & $27 \%$ & 4 & 15 & $30 \%$ \\
\hline 5 & 20 & $36 \%$ & 5 & 18 & $36 \%$ \\
\hline 6 & 12 & $22 \%$ & 6 & 8 & $16 \%$ \\
\hline Total & 55 & $100 \%$ & Total & 50 & $100 \%$ \\
\hline
\end{tabular}

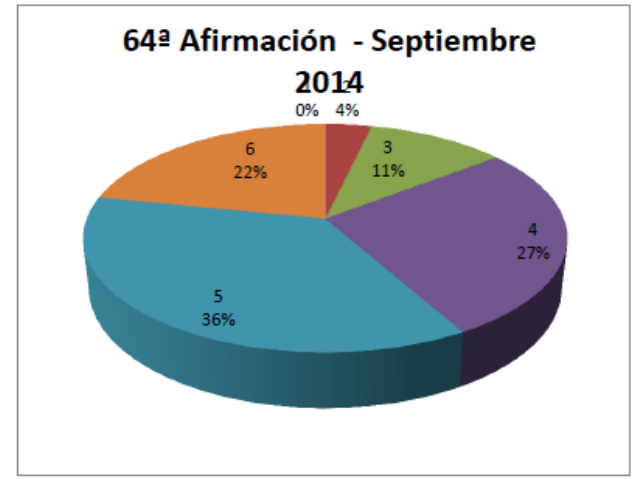

64a Afirmación: Mi profesor de instrumento me da buena información, dando respuestas a las dudas que me surgen en cada momento.

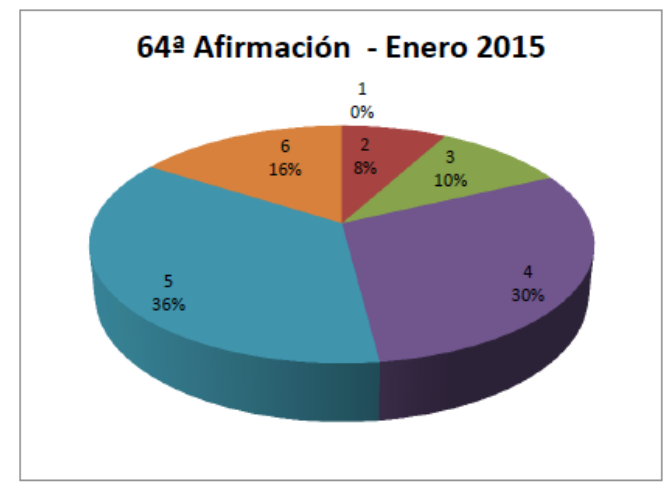

En el caso de la afirmación que nos ocupa, las variaciones son mínimas del primero al segundo test. Casi no cambia ninguno de los valores de acuerdo o desacuerdo, de manera que podemos decir que la influencia del trabajo realizado sobre este ítem es casi nula. Los alumnos están mayoritariamente de acuerdo con que el profesor les da buena información respecto a sus dudas. Si en el primer test el acuerdo global sumaba el $85 \%$, en el segundo fue del $82 \%$. Como decimos, apenas sin variación. 


\begin{tabular}{|c|c|c|c|c|c|}
\hline \multicolumn{6}{|c|}{$64^{2}$ AFIRMACIÓN } \\
\hline \multicolumn{3}{|c|}{ SEPTIEMBRE 2015 } & \multicolumn{3}{|c|}{ ENERO 2016 } \\
\hline Valor & $\begin{array}{c}\text { Total } \\
\text { valores }\end{array}$ & $\%$ & Valor & $\begin{array}{c}\text { Total } \\
\text { valores }\end{array}$ & $\%$ \\
\hline 1 & 1 & $3 \%$ & 1 & 1 & $3 \%$ \\
\hline 2 & 0 & $0 \%$ & 2 & 2 & $6 \%$ \\
\hline 3 & 4 & $13 \%$ & 3 & 4 & $13 \%$ \\
\hline 4 & 7 & $23 \%$ & 4 & 5 & $16 \%$ \\
\hline 5 & 10 & $32 \%$ & 5 & 10 & $32 \%$ \\
\hline 6 & 9 & $29 \%$ & 6 & 9 & $29 \%$ \\
\hline Total & 31 & $100 \%$ & Total & 31 & $100 \%$ \\
\hline
\end{tabular}

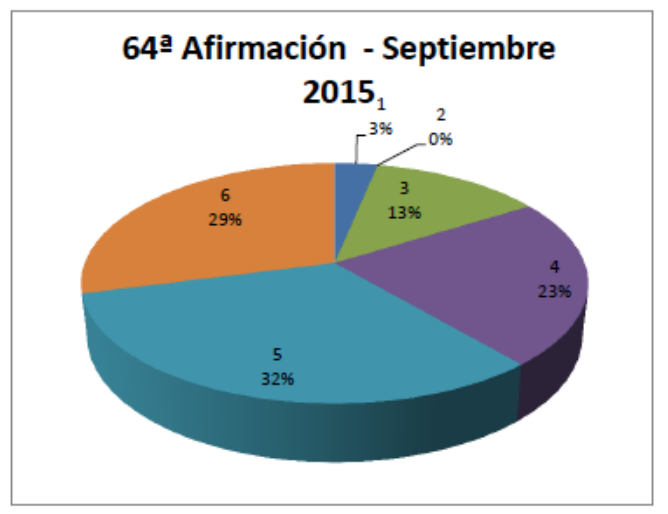

64a Afirmación: Mi profesor de instrumento me da buena información, dando respuestas a las dudas que me surgen en cada momento.

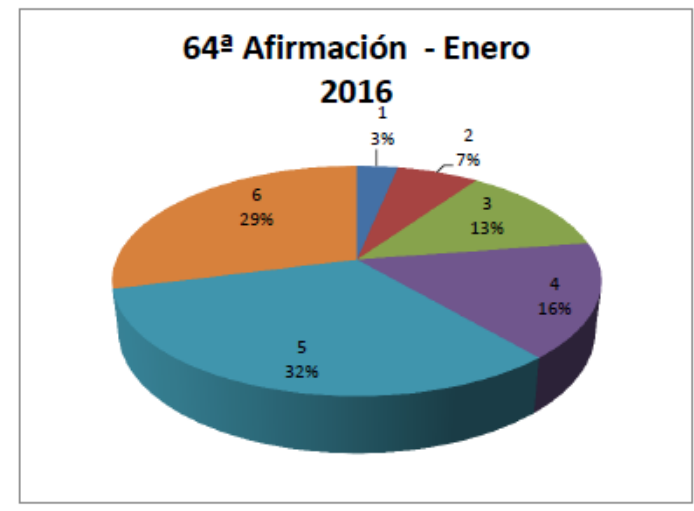

Pocas diferencias de nuevo, aunque con un poco más de variación, en este caso negativa. Del $84 \%$ de acuerdo global en el primer test se pasa al $77 \%$ en el segundo, un descenso que no es exagerado, pero que sí hay que reseñar, si bien los porcentajes que se manejan en cada una de los distintos niveles de acuerdo se mantienen casi estables en todos ellos. Sólo el "más bien de acuerdo" baja del 32\% al 16\%, que es exactamente la bajada del bloque general.

En definitiva, parece que la información que ofrece el profesor de instrumento sigue siendo importante, lo que nos parece muy interesante, ya que esta investigación no pretendía bajo ningún concepto servir de crítica al resto del profesorado, sino más bien hacer ver al alumnado que se pueden buscar vías alternativas de información, sin que por ello se deje a un lado la que ofrece su profesor. Y si echamos un vistazo a la afirmación $\mathrm{n}^{\mathrm{o}} 2$ (“conozco las últimas investigaciones sobre lo que debería ser la práctica instrumental") entenderemos lo que queremos decir, al comprobar cómo es precisamente una de la que más cambian, desde el desacuerdo global al acuerdo mayoritario en el segundo test. 


\subsubsection{Reflexión por parte de los alumnos sobre la realización de los dos cuestionarios.}

Nos parece también de enorme interés reflejar la comparativa que los propios alumnos hicieron de sus cuestionarios, es decir, revisar lo que habían sido sus opiniones en el primer test y analizarlas a la luz de o que habían respondido en el segundo. Como dijimos en su momento, éste también es un elemento importante en la investigación, dado que esta comparación que establece el alumnado les sirve de manera clara para reflexionar y aprender de sí mismos. Dicho de otro modo, el hecho de revisar sus opiniones iniciales tras conocer lo que dicen las investigaciones acerca de la excelencia musical, les permite profundizar en el conocimiento de sí mismos y en la profundización de lo que han aprendido durante del desarrollo de la investigación.

A través del siguiente análisis se muestra la reflexión realizada por los propios alumnos, comparando sus propias opiniones, antes y después de haber conocido lo que dicen las investigaciones, algo que nos sirve para comprobar de primera mano la influencia que ejerce el conocimiento de éstas sobre la propia autoconsciencia del alumnado y que debería revertir en la mejora de la excelencia.

Lo primero que llama poderosamente la atención es el efecto que tiene el trabajo realizado sobre la mejora y afianzamiento de la autoestima del alumnado. Como dice categóricamente un alumno:

Al trabajar con las investigaciones he tenido la oportunidad de escribir y reflexionar sobre mí mismo con respecto a mi práctica instrumental y musical en general. Esta reflexión me ha ayudado a conocerme mejor y ahora me siento un estudiante más activo que antes. Me veo más independiente, más seguro de mi mismo, con un estilo de hacer las cosas más propio y con los pies más en la tierra.

Una reflexión que coincide en esencia con la de otro alumno:

Lo que he cambiado es que me conozco más a mí mismo y le doy importancia a lo que me gusta y al estilo propio, he ganado seguridad y 
confianza en mí mismo, he mejorado mi capacidad de elegir y me he dado cuenta de habilidades y defectos que tengo.

Parece como si el sólo hecho de conocer y entender lo que las investigaciones dicen respecto a la forma en que se deben hacer las cosas para alcanzar la excelencia sirviera, por sí mismo, para afianzar la propia valía del individuo como músico. Da la impresión de que el alumnado camina con cierta incertidumbre a su paso por el conservatorio (quizá presionado por la exigencia de alcanzar esa excelencia de que tanto estamos hablando), y esa presión acabara por minar la confianza que tienen en su propio trabajo. Conocer, por ejemplo, los trabajos de Dweck sobre la mentalidad fija y en crecimiento, y trabajar sobre ella de manera activa les ha permitido precisamente perfeccionar su trabajo, al establecer la posibilidad de transitar de una a la otra. Un alumno lo expresaba de manera clara:

El conocer las investigaciones me ha hecho pensar en mi propio proceso de aprendizaje y reflexionar sobre cómo podía mejorar. Lo que más me ha gustado ha sido la idea de Carol Dweck y el cambio de mentalidad fija a mentalidad en crecimiento. Esto me ha cambiado en varios aspectos de mi vida como músico y como persona.

Es evidente la importancia que todos le dan a este hecho. Y cómo revierte en su formación y su rendimiento. Y es también interesante resaltar el hecho del poco tiempo transcurrido entre la realización de ambos test (apenas 4 meses), algo que no obsta para que el cambio se note de manera clara y distinta. Estos tres testimonios dan perfecta cuenta de esto que estamos comentando:

En general, a pesar de que haya pasado poco tiempo desde la anterior encuesta, creo que me conozco mejor a mí mismo. Tengo más herramientas para el futuro.

Comparando los dos test la gran diferencia entre lo que pensaba en septiembre y lo que pienso ahora es la seguridad de las respuestas, esto es, que tengo más claras mis opiniones que a principio de curso. De esta manera muchos " 4 " se han convertido en "5", algunos "5" en "6" $y$ "3" en " 2 ".

Creo que aunque no he cambiado de forma drástica sí que creo que 
ahora tengo las cosas más claras como por ejemplo a la hora de buscar un estilo propio no he cambiado pero ahora sí le doy más importancia que antes.

Como se ve, el afianzamiento de las posiciones y la percepción de uno mismo con mayor claridad es algo que se repite de manera recurrente. Pero podemos ir incluso más lejos en esta consideración de la mejoría personal y entrar en la idea de que se mejora también en el terreno técnico. Puede parecer obvio que tener una mayor autoestima debería redundar en una mejoría de la práctica musical, pero es reconfortante escucharlo decir con la descarnada sinceridad con la que lo hace esta alumna:

He cambiado la percepción que tenía sobre aprender una obra de memoria, pensaba que no era importante y que no podría hacerlo y he conseguido aprender de memoria una obra cuando antes me resultaba imposible.

Y lo mismo que esta alumna afirma haber sido capaz de cambiar su percepción sobre sí misma (hasta el punto de que ahora sí es capaz de aprenderse una obra de memoria, algo para lo que estaba bloqueada por completo), otro alumno habla de cómo ha experimentado un nuevo enfoque acerca de sus capacidades como músico, que tenía, en cierto modo, aletargadas:

Con la información recibida ha cambiado mi visión como futuro músico, ha aumentado mi creatividad, conozco lo que quiero, antes me proponía objetivos a corto plazo y ahora me propongo también objetivos a largo plazo.

Pero quizá los dos ejemplos más impactantes al respecto los tenemos en los testimonios de dos alumnas, que no sólo tienen ahora una visión más positiva de sí mismas, sino que han sido capaces de ir más allá, tal como podemos comprobar leyendo lo que dicen. La primera reconoce un cambio de opinión bastante drástico, que le ha permitido afianzar su trabajo y definirse como música:

Creo que esta vez me he ido más a los extremos que la otra vez y hay ciertos aspectos que han cambiado de forma considerable como que 
ahora intento planificar mis objetivos más a largo plazo. También un cambio importante es que ahora sí que creo que lo que toco me tiene que gustar y antes no lo consideraba tan importante. Ahora valoro muchísimo que mi profesor sepa cuáles son mis necesidades a la hora de aprender y quiero acabar los estudios oficiales para buscar un estilo propio

Y la segunda fue incluso más allá, llegando al extremo de "plantarse" ante la imposición de una obra que le quería endosar su profesora de cara al concierto fin de carrera:

Cuando mi profesora me quiso planificar el concierto de fin de carrera le dije que había una obra que no me gustaba y que no tenía intención de tocar, porque no me veía en esa tesitura. Y conseguí quitar esa obra, lo que ha ido en mi favor para hacer un mejor concierto. Pero lo que más me ha gustado es esa capacidad de defender mis ideas y enfrentarme (de una manera positiva) a mi profesora. Antes de esto no me hubiera siquiera atrevido a pensarlo.

El autoconocimiento y la mejora de la autoestima, como decimos, son dos constantes en los testimonios, como vemos. Y, en esa línea, lo que conlleva es una mejoría en la forma de trabajo, que se convierte en algo más eficaz y, de alguna manera, más cercano a la excelencia. Como dice escueta pero claramente un alumno:

Ahora soy más consciente de cómo puedo mejorar como músico. Valoro más las herramientas que pueden ayudarme a tener éxito como músico.

La palabra "eficacia" es usada de manera terminante por esta alumna, que apuntala con sus palabras lo que estamos queriendo decir:

Hay varias diferencias entre las respuestas del primer cuestionario y las de ahora, sobre todo en lo referente a mi forma de ver las cosas ahora y de cómo las veía al principio de curso ya que ahora lo veo todo de forma más positiva que antes. Vengo más contenta al conservatorio y me siento más a gusto y feliz conmigo misma porque tengo más claro lo que quiero y cómo conseguirlo. Valoro más mi trabajo y lo utilizo de forma eficaz. 
Otra forma de expresar esta misma idea es usando la palabra "productiva". El trabajo de alguien puede ser, en efecto, constante y, sin embargo, no ver resultados, lo que puede conducir a un desánimo que nunca es positivo. El testimonio de este alumno nos sirve para destacar esto, especialmente cuando, como es su caso, los resultados del test no han sido muy diferentes. Y, sin embargo, sí ve utilidad en las investigaciones realizadas, siquiera sea por la reflexión que le han obligado a llevar a cabo y el efecto de las lecturas sobre su estado de ánimo:

En general, los resultados son muy parecidos, pero se nota el efecto de alguna que otra lectura que hemos hecho este curso para ser más optimista y trabajar de forma más productiva.

Como vemos, las reflexiones del alumnado nos conducen por terrenos que son, de algún modo, los que venimos defendiendo a lo largo de esta tesis. Y el siguiente testimonio nos va a permitir enlazar dos ideas muy interesantes: la que han formulado estos alumnos acerca de la mejora en la ejecución de su trabajo y el aprendizaje informal, que es otro elemento que también apareció en los grupos de discusión. Este testimonio nos sirve para articular estos dos temas:

Al reflexionar sobre mi primer test y este segundo me he dado cuenta que soy más consciente de los puntos clave para mi desarrollo personal y profesional, tengo más identificados los aspectos a mejorar, lo que me motiva y me anima a seguir adelante y ha cambiado la visión de lo que es "ir a clase y aprender" (no ser máquinas que absorben información).

Así, junto a la identificación de sus "puntos clave para el desarrollo personal y profesional" (lo que ya hemos comentado de la autoestima y la eficacia) aparece aquí una idea que otros compañeros van a desarrollar también: la importancia de aprender de otra manera y no sólo como esponjas pasivas que absorben lo que los profesores les van soltando. Esta alumna lo explica de una manera muy explícita:

Tras reflexionar sobre lo aprendido tengo más claro cuáles son las claves para conseguir ser mejor músico y eso ayuda mucho a la hora del día a día. También he notado un cambio sobre el aprender de forma informal. Antes tenía situaciones de aprendizaje informal pero no era consciente del todo de lo que aprendía en ellas. 
Todos los alumnos del conservatorio, como bien indica esta alumna, viven constantemente situaciones de aprendizaje informal, sea en bandas, en grupos que ellos montan para trabajar, en grupos de estudio, etc., pero no eran conscientes de la validez que eso tenía. El hecho de conocer lo que las investigaciones dicen, esto es, que este tipo de aprendizaje es muy valioso, les hace poner en valor una serie de experiencias que mantenían, en algunos casos, incluso casi escondidas. Y más aún, este conocimiento enlaza con otro que es también fundamental a nuestro juicio, el de la importancia de trabajar el punto fuerte. Este alumno lo expresa de una manera tan clara como rotunda:

En general he mantenido bastantes aspectos lo que ha cambiado ha sido: más conocimiento y más ganas de aprender sobre investigaciones, más reforzar los puntos fuertes y no sólo trabajar lo que hay que mejorar, más importancia al trabajo en grupo, a escuchar a mis compañeros, lo que dicen de mí e integrar ese feedback, más importancia a tocar de memoria y componer y más relación con mi profesora y más confianza.

Esta opinión es casi un corolario de todo lo que ha ido apareciendo en las páginas anteriores: mejora de la autoestima, eficacia en el desarrollo musical, aprendizaje informal y colaborativo e importancia de trabajar el punto fuerte. Podríamos terminar perfectamente con este testimonio, pero no nos resistimos a citar otros dos ejemplos, que a nuestro juicio indican la dirección en que se debe trabajar en los conservatorios de música, y que también resumen perfectamente lo que hemos querido demostrar con nuestra tesis. El primero es de un alumno que tiene ahora mucho más claro lo que se debe hacer y cómo:

He definido mejor mis prioridades y estoy explorando mucho mi estilo propio. Conozco mejor mis puntos débiles y mis puntos fuertes y he conseguido aprender más de forma informal y sacar partido a situaciones informales.

Y el segundo es de una alumna que nos permite un cierre brillante, dado que vuelve a incidir en todos los aspectos citados, pero focalizando su idea de la eficacia en el conocimiento y desarrollo de sus puntos fuertes para poder trabajar eficazmente y, digámoslo nosotros, alcanzar la excelencia musical: 
Al comparar las respuestas que contesté el primer día con las que he contestado al repetir el test me he dado cuenta de que he ganado seguridad en mi misma. Antes me importaba mucho lo que los demás pensaran de mí, porque pensaba que tenía que demostrar algo siempre. Ahora no sólo doy importancia a mis puntos débiles, sino que soy consciente que también puedo reforzar mis habilidades y mis puntos fuertes.

\subsection{Resultados del cuestionario de profesores}

A todo lo expuesto anteriormente hay que añadir el otro cuestionario que aparecía en el proyecto inicial, esto es, el dirigido al profesorado. Para ello, se elaboró un cuestionario que compartía algunas preguntas con el del alumnado, para poder luego comparar de algún modo los datos extraídos. El siguiente cuestionario que se encuentra en el Anexo II, se les pasó a los profesores el día 1 de abril de 2015, coincidiendo con uno de los claustros ordinarios del Conservatorio Superior (como consta en acta en el aparto de "Ruegos y preguntas").

Igual que en el caso de los alumnos, se les informó de qué era lo que se pretendía con este test, y se garantizó tanto el anonimato como la confidencialidad de las respuestas. Debo decir que la respuesta de mis compañeros fue muy gratificante, ya que ninguno se negó a participar en el mismo, si bien las cifras finales de test recogidos informan de alguno de los asistentes no lo llegó a entregar: de 73 profesores que forman parte del claustro, 64 asistieron a dicha sesión, pero sólo obran en nuestro poder 54 test respondidos. En cuanto a las especialidades de los profesores, podemos señalar que dieciocho eran de Instrumento Clásico, cinco de Composición, cinco de Instrumento Jazz, cuatro de Musicología, tres de Pedagogía, seis optaron por la opción "Otros" y 15 no contestaron a la pregunta sobre su especialidad. 
Primera Afirmación: Sé cuáles son las habilidades, conocimientos y actitudes para tener éxito como músico.

1a Afirmación: Sé cuáles son las habilidades, conocimientos y actitudes necesarias para tener éxito como músico.

\begin{tabular}{|c|c|c|}
\hline \multicolumn{3}{|c|}{ 1a AFIRMACIÓN } \\
\hline Valor & $\begin{array}{c}\text { Total } \\
\text { valores }\end{array}$ & $\%$ \\
\hline 1 & 0 & $0,0 \%$ \\
\hline 2 & 2 & $3,6 \%$ \\
\hline 3 & 2 & $3,6 \%$ \\
\hline 4 & 17 & $30,4 \%$ \\
\hline 5 & 22 & $39,3 \%$ \\
\hline 6 & 11 & $19,6 \%$ \\
\hline n/c & 2 & $3,6 \%$ \\
\hline Total & 56 & $100,0 \%$ \\
\hline \multicolumn{3}{|c}{}
\end{tabular}

1a Afirmación - Cuestionario Profespres

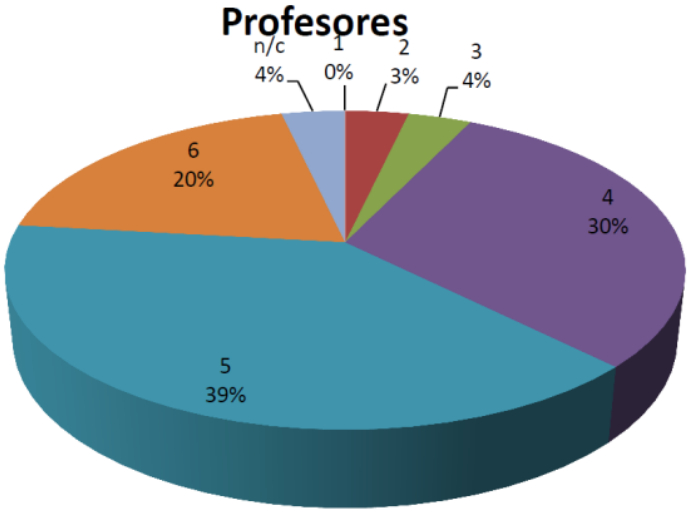

Como se puede apreciar en la gráfica con respecto a esta afirmación la mayoría de los profesores creen conocer las habilidades, conocimientos y actitudes que son necesarias para tener éxito como músicos. El 39,3\% de los profesores responde el valor cinco que corresponde a la expresión "de acuerdo". Si la comparamos con la opinión de los alumnos, podemos ver que este porcentaje es similar al que tienen los alumnos (es también la primera pregunta de su cuestionario) una vez que ha pasado el cuatrimestre de actuación con ellos (superior a la que tenían al inicio del estudio), es decir, que la seguridad que tienen los alumnos se iguala a la de los profesores tras cuatro meses de estudio de las investigaciones. 
Segunda afirmación: Conozco las últimas investigaciones sobre la excelencia musical y cómo trabajar para conseguirla

2a Afirmación: Conozco las últimas investigaciones sobre la excelencia musical y cómo trabajar para conseguirla.

\begin{tabular}{|c|c|c|}
\hline \multicolumn{3}{|c|}{ 2a AFIRMACIÓN } \\
\hline Valor & $\begin{array}{c}\text { Total } \\
\text { valores }\end{array}$ & $\%$ \\
\hline 1 & 2 & $3,6 \%$ \\
\hline 2 & 7 & $12,5 \%$ \\
\hline 3 & 13 & $23,2 \%$ \\
\hline 4 & 21 & $37,5 \%$ \\
\hline 5 & 10 & $17,9 \%$ \\
\hline 6 & 1 & $1,8 \%$ \\
\hline n/c & 2 & $3,6 \%$ \\
\hline Total & 56 & $100,0 \%$ \\
\hline
\end{tabular}

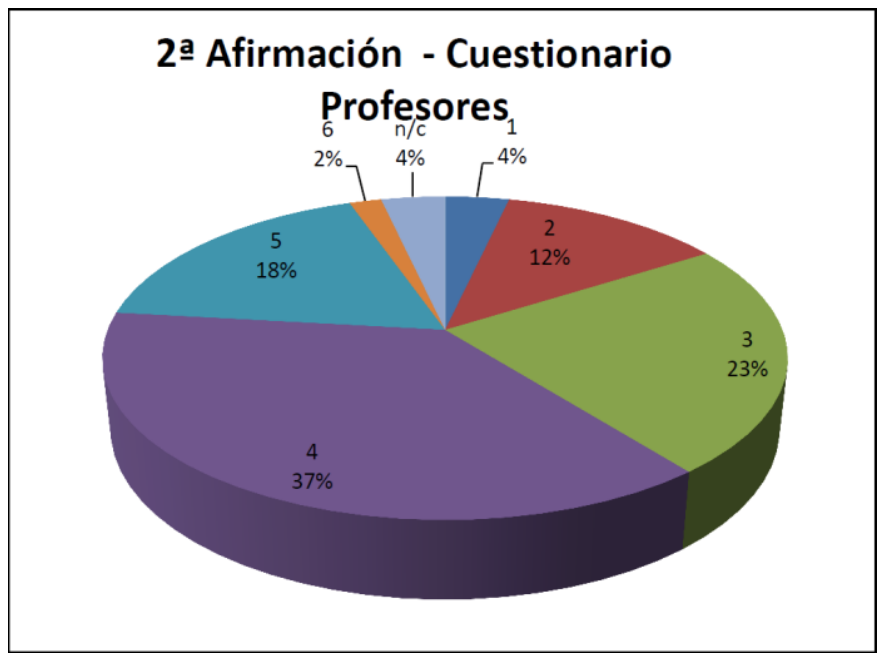

Esta segunda afirmación tiene una mayor diversidad de opiniones, situándose la mayoría en el nivel intermedio de la tabla. Se puede ver que la mayoría no se define de forma muy clara ya que un 37,5 \% elige la expresión "más bien de acuerdo" y un $23,2 \%$ elige la respuesta "más bien en desacuerdo. Es bastante evidente que si los profesores no están seguros con respecto a lo que dicen las últimas investigaciones sobre la excelencia musical y cómo trabajar para conseguirla sus alumnos tampoco lo estén. Y por eso, en el cuestionario de alumnos la afirmación: conozco las últimas investigaciones sobre la excelencia musical, era respondida con una amplia mayoría que no estaba de acuerdo con esta afirmación en distinto grado (en torno al $80 \%$ en los dos cursos académicos de nuestro estudio) al comenzar el curso. Sin embargo tras los cuatro meses de trabajo reconocen que conocen las últimas investigaciones contestando afirmativamente en algún grado en torno al $70 \%$. 
Tercera afirmación: Pienso que es interesante conocer las investigaciones sobre cómo trabajar para conseguir la excelencia musical.

3ạ Afirmación: Pienso que es interesante conocer las investigaciones sobre cómo trabajar para conseguir la excelencia musical.

\begin{tabular}{|c|c|c|}
\hline \multicolumn{3}{|c|}{ 32 AFIRMACIÓN } \\
\hline Valor & $\begin{array}{c}\text { Total } \\
\text { valores }\end{array}$ & $\%$ \\
\hline 1 & 0 & $0,0 \%$ \\
\hline 2 & 2 & $3,6 \%$ \\
\hline 3 & 5 & $8,9 \%$ \\
\hline 4 & 12 & $21,4 \%$ \\
\hline 5 & 17 & $30,4 \%$ \\
\hline 6 & 19 & $33,9 \%$ \\
\hline $\mathrm{n} / \mathrm{c}$ & 1 & $1,8 \%$ \\
\hline Total & 56 & $100,0 \%$ \\
\hline
\end{tabular}

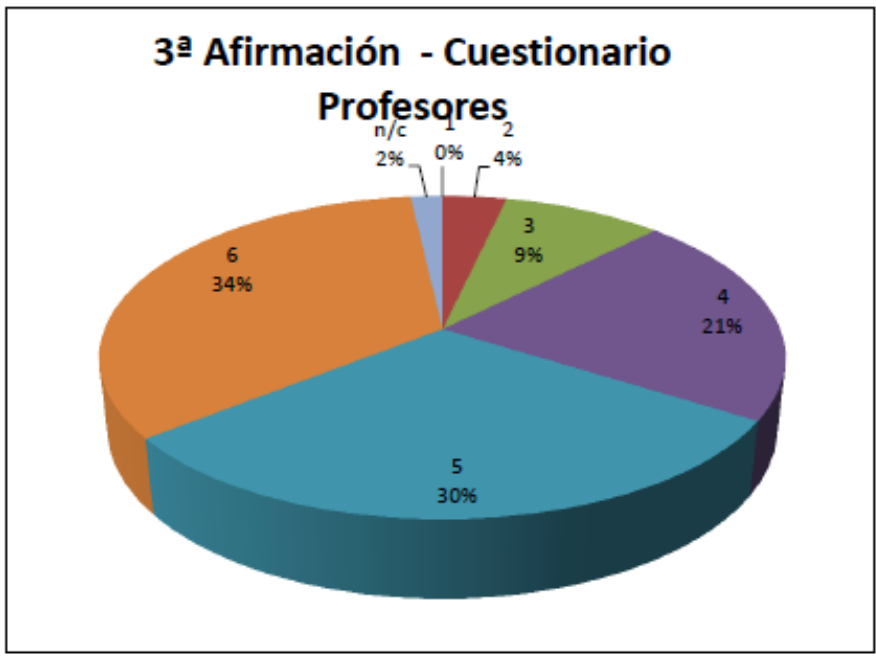

El resultado de la tercera afirmación muestra que una amplia mayoría está de acuerdo con esta afirmación, considerando interesante conocer las investigaciones sobre cómo trabajar para conseguir la excelencia musical y, sin embargo, hay un pequeño grupo que no lo considera interesante y también una persona que no se posiciona al respecto pues no contesta la pregunta. Que algunos profesores no consideren importante conocer las investigaciones sobre cómo trabajar para conseguir la excelencia musical nos trae a la cabeza las afirmaciones de Sloboda (2005 b). En este trabajo afirmaba que es fundamental demostrar los beneficios que las investigaciones aportan, como el factor más explícito para conseguir una mayor valoración del trabajo realizado en los conservatorios, tanto por parte de los músicos como de la sociedad en general. Como se puede observar, esto no es aun evidente para todos los profesores de la enseñanza superior. A la vista de esto, consideramos casi imprescindible este trabajo que se propone. 
Cuarta afirmación: Pienso que es interesante que mis alumnos conozcan las investigaciones sobre cómo trabajar para conseguir la excelencia musical.

4a Afirmación: Pienso que es interesante que mis alumnos conozcan las investigaciones sobre como trabajar para conseguir la excelencia musical.

\begin{tabular}{|c|c|c|}
\hline \multicolumn{3}{|c|}{ 4a AFIRMACIÓN } \\
\hline Valor & $\begin{array}{c}\text { Total } \\
\text { valores }\end{array}$ & $\%$ \\
\hline 1 & 0 & $0,0 \%$ \\
\hline 2 & 1 & $1,8 \%$ \\
\hline 3 & 4 & $7,1 \%$ \\
\hline 4 & 7 & $12,5 \%$ \\
\hline 5 & 21 & $37,5 \%$ \\
\hline 6 & 22 & $39,3 \%$ \\
\hline n/c & 1 & $1,8 \%$ \\
\hline Total & 56 & $100,0 \%$ \\
\hline
\end{tabular}

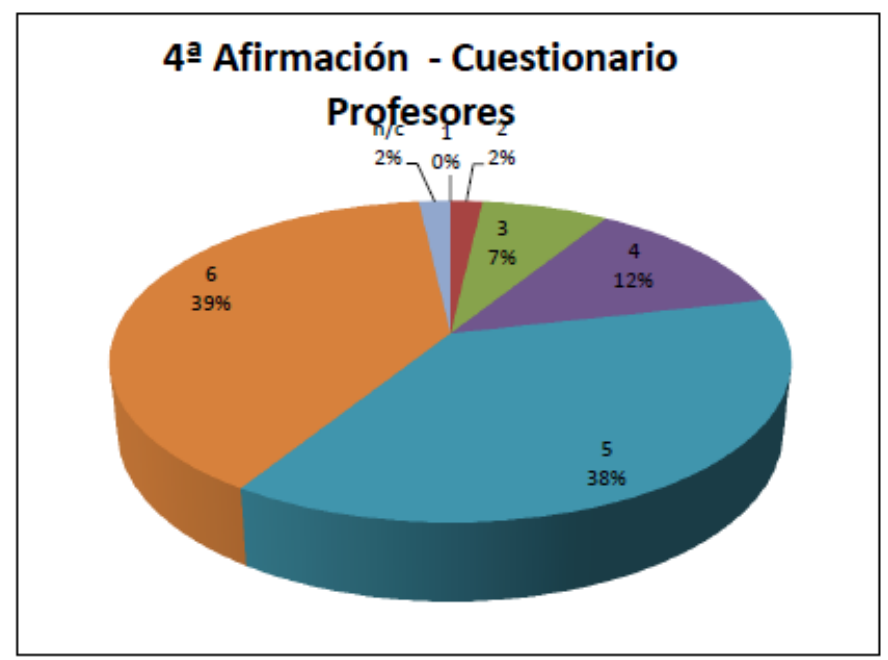

Como se puede apreciar, la inmensa mayoría del profesorado está de acuerdo con esta afirmación (cono no podía ser de otra manera). Más de las tres cuartas partes de los encuestados se sitúa entre el "completamente de acuerdo" y el "de acuerdo". Lo curioso es que sigue apareciendo ese pequeño grupo de profesores que se sigue manifestando "en desacuerdo" o "más bien en desacuerdo". 
Quinta afirmación: Sé cuáles son mis puntos fuertes como músico.

5a Afirmación: Sé cuáles son mis puntos fuertes como músico.

\begin{tabular}{|c|c|c|}
\hline \multicolumn{3}{|c|}{ 53 AFIRMACIÓN } \\
\hline Valor & $\begin{array}{c}\text { Total } \\
\text { valores }\end{array}$ & $\%$ \\
\hline 1 & 0 & $0,0 \%$ \\
\hline 2 & 0 & $0,0 \%$ \\
\hline 3 & 0 & $0,0 \%$ \\
\hline 4 & 10 & $17,9 \%$ \\
\hline 5 & 23 & $41,1 \%$ \\
\hline 6 & 22 & $39,3 \%$ \\
\hline $\mathrm{n} / \mathrm{c}$ & 1 & $1,8 \%$ \\
\hline Total & 56 & $100,0 \%$ \\
\hline
\end{tabular}

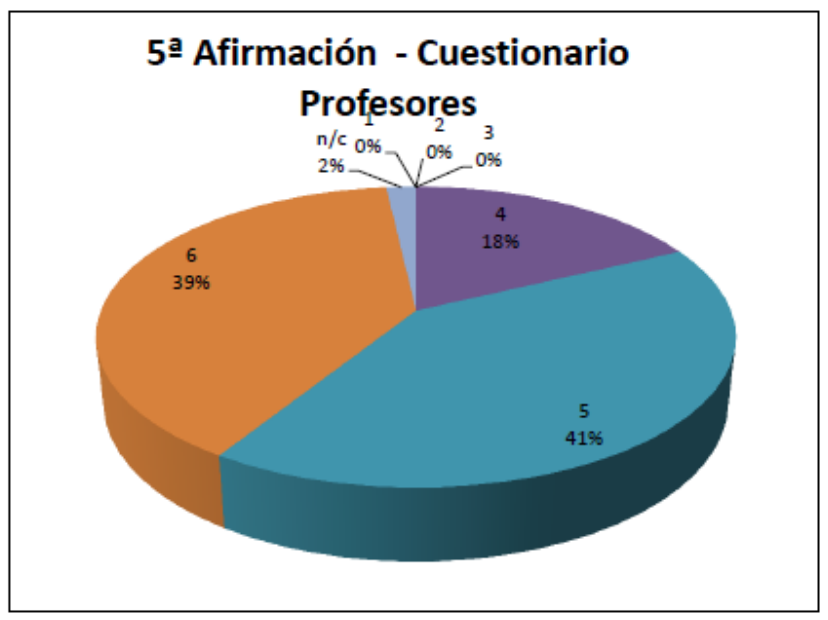

Está claro que los profesores saben cuáles son sus puntos fuertes como músicos. Nadie manifiesta el más mínimo desacuerdo y sólo un exiguo 17'8\% dice estar "más bien de acuerdo". Sólo las afirmaciones acerca de conocer los puntos fuertes y débiles como profesor (como veremos más adelante) superan a ésta en la rotundidad de la respuesta. 
6ạ Afirmación: No me importa reconocer mis puntos fuertes como músico.

\begin{tabular}{|c|c|c|}
\hline \multicolumn{3}{|c|}{ 6a AFIRMACIÓN } \\
\hline Valor & $\begin{array}{c}\text { Total } \\
\text { valores }\end{array}$ & $\%$ \\
\hline 1 & 0 & $0,0 \%$ \\
\hline 2 & 1 & $1,8 \%$ \\
\hline 3 & 4 & $7,1 \%$ \\
\hline 4 & 11 & $19,6 \%$ \\
\hline 5 & 23 & $41,1 \%$ \\
\hline 6 & 15 & $26,8 \%$ \\
\hline $\mathrm{n} / \mathrm{c}$ & 2 & $3,6 \%$ \\
\hline Total & 56 & $100,0 \%$ \\
\hline
\end{tabular}

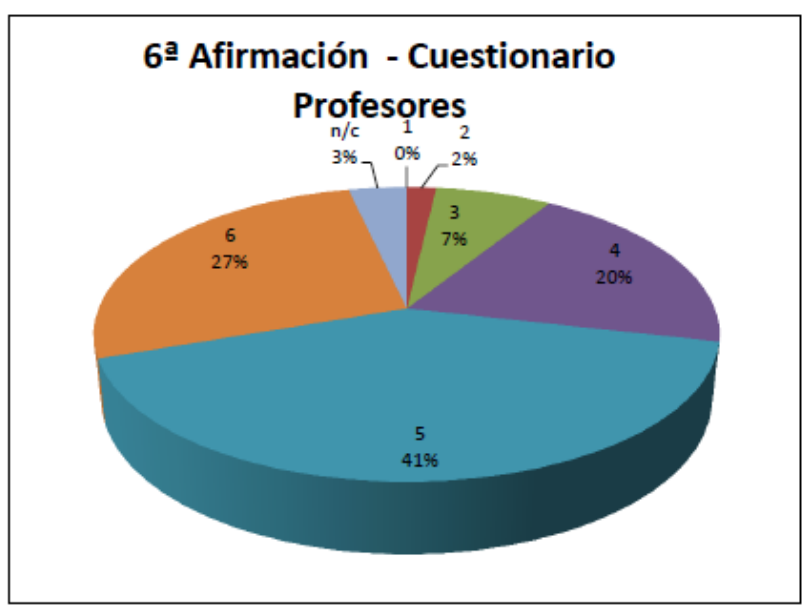

Los profesores tienen seguridad y afirman que en general no les importa reconocer sus puntos fuertes como músico, aunque sólo un 26,8\% lo manifiesta categóricamente. La mayoría (un 41'1\%) prefiere afirmarlo, pero sin llevarlo al extremo, si bien el cómputo general de acuerdo llega hasta el 87'5\%. Sin embargo, siempre existe ese pequeño grupo (que no tiene por qué ser siempre el mismo, lógicamente) que se manifiesta en desacuerdo o más bien en desacuerdo. Como hemos comentado en nuestro estudio, es posible que se deba a ese prurito de prepotencia que puede desprenderse de este tipo de afirmaciones acerca de lo que uno sabe hacer bien.

Es también interesante comparar la respuesta dada ante esta afirmación con la que emite el alumnado (séptima pregunta del cuestionario, en su caso). Como vimos, en un principio, éstos eran más reticentes a reconocer sus puntos fuertes (casi un tercio), algo que cambió luego para bajar a un exiguo 10\%. Parece que la práctica musical te empuja finalmente a admitir que los puntos fuertes son los importantes en tu carrera como músico y hay que reconocerlo como tal, al menos tras reflexionar sobre ello. 


\begin{tabular}{|c|c|c|}
\hline \multicolumn{3}{|c|}{ 72 AFIRMACIÓN } \\
\hline Valor & $\begin{array}{c}\text { Total } \\
\text { valores }\end{array}$ & $\%$ \\
\hline 1 & 0 & $0,0 \%$ \\
\hline 2 & 0 & $0,0 \%$ \\
\hline 3 & 0 & $0,0 \%$ \\
\hline 4 & 7 & $12,5 \%$ \\
\hline 5 & 29 & $51,8 \%$ \\
\hline 6 & 19 & $33,9 \%$ \\
\hline $\mathrm{n} / \mathrm{c}$ & 1 & $1,8 \%$ \\
\hline Total & 56 & $100,0 \%$ \\
\hline
\end{tabular}

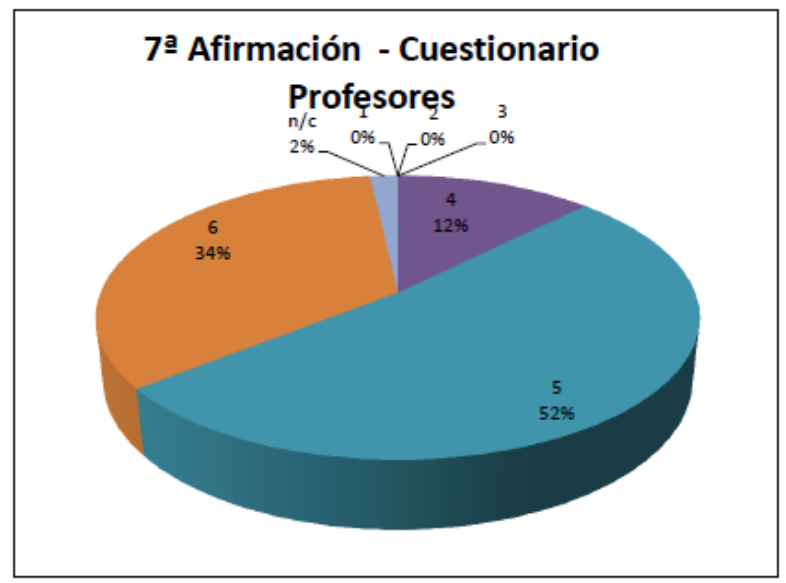

Es claro que todos los profesores creen saber cuáles son sus puntos fuertes como tales. Lo curioso, lo que llama la atención, es que parecen tener más claro cuáles son sus puntos fuertes como profesor que como músico, aunque las diferencias tampoco son exageradas. De todos modos, es interesante constatar que el $100 \%$ manifiesta algún tipo de acuerdo con esta afirmación, siendo mayoritario (51'8\%) los que están "de acuerdo" sin más. Pero nadie, igual que sucedía con su conocimiento de os puntos fuertes como músico, declara estar en desacuerdo con lo que aquí se pregunta. 


\begin{tabular}{|c|c|c|}
\hline \multicolumn{3}{|c|}{8 AFIRMACIÓN } \\
\hline Valor & $\begin{array}{c}\text { Total } \\
\text { valores }\end{array}$ & $\%$ \\
\hline 1 & 0 & $0,0 \%$ \\
\hline 2 & 0 & $0,0 \%$ \\
\hline 3 & 4 & $7,1 \%$ \\
\hline 4 & 12 & $21,4 \%$ \\
\hline 5 & 20 & $35,7 \%$ \\
\hline 6 & 20 & $35,7 \%$ \\
\hline $\mathrm{n} / \mathrm{c}$ & 0 & $0,0 \%$ \\
\hline Total & 56 & $100,0 \%$ \\
\hline
\end{tabular}

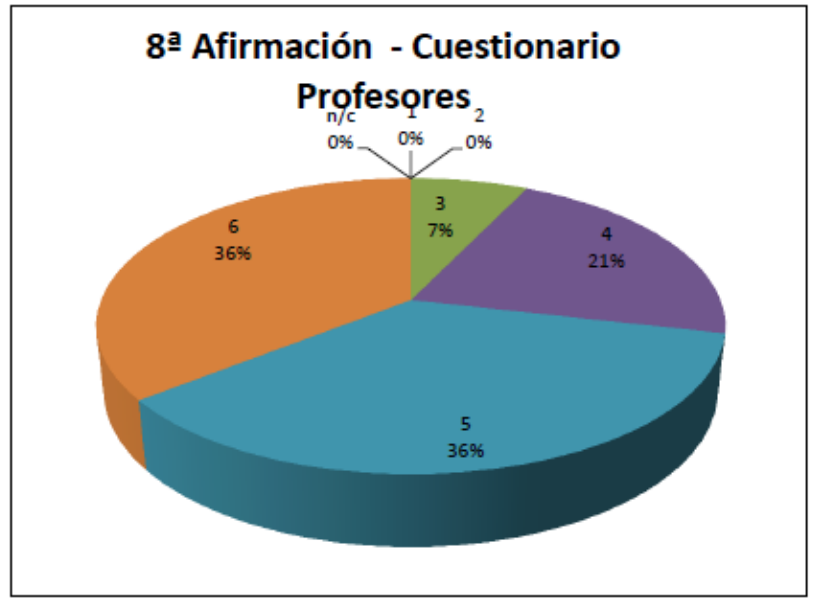

A la hora de reconocer esos puntos fuertes de que hablábamos en el apartado anterior, la cosa vuelve a manifestarse como cuando se hablaba de lo puntos fuertes como músico. Aunque la inmensa mayoría se muestra de acuerdo en mayor o menor grado (un 71'4\% repartido exactamente a medias entre el "completamente de acuerdo" y el "de acuerdo") hay unos pocos, concretamente el 7'1\%, que manifiestan esas dudas ("más bien en desacuerdo") al respecto. 


\begin{tabular}{|c|c|c|}
\hline \multicolumn{3}{|c|}{ 92 AFIRMACIÓN } \\
\hline Valor & $\begin{array}{c}\text { Total } \\
\text { valores }\end{array}$ & $\%$ \\
\hline 1 & 0 & $0,0 \%$ \\
\hline 2 & 0 & $0,0 \%$ \\
\hline 3 & 0 & $0,0 \%$ \\
\hline 4 & 8 & $14,3 \%$ \\
\hline 5 & 26 & $46,4 \%$ \\
\hline 6 & 22 & $39,3 \%$ \\
\hline n/c & 0 & $0,0 \%$ \\
\hline Total & 56 & $100,0 \%$ \\
\hline
\end{tabular}

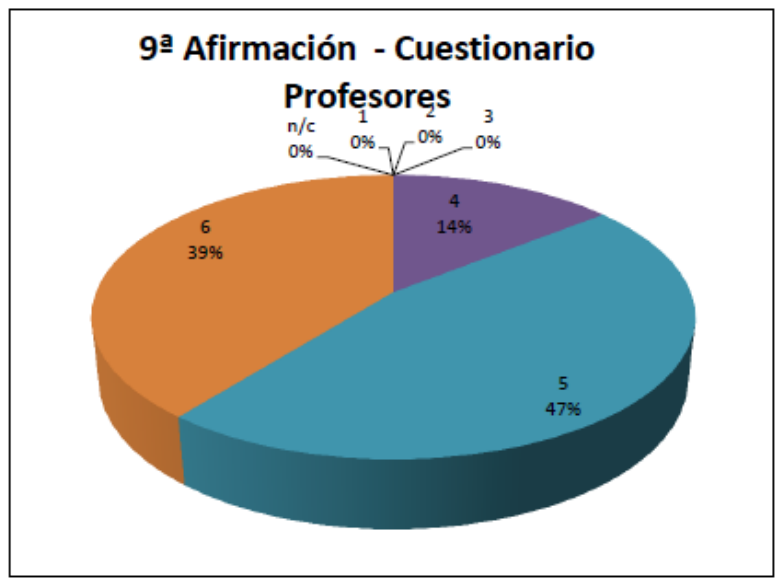

La respuesta a esta afirmación nos confirma cómo todos los músicos (incluso los que están trabajando como profesores) tienen claro cuáles son sus puntos débiles como músico. Se podría decir que, al igual que los alumnos, no hay dudas. De hecho, es la única pregunta que ninguno deja en blanco y en la que hay mayor presencia de acuerdo entre el profesorado, más incluso que entre la afirmación referida al punto fuerte como músico. Es más que posible que también a ellos se les haya "machacado con los puntos débiles", como decía uno de los alumnos en los grupos de discusión y, de esta manera, acaben haciendo lo mismo con sus alumnos ya que, como Sloboda (1987) dice, hay que estar muy atentos cuando enseñamos, porque podemos repetir las mismas prácticas erróneas que nosotros recibimos cuando éramos alumnos. De hecho, la proporción de acuerdo es la misma que manifiestan los alumnos: el 100\%. 
Décima afirmación: No me importa reconocer mis puntos débiles como músico.

10a Afirmación: No me importa reconocer mis puntos débiles como músico.

\begin{tabular}{|c|c|c|}
\hline \multicolumn{3}{|c|}{ 10ミ AFIRMACIÓN } \\
\hline Valor & $\begin{array}{c}\text { Total } \\
\text { valores }\end{array}$ & $\%$ \\
\hline 1 & 1 & $1,8 \%$ \\
\hline 2 & 1 & $1,8 \%$ \\
\hline 3 & 2 & $3,6 \%$ \\
\hline 4 & 11 & $19,6 \%$ \\
\hline 5 & 17 & $30,4 \%$ \\
\hline 6 & 24 & $42,9 \%$ \\
\hline n/c & 0 & $0,0 \%$ \\
\hline Total & 56 & $100,0 \%$ \\
\hline
\end{tabular}

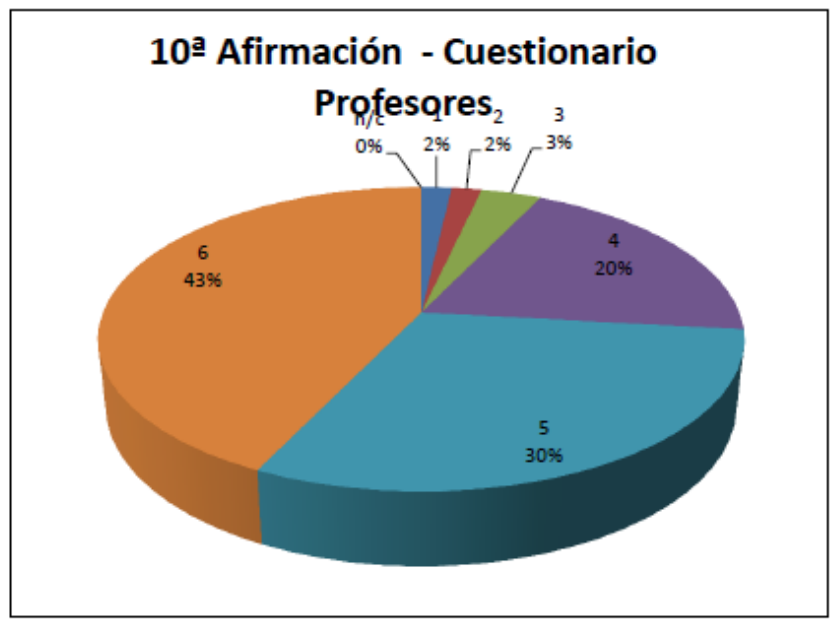

Aquí vemos que sigue apareciendo la misma idea de reconocer tranquilamente los puntos débiles, que son los que más se "machacan" durante los años de aprendizaje (que, no lo olvidemos, duran toda la vida). De todos modos, aquí el consenso no es tan absoluto. Hay 6'5\% que no está de acuerdo (en mayor o menor grado) con esta afirmación, es decir, que prefieren no reconocer abiertamente esos puntos débiles como músico. 


\begin{tabular}{|c|c|c|}
\hline \multicolumn{3}{|c|}{ 11 AFIRMACIÓN } \\
\hline Valor & $\begin{array}{c}\text { Total } \\
\text { valores }\end{array}$ & $\%$ \\
\hline 1 & 0 & $0,0 \%$ \\
\hline 2 & 0 & $0,0 \%$ \\
\hline 3 & 0 & $0,0 \%$ \\
\hline 4 & 7 & $12,5 \%$ \\
\hline 5 & 31 & $55,4 \%$ \\
\hline 6 & 18 & $32,1 \%$ \\
\hline $\mathrm{n} / \mathrm{c}$ & 0 & $0,0 \%$ \\
\hline Total & 56 & $100,0 \%$ \\
\hline
\end{tabular}

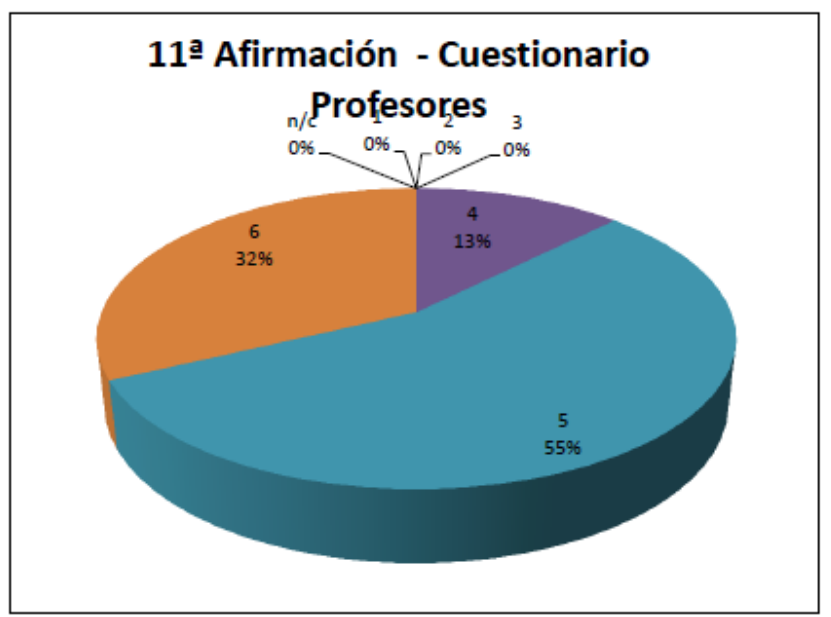

Nuevamente un acuerdo mayoritario entre el profesorado a la hora de saber cuáles son sus puntos débiles como tales. Nadie se manifiesta en desacuerdo con esta afirmación y la mayoría se posiciona en el grado "de acuerdo", con un 55'4\% de porcentaje. Parece que el profesorado es consciente de lo que les falta para convertirse en mejores profesores. Lo que se desprende de aquí es que tendrían que ponerse los medios para corregir esas debilidades, obviamente. 


\begin{tabular}{|c|c|c|}
\hline \multicolumn{3}{|c|}{ 12: AFIRMACIÓN } \\
\hline Valor & $\begin{array}{c}\text { Total } \\
\text { valores }\end{array}$ & $\%$ \\
\hline 1 & 0 & $0,0 \%$ \\
\hline 2 & 2 & $3,6 \%$ \\
\hline 3 & 2 & $3,6 \%$ \\
\hline 4 & 11 & $19,6 \%$ \\
\hline 5 & 20 & $35,7 \%$ \\
\hline 6 & 20 & $35,7 \%$ \\
\hline $\mathrm{n} / \mathrm{c}$ & 1 & $1,8 \%$ \\
\hline Total & 56 & $100,0 \%$ \\
\hline
\end{tabular}

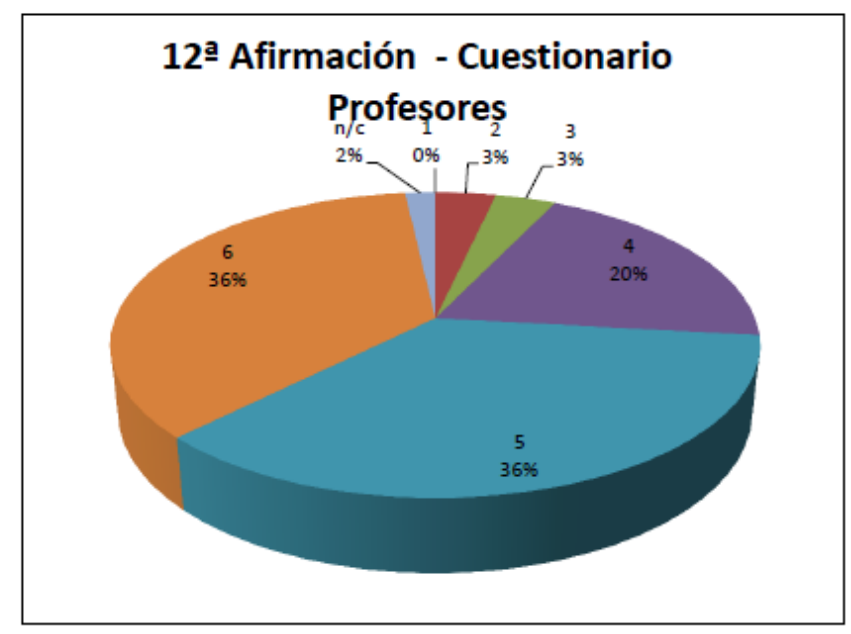

Saber cuáles son los puntos débiles es una cosa, pero reconocerlo es ya otra. Aun así, tres cuartas partes (nuevamente el $764 \%$ repartido a partes iguales entre el "de acuerdo" y el "completamente de acuerdo") no parecen mostrar ningún temor a reconocer esos puntos débiles en su labor docente (esperemos que, del mismo modo, se afanen en corregirlos). Pero, como decimos, existe ese pequeño grupo (el 7'6\%) que no está de acuerdo con la afirmación y prefiere no reconocerlo. En el fondo, como ya hemos dicho anteriormente, es algo que no importa, siempre y cuando se dedique uno a superar ese punto débil de alguna manera. 
Decimotercera afirmación: Me parece importante que mis alumnos sepan reconocer sus puntos débiles y sus puntos fuertes.

13a Afirmación: Me parece importante que mis alumnos sepan reconocer sus puntos débiles y sus puntos fuertes.

\begin{tabular}{|c|c|c|}
\hline \multicolumn{3}{|c|}{ 13æ AFIRMACIÓN } \\
\hline Valor & $\begin{array}{c}\text { Total } \\
\text { valores }\end{array}$ & $\%$ \\
\hline 1 & 0 & $0,0 \%$ \\
\hline 2 & 0 & $0,0 \%$ \\
\hline 3 & 0 & $0,0 \%$ \\
\hline 4 & 7 & $12,5 \%$ \\
\hline 5 & 16 & $28,6 \%$ \\
\hline 6 & 32 & $57,1 \%$ \\
\hline $\mathrm{n} / \mathrm{c}$ & 1 & $1,8 \%$ \\
\hline Total & 56 & $100,0 \%$ \\
\hline
\end{tabular}

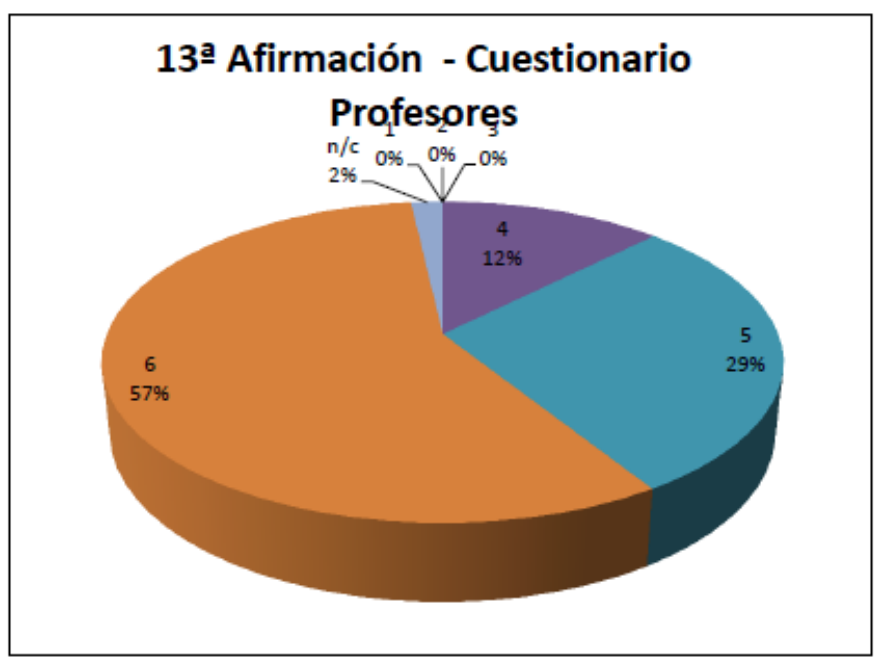

Otra afirmación que se responde de manera casi categórica. Más de la mitad (concretamente el 57'1\%) se manifiesta "completamente de acuerdo" con lo que aquí se plantea. Y, nuevamente, nadie está en desacuerdo con que los alumnos sepan reconocer sus puntos fuertes y débiles. Confiamos en que se siga en esta línea y el profesorado de instrumento valore tanto el reconocimiento de los puntos fuertes como el de los débiles y se trabajen ambos en la misma medida. 
Decimocuarta afirmación: Creo que trabajar con otros músicos me ayuda a desarrollarme como músico

14a Afirmación: Creo que trabajar con otros músicos me ayuda a desarrollarme como músico.

\begin{tabular}{|c|c|c|}
\hline \multicolumn{3}{|c|}{ 14? AFIRMACIÓN } \\
\hline Valor & $\begin{array}{c}\text { Total } \\
\text { valores }\end{array}$ & $\%$ \\
\hline 1 & 0 & $0,0 \%$ \\
\hline 2 & 0 & $0,0 \%$ \\
\hline 3 & 1 & $1,8 \%$ \\
\hline 4 & 1 & $1,8 \%$ \\
\hline 5 & 10 & $17,9 \%$ \\
\hline 6 & 43 & $76,8 \%$ \\
\hline $\mathrm{n} / \mathrm{c}$ & 1 & $1,8 \%$ \\
\hline Total & 56 & $100,0 \%$ \\
\hline
\end{tabular}

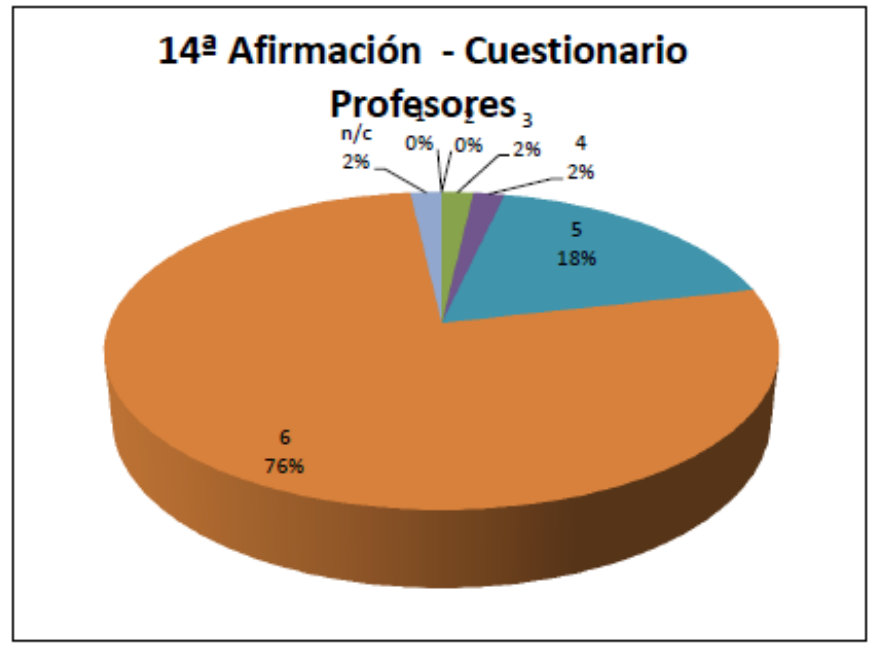

Lo que más nos sorprende aquí no es ese estruendoso 76'8\% que manifiesta estar "completamente de acuerdo" con esta afirmación, sino que haya alguien que pueda estar en desacuerdo (aunque sea "más bien en...") con lo que se plantea. De todos modos, un $94^{\prime} 7 \%$ en acuerdo o completamente de acuerdo es más que significativo acerca de la importancia que los profesores conceden al hecho de trabajar con otros músicos para desarrollar su propia labor musical. Es decir, a priori existe un claro acuerdo acerca de la importancia del trabajo colaborativo entre músicos, tal como hemos venido señalando a lo largo de nuestra investigación. 
Decimoquinta afirmación: Aunque creo que es importante trabajar con otros músicos ahora estoy más centrado en trabajar solo.

15a Afirmación: Aunque creo que es importante trabajar con otros músicos ahora estoy más centrado en trabajar solo.

\begin{tabular}{|c|c|c|}
\hline \multicolumn{3}{|c|}{ 15? AfIRMACIÓN } \\
\hline Valor & $\begin{array}{c}\text { Total } \\
\text { valores }\end{array}$ & $\%$ \\
\hline 1 & 6 & $10,7 \%$ \\
\hline 2 & 13 & $23,2 \%$ \\
\hline 3 & 12 & $21,4 \%$ \\
\hline 4 & 7 & $12,5 \%$ \\
\hline 5 & 9 & $16,1 \%$ \\
\hline 6 & 6 & $10,7 \%$ \\
\hline $\mathrm{n} / \mathrm{c}$ & 3 & $5,4 \%$ \\
\hline Total & 56 & $100,0 \%$ \\
\hline
\end{tabular}

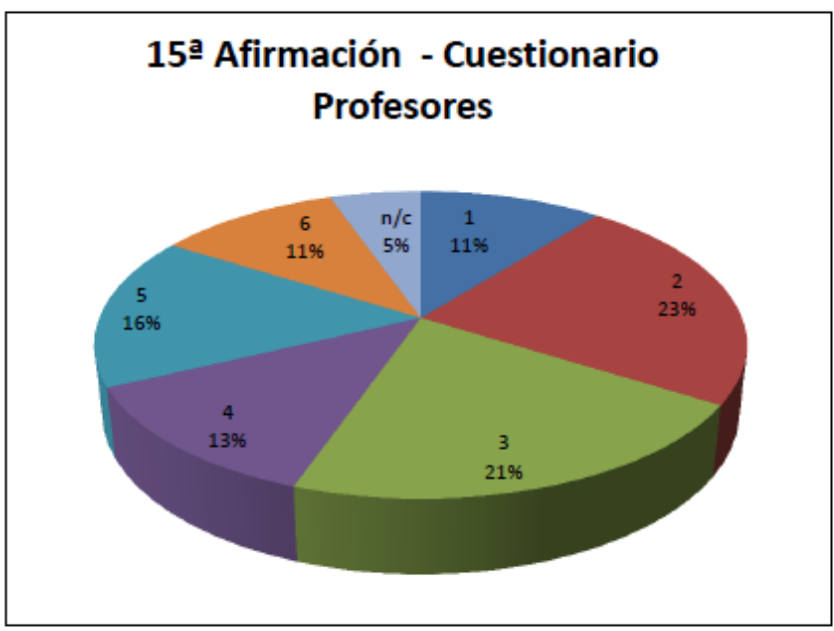

Disparidad absoluta. No podemos encontrar aquí un patrón que nos guíe a la hora de interpretar las respuestas a esta afirmación. Parece que la mayoría está en desacuerdo (en mayor o menor grado) con lo que se dice. En total, un 55'3\% manifestaban esta postura contraria, repartidos de manera bastante equitativa entre las tres opciones, es decir, que no parecen estar centrados en el trabajo individual. Pero no hay que dejar de lado ese 44 '7\% que está de acuerdo (y repartido de manera aún más equitativa entre los tres grados de acuerdo) con que ahora está más centrado en su propio trabajo personal. En resumen, una amplia gama de posiciones personales acerca del trabajo colaborativo en el momento actual. 
Decimosexta afirmación: Creo que trabajar en colaboración con otros profesores me ayuda a ser mejor profesor.

16a Afirmación: Creo que trabajar en colaboración con otros profesores me ayuda a ser mejor profesor.

\begin{tabular}{|c|c|c|}
\hline \multicolumn{3}{|c|}{16 AFIRMACIÓN } \\
\hline Valor & $\begin{array}{c}\text { Total } \\
\text { valore }\end{array}$ & $\%$ \\
\hline 1 & 0 & $0,0 \%$ \\
\hline 2 & 1 & $1,8 \%$ \\
\hline 3 & 2 & $3,6 \%$ \\
\hline 4 & 4 & $7,1 \%$ \\
\hline 5 & 19 & $33,9 \%$ \\
\hline 6 & 29 & $51,8 \%$ \\
\hline $\mathrm{n} / \mathrm{c}$ & 1 & $1,8 \%$ \\
\hline Total & 56 & $100,0 \%$ \\
\hline
\end{tabular}

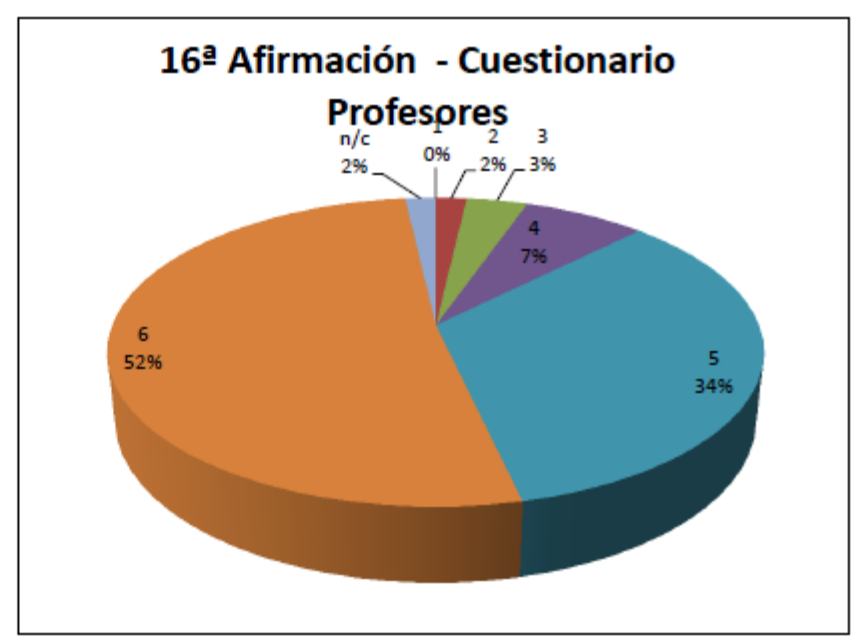

Una vez más, el profesorado se manifiesta teóricamente de acuerdo con que está bien trabajar con otros compañeros, porque así mejoran ellos mismos como músicos. De hecho, la mayoría (un 51'8\%) se manifiesta "completamente de acuerdo con lo que aquí se afirma. Y sólo un exiguo 5'4\% está en desacuerdo con la idea de mejorar trabajando con otros profesores. Parece que aquí podría estar un buen remedio para solucionar esos problemas que se reconocían al hablar de los puntos débiles: una posible colaboración constante entre profesores podría contribuir a eliminar o minimizar éstos y así conseguir acercarnos más a la excelencia. 
Decimoséptima afirmación: Aunque creo que trabajar con otros profesores me ayuda a ser mejor profesor ahora estoy centrado en trabajar solo.

17a Afirmación: Aunque crea que trabajar con otros profesores me ayuda a ser mejor profesor ahora estoy centrado en trabajar solo.

\begin{tabular}{|c|c|c|}
\hline \multicolumn{3}{|c|}{17 AFIRMACIÓN } \\
\hline Valor & $\begin{array}{c}\text { Total } \\
\text { valores }\end{array}$ & $\%$ \\
\hline 1 & 7 & $12,5 \%$ \\
\hline 2 & 13 & $23,2 \%$ \\
\hline 3 & 11 & $19,6 \%$ \\
\hline 4 & 7 & $12,5 \%$ \\
\hline 5 & 13 & $23,2 \%$ \\
\hline 6 & 4 & $7,1 \%$ \\
\hline $\mathrm{n} / \mathrm{c}$ & 1 & $1,8 \%$ \\
\hline Total & 56 & $100,0 \%$ \\
\hline
\end{tabular}

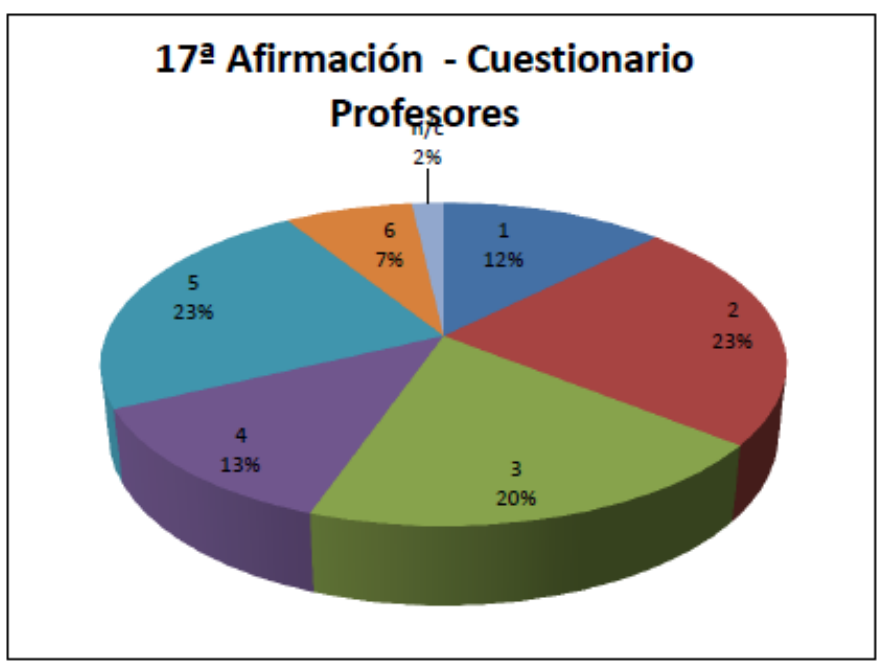

La cruda realidad. Si la teoría nos aconseja trabajar en equipo, la práctica desmiente de facto este hecho. Esta afirmación para decir que, si bien se está de acuerdo con el hecho teórico de que el trabajo colaborativo puede ayudarnos a mejorar, a la hora de llevarlo a la práctica esto implica problemas que son difícilmente salvables, quizá por el esfuerzo que requieren. Eso parece deducirse de ese 45'3 \% que está en desacuerdo con el hecho actual de trabajar con otros compañeros para mejorar como profesores. Por fortuna, la mayoría parece mostrarse de acuerdo (aunque repartidos de manera bastante equitativa entre os tres grados del mismo): un 54'7\% está en esta posición. Esperemos que pueda seguir aumentando esta proporción. 
Décimo octava afirmación: Animo a mis alumnos a trabajar en grupo como medio para mejorar como músico.

18a Afirmación: Animo a mis alumnos a trabajar en grupo como medio para mejorar como músico.

\begin{tabular}{|c|c|c|}
\hline \multicolumn{3}{|c|}{ 182 AFIRMACIÓN } \\
\hline Valor & $\begin{array}{c}\text { Total } \\
\text { valores }\end{array}$ & $\%$ \\
\hline 1 & 1 & $1,8 \%$ \\
\hline 2 & 0 & $0,0 \%$ \\
\hline 3 & 5 & $8,9 \%$ \\
\hline 4 & 9 & $16,1 \%$ \\
\hline 5 & 14 & $25,0 \%$ \\
\hline 6 & 26 & $46,4 \%$ \\
\hline n/c & 1 & $1,8 \%$ \\
\hline Total & 56 & $100,0 \%$ \\
\hline
\end{tabular}

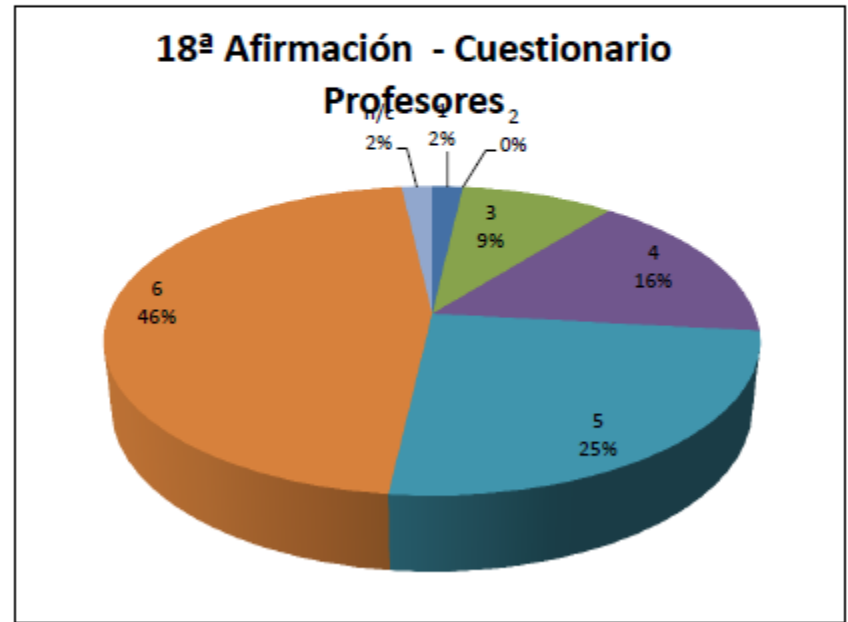

Nuevamente comprobamos cómo el acuerdo es la tónica general en este punto. Casi la mitad (un 46'4\%) está "completamente de acuerdo" con la afirmación y el resto hasta el 87'5\% "de acuerdo" o "más bien de acuerdo". Lo que nos sorprende es que aparezca ese $10^{\prime} 7 \%$ que esté en desacuerdo (incluso un 1'8\% "completamente en desacuerdo") con animar a sus alumnos a trabajar en grupo. Sería bueno que esta mentalidad pudiera ir cambiando poco a poco en los conservatorios. 
Décimo novena afirmación: Mis alumnos prefieren aprender mucho a sacar buenas notas.

19a Afirmación: Mis alumnos prefieren aprender mucho a sacar buenas notas.

\begin{tabular}{|c|c|c|}
\hline \multicolumn{3}{|c|}{ 19? AFIRMACIÓN } \\
\hline Valor & $\begin{array}{c}\text { Total } \\
\text { valores }\end{array}$ & $\%$ \\
\hline 1 & 4 & $7,1 \%$ \\
\hline 2 & 8 & $14,3 \%$ \\
\hline 3 & 13 & $23,2 \%$ \\
\hline 4 & 15 & $26,8 \%$ \\
\hline 5 & 9 & $16,1 \%$ \\
\hline 6 & 6 & $10,7 \%$ \\
\hline n/c & 1 & $1,8 \%$ \\
\hline Total & 56 & $100,0 \%$ \\
\hline & & \\
\hline
\end{tabular}

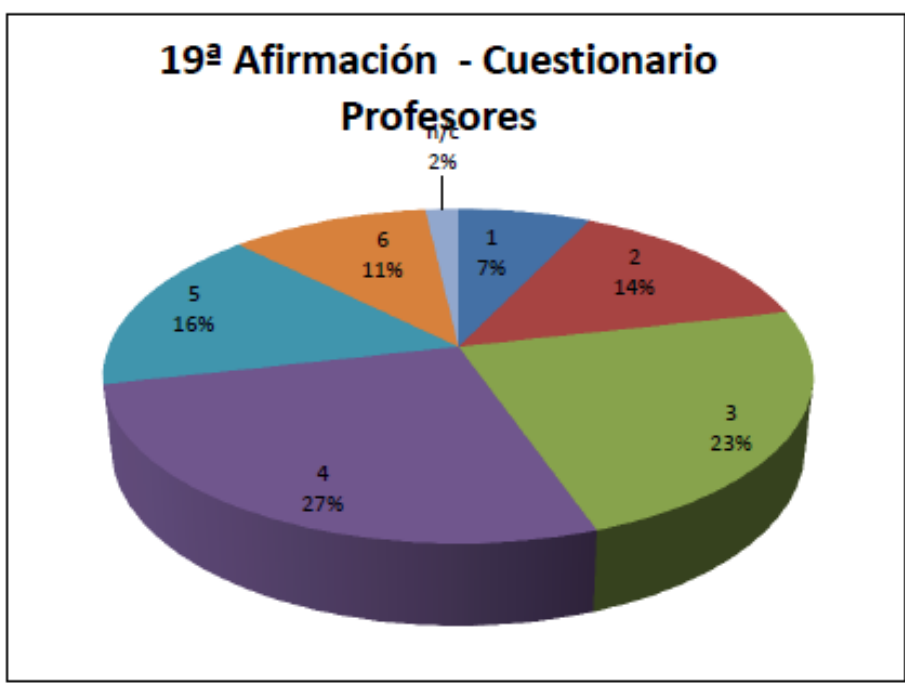

Otra cuestión donde la tónica es la diversidad de opiniones, si bien centrándose en torno al "más bien en desacuerdo" y el "más bien de acuerdo". Una mayoría muy ajustada (52'8\%) se declara de acuerdo, pero con tendencia a lo que ya hemos comentado, y el resto está en desacuerdo, pero igualmente con tendencia hacia una posición "centrada". La impresión del profesorado, por lo tanto, no es uniforme respecto a sus alumnos y poco se puede deducir de esta afirmación. 
Vigésima afirmación: Me parece importante que mis alumnos toquen obras o trabajen contenidos que tienen dominados para comprobar las habilidades que tienen.

20a Afirmación: Me parece importante que mis alumnos toquen obras o trabajen contenidos que tienen dominados para comprobar las habilidades que tienen.

\begin{tabular}{|c|c|c|}
\hline \multicolumn{3}{|c|}{ 20? AFIRMACIÓN } \\
\hline Valor & $\begin{array}{c}\text { Total } \\
\text { valores }\end{array}$ & $\%$ \\
\hline 1 & 0 & $0,0 \%$ \\
\hline 2 & 4 & $7,1 \%$ \\
\hline 3 & 13 & $23,2 \%$ \\
\hline 4 & 12 & $21,4 \%$ \\
\hline 5 & 15 & $26,8 \%$ \\
\hline 6 & 9 & $16,1 \%$ \\
\hline n/c & 3 & $5,4 \%$ \\
\hline Total & 56 & $100,0 \%$ \\
\hline & & \\
\hline
\end{tabular}

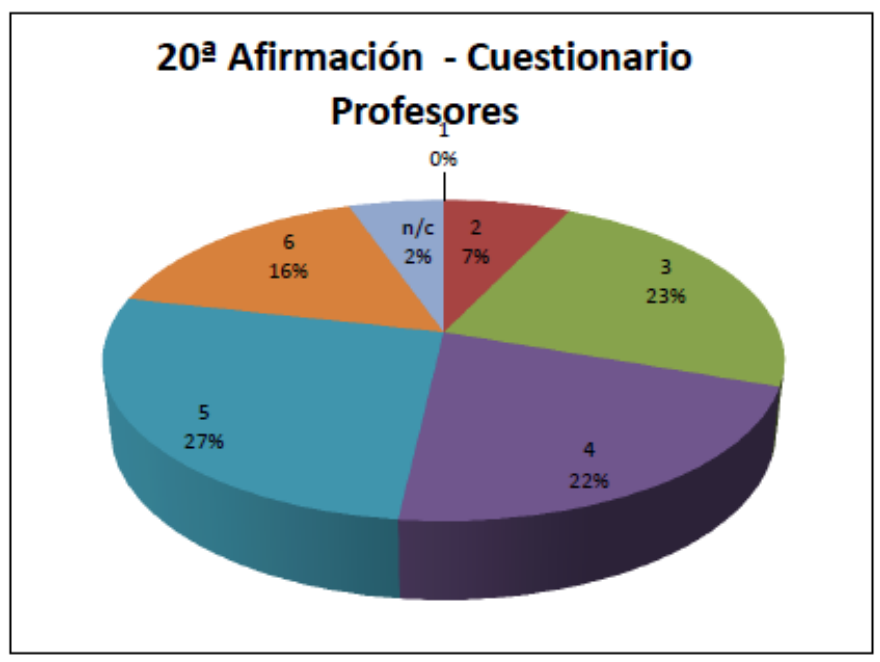

Otra cuestión en la que no hay una posición demasiado clara, si bien el acuerdo es mayoritario (63'5\%), hay un grupo significativo de profesores (un 30'3\%) que está "en desacuerdo" o "más bien en desacuerdo". Parece, pues, que hay una cierta preferencia por el hecho de que toquen piezas que tengan dominadas, pero esta idea está lejos de ser algo que se acerque a la unanimidad (como sucedía con otras afirmaciones). 
Vigésimo primera afirmación: Me parece más importante que mis alumnos tengan que enfrentarse a nuevos retos, esforzarse y aprender de sus errores a repetir lo que ya saben.

21a Afirmación: Me parece más importante que mis alumnos tengan que enfrentarse a nuevos retos, esforzarse y aprendan de sus errores a repetir lo que ya saben.

\begin{tabular}{|c|c|c|}
\hline \multicolumn{3}{|c|}{ 21: AFIRMACIÓN } \\
\hline Valor & $\begin{array}{c}\text { Total } \\
\text { valores }\end{array}$ & $\%$ \\
\hline 1 & 0 & $0,0 \%$ \\
\hline 2 & 0 & $0,0 \%$ \\
\hline 3 & 1 & $1,8 \%$ \\
\hline 4 & 7 & $12,5 \%$ \\
\hline 5 & 22 & $39,3 \%$ \\
\hline 6 & 24 & $42,9 \%$ \\
\hline $\mathrm{n} / \mathrm{c}$ & 2 & $3,6 \%$ \\
\hline Total & 56 & $100,0 \%$ \\
\hline
\end{tabular}

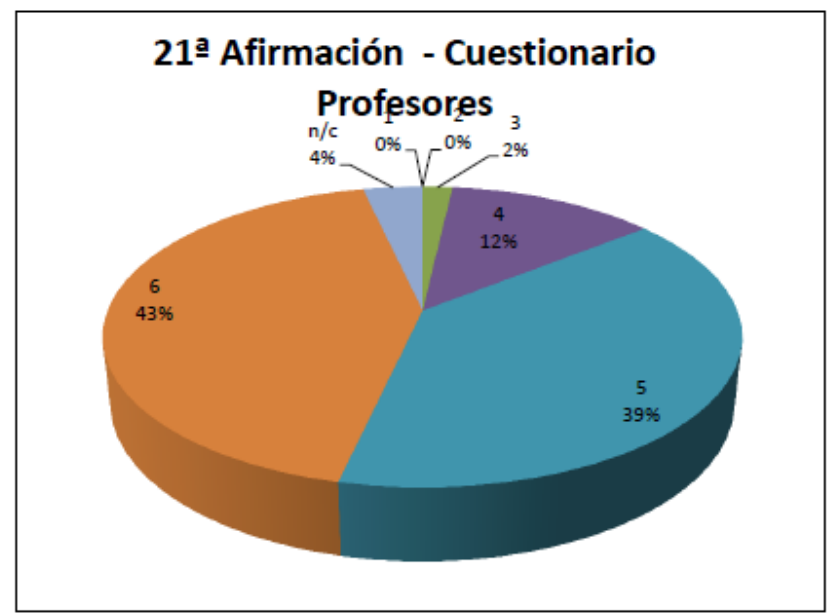

Por contra, en esta afirmación sí que nos volvemos a encontrar con una abrumadora mayoría de profesores que están de acuerdo (con el "completamente de acuerdo" establecido en el 42\% y el "de acuerdo" en el 39,3\%, es decir, un 81 '3\% en total). Sólo 1 profesor se manifiesta "más bien en desacuerdo", pero no hay que perder de vista ese 3'6\% que no contesta, porcentaje muy por encima de lo que llevamos viendo en las anteriores afirmaciones. De todos modos, lo que nos queda es esa impresión de que la voluntad del profesorado está en la dirección correcta, por decirlo de algún modo. 
Vigésimo segunda afirmación: Preparo las clases para enseñar a mis alumnos fundamentalmente lo que más domino.

22 a Afirmación: Preparo las clases para enseñar a mis alumnos fundamentalmente lo que más domino.

\begin{tabular}{|c|c|c|}
\hline \multicolumn{3}{|c|}{$22 \Xi$ AFIRMACIÓN } \\
\hline Valor & $\begin{array}{c}\text { Total } \\
\text { valores }\end{array}$ & $\%$ \\
\hline 1 & 9 & $16,1 \%$ \\
\hline 2 & 8 & $14,3 \%$ \\
\hline 3 & 10 & $17,9 \%$ \\
\hline 4 & 15 & $26,8 \%$ \\
\hline 5 & 10 & $17,9 \%$ \\
\hline 6 & 3 & $5,4 \%$ \\
\hline n/c & 1 & $1,8 \%$ \\
\hline Total & 56 & $100,0 \%$ \\
\hline
\end{tabular}

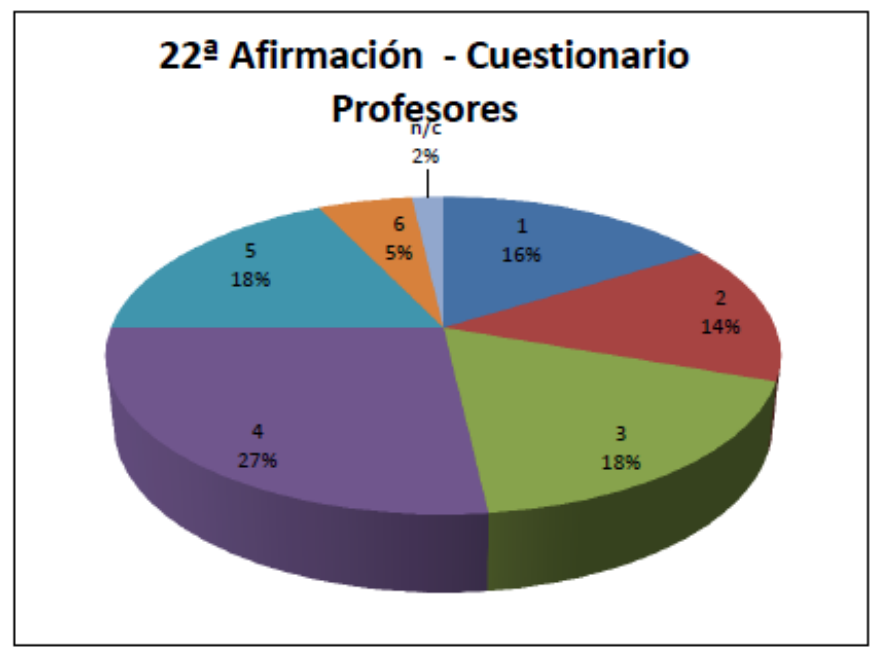

La disparidad de opiniones en este caso es abrumadora y deja el acuerdo y el desacuerdo casi en empate técnico. Un 50'1 \% está de acuerdo, pero no demasiado (sólo un 5'4\% está “completamente de acuerdo” por el 26'8\% que sólo está “más bien de acuerdo”), con esta afirmación. En cambio, el 47'6\% parece que no está de acuerdo en preparar las clases para enseñar a sus alumnos lo que más dominan, desacuerdo, por cierto, perfectamente equilibrado entre sus tres grados de diversidad. En resumen, que hay de todo en este ámbito, desde el profesor que hace lo que reza la afirmación hasta el que parece arriesgar más. 
Vigésimo tercera afirmación: Preparo las clases adaptándome a las características e intereses particulares de cada alumno.

23a Afirmación: Preparo las clases adaptándome a las características e intereses particulares de cada alumno.

\begin{tabular}{|c|c|c|}
\hline \multicolumn{3}{|c|}{ 23a AFIRMACIÓN } \\
\hline Valor & $\begin{array}{c}\text { Total } \\
\text { valores }\end{array}$ & $\%$ \\
\hline 1 & 1 & $1,8 \%$ \\
\hline 2 & 0 & $0,0 \%$ \\
\hline 3 & 5 & $8,9 \%$ \\
\hline 4 & 9 & $16,1 \%$ \\
\hline 5 & 21 & $37,5 \%$ \\
\hline 6 & 18 & $32,1 \%$ \\
\hline $\mathrm{n} / \mathrm{c}$ & 2 & $3,6 \%$ \\
\hline Total & 56 & $100,0 \%$ \\
\hline
\end{tabular}

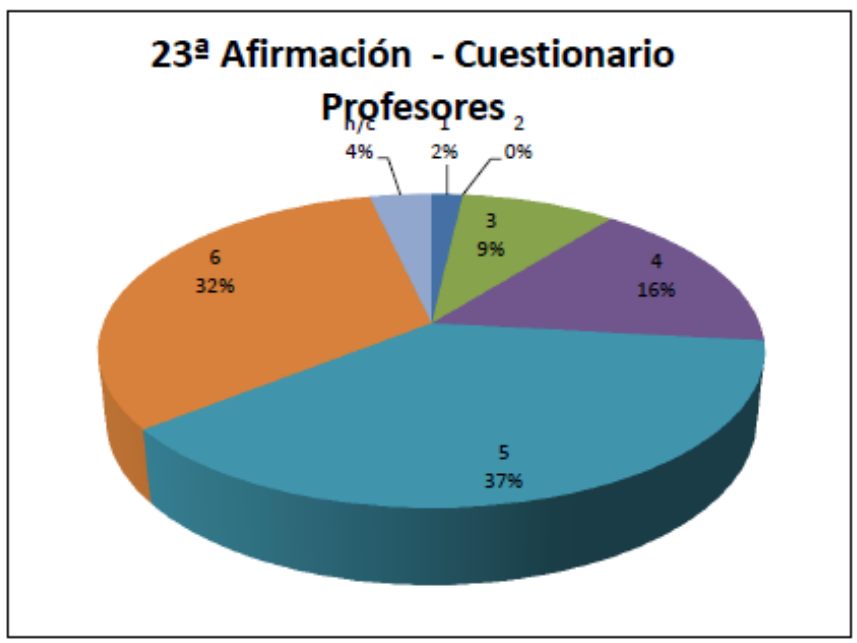

Una nueva declaración de intenciones. La inmensa mayoría declara estar de acuerdo con la afirmación de que preparan sus clases adaptándose a las características e intereses de sus alumnos. Y el 69'6\% está entre el "de acuerdo" y el "completamente de acuerdo" (repartidos con el 37'5 y el 32'1\% respectivamente), lo que indica que estamos ante una enseñanza que roza lo idílico. Lo que nos sorprende es la presencia de ese 9'8\% que afirma no estar de acuerdo con esto. Es inquietante comprobar cómo existen profesores que pasan por encima de los intereses de sus alumnos. 
Vigésima cuarta afirmación: Creo que mis alumnos debería planificar su tiempo diario de estudio en función de sus gustos y su forma personal de aprender

24a Afirmación: Creo que mis alumnos deberían planificar su tiempo diario de estudio en función de sus gustos y su forma personal de aprender.

\begin{tabular}{|c|c|c|}
\hline \multicolumn{3}{|c|}{$24 \geq$ AFIRMACIÓN } \\
\hline Valor & $\begin{array}{c}\text { Total } \\
\text { valores }\end{array}$ & $\%$ \\
\hline 1 & 1 & $1,8 \%$ \\
\hline 2 & 2 & $3,6 \%$ \\
\hline 3 & 9 & $16,1 \%$ \\
\hline 4 & 14 & $25,0 \%$ \\
\hline 5 & 18 & $32,1 \%$ \\
\hline 6 & 10 & $17,9 \%$ \\
\hline $\mathrm{n} / \mathrm{c}$ & 2 & $3,6 \%$ \\
\hline Total & 56 & $100,0 \%$ \\
\hline
\end{tabular}

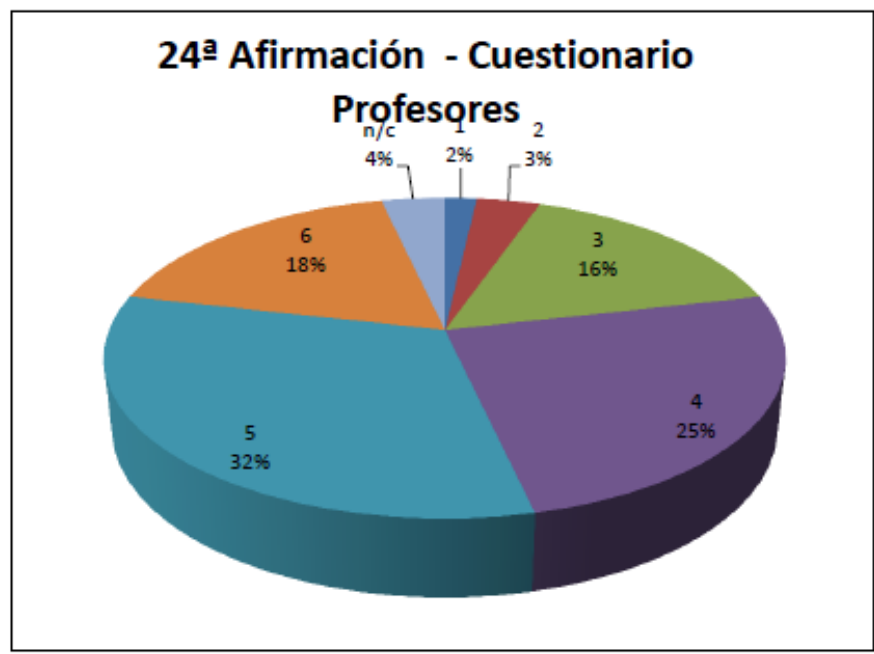

Seguimos con el acuerdo del profesorado en cuanto a la independencia que el alumnado necesita para estudiar provechosamente. Ni más ni menos que un $75 \%$ se manifiesta de acuerdo con esta afirmación, mayoritariamente posicionado en el "de acuerdo" sin más (32'1\%). Pero el 15'1\% está en desacuerdo con esto. Por lo visto, la forma particular de aprender y el gusto del alumnado no es algo que sea importante para este sector del profesorado. 
Vigésimo quinta afirmación: Pienso que las experiencias que aportan los estudiantes pueden ser tan importantes como las mías.

25a Afirmación: Pienso que las experiencias que aportan los estudiantes pueden ser tan importantes como las mías.

\begin{tabular}{|c|c|c|}
\hline \multicolumn{3}{|c|}{$25 ?$ AFIRMACIÓN } \\
\hline Valor & $\begin{array}{c}\text { Total } \\
\text { valores }\end{array}$ & $\%$ \\
\hline 1 & 0 & $0,0 \%$ \\
\hline 2 & 0 & $0,0 \%$ \\
\hline 3 & 5 & $8,9 \%$ \\
\hline 4 & 8 & $14,3 \%$ \\
\hline 5 & 17 & $30,4 \%$ \\
\hline 6 & 25 & $44,6 \%$ \\
\hline n/c & 1 & $1,8 \%$ \\
\hline Total & 56 & $100,0 \%$ \\
\hline & & \\
\hline
\end{tabular}

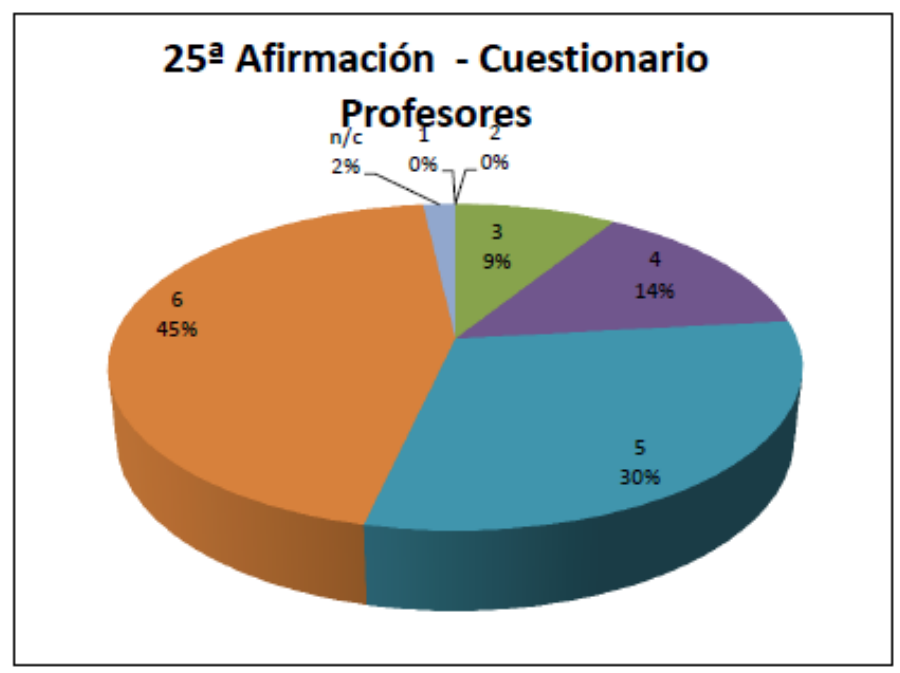

De nuevo un acuerdo casi unánime. Un tremendo 86 '3\% se declara de acuerdo con esta afirmación, es decir, consideran que las experiencias que aportan los estudiantes pueden ser tan importantes como las suyas. Y, además, la tendencia al “completamente de acuerdo" (un 44'6\%, con un 30'4\% que está “de acuerdo"). Sólo un exiguo 8'9 \% está "más bien en desacuerdo" con esta afirmación teórica. Parece que, en principio, la actitud del profesorado sigue en esa línea de conducta que conduce a la excelencia. 
Vigésimo sexta afirmación: Las preguntas de los estudiantes me hacen reflexionar sobre mi propia práctica docente.

26a Afirmación: Las preguntas de los estudiantes me hacen reflexionar sobre mi propia práctica docente.

\begin{tabular}{|c|c|c|}
\hline \multicolumn{3}{|c|}{ 26? AFIRMACIÓN } \\
\hline Valor & $\begin{array}{c}\text { Total } \\
\text { valores }\end{array}$ & $\%$ \\
\hline 1 & 1 & $1,8 \%$ \\
\hline 2 & 0 & $0,0 \%$ \\
\hline 3 & 1 & $1,8 \%$ \\
\hline 4 & 5 & $8,9 \%$ \\
\hline 5 & 17 & $30,4 \%$ \\
\hline 6 & 31 & $55,4 \%$ \\
\hline $\mathrm{n} / \mathrm{c}$ & 1 & $1,8 \%$ \\
\hline Total & 56 & $100,0 \%$ \\
\hline
\end{tabular}

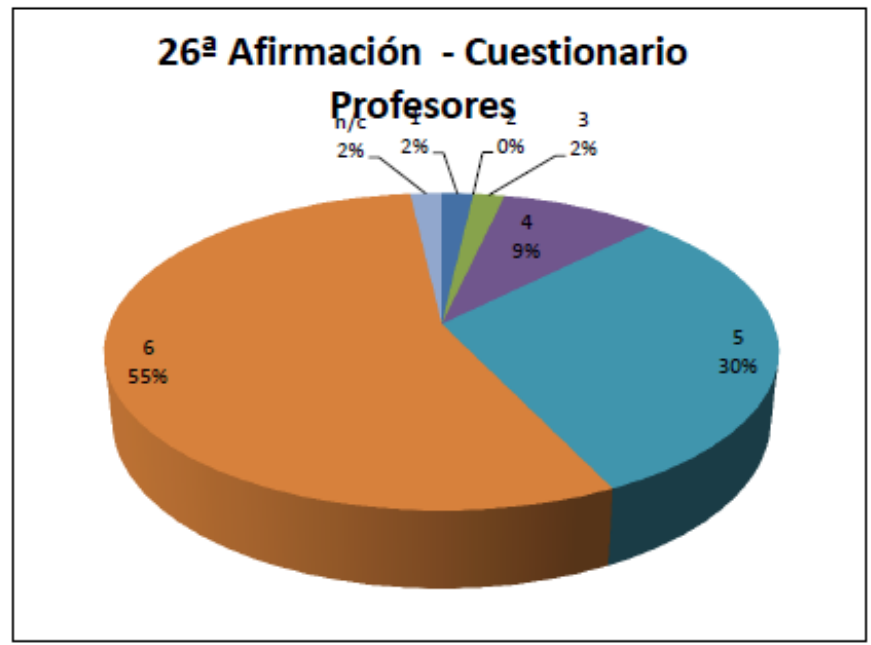

En esta ocasión el "completamente de acuerdo" es mayoritario: 55'1\%. El caso en que más se ha manifestado el acuerdo extremo, sin duda. A esto hay que sumar el 30 '4\% que está "de acuerdo" y el 8'9\% que está "más bien de acuerdo", que suma un inapelable 94'4\%. Sólo el 2\% está en desacuerdo. De todas estas afirmaciones vamos deduciendo que hay una implicación muy grande del profesorado en lo que es su tarea directa con el alumnado. Confiemos en que siga siendo así y las cosas mejoren de manera exponencial. 
Vigésima séptima afirmación: Creo que los alumnos que tengo actualmente van a alcanzar el éxito como profesionales.

27ạ Afirmación: Creo que los alumnos que tengo actualmente van a alcanzar el éxito como profesionales.

\begin{tabular}{|c|c|c|}
\hline \multicolumn{3}{|c|}{ 272 AFIRMACIÓN } \\
\hline Valor & $\begin{array}{c}\text { Total } \\
\text { valores }\end{array}$ & $\%$ \\
\hline 1 & 0 & $0,0 \%$ \\
\hline 2 & 2 & $3,6 \%$ \\
\hline 3 & 12 & $21,4 \%$ \\
\hline 4 & 19 & $33,9 \%$ \\
\hline 5 & 13 & $23,2 \%$ \\
\hline 6 & 7 & $12,5 \%$ \\
\hline $\mathrm{n} / \mathrm{c}$ & 3 & $5,4 \%$ \\
\hline Total & 56 & $100,0 \%$ \\
\hline
\end{tabular}

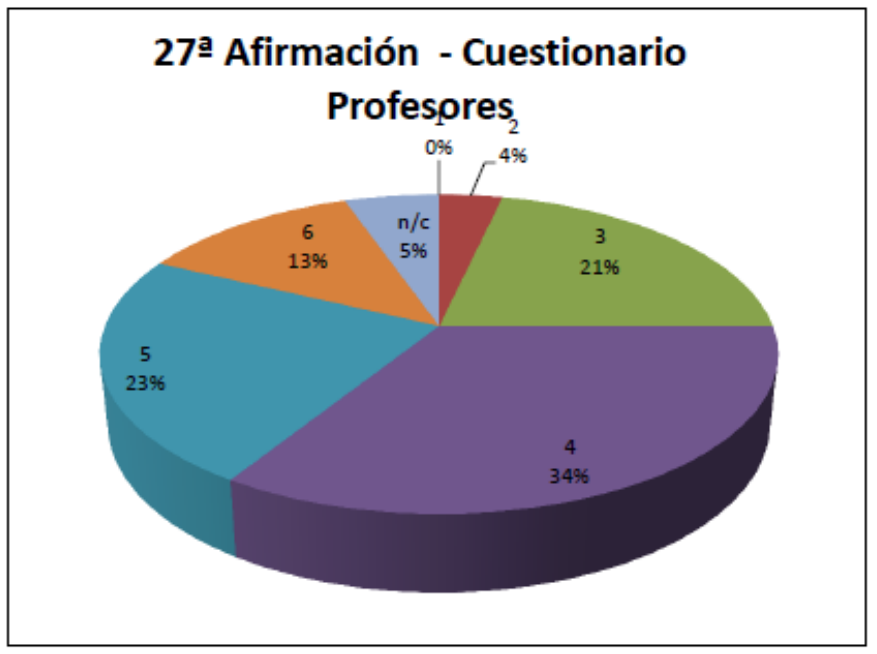

¿Qué expectativas tiene el profesorado acerca de sus estudiantes? Por fortuna, parece que mayoritariamente son positivas y esperanzadoras. Un 69'6\% está de acuerdo con que sus alumnos van a alcanzar el éxito como profesionales. Parece que este sector está de acuerdo con Sloboda en que hay que tener altas expectativas en los estudiantes. Por desgracia, tenemos un elevado porcentaje (el 25\%, es decir, la cuarta parte) que no está de acuerdo con esta afirmación, es decir, está dando clase a alguien en quien no confían como músico de éxito. Y, de nuevo, nos encontramos con un $5 ' 1 \%$ de profesores que no contestan, es decir, un porcentaje algo elevado, a nuestro juicio. 
Vigésimo octava afirmación: Cuando mis alumnos fracasan o no alcanzan los objetivos propuestos pienso que es porque no tienen bastante talento.

28 a Afirmación: Cuando mis alumnos fracasan o no alcanzan los objetivos propuestos pienso que es porque no tienen bastante talento.

\begin{tabular}{|c|c|c|}
\hline \multicolumn{3}{|c|}{ 28a AFIRMACIÓN } \\
\hline Valor & $\begin{array}{c}\text { Total } \\
\text { valores }\end{array}$ & $\%$ \\
\hline 1 & 16 & $28,6 \%$ \\
\hline 2 & 10 & $17,9 \%$ \\
\hline 3 & 16 & $28,6 \%$ \\
\hline 4 & 8 & $14,3 \%$ \\
\hline 5 & 5 & $8,9 \%$ \\
\hline 6 & 0 & $0,0 \%$ \\
\hline $\mathrm{n} / \mathrm{c}$ & 1 & $1,8 \%$ \\
\hline Total & 56 & $100,0 \%$ \\
\hline
\end{tabular}

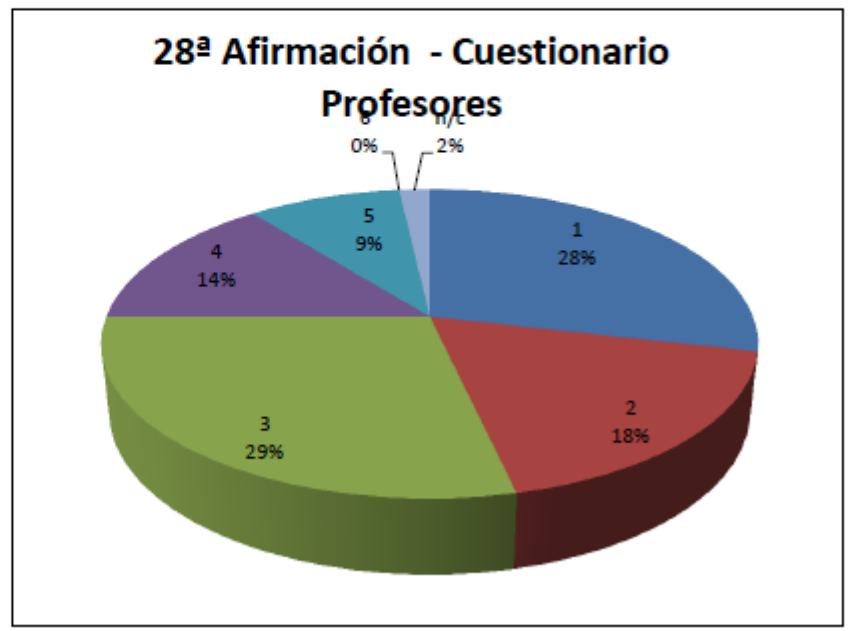

A pesar de lo que se ha afirmado en la cuestión anterior, la mayoría no achaca el "fracaso" a la falta de talento de sus alumnos... salvo en el caso de un interesante 23'2\% (de nuevo casi la cuarta parte), que sí está de acuerdo con esta afirmación, si bien ninguno de manera tajante y categórica. Como decimos, el 74'3\% está en desacuerdo con la afirmación que se plantea, desacuerdo que se distribuye de manera muy equilibrada entre los tres grados propuestos: $28^{\prime} 6 \%, 17^{\prime} 1 \%$ y $28{ }^{\prime} 6 \%$ respectivamente entre "completamente en desacuerdo", "en desacuerdo" y "más o menos en desacuerdo". Parece, pues, que la falta de talento no es la causa, a juicio de la mayoría del profesorado, del "fracaso" de sus alumnos. Y esto es evidente a priori, por cuanto para poder acceder a los estudios superiores los alumnos han de pasar una prueba de acceso muy exigente, donde no tienen más remedio que demostrar su talento. Como ejemplo podríamos decir que para acceder a los estudios de interpretación de guitarra jazz se presentaron 26 candidatos el curso 2015-2016 y sólo se podían admitir 3, lo que hace evidente que ya se han escogido a los más talentosos. 
Vigésimo novena afirmación: Cuando mis alumnos fracasan o no alcanzan los objetivos propuestos pienso que es porque no han estudiado lo suficiente.

29a Afirmación: Cuando mis alumnos fracasan o no alcanzan los objetivos propuestos pienso que es porque no han estudiado bastante.

\begin{tabular}{|c|c|c|}
\hline \multicolumn{3}{|c|}{ 29a AFIRMACIÓN } \\
\hline Valor & $\begin{array}{c}\text { Total } \\
\text { valores }\end{array}$ & $\%$ \\
\hline 1 & 4 & $7,1 \%$ \\
\hline 2 & 7 & $12,5 \%$ \\
\hline 3 & 7 & $12,5 \%$ \\
\hline 4 & 22 & $39,3 \%$ \\
\hline 5 & 11 & $19,6 \%$ \\
\hline 6 & 4 & $7,1 \%$ \\
\hline n/c & 1 & $1,8 \%$ \\
\hline Total & 56 & $100,0 \%$ \\
\hline & & \\
\hline
\end{tabular}

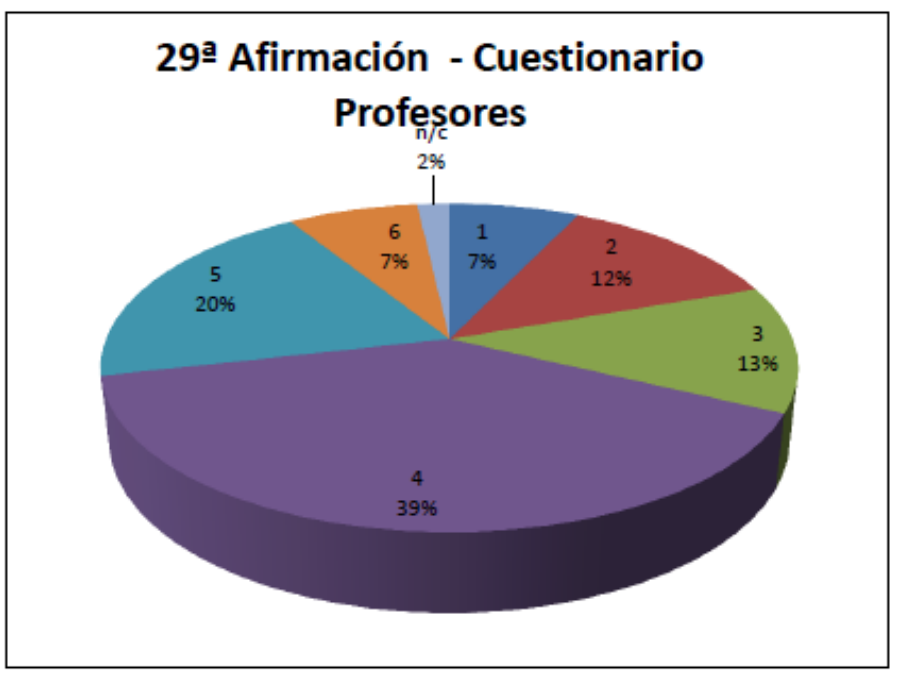

La falta de estudio, en cambio, sí parece ser motivo para explicar ese fracaso. El $65 ' 9 \%$ del profesorado se manifiesta de acuerdo con esta afirmación, aunque de manera moderada. La mayoría (un 39'3\% está "más bien de acuerdo"). El resto (un 32'1\%) no está de acuerdo con lo que aquí se plantea. Es decir, no es la falta de estudio lo que conduce al fracaso, sino algún otro factor. Pero parece, en función de la opinión dominante, que se va aclarando el panorama en lo que respecta a la causa del fracaso. 
Trigésima afirmación: Cuando mis alumnos fracasan o no alcanzan los objetivos propuestos pienso que es porque no han estudiado de la manera adecuada.

30a Afirmación: Cuando mis alumnos fracasan o no alcanzan los objetivos propuestos pienso que es porque no han estudiado de la manera adecuada.

\begin{tabular}{|c|c|c|}
\hline \multicolumn{3}{|c|}{ 30 AFIRMACIÓN } \\
\hline Valor & $\begin{array}{c}\text { Total } \\
\text { valores }\end{array}$ & $\%$ \\
\hline 1 & 1 & $1,8 \%$ \\
\hline 2 & 1 & $1,8 \%$ \\
\hline 3 & 8 & $14,3 \%$ \\
\hline 4 & 17 & $30,4 \%$ \\
\hline 5 & 21 & $37,5 \%$ \\
\hline 6 & 7 & $12,5 \%$ \\
\hline n/c & 1 & $1,8 \%$ \\
\hline Total & 56 & $100,0 \%$ \\
\hline & & \\
\hline
\end{tabular}

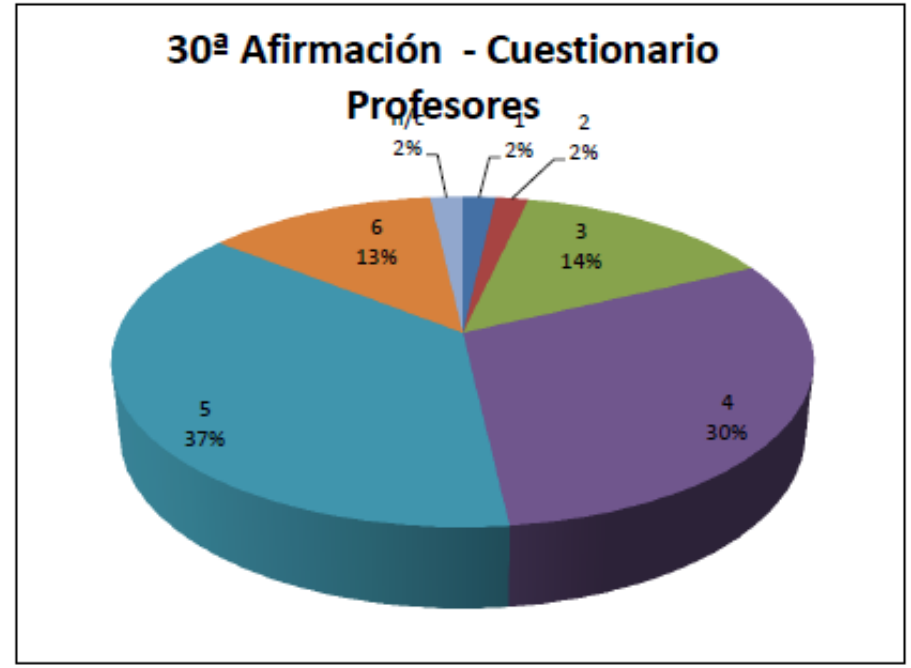

En efecto, se trataba del estudio, pero quizá no tanto su falta como su aplicación, es decir, la forma en que se estudia. Ni más ni menos que el 80'4\% está de acuerdo con este planteamiento, situándose la mayoría en la franja del "más bien de acuerdo" (30'4\%) y el "de acuerdo" (37'5\%). Sólo el 17'1\% está en desacuerdo con esta afirmación y sólo moderadamente ("más bien en desacuerdo"). Lo que parece estar diciendo el profesorado es que el fracaso procede de la falta de estudio y, sobre todo, de un estudio adecuado. Lehmann y Jorgensen, en sus estudios sobre la práctica instrumental, exponen que desde su experiencia y desde la observación informal se ha visto que muy pocos estudiantes planifican realmente su práctica diaria. La planificación es una actividad donde los estudiantes al parecer tienen mucho potencial para mejorar e insisten en que es necesaria más investigación sobre cómo planificar su práctica diaria (2012: 669) e incluso proponen cómo hacerlo. 
Trigésimo primera afirmación: Cuando mis alumnos fracasan o no alcanzan los objetivos propuestos siento que he fracasado yo también.

31a Afirmación: Cuando mis alumnos fracasan o no alcanzan los objetivos propuestos siento que he fracasado yo también.

\begin{tabular}{|c|c|c|}
\hline \multicolumn{3}{|c|}{ 31 AFIRMACIÓN } \\
\hline Valor & $\begin{array}{c}\text { Total } \\
\text { valores }\end{array}$ & $\%$ \\
\hline 1 & 0 & $0,0 \%$ \\
\hline 2 & 2 & $3,6 \%$ \\
\hline 3 & 10 & $17,9 \%$ \\
\hline 4 & 21 & $37,5 \%$ \\
\hline 5 & 19 & $33,9 \%$ \\
\hline 6 & 3 & $5,4 \%$ \\
\hline $\mathrm{n} / \mathrm{c}$ & 1 & $1,8 \%$ \\
\hline Total & 56 & $100,0 \%$ \\
\hline
\end{tabular}

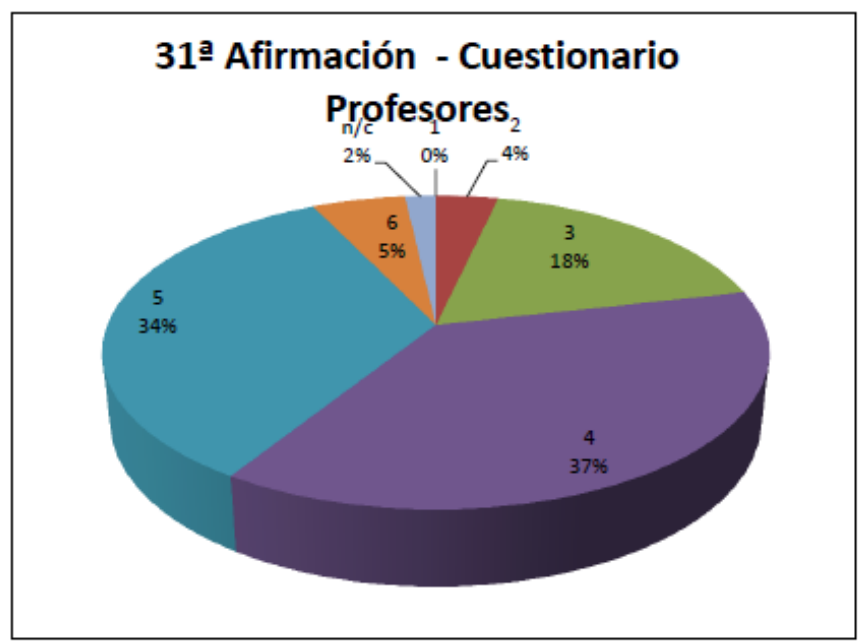

¿Es partícipe el profesor del fracaso del alumno? Parece que mayoritariamente sí. O eso dicen los profesores encuestados. Un elocuente 76'8\% está de acuerdo con esta afirmación, si bien de manera moderada. Sólo el 5'4\% está “completamente de acuerdo", repartiéndose el resto entre el 37'5\% del "más bien de acuerdo" y el 33'9\% del "de acuerdo". Sólo un 21'5\% se considera ajeno al fracaso de su alumno. Es decir, la quinta parte. Parece que el profesorado sí se siente partícipe de lo que vive su alumnado en su carrera profesional. Sería muy interesante insistir en la importancia de conocer las investigaciones que también hablan de cómo puede ayudar el profesor a que el alumno se desarrolle de forma independiente y le ayude a revertir el fracaso. Hallam y Bautista (2012:667-669), recogiendo las últimas investigaciones, proponen que si le ayudáramos a desarrollarse de forma independiente como estudiante, el profesorado podría compartir la responsabilidad del aprendizaje con el alumnado. 
Trigésimo segunda afirmación. Considero que es mi responsabilidad motivar al alumno para ayudarle a conseguir sus metas.

32a Afirmación: Considero que es mi responsabilidad motivar al alumno para ayudarle a conseguir sus metas.

\begin{tabular}{|c|c|c|}
\hline \multicolumn{3}{|c|}{32 a AFIRMACIÓN } \\
\hline Valor & $\begin{array}{c}\text { Total } \\
\text { valores }\end{array}$ & $\%$ \\
\hline 1 & 0 & $0,0 \%$ \\
\hline 2 & 0 & $0,0 \%$ \\
\hline 3 & 3 & $5,4 \%$ \\
\hline 4 & 1 & $1,8 \%$ \\
\hline 5 & 20 & $35,7 \%$ \\
\hline 6 & 31 & $55,4 \%$ \\
\hline $\mathrm{n} / \mathrm{c}$ & 1 & $1,8 \%$ \\
\hline Total & 56 & $100,0 \%$ \\
\hline
\end{tabular}

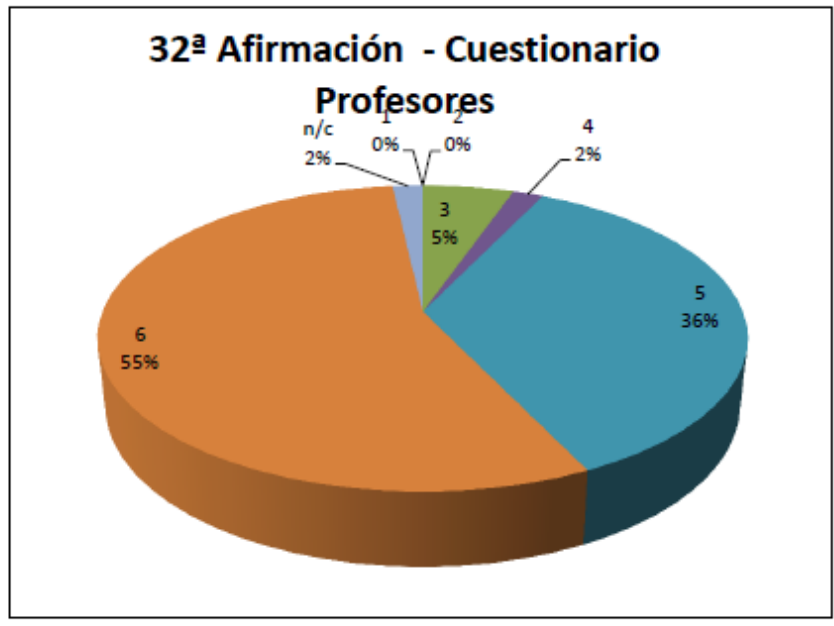

De entrada, podría parecer que esta afirmación tendría que contestarse de manera mayoritariamente favorable, cuando no unánime. Y, en efecto, un 55'4\% está "completamente de acuerdo" con la responsabilidad moral de motivar al alumnado. Que sumado al 35'7\% que está “de acuerdo" suma el 91'1\% del total. Pero tenemos un interesante 5'4\% que está "más bien en desacuerdo" con esta afirmación, es decir, que no cree que sea su responsabilidad motivar al alumnado. Las investigaciones señalan (Sloboda, 1987) que, para aprender algo, es necesaria la motivación, y por lo tanto será necesario que, si una parte del profesorado no ve necesario motivar al alumnado como parte de su responsabilidad, debía al menos enseñarle, como dicen también las investigaciones (Hallam y Gaunt, 2012; Hallam y Bautista, 2012), a autorregularse para manejar el aprendizaje y la motivación. Por todo ello seguimos insistiendo en que se refleja la necesidad de leer las investigaciones para aprender tanto alumnos como profesores. 
Trigésimo tercera afirmación: Me considero bien valorado por mis alumnos.

33å Afirmación: Me considero bien valorado por mis alumnos.

\begin{tabular}{|c|c|c|}
\hline \multicolumn{3}{|c|}{ 33? AFIRMACIÓN } \\
\hline Valor & $\begin{array}{c}\text { Total } \\
\text { valores }\end{array}$ & $\%$ \\
\hline 1 & 0 & $0,0 \%$ \\
\hline 2 & 0 & $0,0 \%$ \\
\hline 3 & 4 & $7,1 \%$ \\
\hline 4 & 13 & $23,2 \%$ \\
\hline 5 & 28 & $50,0 \%$ \\
\hline 6 & 9 & $16,1 \%$ \\
\hline $\mathrm{n} / \mathrm{c}$ & 2 & $3,6 \%$ \\
\hline Total & 56 & $100,0 \%$ \\
\hline
\end{tabular}

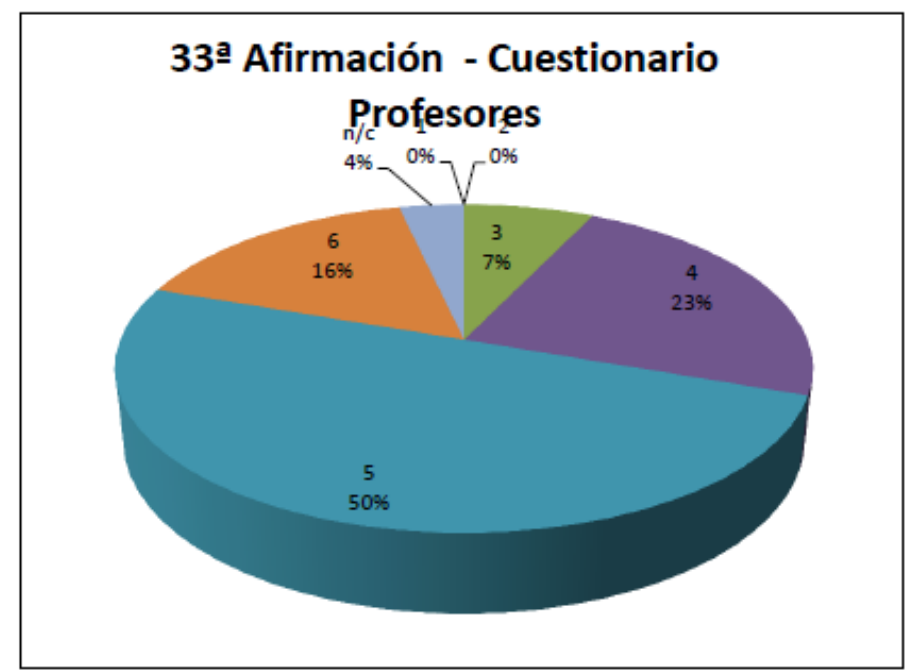

El grado de consideración que creen tener por parte de sus alumnos es bastante elevado. La mitad exacta está "de acuerdo" con que sus alumnos tienen una buena opinión de ellos. Y otro 39'3\% está igualmente en esa idea, si bien un 23'2\% sólo "más o menos de acuerdo" y un 16'1\% "completamente de acuerdo". Como siempre, tenemos ese pequeño grupo (7'1\%) que no se considera bien valorado por sus alumnos, si bien en grado leve ("más bien en desacuerdo"). 
Trigésimo cuarta afirmación: Me considero bien valorado por mis compañeros.

34a Afirmación: Me considero bien valorado por mis compañeros.

\begin{tabular}{|c|c|c|}
\hline \multicolumn{3}{|c|}{ 342 AFIRMACIÓN } \\
\hline Valor & $\begin{array}{c}\text { Total } \\
\text { valores }\end{array}$ & $\%$ \\
\hline 1 & 0 & $0,0 \%$ \\
\hline 2 & 1 & $1,8 \%$ \\
\hline 3 & 4 & $7,1 \%$ \\
\hline 4 & 16 & $28,6 \%$ \\
\hline 5 & 28 & $50,0 \%$ \\
\hline 6 & 4 & $7,1 \%$ \\
\hline n/c & 3 & $5,4 \%$ \\
\hline Total & 56 & $100,0 \%$ \\
\hline
\end{tabular}

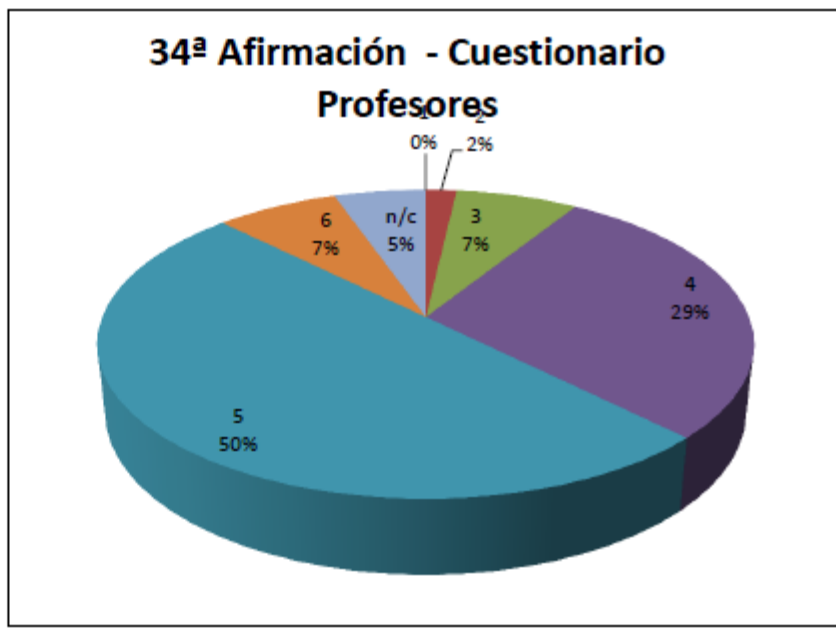

Es curioso comprobar cómo las cifras casi se calcan si preguntamos por la valoración que tienen sus compañeros sobre ellos. De nuevo, la mitad exacta está "de acuerdo" con esta afirmación y hay un porcentaje mayor en el "más bien de acuerdo" (28\%) que en el "completamente de acuerdo" (7'1\%). Parece que cuando se tiene en cuenta la opinión de los demás es irrelevante que hablemos de compañeros o de alumnos. La sensación es muy parecida. De todos modos, es de nuevo interesante comprobar cómo aquí aparece de nuevo un más elevado número de personas que no contestan: el 5'4\%. 
35a Afirmación: Me considero bien valorado por la dirección.

\begin{tabular}{|c|c|c|}
\hline \multicolumn{3}{|c|}{ 35: AFIRMACIÓN } \\
\hline Valor & $\begin{array}{c}\text { Total } \\
\text { valores }\end{array}$ & $\%$ \\
\hline 1 & 3 & $5,4 \%$ \\
\hline 2 & 6 & $10,7 \%$ \\
\hline 3 & 4 & $7,1 \%$ \\
\hline 4 & 11 & $19,6 \%$ \\
\hline 5 & 21 & $37,5 \%$ \\
\hline 6 & 6 & $10,7 \%$ \\
\hline $\mathrm{n} / \mathrm{c}$ & 5 & $8,9 \%$ \\
\hline Total & 56 & $100,0 \%$ \\
\hline
\end{tabular}

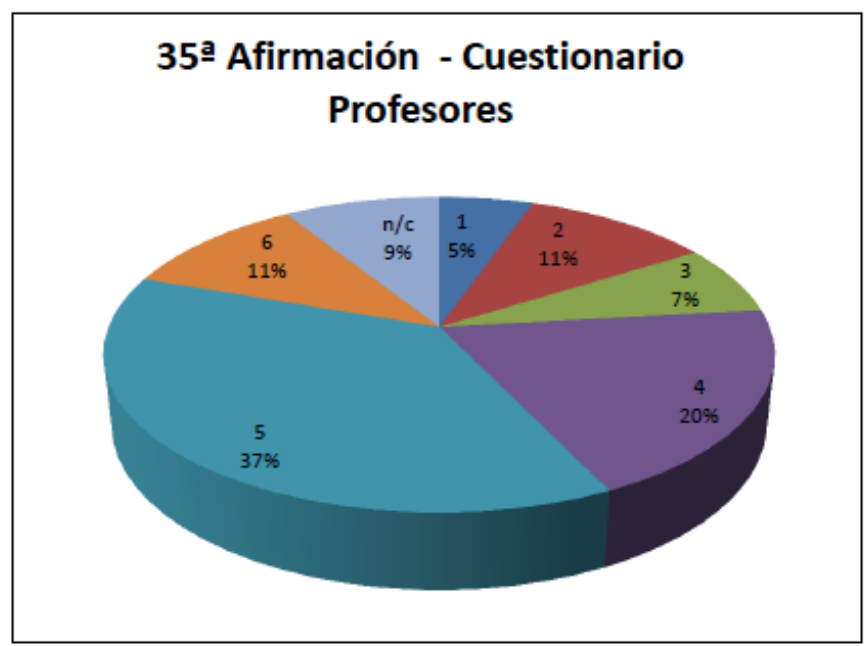

¿Y el equipo directivo? ¿Cómo nos valora? Pues aquí la cosa cambia un poco. A pesar de que el grupo mayoritario sigue siendo el que se manifiesta "de acuerdo", en esta ocasión sólo alcanza el 37'5\% (que es más de un tercio, de todos modos). Y el acuerdo, en general, sigue siendo la nota dominante: en total, el 67'8\% se siente valorado en mayor o menor medida por el equipo directivo, lo que representa los dos tercios del profesorado. Pero es significativo que se incremente el número de profesores que no están de acuerdo y, especialmente, "completamente en desacuerdo" (un 5'4\%). En total, el 23'2\% no están de acuerdo con que la dirección les valore adecuadamente. Casi la cuarta parte del profesorado. Es un dato para reflexionar. 
Trigésimo sexta afirmación: Conozco herramientas para mejorar la comunicación con mis alumnos y otros profesores como la práctica de la inteligencia emocional.

36a Afirmación: Conozco herramientas para mejorar la comunicación con mis alumnos y otros profesores como la práctica de la inteligencia emocional.

\begin{tabular}{|c|c|c|}
\hline \multicolumn{3}{|c|}{ 36? AFIRMACIÓN } \\
\hline Valor & $\begin{array}{c}\text { Total } \\
\text { valores }\end{array}$ & $\%$ \\
\hline 1 & 1 & $1,8 \%$ \\
\hline 2 & 3 & $5,4 \%$ \\
\hline 3 & 10 & $17,9 \%$ \\
\hline 4 & 12 & $21,4 \%$ \\
\hline 5 & 18 & $32,1 \%$ \\
\hline 6 & 10 & $17,9 \%$ \\
\hline $\mathrm{n} / \mathrm{c}$ & 2 & $3,6 \%$ \\
\hline Total & 56 & $100,0 \%$ \\
\hline
\end{tabular}

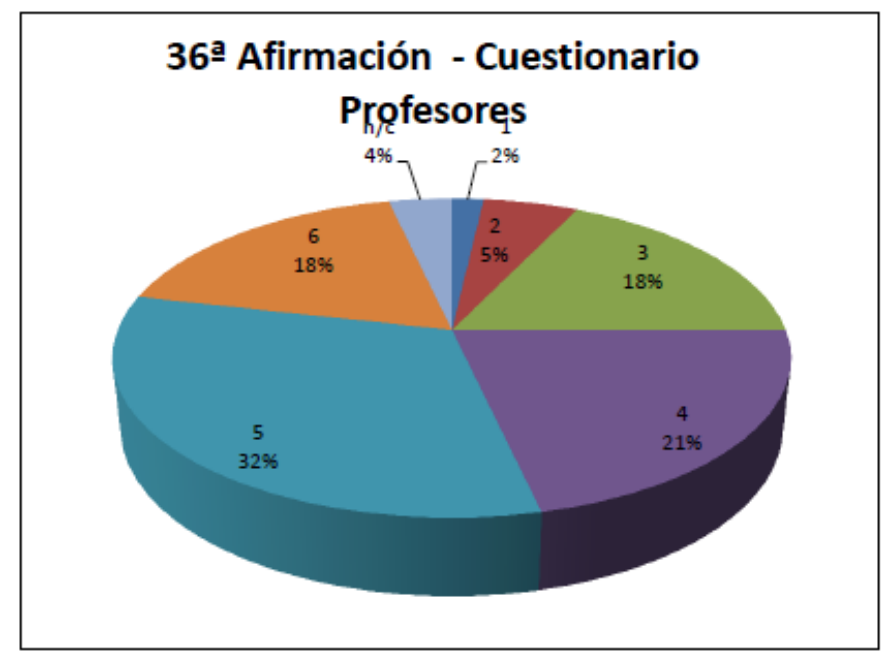

Teniendo en cuenta lo novedoso de la teoría de la inteligencia emocional, nos congratula que el 71'4\% conozca esas herramientas para mejorar la comunicación con sus alumnos y otros profesores. Lástima que una cuarta parte exacta (el 25'1\%) desconozca estas útiles herramientas. Confiamos, no obstante, en que este porcentaje se encuentre entre estos profesores que conocían sus puntos débiles y estén de acuerdo con que trabajar con los compañeros les conviene para mejorar. Ciertamente, los datos que nos ofrecen estas encuestas nos pintan un panorama de lo más esperanzador de cara a conseguir la excelencia musical del alumnado del Conservatorio.

\subsection{Análisis de los resultados obtenidos en la fase experimental}

Tras haber pasado revista a las afirmaciones que nos parecen más relevantes del cuestionario de los alumnos y haber hecho lo mismo, pero de manera más exhaustiva, con el de los profesores, es el momento de efectuar un análisis de estos 
resultados a la luz de las ideas centrales que estamos manejando en esta tesis. Es decir, la propuesta de aprendizaje complejo, que incluye la necesidad de apoyarse en el saber existente, la idea de que el alumno ha de ser su propio profesor, la importancia de trabajar desde el punto fuerte con las particularidades individuales de cada uno (gustos y necesidades en cada momento), la posibilidad de cambiar a mentalidad fija a mentalidad en crecimiento y la certeza de que el aprendizaje colaborativo permite un aprendizaje mucho más rico.

\subsubsection{Los cuestionarios de los alumnos}

De entrada, hay que recordar que los cuestionarios que se presentaron a los alumnos se realizaron a lo largo de dos cursos académicos, de cara a dar más validez a la investigación. Entendíamos que al ampliar el estudio a diferentes años se obtendría una información más fiel y rigurosa al no verse tan afectados los datos por cuestiones como determinadas relaciones especiales entre profesor-alumno o una generación especialmente diferenciada. Por eso nos parece muy interesante destacar que las respuestas obtenidas en uno y otro curso académico sean tan homogéneas. En efecto, los resultados de una y otra encuesta son muy similares $\mathrm{y}$, en algunos casos, prácticamente intercambiables. Con ello se demuestra la validez del mismo de cara a extraer conclusiones en favor de las ideas que presentamos en esta tesis. Se presentan a continuación esas conclusiones.

Lo más evidente que se precia en las encuestas es el cambio que experimentan los alumnos ante el conocimiento de las investigaciones. Las afirmaciones 1 ("Sé cuáles son las habilidades, conocimientos y actitudes necesarias para tener éxito como músico") y 2 ("Conozco las últimas investigaciones sobre lo que debería ser la práctica instrumental”) son quizá las más evidentes en este sentido. En ambas se hace referencia al conocimiento de elementos y habilidades de cara a conseguir el éxito y la excelencia musicales, así como a las investigaciones que tratan el asunto. Pues bien, en ambas es donde más cambian los resultados entre la primera y la segunda ocasión en que se les pidió responder a los cuestionarios. Se obtuvieron unos cambios espectaculares en los porcentajes, que prácticamente pasan, por usar la metáfora clásica, del blanco al negro: en la afirmación 1 se pasaba del $20 \%$ al $78 \%$ de acuerdo más o menos total durante el curso 2014-2015, cifras muy similares a las 
del curso siguiente; mientras que en la afirmación 2 se pasaba del $82 \%$ de desacuerdo general al 74\% de acuerdo en el curso 2014-2015 y del 82\% al 85\% en el curso 2015-2016. Lo que nos está diciendo esto son varias cosas: en primer lugar, que hay un reconocimiento explícito de la necesidad de conocer el saber existente (lo que hemos venido llamando "investigaciones acerca de la excelencia musical") como punto de partida irrenunciable para poder seguir trabajando en una línea exitosa. Si algo queda claro, pues, es que los alumnos han interiorizado esa idea de manera clara.

Y algo muy parecido podemos decir de la idea de punto fuerte, recogida en la afirmación 7 ("No me importa reconocer mis puntos fuertes"). En el curso 20142015 se pasó de un 64\% de acuerdo con la misma a un $90 \%$ en el segundo cuestionario. E igual de espectacular fue el cambio del curso siguiente, donde se pasó del $74 \%$ al 95\%. Se constata con claridad meridiana la importancia que se dio a lo largo del curso al punto fuerte de cada estudiante como piedra angular desde la que se debe partir para progresar en la excelencia. Ya hemos dicho anteriormente que esa reticencia a reconocer el punto fuerte se podría deber a la convención social que recomienda humildad en la expresión de nuestras aptitudes. Pero cruzando este dato del alumnado con el del profesorado podemos comprobar cómo no es del todo cierto. En el cuestionario contestado por los profesores del conservatorio, un $88 \%$ manifestaba su acuerdo con la afirmación, lo que no deja de ser interesante: se trata de una cifra que está más cercana a la que manifestaron los alumnos al final del trabajo de investigación.

Otra afirmación que es interesante reseñar en relación con el objeto de nuestras investigaciones es la que hace referencia a la independencia del alumno respecto al profesor. Se trata de la afirmación 39 (“Además de los objetivos que me marca mi profesor yo suelo marcarme mis propios objetivos individuales para cada curso"). En ésta, si bien el cambio que se produce no es tan espectacular como en las anteriores afirmaciones, sí hay un claro desplazamiento hacia el acuerdo de una a otra encuesta. La idea de que cada uno debe ser su propio profesor (Sloboda, 1987) parece que ha ido arraigando en el alumnado, sin que por ello se menoscabe la importancia que tiene el profesor en su formación musical. 
De hecho, y en esta línea, es interesante también destacar cómo la opinión que el alumnado mantiene acerca de sus profesores no cambia de manera radical en los cuestionarios. Las afirmaciones relativas a este aspecto (de la 60 a la 64) son quizá las que se mantienen más estables, con pequeños cambios de matiz, como hemos visto en lo resultados. Como destacábamos en el momento de reseñar los resultados, esto avala la idea, ya comentada a lo largo de la tesis, de que a un profesor se le conoce con mucha facilidad y rapidez, algunas teorías dicen que en apenas unos minutos, (Ambady y Rosenthal, en Bain, 2004:14) y que las variaciones que puedan producirse en el criterio y la apreciación que podamos tener de uno de ellos sólo se altera, circunstancialmente, si ocurren cambios drásticos en el comportamiento del propio profesor. Es evidente que en el periodo que hemos estudiado (cuatro meses) esos cambios difícilmente podían producirse.

En cambio, sí se produjo un interesante cambio en la afirmación 36 ("Cuando fracaso o no consigo alcanzar los objetivos propuestos pienso que es porque no tengo bastante talento musical"), donde se pasó del 71\% de desacuerdo al $84 \%$ en el curso 2014-2015 y del del $73 \%$ al $81 \%$ en el curso 2015-2016. Es cierto que no se trata de un cambio espectacular (y por eso no lo hemos incluido en el apartado de las afirmaciones que cambian mucho), pero sí es interesante constatarlo, sobre todo porque el matiz indica que, si bien ya tenían una intuición acerca del asunto, el conocimiento de la posibilidad de pasar de mentalidad fija a mentalidad en crecimiento les ayuda a reforzar esa posibilidad de trabajar en la excelencia. No se trata, por tanto, de una cuestión de talento innata, ya que todos ellos han pasado por unas pruebas de selección muy exhaustivas (obligatorias para estudiar en un conservatorio superior), sino de saber aplicar el talento que ya tienen de una manera productiva.

En conclusión, los cuestionarios son la primera prueba que tenemos de que los elementos principales que manejamos en esta tesis han sido aprehendidos de alguna manera por nuestros alumnos. Pero esto que afirmamos se puede comprobar de manera mucho más clara analizando el trabajo realizado en los grupos de discusión, como veremos a continuación. 


\subsubsection{Los grupos de discusión}

Como se ha venido comentando a lo largo de la tesis, con los alumnos se trabajó de manera exhaustiva a partir de una serie de textos que, de algún modo, reflejaban el estado de las investigaciones actuales sobre la excelencia (tanto en su acepción general como en su aplicación más concreta a la práctica musical). A partir de esos textos, se trabajó en el aula en forma de pequeños grupos, de los que se extrajeron multitud de ideas, tal como hemos ido desgranando en las páginas anteriores. A lo largo de la tesis se han presentado algunos de estos testimonios para ilustrar casos específicos. Se presentan a continuación las conclusiones generales que se han obtenido mediante el debate en los grupos de discusión, en relación con los objetivos de esta tesis y sus ideas centrales. Puesto que los testimonios ya se han reflejado de manera literal, nos remitimos al capítulo en que aparecen para su posible revisión.

Lo primero que salta a la vista es la seguridad que se aprecia en los estudiantes tras el trabajo realizado con ellos. Las investigaciones les han permitido profundizar no sólo en el conocimiento de las herramientas que se necesitan para alcanzar la excelencia como músicos, sino también (y casi más importante) en lo que tienen que dar de sí para mejorar personalmente. La mayoría de los testimonios que hemos ido desgranando a lo largo de la parte práctica de esta tesis iban en esa dirección: mejora de la autoestima, afianzamiento de la propia posición, autoconocimiento más profundo, nuevas aportaciones para superar problemas puntuales, etc. Como hemos repetido ya en numerosas ocasiones ( $\sin$ ir más lejos, en el análisis de los cuestionarios de alumnos), apoyarse en el saber existente es la primera premisa para cualquier tipo de aprendizaje que quiera ser válido y funcional.

Ese punto de partida se completa con toda una serie de elementos que ahondan en lo que venimos afirmando en nuestra tesis. Partiendo del saber existente se va a construir un saber sólido, que está en la línea de lo que afirmaba Sloboda (1987) de que el profesor siempre puede mejorar y nos muestra los puntos en los que debemos seguir insistiendo (conocer al alumno, quererse, tener altas expectativas, dar buena información y no aislarse) y que nosotros aplicamos a que el estudiante de música debe ser su propio profesor durante toda su vida y, en consecuencia, debe conocerse, quererse, tener altas expectativas, proporcionarse buena información y no aislarse. 
Esta autoconciencia mejora su práctica musical y les abre a nuevas posibilidades. En esta línea, les va a permitir (como reconocían de manera muy clara y en ocasiones incluso vehemente) la no aceptación de imposiciones que estén en contra de lo que ellos consideran su propio estilo o su propia forma de desarrollo musical (a no ser que se le explique o se le den los argumentos avalados por las investigaciones de por qué les es útil para lo que quieren conseguir y en qué medida). Es la idea que venimos defendiendo del "músico convencido", que se complementaría con la del "músico apoyado" que buscamos a través de nuestra propuesta de Aprendizaje Complejo.

Y ésta idea es otra de las que se han repetido en los comentarios de los grupos de trabajo. En la misma línea que parte del conocimiento de las investigaciones (el saber existente) está la de aceptar otras posibilidades de aprendizaje. Quizá la más repetida ha sido la del aprendizaje informal, que por lo general es algo que tienen interiorizado como "negativo", dado que no suele tener una relación directa con lo que se estudia en las aulas (hablamos de los grupos en los que tocan, las charangas, las escuelas en donde algunos dan clase, las jam sessions, etc.). La certeza, apoyada en las investigaciones, de que se trata de un tipo de aprendizaje que siempre suma y nunca resta les ha hecho valorarlo más y, de paso, abrirse a otras posibilidades y otras herramientas. Pero esta nueva certeza se apoya en otras dos ideas que se han repetido de manera constante en los grupos de trabajo, y que están íntimamente ligadas con la que acabamos de comentar: la del "punto fuerte" y la del aprendizaje colaborativo.

El "punto fuerte" es quizá la idea que más ha sorprendido al alumnado, acostumbrado habitualmente a tener que lidiar con su opuesto, esto es, el punto débil. Es cierto (nadie lo puede negar) que es importante trabajar por mejorar esos puntos débiles que todo músico tiene, no importa el talento que tenga. Pero la idea del "punto fuerte" da una nueva dimensión al aprendizaje (insistimos, desde la perspectiva que denominamos "Aprendizaje Complejo"). Si en lugar de centrar el trabajo partiendo de la frustración que supone el reconocimiento de algo que se hace mal, se parte de la certeza de algo que se hace excepcionalmente bien, el resultado no puede ser otro que la mejoría. Y eso es lo que comentaban de manera general los estudiantes en los grupos de trabajo, con ejemplos realmente plásticos en algunos casos (recordamos aquí, por su expresividad, el del trompetista con una 
impresionante capacidad para dar notas agudas). En este punto, es interesante reseñar el impacto producido por la teoría de Carol Dweck (2006), a la que también han dedicado unos interesantes comentarios, aceptando la posibilidad de transitar de una a otra mentalidad, como forma de mejorar precisamente ese "punto débil" que todos tienen y que tantos quebraderos de cabeza les causa.

En relación a este tema también ha sido especialmente significativo el descubrimiento, por parte de los alumnos, del valor que tiene lo que les diferencia de los demás, en el sentido de hacer algunas cosas mucho mejor o mucho peor que otros. Las investigaciones insistían en que debían desarrollar esa parte individual, al mismo tiempo que defendían la certeza de que para mejorar la práctica de cada alumno, el profesor debía ser consciente de la individualidad de cada estudiante, por lo que no funciona los mismo con todos. Así, es necesario dedicar tiempo a ensayar nuevas estrategias con el alumno, disuadirle de las inútiles y mostrarle estrategias que usan los expertos, pero sin imponerles lo que hacían ellos cuando eran estudiantes (Lehmann y Jorguesen, 2012). El alumnado se ha dado cuenta de la importancia de luchar por tocar lo que les gusta y les parece interesante, de la elección del repertorio como fuente de motivación (Hallam, 1998) y de que se aprende más rápidamente cuando lo que tocas lo conoces y te gusta (McPherson, 2000 y Sloboda et al. 1996). También han comprobado mediante otra experiencia práctica, el tarareo de obras que habían tocado, incluyendo temas que les gustaban y temas que no. Así, las primeras las recordaban casi perfectamente, con detalles técnicos y expresivos mucho más claros. Fue interesante comprobar cómo la forma de tararearlas era muy distinta, pues de las que les gustaban recordaban incluso las notas (cambiaban la vocal del tarareo en función de la nota), marcaban la expresión, la articulación y el fraseo, incluso de la parte del acompañamiento y, sin embargo, esto no se producía en las que no les gustaban, que reproducían con muchos más fallos y dificultad y, en ocasiones, no recordando ni el título. La explicación se puede encontrar en el hallazgo comentado en la tesis de la importancia que ha demostrado la práctica mental, es decir, que las obras que le gustaban las seguían trabajando mentalmente, de manera que, quizá por esa razón, las aprendían antes y las recordaban durante más tiempo, aunque no las interpretasen físicamente.

Y el aprendizaje colaborativo (que está también implícito de algún modo en el 
aprendizaje informal) ha roto también con otra idea preconcebida (casi podríamos decir que es un prejuicio) típica de los conservatorios de música: la de la competitividad y el aprendizaje en solitario. Los testimonios acerca del valor que han encontrado en el trabajo conjunto han sido numerosos y casi podríamos decir que los primeros sorprendidos eran los mismos alumnos.

Como vemos, todos los elementos que presentamos en la tesis aparecen en los comentarios de los grupos de trabajo: partir del saber existente (las investigaciones al respecto), tomar conciencia de la propia dinámica de aprendizaje (ser su propio profesor), reconocer el "punto fuerte" para construir la excelencia sobre éste (admitiendo la posibilidad de mejora, tal como explica la teoría de la mentalidad fijaen crecimiento), utilizar todo tipo de herramientas que puedan resultar eficaces (como, por ejemplo, el aprendizaje informal, el aprendizaje colaborativo o la práctica mental) y, en definitiva, dirigir su aprendizaje de una forma integral, en eso que hemos denominado Aprendizaje Complejo.

\subsubsection{El cuestionario de los profesores}

Como ya se ha comentado, el cuestionario que se le pasó al profesorado no era exactamente igual que el del alumnado y, además, no se hizo un segundo pase del mismo, ya que no hubo intervención alguna sobre este grupo. Dicho de otro modo, los resultados que hemos visto en el apartado dedicado al mismo hay que tomarlos dentro de este contexto, es decir, un grupo que no forma parte directa de la investigación, sino que se sitúa en un margen de la misma, aunque las opiniones que ofrecen pueden ser de cierto interés y afectan de cierta manera a los estudiantes, como veremos, que son precisamente el objeto de nuestra investigación.

La impresión general que nos han proporcionado los resultados del cuestionario es que el profesorado del Conservatorio Superior de Navarra se posiciona de manera bastante clara en la misma línea que defendemos en esta tesis, es decir, en la del Aprendizaje Complejo (salvo un grupo muy minoritario que se manifiesta en una posición muy distinta, por no decir opuesta). No vamos a desgranar aquí las cifras

que hemos reflejado en el apartado correspondiente, sino que nos limitaremos a hablar de mayorías y minorías en las respuestas. 
De entrada, casi todos admiten estar al día en el conocimiento de las últimas investigaciones en el terreno de la excelencia musical (aunque hay una minoría que, sorprendentemente, no cree siquiera importante conocer este tipo de investigaciones). Esto casa de manera extraña con lo que comenta el alumnado acerca de su desconocimiento de este factor, si bien puede suceder que se conozcan las investigaciones y no se compartan con los alumnos.

Otro elemento interesante es la consideración que presentan ante el "punto fuerte" y el "punto débil". Como ya dijimos al comentar el cuestionario de los alumnos, la aceptación del punto fuerte es masiva entre el profesorado, casi tan elevada como el del alumnado tras el segundo cuestionario. Pero es mucho más contundente el resultado ante la pregunta sobre el punto débil. El 100\% de los profesores lo reconoce sin problemas, lo que demuestra que ha sido un caballo de batalla recurrente en el pasado (como sigue siéndolo en el presente).

El trabajo colaborativo también ofrece una interesante respuesta por parte del profesorado. Si bien la mayoría reconoce la importancia de éste, esa mayoría se desvanece cuando se pregunta si se está llevando a la práctica. Y lo mismo sucede cuando se pregunta en teoría por otros elementos del Aprendizaje Complejo, como el aprendizaje informal, el enfrentarse a nuevos retos, el tocar otras cosas aparte de lo que compone el temario, darles autonomía en su desarrollo profesional y personal, etc. Lo que en otra investigación podría proponerse es conocer qué grado de realidad hay en estas afirmaciones bienintencionadas. Pero, obviamente, esto ya no forma parte de nuestro propósito en la investigación. 

PARTE IV

CONCLUSIONES Y LÍNEAS FUTURAS 

A lo largo de esta investigación se ha tratado de desentrañar las características y medios para lograr la excelencia musical entre los estudiantes de música en un conservatorio superior de música con unas determinadas características, unos medios humanos concretos y unos materiales particulares: el Conservatorio Superior de Música de Navarra, donde ejerzo mi labor como docente. Se planteaba así una aproximación desde el paradigma de la investigación-acción, en la que los sujetos son conscientes de estar participando en la investigación con la finalidad de solucionar un problema o mejorar una situación dada.

Para ello se realizaron entrevistas y cuestionarios, éstos últimos tratados de manera estadística, principalmente para obtener ideas claras en torno a si hay consenso entre las opiniones aportadas por los estudiantes, si se puede conocer mejor la realidad a partir de sus apreciaciones y, especialmente, para verificar de qué manera afectó la intervención realizada al logro de $-\mathrm{O}$ al menos a la aproximación hacia- la excelencia musical.

Todo ello fue contrastándose con la información recogida a partir de otros investigadores y con las informaciones que se iban recabando a partir de la observación y de los grupos de discusión. De este modo se abordó el enfoque cualitativo como el más claramente representativo de este trabajo. La implicación de todos los miembros de la comunidad educativa en esta investigación recomendaba la aplicación de una perspectiva holística; la interacción de cada una de las piezas de este puzzle con cada una de las otras para evidenciar así de manera clara su implicación dentro del contexto educativo.

El objetivo general de la tesis es el siguiente:

Conocer las herramientas y habilidades necesarias para convertirse en un músico excelente y buscar los medios para lograrlo en su aplicación específica en el Conservatorio Superior de Música de Navarra. 
Para lograr este objetivo general dividimos éste en otros más específicos que nos han ayudado a llegar al general, de modo que nos permitieran abordar de manera más eficaz nuestro estudio. A lo largo de las siguientes páginas iremos desgranando cómo se han trabajado metodológicamente estos objetivos secundarios y de qué manera han ayudado a conseguir el objetivo general.

En el caso del objetivo específico primero, "Obtener una aproximación objetiva a lo que constituye la excelencia musical en el siglo XXI, de manera que se pueda transmitir a los alumnos y éstos la hagan suya" se partió de una búsqueda bibliográfica inicial, que nos permitiera estar en disposición de presentar a los alumnos ese material teórico.

No cabe duda de que este objetivo era muy ambicioso, pues la excelencia es un concepto muy amplio y aunque parece que es una tarea fácil y hasta evidente el reconocer algo excelente cuando se tiene delante, el problema aparece cuando se busca el camino para lograr esa excelencia. De hecho, en las últimas investigaciones al respecto (Hambrick et al., 2014) se insiste en la importancia de los factores no especificados, que tendrían un peso mucho mayor que la práctica deliberada y consciente, algo que tan sólo puede explicar un $30 \%$ de las diferencias que se manifiestan entre las interpretaciones que pueden realizar varios músicos distintos. De la misma manera, Ackerman (2014) afirma que cualquier intento de reducir los diferentes elementos que entran en juego a uno sólo, o a un extremo demasiado marcado, para conseguir una interpretación excelente (el talento natural o lo aprendido) es ridículo y estéril, pues tanto el talento como la educación son imprescindibles para conseguir esa interpretación excelente. Igualmente, indica que es prácticamente imposible determinar qué individuos desarrollarán finalmente niveles de interpretación excelentes, porque las limitaciones a la hora de estudiar este hecho son innumerables. Por otra parte, se ha visto claramente la necesidad de redefinir a qué llamamos excelencia musical en el siglo XXI (Conway y Hogman, 2009, Eccles, O'Neill y Wigfield, 2005, Ivaldi y O'Neill 2010, O' Neill, 2011, Hallam y Gaunt 2012 y Dobson y Gaunt, 2015) debido a que el panorama musical está cambiando y van apareciendo nuevas profesiones para el músico, mientras que otras que antes eran imprescindibles van perdiendo protagonismo. Por eso, llega el momento de preguntarnos si las habilidades que necesitan los músicos 
contemporáneos son las mismas que se necesitaban hace cien años y si les estamos preparando para el momento en que viven.

Pero no se trata sólo de esto que comentamos. Al tocar el tema de la excelencia se parte siempre de la idea de que todos los alumnos del Conservatorio Superior de Música de Navarra van a ser excelentes músicos, o al menos eso es lo que se entiende cuando se dice que ya de entrada se ha seleccionado a los que reúnen determinadas características (talento) y se les va a dar una enseñanza individualizada. Pero resulta que la propia palabra "excelente" lleva aparejada la idea de "sobresalir, ser mejor que los demás". Y, sin embargo, la idea de que obtener la excelencia es algo unívoco es errónea, puesto que se puede sobresalir en cosas distintas. De hecho, cada músico excelente tiene unas habilidades distintas y, desde luego, no posee todas sus cualidades como tal desarrolladas en el mismo nivel. Cada uno destaca en algo y quizá sea eso lo que le haga ser excelente, de ahí la importancia extrema de seguir trabajando el punto fuerte, porque es ahí donde vamos a conseguir más avances con menor esfuerzo y donde de verdad podemos acabar encontrando nuestra excelencia.

La dificultad comentada a la hora de tratar el concepto de excelencia es evidente. Por eso nuestro planteamiento se ha centrado en ver qué necesidades tienen los alumnos del Conservatorio Superior de Música de Navarra y qué ayudas les son más útiles en este momento para seguir buscando esa excelencia. Esta búsqueda de nuestro modelo de excelencia se asienta en tres ideas que hemos considerado fundamentales:

Toda búsqueda de la excelencia debe estar apoyada en el saber existente. Hemos comprobado, tanto en los resultados de los test como en los grupos de discusión y en la valoración que han hecho después de realizar el segundo test, que el conocimiento de lo que se ha estudiado sobre la excelencia musical les ha ayudado a entender mejor qué tenían que buscar cuando estudiaban, qué podía ayudarles a conseguirlo y además a cuestionarse e incluso eliminar algunas prácticas que no les ayudaban. El conocimiento por parte de nuestros alumnos de algunas de las investigaciones les ha ayudado a reflexionar sobre lo que estaban haciendo y a plantearse cómo mejorarlo.

La idea o producto que merece la etiqueta de "excelente" surge de la sinergia de muchos recursos y no sólo de la mente de una única persona. 
En este sentido, los instrumentos metodológicos utilizados han sido de gran ayuda. Dentro del modelo de investigación acción, se empezó a trabajar por medio de textos teóricos, a partir de los cuales los alumnos respondieron a una serie de cuestiones para posteriormente llevarlo a los grupos de discusión. Se trata del momento que Tripp (2003) señala como aquél en el que los sujetos de la investigación se convierten en participantes, permitiendo la modulación del trabajo que se está realizando y, sobre todo, la consecución del objetivo planteado, que pretendía que los alumnos hicieran suya la idea de cómo se consigue la excelencia musical. Precisamente en los testimonios que han salido de los grupos de discusión se ha visto cómo los alumnos, al reflexionar sobre su carrera musical, reconocen y manifiestan la importancia que ha tenido y sigue teniendo su entorno en lo que ellos son como músicos, empezando por su familia, que les inició en el mundo de la música y, durante mucho tiempo, les paga los estudios musicales (en ocasiones muy caros, incluyendo la compra de instrumentos y materiales); continuando con ese adulto clave en un momento determinado, que les hizo "engancharse" a la música; siguiendo con los profesores y compañeros que comparten las aventuras del día a día. Y también han reconocido en los test y en los grupos de discusión que no están acostumbrados a aprender de forma colaborativa, y que se reconocen más en el viejo paradigma de enseñanza superior, que supone un contexto competitivo e individualista, más que en un contexto de aprendizaje colaborativo donde todo se comparte.

Ven evidente también que en ocasiones les faltan recursos económicos y así lo han manifestado en los grupos de discusión (algunos ni se plantean irse como alumnos de Erasmus, porque la beca no cubre los gastos y explicitan que les gustaría seguir estudiando pero no saben si podrán permitírselo). Por eso, podemos decir que es evidente que faltan apoyos institucionales, necesarios en la búsqueda de excelencia, para que ésta no llegue sólo a unos pocos y que las expectativas puedan ser iguales para todos, premiando su habilidad y esfuerzo.

Para conseguir la excelencia es necesario crear un ambiente que proporcione libertad de acción y estimulación de ideas, junto con una actitud de respeto y apoyo entre todos los miembros de la comunidad educativa. 
Es evidente que el ambiente que se ha creado en los grupos de discusión ha ayudado a los alumnos a explicitar sus puntos fuertes y sus puntos débiles, a conocerse mejor, valorar más la opinión de sus compañeros, valorarse más y todo ello sin cambiar la opinión que tienen con respecto a los profesores, pues como se puede ver en el análisis del cuestionario de alumnos, las opiniones que tienen con respecto a su profesor se mantienen prácticamente iguales en los dos test.

Objetivo específico segundo: "Conocer las características del estudiante ideal de la enseñanza superior, así como del entorno ideal necesario que debe acompañarle, de cara a conseguir la excelencia."

De cara a conseguir este objetivo se desarrolló la parte central del trabajo metodológico, es decir, la realización del cuestionario inicial, el desarrollo del trabajo práctico con los textos y la posterior tormenta de ideas en los grupos de discusión y la reflexión final que supuso la segunda realización del cuestionario y su comparación con el primero. El cuestionario inicial nos sirvió para saber en qué lugar nos encontrábamos al inicio de la investigación, de manera que el trabajo de los grupos de discusión permitió que las ideas y objetivos de los que partíamos se ampliaran y completaran, tal como hemos ido comentando a lo largo de la tesis. Y no nos cabe duda de que ha funcionado con nuestros alumnos, como se desprende de muchos de los comentarios que hemos citado textualmente en el capítulo dedicado al trabajo de los grupos de discusión. Y de eso precisamente es de lo que vamos a hablar a continuación, es decir, de cuáles deben ser las características que debe poseer el estudiante de música ideal.

Se puede decir que el estudiante de música ideal que hemos propuesto como modelo es el estudiante convencido y apoyado. Es evidente que el estudiante de música convencido de lo que hace, lo realiza mejor, con más ganas, a su manera y con muchas más posibilidades de perseverar en la tarea a realizar. Es lo que podríamos llamar un "estudiante responsable de su propio aprendizaje" (Hallam y Gaunt, 2012). Hemos comprobado que el conocimiento de las últimas investigaciones sobre los músicos ha ayudado a los alumnos de nuestra investigación a ganar en autoestima, a sentirse apoyados en sus intuiciones y a hacer descubrimientos que les han animado a reflexionar y cuestionar lo que estaban haciendo (empiezan a darle importancia al 
aprendizaje colaborativo, a buscar un estilo propio, a elegir el repertorio que les gusta, a apoyarse en su punto fuerte y seguir desarrollándolo cada vez más), a atreverse a probar otras cosas (como, por ejemplo, usar la práctica mental o dejar de pensar con mentalidad fija en cosas que no podían hacer y pasarlas a mentalidad en crecimiento, utilizando el "todavía no me sale" en lugar de "en esto soy negado") y todo ello con la ayuda de sus compañeros, que les ayudan a verse desde fuera, como valiosos y únicos, sin competencias, pues cada uno tiene su punto fuerte que desarrollar y que convence a los demás en lo artista que es, tirando de este punto fuerte para desarrollar también lo que le cuesta más esfuerzo pero que es igualmente necesario en algún momento. Consigue así trabajar de la forma que le es más fácil y desarrollar esa mentalidad en crecimiento que ya tienen en muchos ámbitos y trasladarla a otros en los que la tenía en fija. Nuestro descubrimiento ha sido que son capaces de pasar en muchos casos de mentalidad fija a mentalidad en crecimiento y, una vez que se ha transitado a la mentalidad en crecimiento, se ha demostrado (Smith, 2005) que el alumno va a implicar mucho más en la tarea que en realzar su ego. Si, además, lo consigue gracias a la ayuda de sus compañeros (tal como hemos hecho en los grupos de discusión, donde eran los demás los que le ayudaban a pasar los trucos que cada uno utiliza en mentalidad en crecimiento al trabajo que se hacía en mentalidad fija) va a ser mucho más fácil que el éxito de cada uno sea compartido por todos los demás, ya que todos se sienten copartícipes de ese éxito y le va a ser mucho más fácil ser el músico convencido y apoyado que va a conseguir la excelencia o al menos la buscará por el camino adecuado, disfrutando en el intento.

Otra cuestión que ha sido determinante de cara a buscar las características del alumno ideal de la enseñanza superior ha sido el plantear que él mismo va a ser su mejor profesor, el que va a tener más a mano y el que mejor va a poder hacer las cosas a su manera, y por ello le podría ser útil aplicarse las ideas que propone Sloboda (1987) acerca de cómo ser mejor profesor para tratarse mejor a sí mismo. De esta manera, se incluye también la idea de que es responsable de su propio aprendizaje y que es necesario que conozca lo que dicen las investigaciones para poder aplicárselo a sí mismo. En esta propuesta se aplican estas ideas, actualizándolas e incluyendo las últimas investigaciones sobre el tema y los hallazgos que aparecen en nuestros grupos de discusión. Las ideas son: 
Conocerse a sí mismo: donde hemos incluido el análisis de la habilidad exitosa o del "punto fuerte"de cada uno. Es evidente en nuestra investigación que el ser consciente de cuál es su "punto fuerte" o lo que dominan sin demasiado esfuerzo les ha ayudado a aumentar su autoestima y a sentirse con muchas más ganas de estudiar. El análisis de su "punto fuerte" les ha permitido conocerse en su mejor momento, reconociendo el estado que les lleva a conseguir experiencias sublimes, momentos especiales y la sensación de "flow" (Csikszentimihályi, 1996). También les ha permitido darse cuenta de cómo utilizan la mentalidad en crecimiento (Dweck, 2006), dónde ponen el foco de atención (Buma et al. 2015, Goleman, Gonzáles y Mora, 2013) y cómo utilizan la creatividad cuando se está en buen momento (Csikszentimihályi, 1996, Sternberg, 1996, Gardner, 2005, Kaufman y Sternberg, 2006). Tras este análisis, les es más fácil reflexionar sobre cómo abordar sus puntos débiles y mejorar su capacidad de trabajo y resiliencia, reflexionando sobre su propia práctica, tanto a la hora de interpretar como de estudiar (Nielsen 2004 y Hallam et al., 2012), reconociendo cuándo, cómo, dónde y con quién prefieren practicar y actuar.

Quererse. Queda demostrado que el seguir trabajando "el punto fuerte" o la habilidad exitosa, es decir, el talento que han visto más fácilmente desarrollable para conseguir experiencias autotélicas (es decir, experiencias que se recompensan por sí mismas y de las que no se espera una recompensa posterior) ha sido reconocido por los alumnos de nuestra investigación como una de las mejores autorrecompensas. El trabajo en su punto fuerte, donde con un poco de esfuerzo obtienen mucho desarrollo, es lo que anima a seguir buscando para seguir disfrutando. El reflexionar sobre lo que le gusta y con qué disfruta cada uno y utilizar la forma que le es más gratificante para hacer las cosas de forma individual y creativa, disfrutando de la consecución de sus objetivos individuales y a su manera lo han visto como una de las estrategias mejores para lograr bienestar, tal como indican las investigaciones al respecto (Csikszentimihályi, M. y Csikszentimihályi, I. 2006).

Tener altas expectativas. Tanto en los grupos de discusión como en los test y la reflexión que se ha llevado a cabo sobre ellos se ha hecho evidente cómo los alumnos han mejorado las expectativas que tenían al plantearse objetivos y retos a corto, medio y largo plazo, disfrutando de su consecución, y aprendiendo a adaptar las expectativas a las necesidades individuales que se les iban presentando en el día a 
día, animándose así a buscar actividades que se apoyan en sus puntos fuertes y se recompensen por sí mismas.

Darse buena información. Todos los participantes en la investigación han valorado la importancia de conocer las últimas investigaciones sobre cómo conseguir la excelencia musical. En concreto, han valorado muy satisfactoriamente la compilación realizada por Hallam y Gaunt, 2012 de lo que sería interesante para tener éxito como músico profesional, así como la opinión de los distintos profesores, amigos y mentores en los que confían.

No aislarse. La mayoría de los participantes en la investigación reconocen fundamental el tocar con otros y disfrutan de la interpretación en grupo. Sin embargo, no están acostumbrados a contar con los demás a la hora de aprender o estudiar, y tienden a pensar más en un aprendizaje individualizado. Tras la lectura de las investigaciones y ver la importancia que en ellas se da al aprendizaje colaborativo e informal, valoran mucho más tanto lo que le pueden aportar los compañeros como lo que aprenden con músicos con los que se relacionan, a veces de manera más informal.

Tras dejar claro cuáles son las características del estudiante ideal de la enseñanza superior para conseguir la excelencia, que podrían resumirse en ser un músico convencido y apoyado que se conozca, se quiera, tenga altas expectativas, sepa buscar buena información y rodearse de un grupo que le apoye con el que aprender, crear y disfrutar, podríamos plantearnos cuáles son las características del entorno ideal que permita conseguir la excelencia. Tras llevar a cabo la investigación parece claro que la respuesta es la creación de un entorno donde el estudiante tenga los recursos necesarios que le permitan conseguir esa excelencia, donde pueda equivocarse, explorar sin miedos, arriesgar y crear; un lugar, en definitiva, donde pueda elegir lo que quiere aprender en función de sus necesidades y donde pueda convertirse en el músico convencido y apoyado que busca la excelencia. El lugar donde pueda conocerse y sentirse conocido, quererse y sentirse querido, tener altas expectativas y compartirlas con los demás, a la vez que obtiene la información que necesita en cada momento y donde no se sienta aislado sino apoyado por profesores, compañeros y amigos que disfrutan con sus éxitos tanto como él, porque también son 
músicos convencidos y apoyados. Como profesores hemos intentado que en los grupos de discusión los estudiantes de la enseñanza superior se sintieran escuchados y apoyados en un entorno seguro, tal como indican las investigaciones (Bruffee, 1993, Westerlund y Gaund, 2013, Rutherford, 2014, Benett, 2016) que es necesario para que los alumnos de la educación superior puedan dar lo mejor de sí mismos.

\section{Objetivo específico segundo: "Localizar las herramientas útiles para el estudiante de música a la hora de buscar la excelencia musical e indagar sobre la forma de aplicarlas."}

Es con este objetivo donde se ha mostrado más útil el modelo de investigación acción, puesto que ha sido a través del trabajo realizado en los grupos de discusión (tras la realización del conocido cuestionario y previa a la reflexión última que suponía la repetición del cuestionario al final de la intervención) como hemos podido ir modulando este objetivo, de cara a reconocer las herramientas que pueden ser más interesantes para el estudiante de música que quiera conseguir la excelencia. Las respuestas individuales de cada alumno, el trabajo posterior de puesta en común y la discusión final en gran grupo nos han permitido enlazar con los contenidos de las investigaciones existentes y, al hilo de éstas, descubrir cómo surgen una serie de herramientas que pensamos han de ser de gran utilidad en la búsqueda de la excelencia musical.

Como decimos, al profundizar en el estudio de las investigaciones sobre la excelencia musical y trabajar en los grupos de discusión con los alumnos, descubrimos que había algunos aspectos que llamaban especialmente la atención de los alumnos y que los asimilaban y aplicaban casi sin darse cuenta, y producían en ellos tan buen resultado, que no podían dejar de compartirlo con los demás, de modo que animaban a trabajarlo. Entre estas herramientas que se han encontrado muy útiles para los estudiantes de nuestra investigación hemos seleccionado las principales, por el interés que ha suscitado en ellos, por la relevancia y actualidad que tenía en las investigaciones y por la poca presencia que los alumnos encontraban en su práctica diaria. Estas son: el trabajo de la creatividad, el aprendizaje colaborativo, la práctica mental, el trabajo sobre el punto fuerte y la propuesta de aprendizaje complejo que aplica la teoría de mentalidad fija y en crecimiento de Carol Dweck. 
La creatividad. La utilización de la creatividad como su forma de trabajo, la reflexión sobre cuándo, cómo y dónde trabajan de forma creativa y el reconocer cómo pueden intensificar su desarrollo les ha ayudado a disfrutar mucho más de lo que hacen. Han comprobado que el reconocimiento de sus momentos de "flow" hace que se multipliquen (como había explicado Csikszentimihályi, 1996), se dan cuenta de la importancia de tener un estilo propio de hacer las cosas y buscarlo de forma personal y de lo útil que es buscar su propia forma creativa de estudiar para conseguir la excelencia (como había demostrado Hallam, 1995) y lo mejor es que al buscar esta forma individual de hacer las cosas disfrutan mucho más con lo que hacen y se animan a seguir haciéndolo. Todo ello les ha ayudado también a aumentar la confianza en sí mismos y a darse cuenta de la importancia de equilibrar el trabajo creativo con el analítico y el práctico para tener éxito (como sugiere Sternberg, 1996). También han reconocido que la reflexión sobre la creatividad les ha hecho valorar a los demás por lo que tienen de diferente y apreciar otras formas de hacer las cosas, descubriendo otros estilos y ampliando las posibilidades de aprendizaje como lo que aprenden en la enseñanza informal o en conversaciones con otros compañeros de otros instrumentos, estilos y edades. Lo que lleva al siguiente punto: la importancia del aprendizaje colaborativo ya que como explica Csikszentimihályi, (1996) la idea o producto que merece la etiqueta de "creativo" surge de la sinergia de muchos recursos y no sólo de la mente de una persona

- El aprendizaje colaborativo ha resultado ser una de las herramientas más importantes para los estudiantes en el proceso a la hora de convertirlo en algo habitual en su trabajo. Como constatan las investigaciones (Gaunt y Westerlund, 2013), el aprendizaje colaborativo en la educación superior ayuda a controlar mejor el propio aprendizaje, la independencia, la creatividad y la flexibilidad. El resultado obtenido fue especialmente significativo cuando pudieron comprobar esta utilidad y la compartieron en los grupos de discusión. Tras leer el texto de Dweck (2006) y 
pedirles que realizaran la actividad allí explicada ${ }^{42}$, se dieron cuenta de que lo que se presentaba en ese texto no era algo que se puede llevar a la práctica de manera fácil. Sin embargo, cuando aplicamos el aprendizaje colaborativo a la teoría de Dweck es cuando comprobaron la importancia de este aprendizaje en grupo, es decir, que al trabajar con los demás (aprendiendo colaborativamente) es cuando se empieza a pasar de mentalidad fija a mentalidad en crecimiento, por muchas razones: es más fácil persistir dado que estamos apoyados, los esfuerzos que de manera individual consideramos inútiles pasan a convertirse en útiles para el grupo o para parte del grupo, las críticas pueden usarse para mejorar de manera individual y conjunta, el éxito de los otros, que en la enseñanza tradicional pueden verse como una amenaza, aquí se convierten en un éxito compartido, etc. Como hemos visto en varios de los testimonios extraídos de los grupos de discusión, los propios alumnos han valorado como muy positiva esta herramienta que les permite mejorar de manera evidente $y$, dicho sea de paso, encaminarse hacia la obtención de la excelencia musical.

La práctica mental como vimos en su momento, es una herramienta que ha obtenido un reconocimiento importantísimo de cara a alcanzar la excelencia, no sólo en el ámbito de la interpretación musical, sino en otros que requieren de una gran precisión en la ejecución de movimientos (cirujanos, atletas, etc.). El dato que reflejábamos acerca del número de publicaciones que vieron la luz sólo en 2009 (más de 20.000) da fe de este hecho. Como afirmaban Bernardi et al. (2013), "en el campo de la música se ha mostrado que la práctica mental por sí sola puede conducir a los mismos cambios plásticos en el sistema motor que los que se producen con la repetición de la práctica física" Se trata de una afirmación categórica que no viene de una suposición teórica, no de la realización de un gran número de experimentos psicológicos y neurológicos: el citado de Bernardi et al. (2013), Brown y Palmer (2013), Kraeutner et al. (2015) y tantos otros. Quizá precisamente por la novedad que representan estos estudios, los estudiantes no tenían (al menos conscientemente) la

\footnotetext{
${ }^{42}$ Ver Texto 7 en el capítulo 4.5.- Trabajo de los textos en los grupos de discusión.
} 
sensación de haberlos llevado a cabo. Sin embargo mediante un sencillo experimento, pudieron comprobar la influencia que, en efecto, tiene la práctica mental sobre la práctica física y viceversa. El resultado de aquel sencillo experimento de tarareo les demostró cómo la mera práctica mental influía en su práctica física, lo que les dejó gratamente sorprendidos y con ganas de seguir descubriendo el potencial de esta herramienta, tal como describen las investigaciones.

El trabajo del "punto fuerte" no estaba especialmente resaltado en las investigaciones musicales, sí que es cierto que Hallam y Gaunt, (2012) hablan de la importancia de conocer sus puntos fuertes y débiles, sin embargo viendo el efecto que producía en los alumnos el hacerles reconocer cuál era su punto fuerte y animarles a seguir trabajándolo y desarrollándolo, llegamos a la conclusión de que era evidente que el reconocerlo y trabajarlo podía ser de gran ayuda para alcanzar la excelencia musical ya que les ayudaba a mejorar su autoestima y les hacía perseverar también en el trabajo de sus puntos débiles. La seguridad en que tienen su "punto fuerte" y el ver cómo tanto él como su entorno lo reconoce como tal es lo que hace de él el estudiante de música convencido y apoyado que es capaz de seguir trabajando en busca de la excelencia musical. Hemos comprobado con nuestra investigación que el trabajo diario de su punto fuerte les ayudaba a motivarse, a hacer la práctica diaria más efectiva y a disfrutar mucho más de su esfuerzo pues en ese punto siempre se veían recompensados. El analizar y reconocer qué estrategias o trucos utilizan para trabajar y desarrollar este punto fuerte les ayuda a conocerse mejor y ver qué les funciona mejor en su mejor momento. El conseguir que esos trucos individuales se puedan utilizar no sólo para trabajar su punto fuerte, sino que los utilicen de la misma manera para trabajar sus puntos débiles es lo que nos ha llevado a la propuesta de aprendizaje complejo.

\section{Propuesta de aprendizaje complejo}

La propuesta con la hemos trabajado, a la que llamamos "propuesta de aprendizaje complejo" (y que incluye de algún modo todos los elementos que han sido comentados en las líneas que anteceden) se puede caracterizar de la siguiente manera: 
1. Deriva de las tres ideas fundamentales ya expuestas para desarrollar la excelencia (se apoya en el saber existente, necesita muchos recursos materiales y personales y necesita de un ambiente que proporcione libertad de acción y estimulación de ideas junto con actitud de respeto y apoyo entre todos los miembros de la comunidad).

2. Recoge la idea de que cada estudiante de la enseñanza superior va a ser su propio profesor a lo largo de la vida, de modo que le sea muy útil aplicar las ideas que propone Sloboda (1987) para tratarse mejor a sí mismo (conocerse, quererse, tener altas expectativas, proporcionarse buena información y no aislarse). Esta reflexión sobre sí mismo, su forma de hacer las cosas, necesidades e intereses ayuda a poder después plantear mejoras.

3. Insiste en la importancia de reconocer, analizar y ver qué trucos utiliza cada uno, (muchas veces de manera intuitiva o inconsciente) a la hora de desarrollar $\mathrm{su}$ "punto fuerte"

4. Aplica la teoría de Carol Dweck $(1998,2006)$ sobre la mentalidad fija y en crecimiento y ayuda a los estudiantes de la enseñanza superior a transitar de la inteligencia fija a la inteligencia en crecimiento. El solo hecho de conocer que existen las dos les ayuda a cambiar de una a la otra y este cambio es mucho más sencillo en un contexto de aprendizaje colaborativo.

5. Utiliza las ventajas del aprendizaje colaborativo en la educación musical superior, reconocidas por Gaunt y Westerlund (2013), que señalan el impacto que tiene a la hora de apoyar el desarrollo del control del propio aprendizaje, la independencia, la creatividad y la flexibilidad. En nuestra propuesta, el contar con el grupo de apoyo a la hora de aprender le va a ayudar a estar convencido, reconocido y valorado, lo que le va a llevar a valorar lo que tiene de individual, valioso y por tanto excelente y le ayuda a utilizarlo en otros momentos de forma creativa para ampliar su campo de excelencia.

Lo que hemos hecho con los alumnos de nuestro estudio es dar por hecho que tenían mentalidad en crecimiento en alguna de las habilidades musicales, razón por la cual les hemos hecho buscar, analizar y reflexionar sobre su "punto fuerte" o "puntos fuertes" para que vean la forma en que acostumbran a utilizar sus herramientas o trucos propios o individuales en lo que se les da bien y que se atrevan a hacerlo 
público. Les pedíamos a continuación que se fijaran en algo en lo que creían que no son buenos o que se les daba mal y veían muy difícil cambiar (es decir, algo en lo que tuvieran mentalidad fija) e intentábamos comprobar si eran capaces de cambiar de mentalidad fija a mentalidad en crecimiento. Para ello era necesario que conocieran la teoría de Carol Dweck, de modo que vieran que esa posibilidad existía, al mismo tiempo que estudiábamos las investigaciones sobre el aprendizaje musical y la excelencia, para que fueran conscientes de que es importante trabajar en función de sus necesidades, habilidades y expectativas individuales. Igualmente importante era que fueran conscientes de la importancia ayudar a sus compañeros e intercambiar con ellos conocimientos, experiencias y hallazgos que se complementen con los de sus compañeros, para lograr esa excelencia en grupo (tan necesaria) buscando que estén motivados a reflexionar y a dedicar el tiempo y el esfuerzo necesario para conseguirlo.

Dweck (2007) demostraba que conocer los dos tipos de inteligencia ya les mejoraba su motivación para aprender. Pero queríamos dar un paso más y ver si los estudiantes de la enseñanza superior de música se pueden dar cuenta de que utilizan estrategias diferentes cuando están en mentalidad en crecimiento. Por eso les pedíamos que intentaran analizar esas estrategias o trucos que utilizaban en un ámbito en el que se sienten competentes, de modo que probaran a utilizarlo en otro en el que se vean con inteligencia fija. El ser capaz de imaginar cómo aplicar a la inteligencia fija los trucos que ya se tienen en la inteligencia en crecimiento hace que la fija deje de serlo, pues abrimos la posibilidad de utilizar nuestras propias estrategias personales que ya son eficaces para nosotros y nos gustan (por eso son las que aplicamos en lo que nos gusta y se nos da bien) y, por tanto, lo que descubrimos es la posibilidad de hacer que lo que antes nos parecía imposible se vea un poco más accesible. Al realizar esto, lo que sucede es que cada uno está aplicando su propio autoconocimiento, pues analiza lo que hace él y le gusta, cuál es su punto fuerte (donde tiene mentalidad en crecimiento) y su punto débil (donde tiene mentalidad fija) y trabaja la autodeterminación (al abrir la posibilidad de aplicar algo suyo está tomando decisiones propias a ese respecto y reflexionando sobre cómo hacerlo, lo que es el primer paso para llevarlo a cabo) y la independencia que, según Jorgensen (2012), era la habilidad más necesaria para el músico, pues él mismo es el que se está dando 
cuenta de qué es lo que puede cambiar al elegir entre un amplio abanico de posibilidades (pues, en ocasiones, incluyen habilidades musicales, de personalidad, hábitos y estrategias individuales). Ver que busca dónde aplicarlo y ser capaz de exponerlo y compartirlo con sus compañeros les sirve para darse cuenta de que el ámbito en el que lo aplica ya deja de ser algo inalcanzable para convertirse en algo posible, pues ya tenemos hasta estrategias individuales que nos sirven a la hora de conseguirlo. Así, podríamos pasar del "no puedo" al "todavía" no me sale, del que habla Dweck (1999). Lo que hemos constatado es que este trabajo ha sido muy útil para los estudiantes de nuestra investigación ya que algunos han reconocido que había cosas que veían imposibles y han logrado cambiar su percepción, en unas ocasiones aplicando ellos mismos los trucos $\mathrm{y}$, en otras, con los consejos que aportaban sus compañeros, ayudándoles a adaptar y utilizar los mismos trucos en su punto débil que ellos mismos señalaban que habían utilizado para su "punto fuerte". Por ello proponemos este tipo de propuesta como un tipo de herramienta útil para la consecución de la excelencia, tanto individual como en grupo 

Podríamos decir que el principal resultado de la investigación llevada a cabo con los alumnos es el hecho de que éstos, tras el trabajo realizado, han aprendido a valorar e incorporar a su práctica cotidiana la importancia que tiene el conocer los trabajos de investigación acerca de las técnicas que le ayudan a mejorar como músico, en esa búsqueda de la excelencia musical que, tradicionalmente, parecía ligada en exclusiva a la práctica constante, exhaustiva y exclusiva del instrumento. Creemos que sería muy atractivo, como una futura línea de investigación, la realización de esta práctica en otros conservatorios, para observar si los descubrimientos obtenidos en el nuestro son extrapolables a otros contextos nacionales e internacionales.

A lo largo de nuestra investigación hemos ido comprobando como aparecía y crecía una idea que al final ha resultado ser fundamental: la del estudiante de música convencido y apoyado. Es por este motivo que nos parece muy interesante sugerir este concepto como posible línea de investigación de futuro. Se trata además de una idea especialmente atractiva, porque podemos ampliar la hipótesis para comprobar si todo artista o creador (y no sólo en cuanto que estudiante o como músico, sino en cualquier campo artístico) ha obtenido el éxito gracias a la seguridad que tenía en lo que estaba haciendo, es decir, al hecho de estar convencido y, en consecuencia, convencer a los demás para que le valoraran y le apoyaran en sus esfuerzos y logros. En este sentido, nos parece muy importante incluir dentro de esta posible investigación el concepto de "punto fuerte". Y esto porque nos parece bastante claro que la seguridad del creador y del artista en general se construye precisamente sobre eso en lo que destaca especialmente, tal como hemos podido entrever a lo largo de nuestra investigación. El "punto fuerte" sería la piedra angular que nos hace estar convencidos y con el que damos el paso adelante para convencer a los demás.

Y ya que se ha investigado sobre la importancia de la reflexión en la educación superior en general (Rushton, I., y Suter, M. 2012) y en la educación musical en particular (Ryan, 2014), sería interesante plantearse si esa reflexión sobre la práctica 
podría realizarse también incluyendo trabajos prácticos que ayuden a esta reflexión en grupo, tal y como hemos realizado en nuestra investigación, así como lo que aportaría al músico la inclusión de este tipo de tareas en la educación superior como práctica habitual en la búsqueda de la excelencia.

Otro importante resultado de la investigación ha sido el conseguir que los alumnos se hayan dado cuenta de que conocer las nuevas investigaciones al respecto puede ayudarles a estar más seguros de lo que están haciendo. A través de los cuestionarios, hemos descubierto que sus opiniones han cambiado de manera sustancial. De hecho, son capaces de mantener las ideas de una manera más firme. Pensamos que esto es muy importante, porque estar seguro de uno mismo es uno de los elementos más importantes de cara a conseguir ese famoso "flow", que Mihaly Csikszentmihályi describe como el momento en el que todo parece fácil de conseguir, cuando ves con claridad el final al que te diriges, cuando te sientes capaz de hacerlo bien y todos los elementos nos acompañan para conseguirlo, algo fundamental para ser el músico convencido y apoyado que defendemos en nuestra tesis. En ese sentido, sería interesante algún tipo de estudio (de corte psicológico o neurológico) que pudiera certificar la relación existente entre el conocimiento de las investigaciones y la consecución del "flow".

Otra posible línea de trabajo se enmarca en la pujanza que están tomando los proyectos de investigación, innovación y desarrollo en los centros superiores de música. Pero para que esto tuviera cierta relevancia, nos parece imprescindible que asentara sus bases sobre cimientos seguros, es decir, sobre el conocimiento efectivo y real de las investigaciones actuales. Para ello, sería deseable que esto formara parte de los contenidos de la enseñanza reglada en los conservatorios superiores de música.

Finalmente, nos parece de gran trascendencia una investigación (o una serie de éstas) respecto a otra de las herramientas que hemos reseñado como fundamentales: la práctica mental. Sería muy interesante llevar a cabo algún programa que desarrollara la divulgación de ésta como fundamental dentro del aprendizaje musical. Decimos esto porque se trata de algo tan novedoso que ni siquiera está aún contemplado como herramienta útil en la práctica instrumental de manera consciente, al menos en nuestro país. Y lo mismo podríamos decir del aprendizaje colaborativo, 
que aunque ya está teniendo mucho impacto fuera de nuestras fronteras (Hallam y Gaunt, 2012, Gaunt y Westerlund, 2013, Araujo 2016) es algo que todavía falta mucho por trabajar en el contexto de nuestros conservatorios y que consideramos central en el trabajo del músico excelente del siglo XXI. 



\section{REFERENCIAS BIBLIOGRÁFICAS}

- Ackerman, P. L. (2014). Nonsense, common sense, and science of expert performance: Talent and individual differences. Intelligence, 45, 6-17.

- Amabile, T., Hadley, C. y Kramer, S. (2004) Creatividad bajo presión. España: Ediciones Deusto - Planeta de Agostini Profesional y Formación S.L.

- Araújo, M. V. (2015) Measuring self-regulated practice behaviours in highly skilled musicians. Psychology of Music, 44 (2), 278-292.

- Bain, K. (2004) What the best college teachers do. Cambridge: Harvard University Press, 2004.

- Bakker, A. (2005). Flow among music teachers and their students: The crossover of peak experiences. Journal of Vocational Behavior, 66, 26-44.

- Bennet, J. (2016) Creativities in Popular songwriting Curricula: Teaching or Learning? In Burnard, P. y Haddon, E. (2015) Activating Diverse Musical Creativities: Teaching and Learning in Higher Music Education. London: Bloomsbury Academic.

- Bernardi, N.F., De Buglio, M., Trimarchi, P. D., Chielli, A., Bricolo, E. (Agosto 2013). Mental practice promotes motor anticipation: evidence from skilled music performance. Frontiers in Human Neuroscience, 7, 1-14.

- Bonneville-Roussy, A. and Bouffard, T. (2014) When quantity is not enough: Disentangling the roles of practice time, self-regulation and deliberate practice in musical achievement. Psychology of Music, 43 (5), 686-704.

- Brown, R.M., Palmer, C. (Julio 2013). Auditory and motor imagery modulate learning in music performance. Frontiers in Human Neuroscience, 7, 12-24

- Bruffee, K.(1993) Collaborative learning: higher education, interdependence and the authority of knowledge. Baltimore: Johns Hopkins Press.

- Buma, L., Bakker, F. y Oudejans, R. (2015) Exploring the thoughts and focus of attention of elite musicians under pressure. Psychology of Music, Vol. 43(4). 
- Burnard, P. y Haddon, E. (2015) Activating Diverse Musical Creativities: Teaching and Learning in Higher Music Education. London: Bloomsbury Academic.

- Ciarrochi, J, Forgas, J y Mayer, J. D. (2001) Emotional Intelligence in Everyday Life. A Scientific Inquiry. USA: Psychology Press.

- Cisneros-Cohernour, E. (2008). Una propuesta interpretativa para la evaluación de la enseñanza en educación superior. Revista Electrónica de Investigación Educativa Educativa, Especial. Consultado el 25 de Julio 2016, en: http://redie.uabc.mx/NumEsp1/contenido-cisneros.html.

- Cherry, P. (1997) La formación de los pintores en los talleres sevillanos. Zurbarán ante su centenario (1598-1998): textos de las ponencias presentadas en el Seminario de Historia de Arte, en Soria, del 21 al 25 de julio de 1997 / coord. Por Alfonso Emilio Pérez Sánchez, 1999, ISBN 84-7762-948-X, 49-59.

- Cohen, L. Manion, L y Morrison, K. (2013) Research Methods in Education. USA: Routledge.

- Conway, C. M., \& Hodgman, T. M. (2009). Teaching music in higher education. Oxford University Press.

- Cogdill, S. (2015) Applying Research in Motivation and Learning to Music Education: What the Experts Say. National Association for Music Education, 33 (2) 49-57.

- Colwell, R. (2002) The New Handbook of Research on Music Teaching and Learning. Oxford: Oxford University Press.

- Cox, J. (2014) Encouraging and Training Conservatoire Students at Undergraduate. En Harrison, S. (Ed.), Research and research education in music performance and pedagogy: Landscapes: the arts, aesthetics, and education, Vol. 11. New York, NY: Springer, 169-179.

- Csikszentmihályi, M. (1996) Creativity. Flow and the psychology of Discovery and Invention. New York: HarperCollins. 
- Csikszentmihályi, M. (1988) Society, Culture and Person: A systems View of Creativity en R. J. Sternberg (comp.) The Nature of Creativity, New York: Cambridge University Press, 325-339.

- Chaffin, R et Lemieuz, A. (2005) Consideraciones generales sobre el perfeccionamiento musical. Quotlibet, 32, 22-48.

- Csikszentimihályi, M. y Csikszentimihályi, I. (ed) (2006) A Life Worth Living. Contributions to Positive Psychology. Oxford: University Press.

- Csikszentmihályi, M., Rathunde, K. R., Whalen, S., y Wong, M. (1993). Talented teenagers: The roots of success and failure. New York, NY, US: Cambridge University Press.

- Charyton, C. (2015) Creativity and Innovation Among Science and Art. London: Springer.

- Damasio, A. (2003). En busca de Spinoza. Barcelona: Crítica.

- Davidson, J. El desarrollo de la habilidad interpretativa, en Rink, J. (ed.) (2006). La interpretación musical. Madrid: Alianza Música.

- Davidson, J. W., Howe, M. J., Moore, D. G., and Sloboda, J. A. (1996). The role of parental influences in the development of musical performance. British Journal of Developmental Psychology, 14(4), 399-412.

- Davidson, J. W., Howe, M. J., and Sloboda, J. A. (1997). Environmental factors in the development of musical performance skill over the lifespan. In Hargreaves y North, (eds.) The Social Psychology of Music. Oxford: Oxford University Press.

- Dobson, M y Gaunt, H. (2015) "Musical and social communication in expert orchestral performance" Psychology of Music, 43, (1), 24-42.

- Duve, T. (1992) Faire école. Paris: Les Presses du Réel.

- Dweck, C. (1998) "The Development of Early Self-Conceptions: Their Relevance for Motivational Processes" in Heckhausen, J. and Deck, C. (1998) Motivation and Self- Regulation Across the Lifespan. United Kingdom: Cambridge University Press. 
- Dweck, C. (1999) Self-theories: Their role in motivation, personality, and development. New York: Psychology Press.

- Dweck, C. (2006) Mindset. The new psychology of success. How we can learn to fulfill our potential. New York: Ballantine Books.

- Dweck, C. y Leggett, E. (1988). A social-cognitive approach to motivation and personality. Psychological review, 95(2), 256.

- Ericson, K.A., Krampe, R.T. y Tesch-Römer, C. (1993). The role of deliberate practice in the adquisition of expert performance. Psychological Review, 100, 363-406.

- Farrell, T. S. (2007). Failing the practicum: Narrowing the gap between expectations and reality with reflective practice. Tesol Quarterly, 41(1), 193-201.

- Fine, P.A. Wise, K.J., Goldemberg, R., Bravo, A. (2015). Performing Musicians' understanding of the terms "Mental Practice" and "Score Analysis". 6 abril 2015, de Psychomusicology Sitio web: http://dx.doi.org/10.1037/pmu0000068.

- Forcada-Delgado, C. (2014). Good practice in violin pedagogy: psychological aspects related to the acquisition of motor skills (Doctoral dissertation, Birmingham City University).

- Gadner, H. (1998) Inteligencias múltiples. Barcelona: Paidós.

- Gadner, H (2005) Las cinco mentes del futuro: un ensayo educativo. Barcelona: Paidós Ibérica.

- Garcés-Bascal, R. (2013) Finding Flow in Artistic Skill and Technique: Narratives of Young Artists-in-Training in Singapore. En Lum, C. Contextualized Practices in Arts Education: An International Dialogue on Singapore. Singapore: Springer Singapore.

- Gaunt, H. (2007) Learning and teaching breathing and oboe playing: action research in a conservatoire. British Journal of Music Education, 24 (2), 207-231.

- Gaunt, H., y Westerlund, H. (Eds.). (2013) Collaborative learning in higher music education. Surrey, UK: Ashgate.

- Glendinning, N. (1992) Goya, la década de los caprichos: retratos 1792 - 1804. Madrid: Fundacion Central Hispano, 1992. 
- Godoy, R. I, y Jorgense, H. (Eds.) (2012). Musical imagery. London: Routledge.

- Goleman, D., González Raga, D., y Mora Zahonero, F. (2013) Focus: desarrollar la atención para alcanzar la excelencia. Barcelona: Kairós

- Gembris, H., \& Heye, A. (2014). Growing older in a symphony orchestra: The development of the age-related self-concept and the self-estimated performance of professional musicians in a lifespan perspective. Musicae Scientiae, 18(4), 371-391.

- Gutiérrez, M. (2007) La formación de intérpretes profesionales en los conservatorios en el marco de la reforma educativa: Madrid como paradigma. Madrid: CIDE- Ministerio de Educación y Ciencia.

- Hallam, S. (1995) Professional musicians' orientations to practice: Implications for teaching. British Journal of Music Education, 12(01), 3-19.

- Hallam, S. (1997) 'What Do We Know About Practising? Towards a Model Synthesising the Research Literature', en H. Jørgensen and A.C. Lehmann (eds) Does Practice Make Perfect? Current Theory and Research on Instrumental Music Practice. Oslo: Norwegian State Academy of Music. (179-231)

- Hallam, S. (1998) Instrumental teaching: A practical guide to better teaching and learning. Oxford: Heinemann.

- Hallam, S. (2000) The Development of Performance Planning Strategies in Musicians, en C. Woods, G. Luck, R. Brochard, F. Seddon and J.A. Sloboda (eds) Proceedings of the Sixth International Conference on Music Perception and Cognition. Keele: Keele University.

- Hallam, S. (2001) The Development of Metacognition in Musicians: Implications for Education, British Journal of Music Education 18(1), 27-39.

- Hallam, S. (2010) Transitions and the development of expertise. Psychology Teaching Review, 16 (2), 3-32.

- Hallam, S y Gaunt, H. (2012) Preparing for success: A Practical Guide for Young Musicians. London: Institute of Education.

- Hallam, S. (2012) Music Psychology in Education. London: Institute of Education Press. 
- Hallam, S. y Bautista, A. (2012) Processes of Instrumental Learning: The Development of Musical Expertise. In McPherson, G. E. and Welch, G. F. (Ed.) The Oxford Handbook of music education. Vol I. Oxford: Oxford University Press.

- Hallam, S., Rinta, T., Varvarigou, M., Creech, A., Papageorgi, I., Gomes, T., y Lanipekun, J. (2012). The development of practising strategies in young people. Psychology of Music, 40(5), 652-680.

- Hambrick, D. Z., Oswald, F. L., Altmann, E. M., Meinz, E. J., Gobet, F., y Campitelli, G. (2014). Deliberate practice: Is that all it takes to become an expert? Intelligence, $45,34-45$.

- Hayes, J. R. (1989). Cognitive processes in Creativity. En Glover, J.A. Ronning, R. R y C.R. Reynols C. R. (Eds.) Handbook of Creativity. New York: Plenum Press.

- Ivaldi, A. (2010). Routes to adolescent musical expertise. En Deliège, I. and Davidson, J. W. (Eds.) Music and the mind: Essays in honour of John Sloboda. Oxford, UK: Oxford University Press.

- Ivaldi, A. (2016) Students' and teachers' orientation to learning and performing in music conservatoire lesson interactions. Psychology of Music. 2016, Vol. 44(2) $202-218$

- Jaquet, Ch. (2013). L'unità del corpo e della mente. Milano: Mimesis.

- Jorgensen, H. y Lehmann, A. C. (1997) Does practice make perfect?. Current theory and research on instrumental music practice. Oslo: Norges musikkohogskole.

- Jorgensen, E. R. (2003) Transforming music education. Bloomington: Indiana University Press.

- Juslin, P. N., y Sloboda, J. A. (2001) Music and emotion: Theory and research. Oxford: Oxford University Press.

- Karlsson, J. y Juslin, P. (2008) Musical expression an observation study of instrumental teaching. Psycology of music. 309-334. 
- Kaufman, J. C., y Sternberg, R. J. (2006). The international handbook of creativity. Cambridge; New York: Cambridge University Press.

- Klickstein, G. (2009). The Musician's Way: A Guide to Practice, Performance, and Wellness. USA: Oxford University Press.

- Knight, P. (2005) El profesorado de Educación Superior. Formación para la excelencia. Madrid: Narcea.

- Kraeutner S.N., MacKenzie L.A., David A. Westwood, Shaun G. Boe. (2015). Characterizing Skill Acquistion Through Motor Imagery with no prior physical practice. Journal of Experimental Psychology, 42, 257-265.

- Laukka, P. (2007) Instrumental music teachers, views on expressivity: a report from music conservatoires. Music Education Research, 6 (1), 45-56.

- Lehman, A.C. y Jorguesen, H. (2012) Practice. In McPherson, G. E. and Welch, G. F. (Ed.). The Oxford Handbook of music education. Vol I. Oxford: Oxford University Press.

- Lehmann, A. C, Sloboda, J.A., y Woody, R. H. (2007) Psychology for musicians: Understanding and acquiring the skills. Oxford University Press.

- Marcus, G. F. (2012) Guitar zero: The new musician and the science of learning. USA: Penguin Group.

- Manturzewska, M. (1990). A biographical study of the life-span development of professional musicians. Psychology of music, 18(2), 112-139.

- McMillan, J. H., y Schumacher, S. (2005). Investigación educativa: una introducción conceptual. Madrid: Pearson.

- McNamara, A., Holmes, P. y Collins, D. (2006). The pathway to excellence: The role of psychological characteristics in negotiating the challenges of musical development. British Journal of Music Education, 23 (03), 285-302.

- McPherson, G. (2000) Investigación de las habilidades requeridas para tocar un instrumento musical: Boletín de Investigación Educativo-Musical CIEM (Centro de Investigación en Educación Musical), Collegium Musicum, Buenos Aires, 7 (19), 4-11. 
- McPherson, G. E. (2006) The Child as musician. A Handbook of musical development. New York, : Oxford University Press.

- McPherson, G. E. and Lehmann, A. C. (2012) Exceptional musical abilities: musical prodigies. In McPherson, G. E. and Welch, G. F. (Ed.) The Oxford Handbook of music education. (pp.31-51). Vol. II. Oxford: Oxford University Press.

- McPherson, G. E. and Welch, G. F. (Ed.) (2012) The Oxford Handbook of music education. Vol. I. Oxford: Oxford University Press.

- McPherson, G. E. and Welch, G. F. (Ed.) (2012) The Oxford Handbook of music education. Vol. II. Oxford: Oxford University Press

- McPherson, G. E., and Zimmerman, B. J. (2002). Self-regulation of musical learning. En Cowell y Richarson (Ed.). The new handbook of research on music teaching and learning, 2, 327-347. Oxford: Oxford University Press.

- Marin, M., y Bhattacharya, J. (2013). Getting into the musical zone: trait emotional intelligence and amount of practice predict flow in pianists. Frontiers In Psychology, 4.

- Martín, R. (2012) Perspectivas interculturales en la enseñanza musical primaria. Estudio en la ciudad de Guadalajara. (Tesis doctoral no publicada) Universidad de Alcalá, Escuela Universitaria de Magisterio, Departamento de didáctica, España.

- Matthews, W. K. y Kitsantas, A. (2013). The role of the conductor's goal orientation and use of shared performance cues on collegiate instrumentalists' motivational beliefs and performance in large musical ensembles. Psychology of Music, 41, 630-646.

- Miklaszewski, K. (1989). A Case Study of a Pianist Preparing a Musical Performance, Psychology of Music 17(2): 95-109.

- Miksza, P. (2011a). A Review of Research on Practicing: Summary and Synthesis of the Extant Research with Implications for a New Theoretical Orientation. Bulletin of the Council for Reseacrch in Music Education, 90, 5192. 
- Miksza, P. (2015). The effect of self-regulatin instruction on the performance achievement, musical self-efficacy, and practicing of advanced wind players. Psychology of Music, Vol. 43 (2) 219-243.

- Newton, H. B. (2015). The Neurology of creativity: Focus on music. En Charyton, C. Creativity and Innovation Among Science and Art: A Discussion of the Two Cultures. London [England]: Springer.

- Nielsen, S.G. (1999a). Learning Strategies in Instrumental Music Practice, British Journal of Music Education 16(3): 275-91.

- Nielsen, S.G. (1999b) Regulation of Learning Strategies during Practice, Psychology of Music 27(2): 218-29.

- Nielsen, S.G. (2001) Self-Regulating Learning Strategies in Instrumental Music Practice, Music Education Research 3(2): 155-67.

- Nielsen, S. G. (2004). Strategies and Self-Efficacy Beliefs in Instrumental and Vocal Individual Practice: A Study of Students in Higher Music Education. Psychology of Music, 32(4), 418-431.

- Nielsen, S. G. (2012) Epistemic beliefs and self-regulated learning in music students. Psychology of Music 40(3): 324-338.

- O' Neill, S. A. y Sloboda, J.A. (1997) The effects of failure on children's ability to perform a musical test. Psychology of Music, 25 (1), 18-34.

- O'Neill, S. (1999). Flow Theory and the Development of Musical Performance Skills. Bulletin of the Council for Research in Music Education, (141). 129.

- O' Neill, S. A. (2011). Developing a young musician's growth mindset: The role of motivation, self-theories, and resiliency. En Deliège, I. y J. W. Davidson, J. W. (Eds.), Music and the mind: Essays in honour of John Sloboda (pp. 31-46). Oxford, UK: Oxford University Press.

- O’Neill, S. A. (2014). “Complicated conversation: Creating opportunities for transformative practice in higher education music performance research and pedagogy”. En S. Harrison (Ed.), Research and research education in music performance and pedagogy (pp.169-179): Landscapes: the arts, aesthetics, and education, Vol. 11. New York, NY: Springer. 
- Papageorgi, I. \& Welch, G. (2014). Advanced Musical Performance: Investigations in Higher Education Learning. United Kingdom, Europe: Ashgate Press.

- Papageorgi, I., Creech, A., Haddon, E., Morton, F., De Bezenac, C., Himonides, E., y Welch, G. (2010). Perceptions and predictions of expertise in advanced musical learners. Psychology of Music, 38(1), 31-66.

- Porta, A. (2015). El hábitat sonoro como tiempo y espacio para la participación, la reflexión y la investigación educativa. Aproximaciones metodológicas desde la educación musical. DEDICA (Revista Electrónica). 8, 189 - 204.

- Privette, G. (1983). Peak experience, peak performance, and flow: A comparative analysis of positive human experiences. Journal Of Personality And Social Psychology, 45(6), 1361-1368.

- Rayner, S., Sternberg, R. J., y Zhang, L. (2012). Handbook of Intellectual Styles: Preferences in Cognition, Learning, and Thinking. New York: Springer Pub. Co.

- Rushton, I., y Suter, M. (2012). Reflective Practice for Teaching In Lifelong Learning. Maidenhead: McGraw-Hill Education

- Rutherford, S. (2014). Collaborative Learning: Theory, Strategies, and Educational Benefits. New York: Nova Science Publishers, Inc.

- Ryan, M. E. (2014). Teaching Reflective Learning in Higher Education: A Systematic Approach Using Pedagogic Patterns. Cham: Springer.

- Sagastizabal, M. A. Y Perlo, C. L. (2002). La investgación-acción como estrategia de cambio en las organizaciones. Buenos Aires: Stella.

- Schlegel, F. (2005). Conversaciones sobre la poesía. Buenos Aires: Biblos.

- Schuster, C. Hilfiker, R., Amft, O, Scheidhauer, A, Andrews, B., Butler, J. y Ettlin, T. (2011) Best practice for motor imagery: a systematic literature review on motor imagery: a systematic literature review on motor imagery training elements in five different disciplines. BMC medicine, 9 (1), 75.

- Sloboda, J. (1987) ¿Qué puede enseñar la psicología de la música a los músicos? Música y Educación, n. 44, 335-355. 
- Sloboda, J. A., Davidson, J. W., Howe, M. J., y Moore, D. G. (1996). The role of practice in the development of performing musicians. British journal of psychology, 87(2), 287-309.

- Sloboda, J. (1994). What makes a musician? Guitar Journal, 5.

- Sloboda, J. A. (2002). Factores ambientales en el desarrollo de las habilidades musicales interpretativas a lo largo del ciclo vital. Quodlibet: Revista De Especialización Musical, (23), 116.

- Smith, B. P. (2005). Goal orientation, implicit theory of ability, and collegiate instrumental music practice. Psychology of Music, 33, 36-57.

- Spinoza, B. (1987). Ética. Madrid: Alianza

- Sternberg, R. (1996) Inteligencia exitosa. Barcelona: Paidós Ibérica.

- Stenberg, R. (1997) Thinking Styles. Cambridge: University Press.

- Sternberg, R. (2005) Intelligence, Competence and Expertise. In Elliot, A. y Dweck, C. (ed.) Handbook of Competence and Motivation. New York: The Gilford Press.

- Stoeger, H. (2013) Learning as a creative process. En Tan, A. G. (ed.) Creativity, Talent and Excellence. Singapore: Springer Singapore.

- Schuster, C. Hilfiker, R., Amft, O, Scheidhauer, A, Andrews, B., Butler, J. y Ettlin, T. (2011) Best practice for motor imagery: a systematic literature review on motor imagery: a systematic literature review on motor imagery training elements in five different disciplines. BMC medicine, 9 (1), 75.

- Tan, A.G. (ed.) (2013) Creativity, Talent and Excellence. Singapore: Springer Singapore.

- Urriza, M. (2010) Cómo grabar el primer disco. Tres efes. Revista de pensamiento musical, 1.

- Varela, W., Abrami, P. C., y Upitis, R. (2016). Self-regulation and music learning: A systematic review. Psychology of Music, 44 (1), 55-74.

- Westerlund, H., y Gaunt, H. (2013). Collaborative Learning in Higher Music Education. Burlington: Ashgate. 
- Woznicki, L. (2015). Advanced Musical Performance: Investigations In Higher Education Learning edited by Ioulia Papageorgi and Graham Welch. Music Reference Services Quaterly18 (3/4) 212-214.

- Zhang, L. F. (2013). The Malleability of Intellectual Styles. Cambridge University Press.

- Zimmerman, B.J. (1989). A social cognitive view of self-regulated academic learning. Journal of Educational Psychology, 81, 329-339. 


\section{ANEXO I: CUESTIONARIO ALUMNOS}

A continuación encontrarás un cuestionario que nos servirá para ver las ideas que tenemos con respecto a nuestra preparación como músicos profesionales Se contesta de forma anónima. Debes leer con atención cada pregunta o afirmación y responder con arreglo a la escala que verás más abajo. El 1 representa el grado máximo de desacuerdo y el 6 el grado máximo de acuerdo. Los valores entre el 1 y el 6 señalan, lógicamente, respuestas intermedias. No hay respuestas correctas ni incorrectas, de modo que trata de ser lo más sincero y objetivo posible. Si crees que falta algo interesante, puedes ponerlo al final del folio. Muchas gracias por tu colaboración.

Especialidad:

Año de nacimiento:

1 Completamente en desacuerdo, 2 En desacuerdo, 3 Más bien en desacuerdo. 4. Más bien de acuerdo 5. De acuerdo y 6. Completamente de acuerdo.

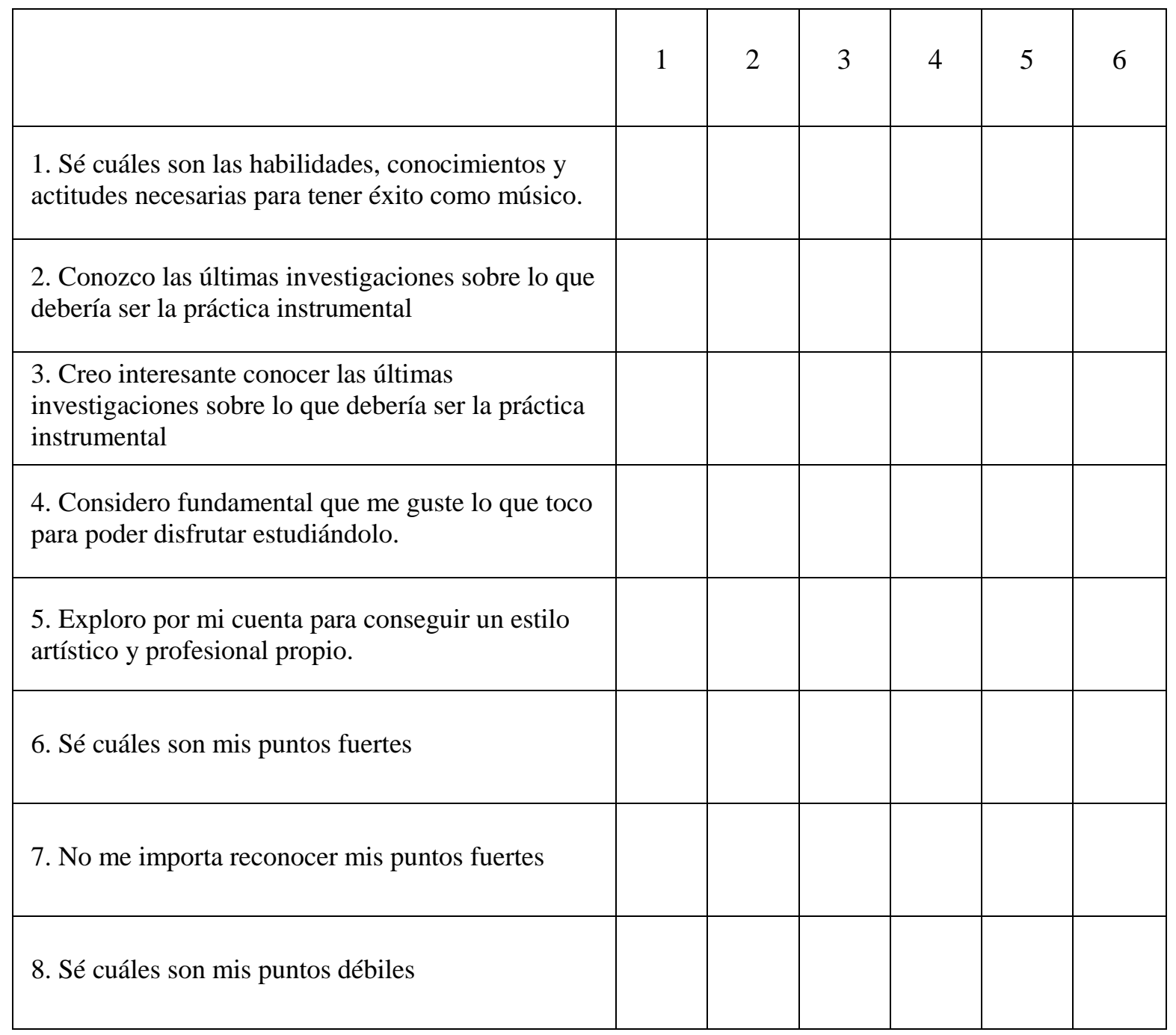




\begin{tabular}{|c|c|c|c|c|c|c|}
\hline & 1 & 2 & 3 & 4 & 5 & 6 \\
\hline $\begin{array}{l}\text { 9. No me importa reconocer cuáles son mis puntos } \\
\text { débiles }\end{array}$ & & & & & & \\
\hline $\begin{array}{l}\text { 10. Sé cómo trabajar para solucionar mis puntos } \\
\text { débiles (aquéllos que son necesarios para conseguir } \\
\text { mis expectativas como músico) }\end{array}$ & & & & & & \\
\hline $\begin{array}{l}\text { 11. Me faltan estrategias para solucionar mis puntos } \\
\text { débiles }\end{array}$ & & & & & & \\
\hline 12. Toco en distintos grupos & & & & & & \\
\hline $\begin{array}{l}\text { 13.Creo que tocar con otros me ayuda desarrollarme } \\
\text { como músico }\end{array}$ & & & & & & \\
\hline $\begin{array}{l}\text { 14.Aunque pienso que es importante tocar con otros } \\
\text { ahora estoy más centrado en tocar sólo }\end{array}$ & & & & & & \\
\hline $\begin{array}{l}\text { 15. Me esfuerzo por hacer de mi práctica diaria un } \\
\text { trabajo eficaz }\end{array}$ & & & & & & \\
\hline $\begin{array}{l}\text { 16. Me esfuerzo por hacer de mi práctica diaria un } \\
\text { trabajo creativo }\end{array}$ & & & & & & \\
\hline $\begin{array}{l}\text { 17.Aunque me gustaría que mi práctica diaria fuera } \\
\text { un trabajo creativo, no sé cómo hacerlo }\end{array}$ & & & & & & \\
\hline $\begin{array}{l}\text { 18. Sé cómo planificar mi práctica diaria en función } \\
\text { de mis gustos y forma personal de aprender. }\end{array}$ & & & & & & \\
\hline $\begin{array}{l}\text { 19. Suelo improvisar la forma de estudiar y el } \\
\text { tiempo que dedico a cada cosa cada día. }\end{array}$ & & & & & & \\
\hline $\begin{array}{l}\text { 20.Tengo unas ciertas habilidades musicales y } \\
\text { realmente no puedo cambiarlas }\end{array}$ & & & & & & \\
\hline $\begin{array}{l}\text { 21.Tengo unas habilidades musicales que puedo } \\
\text { cultivar y desarrollar }\end{array}$ & & & & & & \\
\hline 22. Confío en mi habilidad para hacer las cosas bien & & & & & & \\
\hline
\end{tabular}




\begin{tabular}{|c|c|c|c|c|c|c|}
\hline & 1 & 2 & 3 & 4 & 5 & 6 \\
\hline $\begin{array}{l}\text { 23. Sé perfectamente cuándo he entendido algún } \\
\text { contenido }\end{array}$ & & & & & & \\
\hline $\begin{array}{l}\text { 24.Para mí es muy importante poder elegir el } \\
\text { repertorio que voy a tocar o los temas de los } \\
\text { proyectos que tenga que trabajar para poder hacerlo } \\
\text { bien }\end{array}$ & & & & & & \\
\hline $\begin{array}{l}\text { 25.Si sé que no puedo tocar un obra correctamente } \\
\text { prefiero no tocarla aunque piense que puedo } \\
\text { aprender mucho si la toco }\end{array}$ & & & & & & \\
\hline $\begin{array}{l}\text { 26.Prefiero que lo que toco le guste a mi profesor y } \\
\text { me ponga buenas notas a aprender mucho }\end{array}$ & & & & & & \\
\hline $\begin{array}{l}\text { 27. Para mí es mucho más importante aprender a } \\
\text { tocar bien que sacar buenas notas }\end{array}$ & & & & & & \\
\hline $\begin{array}{l}\text { 28.Me gusta tocar obras y trabajar contenidos que } \\
\text { tengo dominados para comprobar las habilidades } \\
\text { que tengo }\end{array}$ & & & & & & \\
\hline $\begin{array}{l}\text { 29.Me gustan las dificultades y los retos y prefiero } \\
\text { tener que esforzarme, equivocarme y aprender de } \\
\text { mis errores a repetir lo que ya sé }\end{array}$ & & & & & & \\
\hline $\begin{array}{l}\text { 30. Cuando algo me sale mal me obsesiono y me } \\
\text { cuesta mucho salir adelante }\end{array}$ & & & & & & \\
\hline $\begin{array}{l}\text { 31. Sé como quiero tocar o qué quiero hacer y } \\
\text { pongo todo mi empeño en conseguirlo }\end{array}$ & & & & & & \\
\hline $\begin{array}{l}\text { 32. Dejo en manos de mi profesor la tarea de } \\
\text { marcar los objetivos que tengo que conseguir en } \\
\text { cada curso y la planificación para lograrlo. }\end{array}$ & & & & & & \\
\hline $\begin{array}{l}\text { 33.Considero importante trazarme mis propios } \\
\text { objetivos a corto, medio y largo plazo } \\
\text { independientemente de los que me marque mi } \\
\text { profesor }\end{array}$ & & & & & & \\
\hline $\begin{array}{l}\text { 34.Aunque considere importante trazarme mis } \\
\text { propios objetivos no me he parado a hacerlo todavía }\end{array}$ & & & & & & \\
\hline $\begin{array}{l}\text { 35.Planifico y organizo yo mismo los objetivos que } \\
\text { quiero alcanzar en cada curso }\end{array}$ & & & & & & \\
\hline $\begin{array}{l}\text { 36. Cuando fracaso o no consigo alcanzar los } \\
\text { objetivos propuestos pienso que es porque no tengo } \\
\text { bastante talento musical }\end{array}$ & & & & & & \\
\hline
\end{tabular}




\begin{tabular}{|c|c|c|c|c|c|c|}
\hline & 1 & 2 & 3 & 4 & 5 & 6 \\
\hline $\begin{array}{l}\text { 37. Cuando fracaso o no consigo alcanzar los } \\
\text { objetivos propuestos pienso que es porque no he } \\
\text { estudiado bastante }\end{array}$ & & & & & & \\
\hline $\begin{array}{l}\text { 38. Cuando fracaso o no consigo alcanzar los } \\
\text { objetivos propuestos pienso que es porque no he } \\
\text { estudiado de la manera adecuada. }\end{array}$ & & & & & & \\
\hline $\begin{array}{l}\text { 39. Además de los objetivos que me marca mi } \\
\text { profesor yo suelo marcarme mis propios objetivos } \\
\text { individuales para cada curso. }\end{array}$ & & & & & & \\
\hline $\begin{array}{l}\text { 40. Me entusiasmo cuando pienso en poder tocar } \\
\text { algo como alguien que admiro }\end{array}$ & & & & & & \\
\hline $\begin{array}{l}\text { 41. Me entusiasmo pensando en poder tocar algo de } \\
\text { forma personal con un estilo propio }\end{array}$ & & & & & & \\
\hline $\begin{array}{l}\text { 42. Creo que mis compañeros y amigos pueden } \\
\text { ayudarme mucho a ser mejor músico }\end{array}$ & & & & & & \\
\hline $\begin{array}{l}\text { 43. Considero importante escuchar distintas } \\
\text { versiones de las obras que tengo que tocar para } \\
\text { aumentar mi capacidad de elección }\end{array}$ & & & & & & \\
\hline $\begin{array}{l}\text { 44. Dedico tiempo a escuchar distintas versiones de } \\
\text { las obras que tengo que tocar }\end{array}$ & & & & & & \\
\hline $\begin{array}{l}\text { 45. Aprendo mucho de manera informal (sacando } \\
\text { canciones de oído, tocando con amigos, } \\
\text { aprendiendo temas sólo por placer, etc.) }\end{array}$ & & & & & & \\
\hline $\begin{array}{l}\text { 46. Prefiero emplear mi tiempo en tocar lo que me } \\
\text { enseñan formalmente que aprendiendo de manera } \\
\text { informal }\end{array}$ & & & & & & \\
\hline $\begin{array}{l}\text { 47. Aunque crea que puedo aprender mucho de } \\
\text { manera informal no empleo tiempo en hacerlo }\end{array}$ & & & & & & \\
\hline $\begin{array}{l}\text { 48. Sé cuáles son mis necesidades individuales de } \\
\text { aprendizaje y valoro mucho que se tengan en cuenta } \\
\text { (ej. edad, estilo de aprendizaje, experiencia, } \\
\text { intereses, etc.) }\end{array}$ & & & & & & \\
\hline $\begin{array}{l}\text { 49. Sé que es muy importante cuidar mi cuerpo y } \\
\text { mi mente }\end{array}$ & & & & & & \\
\hline $\begin{array}{l}\text { 50. Cuido mi cuerpo y mi mente porque son mis } \\
\text { herramientas de trabajo }\end{array}$ & & & & & & \\
\hline
\end{tabular}




\begin{tabular}{|c|c|c|c|c|c|c|}
\hline & 1 & 2 & 3 & 4 & 5 & 6 \\
\hline $\begin{array}{l}\text { 51. Valoro especialmente el aprender herramienta } \\
\text { de estudio que me permitan ser autónomo cuando } \\
\text { termine mi carrera }\end{array}$ & & & & & & \\
\hline $\begin{array}{l}\text { 52. En mi concierto o trabajo fin de carrera he } \\
\text { elegido el repertorio que voy a tocar o el tema . }\end{array}$ & & & & & & \\
\hline $\begin{array}{l}\text { 53. Creo que voy a hacer un concierto o trabajo fi } \\
\text { de carrera del que podré estar orgulloso }\end{array}$ & & & & & & \\
\hline $\begin{array}{l}\text { 54. Confío que mi concierto o trabajo fin de carre } \\
\text { será mejor que el de la mayoría de mis compañerc }\end{array}$ & & & & & & \\
\hline $\begin{array}{l}\text { 55. Mi concierto o trabajo fin de carrera va a ser } \\
\text { más el que mi profesor quiere que sea que el que } \\
\text { quiero hacer. }\end{array}$ & & & & & & \\
\hline $\begin{array}{l}\text { 56. Espero terminar los estudios oficiales para } \\
\text { empezar a buscar un estilo propio. }\end{array}$ & & & & & & \\
\hline $\begin{array}{l}\text { 57. Al mismo tiempo que estudio el título oficial } \\
\text { intento buscar mi propio estilo personal. }\end{array}$ & & & & & & \\
\hline $\begin{array}{l}\text { 58. Conozco las salidas profesionales que puedo } \\
\text { tener y de hecho ya empiezo a hacer algún trabajo }\end{array}$ & & & & & & \\
\hline $\begin{array}{l}\text { 59. Creo que enseñar a otros puede ayudarme a } \\
\text { profundizar y reforzar mi propio aprendizaje }\end{array}$ & & & & & & \\
\hline $\begin{array}{l}\text { 60. Mi profesor de instrumento me conoce bastan } \\
\text { bien no sólo musicalmente sino también } \\
\text { personalmente }\end{array}$ & & & & & & \\
\hline $\begin{array}{l}\text { 61.Siento que mi profesor de instrumento me } \\
\text { escucha }\end{array}$ & & & & & & \\
\hline $\begin{array}{l}\text { 62. Siento que mi profesor de instrumento me } \\
\text { aprecia como persona }\end{array}$ & & & & & & \\
\hline $\begin{array}{l}\text { 63. Siento que mi profesor de instrumento tiene } \\
\text { grandes expectativas puestas en mí como músico }\end{array}$ & & & & & & \\
\hline
\end{tabular}




\begin{tabular}{|c|c|c|c|c|c|c|}
\hline & 1 & 2 & 3 & 4 & 5 & 6 \\
\hline $\begin{array}{l}\text { 64. Mi profesor de instrumento me da buena } \\
\text { información, dando respuestas a las dudas que me } \\
\text { surgen en cada momento }\end{array}$ & & & & & & \\
\hline $\begin{array}{l}\text { 65. Los profesores de asignaturas distintas al } \\
\text { instrumento me conocen bastante bien no sólo } \\
\text { musicalmente sino también personalmente }\end{array}$ & & & & & & \\
\hline $\begin{array}{l}\text { 66. Los profesores de asignaturas distintas al } \\
\text { instrumento me escuchan }\end{array}$ & & & & & & \\
\hline $\begin{array}{l}\text { 67. Los profesores de asignaturas distintas al } \\
\text { instrumento me aprecian como persona }\end{array}$ & & & & & & \\
\hline $\begin{array}{l}\text { 68. Los profesores de asignaturas distintas al } \\
\text { instrumento tienen grandes expectativas puestas e }\end{array}$ & & & & & & \\
\hline $\begin{array}{l}\text { 69. Creo que es importante para un músico leer bi } \\
\text { primera vista }\end{array}$ & & & & & & \\
\hline 70. Soy capaz de leer bien a primera vista & & & & & & \\
\hline $\begin{array}{l}\text { 71. Creo que es importante para un músico tocar c } \\
\text { oído }\end{array}$ & & & & & & \\
\hline 72.Soy capaz de tocar de oído & & & & & & \\
\hline $\begin{array}{l}\text { 73. Creo que es importante para un músico poder } \\
\text { improvisar bien }\end{array}$ & & & & & & \\
\hline 74. Soy capaz de improvisar bien & & & & & & \\
\hline $\begin{array}{l}\text { 75. Creo que es importante para un músico poder } \\
\text { ejecutar música ensayada }\end{array}$ & & & & & & \\
\hline 76. Soy capaz de ejecutar música ensayada & & & & & & \\
\hline
\end{tabular}




\begin{tabular}{|l|l|l|l|l|l|l|}
\hline & 1 & 2 & 3 & 4 & 5 & 6 \\
\hline $\begin{array}{l}\text { 77. Creo que es importante para un músico tocar de } \\
\text { memoria }\end{array}$ & & & & & & \\
\hline 78. Soy capaz de tocar de memoria & & & & & & \\
\hline $\begin{array}{l}\text { 79. Creo que es importante para un músico ser capaz de } \\
\text { componer }\end{array}$ & & & & & & \\
\hline \begin{tabular}{l} 
80. Soy capaz de componer \\
\hline
\end{tabular}
\end{tabular}





\section{ANEXO II : CUESTIONARIO PARA EL PROFESORADO}

Se contesta de forma anónima. Leer con atención cada afirmación y responder con arreglo a la escala que se presenta. El 1 representa el grado máximo de desacuerdo y el 6 el grado máximo de acuerdo. Los valores entre el 1 y el 6 señalan, lógicamente, respuestas intermedias. No hay respuestas correctas ni incorrectas, de modo que trata de ser lo más sincero y objetivo posible. Muchas gracias por tu colaboración.

Profesor de: (rodea con un círculo el que corresponda)

\section{Instrumento clásico, Instrumento Jazz, Composición, Musicología，Pedagogía，Otros}

1.Completamente en desacuerdo, 2 En desacuerdo, 3 Más bien en desacuerdo. 4. Más bien de acuerdo 5. De acuerdo y 6 . Completamente de acuerdo.

\begin{tabular}{|c|c|c|c|c|c|c|}
\hline & 1 & 2 & 3 & 4 & 5 & 6 \\
\hline $\begin{array}{l}\text { 1. Sé cuáles son las habilidades, conocimientos y } \\
\text { actitudes necesarias para tener éxito como músico }\end{array}$ & & & & & & \\
\hline $\begin{array}{l}\text { 2. Conozco las últimas investigaciones sobre la } \\
\text { excelencia musical y cómo trabajar para } \\
\text { conseguirla. }\end{array}$ & & & & & & \\
\hline $\begin{array}{l}\text { 3. Pienso que es interesante conocer las } \\
\text { investigaciones sobre cómo trabajar para conseguir } \\
\text { la excelencia musical. }\end{array}$ & & & & & & \\
\hline $\begin{array}{l}\text { 4. Pienso que es interesante que mis alumnos } \\
\text { conozcan las investigaciones sobre como trabajar } \\
\text { para conseguir la excelencia musical }\end{array}$ & & & & & & \\
\hline
\end{tabular}




\begin{tabular}{|c|c|c|c|c|c|}
\hline & 1 & 2 & 3 & 4 & 5 \\
\hline 5. Sé cuáles son mis puntos fuertes como músico & & & & & \\
\hline $\begin{array}{l}\text { 6. No me importa reconocer mis punto fuertes } \\
\text { como músico. }\end{array}$ & & & & & \\
\hline 7. Sé cuáles son mis puntos fuertes como profesor. & & & & & \\
\hline $\begin{array}{l}\text { 8. No me importa reconocer mis puntos fuertes } \\
\text { como profesor. }\end{array}$ & & & & & \\
\hline 9. Sé cuáles son mis puntos débiles como músico & & & & & \\
\hline $\begin{array}{l}\text { 10. No me importa reconocer mis puntos débiles } \\
\text { como músico }\end{array}$ & & & & & \\
\hline $\begin{array}{l}\text { 11. Sé cuáles son mis puntos débiles como } \\
\text { profesor }\end{array}$ & & & & & \\
\hline $\begin{array}{l}\text { 12. No me importa reconocer mis puntos débiles } \\
\text { como profesor. }\end{array}$ & & & & & \\
\hline $\begin{array}{l}\text { 13. Me parece importante que mis alumnos sepan } \\
\text { reconocer sus puntos débiles y sus puntos fuertes }\end{array}$ & & & & & \\
\hline $\begin{array}{l}\text { 14. Creo que trabajar con otros músicos me ayuda } \\
\text { a desarrollarme como músico }\end{array}$ & & & & & \\
\hline
\end{tabular}




\begin{tabular}{|c|c|c|c|c|c|c|}
\hline & 1 & 2 & 3 & 4 & 5 & 6 \\
\hline $\begin{array}{l}\text { 15. Aunque creo que es importante trabajar con } \\
\text { otros músicos ahora estoy más centrado en trabajar } \\
\text { solo. }\end{array}$ & & & & & & \\
\hline $\begin{array}{l}\text { 16. Creo que trabajar en colaboración con otros } \\
\text { profesores me ayuda a ser mejor profesor. }\end{array}$ & & & & & & \\
\hline $\begin{array}{l}\text { 17. Aunque crea que trabajar con otros profesores } \\
\text { me ayuda a ser mejor profesor ahora estoy } \\
\text { centrado en trabajar solo. }\end{array}$ & & & & & & \\
\hline $\begin{array}{l}\text { 18. Animo a mis alumnos a trabajar en grupo como } \\
\text { medio para mejorar como músico. }\end{array}$ & & & & & & \\
\hline $\begin{array}{l}\text { 19. Mis alumnos prefieren aprender mucho a sacar } \\
\text { buenas notas. }\end{array}$ & & & & & & \\
\hline $\begin{array}{l}\text { 20. Me parece importante que mis alumnos toquen } \\
\text { obras o trabajen contenidos que tienen dominados } \\
\text { para comprobar las habilidades que tienen. }\end{array}$ & & & & & & \\
\hline $\begin{array}{l}\text { 21. Me parece más importante que mis alumnos } \\
\text { tengan que enfrentarse a nuevos retos, esforzarse y } \\
\text { aprendan de sus errores a repetir lo que ya saben. }\end{array}$ & & & & & & \\
\hline
\end{tabular}




\begin{tabular}{|c|c|c|c|c|c|c|}
\hline & 1 & 2 & 3 & 4 & 5 & 6 \\
\hline $\begin{array}{l}\text { 22. Preparo las clases para enseñar a mis alumnos } \\
\text { fundamentalmente lo que más domino }\end{array}$ & & & & & & \\
\hline $\begin{array}{l}\text { 23. Preparo las clases adaptándome a las } \\
\text { características e intereses particulares de cada } \\
\text { alumno }\end{array}$ & & & & & & \\
\hline $\begin{array}{l}\text { 24. Creo que mis alumnos deberían planificar su } \\
\text { tiempo diario de estudio en función de sus gustos y } \\
\text { su forma personal de aprender }\end{array}$ & & & & & & \\
\hline $\begin{array}{l}\text { 25. Pienso que las experiencias que aportan los } \\
\text { estudiantes pueden ser tan importantes como las } \\
\text { mías. }\end{array}$ & & & & & & \\
\hline $\begin{array}{l}\text { 26. Las preguntas de los estudiantes me hacen } \\
\text { reflexionar sobre mi propia práctica docente. }\end{array}$ & & & & & & \\
\hline $\begin{array}{l}\text { 27. Creo que los alumnos que tengo actualmente } \\
\text { van a alcanzar el éxito como profesionales }\end{array}$ & & & & & & \\
\hline $\begin{array}{l}\text { 28. Cuando mis alumnos fracasan o no alcanzan } \\
\text { los objetivos propuestos pienso que es porque no } \\
\text { tienen bastante talento. }\end{array}$ & & & & & & \\
\hline
\end{tabular}




\begin{tabular}{|c|c|c|c|c|c|c|}
\hline & 1 & 2 & 3 & 4 & 5 & 6 \\
\hline $\begin{array}{l}\text { 29. Cuando mis alumnos fracasan o no alcanzan } \\
\text { los objetivos propuestos pienso que es porque no } \\
\text { han estudiado bastante }\end{array}$ & & & & & & \\
\hline $\begin{array}{l}\text { 30. Cuando mis alumnos fracasan o no alcanzan } \\
\text { los objetivos propuestos pienso que es porque no } \\
\text { han estudiado de la manera adecuada }\end{array}$ & & & & & & \\
\hline $\begin{array}{l}\text { 31. Cuando mis alumnos fracasan o no alcanzan } \\
\text { los objetivos propuestos siento que he fracasado yo } \\
\text { también }\end{array}$ & & & & & & \\
\hline $\begin{array}{l}\text { 32. Considero que es mi responsabilidad motivar al } \\
\text { alumno para ayudarle a conseguir sus metas }\end{array}$ & & & & & & \\
\hline 33. Me considero bien valorado por mis alumnos & & & & & & \\
\hline $\begin{array}{l}\text { 34. Me considero bien valorado por mis } \\
\text { compañeros. }\end{array}$ & & & & & & \\
\hline 35. Me considero bien valorado por la dirección. & & & & & & \\
\hline $\begin{array}{l}\text { 36. Conozco herramientas para mejorar la } \\
\text { comunicación con mis alumnos y otros profesores } \\
\text { como la práctica de la inteligencia emocional }\end{array}$ & & & & & & \\
\hline
\end{tabular}





\section{ANEXO III}

Gráfica comparativa de las preguntas 1 a 20, cambios producidos entre septiembre y enero del curso 2014-2015.

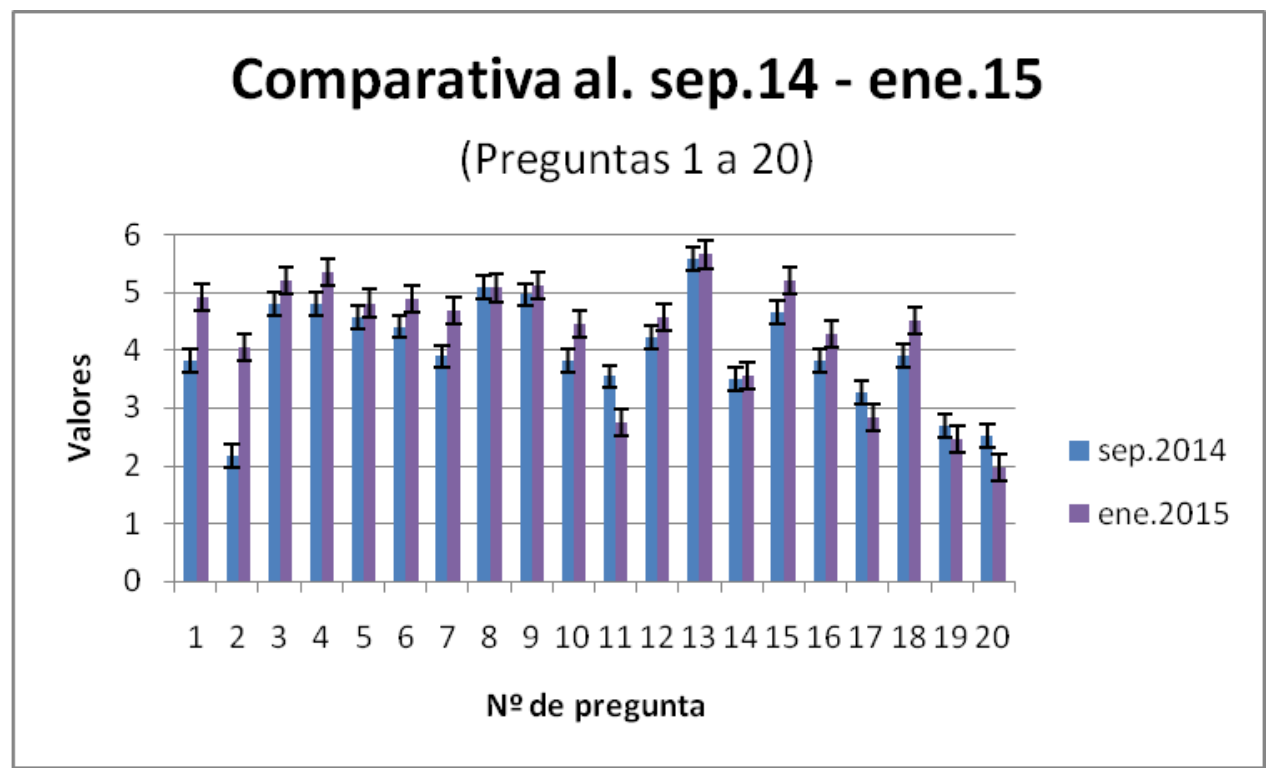

\begin{tabular}{ccc|ccc}
\hline \multicolumn{2}{c|}{ SEPTIEMBRE 2014 } & \multicolumn{3}{c}{ ENERO2015 } \\
\hline $\mathbf{N}^{\mathbf{0}}$ pregunta & Media & Error & $\mathbf{N}^{\mathbf{o}}$ pregunta & Media & Error \\
\hline $\boldsymbol{1}$ & 3,816 & 0,114 & $\mathbf{1}$ & 4,916 & 0,110 \\
\hline $\mathbf{2}$ & 2,168 & 0,151 & $\mathbf{2}$ & 4,048 & 0,155 \\
\hline $\mathbf{4}$ & 4,809 & 0,156 & $\mathbf{3}$ & 5,208 & 0,119 \\
\hline $\mathbf{5}$ & 4,809 & 0,165 & $\mathbf{4}$ & 5,348 & 0,136 \\
\hline $\mathbf{6}$ & 4,569 & 0,131 & $\mathbf{5}$ & 4,810 & 0,118 \\
\hline
\end{tabular}




\begin{tabular}{|c|c|c|c|c|c|}
\hline 7 & 3,891 & 0,158 & 7 & 4,678 & 0,121 \\
\hline 8 & 5,080 & 0,094 & 8 & 5,078 & 0,096 \\
\hline 9 & 4,959 & 0,126 & 9 & 5,112 & 0,107 \\
\hline 10 & 3,808 & 0,127 & 10 & 4,458 & 0,116 \\
\hline 11 & 3,545 & 0,170 & 11 & 2,752 & 0,189 \\
\hline 12 & 4,231 & 0,208 & 12 & 4,566 & 0,189 \\
\hline 13 & 5,588 & 0,091 & 13 & 5,655 & 0,073 \\
\hline 14 & 3,500 & 0,170 & 14 & 3,559 & 0,216 \\
\hline 15 & 4,644 & 0,141 & 15 & 5,206 & 0,108 \\
\hline 16 & 3,831 & 0,169 & 16 & 4,282 & 0,147 \\
\hline 17 & 3,269 & 0,166 & 17 & 2,838 & 0,189 \\
\hline 18 & 3,918 & 0,138 & 18 & 4,502 & 0,144 \\
\hline 19 & 2,689 & 0,212 & 19 & 2,454 & 0,240 \\
\hline 20 & 2,507 & 0,150 & 20 & 1,963 & 0,177 \\
\hline
\end{tabular}




\section{ANEXO IV:}

Gráfica comparativa de las preguntas 21 a 40, cambios producidos entre septiembre y enero del curso 2014-2015.

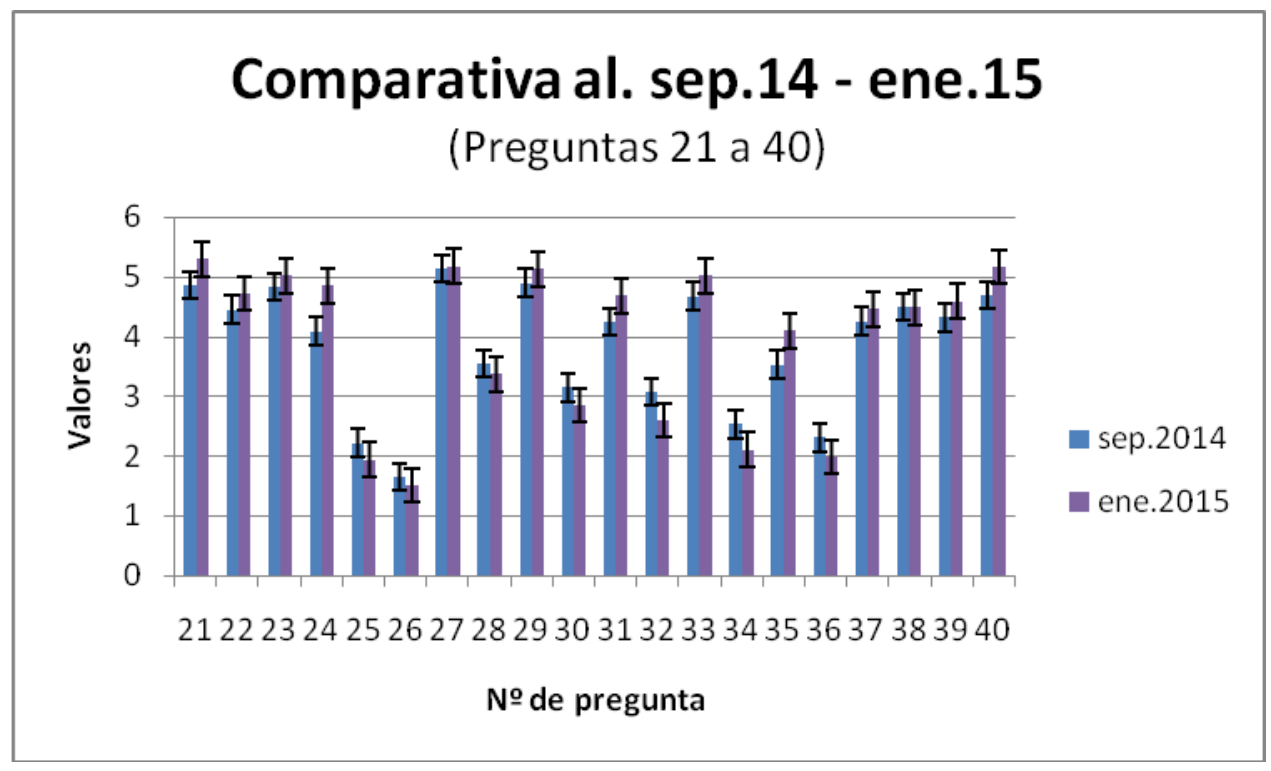

\begin{tabular}{ccc|ccc}
\hline \multicolumn{2}{c|}{ SEPTIEMBRE 2014 } & \multicolumn{3}{c}{ ENERO 2015 } \\
\hline$N^{\boldsymbol{o}}$ pregunta & Media & Error & $N^{\boldsymbol{o}}$ pregunta & Media & Error \\
\hline $\mathbf{2 1}$ & 4,861 & 0,110 & 21 & 5,300 & 0,099 \\
\hline $\mathbf{2 2}$ & 4,454 & 0,137 & 22 & 4,722 & 0,149 \\
\hline $\mathbf{2 3}$ & 4,832 & 0,112 & 23 & 5,022 & 0,107 \\
\hline $\mathbf{2 5}$ & 4,087 & 0,174 & 24 & 4,852 & 0,141 \\
\hline $\mathbf{2 6}$ & 2,216 & 0,178 & 25 & 1,941 & 0,179 \\
\hline
\end{tabular}




\begin{tabular}{|c|c|c|c|c|c|}
\hline 27 & 5,145 & 0,142 & 27 & 5,176 & 0,132 \\
\hline 28 & 3,553 & 0,170 & 28 & 3,379 & 0,184 \\
\hline 29 & 4,903 & 0,127 & 29 & 5,135 & 0,094 \\
\hline 30 & 3,154 & 0,165 & 30 & 2,853 & 0,168 \\
\hline 31 & 4,248 & 0,136 & 31 & 4,688 & 0,123 \\
\hline 32 & 3,078 & 0,180 & 32 & 2,599 & 0,180 \\
\hline 33 & 4,677 & 0,126 & 33 & 5,023 & 0,120 \\
\hline 34 & 2,535 & 0,189 & 34 & 2,104 & 0,175 \\
\hline 35 & 3,531 & 0,153 & 35 & 4,105 & 0,162 \\
\hline 36 & 2,309 & 0,203 & 36 & 1,986 & 0,163 \\
\hline 37 & 4,260 & 0,164 & 37 & 4,464 & 0,162 \\
\hline 38 & 4,500 & 0,147 & 38 & 4,488 & 0,162 \\
\hline 39 & 4,327 & 0,172 & 39 & 4,587 & 0,152 \\
\hline 40 & 4,700 & 0,165 & 40 & 5,169 & 0,128 \\
\hline
\end{tabular}




\section{ANEXO V}

Gráfica comparativa de las preguntas 41 a 60, cambios producidos entre septiembre y enero del curso 2014-2015.

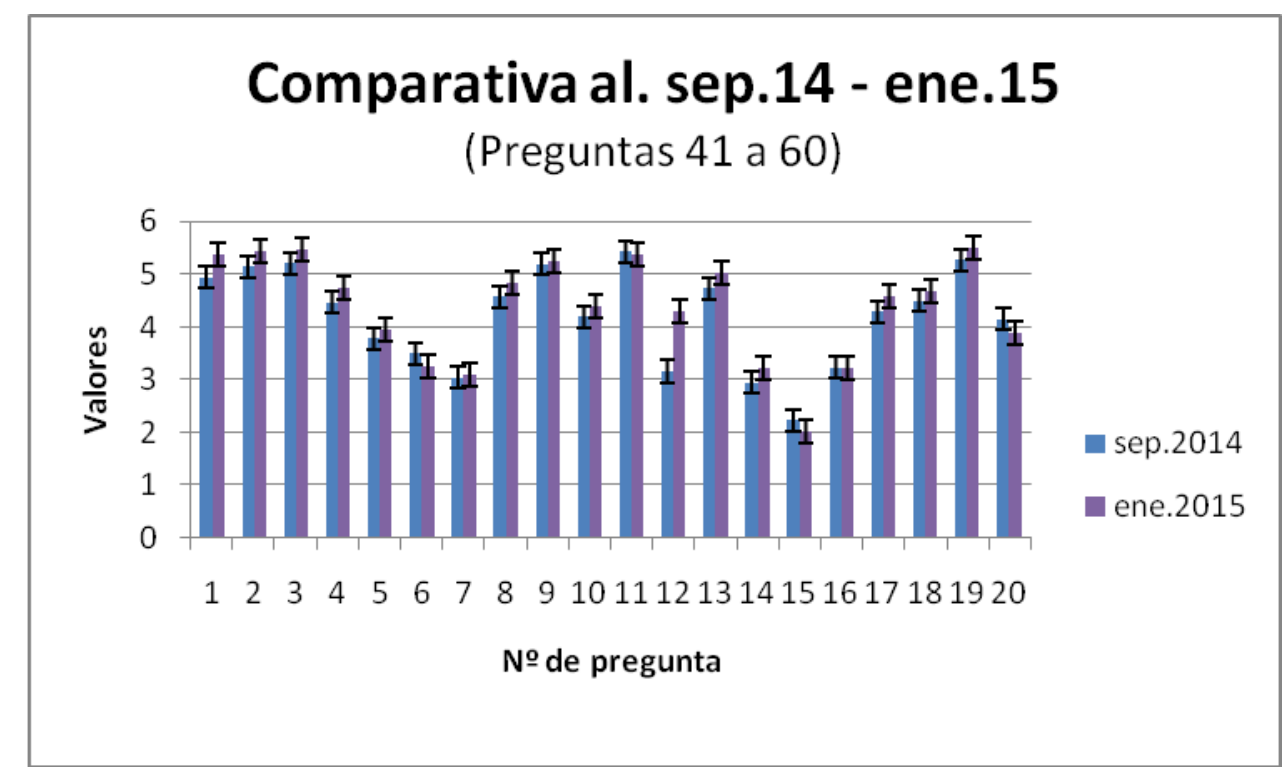

\begin{tabular}{ccc|ccc}
\hline \multicolumn{2}{c|}{ SEPTIEMBRE 2014 } & \multicolumn{3}{c}{ ENERO 2015 } \\
\hline $\boldsymbol{N}^{\boldsymbol{o}}$ pregunta & Media & Error & $\boldsymbol{N}^{\boldsymbol{o}}$ pregunta & Media & Error \\
\hline $\mathbf{4 1}$ & 4,946 & 0,144 & $\mathbf{4 1}$ & 5,369 & 0,100 \\
\hline $\mathbf{4 2}$ & 5,143 & 0,115 & $\mathbf{4 2}$ & 5,424 & 0,088 \\
\hline $\mathbf{4 3}$ & 5,215 & 0,125 & $\mathbf{4 3}$ & 5,457 & 0,092 \\
\hline 44 & 4,470 & 0,164 & $\mathbf{4 4}$ & 4,753 & 0,143 \\
\hline
\end{tabular}




\begin{tabular}{|c|c|c|c|c|c|}
\hline 45 & 3,782 & 0,181 & 45 & 3,941 & 0,197 \\
\hline 46 & 3,502 & 0,149 & 46 & 3,265 & 0,161 \\
\hline 47 & 3,045 & 0,178 & 47 & 3,085 & 0,187 \\
\hline 48 & 4,580 & 0,119 & 48 & 4,823 & 0,120 \\
\hline 49 & 5,200 & 0,111 & 49 & 5,262 & 0,119 \\
\hline 50 & 4,188 & 0,157 & 50 & 4,388 & 0,164 \\
\hline 51 & 5,426 & 0,093 & 51 & 5,388 & 0,109 \\
\hline 52 & 3,158 & 0,233 & 52 & 4,290 & 0,212 \\
\hline 53 & 4,727 & 0,141 & 53 & 5,015 & 0,137 \\
\hline 54 & 2,946 & 0,178 & 54 & 3,225 & 0,158 \\
\hline 55 & 2,228 & 0,185 & 55 & 2,014 & 0,182 \\
\hline 56 & 3,224 & 0,200 & 56 & 3,227 & 0,229 \\
\hline 57 & 4,288 & 0,142 & 57 & 4,592 & 0,144 \\
\hline 58 & 4,489 & 0,131 & 58 & 4,678 & 0,139 \\
\hline 59 & 5,266 & 0,104 & 59 & 5,492 & 0,097 \\
\hline 60 & 4,151 & 0,537 & 60 & 3,876 & 0,211 \\
\hline
\end{tabular}




\section{ANEXO VI:}

Gráfica comparativa de las preguntas 61 a 80, cambios producidos entre septiembre y enero del curso 2014-2015.

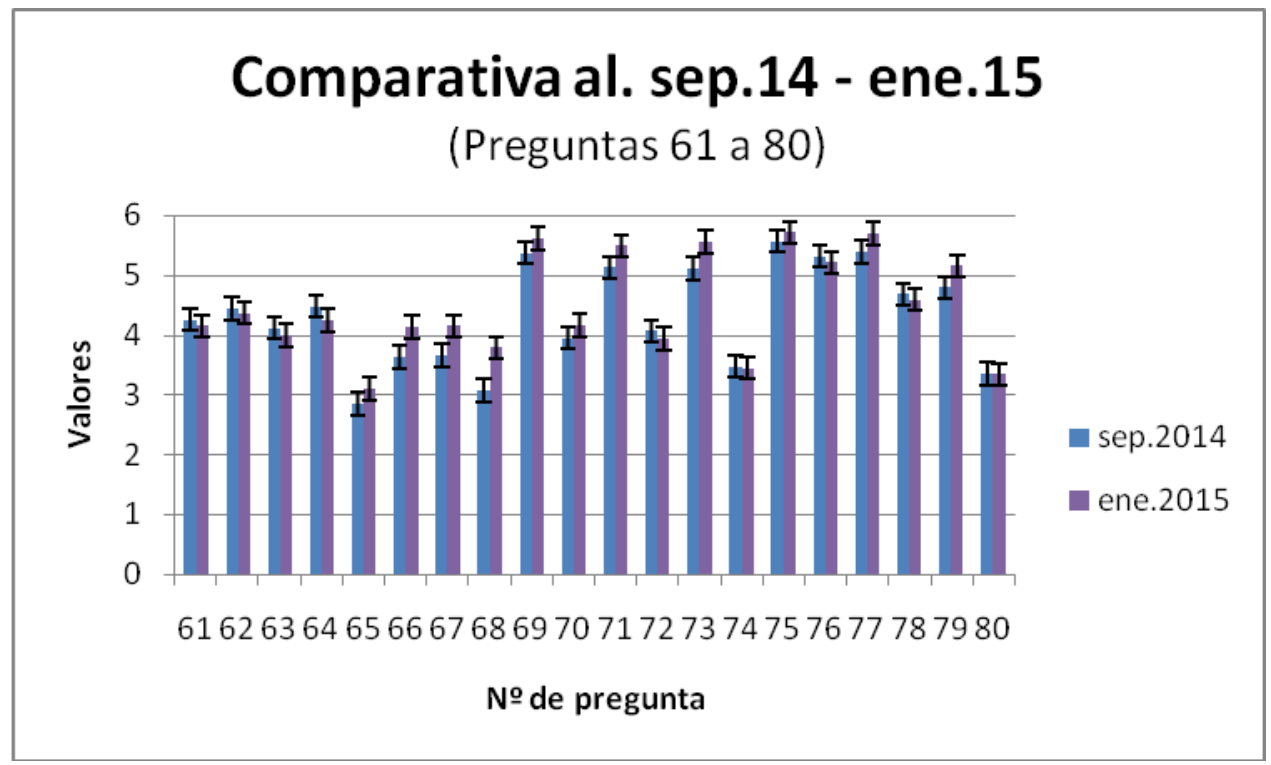

\begin{tabular}{ccc|ccc}
\hline \multicolumn{2}{c|}{ SEPTIEMBRE 2014 } & \multicolumn{3}{c}{ ENERO2015 } \\
\hline$N^{\mathbf{o}}$ pregunta & Media & Error & $N^{\mathbf{o}}$ pregunta & Media & Error \\
\hline $\mathbf{6 1}$ & 4,255 & 0,172 & $\mathbf{6 1}$ & 4,153 & 0,205 \\
\hline $\mathbf{6 2}$ & 4,441 & 0,150 & $\mathbf{6 2}$ & 4,374 & 0,182 \\
\hline $\mathbf{6 3}$ & 4,114 & 0,171 & $\mathbf{6 3}$ & 3,996 & 0,199 \\
\hline $\mathbf{6 4}$ & 4,479 & 0,143 & $\mathbf{6 4}$ & 4,252 & 0,161 \\
\hline $\mathbf{6 5}$ & 2,852 & 0,145 & $\mathbf{6 5}$ & 3,107 & 0,185 \\
\hline
\end{tabular}




\begin{tabular}{|c|c|c|c|c|c|}
\hline 67 & 3,664 & 0,130 & 67 & 4,152 & 0,162 \\
\hline 68 & 3,078 & 0,151 & 68 & 3,795 & 0,182 \\
\hline 69 & 5,376 & 0,103 & 69 & 5,614 & 0,075 \\
\hline 70 & 3,947 & 0,180 & 70 & 4,166 & 0,157 \\
\hline 71 & 5,133 & 0,134 & 71 & 5,495 & 0,097 \\
\hline 72 & 4,074 & 0,166 & 72 & 3,939 & 0,184 \\
\hline 73 & 5,111 & 0,117 & 73 & 5,560 & 0,082 \\
\hline 74 & 3,477 & 0,173 & 74 & 3,447 & 0,181 \\
\hline 75 & 5,574 & 0,072 & 75 & 5,717 & 0,064 \\
\hline 76 & 5,322 & 0,102 & 76 & 5,217 & 0,100 \\
\hline 77 & 5,394 & 0,110 & 77 & 5,697 & 0,071 \\
\hline 78 & 4,687 & 0,148 & 78 & 4,589 & 0,158 \\
\hline 79 & 4,797 & 0,148 & 79 & 5,159 & 0,132 \\
\hline 80 & 3,356 & 0,204 & 80 & 3,344 & 0,221 \\
\hline
\end{tabular}




\section{ANEXO VII:}

Gráfica comparativa de las preguntas 1 a 20, cambios producidos entre septiembre y enero del curso 2015-2016.

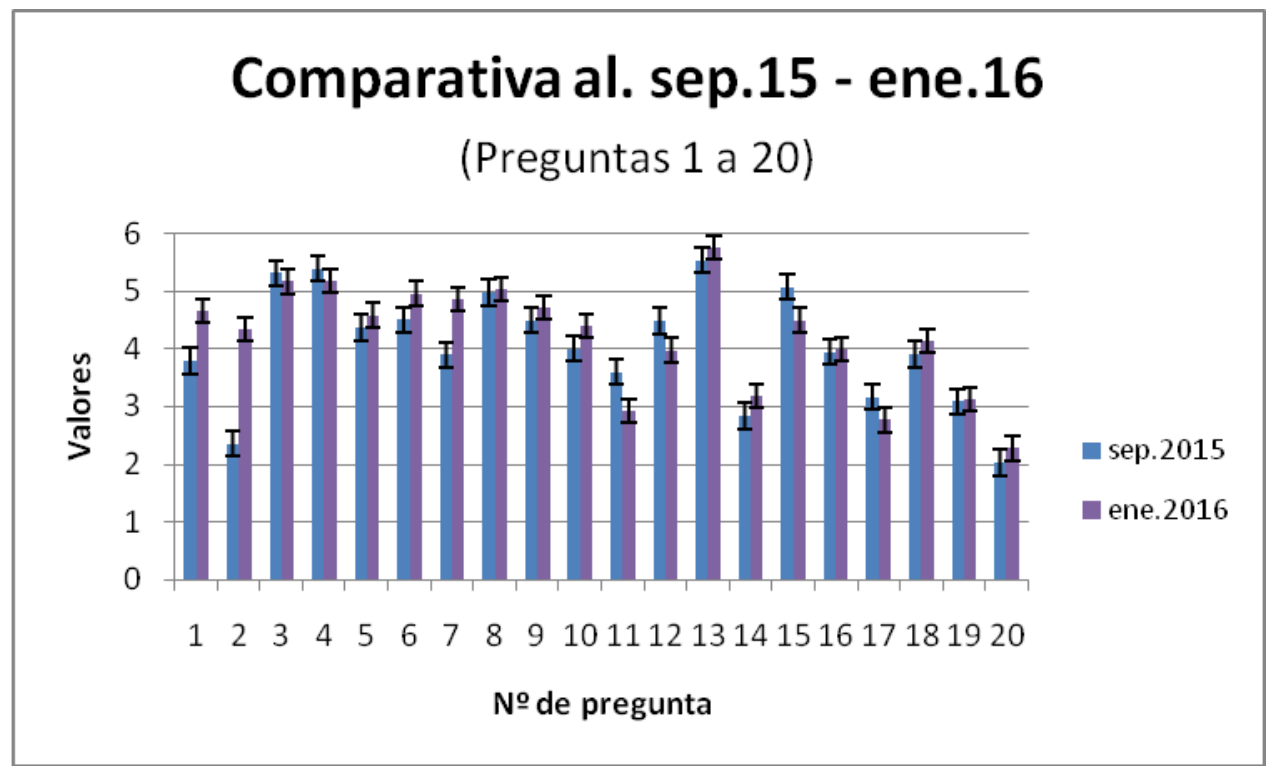

\begin{tabular}{ccc|ccc}
\hline \multicolumn{2}{c|}{ SEPTIEMBRE 2015 } & \multicolumn{3}{c}{ ENERO2016 } \\
\hline $\mathbf{N}^{\mathbf{0}}$ pregunta & Media & Error & $\mathbf{N}^{\mathbf{0}}$ pregunta & Media & Error \\
\hline $\boldsymbol{1}$ & 3,789 & 0,164 & $\mathbf{1}$ & 4,658 & 0,164 \\
\hline $\mathbf{2}$ & 2,360 & 0,203 & $\mathbf{2}$ & 4,344 & 0,164 \\
\hline $\mathbf{4}$ & 5,309 & 0,142 & $\mathbf{3}$ & 5,166 & 0,158 \\
\hline $\mathbf{5}$ & 5,389 & 0,166 & $\mathbf{4}$ & 5,180 & 0,151 \\
\hline $\mathbf{6}$ & 4,365 & 0,228 & $\mathbf{5}$ & 4,579 & 0,195 \\
\hline
\end{tabular}




\begin{tabular}{|c|c|c|c|c|c|}
\hline 7 & 3,898 & 0,249 & 7 & 4,861 & 0,151 \\
\hline 8 & 4,978 & 0,133 & 8 & 5,031 & 0,140 \\
\hline 9 & 4,494 & 0,243 & 9 & 4,718 & 0,183 \\
\hline 10 & 4,001 & 0,169 & 10 & 4,400 & 0,158 \\
\hline 11 & 3,599 & 0,261 & 11 & 2,917 & 0,190 \\
\hline 12 & 4,487 & 0,283 & 12 & 3,976 & 0,302 \\
\hline 13 & 5,532 & 0,136 & 13 & 5,758 & 0,088 \\
\hline 14 & 2,840 & 0,308 & 14 & 3,183 & 0,302 \\
\hline 15 & 5,065 & 0,165 & 15 & 4,492 & 0,201 \\
\hline 16 & 3,946 & 0,221 & 16 & 3,988 & 0,218 \\
\hline 17 & 3,165 & 0,203 & 17 & 2,767 & 0,214 \\
\hline 18 & 3,909 & 0,195 & 18 & 4,136 & 0,149 \\
\hline 19 & 3,091 & 0,274 & 19 & 3,119 & 0,274 \\
\hline 20 & 2,026 & 0,245 & 20 & 2,279 & 0,231 \\
\hline
\end{tabular}




\section{ANEXO VIII}

Gráfica comparativa de las preguntas 21 a 40, cambios producidos entre septiembre y enero del curso 2015-2016.

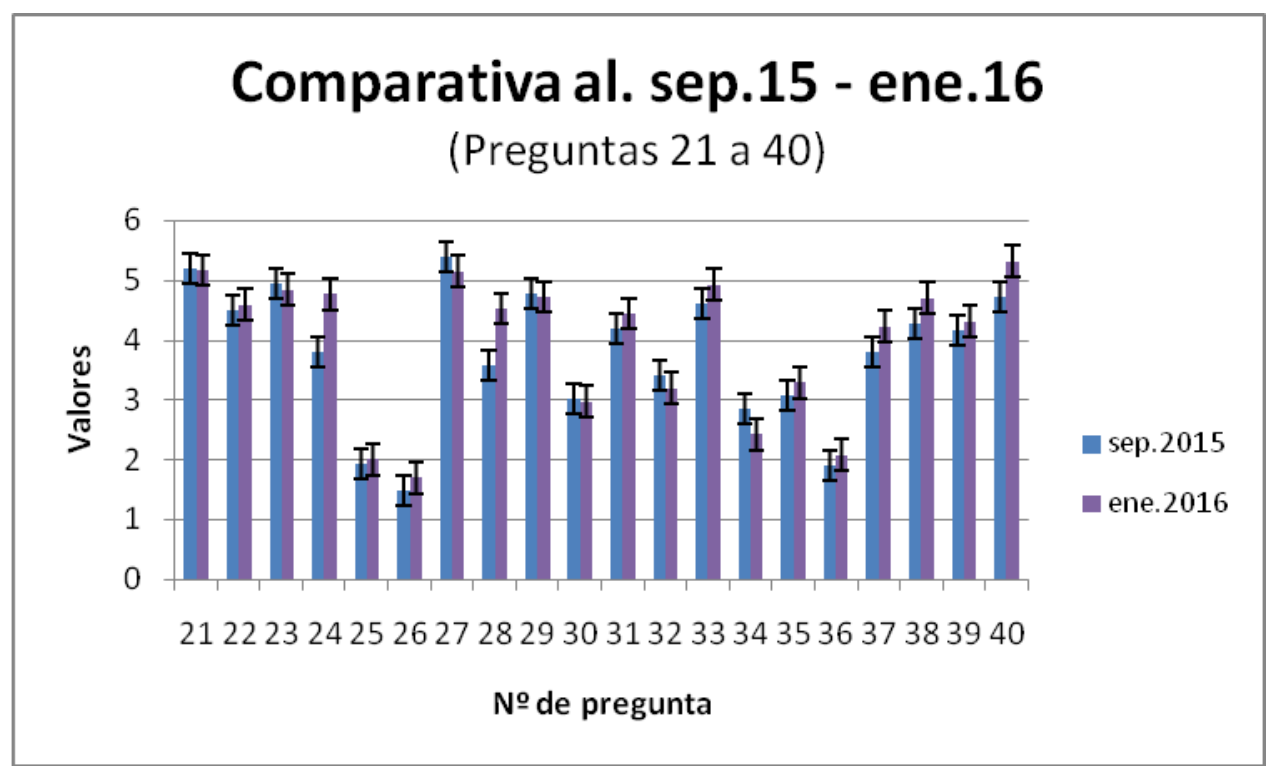

\begin{tabular}{ccc|ccc}
\hline \multicolumn{2}{c|}{ SEPTIEMBRE 2015 } & & \multicolumn{3}{c}{ ENERO 2016 } \\
\hline $\mathbf{N}^{\mathbf{0}}$ pregunta & Media & Error & $\mathbf{N}^{\mathbf{0}}$ pregunta & Media & Error \\
\hline 21 & 5,193 & 0,137 & $\mathbf{2 1}$ & 5,170 & 0,127 \\
\hline $\mathbf{2 2}$ & 4,507 & 0,175 & $\mathbf{2 2}$ & 4,594 & 0,167 \\
\hline $\mathbf{2 3}$ & 4,939 & 0,168 & $\mathbf{2 3}$ & 4,845 & 0,164 \\
\hline $\mathbf{2 5}$ & 3,802 & 0,251 & $\mathbf{2 4}$ & 4,775 & 0,175 \\
\hline $\mathbf{2 6}$ & 1,929 & 0,208 & $\mathbf{2 5}$ & 2,007 & 0,199 \\
\hline
\end{tabular}




\begin{tabular}{|c|c|c|c|c|c|}
\hline 27 & 5,401 & 0,144 & 27 & 5,153 & 0,171 \\
\hline 28 & 3,582 & 0,236 & 28 & 4,525 & 0,163 \\
\hline 29 & 4,766 & 0,209 & 29 & 4,723 & 0,203 \\
\hline 30 & 3,012 & 0,256 & 30 & 2,975 & 0,216 \\
\hline 31 & 4,183 & 0,202 & 31 & 4,444 & 0,188 \\
\hline 32 & 3,414 & 0,226 & 32 & 3,200 & 0,226 \\
\hline 33 & 4,602 & 0,184 & 33 & 4,927 & 0,151 \\
\hline 34 & 2,858 & 0,262 & 34 & 2,426 & 0,252 \\
\hline 35 & 3,081 & 0,206 & 35 & 3,295 & 0,240 \\
\hline 36 & 1,911 & 0,247 & 36 & 2,084 & 0,223 \\
\hline 37 & 3,797 & 0,270 & 37 & 4,231 & 0,213 \\
\hline 38 & 4,289 & 0,223 & 38 & 4,702 & 0,179 \\
\hline 39 & 4,156 & 0,222 & 39 & 4,314 & 0,227 \\
\hline 40 & 4,725 & 0,241 & 40 & 5,322 & 0,157 \\
\hline
\end{tabular}




\section{ANEXO IX}

Gráfica comparativa de las preguntas 41 a 60, cambios producidos entre septiembre y enero del curso 2015-2016.

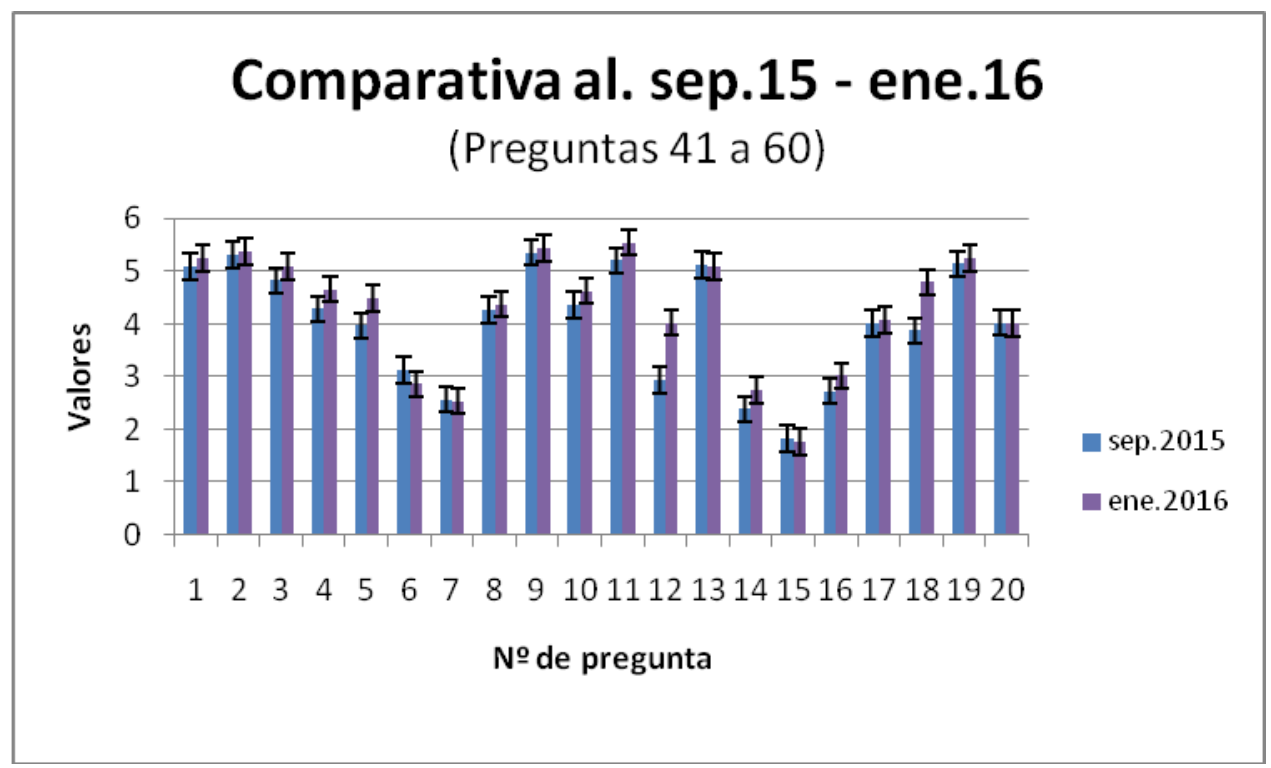

\begin{tabular}{ccc|ccc}
\hline \multicolumn{2}{c|}{ SEPTIEMBRE 2015 } & \multicolumn{3}{c}{ ENERO 2016 } \\
\hline $\mathbf{N}^{\mathbf{0}}$ pregunta & Media & Error & $\mathbf{N}^{\mathbf{0}}$ pregunta & Media & Error \\
\hline $\mathbf{4 1}$ & 5,096 & 0,187 & $\mathbf{4 1}$ & 5,242 & 0,147 \\
\hline $\mathbf{4 2}$ & 5,316 & 0,135 & $\mathbf{4 2}$ & 5,377 & 0,136 \\
\hline $\mathbf{4 3}$ & 4,823 & 0,218 & $\mathbf{4 3}$ & 5,084 & 0,195 \\
\hline $\mathbf{4 4}$ & 4,287 & 0,250 & $\mathbf{4 4}$ & 4,658 & 0,206 \\
\hline
\end{tabular}




\begin{tabular}{|c|c|c|c|c|c|}
\hline 46 & 3,120 & 0,281 & 46 & 2,858 & 0,199 \\
\hline 47 & 2,563 & 0,292 & 47 & 2,536 & 0,301 \\
\hline 48 & 4,272 & 0,219 & 48 & 4,373 & 0,185 \\
\hline 49 & 5,356 & 0,158 & 49 & 5,431 & 0,144 \\
\hline 50 & 4,365 & 0,228 & 50 & 4,628 & 0,216 \\
\hline 51 & 5,206 & 0,167 & 51 & 5,546 & 0,119 \\
\hline 52 & 2,933 & 0,378 & 52 & 4,027 & 0,316 \\
\hline 53 & 5,124 & 0,156 & 53 & 5,091 & 0,190 \\
\hline 54 & 2,386 & 0,264 & 54 & 2,754 & 0,229 \\
\hline 55 & 1,830 & 0,243 & 55 & 1,759 & 0,217 \\
\hline 56 & 2,726 & 0,309 & 56 & 3,020 & 0,261 \\
\hline 57 & 4,013 & 0,234 & 57 & 4,085 & 0,235 \\
\hline 58 & 3,875 & 0,234 & 58 & 4,794 & 0,173 \\
\hline 59 & 5,140 & 0,156 & 59 & 5,249 & 0,140 \\
\hline 60 & 4,028 & 0,199 & 60 & 4,010 & 0,185 \\
\hline
\end{tabular}




\section{$A N E X O X:$}

Gráfica comparativa de las preguntas 61 a 80, cambios producidos entre septiembre y enero del curso 2015-2016.

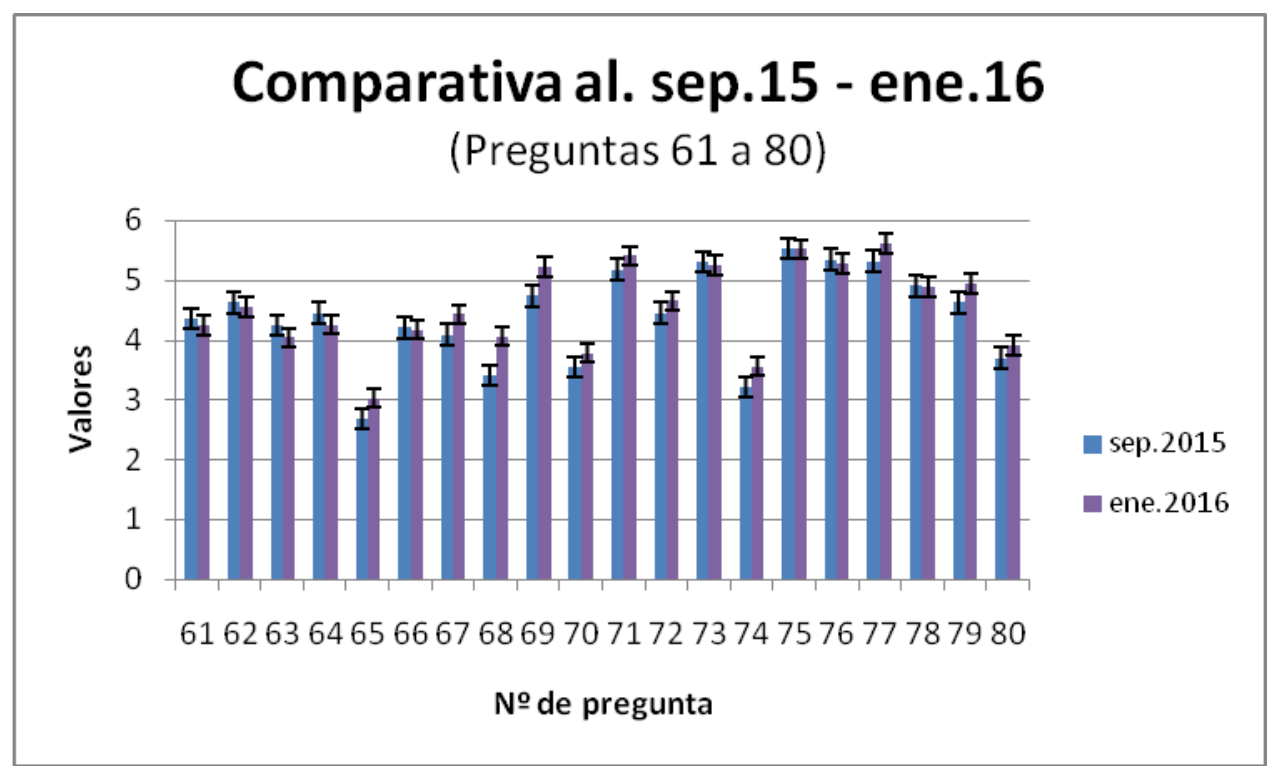

\begin{tabular}{ccc|ccc}
\hline \multicolumn{2}{c|}{ SEPTIEMBRE 2015 } & \multicolumn{3}{c}{ ENERO2016 } \\
\hline $\mathbf{N}^{\mathbf{0}}$ pregunta & Media & Error & $\mathbf{N}^{\mathbf{0}}$ pregunta & Media & Error \\
\hline $\mathbf{6 1}$ & 4,363 & 0,217 & $\mathbf{6 1}$ & 4,252 & 0,203 \\
\hline $\mathbf{6 2}$ & 4,632 & 0,195 & $\mathbf{6 2}$ & 4,549 & 0,176 \\
\hline $\mathbf{6 3}$ & 4,245 & 0,227 & $\mathbf{6 3}$ & 4,042 & 0,248 \\
\hline $\mathbf{6 5}$ & 4,456 & 0,219 & $\mathbf{6 4}$ & 4,261 & 0,249 \\
\hline $\mathbf{6 6}$ & 2,682 & 0,260 & $\mathbf{6 5}$ & 3,028 & 0,208 \\
\hline
\end{tabular}




\begin{tabular}{|c|c|c|c|c|c|}
\hline 67 & 4,088 & 0,179 & 67 & 4,432 & 0,146 \\
\hline 68 & 3,412 & 0,179 & 68 & 4,060 & 0,182 \\
\hline 69 & 4,744 & 0,223 & 69 & 5,229 & 0,161 \\
\hline 70 & 3,548 & 0,251 & 70 & 3,780 & 0,289 \\
\hline 71 & 5,179 & 0,144 & 71 & 5,407 & 0,137 \\
\hline 72 & 4,453 & 0,170 & 72 & 4,660 & 0,172 \\
\hline 73 & 5,313 & 0,119 & 73 & 5,259 & 0,133 \\
\hline 74 & 3,216 & 0,257 & 74 & 3,559 & 0,266 \\
\hline 75 & 5,533 & 0,101 & 75 & 5,519 & 0,120 \\
\hline 76 & 5,347 & 0,099 & 76 & 5,279 & 0,141 \\
\hline 77 & 5,322 & 0,157 & 77 & 5,621 & 0,108 \\
\hline 78 & 4,906 & 0,204 & 78 & 4,888 & 0,182 \\
\hline 79 & 4,626 & 0,197 & 79 & 4,950 & 0,182 \\
\hline 80 & 3,697 & 0,260 & 80 & 3,915 & 0,229 \\
\hline
\end{tabular}

